\title{
TEXTBOOK OF BOTANY
}

\author{
ALLEN AND GILBERT
}




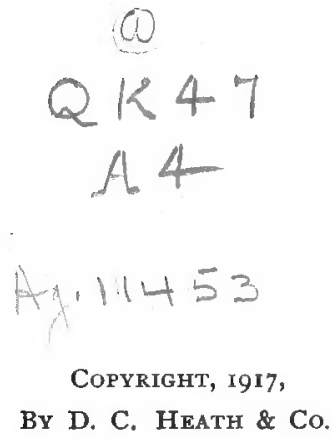

I J 7 


\section{PREFACE}

THERE are such wide differences of opinion regarding the proper content of an elementary course in botany that no teacher would venture to put forth a particular selection of facts and principles as the only one wisely to be made from the great body of knowledge concerning plants. The present writers are quite uninclined to adopt such an attitude toward their own choice; still less would they insist upon the precise order in which the materials they have selected should be presented.

We are convinced, however, that an introductory course can best be centered about a fairly intensive study of a small number of plants, and that an attempt at a more desultory treatment of the subject must prove unsatisfactory. The plants used as types should be easily available; and so far as possible they should be selected from among those that already have definite meanings to the pupil, either because of their familiarity or because of their utility. In addition, the predominance and the practical significance of the seed plants may be recognized by devoting some time to a study of their divers forms and uses; and in this study, too, illustrations should be drawn chiefly from those plants of which the pupil sees or hears most in his everyday life. At whatever point in the course this latter work is done, it should have been preceded by an intensive study of the life of at least one particular seed plant.

The present book offers a sufficient amount of work for a year's course. Probably all teachers will agree that a secondary school course in botany should not occupy less time than this, although, unfortunately, the ideal is often impossible of attainment. The order of presentation here adopted is that which will probably, in general, be most satisfactory in schools that begin the study of botany in the fall. It involves, first, a short study of a familiar seed plant (Chapter I); this is followed by the examination of a 
series of plant types (Chapters II-XIII), arranged in an ascending series; then follows (Chapters XIV-XVIII) a discussion of the varied forms and uses of the conspicuous organs of seed plants and (Chapter XIX) of the classification of angiosperms; and finally (Chapters XX-XXIV) there is a brief consideration of some of the more important practical aspects and applications of botany.

If the course in botany occupies less than a year, or if it begins at midyear or in the spring, it is plain that the work here outlined will require abridgment, or modification in the order of topics, or both. The teacher should, therefore, feel free to select from and to rearrange the material given in the textbook. There are other reasons why the teacher should not be too closely bound by the arrangement of matter in the text; local needs and conditions must be carefully considered if the greatest possible effectiveness is to be attained. For courses which begin at other times than in the fall, or for which less than a year is allowed, the following modifications are suggested:

For a year beginning in February, Chapter I may be studied first, with the substitution if necessary of the flowers of some of the plants stggested in the laboratory directions (page 39I); this may be followed by Chapters XIV to XIX, then by Chapters II to XIII, and these in turn by Chapters XX to XXIV.

For a course of two terms only, beginning in the spring ("spring and fall botany"), the outline given in the preceding paragraph may be followed, with the omission of Chapters III, VII (or VIII), XIII, and XX to XXIV.

For a half-year's course beginning in the fall, we recommend the following order: Chapters I, II, IV, V, VI, IX, X, XI ( $\$ \$ I 39-$ I53), XII, XIV to XVIII (abbreviating the laboratory work outlined in connection with the latter five chapters).

For a half-year's course starting in February, we recommend beginning with Chapter I, substituting the flowers of other plants for those of the cucumber; this may be follcwed by Chapters XIV to XVIII, abbreviating the laboratory work suggested in connection with these chapters, then by Chapters II, IV, V, VI, IX, X, XI (\$\$ I39-I53), and XII.

Special emphasis should be laid upon the importance of laboratory 
work. Directions for laboratory study, if included at all in a textbook, are necessarily so placed as unfortunately to suggest the relative unimportance of the laboratory. Secondary school work in a natural science should invariably have laboratory study as its central feature, and the textbook should be considered an accessory which helps to elaborate and to tie together the knowledge obtained from the study of the objects themselves. Ample time should be allowed for laboratory work, and whenever possible double periods should be arranged for this purpose. In general, too, the laboratory study of a topic should precede the textbook study and recitation upon that particular topic; but this rule cannot always be rigidly insisted upon, and here as elsewhere the judgment of the teacher must play an important rôle. The laboratory directions given in the present book (Appendix I) are intended to be only suggestive. It may well be that in places the teacher will find it advisable to abbreviate. In many more places it will be necessary to supplement by additional directions and by the demonstration of structures which cannot well be studied, or of experiments which cannot well be carried on, by the pupils individually. Much the greater part of the work outlined can be done with very simple apparatus, including hand lenses or dissecting microscopes, of which there should be one for each student. Some of the study necessarily involves the use of a compound microscope. We do not feel, however, that the secondary school student should spend any considerable part of his time with the compound microscope, and in general we recommend that this instrument be used only for demonstrations arranged by the teacher. If the school is sufficiently equipped, there are certain points, for example in the study of bacteria, at which individual study with the aid of the compound microscope is helpful. Even in the study of bacteria, however, this individual work may be omitted and yet with the aid of a few demonstrations the student may obtain a very satisfactory conception of the nature and activities of the organisms in question.

A word may be added regarding work out-of-doors. There is no way in which an enthusiastic teacher can more successfully impart his enthusiasm to his pupils than by means of field work. The successful teacher of botany is the one who induces his students to explore the world of plants for themselves. Field work, 
however, meets certain practical difficulties. In the crowded condition of the average curriculum it is difficult to find time for trips long enough for real accomplishment; moreover, climatic conditions in large portions of the country make field work possible only for a limited period at the beginning and the end of the year. However, within the limits set by these practical conditions, field work is to be encouraged; and, assuming that the teacher is gifted with enthusiasm of the right sort, even voluntary excursions at out-of-class periods will be productive of valuable results. Especially in connection with the work at the beginning of the year there should be some trips, which may also be utilized by the teacher in collecting material for later study. But the mistake must not be made of substituting, in any large measure, field work for laboratory work. Nothing can replace the individual study of plants in the laboratory under careful direction and supervision. So far as possible, this laboratory study should be of live plants. There is perhaps no way in which a teacher can add more to the interest and consequently to the value of a course in botany than by the actual growing of plants in the schoolroom.

If the course extends throughout the year, some time may well be devoted in the spring and early summer to the collection and identification of wild plants. The exact amount of work of this nature must be left to the discretion of the teacher; it will necessarily depend upon much the same factors that govern field work in general. If circumstances allow, the ability to identify unknown plants by means of a manual is an accomplishment to the attainment of which a reasonable amount of time may profitably be devoted.

The interest and value of laboratory and textbook study may be greatly enhanced by carefully selected supplementary reading. Lists of references are given in Appendix II for each of the more important topics to be studied, and a fair proportion of the books cited in these lists should be in the school library. Large use may profitably be made of the bulletins and circulars issued by the United States Department of Agriculture and by the experiment stations of the various states. We have included references to many of these publications which will be helpful to the teacher of botany, but the list is by no means complete. They may be 
obtained in most cases from the respective experiment stations or from the Superintendent of Documents at Washington, either gratis or at a nominal price.

It is a pleasure to the authors to acknowledge their indebtedness to Professor R. A. Harper, now of Columbia University. Whatever value this book may have is due in large measure to the stimulus that came through their years of association with him and to the inspiration furnished by his discussions of the problems of botanical teaching, and by his example as a teacher. Of the many others to whom the authors are indebted for assistance, special mention should be made of Dr. C. A. Fuller, now of Providence, Rhode Island, whose valuable suggestions aided in the preparation of Chapter II ; Professor E. T. Harper, of Geneseo, Illinois, upon whose collection of photographs of the fleshy fungi we have freely drawn; Mr. F. B. Moody of the Wisconsin State Conservation Commission, who furnished several of the photographs used in illustrating Chapter XXII; President V. E. McCaskill of the Superior State Normal School, who has read and criticized several of the chapters; Professors L. R. Jones, G. W. Keitt, and A. G. Johnson, of the Department of Plant Pathology of the University of Wisconsin, for assistance especially in the preparation of Chapter XXIV; Professor Alban Stewart of the Florida College for Women; and to the various members of the Department of Botany of the University of Wisconsin, especially Professors J. B. Overton, R. H. Denniston, E. T. Bartholomew, and G. M. Smith, Dr. W. N. Steil, Dr. G. S. Bryan, and Mrs. P. M. Smith, for assistance and suggestions in connection with all parts of the work.

Madison, Wisconsin.

May, I9I7. 


\section{Cornell University Library}

The original of this book is in the Cornell University Library.

There are no known copyright restrictions in the United States on the use of the text.

http://www.archive.org/details/cu31924001797129 


\section{CONTENTS}

CHAPTER

I. A. Brief Study of a Familiar Plant The Squash, Pumpkin, or Cucumber

II. BACTERIA

III. Protococcus .

IV. YEASTS .

V. A POND Scum . . . . . . . . 39

VI. The Bread Mold . . . . 53

VII. The Wheat Rust . . . . . . 60

VIII. A Mushroom . . . . . . . 74

IX. A Moss . . . . . . . . . . 86

X. The Bracken Fern . . . . . . . 97

$\mathrm{XI}$. The Pine . . • • . . . II3

XII. The BeAN . . . . . 137

XIII. The Indian Corn . . . . . 156

XIV. Roots and Their Uses . . . . . 169

XV. Stems and Branches and Their Uses . . 186

XVI. Leaves and Their Uses . . . 228

XVII. Flowers and Their Uses . . . . . 258

XVIII. Fruits and Seeds and Their Uses . . . 28.3

XIX. Some Important Families of Angiosperms . 295

XX. Some Useful Plants and Plant Products - 3I3

XXI. Weeds and Poisonous Plants . . . . 328

XXII. Forestry and Forfast Management . . . 342

XXIII. Plant Breeding . . . . . . $35^{8}$

XXIV. Plant Diseases . . . . . 373 
ApPEndix I. - Directions for Laboratory and Field Work 39 PAGE Appendix II. - Reference Books • . 426 Appendix III. - The State and Territorial Agricultural Experiment Stations . $\quad 438$

Appendix IV. - Botanical Supplies . . . . 440

Glossary . . . . . . . . $\quad 443$

Index . . . . . . . . . . . 45 I 


\section{A TEXTBOOK OF BOTANY}

\section{CHAPTER I}

\section{A BRIEF STUDY OF A FAMILIAR PLANT}

The Squash, Pumpkin, or Cucumber ${ }^{1}$

1. The Squash Seed (Fig. I). - This is a hard, flat, white object, rounded at one end and more or less pointed at the other. At the pointed end is a scar marking the part of the seed by which it was attached to the inside of the fruit (which we commonly call the "squash"). In this scar and a little to one side of the point is a conspicuous depression or hole, the micropyle. If a seed has first been soaked overnight, it is easier to remove the outer hard covering, the seed coat. Just inside this is a thin, greenish, skin-like layer, the endosperm. Within this is the embryo, or young plant, which makes up the larger part of the seed. One end of the embryo is rather pointed and is called the radicle; this is turned toward the micropyle. The greater part of the embryo is made up of two thick seed leaves, in which food is stored that is to be used by the embryo when the seed germinates. The seed leaves are attached to the radicle, and between the seed leaves, at the point where they join the radicle, is a small swelling, the plumule. The plumule bears two very small secondary leaves, which, however, can hardly be made out by

1 Although any one of the three plants mentioned may be used for the work of the present chapter, the cucumber will usually be found most convenient because of its smaller size. But the cucumber seed is not so favorable for study as is the larger seed of the squash or pumpkin. Specific reference is made, therefore, to the seed and seedling of the squash, and to the mature plant, flowers, and fruit of the cucumber. 
the use of an ordinary lens. The important fact for us to notice is that the seed consists of a small plant (the embryo) which is ready to continue its growth as soon as conditions
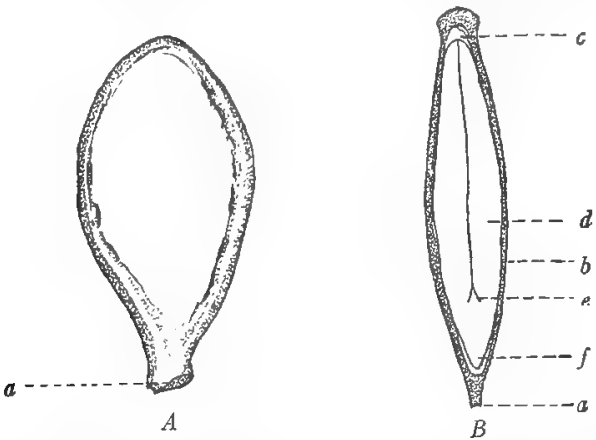

Fig. x. $-A$, side view of a squash seed; $B$, a lengthwise section through the middle of a squash seed; $a$, scar, showing the place at which the seed was attached; $b$, seed coat; $c$, endosperm; $d$, seed leaves; $e$, plumule; $f$, radicle.

are favorable; and also of some surrounding layers which protect the embryo.

2. Germination of the Seed. - If some squash seeds are placed in moist sand or sawdust and are examined from time to time, it will be found that they gradually swell. This is because water is taken in both by the secd coat and by the embryo. After a few days the seed coat begins to crack; the crack starts at the micropyle and extends down the two edges of the coat. Then the end of the radicle begins to push out through the opening in the seed coat (Fig. 2, A). This is because all parts of the embryo, and especially the radicle, are beginning to grow, and there is no longer room for the whole embryo within the seed coat. As soon as the end of the radicle is well outside the seed, it turns downward and grows in that direction. This downward growth pushes the tip of the radicle farther into the soil. From the radicle, therefore, is developed the primary root of the young plant, 
as well as a short part of the very base of the stem. Before the young root has grown very far, branch roots begin to grow from it (Fig. 2, B). At this time we can see that the seed leaves and the part of the radicle still within the seed coat are also swelling, and that just within the edge of the splitting seed coat there is a flat projection (a peg) which has grown out of one side of the radicle. Now the upper portion of the
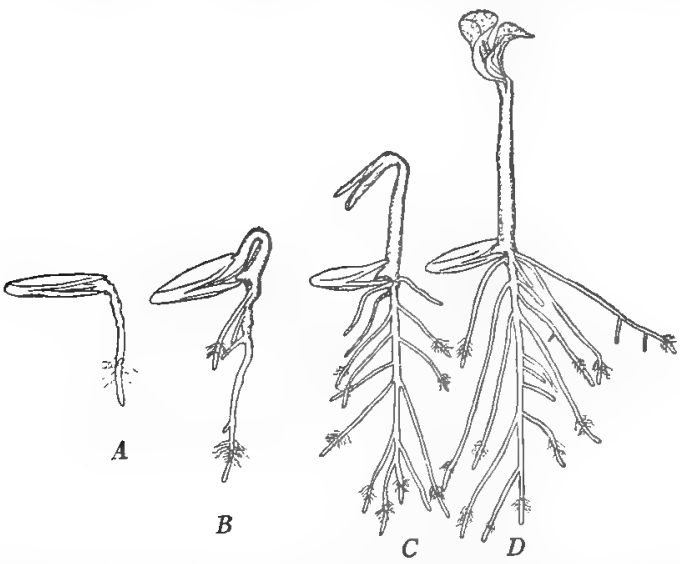

Frg. 2. - $A$, a germinating squash seed; $B, C$, and $D$, stages in the development of the seedling. Notice how the "peg" and the lengthening upper part of the radicle help to free the seed leaves from the seed coat.

radicle grows still more and bends so as to push out of the seed. This lengthening of the radicle finally pulls the seed leaves out of the seed coat, the latter being held firmly in place by the peg (Fig. 2, C). The seed coat has now been thrown off entirely, and the radicle straightens so that the end bearing the seed leaves and the plumule is turned upward.

3. Growth of the Seedling. - The young plant just beginning to grow is called a seedling. When the growth of the radicle has pushed the seed leaves well above the surface of the soil, they spread apart, grow, and become green like ordinary leaves (Fig. 2, D), although they are different in 
shape and not so large as the leaves formed later. The plumule, which has already begun to grow, now grows more rapidly; the two secondary leaves which it bears, and which were already formed within the seed, spread out and become large and green; they are shaped much like the later leaves of the plant. By the further growth of the plumule into a long stem and by the production of more leaves upon the stem, the above-ground portion of the seedling develops into that of the mature plant at the same time that the root and its branches are growing and pushing into the soil.

4. The Mature Cucumber Plant: Roots. - The primary root is developed from the lower end of the radicle, which continues to grow farther and farther into the soil. After a time, however, the primary root grows more slowly, and some of the branch roots grow fast enough so that thcy come to be fully as long as the primary root. These branch roots occasionally branch also, so that the root system of an older plant is made up of a great many slender roots. It is by means of this system of roots that the plant is firmly anchored in the soil. The roots also take up from the soil large amounts of water as well as some other substances that the plant needs, and these are carried through the roots to the stem and thence to all parts of the plant above ground. The water and other materials are not taken in from the soil by all parts of the roots, but only through very short, slender root hairs (see Fig. 2). These root hairs are borne in large numbers, but only on the youngest parts of the root system that is, close to the growing ends of the primary root and of each branch root.

5. The Stem. - We have seen that the plumule grows into the stem of the mature plant. The stem branches, like the primary root, though less frequently, and each branch of the stem may branch again. The stem and its branches, like the primary root and its branches, may continue to grow in length as long as the plant lives. The stem at first grows 
upward. But it is not very strong, and when it is a few inches in length its weight and that of the leaves make it bend over; from this time on, unless care is taken to train it upward on a trellis or other support, the stem sprawls on the surface of the ground.

6. Leaves. - The secondary leaves (a name given to all the leaves that are formed after the two seed leaves) are produced at intervals along the stem. They are alternately arranged - that is, at one point on the stem only one leaf arises, and the leaf next above will be not on the same side but on a different side of the stem. Each leaf has two parts, the leaf-stalk and the blade (Fig. 3). The blade is the large, flat portion of the leaf. It has a lobed outline, the three or five lobes being pointed, and the edge of each lobe irregularly toothed.

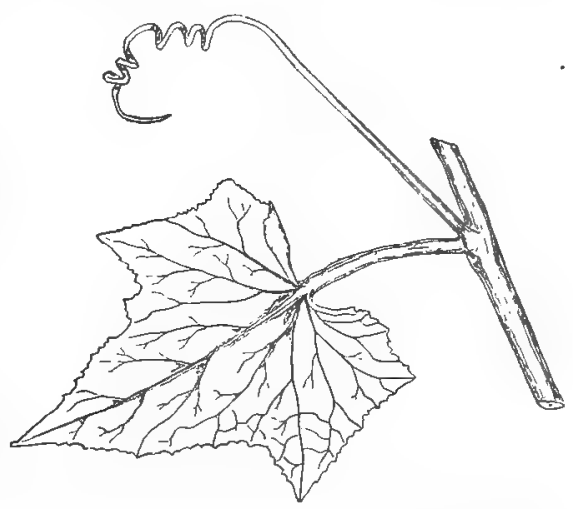

Frg. 3. - Portion of a cucumber stem bearing a leaf and a tendril.

There are many hairs growing on both the upper and lower surfaces of the leaf, as well as on the leaf-stalk and on the stem and branches of the plant. If the leaf be held up between the eye and a window, one can see in the blade many light green lines, the veins. Five large veins spread out from the point where the blade is attached to the leaf-stalk; as these main veins spread out in the blade they give off branches, the branches branch, and so on until the whole system of veins looks like a network. It is in the leaf that much of the food is manufactured which is to be used in the growth of the plant, and the veins are useful in two ways: 
first, they carry to all parts of the leaf the water and other substances that have been brought up from the roots; and second, they carry from all parts of the blade to the leafstalk and so finally to other parts of the plant the food that has been manufactured in the leaf.

7. Tendrils. - Here and there, growing from the same level on the stem as one of the leaves, is a slender structure that looks like a branch, but is more or less curved or coiled (Fig. 3). If the end portion of a young tendril is gently stroked on one side with the finger or with a pencil, it will often begin to bend toward the object that is stroking it. It is in this way that tendrils coil about the objects that they touch. Some of the relatives of the cucumber climb by means of their tendrils. But the tendrils of the cucumber are not numerous enough or strong enough to support the weight of any large part of the plant; for this reason the plant usually sprawls on the ground, although sometimes the ends of branches clamber up a short distance on neighboring objects. However, with a little assistance, a cuctumber plant can be induced to climb.

8. Terminal Buds. - The tip of the stem is covered by young leaves which have not yet unfolded. The stem tip and the young leaves that cover it are together called a bud. This bud includes not only the few leaves that one sees on the outside; for if these are stripped off, several smaller leaves will be found within. As the part of the stem inclosed within - the bud grows, the distance between the older leaves of the bud increases, and these older leaves unfold, leaving the next younger leaves as the outer covering of the bud; at the same time new leaves are being formed within the bud as minute swellings upon the stem, just back of its very end. It is by means of these changes within the bud that the stem grows in length and that new leaves are formed. A part of the stem for a short distance back of the bud is also growing longer, but the older parts do not grow in length. There 
is a bud at the end of each branch like that at the end of the stem, and each branch grows in the way that has just been described for the stem.

9. Axillary Buds. - In the axil of each leaf - that is, in the angle where the leaf joins the stem or branch - there is also a small bud. Now and then one of these buds grows out into a branch. This explains why a branch always grows from the axil of a leaf. As a rule most of the axillary buds remain very small, and only here and there one grows farther. But if the bud at the end of the stem or of a branch is killed or removed, the axillary buds are stimulated to grow, and several or even all of them for some distance back from the end may grow into branches. This fact is often taken advantage of by gardeners, because by pinching off the terminal buds one can stimulate the growth of branches and so in the end induce the plant to bear more fruit than it otherwise would.

10. Flower Buds and Flowers. - As the plant grows older, we find on examination that in many cases an axillary bud contains not only the growing point of a branch and several young leaves, but the beginnings of flowers as well. Such a bud is called a flower bud; one that contains only a growing point and young leaves is a leaf bud. When the flowers open (Fig. 4), we see that they are of two kinds. In some, below the yellow part of the flower there is a swollen, spiny region which seems to be a part of the flower-stalk, but which really belongs to the flower; flowers with this swollen portion are pistillate flowers. Others have no such swollen part; they are staminate flowers. Both kinds grow from axillary buds. The pistillate flowers are usually single, the staminate flowers 1usually in clusters.

11. A Pistillate Flower (Fig. 4, A). - The outermost part of the flower consists of five hairy, greenish-yellow, leaf-like structures called sepals, which are grown together except at their tips. Next within comes another series of five leaf- 
like structures, the yellow petals, which are the largest and most conspicuous parts of the flower; they are attached below to the sepals and are grown together with each other about half-way up, their outer ends being free and spreading. In the very center of the flower is the pistil. The upper end of the pistil is the stigma, composed of three lobes having a very rough surface; each lobe is two-parted. Below the stigma is the style, a short stalk that connects the stigma with the green, swollen, spiny lower part of the pistil, the ovary. The ovary seems to be below the petals and sepals,
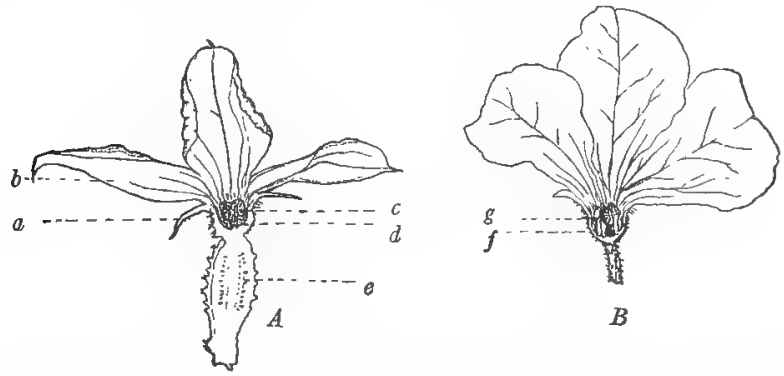

FIG. 4. - $A$, a pistillate flower of the cucumber; $a$, sepal; $b$, petal; $c$, stigma; $d$, style; $e$, ovary. $B$, a staminate flower; $f$, filament; $g$, anther.

as though these parts of the flower were growing out of its top, but really the lower parts of the sepals and petals have grown closely together with the wall of the ovary. Below the ovary is the short flower-stalk. A section cut across the ovary shows that it is divided by cracks, usually three in number, each of which begins at the center of the ovary and, as it approaches the outer wall, divides into two branches that curve inward toward the center. In the branch cracks are found a number of small rounded swellings, the ovules. The way in which the ovules are attached to the solid flesh of the ovary cannot well be made out except in thin, specially colored sections. 
12. A Staminate Flower (Fig. 4, B). - This looks much like the pistillate flower, and like it has sepals and petals. But within the petals, instead of a pistil are three stamens, which are attached ncar the base of the petals. Each stamen has a short stalk or filament, and a larger head or anther. Growing out from the upper end of each anther is a forked leaf-like projection. When the anthers are ripe, they open by long, curved slits and allow the dust-like pollen to escape. This pollen is made up of small round grains. Some of the pollen grains must fall upcn the stigma of a pistillate flower if seeds are to be formed. ${ }^{1}$ The history of the germination of the pollen grain on the stigma and of the growth of the pollen tube from the pollen grain is a difficult one to follow and will be taken up more fully in a later chapter. At the center of the staminate flower is a whitish, three-lobed swelling that loois like a small stigma. This really is a rudimentary pisill which is quite useless in the staminate flower. In the same way, the pistillate flower has a circle of rudimentary stamens, which are very small and easily overlooked.

13. The Fruit (Fig. 5). - The fruit of the cucumber is the part of the plant that is of use to us, and so it is with the fruit that we are likely to be most familiar. It is developed from the ovary of the pistillate flower. As this part of the flower grows rapidly, the other parts (sepals and petals,

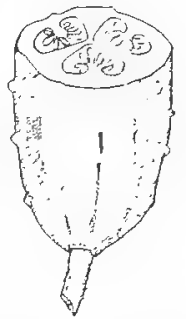

FIG. 5. - Portion of a cucumber fruit, showing the arrangement of the seeds. style and stigma) wither away and may be seen for some time as little dried-up structures at the outer end of the fruit. Ordinarily the fruit is picked for use while it is still green. But if it is allowed to remain on the vines it becomes yellow

1 As a rule, plants will not form seeds or fruits unless pollen grains land upon their stigmas. Cucumbers of some varieties are exceptions to this rule, for they may form fruits (but fruits without seeds) though thcir stigmas receive no pollen. 
and, as we say, ripe. The spines that were noticed on the surface of the ovary remain hard and sharp while the fruit is growing, but many or all of them (in most varieties of cucumber) dry and fall or are rubbed off before it is ripe. A cross section of the ripe fruit shows about the same structure as one through the ovary, except that all the parts are much larger. The ovary wall has become thicker and hard; it is now the fruit coat or rind. The tissues that made up the inside of the ovary have become soft and juicy, and the ovules have grown into seeds, whose structure we have studied. The fruit of the cucumber, unlike many other fruits, has no means of opening or of scattering its seeds. Therefore, unless the fruit is broken open in some way, the seeds remain inside, protected by the fruit coat until the latter decays; then they fall upon the ground and are in a position to germinate.

14. Length of Life. - The whole history that we have followed is passed through in one season. The cucumber is an annual; that is, no part of the plant lives through the winter, but new plants must be raised from seed each year.

15. Relatives of the Cucumber. - The cucumber is a representative of the genus Cucumis. The botanical name of the species is Cucumis sativus. Another species of the same genus is Cucumis melo, the muskmelon. These plants belong to the gourd family, which includes about 7oo species, the greater part of them natives of the tropics. The pumpkin and the summer squash (both forms of Cucurbita pepo) are members of the same family; so are the Hubbard squash (Cucurbita maxima), the winter crookneck squash (Cucurbita moschata), the watermelon (Citrullus vulgaris), and gourds of various forms (Lagenaria vulgaris).

16. Historical Note. - The cucumber is thotight to have been originally a native of East India. It has been cultivated from the earliest times, and is said to have been introduced into China about 200 B. C. Many different varicties have been produced. The pumpkin is probably a native either of Central or of South America. Pumpkins were under cultivation by North American Indians when the continent was discovered by white men; but the pumpkins then grown seem to have been more like the gourd pumpkins than like the field pumpkins of the present day. The origin of the diflerent squashes is uncertain. 


\section{CHAPTER II}

\section{BACTERIA}

17. A Hay Infusion. - If we place some hay in water and allow the mixture to stand in a warm place, after two or three days we shall find on examination that it contains a great number of small living organisms. Some of these swim actively; others are quict except as they are carried about by currents in the liquid. Among the most numerous forms are likely to be rod-shaped bodies, some of them single, others joined end to end in chain-like rows. Some of the single bodies as well as some of the rows of bodies are in active

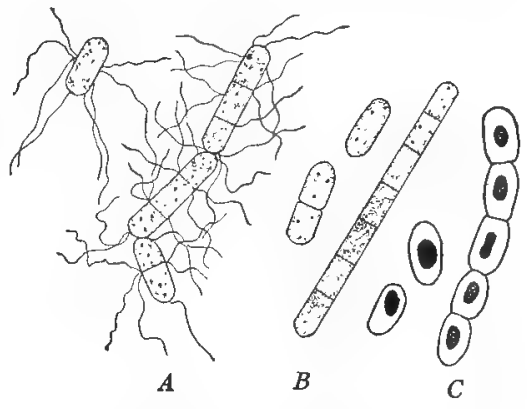

FIG, 6. - Bacillus subtilis. $A$, in the motile condition; $B$, in the resting condition, the vibrating threads having been lost; $C$, in the spore condition. After Brefeld.

motion; others are quiet. The rod-shaped bodies belong to the group of bacteria. Even among the rod-shaped bacteria in the infusion there may be two or three different kinds; but the differences between them are slight, and we may consider them under the name of what will probably be the most abundant species, Bacillus subtilis (Fig. 6).

18. The Structure of a Bacillus. - Each rod-shaped body is a cell; Bacillus subtilis is a plant composed of a single cell. 
A living bacillus secms under a microscope even of the highest power to be merely a colorless body, two or three times as long as wide, with rounded ends. If two or more cells are attached, the ends by which they join one another are flattened rather than rounded.

Something more of the structure of the cell may be made out if it is killed and stained by the use of suitable dyes. The process of staining is a delicate one and can be carried on successfully only after considerable experience. A cell prepared in this way (Fig. 6, A) is seen to be surrounded by a thin reall; within the wall is the protoplasm, through which are scattered a few dark granules. Extending outward from the wall are a number of long threads. These threads were part of the living matter of the cell when it was alive, and it was by means of the rapid vibration of the threads that the cell moved about in the water.

19. Food. - This bacillus is commonly found in solutions which, like the hay infusion, contain dead and more or less decaying organic matter - that is, matter which has been a part of the bodies of plants or animals. From this fact we may infer that the bacillus needs ready-made organic food just as animals do, and this is the case. We shall see later that green plants can build up their living matter out of very simple materials; but this is not true of bacteria. Many bacteria live, like Bacillus subtilis, on the dead substances of animals and plants. Bacteria and other plants which use dead food are spoken of as saprophytes. Other bacteria, which live upon or in the living tissues of plants or animals, are parasites.

20. How the Bacillus Obtains Food. -- The wall of the bacillus cell is firm and rigid, and has no opening through which food materials can be taken into the cell. Therefore it is necessary that anything which the cell is to take in as food must first be dissolved, since water and many substances dissolved in water can pass through the cell wall. Such a substance as the hay with which we started is, of course, not soluble in water; so the bacillus must change some or all of 
the material of the hay into a soluble form before it can use it. This is one of the things that bacteria do on a large scale. They are able to change many organic materials with which they come in contact into a soluble form - or, as we commonly say, the materials are digested - and then the bacteria absorb such parts of the solution as they can use.

If we keep the hay infusion supplied with water so that it does not dry out, the solid substance of the hay will gradually disappear, and finally there will remain only a slimy solution with a disagreeable smell. The same thing would happen to bread or meat or to a potato that was left in water under similar conditions. The organisms that would be at work in the digestion of meat would not be altogether the same as those we find in the hay infusion; but the most numerous and active among them would be bacteria, although Bacillus subtilis might not be one of them. Bacteria digest solid foods like hay or meat by means of special substances which they form within their cells and pass out through the walls, just as the cells that line the human stomach form the gastric juice which digests meat and other foods within the stomach. Such substances, formed inside living cells, which can produce changes in the chemical nature of other substances, are called enzyms. We shall learn that very many different enzyms are produced by plant and animal cells, and that each kind of enzym can catuse one particular kind of chemical change.

21. Respiration. - Like ourselves, the bacillus must respire; that is, it must have oxygen if it is to remain active, and this oxygen it takes in from the air. The oxygen is used, not in building up, but in tearing down the substances within the cell wall. This tearing down is just as necessary as the building up; it supplies the energy that the cell must have in order to do work. One form of the energy so obtained is heat. 
22. Growth. - In the hay infusion we find bacillus cells of different lengths. This is because a cell does not remain the same size, but if it is supplied with food, and if other conditions, such as moisture and temperature, are favorable, it grows. Growth goes on because the cell builds up into living matter some of the food that it takes in, and this becomes a part of the cell body, just as the food that we eat is in part built up into the substance of our own bodies. It is true, as we have just seen, that the opposite process also goes on; that is, the living matter is at the same time being broken down into simpler substances by respiration, and these simpler substances are given off to the outside through the cell wall as waste matter. If the building up and tearing down should just balance each other, the cell might remain of the same size. But if food is abundant, as it is in a hay infusion, the building up goes on more rapidly than the tearing down, and the cell grows.

23. Reproduction. - The growth of a cell does not go on indefinitely. When it reaches a certain size (which is always about the same for any particular species so long as the conditions remain unchanged) it can grow no longer, but divides. The division of the cell is always crosswise, so that the two smaller cells thus formed are attached end to end. These may remain attached, and each one then grows to full size and divides, and by this alternate growth and division rows or colonies of cells are formed. The cells, however, are easily broken apart, so that in an infusion we always find single cells as well as colonies of various lengths. It is by division that the bacillus reproduces, and cell division is the only kind of reproduction that is found among bacteria. Many bacteria are able to grow and divide very rapidly; some kinds have been observed to divide about every half-hour. In such a case a single cell might give rise in the course of ten hours to $\mathrm{r}, 048,576$ cells; and in the course of twenty-four hours, if the food supply were abundant and all other con- 
ditions remained favorable, to an almost inconceivable number.

It is not surprising, therefore, that bacteria are as numerous as they are and that they are found practically everywhere; nor that, although each one is so extremely small, they are able to accomplish tremendous results. The "scum " that rises to the surface of the hay infusion contains great numbers of separate cells and rows of cells in a quiescent condition held together by a sticky, slimy substance which is secreted by the bacteria. Although the cells in this scum are not moving (because they have lost their vibrating threads), they may still be actively dividing (Fig. 6, B).

24. Spore Formation. - If the liquid in which the bacteria live is allowed to dry up slowly, or if we keep it from drying up until the supply of food for the bacteria is exhausted, a change takes place in the appearance of many of the cells. The protoplasm of each cell shrinks away from the wall and rounds up into a body much smaller than the original cell (Fig. 6, C), which lies at the center or toward one side or one end of the old cell cavity and is closely surrounded by a thick new wall. This shrinkage is at least partly due to the loss of water, and the spore so formed is much less easily affected by unfavorable conditions, such as dryness, heat, and cold, than is the ordinary cell. Many kinds of bacteria (though by no means all) are able to pass into the form of spores, in which condition they may remain unaffected by surrounding conditions for a long time. In this form they may be blown about in the air, and when they land in a place where conditions are favorable they can return to their original form and then grow and multiply as before. This ability to change from one form to another is of great advantage to bacteria, since it enables them to adapt themselves to great changes in their surroundings.

25. Distribution and Forms of Bacteria. - More than two thousand kinds or species of bacteria have been recognized, and new species are 
discovered every year. The majority of them are saprophytes, like the one we have studied. They are found in every conceivable situa-

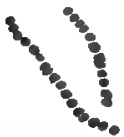

FIG. 7. - A pusforming bacterium, Sireptococcus pyogenes. tion - in the air, in both salt and fresh water, and in the soil. They live in the food we eat, in the water we drink, and upon and within many parts of our own bodies, as well as of the bodies of lower animals and plants. Three classes of bacteria are distinguished which differ from one another in the general shape of their cells; but within each class there is considerable variety. Those of one class are nearly or quite globular. They form colonies of different kinds, depending upon whether the divisions take place all in the same direction or in different directions. Some of the globular species form chains, as for
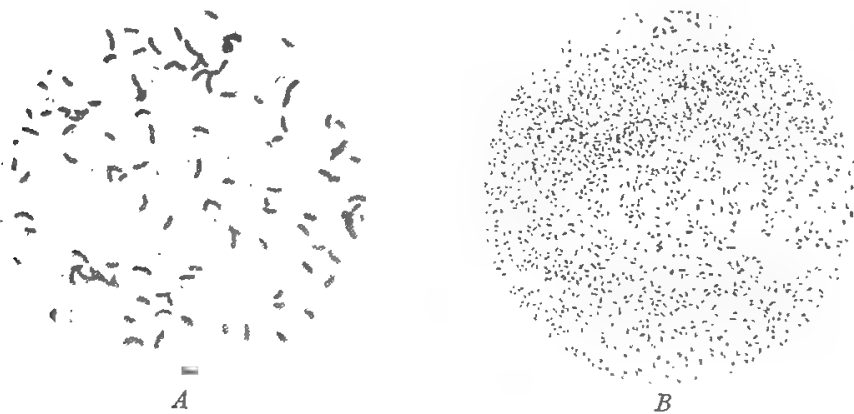

$B$

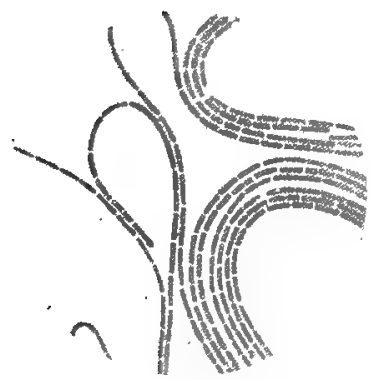

$C$

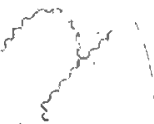

FIC. 8. - Disease-producing bacteria. A, the bacillus of Isiatic cholera; $B$, the bacillus of chicken cholera; $C$, the bacillus of splenic fever; $D$, the spirillum of recurrent fever, $\Lambda$ fter Günther. 
example Streptococcus pyogenes (Fig. 7), one of the pus-forming bacteria; others form plates or masses of cells. Another class includes the rod-shaped bacteria, many of which form chain-like colonies; Bacillus subtilis is a type of this group. Those of the third class are spiral or corkscrew-shaped. The spiral may be very short, as in the "comma bacillus" that causes Asiatic cholera (Fig. 8, $A$ ); or it may be composed of several coils, as in the species of Spirillum, one of which (Fig. 8, D) is the germ of recurrent fever. Bacterial cells differ in size as well as in form, although they are all very small; in general they are the smallest known living organisms. One of the smallest is $\mathrm{x}$. 1000 inch long and $\frac{1}{2} \frac{1}{3} \sqrt{00}$ inch wide. One of the largest is $\frac{1}{1060}$ to $\frac{1}{3} \frac{1}{0}$ inch long and $\frac{1}{8} \frac{1}{6}$ to $\frac{1}{1}$ inch wide. It is estimated that it would require $\mathbf{I} 6,800,000,000,000$ bacilli of average size to weigh an ounce.

26. The Activities of Bacteria. - We have seen that in the process of obtaining food for their own use, bacteria by means of enzyms change the nature of organic substances such as meat and hay and make them soluble. One of the most striking, and from our point of view one of the most important, characteristics of bacteria is their power of thus changing the chemical nature of substances with which they come in contact. All such changes are, of course, of direct benefit to the bacteria ; but they are also in many cases of great consequence to other plants and to animals. If, as is very commonly the case, the change is a breaking down of organic substances - that is, of materials which have once been parts of the living bodies of plants or animals - the process is called decay. Not all forms of decay are due to bacteria; but bacteria are more largely concerned in decay and produce more kinds than all other sorts of organisms taken together. If in the process of decay bubbles of gas are formed, we often speak of the process as fermentation; if an unpleasant odor arises, we call it putrefaction.

Bacteria are often thought of as a group of useless and harmful creatures; as a matter of fact, only a small number of species are injurious to man, and a much greater proportion are useful in one way or another. Processes of decay, due largely to bacteria, are constantly destroying the dead 
bodies of plants and animals and returning the elements of which they are made to the soil, water, and air to be used again in building up the bodies of living animals and plants. If it were not for decay, the surface of the earth would long ago have been covered with dead organic matter, and the life of the higher plants and animals, including man, would now be impossible.

Most bacteria, including many that cause decay, like Bacillus subtilis, can obtain the oxygen that they need for respiration only from the air. For this reason, the decay of a substance can often be stopped or prevented if air is entirely excluded from it. This is one reason why fruits and vegetables are preserved in air-tight cans and jars. On the other hand, some bacteria cannot grow in the presence of air; so they thrive only in places, for example deep in the soil, to which air does not reach. Such bacteria need oxygen for respiration just as all living organisms do; but they obtain it from the organic substances that they decompose, and not directly from the air. An example of this class is Bacillus tetanus (Fig. 9, D), which causes lockjaw. Since this bacillus cannot multiply in the presence of air, it is important not to allow wounds into which the lockjaw germ may have entered to heal over too soon upon the surface, and not to keep them covered so tightly as to keep out the air. There is a third group of bacteria that can take their oxygen from the air, but which, if they are shut away from the air, can obtain it by the breaking down of organic materials.

27. Soil Bacteria. - Great numbers of bacteria are found in the soil, especially in the upper layers to a depth of six inches or a foot. Various countings of bacteria in the surface layers of different kinds of soil have shown from I 5,000,000 to $300,000,000$ bacteria per ounce of soil. At greater depths the numbers are smaller, and relatively few are found more than five or six feet below the surface. Among those in the deeper soil layers are many kinds that cause decay and putrefaction. 
Another group of soil bacteria that are of great importance, particularly to the farmer, are the nitrifying bacteria. The decay-producing bacteria, as we have seen, decompose the remains of plants and animals into simpler substances, but not for the most part into materials which higher plants, like the squash and the cucumber, can use for food. Among the substances formed by decay are compounds containing ammonia. The nitrifying bacteria change these ammonia compounds first into a class of compounds called nitrites, and then into nitrates, and the nitrates are substances which the cucumber and other garden and farm plants can absorb through their root hairs and can use in the building up of their own bodies. It' is not sufficient, therefore, that the soil be fertilized by the addition of organic substances, such as manures; it must contain also both the decay-producing and the nitrifying bacteria to change these substances into a form suitable for plant food.

28. Bacteria in Milk. - One of the means used to measure the cleanliness of milk is to count the bacteria contained in a certain amount. The number of bacteria present varies enormously with the care taken to secure clean milk and to prevent the entrance of bacteria while handling and transporting it. If extreme care is taken, the number may be kept down to a few hundred per cubic centimeter. In certified milk the number of bacteria is frequently limited to 10,000 per cubic centimeter, and in some cities milk cannot be sold that contains more than 250,000 bacteria per cubic centimeter. On the other hand, the bacterial content of dirty milk offered for sale has been found to run in some cases to more than I5,000,000 per cubic centimeter. Of the many kinds of bacteria found in milk, some are harmless and produce no particular effect; some cause disease in persons who drink the milk, and these, of course, are the forms that it is especially important to keep out; and some produce fermentations of various kinds, most of which make the milk unfit 
for use. Of the forms producing fermentation, the lactic acid bacteria are of most interest. These grow and multiply rapidly in milk at ordinary temperatures, so that if only a few get in they will cause the milk to sour in a short time. However, lactic acid bacteria multiply very slowly at lower temperatures $\left(40^{\circ}-50^{\circ} \mathrm{F}\right.$.), and this is the reason why milk remains sweet longer if it is kept cool. While lactic acid fermentation spoils milk for most purposes, it is necessary in order to prepare the milk for butter-making.

29. Sterilization and Pasteurization. - Milk as well as other liquids may be sterilized by heating it three or four times on successive days to the boiling point $\left(2 \mathrm{I} 2^{\circ} \mathrm{F}\right.$.). This kills all bacteria whether in the active or the spore condition, but it also produces changes in the chemical make-up of the milk which render it less desirable for some purposes. By heating the milk to about $155^{\circ} \mathrm{F} .{ }^{1}$ for twenty minutes and then cooling it, the great majority of the bacteria in the active condition (but not those in the spore condition) are killed and little change is caused in the milk itself. This process is called pasteurization, and properly pasteurized milk, kept in a cool place, should remain sweet for several days. In time, however, some of the bacteria which were not killed will grow, divide, and become numerous, and the milk will sour or change in other ways, depending upon the kinds of bacteria that it contains.

30. Other Saprophytic Bacteria. - Among the many saprophytic bacteria that occur in milk are those which are concerned in the "ripcning" of cheese. The characteristic flavors of many different linds of cheese are due to substances produced in the cheese by the action of particular species of bacteria. To make one of these cheeses, therefore, it is necessary not only to treat the materials in the proper way, but also to make sure that the right kinds of bacteria are present. Another

1 The temperature actually used in the pasteurization of milk varies considerably, but is usually between $140^{\circ} \mathrm{F}$. and $160^{\circ} \mathrm{F}$. 
familiar process due to bacteria is the fermentation that produces vinegar.

31. Ptomains. - Wre have seen that bacteria decompose organic substances into a great number of simpler compounds. Some of these simpler compounds are useful to the bacteria as food; but many of them are merely ry-products. Among the latter are a class of substances called ptomains. Some of the ptomains, produced for example in decaying meat, cheese, or milk, are extremely poisonous to human beings. Many deaths are caused by eating partly spoiled foods, especially canned meats, in which ptomains have been formed by the action of bacteria.

32. Disease-producing Bacteria. - Although only a small proportion of the known species of bacteria are parasitic, the

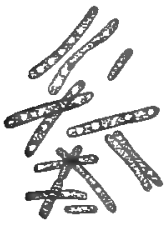

$A$

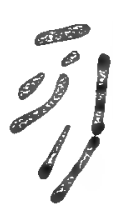

$B$

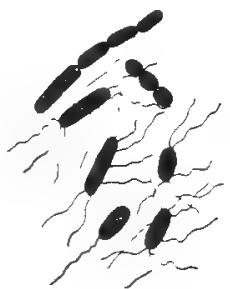

C

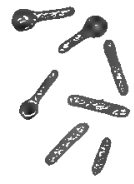

$D$

FIG. 9. - Disease-producing bacteria. -1 , the tuberculosis bacterium; $B$, the diphtheria bacterium; $C$, the bacillus of typhoid fever; $D$, the bacillus that causes lockjaw; some of the cells are forming spores.

parasitic forms include those that cause most of the contagious and infectious diseases of man and animals. Bacteria are not responsible for all these diseases; some, such as malaria and the African sleeping sickness, are produced by one-celled animals; and the organisms which cause some common diseases (for example, smallpox) are unknown. Many important plant diseases, too, are due to bacteria, though the number of such diseases thus far known is smaller than the number of bacterial diseases in animals. Some 
of the most important bacterial plant diseases will be discussed in Chapter XXIV.

33. Tuberculosis. - This name is given to diseased conditions which are caused in various parts of the body by Bacterium tuberculosis (Fig. 9, $A$ ). The most frequent form is tuberculosis of the lungs, often called consumption. This is the most serious and widespread disease that attacks the human race. Each year about I 50,000 persons are killed by tuberculosis in the United States, and about $1,500,000$ in the world. Although the fight now being waged against tuberculosis is reducing the death rate from year to year, it is still true that of the persons now living in the United States more than 5,000,000 will die of tuberculosis unless more successful methods than are now known are found for treating the disease.

34. How Tuberculosis is Caused. - The lung cells that are attacked by the bacteria are destroyed. Then there is a growth of new cells around the diseased region, forming a tubercle, which gave the disease its name. By the decomposition of the lung tissues, the bacteria produce, among other substances, one which passes into solution in the blood of the patient and there acts as a poison. This is one of a class of poisons, or toxins, which many parasitic bacteria produce. The toxin of the tubercle bacteria is responsible for many of the serious features of the disease. Eventually, if the disease is not in some way checked, the tissues of the lungs are largely destroyed. In many cases, however, in otherwise healthy and vigorous persons, the disease does not progress far. This is because the white corpuscles of the blood attack and kill the bacteria. The patient then recovers.

The possibility of a cure of tuberculosis in its early stages shows the importance of keeping in good general health as a precaution against the disease, and also the necessity of beginning the treatment of tuberculosis at the earliest possible 


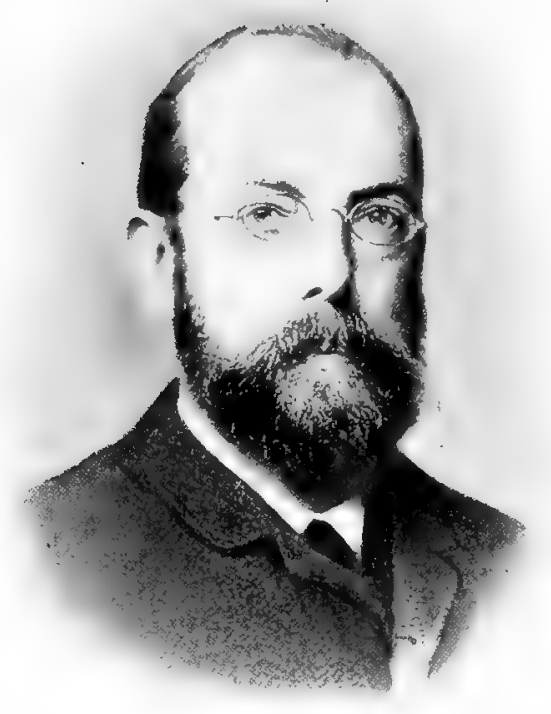

\section{ROBERT KOCH}

Born at Klausthal, in Hanover, Germany, I 843 ; died at Baden-Baden, IgIo. One of the greatest investigators of the disease-producing bacteria, many of which he first discovered by means of methods that he devised. Among his discoveries are those of the organisms which cause tuberculosis and Asiatic cholera. 

moment. Thus, it is said that about go per cent of all adult Europeans have at one time or another been afflicted with tuberculosis, although only I 5 per cent die of the disease. There is no doubt that every one of us has many times taken the tubercle bacteria into his throat and lungs; but if they were not too numerous, and if we were in vigorous health, the bacteria were quickly killed and no harm resulted. Although tuberculosis most commonly affects the lungs, it occurs also in the skin, in the spinal column, the hip joint, the glands of the neck, the intestines, and the brain.

35. Tuberculosis in Cattle. - Tuberculosis is a disease of "ome of the lower animals, including cattle, as well as of man. The bacteria pass into the milk of diseased cows, and it has been shown that tuberculosis may be conveyed to babies by such milk. This is one reason for the adoption of laws by various states requiring the testing of cattle for tuberculosis ... A the killing of those found to be diseased. There is also a rossibility of getting the disease by eating the flesh of affu ted cattle, but since most of the bacteria are killed in the cool ing of the meat, this danger is not so serious as is that from milk.

36 How Tuberculosis is Spread. - The bacteria enter the body by being breathed into the lungs, or by being taken into the stomach with food, or through a wound. The first method is prolably by far the most common. The disease germs are distributed in the sputum of diseased persons. If, therefore, all the sputum were destroyed, the spread of the disease would be $v \epsilon$ :y largely checked, and the immediate destruction of the sputum is one of the most important means to be used in combating tuberculosis. If it is not destroyed but is allowed to dry, the bacterial cells also become dry and are carried about like dust in currents of air (see Fig. Io). In this dried condition the germs can live for a long time. They are killed, however, by prolonged exposure to sunlight, and they live longer in bad air, as in close, poorly ventilated rooms, 
than in fresh air. Plenty of fresh air and sunshine are therefore very important, and especially so in the house where a

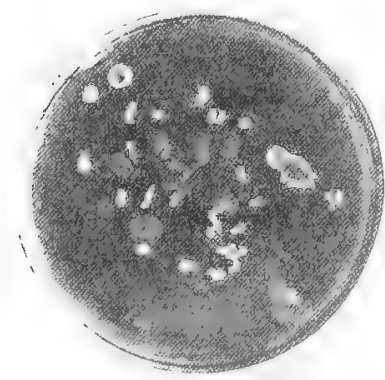

FIG. 10. - Photograph showing the growth of bacterial colonies on an agar plate that had been exposed for a short time to the air. The bacteria floating about in the air settled upon the plate and there grew and multiplied. tuberculous person lives or has lived. It is in crowded, unventilated, and poorly lighted tenements that a large proportion of cases of tuberculosis occur, both because conditions there are more favorable for the bacteria, and because persons living under such conditions are less healthy and so less able to throw off the disease.

37. Diphtheria. - This is caused by a bacterium. that finds lodgment in the throat (Fig. 9, B). Living and multiplying here, the bacterium gives off a toxin which is carried by the blood to other parts of the body and there produces the serious symptoms of the disease. The presence of the toxin in the blood of the sufferer cattses the blood to form an antitoxin - a substance which counteracts the poisonous effects of the toxin. If the antitoxin is formed in large enough quantity, the most serjous effects of the disease do not appear; the patient finally gets rid of the bacteria that are producing the poison and recovers. If the antitoxin is not formed rapidly enough, the disease grows worse and the patient dies. Fortunately it has been found that a horse or mule inoculated with diphtheria toxin produces a large amount of antitoxin, and that this antitoxin, taken from the animal and injected under the skin of the human sufferer, has the same effect as the human antitoxin.

To be effective in curing diphtheria, the antitoxin must be given early in the course of the disease; so it is most im- 
portant that diphtheria be recognized and treated at the carliest possible moment. The use of this antitoxin has greatly reduced the proportion of deaths from diphtheria. For instance, in New York the average annual death rate from diphtheria fell from 15.19 in each 10,000 of the population before the introduction of antitoxin to 6.62 in 10,000 after its introduction; and in Vienna it fell from 8.I 4 to 2.95 in $10, \infty 00$. If a person recovers from an attack of diphtheria, he will not as a rule have the discase again, no matter how often he may be exposed; he is immune. Exceptions to this rule, however, occur. Similar immunity is known in the case of many other diseases, such as measles, smallpox, and yellow fever.

38. Typhoid Fever. - This is due to a bacillus which seems to be taken in only with food or drink (Fig. 9, C). The bacillus lives and multiplies chiefly in the small intestine, but also in other parts of the body, as the blood and the marrow of the bones. As in the case of the diphtherja bacterium, its evil effects are due to a toxin which is absorbed by the blood. This toxin, however, is not given off by the living typhoid bacilli, but is a part of their living matter, and it passes into the blood of the human victim only after the bacilli have died. The most common source of typhoid infection is impure water, and the purity of the water supply of a city can be quite accurately judged by the number of cases of typhoid in that city. Flies, which brecd and seck their food in filthy places, carry the typhoid germs about upon their bodies and deposit them in milk, cream, or other food that they touch. Flies carry many other germs besides that of typhoid, and they are now well recognized as dangerous distributors of disease.

Persons who have been cured of typhoid fever may still carry large numbers of actively multiplying typhoid bacteria in their intestines or bile ducts; this condition often lasts for several months, and in some cases for years. Such carriers, 
as they are called, as well as persons who are suffering from a light attack which is not recognized as typhoid, are a source of danger to others, especially if they are careless or uncleanly in their habits. One case of a typhoid carrier that has been carefully studied was that of a cook; in several families in which she worked for a term of years typhoid cases occurred, and she was the cause of a number of deaths. An outbreak of typhoid fever involving forty-one cases and three deaths occurred at Madison, Wisconsin, in the fall of rgo8, among those who lived or ate at a certain boarding house. The source was found to be a student who was employed in cleaning and wiping dishes and who had returned to Madison in the fall in the early stages of typhoid fever. Sufferers from typhoid are not immune to the disease after recovering from it; they may be repeatedly attacked. However, an artificial immunity can be produced by vaccination with typhoid bacilli that have been killed by heat or other means; and the use of this method of vaccination has practically eliminated typhoid from the armies of many nations.

39. Lockjaw. - The germ of lockjaw or tetanus (Fig. 9, $D$ ), is a bacillus that lives in the soil and is found practically everywhere. The disease, like diphtheria, is caused by a toxin which is given off by the bacillus and is taken up by the blood. Infection occurs from soil that gets into cuts and wounds. It follows that a cut should always be thoroughly cleaned and then treated with an antiseptic, such as iodine, which will check the growth and reproduction of any bacteria that may be present. We have already seen that the wound should not be so tightly covered as to prevent the entrance of air, because it is in the absence of air that the tetanus bacillus thrives.

40. Anthrax. - This is a serious disease of cattle and sheep. It is highly contagious and difficult to combat, partly because the spores of the anthrax bacillus are very resistant to drying and can live in the soil for many years. 
For this reason, anthrax sometimes appears suddenly and without any apparent cause when cattle are turned into a pasture where diseased animals had fed years before. The disease is largely due to the rapid multiplication of the bacteria in the blood vessels so that the circulation is stopped. A toxin is also produced. Animals are made immune to anthrax for about a year by vaccinating them with a culture of anthrax bacilli that have been weakened by exposure to air at a rather high temperature.

41. Nitrogen-fixing Bacteria (Fig. I I). - Disease-producing bacteria live within the tissues of the host and are

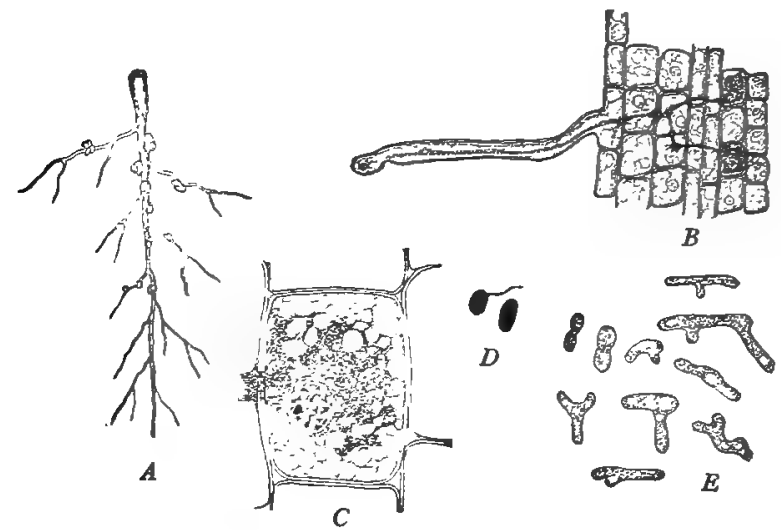

FIG. II. - Nitrogen-fixing bacteria. $A$, roots of a leguminous plant (such as clover), bearing many small swellings. $B$, the method of entrance of the bacteria through a root-hair, and their progress through the tissues of the clover. $C$, a single cell of a clover root containing many bacteria, which appear as small dark dots. $D$, single bacteria as they appear in an artificial culture. E, as they appear in a cell of the clover.

injurious to it. A quite different relation exists between clover, alfalfa, beans, peas, and other plants of the same family, and the bacteria which live within their roots. If we pull up a clover plant we find many small swellings on all parts of the roots. The swellings are outgrowths of the root 
tissues and contain immense numbers of a particular sort of bacillus. These bacilli can use nitrogen, which makes up about four-fifths of the air, in manufacturing complex substances and ultimately in building up the living matter of their own cells. The power of using the nitrogen of the air in this way is possessed by some other bacteria and possibly by some fungi, but not by green plants.

Now, nitrogen is necessary to the building up of all living matter, and green plants as a rule obtain it from the soil in the form of the compounds called nitrates. A soil that contains too small an amount of nitrates will raise only poor crops of grain or potatoes or of almost any useful plant. But in the case of clover and related plants; when the bacteria in their root swellings die, as they do in large numbers, the nitrogen-containing compounds in the bodies of the bacteria are taken up by the host plant and are used by it as food. Thus clover and alfalfa are able with the help of the bacteria in their roots to use the nitrogen of the air, and this is the reason why crops of these plants can be raised in soil that is poor in nitrates. It also explains why soil is enriched by growing clover or alfalfa upon it, especially if the crop is plowed under, because then the nitrogen-containing substances of the plant are broken down by the soil bacteria into nitrates which can be used by other plants. The root bacteria of clover and alfalfa are not parasites, but are in a sort of partnership with the host plant; the host supplies a moist place for development and also probably some forms of food for the bacteria, and the bacteria supply nitrogencontaining compounds for the host plant.

42. Historical Note. - Perhaps the first observation of bacteria was in 1659 by Kirchner, who saw " minute living worms " in putrefying meat and other foods. Leeuwenhoek first described and figured bacteria in a letter to the Royal Society of London in 1683. The modern study of bacteria began with the work of Cohn, published chiefly between the years 1853 and 1872 . Pasteur in 1857 found that the souring of milk is due to bactcrial action, and he showed the 
practical importance of bacteria in producing fermentations of various sorts. A paper by Koch in 1876 on anthrax was the first thorough study of the production of a disease by bacteria, although the anthrax bacillus had been suspected as early as 1863 of being the cause of the disease, and Pasteur in 1870 had shown that a disease of silkworms is due to bacteria. Koch devised ways of isolating and cultivating bacteria and of staining them with anilin dyes, and by means of his staining methods he discovered the tuberculosis bacterium in $\mathbf{I} 882$. 


\section{CHAPTER III}

\section{PROTOCOCCUS}

43. General Appearance. - On the sides of fences or of old buildings, especially in spots that are shaded much of the time, we often see a layer of a dark-green, powdery substance which becomes bright green when moist. A similar
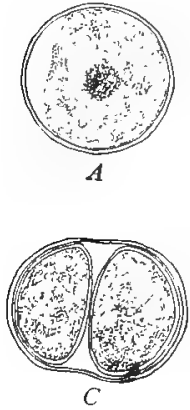

FIG. I 2, - Protococcus. $A$, a single cell; $B$, a dividing cell; $C$, the division completed, the two daughter cells being still within the wall of the mother cell; $D$, a colony of three cells.

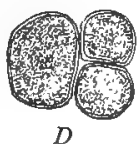

green layer is found on many other objects, such as flowerpots, trees, rocks, and stone walls. If we examine a small bit of this green coating under the microscope, we shall probably find in it several different kinds of minute plants, but the one that is likely to be most abundant appears in the form of single green cells or of two, four, or more cells joined together. This little plant is Protococcus viridis.

44. Structure. - A single cell of Protococcus (Fig. I 2, $A$ ) reminds us of a bacterial cell; but it is green and is larger than most bacteria. The average diameter of a Protococcus cell is said to be about $\frac{1}{2000}$ inch. It is surrounded by a wall that is thicker than that of a bacterium. Its green color is due to a substance called chlorophyl; this is the same substance that gives the green color to the cucumber and to other familiar plants. It is never present in bacteria. 
Sometimes the chlorophyl seems to be scattered all through the protoplasm of Protococcus, but usually it is seen only in a part of the cell ; in the latter case it is located in a body called a chloroplast, which is a special, rather firm part of the protoplasm. The chlorophyl is used by the plant in manufacturing certain complex foods (especially sugars) out of very simple substances (water and carbon dioxid) which are taken in from the outside. All green plants have this power of building complex foods out of simple ones. Plants that have no chlorophyl, such as the bacteria, cannot do this; which explains why bacteria must obtain their food ready-made and so are dependent upon other organisms. Each cell of Protococcus also contains a very small nucleus, which cannot be clearly seen except after a special treatment of the cell.

45. Conditions of Life. - In the situations in which it lives, Protococcus must be able to endure dry weather as well as extreme heat and cold. When it has a supply of water, such as may be caught during a rain in the crevices of the bark of a tree on which it lives, it makes sugars and other complex foods, as well as new living matter, and grows and divides rapidly. When the water dries up or drains away, the plant ceases to grow, and rests until another supply of water comes to it. It is thought, however, that Protococcus may take in some of the water that it needs from moist air. The carbon dioxid that is necessary is taken from the air; in the water that the cells absorb from the bark or stone or other surface on which they live, there are small amounts of the nitrates and other substances that are needed in building up living matter.

46. Reproduction. - Like the bacteria, Protococcus reproduces only by a division of the cell, when it has grown to a certain size, into two (Fig. I $2, B, C$ ). If the daughter cells separate, each rounds up into a globular form; but often they remain together, flattened on the sides which touch, thus forming a colony of two cells. By further divisions, colonies of three, four, or sometimes more, cells are produced (Fig. I 2, D). The divisions of Protococcus are not all in the same direction, as is the case in the bacillus that we 
studied, but they take place in three directions at right angles to each other; consequently, a colony of four cells forms a plate, and one of more than four usually forms a group of two or more cell layers.

47. Resting Cells. - Sometimes, under very unfavorable circumstances, the cells of Protococcus stop growing and dividing, and pass into a condition somewhat like that of the spores of bacteria. The cell contents do not shrink away from the wall, but the wall becomes thicker and oil drops appear in the protoplasm. Such cells can return to the ordinary condition when circumstances are once more favorable for growth.

48. Distribution and Relationships. - Protococcus is found in practically all parts of the world. There are also many other widely spread species of one-celled green plants different from Protococcus but probably related to it. These and many other plants containing chlorophyl are grouped under the name of algee (singular, alga). Although, as we shall see, many of the algæ are larger and more complex than Protococcus, they are all much simpler than the higher green plants, such as the cucumber, wheat and other grains, and the trees. Protococcus and its relatives are of special interest because all the higher plants are undoubtedly descended from one-celled green algæ which were something like Protococcus, although probably not exactly like any alga now living. The relationship of the bacteria to the algæ is not clear. Probably the bacteria or most of them are degenerate descendants from algæ even simpler in structure than Protococcus. 


\section{CHAPTER IV}

\section{YEASTS}

49. A Yeast Culture. - If a portion of a cake of compressed yeast or of dried yeast is put into a solution of molasses and the mixture is left in a warm place, in the course of twenty-four hours the liquid is likely to become cloudy
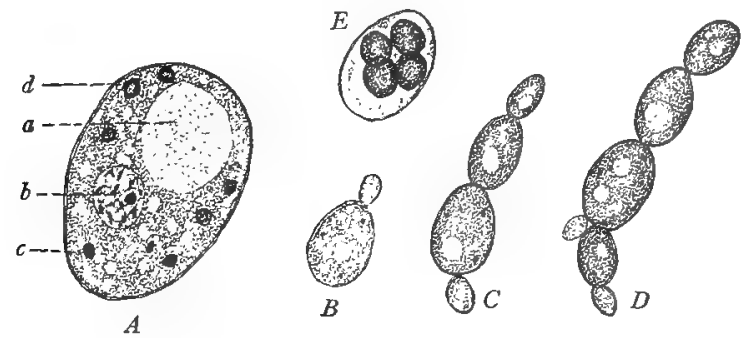

FIG. I3. - A yeast. $A$, a single cell, killed and stained so as to show its parts; $a$, vacuole; $b$, nucleus; $c, d$, reserve food. $B$, the division of the cell by budding. $C, D$, chains or colonies, formed by the remaining together of the daughter cells after division. $E$, spores inside the wall of the mother cell.

and full of small bubbles that rise slowly to the surface. Examining a drop of the liquid, we shall find that it contains great numbers of rounded cells, some single and others in chains of two, three, or more. These cells are yeast plants. A yeast cell (Fig. I3, A) is larger than the bacillus that we have studied (it is about $\frac{1}{300}$ inch in diameter), but resembles the bacillus in being colorless. It is either globular or, more commonly, a little longer in one direction. It is surrounded by a wall. 
The protoplasm contains many small bodies or granules, some of which often are yellowish in color; these latter are drops of oil. There is commonly also a large, round, clear space; this is a vacuole-a part of the protoplasm which contains chiefly water with small amounts of various substances dissolved in it, and which because of its watery nature is clearer and more transparent than the rest of the protoplasm. Sometimes, instead of a single large vacuole, a cell contains two or more smaller ones. There is also a nucleus, which cannot be seen in the living cell, but which can be made visible by careful staining of a killed cell.

50. Food. - From the fact that the yeast reproduces so rapidly in the molasses solution, we may conclude that it finds there the substances necessary for its food. Since it has no chlorophyl, it cannot make use of as simple food materials as can Protococcus. We have seen that Protococcus can build up sugars out of carbon dioxid and water. The yeast cannot do this, so must obtain sugar or some similar food ready-made. Sugar, of course, it finds in the molasses solution. But sugars contain no nitrogen, nor do they contain certain other elements (especially sulphur and phosphorus) that are needed in building up living matter. For this reason the yeast could not long continue to live and grow in a pure sugar solution - that is, in one that contained only sugar and water. But in reality our molasses solution is not pure; it contains small amounts of substances other than sugars, and these other substances supply the additional elements that the yeast must have.

51. Respiration. - Like all other living organisms, the yeast requires oxygen, which plays its part in breaking down the living matter and other substances within the cell arid so in furnishing a supply of energy. Like Protococcus and most other organisms, excepting some bacteria, the yeast must obtain oxygen from the air. It can, however, get along for a time if air is excluded, and in this respect it resembles those bacteria that can do without oxygen from the air; but the yeast must have access to the air from time to time if it is to continue to thrive. 
52. Fermentation. - What makes the yeast of so great practical importance to us is its power of carrying on alcoholic fermentation. This consists in breaking down a sugar into carbon dioxid and alcohol. The carbon dioxid is the gas, bubbles of which are so plentiful in a vigorous yeast culture. This fermentation has nothing to do with the use of sugar by the yeast as food. Neither the carbon dioxid nor the alcohol produced by fermentation is of any use to the yeast; in fact, alcohol in any considerable quantity is a poison to it, and so when the alcohol accumulates in the solution to a strength of about I 2 per cent the activity of the yeast is checked; I4 per cent of alcohol entirely stops its action, and more than I4 per cent kills the yeast. The sugar that is used by the yeast as food is taken directly into the cell, and is not fermented.

The usefulness of fermentation seems to be that it sets free large amounts of energy' which the yeast can use in somewhat the same way that most plants and animals use the energy set free in the process of respiration. The ability to obtain energy through fermentation probably explains why the yeast can get along for a time without oxygen from the air - that is, fermentation in part replaces respiration in the life of the yeast. This notion is supported by the fact that fermentation is most rapid when the supply of oxygen is small and when, therefore, respiration is slow. Yeast is used in bread-making because by fermentation it produces carbon dioxid; this gas makes its way throughout the dough, forming minute cavities and, as we say, making the bread light. The alcohol which is also produced is driven off by the heat used in baking the bread, and the size of the cavities in the dough is increased because the gas expands when it is heated. In the manufacture of fermented beverages, such as beers and wines, the alcohol is the important product of fermentation and the carbon dioxid is of less consequence.

53. Enzyms. - The yeasts, like bacteria and all other organisms, produce enzyms which bring about chemical 
changes both inside and outside the cell. Since the changes produced by yeasts are of such great practical importance, their enzyms have been much studied. The fermentation of sugar is due to one of these enzyms. This is shown by the fact that the yeast cells can be killed and the enzym extracted and filtered, and the substance so obtained will produce exactly the same change in sugar that goes on in the presence of living yeast. This particular enzym will not ferment all sugars, but only certain comparatively simple ones, and especially those of the class to which glucose belongs, If the yeast is placed in a solution containing cane sugar (or beet sugar, which is chemically the same thing), it first changes the cane sugar into a simpler sugar by means of a sugarchanging enzym, and then this simpler sugar is fermented.

54. Reproduction by Division. - The yeast cells reproduce, like those of bacteria and Protococcus, by division, but the method of division is somewhat different. The first indication that it is to occur is the appearance of a small swelling like a bud at one side or one end of the cell (Fig. I3, B). This is caused by the pushing out of the protoplasm and the cell wall at that point. The bud grows rather rapidly. The nucleus of the cell divides into two, and one of the daughter nuclei moves out into the bud. When the bud has reached a certain size it is cut off by a wall, so that there are now two cells, of which one (the former bud) is smaller than the other. The smaller cell grows to full size. Both cells may then form new buds. The cells may remain attached after a division, so forming a colony of two cells; but sooner or later they are likely to be separated. If growth and division are going on rapidly, we frequently see not merely two cells but a row of several cells (Fig. I3, C, D), and sometimes even branched rows due to the formation of buds on two or more sides of a particular cell.

55. Reproduction by Spore Formation. - Some yeasts under unfavorable conditions, as when they are starved or when the liquid in which they live dries up, form two, three, or four thick-walled cells within the original cell wall (Fig. I3, E). These thick-walled cells are called spores, and like the spores of bacteria they are able to endure heat, cold, and dryness better than the ordinary yeast cells. Sporeformation in yeasts, however, is quite different from spore-formation in bacteria, because it results from cell division and is therefore a 


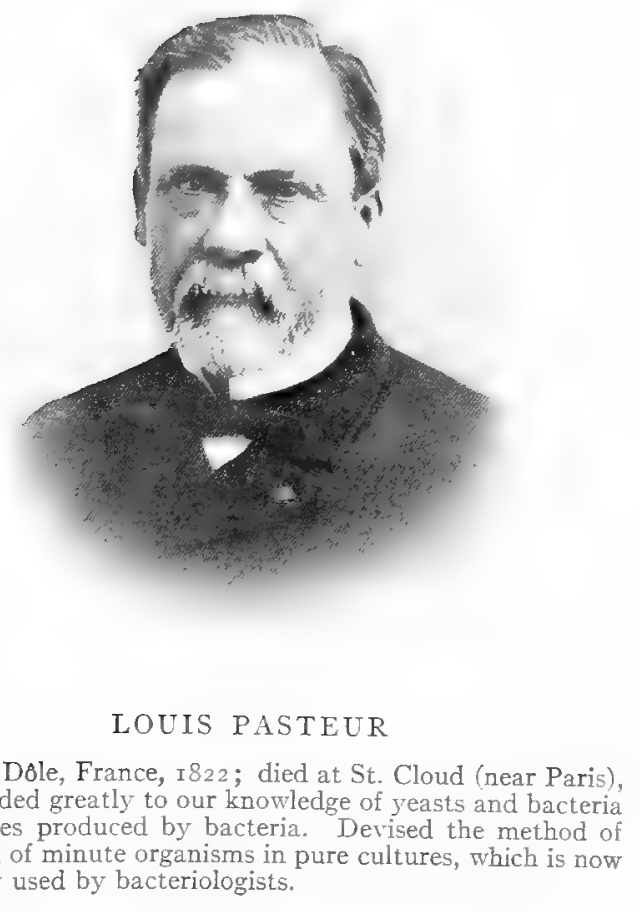



method of reproduction. In the bacteria, as we know, the spore is formed by a shrinking of the cell contents without any division.

56. Species of Yeasts. - The yeasts belong to the genus Saccharomyces. There are many species and varieties, which are not easily distinguished from one another. Commercial yeast used in bread-making is ordinarily a mixture of several species. The yeasts used in Deer-making are of two distinct sorts which are very different in form and size. "Bottom " yeast, used in brewing most German and American beers, is found in the lower part of the malt solution, and produces fermentation at low temperatures. "Top " yeast, used for English ale, stout, and porter, lives at the top of the liquid, and its fermentation goes on at relatively high temperatures. The yeasts that ferment grape juice are of different varicties, and the characteristic flavors of the many different wines are due in large part to the different yeasts which produce them and which cause, in addition to the ordinary alcoholic fermentation, the formation of other substances that modify the flavor of the wine.

Besides beers and wines, there are many other fermented beverages due to the action of yeasts, such as kumiss and pulque. Distilled liquors, like brandy and whisky, and commercial alcohol itself, are also the result of a fermentation. by yeasts, followed by distillation. The beer yeasts and the bread yeasts are known only in cultivation. The wine yeasts live on the soil of vineyards and are carried to the skins of the grapes in the dust that is blown about. They are "wild" yeasts, and different varieties occur in different localities. In the same way, a wild yeast that lives on the soil under apple trees causes the fermentation of cider; and many other wild yeasts produce a variety of fermentations.

57. Relationships. - The yeasts belong to the great group of fungi (singular, fungus), which includes the relatively simple plants that are without chlorophyl. In the broadest sense of the term, the fungi include the bacteria also. The relation of yeasts to other fungi is not 
clear. There is some reason to think that they may be descendants of more complex fungi which have degenerated in the course of evolution; but this is by no means certain.

58. Historical Note. - In I680, Leeuwenhoek noticed that yeast seen under the microscope consists of small, rounded particles. About I 838 it was discovered by several observers that the particles which Leeuwenhoek had seen are really plant cells, and it was concluded that these living cells in some way produce the chemical changes that go on only when they are present. Nearly twenty years later, Pasteur took up the study of yeasts at the request of German brewers, who were greatly troubled by impure yeasts. In 1856 , Pasteur found a method of securing "pure cultures" - that is, cultures which contain only one variety of yeast and no other organism whatever. By this method he studied many different forms of yeast; he not only succeeded in revolutionizing the brewing industry, but his method of pure cultures was the starting-point of the modern study of bacteria as well. 


\section{CHAPTER V}

\section{A POND SCUM}

59. Pond Scums. - The appearance of a green layer on the surface of pools, ponds, and lakes is a familiar one, especially during the warm months of the year. This scum is made up of green plants which belong, like Protococcus, to the group of algæ. Of the many species that may be found in such a green layer, some, like Protococcus, are one-celled, or are made up of small groups of cells; others have the form of long threads, and one of the commonest of these threadshaped scum-forming algæ is Spirogyra. Sometimes me find several species of algæ growing together on the surface of a pond; sometimes the scum is composed largely or wholly of one species. Spirogyra may be distinguished from most of the other thread-shaped algz found in similar places by the slippery feeling of a mass of the long, unbranched threads.

60. The Spirogyra Plant. - The simple plants that we have studied thus far (bacteria, Protococcus, and yeasts) are sometimes found in colonies of various sizes; but often their cells are separate, and the single cells seem to get along just as well as do those that are parts of colonies. Under certain special conditions and at particular stages, the cells of Spirogyra may occur singly; but practically we always find the plant in the form of a row of cells firmly attached to one another. That is, the colony habit has become firmly fixed in Spirogyra, whereas in the cases of the simpler plants that we have studied a colony was a temporary and a more or less accidental arrangement. 
61. The Cell (Fig. I4). - A cell of Spirogyra is longer than it is wide, and cylindrical, like a length of stovepipe. The cells are joined end to end, and the whole plant is surrounded by a continuous, rather thick wall, which is made up of several layers. The outermost layer, which is very transparent and therefore not easily seen, is composed of a slimy substance, and it is this layer that gives to the plant its slippery feeling. There are cross walls also between adjacent cells. The most noticeable part of the cell is the green chloroplast. Each chloroplast winds about spirally, within and close to the wall. There are about one hundred known species of Spirogyra, and one of the points of difference between species is the number of chloroplasts in

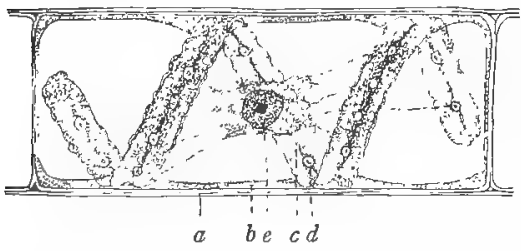

FIG. I4. - A single cell of a Spirogyra plant; $u$, wall; $b$, outer layer of slimy cytoplasm; $i$, chloroplast, containing (d) pyrenoids; $e$, nucleus, imbedded in a central mass of slimy cytoplasm which is connected by strands of the same substance with the outer cytoplasmic layer. each cell. Some species have only one chloroplast, some two, and some have much larger numbers. Often we find two or three species mixed together, and it is best to select for study a form with one or two, or as small a number of chloroplasts as can be found.

The body of the chloroplast itself is distinct from the coloring matter (the chlorophyl) which makes it appear green. This is shown by the fact that the green color can be dissolved out of the chloroplast by placing the plant in alcohol. Scattered along the middle line of the chloroplast are a number of colorless pyrenoids. At just about the center of the cell is a rather large, colorless, rounded nucleus. The nucleus is often hidden by a coil of the chloroplast, but in some of the cells of a plant it can usually be seen quite plainly if the microscope is carefully focused upon the interior of the cell. In the nucleus there is a rounded body that looks brighter than the rest of the nucleus; this body is the nucleole.

By careful study, one can see a thin layer of granular substance just within the cell wall; sometimes the layer is in active movement, as is shown by the streaming of the granules that it contains. This layer of granular material is a part of the slimy cytoplasm. ${ }^{1}$ Another layer

${ }^{1}$ Sometimes this slimy portion of the living matter of the cell is spoken of simply as cytoplasm, or "ven as protoplasm. These terms are often confused; but in the usage of the most careful modern writcrs, protoplasm refers to all the substances 
of slimy cytoplasm (also difficult to see) surrounds the nucleus, and strands of the same material connect the layer about the nucleus with the layer next the wall. Thus all parts of the slimy cytoplasm are connected with one another, and the nucleus and chloroplast are imbedded in it.

The rest of the space inside the wall that is not occupied by the slimy cytoplasm, chloroplast, and nucleus is the central vacuole. From the description that has been given it is plain that this vacuole is of very irregular shape. It contains a clear liquid. (cell sap), composed of water containing a weak solution of salts, sugars, acids, and other substances.

62. The Food of Spirogyra. - The word food may be applied to any substance that is used by a living cell in any stage of the building up of living matter. This building-up process is one of many steps. Therefore there is a long series of substances that may be used by plants, beginning with very simple things (water and carbon dioxid), and ending with certain very complex ones (proteins), which represent the last steps previous to the formation of living matter itself. In taking in food substances from outside, and in using these substances within its own body, Spirogyra behaves very much as does Protococcus and as do the higher green plants (such as the cucumber) with which we are more familiar. In the higher green plants, the work of absorbing and of manufacturing food is divided between many different kinds of cells; but in Spirogyra, as in Protococcus, each cell does practically all this work for itself. Spirogyra, like all other plants, can take in materials from the outside only in a dissolved condition; everything that is to be absorbed, therefore, must be dissolved in water before it can pass through the cell wall.

63. Manufacture of Carbohydrates. - It is true of all green plants that they take in from the outside world only a few very simple substances and that they build up these sub-

within the cell wall, and cyloplasm to all of the protoplasm excepting the nucleus. Using the terms in this way, the chloroplasts, vacuoles, and some other parts of the cell are parts of the cytoplasm, as is also the slimy, viscous material here called the slimy cytoplasm. 
stances within their own bodies into more complex foods. In this respect the green plants have a great advantage over plants without chlorophyl (like the bacteria and the yeasts), and over the animals (including ourselves) as well. Green plants can live and thrive on a food supply that would be quite useless to an organism without chlorophyl. Among the simple substances absorbed by Spirogyra are water (which is made up of hydrogen and oxygen), and carbon dioxid (composed of carbon and oxygen). Carbon dioxid is a gas which makes up about three-hundredths of one per cent of the air; it is also present in solution in the water in which Spirogyra lives. Cells containing chlorophyl can manufacture out of carbon dioxid and water certain substances known as carbohydrates (composed of carbon, hydrogen, and oxygen). Starch and sugars are among the commonest carbohydrates. Probably the first carbohydrate formed in the Spirogyra cell is glucose or a similar sugar. When a sugar is built up out of carbon dioxid and water, some of the oxygen which these substances contain is given off. This oxygen appears as bubbles of gas in the water, and if we examine a mass of vigorous Spirogyra that is floating on the surface of a pond on a bright day, we shall find many of these bubbles tangled among the Spirogyra threads. Carbohydrates are manufactured only by cells that contain chlorophyl, and only in the presence of sunlight.

64. Starch. - The first carbohydrates manufactured by the Spirogyra cell, as we have seen, are probably sugars. They are at once dissolved in the cell sap. As time goes on, the sap contains more and more sugar. But when the sugar in the sap reaches a certain proportion, some of the sugar is changed into another carbohydrate called starch. Starch is a solid, insoluble stubstance and, being compact, it is a convenient form in which to store carbohydrates when more are manufactured than can be used at once. The pyrenoids are the parts of the cell that actually do the work of changing 
sugars into starch. If we place a drop of iodine solution upon a cell of Spirogyra, each pyrenoid seems to turn blue or blue-black. Careful examination, however, shows that it is not the pyrenoid itself that is colored by the iodine, but a layer, or sometimes two or more layers, of small bodies surrounding the pyrenoid. These small bodies are grains of starch. Iodine is a valuable test for starch; any substance which turns blue or blue-black when in contact with iodine, we may be sure is made of starch or contains starch. ${ }^{1}$

65. Digestion of Starch. - As wre have seen, sugar is made only in the sunlight, and when it is manufactured rapidly (as on a bright day) much of it is changed into starch. During the night no sugar is made. The cell needs about as much food at night as it does during the day, and so some of the starch that has been stored up during the day is used for food at night. Since the starch itself is not soluble, it must be changed into a soluble form before it can be used - that is, it must be digested. Spirogyra digests starch by means of certain enzyms which it produces and which change the starch back into a sugar.

66. Other Food Substances. - Carbohydrates are made up of carbon, hydrogen, and oxygen. In addition to these elements, living matter contains nitrogen, sulphur, and phosphorus, as well as smaller amounts of several other elements. The elements that are not present in carbohydrates are obtained by the plant in the form of simple salts - largely nitrates, sulphates, and phosphates - which are present in small quantities in the water in which Spirogyra lives. Out of carbohydrates and some of these absorbed salts, the cell builds up a class of very complex compounds known as proteins. Proteins are always present in living cells, and up to the present. time they have never been made outside of living cells.

${ }^{1}$ Some other substances, very similar in chemical composition to starch, are also turned blue or violet by iodine; but starch is the only substance so affected that we are likely to meet in everyday life. 
67. Living Matter. - Proteins, complex as they are, are not themselves living matter, but living matter is built up in turn out of proteins and some other food substances that the cell has either taken in or made for itself. The living matter of the Spirogyra cell is found in the slimy cytoplasm, in the chloroplasts, and in the nucleus. It is a very unstable substance; and just as it is being continually built up, so it is being constantly torn down. This continual change that living matter is undergoing is one of the most striking things about it. We must think of a living cell as something like a chemical laboratory in which there are going on at the same time one long series of changes that lead from the simple substances that come in from the outside, through the carbohydrates and proteins, to living matter itself ; and another equally long series of changes that lead from living matter downward again to very simple substances (including carbon dioxid and water), which in turn may be given off by the cell as waste materials, or may be used once more in rebuilding living matter. Even in the living parts of the cell there is a good deal of water; the cell wall is thoroughly water-soaked; and since the cell sap is mostly water, it follows that water makes up a very large proportion of the whole bulk of the Spirogyra cell.

68. Respiration. - Like the yeasts and other plants that have been studied, Spirogyra must respire - that is, it must take in oxygen, which like carbon dioxid is present in solution in the water in which the plant lives. Oxygen is not a food as carbon dioxid is, because it is not used in building up new substances. Its use is rather to assist in the tearing down which, as we have seen, goes on side by side with the building-up process. In this tearing down, energy is liberated which the cell uses in various ways - for instance, in growth, as well as in other activities that are continually going on in the plant. Thus resprivation is a source of energy to the cell. One substance that is formed in large 
quantities as a result of the tearing-down process of respiration is carbon dioxid. In respiring, therefore, Spirogyra, like nearly all plants and animals, takes in oxygen and gives off carbon dioxid; at the same time it may be taking in carbon dioxid as a food and giving off oxygen as a waste product of carbohydrate formation. The net result of these two oppositc processes upon the supply of oxygen and carbon dioxid in the water and the air about the plant depends upon which process gocs on more rapidly. During the day, carbohydrate formation ordinarily goes on so actively that much more carbon dioxid is taken in for this purpose than is given off in respiration, and much more oxygen is given off than is absorbed. At night, respiration continues but carbohydrate formation is stopped, and so only oxygen is taken in and only carbon dioxid is given off.

69. Reproduction by Division. - As in the other plants that we have studied, the number of cells of Spirogyra is increased by the division of one cell into two, each of these into two, and so on. The cells are so much larger than those of the bacteria, Protococcus, or yeasts that the method of division can be more easily studied. Unfortunately, division almost always goes on in Spirogyra during the night. The first step in preparation for

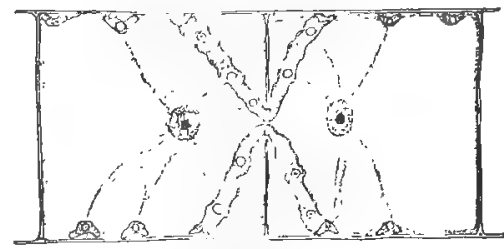

FIG. I5. - A stage in the division of a Spirogyra cell (as seen in a lengthwise section). After Strasburger. the division of the cell is a division of the nucleus into two. This division of the nucleus is brought about by a long and complicated process. The two daughter nuclei then move apart toward the ends of the cell, and about halfway between them the outer layer of the cytoplasm (just within the wall) becomes furrowed inward (Fig. 15), much as though some one had wound a thread about the middle of the cytoplasm and then had begun to tighten the thread. The furrow, which extends entirely around the cell, becomes deeper and deeper, until the cell is cut into two cells, the chloroplast also being cut in two in the middle. As the furrow cuts inward, a new wall is formed within the furrow, connected with 
the outer wall of the cell; finally, when the new wall has grown clear across the cell, the two daughter cells are fully formed, each having all the parts that the mother cell had, but being only half as large.

In examining a Spirogyra plant, one always finds that the cells are of different lengths; and often there are two short cells side by side, each about half the length of the longer cells of the thread. Such a pair of short cells is the result of a recent division, probably one that occurred during the previous night. After a division the daughter cells grow, and when they have reached their full size each of them again divides. It is by a series of alternate periods of growth and division that the number of cells in a thread increases, and that the thread as a whole grows longer.

Cell division is a method of reproduction because it increases the number of cells; it does not, however, at least directly, increase the number of plants. Sometimes a plant is accidentally broken into two or more; and the plants of some species of Spirogyra have a definite method of breaking up at times into single cells or groups of cells. Such a process of breaking up is also one of reproduction which increases the number of plants, but not the number of cells.

70. Conjugation. - After the Spirogyra plants have been growing for a time, their cells cease to divide and prepare instead for a very

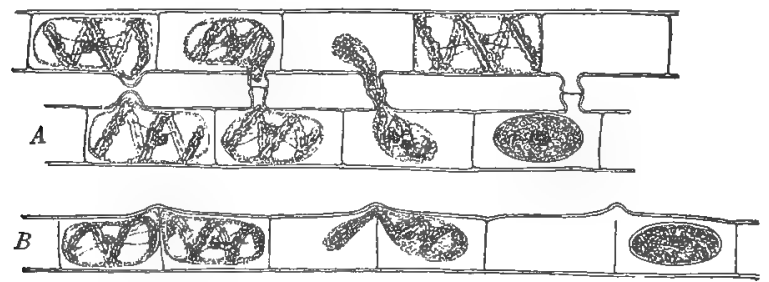

FIG. I6. - Conjugation in Spirogyra. $A$, the commoner method, by which gametes from different plants unite to form a zygote; $B$, the conjugation of gametes produced by the same plant.

different process, in which two cells are to unite and form a single cell. The first step in preparation for this conjugation is an arrangement of the plants so that two lie parallel and near together. Then many or all of the cells of each plant put out projections, one from each cell (Fig. I6, A), which grow toward the cells of the neighboring plant. Usually a cell in one plant is opposite a cell in the other; the projections from two opposite cells grow toward each other, come in 
contact, and the wall of each projection is dissolved at the point of contact; the two cells, one in each plant, are now joined by a conjugation ube. The two plants are thus connected by a series of tubes.

Occasionally, of course, since the cells are not all of the same length, a cell in one plant fails to find a mate in the other; but the majority of the cells are connected in pairs. While the conjugation tubes are being formed, the contents of each cell shrinks away from the wall and rounds up; and of the two cells of a pair (one in each plant), one begins to round up a little earlier than the other. We shall speak of the one that rounds up first as the male cell, or male gamete, and of the other as the female cell or female gamete. After the conjugation tube has been formed, the male cell (of course without its wall) moves through the tube into the cavity occupied by the female cell. The two cells now lie close together inside the same wall. They gradually unite to form a single rounded cell, the zygote (Fig. I7, C), which builds a new thick wall about itself. In the union of the male and female cells, the cytoplasms of the two flow together, and their nuclei unite to form a single nucleus (Fig. I7, A, B); the chloroplast of the male cell disappears, and that of the female cell becomes the chloroplast of the zygote. When conjugation takes place by the method just described, all the gametes produced in one plant are usually of the same sex; in such a case we may speak of male plants and female plants.

71. Lateral Conjugation (Fig. I6, B).-In some species of Spirogyra, conjugation takes place between two cells which lie next each other in the same plant - that is, one plant bears both male and female gametes. Each gamete puts out a short projection close to the cross wall that separates them, and these projections unite to form a short conjugation tube. In other respects, this method of conjugation is the same as that already described.

72. Germination of the Zygote. - The zygote is a resting cell which can endure unfavorable conditions (as the spores of bacteria and yeasts can) and can remain dormant for a long time. Ordinarily the zygote is formed by conjugation in the late spring or
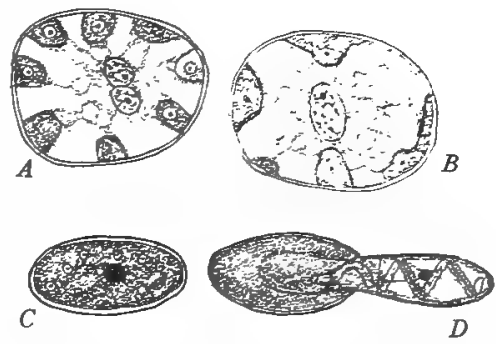

FIG. I7. - .1, a section of a zygote of Spirogyra, showing the nuclei from the two gametes. $B$, the union of the nuclei completed. $C$, a mature zygote. $D$, a germinating zygote. $A$ and $B$ after Tröndle; $C$ and $D$ after Strasburger. 
summer, or in some species of Spirogyra in the fall; it sinks to the bottom of the body of water in which the plants live and remains there until the next spring, when it germinates. If the plants live in a small pond that dries up during the summer, the zygote remains alive in the dried mud and germinates when the pond again fills with water the next spring. The old cell walls, within which the zygotes were formed, decay and largely or entirely disappear. In germination, the zygote simply grows in one direction (Fig. I7, D), becoming a long cell and breaking through its outer wall at one side or end. Then it divides and a cross wall is formed; the zygote has now become a two-celled plant. One of the two cells (the one that is not surrounded by the outer wall of the zygote) divides, its daughter cells divide, and by a series of repeated divisions a long, thread-like plant is again formed.

73. Nature of Sexual Reproduction. - A union of two sexual cells (gametes) to form a zygote is commonly called sexual reproduction. Conjugation - that is, the union of two gametes that are nearly or quite alike, as those of Spirogyra are - is one form of sexual reproduction. Strictly speaking, a union of gametes is not reproduction, because reproduction means an increase in numbers, and when two cells unite to form one there are fewer cells than there were before. However, each of the many zygotes formed by the gametes from two Spirogyra plants may grow into a new plant; in this way the number of plants is increased, and so it is truc that indircetly the union of gametes results in a reproduction of the plant. A similar union of gametes occurs at some stage in the life, not only of many other green algæ more or less like Spirogyra, but also in that of most of the higher plants. The same is true of the higher animals. The gametes of Spirogyra are very much alike in size and appearance; they differ in behavior in that one (the male gamete) is more active than the other (the female). In most of the plants that we are to study, we shall find a great difference in size and appearance as well as in behavior between the male and the female gametes.

74. Distribution and Relationships. - The various species of Spirogyra occur in bodies of fresh water in all parts of the world. Spirogyra is a representative of the higher green algæ, others of which differ from Spirogyra in many respects, but most of which resemble it in being thread-like. Somc of them are unbranched threads like Spirogyra; others are branched. A common branched form is Cladophora (Fig. I8, A), dense masses of which are found in the same sort of places as those in which Spirogyra grows. V'aucheria (Fig. 18, B), which forms a dark-grecn felt on damp soil and greenhouse benches or is attached to rocks and other objects in streams, is a branched alga, 
composed, like the bread mold to be described in the next chapter, of a single large cell containing many nuclei. Most of the threadlike green algæ have some form of sexual reproduction, some of them by means of gametes nearly or quite alike, as are

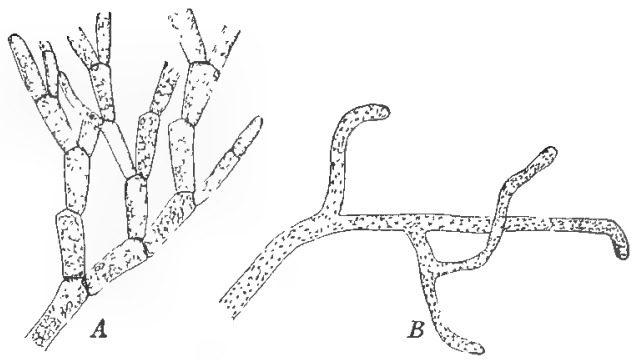

FIG. 18. - Branched green algæ:

$A$, Cladophora; $B$, Vaucheria. those of Spirogyra; others by means of large, passive female gametes' and small, active male gametes.

75. Algæ of Water Supplies. - The drinking water of cities, whatever its source, is sure to contain some algæ, especially if it is stored in reservoirs. Certain kinds of algæ, of which Spirogyra is one, sometimes multiply very rapidly in reservoirs of city water. This leads to unpleasant results, partly because the mains or pipes may become clogged, but chiefly because when the algæ die they decay and give an unpleasant taste and odor to the water. It has been found that the growth of algæ in drinking water can be checked by the use of small amounts of copper sulphate, a solution of which will kill the algæ even though it is much too weak to be poisonous to human beings.

76. Marine Algæ. - The salt waters of seas and oceans, like fresh waters, contain an abundance of plant life. Among the inhabitants of salt water are a good many green algæ, not, however, including any of the species of Spirogyra. But the most characteristic marine plants ("seaweeds") belong to the groups of brown and red alge - so-called because their cells contain a coloring matter, brown in the one case and red in the other, masking the green color of the chlorophyl which is also present. The brown algæ include 
the large seaweeds known as kelps, one of which is the very

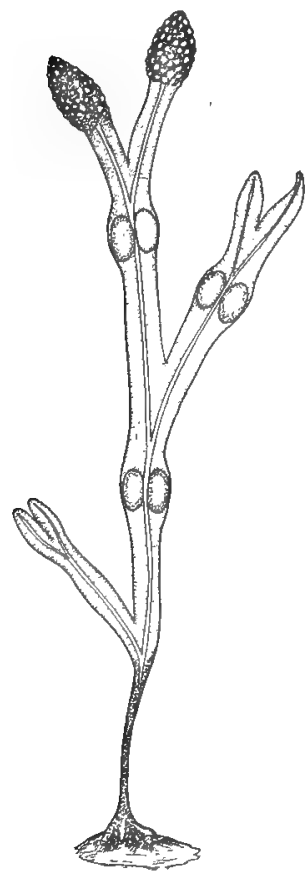

FIG. Ig. - The rockweed (Fucus), a brown alga. At the bottom is an irregularly flattened part that attaches the plant to the rock or other object on which it grows. At various places on the branches are bladder-like swellings which help to buoy the plant in the water. In the swollen portions at the ends of the branches, the reproductive structures are produced. common rockweed (Fig. I9). A close relative of the rockweed is Sargassum, which is torn by storms from the places where it grows along the American coast, and is carried out into the ocean by currents, especially by the Gulf Stream. Great numbers of the plants come to rest in that part of the north Atlantic which is most free from currents - the so-called "Sargasso Sea."

Certain kelps grow to be several hundred feet in length; they are therefore among the longest of living plants, although of course the bulk of such a plant is not equal to that of a large tree. Kelps have been used for many years as soil fertilizers on the coasts of the Scandinavian countries, the British Isles, France, and New England. Their value for this purpose is due chiefly to the large proportion of potash salts that they contain. Immense beds of kelps exist along the Pacific coast of the United States and Canada, and it is thought that they will prove a most valuable source of potash. Some of the brown algæ supply iodine on a commercial scale; some are sources of mannite. Many brown algæ are used for food in China and Japan, on the Pacific islands, and in the Arctic regions. None of the red algæ grow to be so large as the great kelps, but many of 
them are good-sized plants; some of them are also used for food in various parts of the world.

77. The Plankton. - The surface layers of any body of water, salt or fresh, contain vast numbers of small organisms. All of these floating plants and animals are spoken of together

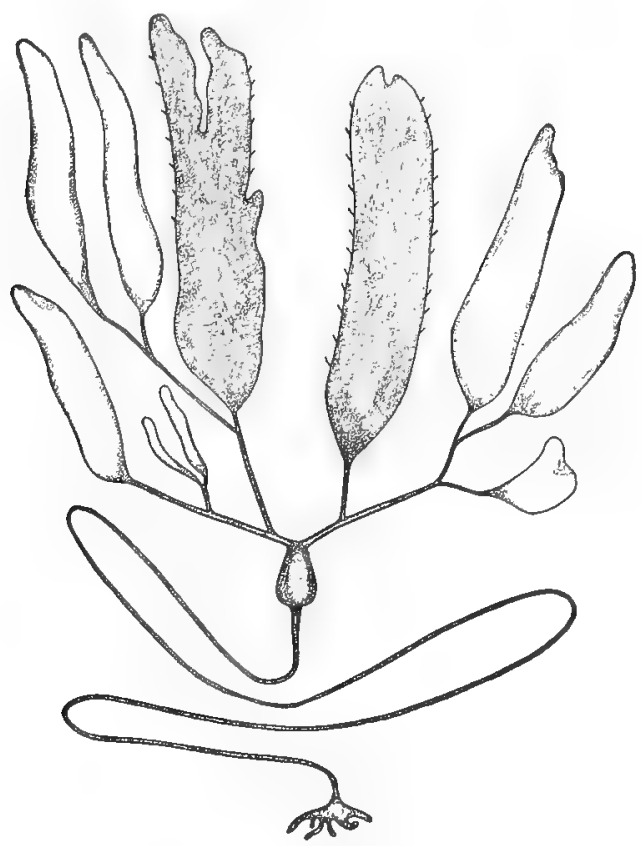

FIG. 20. - One of the giant kelps (Nereocysitis).

as the plankton. The number of minute living organisms present in and near the surface of a lake or river, and the rapidity with which such organisms grow and multiply, are almost inconceivable to one who has not made a microscopic study of such waters. It has been estimated, for example, that more than I49,000,000 pounds of small plankton organisms are produced each year in the Illinois River; this is 
about fifteen times the weight of all the fish hatched in the same river in the course of a year. The plankton includes various one-celled algæ more or less like Protococcus, as

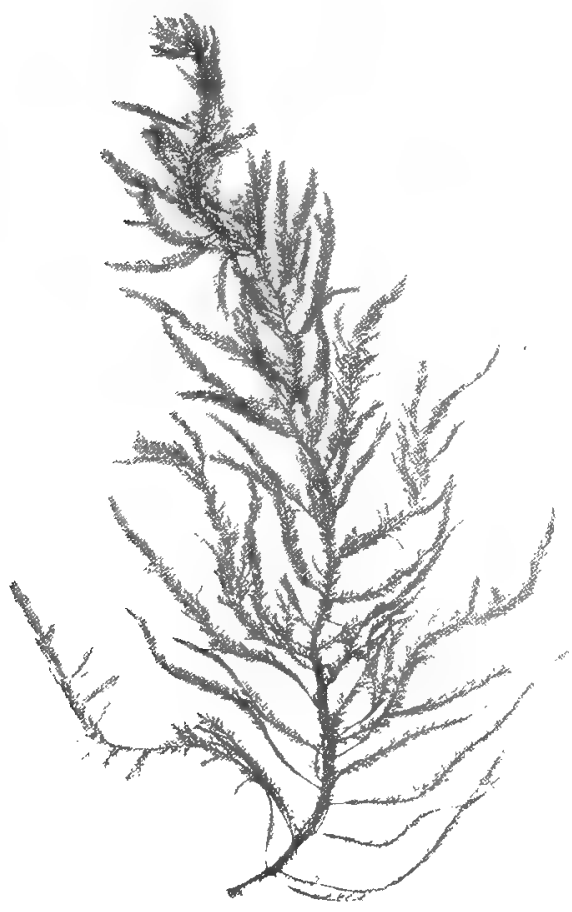

Fig. 2r. - A red alga (Dasya elcgans). well as many species that form small colonies. Algre as large as Spirogyra are not ordinarily thought of as belonging to the plankton; the use of the term is commonly limited to organisms that are microscopic or but little larger. The plankton algæ, building up their bodies as we have scen that Spirogyra does out of the simple substances that are dissolved in the river, lake, or sea water, themselves serve as food for the many kinds of minute animals in the plankton. Both the plankton algæ and the plankton animals in turn are used as food by the larger water animals, especially the fish, and the latter in their turn are an important item of human food. We are ourselves concerned, therefore, with anything that affects the number and the growth of the plankton organisms. 


\section{CHAPTER VI}

\section{THE BREAD MOLD}

78. Molds. - We know that bread, if allowed to stand for a time, becomes moldy. Spots, at first small and white or gray, appear upon its surface. Many of these spots are covered with a fluffy substance. Under a hand lens, the fluffy substance is found to be made up of many white or grayish branching threads. The spots grow rather rapidly, and in time they may cover the whole surface of the bread; their color changes to black, pink, red, blue, or green, and they take on a powdery rather than a fluffy appearance. The bread now has a characteristic "moldy" smell, and it gradually loses its firm consistency, changing to a slimy mass. Some of the changes in the bread are due to the action of bacteria, which may be present in immense numbers; but the fluffy spots consist of fungi of various kinds that are commonly called molds; they are much larger and more highly developed than the bacteria and yeasts, and they live upon the bread, using it as food. Similar mold spots appear on exposed surfaces of cake, fruits, preserves, damp leather, or in fact of almost any moist organic substance.

One of the commonest of the molds is Rhizopus nigricans, often called the bread mold, because it occurs so commonly on bread, although it appears also on many other substances and is said to cause a rot of sweet potatoes and of strawberries. The fluffy mass that we first see on the bread is the body of the fungus, and the powdery appearance as it grows older is caused by the presence of its very numerous spores. The older spots produced on the bread by this mold are black. 
79. A Mold Plant (Fig. 22). - We can see with the aid of a hand lens that the body of the bread mold is made up of threads, somewhat like those of Spirogyra, but branching abundantly, light-colored when young and darker or almost black when old. If we pick off a piece of a young mold plant and examine it under the microscope, we find that the

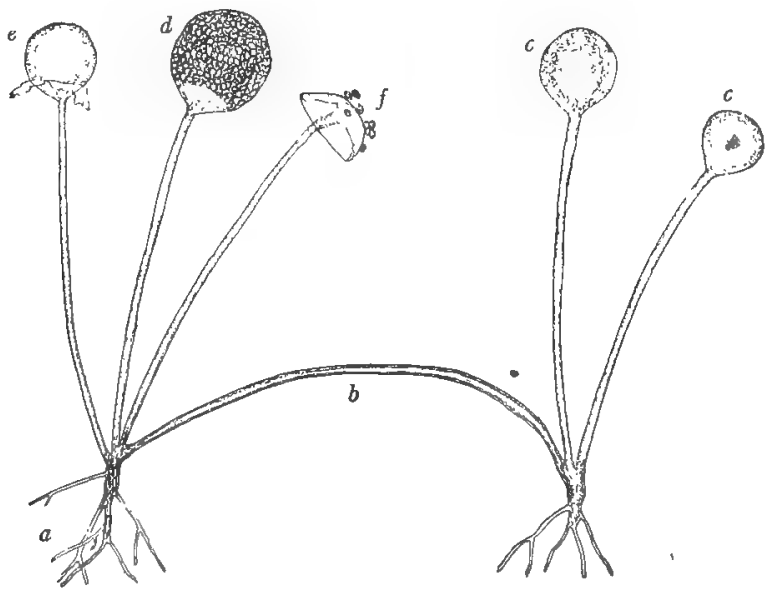

FIG. 22. - Part of a bread mold plant; $a$, downward-growing branches which obtain food for the plant; $b$, a horizontal branch; $c$, young spore sacs, borne at the ends of upright branches; $d$, an older spore sac containing ripe spores; $c$ and $f$, broken spore sacs from which the spores have escaped; in $f$, the internal dome-shaped wall has collapsed.

threads are not divided by cross walls. In fact, the whole plant - making, with all its branches, a large, interlacing structure - is, at least while it is comparatively young and growing rapidly, a single cell. This cell is much larger as well as more complex in form than any cell we have yet studied. The branches of the plant are of two kinds: horizontal ones (Fig. 22,b) which grow upon or near the surface of the bread, and others that grow in groups from the horizontal branches downward into the substance of the bread (Fig. 22, a). 
Each group of domnward branches is connected by horizontal branches with neighboring groups.

ITithin the cell wall which covers the plant is a colorless protoplasm that includes many vacuoles of different sizes, and often also yellowish fat drops, similar, except for their color, to the vacuoles. Frequently the protoplasm is seen to be in motion. Scattered through it also are many nuclei; but they are too small to be seen in the living plant. The presence of many nuclei in a single cell is another important difference between the bread mold and any of the plants previously studied. As the mold plant grows older, and especially when it is forming spores, cross walls appear here and there in various places, dividing the plant into several or many cells, each of which still commonly contains many nuclei. The same sort of cell division may occur earlier in the life of the plant if the supply of water becomes insufficient, or if for any reason conditions are unfavorable for growth.

80. Food. - Since it has no chloroplast and no chlorophyl, the bread mold cannot use carbon dioxid and rater to build up carbohydrates, and, like the bacteria and the yeasts, it must obtain its carbohydrate food ready made. Like the yeast, the bread mold is a saprophyte - that is, it lives upon dead organic materials. The carbohydrate food present in bread is chiefly starch; there is also some cellulose and there are probably traces of sugar. The starch, as well as the proteins which are present in the bread, must be digested that is, must be changed by enzyms into simpler substances that can be dissolved and so taken in by the mold through its wall. The bread also supplies water, of which the mold requires a great deal, and probably small amounts of other food substances as well. Then more carbonydrate food is taken in than the plant can use at once, the surplus is trans-. formed into fat. Fat is a very common reserve food in fungi, taking the place of the starch that is so abundant in most green plants.

81. Spore Formation. - After the mold has been growing for some time and has reached a considerable size, branches of a third kind begin to appear. These are stouter than the 
branches we have already studied; they start from the horizontal branches at about the same places at which the groups of downward branches start, but they grow upward into the air. After one of these upright branches has grown for a time, its upper end begins to swell, forming a globular body that will become a spore sac (Fig. 22, c). When the spore sac has reached nearly its full size, a dome-shapea wall is formed in it, dividing it into a central portion and an outer portion. The protoplasm (including cytoplasm and nuclei) which fills the outer portion of the spore sac now cuts itself up into a large number of small cells (Fig. 22, $d$ ). When the spores are ripe, the outer wall of the spore sac breaks (Fig. 22, $e, f$ ), and the spores are scattered. If a spore falls upon moist bread or some other substance on which the mold can live, it begins to grow into a new plant. The spores are so light
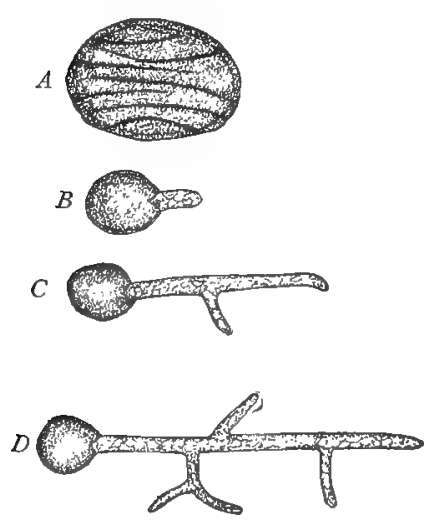

FIG. 23. $-A$, a ripe spore of the bread mold, much enlarged. $B, C, D$, stages in the development of spores into young plants. that they are easily carried about by currents of air. Like the spores of bacteria and of yeasts, they are present in the air practically everywhere that human beings live, and this is why Rhizopus nearly always appears on moist bread that is exposed to the air.

82. Germination of the Spores. - A mold spore can live for some time in a dry place without germinating. But if it falls in a place favorable for growth, it soon develops into a new plant. Germination begins with the appearance of a swelling at one side of the spore (Fig. 23, B); this swelling grows longer and begins to look like a branch of a mature plant. Sometimes two or more outgrowths 
appear on different sides of the spore, and each grows into a part of the new plant. Soon branches appear upon these outgrowths (Fig. 23,C,D), and by continued growth and repeated branching the condition of the mature plant is reached.

83. Aserual Reproduction. - Te have seen that the cells of Spirogyra reproduce by division, but that cell division does not result, at least directly, in a reproduction of the Spirogyra plant. Spore formation in the bread mold is brought about by cell "livision which, like cell division in Spirogyra, increases the number of cells; but the spores of the mold are a special sort of cells, each of which grows as soon as possible into a new plant. Thus this particular kind of cell division by which the mold spores are formed is a means of reproduction of the plant as well as of the individual cells. Reproduction by means of spores is commonly called asexual reproduction, to distinguish it from the union of gametes, which is called sexual reproduction. Te see that the essential thing in asexual reproduction is a cell division; but that in sexual reproduction the essential thing is a cell union.

84 Sexual Reproduction. - The bread mold has also a method of sexual reproduction similar in some respects to that of Spirogyra.

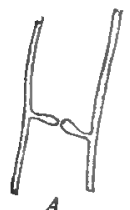

$\boldsymbol{A}$

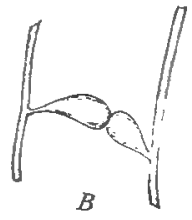

$B$

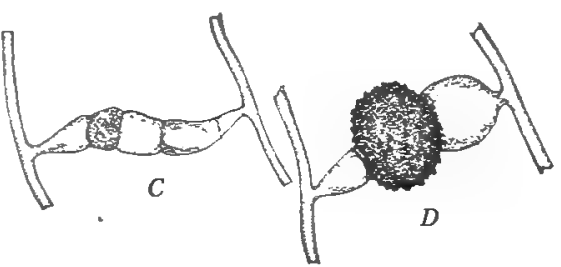

FIG. 24. - The development of the gametes of the bread mold and their union to form a zygote.

The two gametes that unite are always borne on two separate plants which belong to two different races or strains, spoken of as plus and minus strains. As a rule, when we find Rhizopus growing on bread all the plants belong to one strain. Two plants of the same strain growing together will not form gametes, and this is why we do not often see the sexually produced zygotes. But when two plants, one of a plus and one of a minus strain, grow so close together that a branch of one comes in contact with a branch of the other, on each of these branches a projection appears. 
These two projections (which are themselves really short branches) grow in length, their ends being in contact all the time (Fig. 24, A, B); they look much like the projections which form the conjugation tube of Spirogyra. Next, the end of each projection becomes a separate cell cut off by a wall from the rest of the projection (Fig. 24, C). The two short end cells thus formed are the gametes. The walls of the two gametes are now dissolved where they touch each other, and the gametes unite to form a single cell - the zygote. The zygote becomes a large, spherical cell with a thick wall, still attached by short branches to both the parent plants (Fig. $24, D$ ). Of

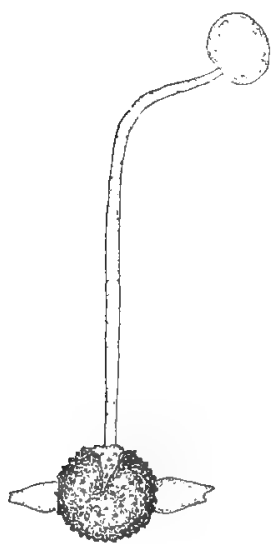

FIG. 25. - Germination of a zygote of Rhizopus. After Brefeld. the branches which bear the gametes, one is somewhat smaller than the other, and the smaller branch usually bears a smaller gamete than the larger one.

85. Germination of the Zygote (Fig. 25). - The zygote of Rhizopus, like that of Spirogyra, is a resting cell; that. is, it may remain for a long time without apparent change and still be able to germinate when conditions become favorable for the growth of the plant. When the zygote germinates, a swelling appears on one side, much as in the germination of a spore; this swelling grows, not into a large, much-branched plant like the one we have studied, but into a short stalk, which, like the upright branches of the ordinary mold plant, bears a spore sac. The spores produced in this spore sac germinate in turn into branched plants exactly like the plant that we studied first. Thus, instead of developing a single ordinary plant from each zygote, as Spirogyra does, the mold forms many spores almost at once, and so a great many mold plants result from the germination of a single zygote.

86. Advantages of Spore Formation. It is plain that this method of quickly multiplying its numbers after a zygote germinates is very useful to the mold, especially as the zygotes are scattered about and subjected to all kinds of unfavorable conditions, and it is probable that only a small proportion of them ever germinate. The same sort of advantage to the plant results from the production of spores throughout its 
life. Saprophytic plants like the mold, and parasitic ones like many of the other fungi, are likely to produce great numbers of spores. This habit enables them to multiply their numbers quickly when food of the sort that they need is plentiful; and it gives them a much better chance of living over the unfavorable periods that are bound to come to such plants, when the food that they need is not to be had. On the other hand, plants which, like Spirogyra, live under conditions that are likely always to be much the same, at least at the same season of the year, have much less need of a means of rapid multiplication at special times. This is why Spirogyra succeeds as well as it does without producing any cells that correspond to the spores of the mold.

87. Relatives of the Bread Mold. - Rhizopus is one of a group of fungi which are commonly called the black molds. Other members of this group are 1 incor, whose species are common, especially on soil; Pilobolus, which grows on dung; Phycomyces, living on old bones and other oily organic matter; and Sporodinia, found on decaying mushrooms. All the black molds are characterized by a one-celled body made up of branching threads and by a method of sexual reproduction closely similar in each case to that of Rhizopus. In most of the black molds the two gametes of a pair are of the same size, instead of being different in size as are those of Rhizopus. In Sporodinia and in some other forms, both gametes are borne on branches of the same plant; but in most species they are borne, as in the bread mold, on separate plants belonging to two different strains. All the black molds produce large numbers of asexual spores, but these spores are produced in rerr different ways in different species. Most of the black molds are saprophytes, but a few are parasitic upon other fungi. 


\section{CHAPTER VII}

\section{THE WHEAT RUST}

88. The Rusts. - There is a very large group of parasitic fungi which cause great damage to the plants on which they live. Growing inside the tissues of its host plant, a
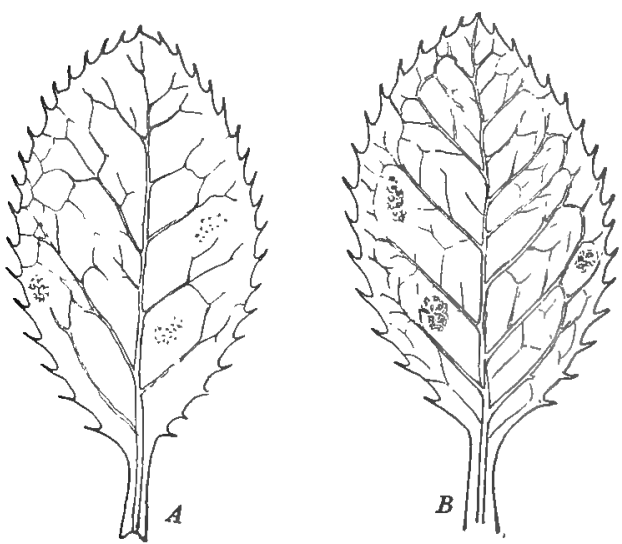

Fic. 26. $-A$, the upper surface of a barberry leaf, showing the diseased areas caused by the rust; the dark dots represent the openings into the cavities in which spermatia are formed. $B$, the lower surface of a leaf, showing infected areas and the cluster cups.

the life history of the parasite is passed. The common wheat rust, which we are to study, is one that lives for part of the year upon one host, and then transfers its activities to a second victim.

rust forms masses of spores which break through the epidermis of the host. But instead of forming only one kind of spore, as the bread mold does, a single species of rust may bear four different kinds of spores; although not all the rusts actually do bear so many. Many rusts require two hosts, in each of which a part of 
89. Spring Stage of the Wheat Rust. - The first plant attacked by this rust is not the wheat, but the barberry. The branching threads of the fungus live in the leaves, young stems, and fruits of the barberry. The threads, made up of rather short cells attached end to end, grow for the most part in the spaces between the cells of the host; but they give off, here and there, short branches which make their way by means of a cell-wall-dissolving enzym into the cells of the barberry. These short branches digest and absorb the food materials of the host. Sometimes, though not usually, they kill and absorb the living matter of the host cells themselves. More often the growth and division of the host cells are abnormally stimulated, so that an infected leaf is swollen, especially on the under side (Fig. $27, A$ ), in the regions in which the rust threads are most abundant. However, although such parts become unusually large, the barberry plant as a whole is deprived of much of its food, and so is more or less reakened. After the rust has become well established in the barberry tissues, it proceeds to form spores.

90. Spring Spores. - These spores are formed in small cup-shaped structures. The cups appear most commonly on the under sides of the leares of the barberry (Fig. 26, B), projecting from the surface and just visible to the naked eye ; but sometimes they grow on the upper sides of the leaves, on the fruits, or on the young twigs. The cups are formed in groups, and so are called cluster cups. The part of the leaf on which a cluster of cups is borne is usually yellowish for a short distance about the cluster; and the leaf tissues in this yellow spot die early.

The formation of the cups and of the spores can best be studied in a cross section of a leaf. It the place where a cup is to appear, a cushion, composed of fungous threads packed closely together, is formed beneath the epidermis of the leaf. Then the ends of the threads turn directly toward the epidermis and grow so as to make a basal layer of rather large vertical cells (Fig. $27, B$ ). The pressure caused by the growth of this layer and of the cushion of threads beneath it 
finally breaks the epidermis of the leaf. Each cell of the basal layer, like each of the other cells of the fungus up to this time, contains a single nucleus. These basal cells become joined in twos by a dissolving of part of the walls between each pair of adjoining cells (Fig. 27, $D, a)$; the two cells of each pair have now become a single cell of ir-
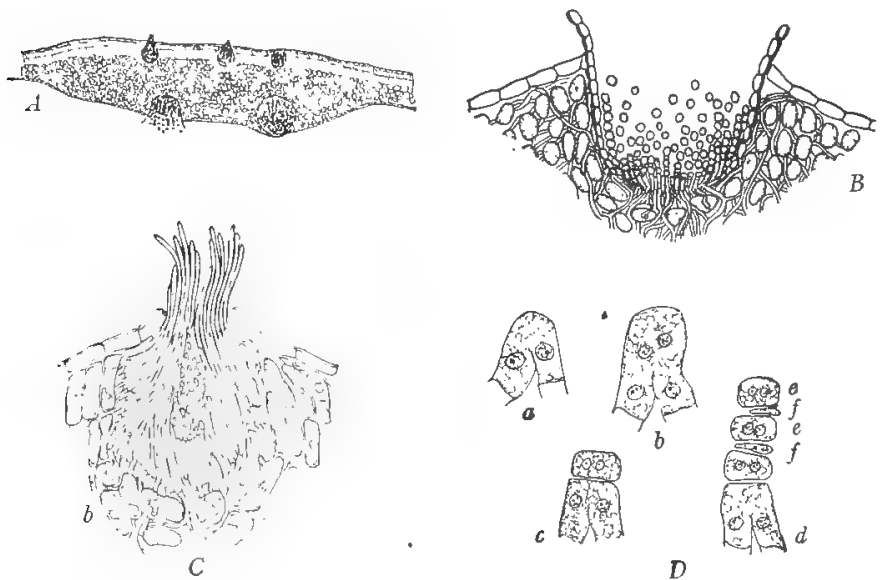

$D$

FIG. 27. - $A$, a section through a portion of an infected barberry leaf bearing spring spores on the lower surface and spermatia on the upper surface. $B$, a section through a cluster cup, showing the spring spores. $C$, a section through a cavity in which spermatia are being formed. $D$, the formation of spring spores: $u$, the union of two gametes in the basal layer of the cluster cup; $b$, the two nuclei of the zygote have divided; $c$, the zygote has cut off a two-nucleate cell ; $d$, the zygote has formed a chain of spring spores $(e)$ alternating with small cells $(f)$ which will soon disappear. $D$ after Christman.

regular shape, containing two nuclei. The two nuclei of each such irregular cell now divide, one of each pair of daughter nuclei passes to the upper end of the cell, and this end is cut off as a small twonucleate cell (Fig. 27, D, b and c). Then the two nuclei left in the large lower cell divide again, and another small two-nucleate cell is produced just below the first one.

The process of division is repeated again and again, so that a long chain of two-nucleate spring spores is formed (Fig. 27, D, d). ${ }^{3}$ From

${ }^{1}$ Really each cell of the chain in turn divides into two cells, of which one (the upper) becomes a spore; the lower one remains small and very soon breaks down 
each of the large irregular cells in the basal layer a chain of spores is produced in the way just described, excepting that the chains of cells at the very outside of the group remain connected with one another, and form, not spores, but the outer wall of the cup. The cell unions that take place at the base of the cluster cup are to be compared with the sexual unions which we have studied in Spirogyra and in the bread mold. The cells of the basal layer, therefore, before they unite in pairs, are gametes, and the irregular cells formed by their union are zygotes. An important difference, however, lies in the fact that a zygote of Spirogyra is produced by a cell union and a nuclear union, but a zygote of the rust results from a cell union only. The rust zygote proceeds at once to the formation of many spores, and so the chances for the survival and increase of the plant are greatly improved.

91. Spermatia. - Is we have seen, the cluster cups containing spring spores are borne for the most part on the under surface of the barberry leaf. On the upper surface of the leaf, and usually just opposite a group of cluster cups, there appears a yellowish spot in the midst of which are a number of small dark dots (Fig. 26, A). One can see in a cross section of the leaf (Fig. $27, A, C$ ) that each dot corresponds to an opening in the upper epidermis of the leaf. Before this opening was made, the fungous threads formed a cushion below the epidermis, such as was formed before the appearance of the cluster cup. Then the ends of the threads grew upward, making a layer of slender, vertical cells whose growth finally broke the epidermis. Some of the slender cells grow out through the opening so made; but most of them end within the carity produced by the pushing up and breaking of the epidermis, and from their ends small rounded cells (spermatia) are cut off one after the other. The spermatia look like spores, excepting that they are much smaller; but they never, so far as has been discovered, develop into new plants; and they seem to be quite useless.

and disappears. These disappearing cells are to be seen only between the younger spores (that is, the lower ones in each row), and even there they are often hard to find. 
92. Infection of the Wheat. - For some reason the spring spores produced on the barberry cannot infect a barberry plant, but they can infect wheat. If one of these spores, carried by the wind or other agency (sometimes, perhaps, by an insect), falls upon a young wheat plant, the conditions of temperature and moisture being favorable, it swells and pushes out a projection (a germ tube). The germ tube grows into a thread which makes its way along the surface of the wheat leaf or stem until it reaches an air-pore. The thread swells at a point just above the pore; from the swelling a new branch grows down through the pore, and in the spaces between the cells of the host it develops into a branching plant body which may infect a large area of the wheat plant. Short branches of the fungus grow into the cells of the wheat, whose food supply is used by the parasite in the same way as was that of the barberry cells. The portion of the rust on the outer surface of the host (the germ tube and swelling) soon withers and disappears.

93. Summer Spores. - As soon as the fungus is well established in the wheat tissues, it proceeds to form spores

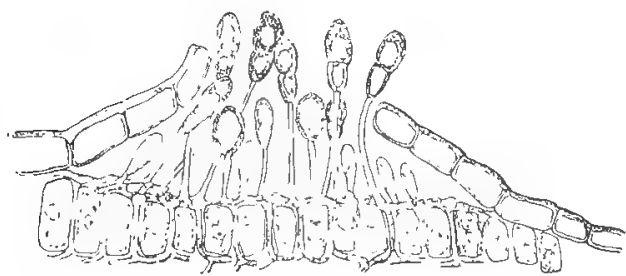

FIG. 28. - Section through a sorus on the wheat, in which both one-celled summer spores and twocelled winter spores are being formed. of a second kind. Here also the first step toward spore formation is the appearance of $\mathrm{a}$ cushion of fungous threads beneath the epidermis of the host; then the threads grow outward to form a layer of rather broad parallel basal cells, which push directly against the epidermis of the wheat and finally break it. The break in the epidermis is irregular in shape and often large; it is called a sorus. From the outer end 
of each basal cell now grows a slender stalk; the end of this stalk is cut off by a wall, strells, and becomes an eggshaped summer spore (Fig. 28). When the summer spore is ripe, it is easily broken away.

After the first summer spore has begun to develop, a second, and sometimes a third and a fourth, each with its stalk, may be formed from the same basal cell. Thus a single sorus, containing many basal cells, continues for some time to produce ner summer spores. The summer spores seen separately have a yellowish color; the sorus containing a mass of them appears orange, and it is for this reason that the appearance of the sori on the wheat is spoken of as the "red rust." The summer spores, if carried to other wheat plants, may germinate (Fig. 29, $A$ ), causing new infections in the same way that the first infection of the wheat was caused by the spring spores. Thus the summer spores carry the infection from one wheat plant to another. If the season is favorable to the
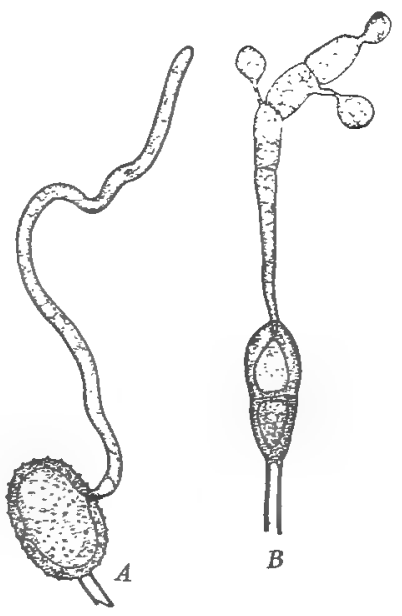

FIG. 29. - $A$, a germinated summer spore; the young plant growing from it may infect a wheat plant. $B$, a germinated winter spore; the small plant which has grown from it is bearing sporidia. growth of the rust, the disease may spread in the course of the summer from a few plants that were infected by the spring spores throughout a whole field of wheat.

94. Winter Spores. - As the end of the growing season approaches, the rust produces spores of still another sort. These are borne in the same kind of sori as are the summer spores, and indeed some of the earliest winter spores often 
appear mixed with summer spores in the same sorus (Fig. 28). But in the sori that are formed later, only winter spores are produced. Each winter spore has a slender stalk and consists of two cells whose walls are thicker and darker than those of the spring and summer spores. A sorus containing only winter spores is black, and so the appearance of these sori is spoken of as the "black rust." Thus the "red rust" and the "black rust" are different stages in the history of the same disease.

Each cell of a young winter spore contains two nuclei (as does the summer spore); but as the spore ripens, the two nuclei in each cell unite, so that the mature spore consists of two one-nucleate cells. Since the two nuclei which are present at first in each cell of the winter spore are direct descendants of the two nuclei of the spring spore, the union of nuclei in the winter spore is really the completion of the sexual process which began with the union of cells at the base of the cluster cup just before the formation of spring spores. Whereas in Spirogyra nuclear union follows closely upon the cell union which produces the zygote, cell union and nuclear union in the rust are separated by a whole generation of the rust plant - that generation, namely, which lives in the tissues of the wheat.

95. Germination of Winter Spores; Sporidia (Fig. 29, B). - The winter spores are adapted by their thick walls and probably by the comparatively dry condition of their protoplasm to endure unfavorable conditions. They represent a stage, therefore, in which the rust may live through the winter. They remain upon the ground or the stubble, or are scattered widely in the harvesting and threshing of the grain. In order to produce new plants, they do not require, as the spring and summer spores do, a particular host upon which to grow. On the contrary, they germinate wherever they may be when warm weather returns in the spring, provided sufficient moisture is present. Each cell of the winter spore can put out a germ tube and develop a new plant, so that the "winter spore" is practically two spores that have remained together. The plant that grows from each cell of the winter 
spore is small, consisting of (usually) four cells. From each cell of this small plant a short branch grows; the outer end of the branch swells, is cut off by a wall, and becomes a spore of a fourth kind which is called a sporidium. A rust sporidium, carried to a leaf, young stem, or flower of a barberry, may germinate there. The germ tube makes its way directly through a surface cell (not as a rule, at least, through an air-pore) and so infects the barberry.

96. Outline of the History of the Wheat Rust. - We see that the complete life story of the wheat rust includes three different plants, which are really so many distinct generations. These three plants produce four different kinds of spores (or, if we include the spermatia, five spore-like structures). The plant living on the barberry bears spring spores (and spermatia); the plant living on the wheat bears summer spores and winter spores; and the small plant developed from a winter spore bears sporidia.

97. Damage Done by the Wheat Rust. - The wheat plant is weakened because the food stored in its cells for its own use is taken by the rust. An infected plant does not grow to its normal size, its grains are small and shriveled, and so the wheat crop is injured both in quality and in quantity. The rust occurs in all parts of the world where wheat is grown, and in some regions the cultivation of wheat has been given up because of the prevalence of the disease. It is worst in damp regions and in years when there is much rain. The loss in the United States in a single year from wheat rust alone has been estimated at $\$ 67,000,000$.

98. Prevention of Wheat Rust. - Although this disease has been known and studied for years, it is still most difficult to deal with. No practicable method has been found for the direct treatment of infected wheat plants. The disease can be partly checked by removing all barberries from the neighborhood of wheat fields. Since the young wheat plant is infected by spores from the barberry, and since neither winter 
spores nor sporidia can infect the wheat, it would seem that the removal of all the barberries within a considerable distance would make the infection of the wheat impossible. But, as a matter of fact, serious epidemics of wheat rust occur year after year in various parts of the world - for example, in Australia and in some of the northwestern United States - in which barberries are very rare or even unknown. So it would seem that the rust is able to survive the winter in some other form than in that of the winter spore. The most probable explanation of this fact seems to be that some of the summer spores live through the winter and infect the young wheat plants in the spring. The summer spores are thin-walled, and apparently most of them are shortlived and easily killed; but a few are longer-lived and remain able to cause infection for some months after their production.

Another explanation for the survival and reappearance of the rust in some cases is found in the fact that in warm regions it can live and continue to form summer spores during the winter. So, when new wheat plants appear in the spring, there are fresh spores ready to infect them. The spread of the rust from warmer to colder regions during the growing season of the wheat may be brought about by the wind; for it has been shown that summer spores can be carried by the wind to great distances. The most promising method of combating the wheat rust seems to be the raising of varieties of wheat that are rust-resistant - that is, are little or not at all affected by the rust. The varieties of durum or macaroni wheat, which are much cultivated in Mediterranean countries, are very resistant to rust, and they are being raised with some success in certain American states. Attempts are also being made, by crossing these with American varieties which are susceptible to rust but are valuable in other respects, to secure new resistant forms; and alrcady some very promising results have been attained. 
99. Other Rusts of Cereal Grains. - Is a group, the rusts have been remarkably successful in adapting themselves to a parasitic life - partly, no doubt, because of the number and variets of spores that they produce. So successful have they been that most of the species of seedbearing plants are attacked each by one or more species of rust. Some rusts seem to have become so specialized as to be able to live upon only one or a very few hosts; in other instances, a single rust may attack a considerable number of hosts. ${ }^{1}$ Besides the common wheat rust which has been described in this chapter and which is called Puccinia graminis, there are at least two other rusts that infect the wheat. Ill the other cereal grains, too, are attacked by rusts, some of which cause large losses. The known grain rusts, in addition to Puccinia graminis are: the crown rust, one of whose races or varieties

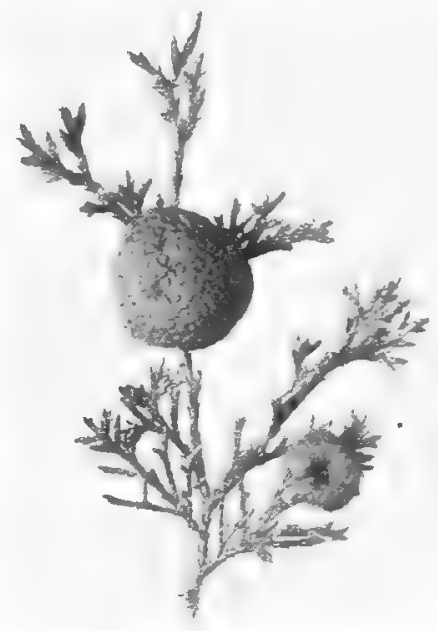

FIG. 30. - A branch of the red cedar bearing two "cedar apples" - swellings caused by the presence of a rust - in the winter condition. After Jones and Bartholomew. causes a serious disease of oats; the yellow rust, races of which attack wheat, barley, and rie; the brown rust of rye; the brown rust of wheat; the dwarf rust of barler; and

I A word of caution should accompany this statement. In some cases the rusts appearing upon two or more hosts seem to be exactly alike, but the spores produced by the rust upon one host will not infect the other host, and sice iersu. Thus, there are rusts on rye, oats, barley, and several common grasses which appear to be the same as that upon the wheat and which are called by the same name (Puccinia graminis). But the summer spores of the wheat rust will not infect the oat at all, or only with great difficulty, and in the same way summer spores from Puccinia graminis on oats will not infect the wheat, although both the rust on wheat and that on oats pass their spring stage upon the barberry. These facts have given rise to the notion of specialized races of parasitic fungi. Two such races may seem to have exactly the same structure, but they differ in that they have adapted themselves in some way to life upon different hosts. 
the Indian corn rust. In the case of each of these rusts, the summer stage is passed upon a cereal grain, and the spring stage, where one has been found, is passed upon an entirely different plant. For example, the crown rust of the oat has its spring stage on the buckthorn, and the spring stage of the corn rust is found on the wood sorrel.

100. Apple Rust. - The fungus that causes this disease produces its winter spores upon the red cedar (juniper),

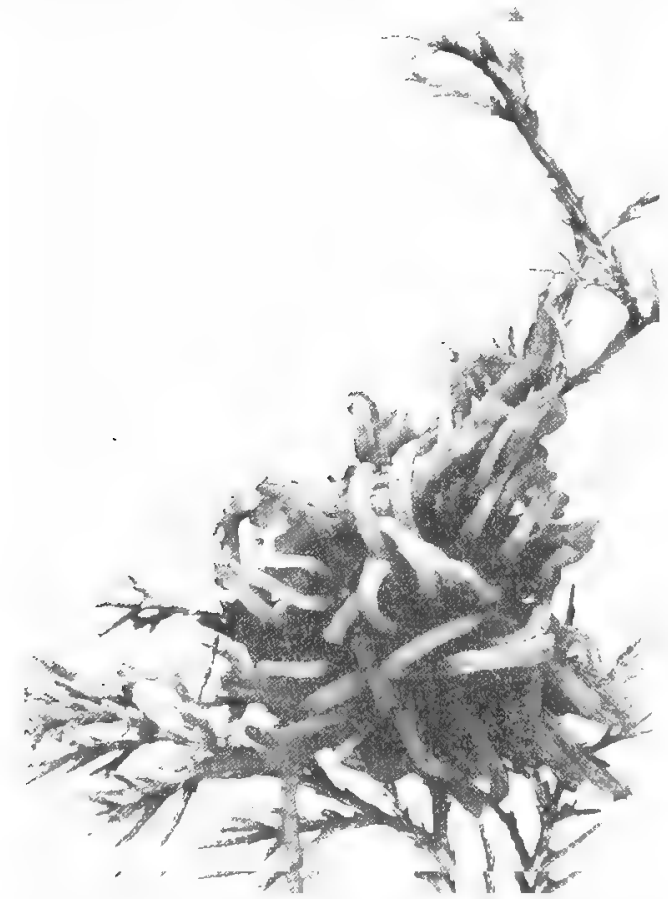

FIG. 31. - A "cedar apple" in the spring; the fingerlike projections are masses of jelly in which the winter spores germinate. After Jones and Bartholomew.

where it causes the swellings of the twigs and small branches that are called "cedar apples" (Fig. 30). The cedar tree is weakened if it is seriously affected, and sometimes it is 
killed. The winter spores of the rust are formed within the cedar apple. In the spring the inner part of the cedar apple becomes soft and sends out finger-like masses of jelly in which the winter spores germinate (Fig. 3I). The small plants that grow from the winter spores bear sporidia within and on the surface of the jelly. The sporidia are distributed by the wind. If they fall upon leaves, flowers, young fruits, or twigs of the apple, they produce an infection. In a few weeks, cluster cups begin to appear, mostly on the leaves but sometimes on the fruits or trigs of the apple (Fig. 32); the spores formed in these cups, often as late as August, which correspond to the spring spores of the wheat rust, may then cause a new infection of the red cedar. No spores are produced by this rust that correspond to the summer spores of the wheat rust. If the apple

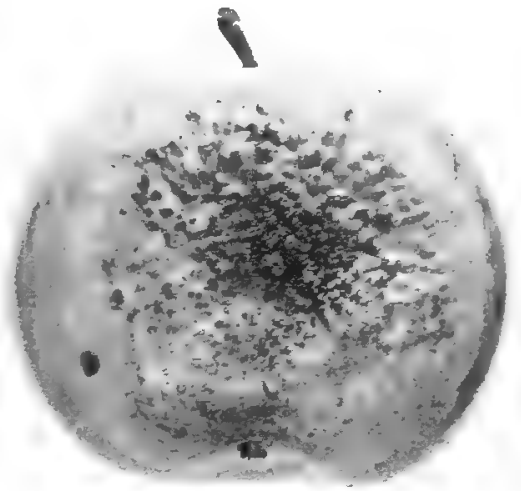

FIG. 32. - In apple infected by the spores produced as a result of the germination of the winter spores. The spring spores produced in the little cup-like structures will infect the red cedar, causing the formation of "cedar apples." After Jones and Bartholomew. tree is badly diseased, its fruit crop is greatly damaged. Not only does the fruit that is directly attacked fail to develop normally, but the diseased condition of the leaves affects the nutrition of the tree as a whole, and so indirectly checks the growth of the fruit.

The disease of the apple trees may be absolutely prevented by the removal of red cedars from the neighborhood of the apple orchard. Apparently the fungus has no way of surviving the winter except within the tissues of the red cedar. 
If the removal of cedars is out of the question, the disease can be greatly checked by spraying the apple trees at the proper times with Bordeaux mixture. It may be largely avoided also by planting resistant varieties of apple; but unfortunately some of the most valuable varieties are very susceptible to the rust.

101. Some Other Rusts. - The blister rust of the pine, until recently known only in Europe, passes its summer stage and forms summer and winter spores upon currants and gooseberries, sometimes seriously injuring these hosts; its spring stage causes a very destructive disease of the white pine. This rust has lately been found in North America, and it is not unlikely that it will greatly interfere with the future raising of white pine for forestry purposes. The fungus may live for years in the bark of the pine. Its winter spores differ from those of the wheat rust in being only one-celled. The rose rusts, differently from the rusts so far mentioned, pass their whole life upon a single host plant. Their spring spores are borne in irregular sori rather than in cups, and each winter spore consists of a row of several cells. Some varieties of roses are badly injured by these rusts. The common orange leaf rust of raspberries and blackberries produces both spring and winter spores upon the same host; it has no summer spores. The asparagus rust also has no summer spores; it forms its spring and winter spores on the asparagus. The life cycle of the rust of mallows and hollyhocks is very short. It has nothing that corresponds to the spring stage of the wheat rust, and no spring spores, spermatia, or summer spores. Spores are formed that correspond to the winter spores of the wheat rust. Some rusts, living from year to year in the tissues of certain trees, stimulate the host plant to the very rapid production of branches in the infected part, and so cause the formation of a "witches' broom." Such "brooms " are produced on the red cedar by relatives of the apple rust.

102. Historical Note. - The notion that the presence of barberries is in some way harmful to growing wheat was prevalent in Europe as early as the middle of the seventeenth century. It is said that the parliament of Rouen in I660 ordered the destruction of barberries. Similar laws were adopted in Massachusetts in 1755 , in Lippe in 1805 , and in Bremen in 1815. Experiments carried on in the latter part of the eighteenth century and the early part of the nineteenth in England, Denmark, and Germany indicated that barberries are in some way responsible for the occurrence of the wheat disease which was then 
variously called "blight," " mildew," or " rust." In I864, De Bary proved that the rust on the barberry and that on the wheat are different stages in the life history of a single fungus. This was the first case in which two hosts were shown to be necessary to complete the life history of a fungous parasite. De Bary's results were announced in January, 1865. In June of the same year, Oersted showed the connection between the rust on red cedars and that on pear trees. Since De Bary's discovery, the planting of barbcrries in grain-raising regions has been forbidden by law in England and other European countries, as well as in some American states. Meren suggested in I 8 I I that the structures in which the spermatia and the spring spores are borne are respectively male and female organs. This notion received much support. But in I904, Blackman and Christman discovered the cell unions that occur at the base of the cluster cups, and so showed that the spermatia do not now act as male cells, whatever may have been the case in the past. Beginning with De Bary and his contemporaries, a great amount of study has been devoted to rusts. Up to I 888 , I 225 species of rusts had been described, of which 455 belonged to Puccinia, the genus to which the wheat rust belongs. In 1897 , about 1700 rusts were known, of which over 700 were species of Puccinia; and in I904, the number of species of Puccinia alone had risen to 1226 - as many as the total number of rusts known sixteen years before. 


\section{CHAPTER VIII}

\section{A MUSHROOM}

103. The Field Mushroom: Vegetative Body. - Among the largest and best-known fungi are those which are called mushrooms or toadstools. They are most abundant in damp,

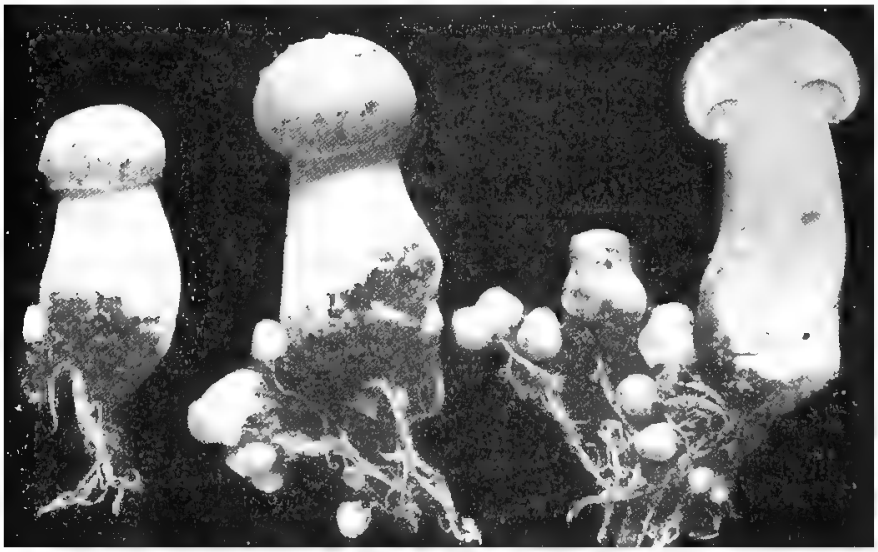

FIG. 33. - The field mushroom; threads and strands of the vegetative body living in the soil, and various stages in the development of the fruiting bodies. At the right is a half-grown fruiting body cut lengthwise through the middle, showing how the veil attaches the margin of the cap to the stalk and covers the cavity in which the gills are being formed.

shady woods, though some, like the common field mushroom, live in open woods, fields, pastures, or gardens. Many of them are saprophytes, obtaining their food from decaying leaves, wood, manure, and the like; but some live as para- 
sites on the roots or other parts of living trees. What we ordinarily call a "mushroom " is merely the part of the fungus that grows above ground and bears the spores; it is the fruiting body of the plant. The vegetative body, like that of the bread mold or the rust, consists of colorless or whitish branching threads which live for the most part underground. Some of them are combined into thicker strands, but these strands, as well as the separate threads, are delicate and easily broken when the soil is disturbed. For this reason we usually see little or nothing of the regetative body of the mushroom, excepting some fragments that remain attached to the fruiting body when the latter is pulled from the soil (Fig. 33). The threads, like those of smuts and rusts, are made up of rather short cells joined end to end. They attach themselves to particles of dead organic matter with which they come in contact in their growth through the soil, and digest such parts of these substances as they can use for food.

104. Fruiting Body. - In the summer or fall, after the plant has been growing for some time, small knots appear upon it here and there, near the surface of the soil. These knots are composed of some of the branches of the fungus which are beginning to pack themselves more closely together. Each knct is the beginning of a fruiting body. The threads composing the knot grow and branch, and so the knot develops into a firm, rounded "button." By further growth this button develops into the fruiting body of the mushroom (Fig. 34). It becomes divided into an upper part which is to form the cap, and a lower portion, the stalk. The margin of the cap is at first attached to the stalk by a thin membrane, the veil, which hides the lower side of the cap where vertical folds or gills are being formed.

When the fruiting body reaches nearly its full size, the margin of the cap, which until now has been curved downward and inward, begins to spread outward; this makes the cap flatter on top, and causes a pull on the veil; the veil is 
torn irregularly, part of it going with the margin of the cap but the greater part remaining attached to the stalk in the form of a ring. The breaking of the veil leaves the gills on the lower side of the cap uncovered. The gills hang downward; they extend, somewhat like the spokes of a wheel,

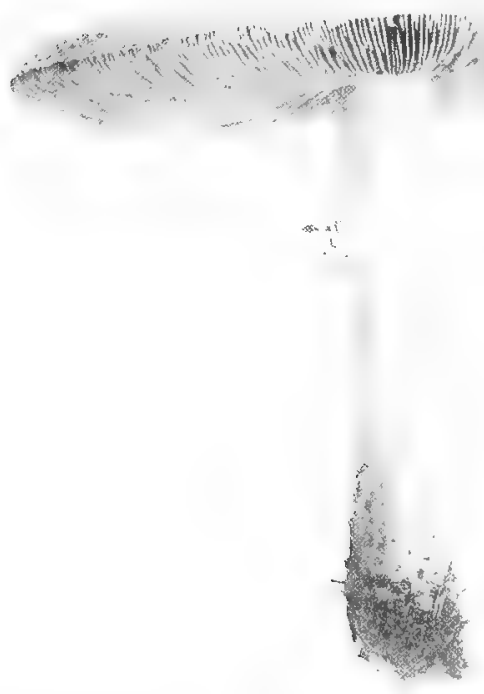

FIG. 34. - The fully developed fruiting body of Psalliota arvensis, closely related and very similar to the common field mushroom.

from the central part, where the cap is attached to the stalk, to the outer margin of the cap; there are also short gills, between the longer ones, which reach to the outer margin of the cap but not to its center. The cap varies in breadth from two to six inches; its top is white, cream-colored, or brownish; it bears many fine, silky hairs, and often some small brownish scales. The flesh of the cap is white, turning 
pink if broken. The gills are at first flesh-colored or pink, gradually changing, as the fruiting body grows older, to dark brown or black. The stalk is white, and from two to four inches high.

105. Structure of the Fruiting Body. - In a thin section of the stalk, examined under a low power of the microscope, one sees many cells of different shapes. From the way in which the fruiting body has been developed, we know that these are the cells of the separate threads that make up the fruiting body, cut across in various ways. Such a structure as this, composed of threads closely packed together, is sometimes called a false tissue, to distinguish it from the true tissues which make up the bodies of the higher plants. The cap of the mushroom is composed likewise of a false tissue. A section through the cap which cuts a gill crosswise shows how the spores are formed (Fig. 35). Each surface of the gill is made up of a layer of rather long cells that are perpendicular to the surface. Some of the cells of this layer are rather slender; others, when they reach their full size, are much broader. Each of the broad cells of the surface layer is a

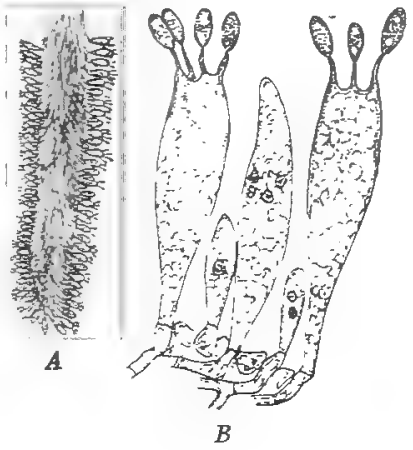

FIG. 35. - $A$, section through a gill, showing the arrangement of threads and basidia. $B, a$ group of basidia of different ages, showing their attachment to the threads of the fungus, and the way in which spores are formed. basidium. From the end of each basidium four slender projections grow out; the outer end of each projection swells and is cut off by a wall, so becoming a spore. ${ }^{1}$

106. Distribution and Germination of Spores. - When the spores are ripe they are shot off from the short stalks on which they were borne. This shooting seems to be caused by a sudden bulging of the wall at the end of each stalk. By this means the spores are thrown far enough so that they may fall without touching any of the neighboring basidia. Being

${ }^{1}$ In some cultivated varieties (perhaps all) of the field mushroom, and occasionally in wild races, each basidium forms only two projections and two spores. 
very light, they are caught by currents of air as soon as they have fallen below the lower surface of the cap in which they were borne, and are scattered, often probably to great distances. The spores of some kinds of mushrooms are distributed by flies and other insects, which, attracted by the odor of the decaying mushrooms, carry away great numbers of spores upon their bodies. If a spore falls in a favorable place it soon germinates, developing into a branching thread in much the same way as does a mold spore, excepting that cell divisions occur so that the thread and its branches are made up of short cells.

107. Length of Life. - Although the fruiting body lasts but a few days, the vegetative body of the mushroom may live within the soil for a long time - even for many years each branch growing at its forward end while the older parts of the plant die away. Perhaps it is because it can live undisturbed from year to year within the soil that it has not been necessary for the mushroom to form so many kinds of spores as the wheat rust, for example, has developed. At any rate, the mushroom certainly finds in a single kind of spores a very successful means of reproduction and distribution.

108. Use and Culture of the Field Mushroom. - This mushroom, which botanists call Psalliota campestris (or Agaricus cumpestris), has been known for centuries. Its usefulness as an article of food was referred to by Horace $(65-8$ B.c.), and it was described by Pliny (about $23-79$ A.D.). It is still much more widely used as food throughout the civilized world than any other fungus, and is the only one that is cultivated on a large scale. Numerous varieties are in cultivation. Mushroom beds are usually prepared in dark places and require soil that is rich in organic substances. The beds are started by means of what is called "spawn," which consists simply of masses of rich soil or manure in which many of the fungous threads are growing. Small portions of the spawn are distributed through the soil of the 
new bed, which, if the culture is successful, soon becomes penetrated in all parts by the growing threads. The fruiting bodies are gathered when the margin of the cap begins to break away from the ring.

109. Some Other Mushrooms. - There are many species that are like the field mushroom in their general characters, but are distinguished from it and from one another $k y$ the

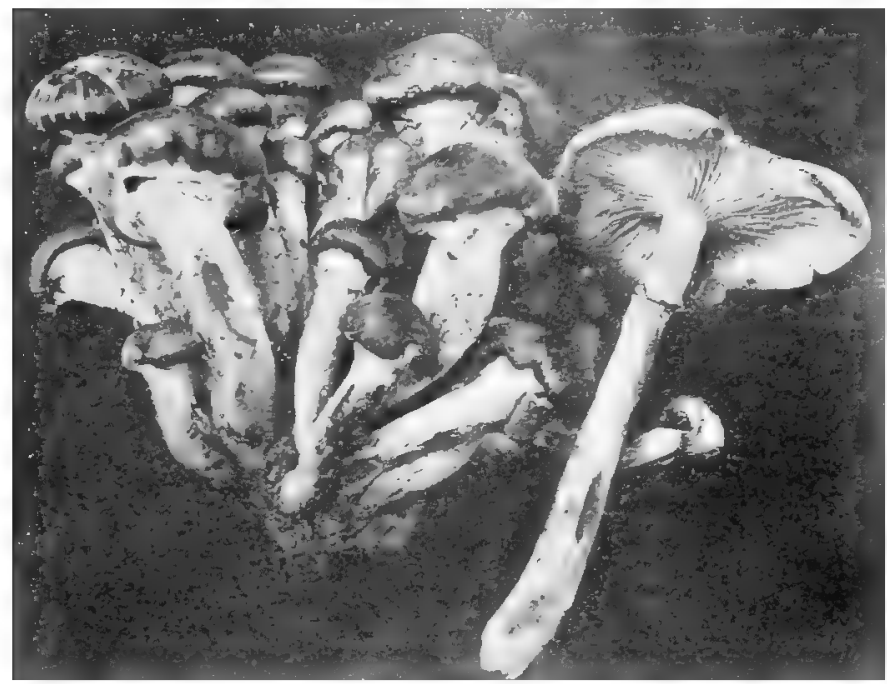

FIG. 36. - The honey mushroom (Armillaria mellea).

color, size, and structure of different parts of the fruiting body. Often it is very difficult to distinguish related species. The common honey mushroom (Fig. 36 ), which is considered one of the best of the edible forms, produces its fruiting bodies in clusters, especially about old tree stumps, in late summer and fall. The fruiting bodies are somewhat larger than those of the field mushroom; they are yellow or yellowish brown, usually with darker patches on the top of the cap, with a ring, white to rusty-brown gills and stalk, and white spores. The 
cap is hemispherical at first, later flattened but with a slightly builging center. The vegetative threads penetrate the bark of the roots of living trees, especially of some of the conebearing trees, and between the bark and the wood they mass together into flat strands that grow upward into the trunk as well as through the roots. From these strands, separate

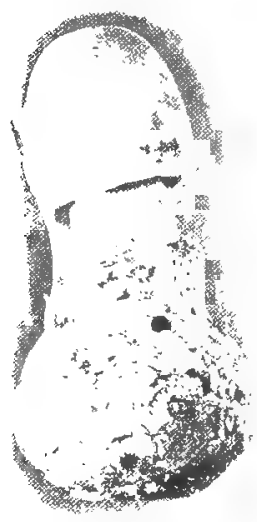

$A$

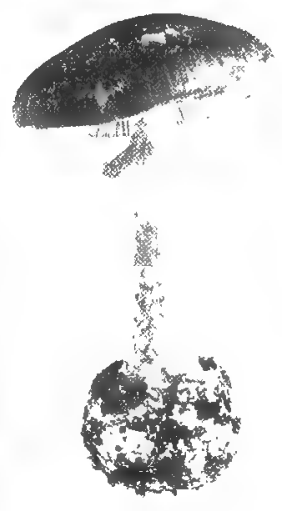

$B$

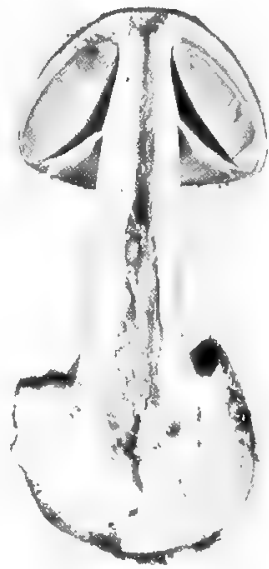

C

FIg. 37. - Poisonous mushrooms: A, Amanita verna; the main portion of the fruiting body emerging from the egg-shaped structure which completely enclosed it at an earlier stage; a part of this enclosing structure remains in the form of a cup at the base of the stalk. $B$, a mature fruiting body of Amanita pantherina. $C$, a somewhat younger fruiting body of the latter species cut lengthwise, showing the ring still attached to the edge of the cap. Photographs by E. T. Harper.

threads grow into the bark and wood, whose cells are destroyed (rotted) by the fungus; in time the tree is killed. By means of other strands which penetrate the soil for long distances, the fungus spreads from trec to tree. The strands can also live saprophytically in the soil or in the dead wood at the bases of stumps. Thus the honey mushroom is a widely spread saprophyte as well as one of the most dangerous 
parasites of forest trees. Its fruiting bodies grow from the underground strands as well as directly out of the bark of killed trees. Another common edible mushroom of summer and fall is the "shaggy mane" or "inky cap," found on roadsides and in gardens. Its fruiting body is white, with a narrow, thimbleshaped cap one to two inches long, bearing ragged brownish or yellowish scales on its upper surface. The ring is thin; the gills are at first white, but blacken rather quickly; after a few days the whole fruiting body dissolves into an inky-black liquid in which the black spores are immersed.

Some of the most poisonous mushrooms belong to the genus

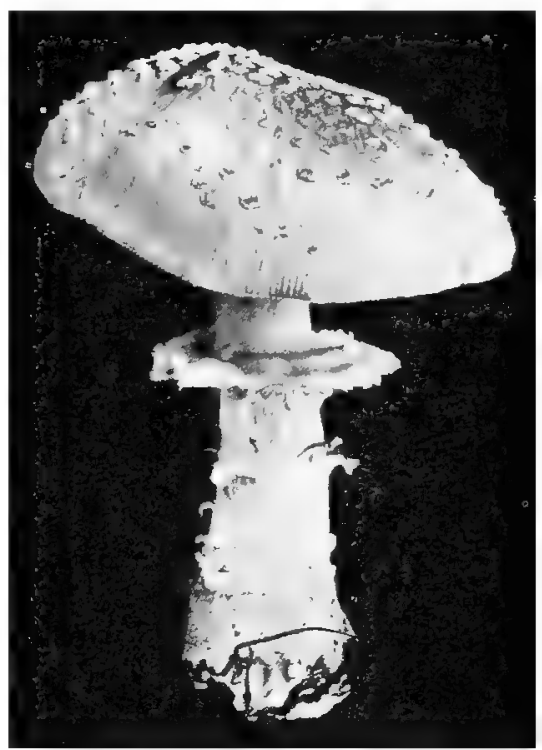

Fic. 38. - The fly mushroom (1manita muscaria). One of the most poisonous mushrooms known. Photograph by E. T. Harper. Amanita (Figs. 37 and

38). Amanita phalloides is the "deadly Amanita" or "death cup" which appears in summer and fall in rich woods. Its cap and stalk are usually white, sometimes brownish; the gills and spores are white. At the base of the stalk is a cup out of which the stalk seems to grow. Sometimes, however, the cup is not easy to recognize. A long, delicate ring is attached about the middle of the stalk and hangs downward. 
A related species is the fly mushroom (Fig. 38), which also has a hanging ring, a cup, and white gills and spores; but its cap is red on top with. some scattered white scales. This mushroom grows alone or in groups, in woods of the most varied sorts. Both of these latter species are so poisonous that 50 grams (less than two ounces) of their flesh is a fatal dose.

Only one who is thoroughly familiar with mushrooms can be sure of distinguishing the edible from the poisonous species. The only safe plan, if one is to eat mushrooms at all, is to become acquainted with a few forms that cannot be mistaken, and to eat no others except upon the advice of an

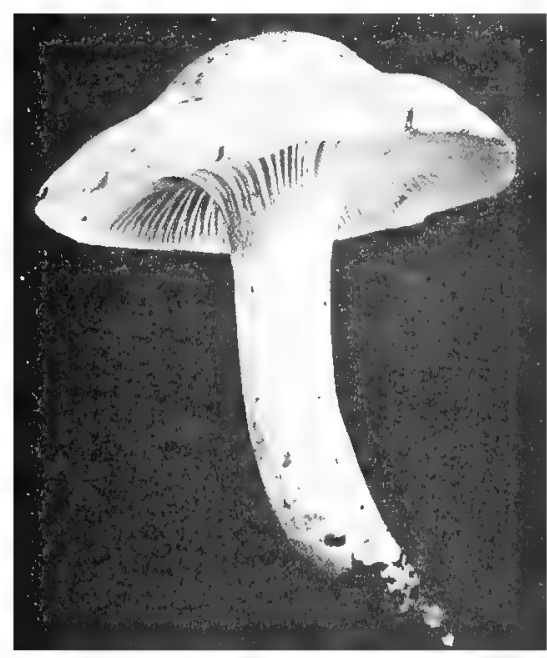

Fig. 39. - An edible mushroom (Hygrophorus virgineus). Photograph by E. T. Harper. expert. The food value of mushrooms is small at best, and it is not worth while to run the slightest risk of what may prove a serious mistake. No fungus should ever be eaten unless it is young and fresh and shows no traces of being decayed or worm-eaten.

\section{0. "Fairy Rings."} - These more or less regular circles of fruiting bodies, growing in lawns or pastures, are produced by certain species of mushrooms.

The ring-like arrangement of the fruiting bodies results from the growth of the vegetative threads within the soil year after year. At first a small area of the soil is penetrated 
by the threads, and a small group of fruiting bodies is formed. As the available food in this part of the soil is used up, the older threads die and the younger branches push out into the surrounding soil, where they produce a new crop of fruiting bodies in a ring about the place where the first ones grew. The growth outward from the original center continues from year to year, and each successive ring of fruiting bodies is a little wider than the preceding ring.

111. Relationships of Mushrooms. - The mushrooms, with some related forms, are classed as basidium fungi. The rusts are also often classed among the basidium fungi, because their winter spores, together with the small, few-celled plants to which the winter spores give rise, are thought to be comparable with the basidia of mushrooms and with the projections growing from the basidia that bear the spores. If this notion is correct, the sporidia of a rust would correspond to the spores of a mushroom. Aside from the rusts (and the smuts, which are probably related to the rusts), there are about 12,000 known species of basidium fungi.

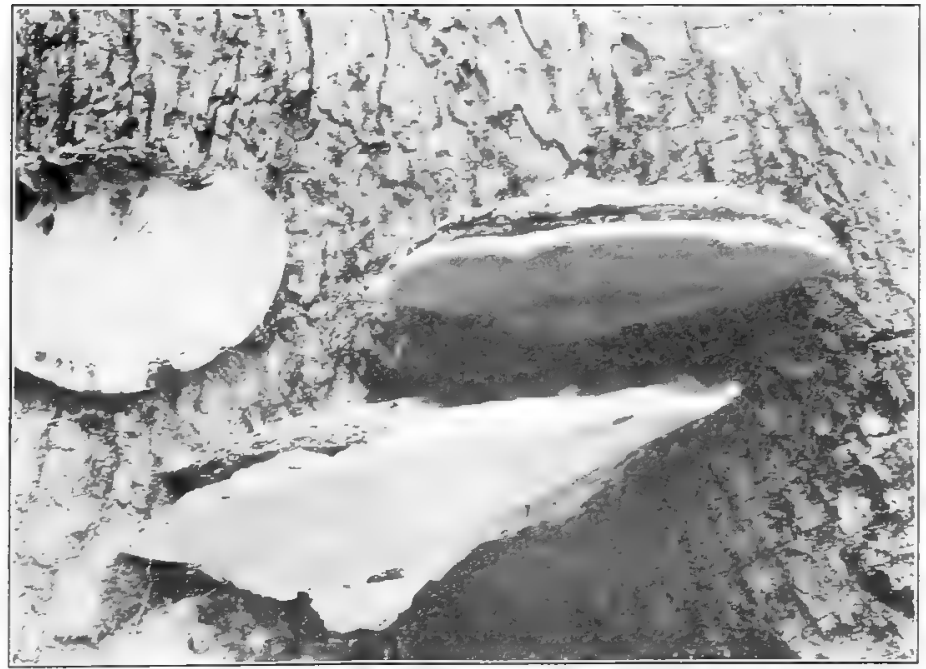

Fig. 40.- Specimens of a bracket fungus (Fomes applanatus). At the left is shown one with its under surface exposed. Photograph by $\mathrm{E}$. T. Harper. 
112. Bracket Fungi. - A rather large class of basidium fungi, closely related to the mushrooms, includes those that produce the familiar "brackets" upon the sides of trees, especially dead trees. A common member of this class is Fomes applanatus (Fig. 40), whose brackets are flat, rather thin, and sometimes very broad. The lower surface is white
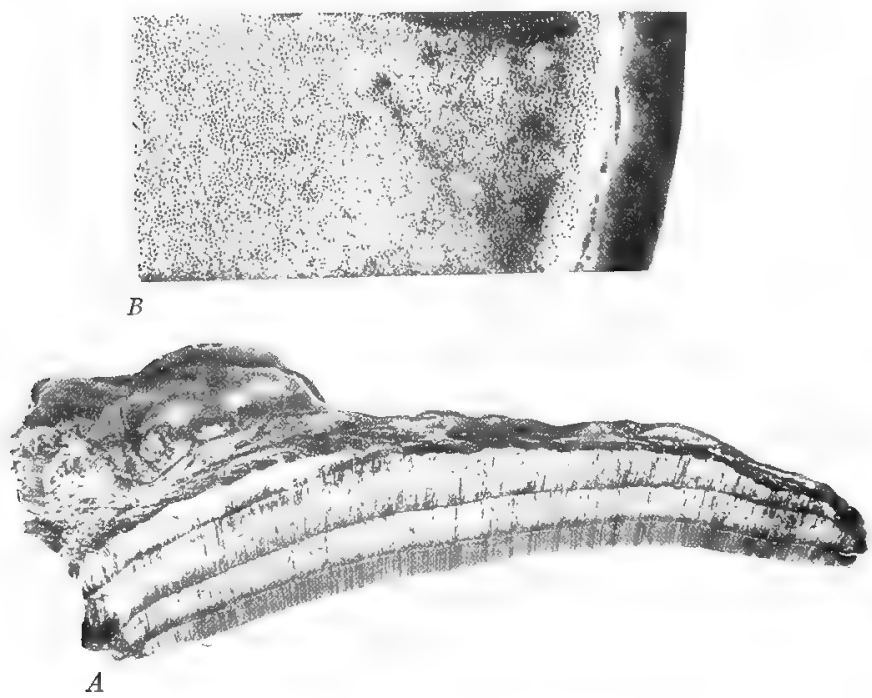

Frg. 4r. - A bracket fungus (Fomes applanatus). A, a fruiting body cut so as to show the layers of which it is composed, each the growth of a single year. $B$, a portion of the lower surface of a fruiting body enlarged, showing the pores inside which spores are formed.

when fresh, but turns brown if bruised. The tendency to turn brown is sometimes made use of in sketching by means of scratches upon the white surface. The brackets are the fruiting bodies of the fungus. They have no gills; but the flesh of their lower surfaces is penetrated by many very fine pores (Fig. 4I). The inner surface of each pore is lined with a layer of basidia, each of which as a rule, like the basidia 
of most of the mushrooms, bears four spores. The fruiting body of Fomes lives and grows from year to year, forming new spores each year. But the fruiting bodies of some other bracket fungi, such as the sulphur mushroom, a large, yellow, quickly growing form that is soft and edible when young, die after bearing one crop of spores. The branching threads that make up the vegetative body of a bracket fungus live in the tissues of the trees upon which the fruiting body appears. Many species of bracket fungi live on dead trees; they are saprophytic. But others are parasitic; they enter the host tree through mounds, cause a decay of the wood, and finally kill the tree.

113. Puffballs (Fig. +2 ). - These are still another class of basidium fungi whose basidia are entirely enclosed within a rounded mass of tissue which either

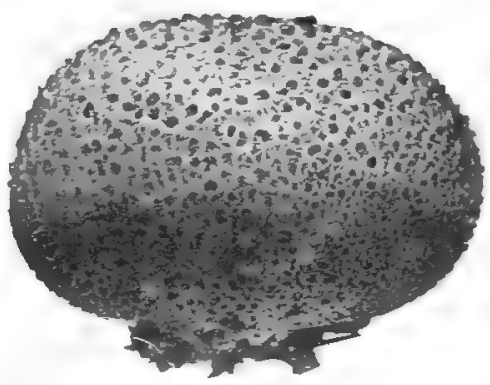

Fig. 42. - A puffball (Scleroderme vulgare). lies close to the ground or is raised upon a short stalk. The largest of the group is the "giant puffball," specimens of which sometimes reach a diameter of one and one-half or two feet. When young, the flesh of this puffball is firm and white, and it is then edible. As it grows older, the inner part becomes darker because of the formation and ripening of the spores. Finally the interior consists of a mass of dark-brown or black spores which escape through cracks in the wall of the puffball. 


\section{CHAPTER IX}

\section{A MOSS}

114. Mosses. - Although none of them are large plants, some of the mosses grow in such great numbers that they are rather conspicuous features of the earth's vegetation. On the whole, they have not been so successful in the struggle for
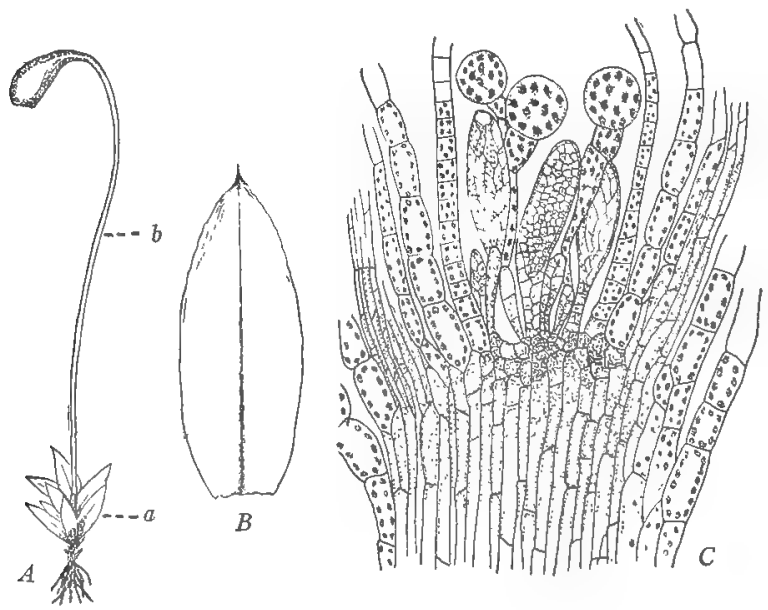

FIG. 43. - A, Funaria hygrometrica: $a$, the sexual plant; $b$, the asexual or spore-bearing plant, attached to the sexual plant. $B$, a single leaf of Funaria. $C$, upper end of a male plant, showing how the sex organs are borne. $C$ after Sachs.

existence as have the secd-bearing plants; and perhaps this is the rcason why mosses have adapted themsclves to conditions that are not favorable for larger and more highly developed plants. Thus we find mosses in very cold regions 
where otherwise only a few much simpler plants can live; on the faces of rocks, where food material is scanty; on decaying wood, and the trunks of living trees; on the soil of deeplyshaded forests; in shallow water, and in bogs and marshes. Some mosses, like the one we are to study, can endure long dry spells and can resume growth upon the return of moisture. Not all mosses are adapted to all of these different conditions; but each sort of location has its characteristic species.

One of the commonest mosses is Funaria hygrometrica (Fig. 43, A), which is selected for the present study. It grows on dry or well-drained soil, on roadsides, in open fields, gardens, and waste places. When it is fruiting it may be recognized by its very numerous, reddish, curved, pearshaped spore sacs, which are borne on slender, twisted, red stalks.

115. The Moss Plant. - What is commonly thought of as a. moss plant has an upright stem which bears green leaves and colorless or brownish, hair-like rhizoids. A great difference between the moss and any of the fungi or algæ is in the fact that its body is divided into stem and leaves. This upright plant is especially well adapted to secure light, carbon dioxid, and oxygen. The stem supports the leaves in a position favorable for their work, and conducts food substances from place to place within the plant. For these purposes, the stem has become a compact, cylindrical structure. It is more or less green because its outer cells contain some chlorophyl, but for the most part the manufacture of carbohydrates is carried on in the leaves, and only a small part of this work is done in the stem. Besides leaves and rhizoids, the stem bears, usually near its base, occasional branches. A leaf (Fig. $43, B$ ) is the part of the plant that is chiefly concerned with the manufacture of food substances, particularly of carbohydrates. It has a midrib, made up of long, slender cells. The rest of the leaf, to right and left of the midrib, is composed of a single layer of green cells. 
The rhizoids are outgrowths from surface cells of the stem, chiefly from its lower part. Each rhizoid is a branching row of cells. For the most part, the rhizoids grow downward into the soil, anchoring the plant and absorbing from the soil the water and other substances which the plant can use as food. For the moss, as well as for most ferns and seed plants, the soil is the source of supply of practically all the food that is received from outside, excepting the carbon dioxid which comes directly from the air.

116. Sex Organs. - The sex organs of mosses are borne in groups, in the midst of a cluster of leaves at the end either of

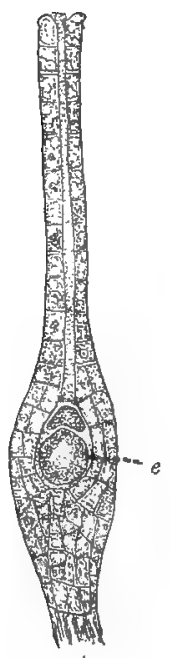

A

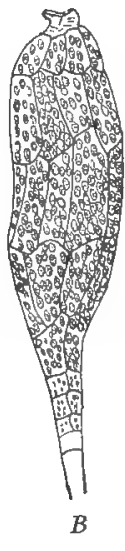

$B$

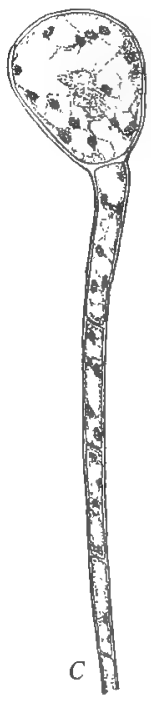

FIG. 44. - $A$, an archegone of Funaria ; $e$, the egg. $B$, an antherid. $C$, one of the hair-like structures growing among the antherids. the main stem or of a branch. In some mosses, male organs (antherids) and female organs (archegones) occur in the same group; in other mosses they are separate, but groups of antherids and groups of archegones are borne on different branches of the same plant; and in still other cases the separate groupsare produced on different plants. In Funaria the general rule secms to be that a group of antherids appears at the end of the main stem (Fig. 43, C). and a group of archegones at the end of a side branch; but sometimes the female branch is separated and becomes a 
small independent plant. Between the antherids are short, hair-like rows of cells (Fig. $44, C$ ), the end cell of each row being larger than the others. Similar structures are found also in the clusters of archegones, but the end cells of these sterile hairs are no larger than the other cells.

117. Formation of Gametes. - An archegone (Fig. 44, A) is a long, many-celled organ in whose basal part is a single female gamete, here called an egg. Above the egg is a long narrow neck, surrounding a canal filled with a thick, sticky liquid, which leads from the egg to the open end of the neck. An antherid (Fig. $H, B$ ) has the shape of a rather slender sac. Its outer part is composed of a layer of flat
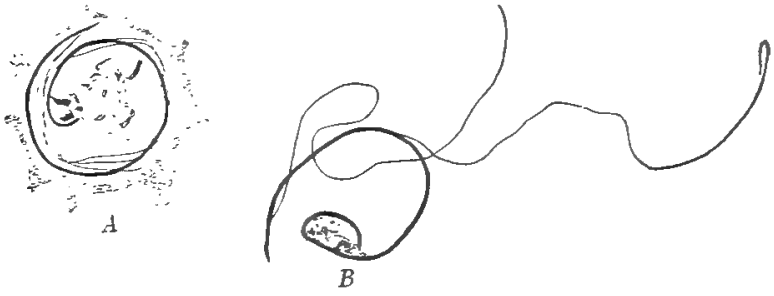

Frg. 45. - $A$, an antherozoid just escaped from the antherid. $B$, a swimming antherozoid, freed from the surrounding sticky substance.

cells; inside are produced many hundreds, perhaps thousands, of antherozoids (Fig. 45), which are very small male gametes, each with a slender body and two long vibrating hairs. If a drop of water is placed upon a male head, the antherids that contain mature antherozoids burst, and the mass of antherozoids oozes out into the water. Each one can be seen moving about within a drop of a clear liquid which is enclosed in a denser, sticky substance. In time this sticky substance is dissolved, and the antherozoids swim about freely in the water.

118. Union of the Gametes. - Since an antherid bursts only when it is moistened, the antherozoids are most likely to escape at the time of a rain, or possibly of a heavy dew. There must be water about the archegone also if an antherozoid is to swim to the archegone and enter its neck. When, as in Funaria, eggs and antherozoids are produced on distinct branches, some outside agency must carry the antherozoids to the female head. Probably they are carried often by the splashing of raindrops from branch to branch or from plant to 
plant; sometimes they may be carried by insects. In some way, at any rate, antherozoids reach the female head; and, swimming about here, some of them come into the neighborhood of an archegone and immediately swim to the opening of the neck. They do this because a substance is given off from the archegone which serves as a stimulus to the antherozoids; they swim toward the point from which the stimulating substance comes, and many antherozoids thus attracted may swarm about the mouth of the archegone. Some of them enter it and swim down the canal, through the liquid which fills it, and finally one antherozoid unites with the egg. Since this union of antherozoid and egg occurs inside the archegone, from which the egg (and the zygote as well) cannot escape, it follows that the new plant which is to grow from the zygote must begin to develop within the archegone.

119. Germination of the Zygote. - Germination occurs very soon after fertilization. As a result of the growth of the zygote and of a series of cell divisions, a long, slender embryo is formed. The lower end of the embryo grows down through the base of the archegone into the tissues of the stem of the parent plant. The growth of the new plant inside the archegone seems to stimulate some of the cells of the latter to renewed growth and division, and for a time the lower part of the archegone grows rapidly enough to keep pace with the development of the embryo. But after a time the growth of the embryo becomes more rapid than that of the archegone; the latter is now broken, and the greater part of it is carried up on the top of the embryo (Fig. 46, A). This cap, formed from the archegone, remains for a time, but sooner or later it falls off. The lower end of the embryo remains imbedded in the tissues of the parent plant.

120. The Spore-bearing Plant (Fig. 43, A, b). - As the new plant continues to grow, its upper portion becomes thicker and develops into a spore sac; this is supported on a long, slender stalk. It is by means of the lower end of the stalk, which is imbedded in the tissues of the parent plant, that the new plant absorbs water and other food substances from the parent. The upper end of the stalk, where it is 
attached to the spore sac, is somewhat enlarged; many of the cells of this part contain chlorophyl, and so can make carbohydrate food.

The spore sac (Fig. 46, B) has a rather complex structure, but the important thing for us to note is that the spore-bearing part is in the form of a hollow cylinder, and that inside and outside this spore-bear-
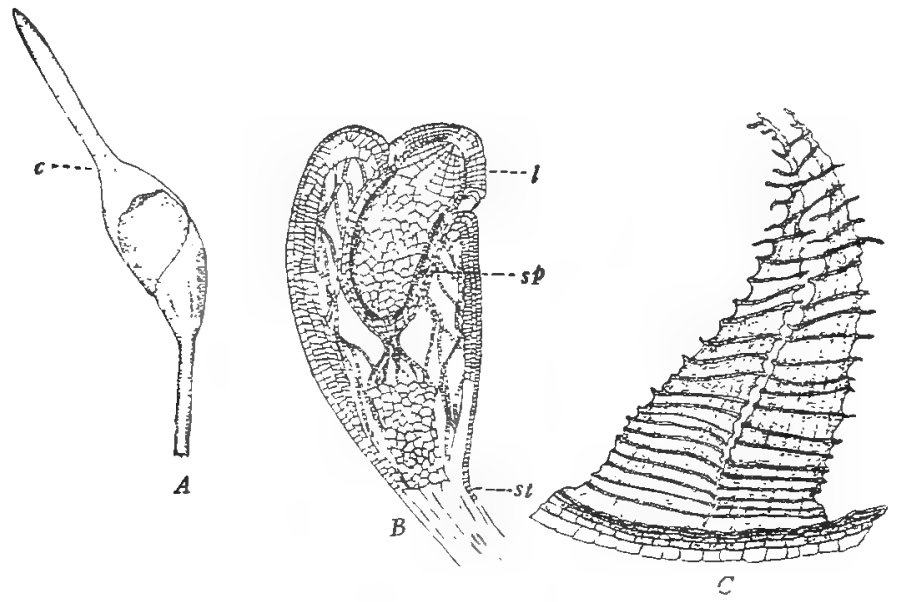

Fig. 46. $-A$, the upper end of the spore-bearing (asexual) plant of Funaria, still carrying the cap (c) which was formed from the archegone. $B$, a spore sac (as seen in lengthwise section) from which the cap has fallen; $l$, the part of the sac which will form the lid; $s p$, spore-bearing region; $s t$, enlarged upper end of the stalk. $C$, two teeth from the upper end of the spore sac. $B$ after Sachs.

ing region are various layers and groups of ceils which make and store food, and which have nothing directly to do with spore formation. Many of these food-making cells, like those in the upper enlarged part of the stalk, contain chlorophyl. Since so many cells in the spore sac and in the stalk can manufacture food, this spore-bearing plant is not wholly dependent upon the parent plant to which it is attached. However, since it is not directly connected with the soil, the spore-bearing plant must take from the parent its whole supply of water and of the other food substances that come from the soil; to this extent, therefore, it is parasitic upon the parent plant. The spore sac is curved; the upper part of the stalk also bends as the sac becomes mature, so 

that the upper, broader end of the spore sac is turned downward. This upper end forms a lid which drops off when the spores are ripe. But the falling of the lid does not leave entirely uncovered the cavity in which the spores lie; for attached to the margin of this cavity are two circles of teeth (Fig. 46,C).

In moist weather the teeth bend inward, closing the mouth of the cavity and so preventing the escape of the spores as well as the entrance of water into the spore sac. In dry weather the teeth curve outward, and through the open spaces between them the spores may sift out. Because of the presence of the teeth and of their changes in position, the spores are scattered a few at a time; thus, the chances are increased that some spores at least will land in a convenient place and under conditions favorable for germination. The spores are much like those of fungi excepting that they contain chloroplasts.

121. The Protonema. - A moss spore, falling upon moist soil or upon a moist stone, brick, or picce of wood, germinates

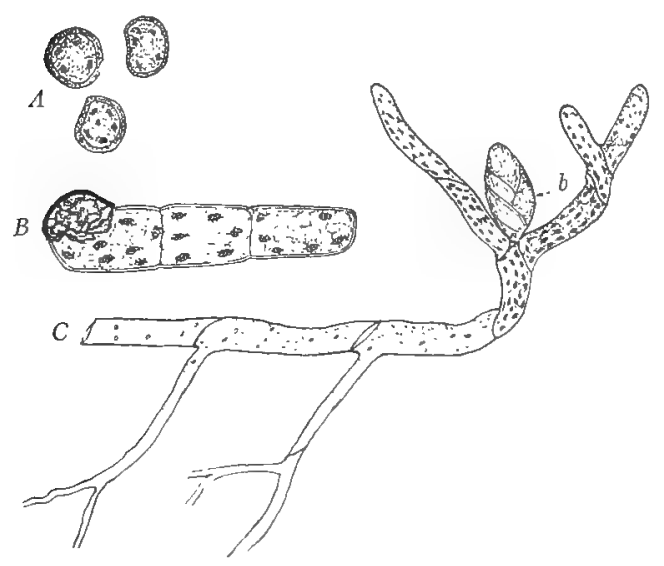

Fis. 47.- $A$, spores of Funaria. $B$, a young plant developed from a germinating spore; this plant grows into the protonema $(C) ; b$, a bud of the protonema which will develop into an upright leafy branch (or "moss plant"). spore and develops into a part of the same plant. The plant branches freely and looks much like a branching green alga a projection that grows in length and is soon divided by a cross wall. As the young plant continues to grow, more cross walls are formed; the plant now consists of a row of cells arranged cnd to end ( $F i g$. $47, B)$. A second projection often srows out from the opposite side of the

by pushing out (n)

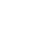

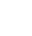


(Fig. $4, C$ ). This alga-like plant is called a protonema. Some short green branches of the protonema grow upright, instead of creeping as the longer branches do. Other branches, losing their chlorophyl, push downward into the soil or into the crevices of the substance on which the protonema is growing; these colorless or brownish branches are rhizoids. The protonema grows and branches in this ray for some time; but sooner or later a bud appears which develops, not into a thread-like branch, but into a rounded. group of cells; and this group of cells grows into an upright branch or stem that bears leaves and rhizoids. This upright branch is in fact exactly like the plant with which we began the study of the life of the moss. Since a single protonema may bear several of these leafy branches, it might be more accurate to consider the protonema together with all the upright branches growing from it as a single plant; but as the protonema dies sooner or later, each leafy branch comes to be actually a separate plant, and so it is most convenient to speak of it in that way.

122. The Two Generations of the Moss. - The whole life of the moss dirides itself naturally into two parts. The first, beginning with the spore, includes the protonema and the leafy branches or plants which grow from it; in this part of the life cycle the gametes (egg and antherozoid) are formed. The second part of the history consists of the small plant which grows from the zygote, and which in turn bears spores. As we have seen, this spore-bearing plant is parasitic upon the larger one which bore the egg, but it is none the less a distinct plant. These two divisions of the life of the moss are two distinct generations; the longer-lived one, in which gametes are produced, is the sexual generation; the shorterlived one, in which spores are produced, is the asexual gencration. In tracing the history of the moss, we must follow through these two generations in order to return to the point at which we started; so this history may be represented, as 
in Figure 48 , by a circle with two main divisions. The formation of spores by the asexual generation of the moss results in a rapid increase in the number of plants as well as

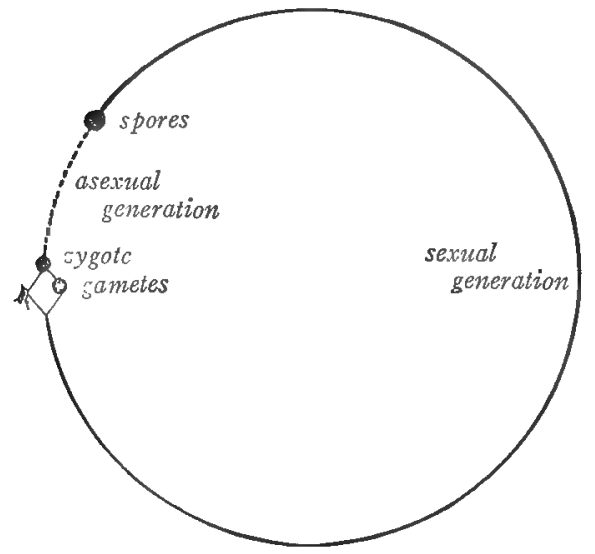

FIG. 48. - Diagram illustrating the life cycle of a moss. in a wide distribution of the species. Something of this sort seems to be necessary, for the moss can produce only a small number of eggs, which are confined within the archegones and whose fertilization is not at all certain. So, if the moss depended entirely upon sexual reproduction, the chances for its continued existence would be comparatively slight. The occurrence of two very different generations in the life of the moss is not unlike what happens in the case of the bread mold, whose zygote develops into a small plant quite different from the one that produced the gametes; and this small plant in turn bears spores, each of which may grow into a plant that produces gametes.

123. Other Mosses. - There are about eleven thousand known species of mosses, most of them very similar in their life histories to the one that we have studied. Among our common and larger mosses are the bird's wheat or pigeon wheat mosses and the tree moss. A very important family is that of the peat mosses which grow in great numbers in peat bogs. Peat mosses live through the winter by means of branches that start near the upper end of each plant; these branches live and grow the next year, while the older parts die. In this way the plants live and grow, it may be for centuries, the older 


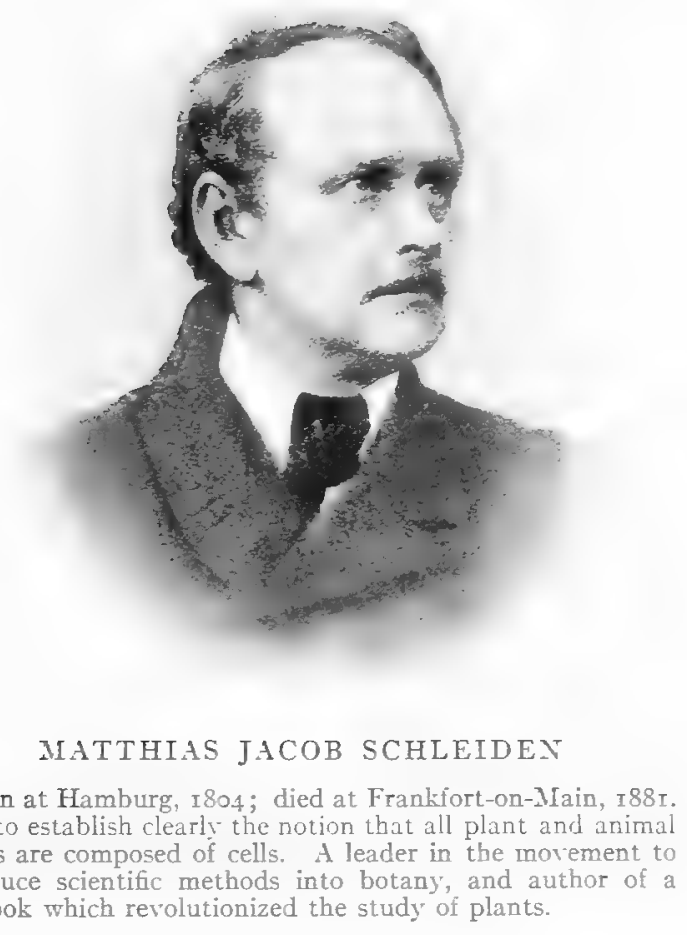



parts dying each year and being pressed and packed down by the weight of the younger growing branches above. The dead parts of the moss plants, together with plants of other species growing among them, and fallen leaves, twigs, bark, and the like, undergo changes which result in the formation of beds of peat. Further changes in the peat may in the course of ages lead to the formation of certain kinds of coal. Such peat bogs, whose material is steadily heaped up, play a large part in the filling in of swamps as well as of small ponds and lakes. Many lakes in the northern United States are thus being gradually filled by the ingrowth of beds of peat mosses from about their borders. In some locations, for example on cliffs and rocky hillsides, clumps of mosses of various kinds catch and hold soil-making materials such as dust and fragments of animal and plant bodies. As parts of the moss plants die and decay, their own substance is added to the collection; in this way, mosses, aided by the decayproducing bacteria, prepare a soil in which larger and more highly developed plants can in time establish themselves.

124. Relationships of the Mosses. - Most closely related to the mosses are the liverworts. Some of these are leafy

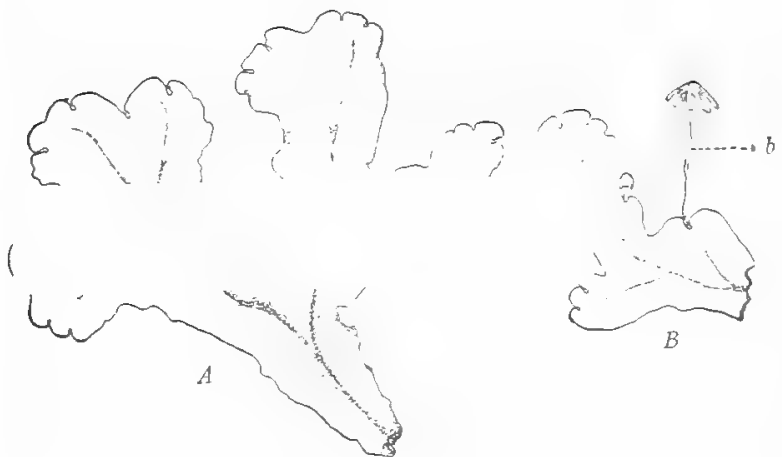

FIG. 49. - $A$, a liverwort (Marchantia). B, part of a liverwort plant, showing the upright branches (b) which bear sex organs (in the case shown, archegones).

plants quite similar to the mosses; others are flat, creeping plants which grow on damp earth and rocks (Fig. 49). Liverworts also have distinct sexual and asexual generations, but the asexual generation of a liverwort is smaller and much 
simpler than that of a moss. In all probability, liverworts and mosses are descended from green algæ more or less like Spirogyra, which originally lived in the water but which in some long past period were forced to adapt themselves to life on land. But no plants are now known, living or fossil, that illustrate the steps by which such algæ developed into the present-day liverworts and mosses. 


\section{CHAPTER $\mathrm{X}$ \\ THE BRACKEN FERN}

125. The Fern Plant (Fig. 50). - Many of the ferns are known for the beauty of their leaves, which are the only parts of most ferns that appear above ground. In the tropics there are some tree ferns, which have an upright trunk with a crown of leaves at the top. Of all the ferns, one of the best known is that which is called the brake, the bracken fern, or the eagle fern. Its botanical name is Pteris aquilina. It occurs in open woods and in clear spaces, sometimes growing very abundantly and covering large areas, especially in sandy soil. Its long, slender stem grows horizontally, from a few inches to a foot or more below the surface of the ground. It continues to live and grow slowly for many years. In some parts of the world, this stem is ground and used as food.

The stem grows at the forward end, which, covered and protected by scales, pushes its way through the soil. The older part of the stem dies as the younger part grows. Now and then the growing point divides; two buds are so produced, each enclosing one of the trro new growing points, and thus the stem branches by forking. Occasionally, also, a bud arises at the base of a very young leaf and grows into a branch of the stem. When the dying region of the stem reaches a point at which branching has occurred, the two forks (or main stem and branch) of course become independent plants. Thus the number of plants is increased. From the upper side of the stem, leaves grow upward; one or more leaves of the present year are to be found attached near the growing end of the stem as mell as near that of each 
branch; and farther back, on the older parts of the stem, are the bases of the leaves of previous years. Ahead of this year's leaves - that is, nearer the growing point of the stem are young leaves, still very small and protected by scales,

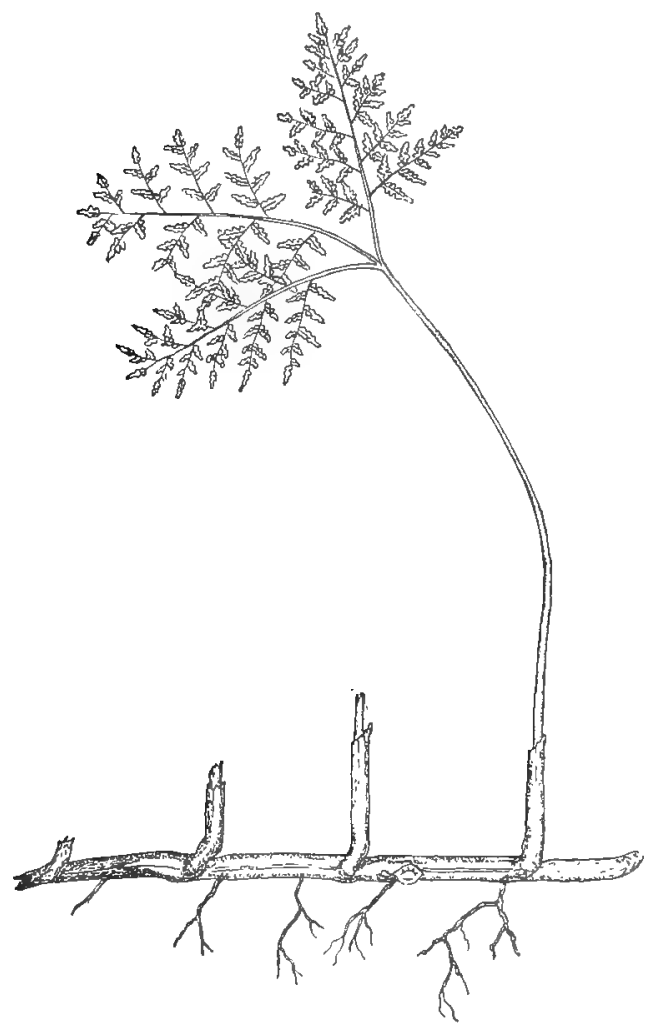

FIG. 50. - General appearance of a plant of the bracken fern, showing a portion of the underground stem, roots, and leaves. The youngest leaves (those nearest the growing point of the stem) are still very small and do not show in the figure; back of this year's leaf are the bases of the dead leaves of previous years. which will push above ground next year or the year after. Growing from the lower side of the stem, here and there, are roots.

126. Structure of the Stem. New cells are being continually formed at the growing point; as these new cells become older they grow and develop in various ways to form the different $t i s$ sues of the stem. A cross section through an older part of the stem (Fjg. 5I) shows us something of the way in which these tissues are arranged.

In such a section 
we may notice especially a number of rounded groups of cells of different sizes; these groups are the iascular bundles (Fig. 5 $\mathrm{I}, \mathrm{c}$ ). It must be remembered that in a cross section we see the breadth and the thickness but not the length of cells; some of the cells of the vascular bundles are many times as long as they are broad. If we follow the course of the vascular bundles in the stem, we find that they

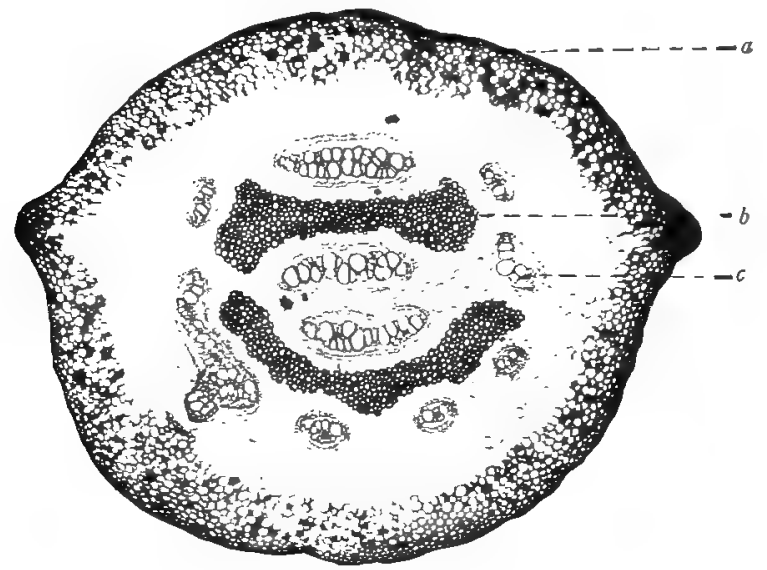

FIG. 5I. - Cross section of the stem of the bracken fern; $a$, epidermis; $b$, groups of very thick-walled cells which help to strengthen the stem; $c$, a vascular bundle.

do not run parallel with one another throughout their length; here and there two bundles unite, and at other places they give off branches, so that the whole system of bundles forms a network. Of the branch bundles that pass off from the bundles of the stem, some run into the leaves and others into the roots, so that all parts of the plant are connected with one another by means of the network of bundles. The long cells in the vascular bundles supply a path for the passage of food materials from one part of the plant to another. In a plant so large as the fern this work of conduction is an important 
one; and it is not surprising that a large amount of special tissue has been developed for the purpose.

127. Roots. - Now and then a root arises a short distance back of the growing point of the stem; other roots grow from the bases of the lcaf-stalks. The roots are short and slender; occasionally they branch. A short portion of each root, just back of its end, bears many root hairs. Each root hair is a surface cell of the root which has grown out beyond its neighbors. These hairs come into very close contact with the particles of soil, and take in some of the water which is always present between and about the soil particles. With the water the root hairs absorb salts and other substances which are dissolved in the soil water and which the fern can use as food. Thus all the materials which come from the soil, including the plant's supply of water, are taken in by the root hairs; these materials are passed on to the inner cells of the root, finally reaching the vascular bundles whose cells conduct the materials through the root and thence to the stem and leaves.

128. Leaves. - A leaf begins as a small swelling upon the growing point of a stem or branch. The life of a single leaf covers the greater part of three years. It passes the first two years below ground; in the spring of the third year it pushes above the surface and unrolls from the base, growing at the tip as it unrolls, until it has reached its full size; in the fall of the same year it dies, and finally it withers, is broken, and the parts above ground decay. Under ordinary conditions, the leaves grow to be from two to four feet high; but they may become much larger, and in some countries they reach a height of twelve or fourteen feet. A leaf consists of a slender stalk and a much-divided blade. The central axis of the blade is a continuation of the leaf-stalk and corresponds to the midrib of an undivided leaf like that of an oak; borne upon this central axis are two rows of leaflets. The two lower leaflets are often much larger than the upper ones, and 
are themselves divided into smaller divisions, the lower ones of which are again divided. The upper leaflets of the leaf are less divided than the lower ones, and the uppermost leaflets are very small and not divided at all. Several vascular bundles, branches of some of the bundles in the stem, pass up the leaf-stalk into the central axis of the blade, from which, in turn, bundles pass off into the midribs of the leaflets. The bundles in each leaflet again separate and branch, and their branches divide still further, so that finally vascular bundles pass into all parts of each division of the leaf-blade. These branching bundles are the veins of the leaf. They look like fine, light-green lines when the leaf is held be-
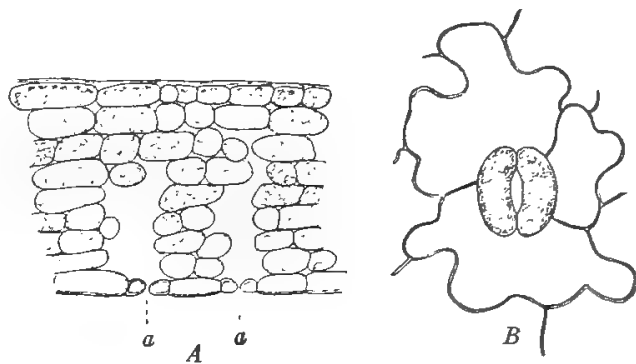

Fig. 52. $-A$, small part of a cross section through a fern leaflet, showing spaces between the cells which open to the outside through air-pores $(a)$ in the lower surface. $B$, an air-pore from the under surface of the leaf; it is a narrow opening between two curved guard cells which are surrounded by larger cells of very irregular shape.

\section{tween the eye}

and the light. On the under surface of the leaf are many small air-pores (Fig. 52), which lead into spaces between the cells in the interior of the leaf; thus the inner cells can obtain carbon dioxid from the air for the manufacture of carbohydrates, as well as oxygen for respiration.

129. Formation and Germination of Spores. - The spores of the bracken fern are borne in small spore sacs, great numbers of which grow in a line on the under surface of a leaf and close to its outer edge. Not all the leaves, however, bear spore sacs. The sacs are protected by the margin of the leaf, which folds under so as to cover the sacs while they 
are growing (Fig. 53, A), and which withers when the spores are ripe.

Each spore sac (Fig. 53, B) has a slender stalk and a wall which is composed of a layer of cells. The wall cells of one row, forming a
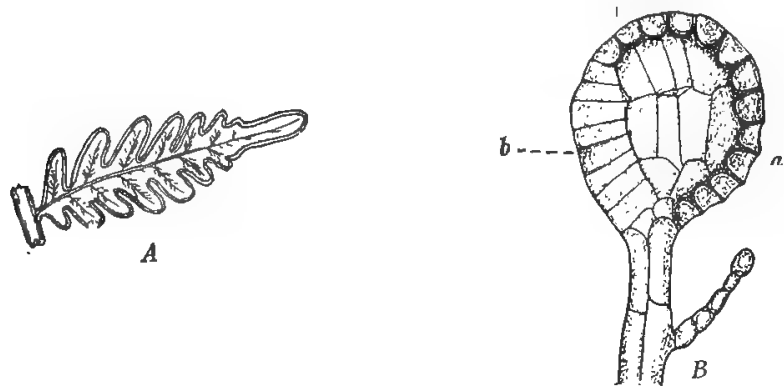

FrG. 53. - $A$, a leaflet of the bracken fern, seen from below; the margin is folded over so as to cover the spore sacs, which are borne near the edge. $B$, a spore sac; $u$, cells with specially thickened walls, which will bring about the opening of the sac; $b$, place at which the sac will open.

partial ring that runs from the base of the sac up one side, over the end, and part way down the other side, have very thick walls and project beyond the neighboring cells. When the spores are ripe, this ring of cells straightens suddenly, tearing the sac open and throwing out the spores.

The spores germinate in moist places, commonly on damp soil. A spore develops at first into a row of cells, usually not

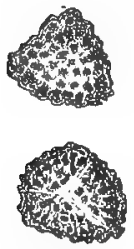

A

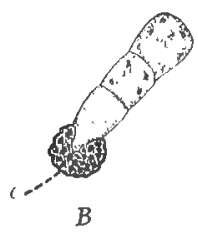

$B$

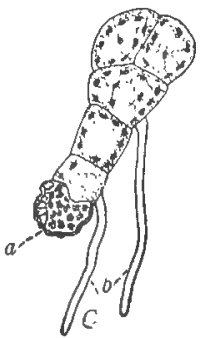

FiG. 54. - $A$, fern spores. $B, C$, early stages in the development of a sexual plant from a spore; $a$, wall of the spore; $b$, rhizoids. 
more than three or four in number (Fig. it, $B$ ). Later cell divisions are in different directions (Fig. $54, C$ ), so that the young plant comes to consist not of a row but of a triangular plate of cells, which as it grows becomes broader at the end farthest from the old spore wall. As this small plant, which is the sexual generation of the fern, continues to grow, a notch appears in the forward (broader) end.

130. The Sexual Generation. - An older sexual plant, if it has not been crowded while growing, has typically the heart
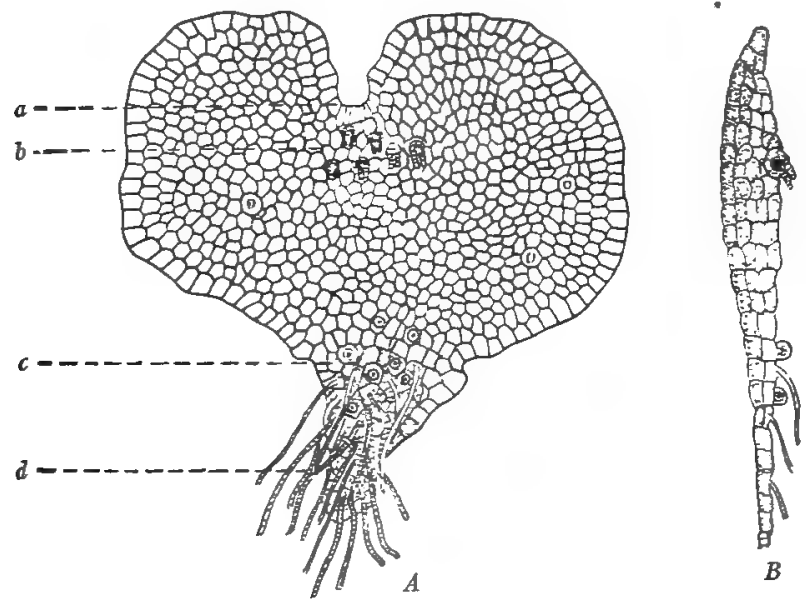

FIG. $55 .-A$, the sexual plant of a fern seen from below; $a$, notch at the forward end (the growing point); $b$, archegones; $c$, antherids; $d$, rhizoids. $B$, a section through the sexual plant, showing an archegone borne on the thickened part (just behind the growing point), and antherids and rhizoids on the older, thinner parts.

shape shown in Figure 55, $A$. This plant grows very slowly and remains so small that it is likely not to be noticed unless we are specially looking for it. A plant a half-inch in diameter is a large one. Its growth continues for some months, and under certain conditions a plant may grow for a year or more. It consists of one or two layers of green cells, 
excepting that a small part just back of the growing point (the notch) is several cells thick. This thicker part is not found in smaller and younger plants, but only in those that have been growing for some time. From the lower surface of the plant rhizoids grow downward into the soil, serving the same purposes as the rhizoids of a moss. Each rhizoid is a long cell. The rhizoids are borne mostly on the older part of the plant - that is, on the narrower portion farthest from the growing point.

The sexual plant of the fern, like that of the moss, bears sex organs. Both archegones and antherids are borne on the same plant; as a rule they grow, like the rhizoids, from the lower surface. Most of the antherids are formed on the older parts of the plant - in the same general region, therefore, as the rhizoids. But antherids sometimes appear also on the younger portions of the plant. The archegones are borne, in smaller numbers than the antherids, on the thicker part of the plant near the growing point. They develop in general later than the antherids; consequently one is likely to find many young plants, as well as older ones whose growth was checked in some way while they were still small, which bear antherids but no archegones.

131. Sex Organs, Gametes, and Fertilization. - The archegone of a fern (Fig. 56, A) is shorter than that of a moss. It has no stalk and its base is embedded, as though it had been pressed down among the vegetative cells. The neck is short and is curved backward toward
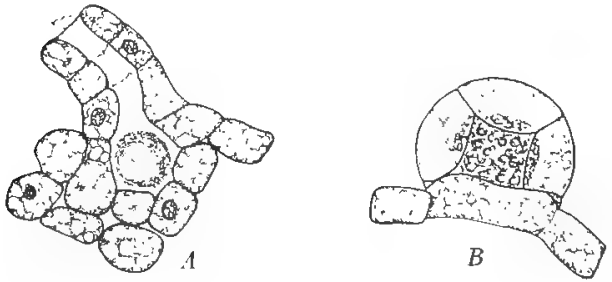

FIG. $56 .-$ Sex organs of a fern: 1 , an archegone; $B$, an antherid. the part of the plant where antherids are borne. The antherid of a fern (Fig. 56, B) is also smaller and simpler than that of a moss, and it produces a much smaller number of antherozoids (Fig. 57). Although both kinds of 
gametes are borne close together on the same plant, it is probable that as a rule self-fertilization - the union of an egg with an antherozoid produced by the same plant-does not occur in the fern. That it does not is suggested by the fact that the antherids usually ripen and discharge their antherozoids before the archegones on the same plant are mature. This would seem to make cross-fertilization necessary - that is, the union of an egg and an antherozoid borne by different plants. On the other hand, young antherids are sometimes found on the same plants with welldeveloped archegones, and it is quite possible that self-fertilization occurs now and then. Cross-fertilization is made easier by the fact that sexual plants commonly grow in groups, because many spores were dropped and

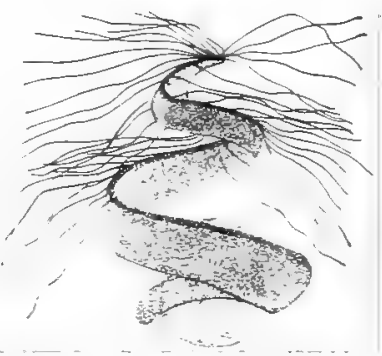

FIG. 57. - 1 fern antherozoid. From a preparation by Dr. II. N. Steil. germinated near one another. Since

these little plants grow in moist places, there is enough water present much of the time on their lower surfaces so that the antherids can open and the antherozoids can swim to the mouths of the archegones either on the same or on neighboring plants.

132. Development of the Asexual Plant. - Doubtless it often happens that more than one egg is fertilized and so that more than one zrgote is formed in the archegones of a single plant; but re seldom find that more than one zrogote has developed into a plant of the next generation. This is probably because the new plant growing from the zygote receives food for some time from the sexual plant that bore the egg; since the sexual plant is small and can supply only a limited amount of food, only that one embryo develops which has an advantage because of its greater vigor or its better location; the less fortunate embryos are starred and cease to grow.

The zygote, like the zygote of the moss, germinates in the archegone. Tery early the embryo (the young asexual plant, Figure 58 ) develops four parts: one of these, the foot, remains small and imbedded in the tissues of the sexual plant, from which it absorbs food for the use of the embryo. Two other parts of the embryo, the primary root 
and the primary leaf, push their way out through the surrounding tissues. First to break out, usually, is the root. As soon as its tip is free, it turns downward and grows into the soil. Next the primary leaf pushes out its tip; it grows forward beneath the parent plant until it reaches the notch at the growing point; then it turns upward and forms a flat green blade, which is much simpler in outline than are the blades of the leaves formed later.

Thus far the embryo has remained connected with the parent plant by means of the foot, and dependent upon the parent for food; but
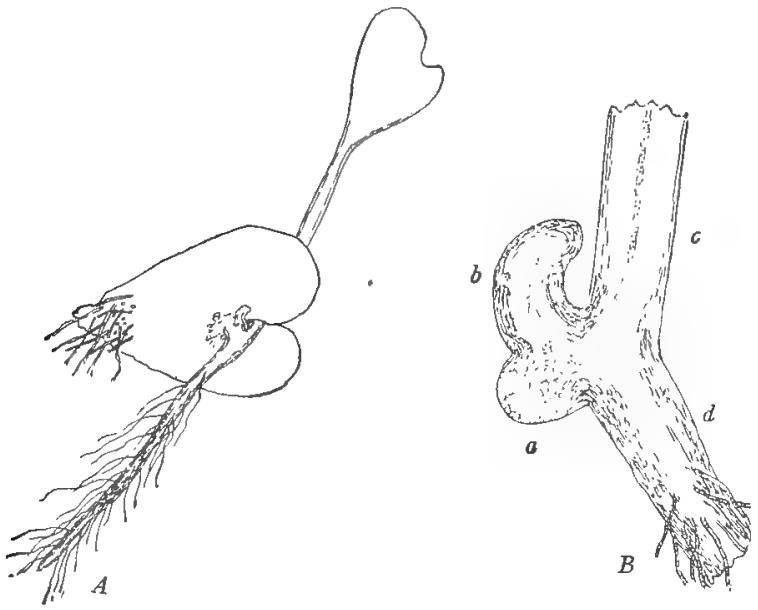

FIG. 58. - $A$, the young asexual plant of a ferm still attached to the sexual plant; the primary leaf and the primary root are both fully formed. $B$, a portion of the young asexual plant, removed from the sexual plant and considerably enlarged; $a$, the foot, by which the asexual plant is attached to the sexual plant; $b$, the young stem; $c$, the base of the primary leaf; $d$, the upper part of the primary root.

now, having a root pushing into the soil and a leaf exposed to the air the young plant can obtain or manufacture all its food. The sexual plant by this time has given up most of its available food; it withers and dies, but what is left of it remains for a time attached to the young asexual plant. The stem of the asexual plant is the last of the four embryonic parts to develop. For some time it is merely a bud-like swelling at the base of the leaf; but after the primary root and the primary leaf have begun to supply food for the plant, this bud grows 
slowly into a horizontal underground stem. In time, new leaves grow from the upper side of this stem and new roots from the lower side. After the first of these new leaves and roots have appeared, the primary leaf and primary root, which up to now have supplied food for the plant, die and disappear. Now the asexual plant has reached the condition at which we began to study it.

133. Outline of the Life of the Fern. - The fern, like the moss, has a sexual generation which develops from a spore and bears gametes, and an asexual generation which develops from a zygote and bears spores. In both moss and fern, a spore can develop only into a sexual plant, and a zygote can develop only into an asexual plant. The great difference between the moss and the fern is that the sexual plant of the moss is large and long-lived, and its

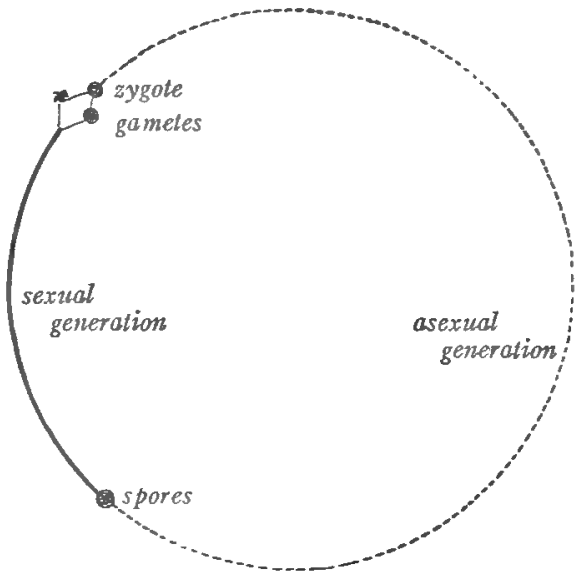

Fig. 59. - Diagram illustrating the life cycle of a fern.

asexual plant small and short-lived; but in the fern the conditions are just the opposite, the sexual plant being small and relatively short-lived, and the asexual plant large and long-lived. Thus what is commonly known as the moss plant is the sexual generation; what is commonly known as the fern plant is the asexual generation.

There seems to be little doubt that the fern is descended from some plant (perhaps a liverwort) which like the moss had a long-lived sexual generation and a short-lived asexual generation. In the evolution of the fern from this ancestor 
most of the work of food-making and food-storage was transferred from the sexual to the asexual generation. This transfer of work could not take place in a plant like the moss, whose asexual generation has no direct connection with the soil and so must receive water and other substances from the sexual generation. Before the asexual generation can become independent, it must find a way of reaching the soil ; and this some ancestor of the fern did by the development of a root. Nothing at all like a root was ever developed, so far as we know, by a sexual plant; and the possession by the asexual generation of this new organ, which can draw upon the resources of the soil and can firmly anchor the plant, is one reason why the asexual generation of the fern (and of seed plants as well) has come to be so large and complex. The sexual generation of the fern, on the contrary, having little need of food-making and food-storing tissues, has become very small. The history of the life of the fern may be represented by a diagram (Fig. 59) which is like that used for the moss (Fig. 48) except for the relative length of the lines representing the sexual and asexual generations.

134. Other Ferns. - A comparatively small number of species of ferns live in temperate regions, where they do not as a rule grow in large numbers. But in tropical and subtropical countries we find many more species, and in such countries ferns often form conspicuous features of the landscape. Most of the ferns bear spore sacs in groups on the under surface of the leaf, and not in a line near the margin as those of the bracken fern are borne. Among the common species in the United States and Canada are the lady fern, the rock fern, and the maidenhair fern. Others of interest, but not so common, are the royal fern, our largest species; the ostrich fern, the cinnamon fern, and the walking fern. Among those of the tropics are the various specics of tree ferns already mentioned. Some small tropical ferns live on the trunks of trees high above the ground. 
135. Relatives of the Ferns: Water Ferns. - With the true ferns, of which about four thousand species are known, and which include the brake and the others that have been mentioned, are grouped about eight hundred other species of plants whose relationship to the ferns is more or less close. All of these plants resemble true ferns in the fact that their asexual generation is a large, highly developed plant, their sexual generation being small and inconspicuous. The water ferns are a small group, living either on mud or on the surface of bodies of water. Their spore sacs are formed inside a hard, nut-like structure. The spores are of two kinds: one kind, which is small, develops into a small male plant that bears antherozoids; and the other kind, much larger, develops into a female plant that produces eggs.

136. Horse-tails. - These, like the brake, have an underground stem. The stem sends up erect branches, whose appearance gives the plant its name. The leaves

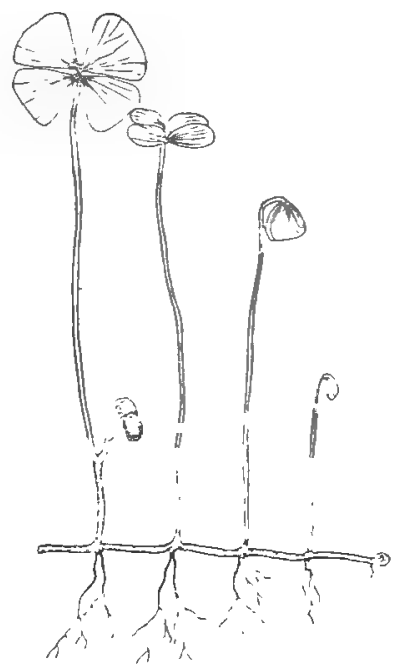

Fig. 60. - Marsilea, one of the water ferns. This plant lives in very wet places, usually on'mud, the stem creeping along the surface. Growing on the lower part of the left-hand leaf are two nut-like bodies. It is in these that the spores of the plant are borne.

are very small scales which grow in circles upon the branch; the branch is green, and its cells manufacture most of the plant's carbohydrate food. The upright branches have a hard, rough surface, and some of the larger species are called "scouring rushes," from the use to which they were formerly put. The spore sacs are borne on leaves of a special form which are crowded together at the upper end 
of the branch so as to form a structure much like a pine cone.

137. Club-mosses. - These are small, mostly creeping plants, looking more like mosses than ferns. The moss-like plants, however, belong to the asexual generation, so that the

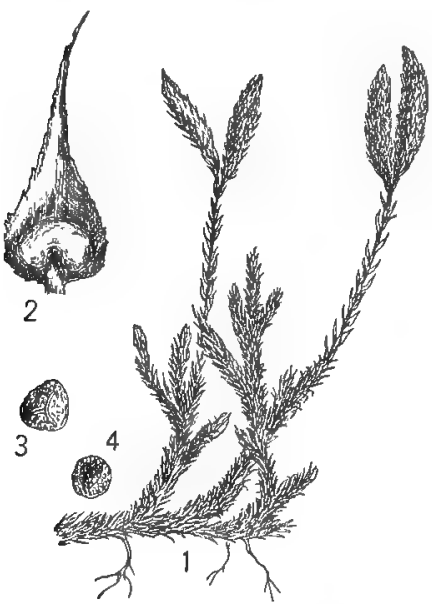

FIG. 61. - A club-moss (Lycopodium) that bears but one kind of spores. $r, i$ portion of the plant showing the branching stem, leaves, and roots, the spore-bearing leaves being arranged in cone-like structures at the ends of upright branches. 2 , a spore-bearing leaf, with a spore sac at its base. 3 and 4 , spores. After Wossidlo.

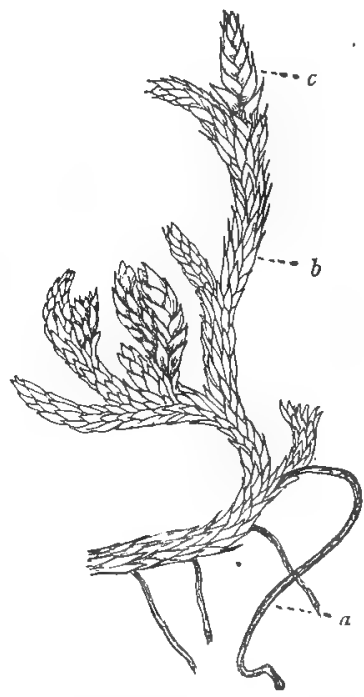

Fig. 62. - A club-moss (Selaginella) that bears spores of two different sizes; $a$, special branches which bear roots at their ends; $b$, foliage leaves; $c$, spore-bearing leaves.

likeness to mosses is only apparent. Some of the club-mosses (Fig. 6r) bear one kind of spore, like the true ferns; others (Fig. 62) have two kinds of spores, like the water ferns, and their sexual generation consists of male and female plants that are very different in size. The spore sacs are borne singly either on ordinary lcaves, or on special leaves which 
grow in a cone-like group as do the spore-bearing leaves of the horse-tails.

138. Fossil Ferns. - The ferns and some of their relatives, having hard, resistant structures, have been preserved in large numbers in the rocks whose material was deposited in past ages. This is not true of most of the plants simpler than the ferns, whose tissues are soft and have been destroyed,

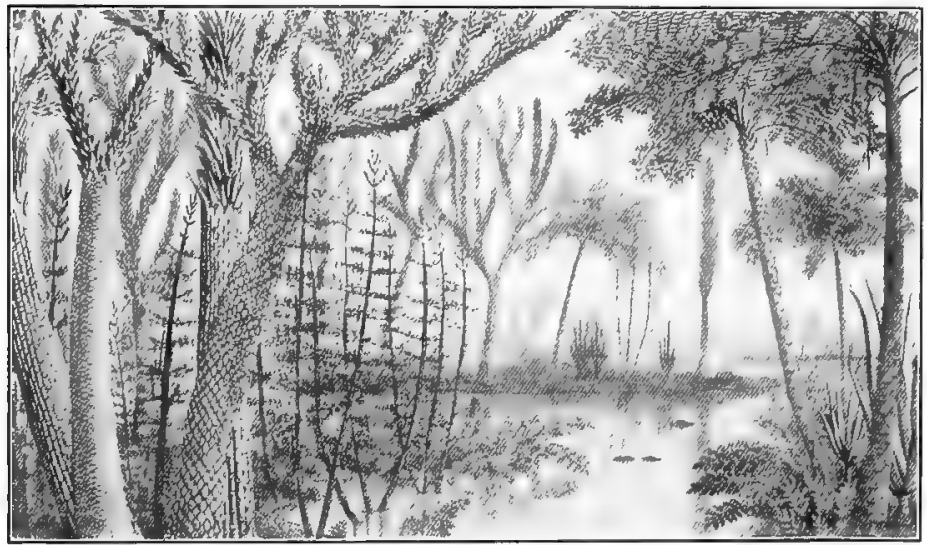

Fig. 63. - Plants of the ages when the coal beds were being formed. In the foreground, on the left, relatives of the club-mosses; just back of these, tree-like forms related to the horse-tails; on the right, tree ferns. After Stevens.

except for occasional fragments, by the pressure, heat, and chemical changes to which the rock layers have been subjected. For this reason, much more is known about the past history of the ferns than about that of mosses, for example, or that of most of the algæ or fungi. Our great beds of coal were formed at a time when ferns and their relatives made up a large part of the vegetation of the earth, and so it is especially in the coal measures that rich material is found for the study of fossil ferns (Fig. 63). Among the ferns of the coalforming period were many true ferns evidently related to 
certain species of the present day; some of these grew to be large trees. There were other tree-like forms, some related to the horse-tails and some to the club-mosses. There were also plants which had fern-like leaves but produced true seeds; and these fossil plants have taught us much of the way in which some of the living seed plants have developed from the ferns. 


\section{CHAPTER XI}

\section{THE PINE}

139. The Pine Tree. - The pine tree, like the fern plant, belongs to the asexual generation. Te may expect, therefore, to find that in some way the tree produces spores. First, howerer, we shall study the vegetative parts of the tree, namely, the stem (trunk) and its branches, the leaves, and the roots. The trunk, because it contains many thickralled cells, can stand erect and support its omn weight as mell as that of the branches and leaves. The trunk grows in length by means of a terminal bud, which includes, besides the

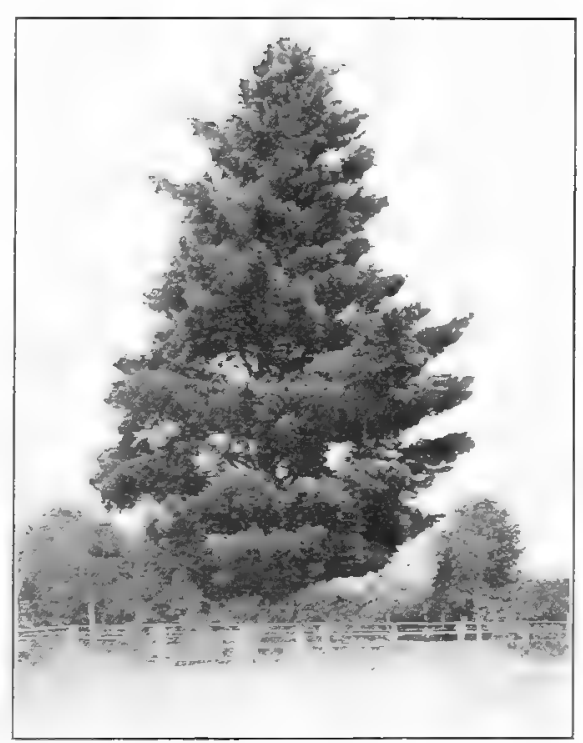

FrG. 64. - A pine tree grown in the open. Photograph by L. S. Cheney: growing point of the stem, the very youngest and smallest branches and leaves. By the formation of new cells at the growing point, and by the growth of these cells, the trunk is 
lengthened and new branches and leaves are formed during the growing season.

At the coming of winter, growth stops and scale leaves covered with resin are formed that protect the bud. When growth begins again in the spring, the scale leaves drop off;

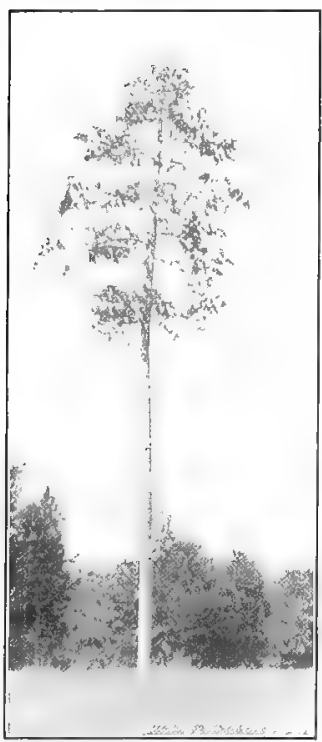

FIG. $65 .-A$ pine tree that grew in a forest. Photograph by L. S. Cheney. but their bases remain, forming a ring that looks like a thickening of the stem. By means of this ring one can see where the growth of one year ended and that of the next year began. From the thickened ring grow one or more branches, which have developed from buds in the axils of the fallen scale leaves. If the terminal bud is destroyed or killed, the growth of the trunk ceases; but commonly, in such a case, one of the branches near the top of the tree bends and grows upward, so that the tree continues to become taller. The stem of the fern grows only in length; but that of the pine grows both in length and in thickness. The trunk is slenderest at the top and gradually thicker toward the base, because the base is the oldest part and has been growing in thickness for the longest time.

140. Inner Structure of the Stem. - At the very tip of the stem (Fig. 66) are many small cells, which, during the growing season, are continually growing and dividing. In this region, too, are some very small swellings; these are the beginnings of new leaves and branches. Below the tip the cells are larger; farther down they are still larger, and different groups of them are gradually taking on the forms that 
are peculiar to the different tissues of the trunk. These tissues are well shown in a section of a stem cut some distance below the growing point (Fig. 67). In the center of the stem is the pith. Just outside this is a ring of vuscular bundles, the spaces between which (looking like dark lines in the figure) contain cells much like those of the pith. Each vascular bundle is composed of wood and bast.

The wood is the part of the bundle that is turned toward the center of the stem; the bast is the part turned outward. The wood carries the sap from the roots to the upper parts of the plant, and the bast carries manufactured food from the leaves to the other organs. Most of the cells of the vascular bundles, especially those of the

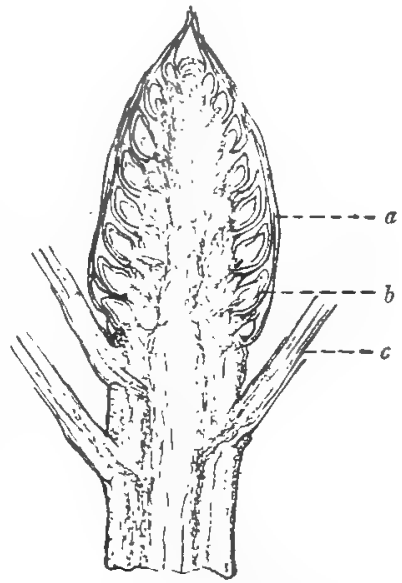

FIG. 66. - A lengthmise section through the tip of a growing pine stem (winter bud) ; $u$, bud scales; $b$, a young spur branch; $c$, an older spur branch, with the bases of the foliage leaves that it bore. wood, have very thick walls; and the strength and stiffness of the stem are due mainly to the thick-walled cells of the wood. Outside the ring of vascular bundles is the cortex, and outside this is the epidermis, which is composed of a single laver of cells. Here and there in the cortex, groups of cells are breaking down to form resin passages - cavities which extend for some distance up and down in the stem, and which contain resin.

141. Growth in Thickness. - The way in which the stem grows thicker is shown by a cross section of a part of the stem that has been growing for several vears (Fig. 68). After the different tissues have reached the condition already described, divisions begin to occur in each vascular bundle in 
a layer of cells lying between the wood and the bast. The cells of this layer divide so as to form two layers, three layers, and so on. Then some of the cells between the vascular bundles begin to divide in the same way. Thus a continuous zone of dividing cells, called the cambinm (represented by a

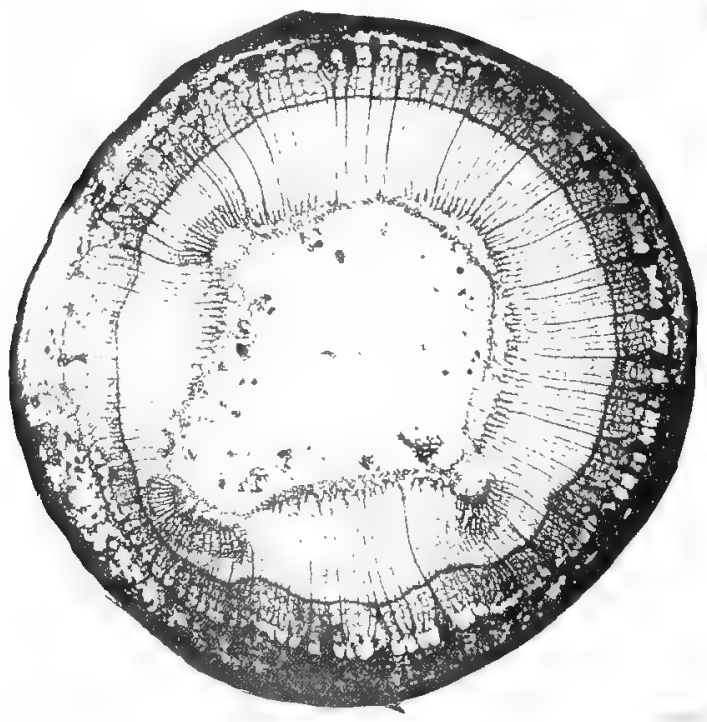

FIG. 67. - A cross section through a portion of a pine stem in which the different tissues have developed. The narrow dark zone is the cambium layer, separating the wood (on the inner side of the cambium) from the bast (on the outer side). At the center, inside the wood, is the pith.

narrow dark ring in Figure 67), is formed which cuts through the middle of each vascular bundle; outside this zone lie the bast, cortex, and epidermis, and inside it are the wood and pith. The formation of new layers of cells pushes the wood and bast farther apart, and so makes the stem thicker.

Most of the new cells that are formed on the inner side of the cambium zone develop into wood cells, and most of those formed on the outer side of the cambium become bast cells. 
But some rows of cells (called mcdullary rays) running from the central part of the stem toward the outside remain thinwalled, and, except that they grow somewhat larger, do not become very different from the cambium cells themselves. The medullary rays thus cut across both the wood and the bast; but except for these rays, the wood forms a continuous zone of increasing thickness just within the cambium, and the bast forms a continuous zone just outside the cambium. Within the newly formed wood, resin passages develop like

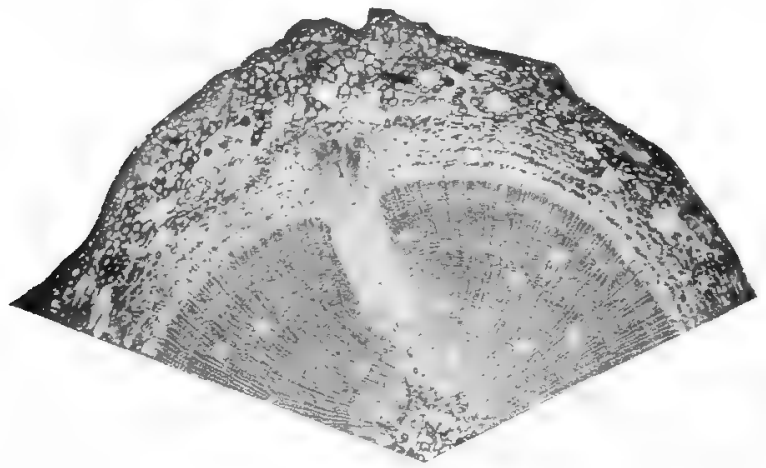

Fig. 68. - Part of a cross section through a portion of a pine stem which has been growing in thickness for several years. The small light spots in the wood represent resin passages.

those in the cortex. Although the process of growth in thickness can best be studied in thin sections of the stem, we must bear in mind that the zones of rood, cambium, and bast which we see in such a section really represent cylinders running up and down within the trunk.

142. Annual Rings. - The new wood cells formed from the cambium in the spring grow large and remain thin-walled. Later in the season, smaller, thicker-walled cells are formed, and those produced at the close of the growing season (in late summer or early fall) are smallest and thickest-walled of all. No divisions occur in the cambium during the winter; 
when it becomes active in the spring, it again forms large, thin-walled cells. This new spring wood is next to the summer wood of the year before; and the sharp contrast between the dark summer wood and the lighter-colored spring wood causes the familiar appearance of rings in a section of a tree trunk. It is because these rings are formed as just described that one can tell about how old a tree is by counting the rings in a section near its base. The number of rings is not a perfectly accurate measure of a tree's age, because the development of new wood may have been changed or prevented in places by pressure or by wounds, and because occasionally in a year of exceptional weather, as when a long summer drought is followed by heavy rains, two rings are produced instead of one. It is only in the outermost part of the wood - much more than the present year's growth, however - that the sap flows upward; this outer wood - the sapwood - is soft and moist. In the cells and cell walls of the older heartwood changes have taken place which prevent the passage of water. The heartwood is therefore dryer and harder than the sapwood.

143. Cork and Bark. - Another kind of thickening occurs in the cortex of the trunk. This results from the division of the cells of a layer a short distance within the epidermis, called the cork cambium. The new cells formed on the outer side of the cork cambium develop thick walls that contain a fat-like substance called cork. Water will not pass through the walls of these cork cells. Now, since the whole rater supply of the trunk comes from the roots and is carried up inside the trunk in the sapwood, the cork cells and the cells outside them are cut off by the corky walls from a supply of water; these cells therefore become dry and dead, cracks appear in their walls, and so a hard, dry bark is formed. Later (in some species of pine only in parts of the tree that are eight to ten years old), a new layer of cork cambium appears a little way beneath the first layer, new layers of cork 
cells and bark are formed, and the older layer of bark peels off. Then a third layer of cork cambium appears within the second, then a fourth, and so on, and in time the whole cortex has been changed to bark. Later layers of cork cambium therefore must be formed within the bast. So the outer part of the bast is also gradually changed to bark and scaled off, at the same time that new bast is being formed from within by the division of the cambium cells. This change of the outer layers of the bast into bark explains why the bast never becomes thick, although new bast is formed each year; and why most of the thickness of an older tree is made up of rings of wood.

144. Branches. - These, in the pine, are of two kinds: long branches and spur branches. The long branches develop chiefly from the buds borne in the axils of winter bud scales; but sometimes adientive buds, which appear in various places - for example, upon wounded parts of a trunk or branch grow into long branches. 1 long branch has the same structure as the trunk: it groms in length and in thickness; it forms bark; and from the axils of its minter bud scales new long branches may grow. The spur branches are very short, never more than a fraction of an inch in length. They grow from the buds in the axils of the numerous scale leaves that are formed during the groming season upon the trunk and the long branches. A spur branch lives and grows very slowly for several years, never itself branching. At its end is a cluster of green foliage leares.

145. Leaves. - $\Pi^{T}$ e have seen that two kinds of leaves are borne by the pine: scale leaves (which include the winter bud scales) and foliage leaies. Scale leaves are protective organs and are usually short-lived. Much more conspicuous are the long, green foliage leaves - the "pine needles" which grow in clusters at the ends of the spur branches. Each cluster is surrounded in the bud br a thin membrane, which later is torn and partly or entirely disappears. The 
foliage leaves of the pine are not borne directly on the trunk or on long branches, except in the case of young seedlings. The number of leaves in the cluster at the end of each spur branch varies with the species; for example, the red pine has two needles in each cluster and the white pine has five. The foliage leaves do not fall off at the end of their first season as do the leaves of most of our common trees; they live and remain on the tree for more than one year. The leaves of

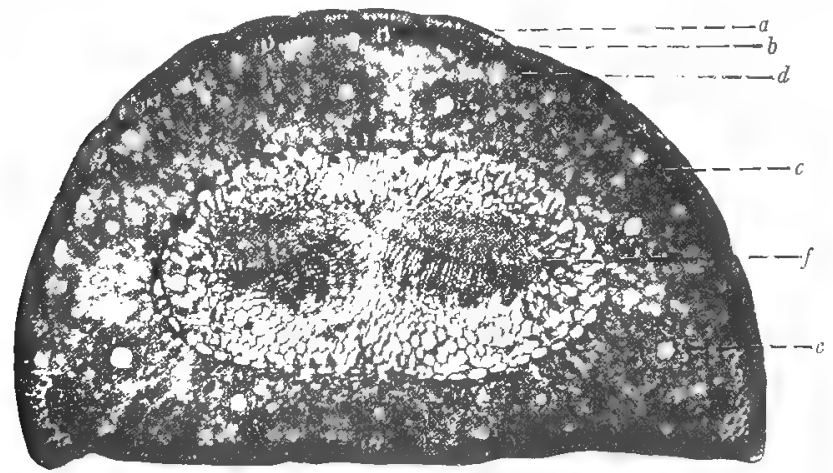

FIG. 69. - Cross section through a foliage leaf of the Scotch pine; $u$, epidermis; $b$, an air-pore; $c$, layers of thick-walled cells just within the epidermis; $d$, thin-walled cells between which are air-spaces; $e$, resin passage; $f$, vascular bundles.

some pines are said to live for ten years, but the average is probably much less than this. A pine tree, at any rate, is never bare of leaves, although each year some of the older leaves drop off. When the leaves of a cluster fall, the spur branch that bore them dies; therefore spur branches and foliage leaves (as well as scale leaves) are found as a rule only on the younger portions of the trunk and of each long shoot.

A pine needle is not cylindrical, but has one or more flattened surfaces, depending upon whether it is one of a cluster of two, three, or five which were pressed together in the bud. On both upper and 
lower surfaces are air-pores, like those on the lower surface of the fern leaf. In a cross section through a pine leaf (Fig. 69) we find a variety of tissues, in general much like those of the stem. In the central part of the section are tro vascular bundles, ${ }^{1}$ each composed of wood and bast; the wood is that part of each bundle turned toward the upper side, and the bast is the part toward the lower side of the leaf.

146. Roots. - The long tap root of the pine is continuous with the trunk; it may grow downward for a great distance. The tap root gives off branch roots, which in turn branch, and both the tap root and the branch roots form bark and grow in thickness in much the same nay as the trunk does. There is a marked difference between the way in which branches start from the stem and that in which branch roots start from the tap root. A branch of the stem begins as a surface swelling at the growing point of the stem; a branch root begins its development within the tap root, some distance back of the growing point and just outside the ring of vascular bundles; so the new root must break its way through the outer tissues of the older root within which it has begun to grow. Although we ordinarily see little of the roots of the pine, we must remember that they really make up a large system, comparable in size with the trunk and its branches. The weight of the parts of a tree above ground, and the great pressure exerted upon it by the ninds, make necessary an extensive root system that will anchor the tree firmly in the soil.

A root of the pine, as of the fern, bears root hairs just back of the growing point. Ner root hairs are constantly being formed in this region, but ther soon die and fall or are rubbed off. For this reason the zone in which root hairs are borne is a short one. Since it is only through the root hairs that water and other substances are taken from the soil, this work of absorption can go on in only a small part of the root system of

1 In some species, including the white pine, the leaf contains only one vascular bundle. 
a large tree, and that the youngest part. A root contains the same tissues as does a stem or branch, although somewhat differently arranged.

147. The Staminate Cone. - The pine bears two kinds of cones. It is not easy at first to think of these as corre-

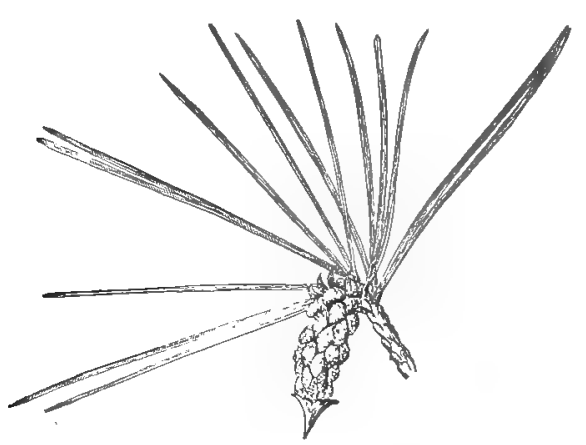

FIG. 70. $-A$ cluster of staminate cones of the pine. After Stevens.

sponding to the staminate and pistillate flowers of the cucumber. But the cones really are very primitive flowers. The two kinds of cones differ in size, the staminate cone being much smaller than the carpellate. Both are borne on the same tree. Staminate cones (Fig. 7o) grow in clusters; carpellate cones grow singly. A staminate cone has a large number of leaf-like or scale-like parts, attached to a central stalk. As a matter of fact, the central stalk of the cone is a branch, and the leaf-like structures that it bears are really leaves. These leaves are not green and so cannot manufacture food, as foliage leaves do; their work is to produce spores, and so we call them spore leaves.
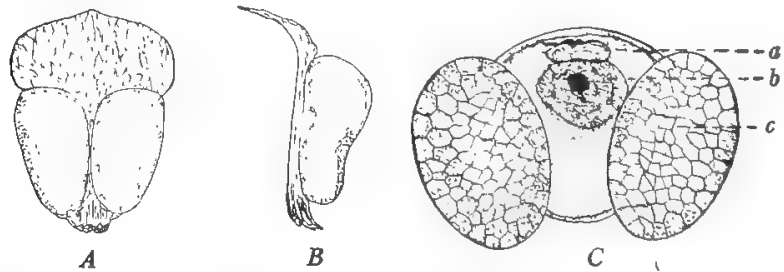

FIG, 7I. - $A$, a microspore leaf of the pine as seen from below, showing the pollen sacs. $B$, the same, seen from the side. $C$, a pollen grain; $u$, the generative cell; $b$, the nucleus of the large vegetative cell; $c$, the bladderlike expansion of the outer wall of the pollen grain. 
We saw that the green leaf of the fern does two kinds of work: it manufactures food and it bears spores. In the pine, these tro kinds of work are performed br two distinct kinds of leaves - the foliage leaves and the spore leaves. The spores borne on the spore leaves of the staminate cone are very small, and so are called microspores; therefore the leaves of the staminate cone are microspore leaies. The under surface of each microspore leaf (Fig. $i$ I. $A$ ) is nearly covered by two microspore sacs (or pollen sacs); within these sacs a great many microspores or pollen grains are produced.

\section{The Carpellate Cone} (Fig. 72). - This, like the staminate cone, is a branch to which many spore leaves are attached; since these leaves bear large spores (macrospores), they are called macrospore leaies. ${ }^{1}$ On the upper surface of each macrospore leaf (Fig. 73, A) are two small swellings; these are macrospore sacs or, as

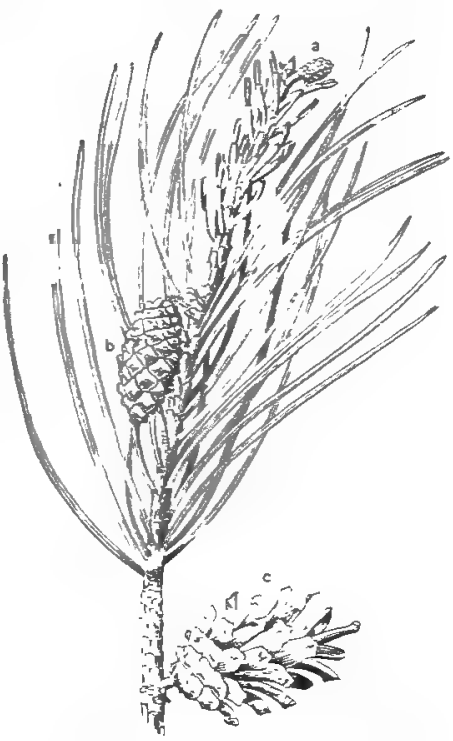

Fic. 72. - Carpellate cones of the pine : $a$, a young cone ready for pollination; $b$, a cone one year older, the eggs in which are nearly ready for fertilization; $c$, one still older, whose macrospore leaves have spread apart, allowing the seeds to drop out. After Stevens.

they are more commonly called, oiules. Each sac is surrounded by an integument, excepting that at one end, where the integument projects in the form of two horns, there is a narrow opening through the integument called a micropyle.

1 The organ that is here called a macrospore leaf is more complex than the microspore leaf, and there is a question as to whether it is not really more than a leaf. 
In the central part of the macrospore sac, four macrospores are formed (Fig. 73, C) ; they are much larger than microspores. All the spores that we have studied hitherto were produced in such a way that when they were ripe they could escape from the parent plant. But the macrospores of the
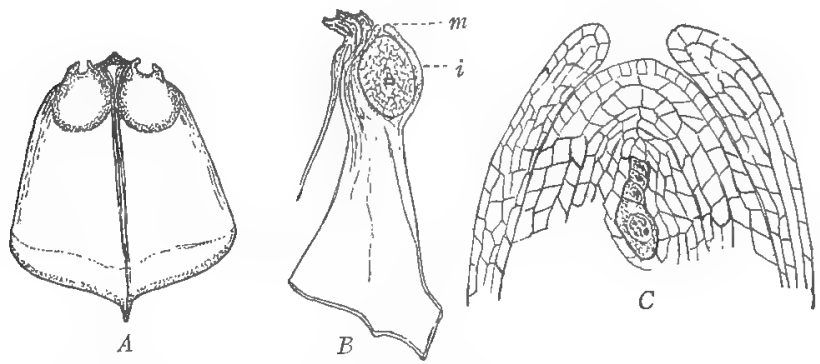

FIG. 73. - $A$, a macrospore leaf of the pine bearing two macrospore sacs (ovules). $B$, a lengthwise section of a macrospore leaf; $i$, integument; $m$, micropyle. $C$, part of a lengthwise section of an ovule on a larger scale, showing the four macrospores.

pine are so tightly imbedded in the tissues of the spore sac that they cannot escape, and so if they are to germinate they must do so inside the spore sac. This imprisoning of the macrospores is one thing that distinguishes the seed plants, and it leads to some very important consequences.

149. Germination of the Macrospore. - Of the four macrospores, only one germinates. It develops into a small, rounded mass of tissue which, since it grows from the spore, belongs to the sexual generation of the pine. This mass of tissue is a female plant; but, 1)cause of the position of the spore from which it has growt1, this small plant remains inside the macrospore sac (Fig. 74). At the end of the female plant nearest the micropyle, archegones (one to nine in different species) are formed. Each archegone consists of a large cgg and a very short canal that leads from the surface of the female plant to the egg. 
150. Germination of the Microspore. - We have seen that many microspores (pollen grains) are formed in each pollen sac (microspore sac). The microspores also germinate in the spore sac in which they mere formed. But the male plant that is formed from a microspore is not, like the female plant, firmly held in the spore sac; after it has developed for a time within the sac, it becomes free. The germinating microspore does not at first grow larger; it merely divides to form four cells, all lying inside the microspore wall (Fig. ; $1, C)$.

Of the four cells which now make up the young plant, three are small and lie in a group at one side, close to the spore wall. The two small cells nearest the wall seem to be of no use, and they break down and almost entirely disappear soon after they are formed. The third small cell remains alive; it is the generative cell. The fourth, a large vegetative cell, fills the greater part of the space within the spore wall. At this stage the development of a microspore into a male plant stops; the spore sac splits open, and the pollen grains escape. Thus we see that a pollen. grain is a microspore when it is first formed; but by the time that it escapes from the spore sac, the pollen grain is no longer a spore, but a young male plant. A pollen grain has two bladder-like projections, one at either side; these are cavities formed by the expansion of the outer layer of the wall of the pollen grain; these projections, by increasing the surface area of the pollen grain, help in its scattering by the wind.

151. Pollination. - Since the female plant remains inside the spore sac, the male plant (the pollen grain) must in some way be brought to its neighborhood before a union of gametes can occur. The wind is the agent that carries the pollen of the pine. Since the mind scatters the pollen in every direction, so that only one grain in many thousands will land in the right place, the pine must produce much more pollen than can actually be used. At about the time that the pollen is being shed, the carpellate cone grows rather rapidly in length; this growth separates the macrospore leaves, and some of the pollen grains which fall upon the cone sift down between the spore leaves and so come near the opening of a 
micropyle. A sticky liquid is formed in the micropyle and oozes from its mouth. The jarring of the cone by the wind shakes the pollen grains about, and when they come in contact with this liquid they are held by it. Then a drying occurs within the micropyle and the drop of liquid is sucked back, carrying the pollen grains to the bottom of the micropyle. The pollen grains are now in contact with the macrospore sac, within which is the female plant. The set of proc-

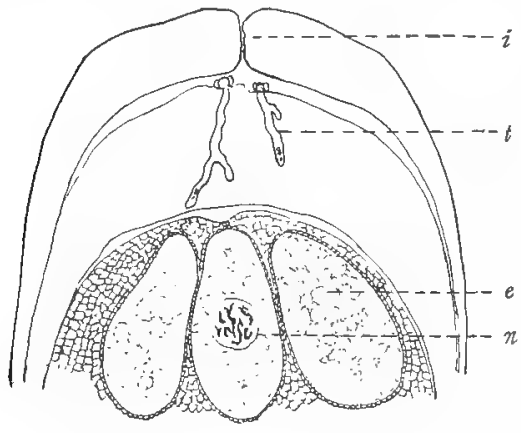

FIG. 74. - A lengthwise section of an ovule older than that shown in Fig. 73, C, showing germinating pollen grains, pollen tubes, $t$, and the upper part of the female plant with three archegones; each archegone contains a large egg, $e$; $i$, integument; $n$, an egg nucleus. esses which thus bring the pollen grain close to the female plant is called pollination. It is plain that pollination must take place before fertilization can occur.

152. Fertilization. After the pollen grain has reached the base of the micropyle, its development into a male plant continues. The vegetative cell of the pollen grain pushes out a long projection - the pollen tube (Fig. 74, t). This tube burrows into the tisstues of the macrospore sac, growing very slowly, occasionally branching, and using for food some of the cells of the spore sac. While the tube is growing, the generative cell within the pollen grain divides, forming a stalk cell and a body coll. The body cell next divides into two male gametes, which move, following the vegetative nucleus, toward the growing end of the pollen tube. The gametes are simple cells consisting of nucleus and some cytoplasm, and with no vibrating hairs such as are borne by the male gametes (antherozoids) of mosses and ferns. 
The male plant is now fully formed. It includes at most six cells, of which two mere small and have almost or quite disappeared; the four remaining are the stalk cell, the two gametes, and the vegetative cell of which the tube is a part. Finally, the end of the tube makes its way through the tissue of the macrospore sac into the neck of an archegone, and there comes in contact with the egg. Then the end of the pollen tube bursts, and its contents, including the male gametes, are forced into the egg. One male gamete unites with the egg. The result of this union is a zygote, which very soon begins to develop into a new asexual generation. The second male gamete and the other substances that pass from the pollen tube into the egg seem to have no further use, unless it is to serve as food for the egg.

153. The Seed (Fig. 75 ). The growth and division of the zygote result in the formation of a young asexual plant (the embryo) which lies in the center of the tissues of the female plant, part of which the embryo has destroyed and used as food. The embryo develops the same parts that we found in the embryo of the squash: a radicle

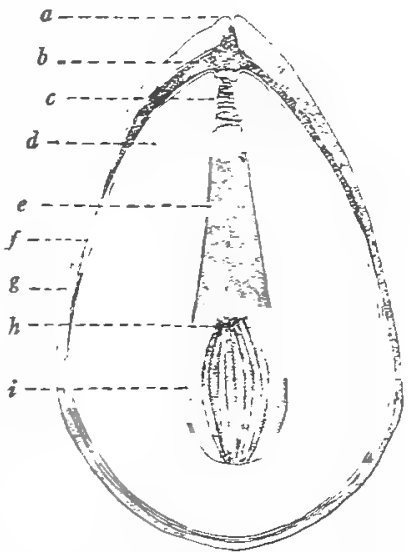

FIG. 75.- $A$ lengthwise section through a pine seed; $a$, micropyle; $b$, remains of the body of the ovule; $c$, suspensor (a part of the embryo that takes no part in the development of the mature plant); $d$, endosperm; $e$, radicle; $f$, inner seed coat; $g$, outer seed coat; $h$, plumule; $i$, seed leaves. whose growing point is turned toward the micropyle, several seed leaves, and a very small plumule. When these parts have been developed, the embryo ceases to grow for a time. This stopping of the growth of the new plant at a very early age is another 
thing that distinguishes the seed plants. The embryo now lies within the tissues of its parent, the female plant; the latter lies within the macrospore sac, which in turn is surrounded by the integument. All these parts together make up the seed. Thus the seed is a complex structure, whose different parts represent three generations. The integument and the macrospore sac belong to the same generation as the tree, that is, to the old asexual generation. The female plant belongs to the sexual generation; and the embryo is the new asexual generation.

Changes take place in all these parts as the seed ripens. The integument develops into two seed coats: an outer one
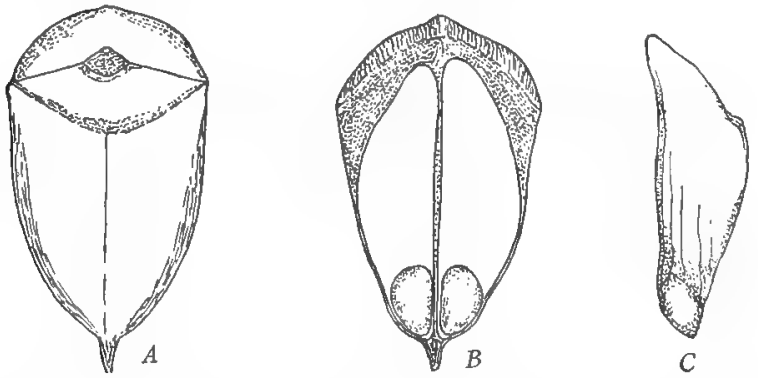

FIG. $76 .-1$, a mature macrospore leaf bearing seeds, seen from the lower side. $B$, the same, seen from above. $C$, a single seed with its wing.

which is hard and resistant, and an inner one which is very thin and papery. The tissues of the ovule (inside the integument) have been largely destroyed by the growth of the female plant; but something of them remains in the mature seed in the form of a cap over the micropylar end of the female plant. The female plant in turn has been partly used as food for the embryo; but much of its tissue remains, surrounding the embryo except at the root end, its cells filled with starch and other foods which the embryo will use later. This food-containing tissue of the female plant is called codosperm in the ripe seed. A seed usually contains but one 
embryo, although very rarely two or more are found, which have resulted from the fertilization of more than one of the eggs of a female plant. When the seed separates from the macrospore leaf on which it is borne, a thin layer of the outer tissue of the leaf remains attached to it (Fig. $; 6, C$ ). This wing helps in the carrying of the seed by the rind.

154. Times of Pollination, Fertilization, and Seed Development. Small buds which will grow into staminate and carpellate cones are formed in the summer or fall. The next spring (in the northem L nited States, late in May or early in June), the pollen ripens and pollination occurs. It this time the carpellate cone, the macrospore leaf, and the macrospore sac are still small, and the female plant has just begun to develop from the macrospore. Fertilization of course cannot occur until the female plant has formed its eggs. So the pollen tube, after it begins to develop, grows slowly in the tissues of the macrospore sac while the female plant also continues to grow. It is not until June. or July of the following year, when the pollen tube has been growing for about thirteen months, that the eggs are ripe and fertilization occurs. In the summer following fertilization, the zygote develops into an embry and the seed is ripened; this seed is shed in the fall or in the following spring. Thus the history of a single carpellate cone covers parts of three years.

155. Germination of the Seed. - The seed may germinate in the spring following its ripening, or, if conditions then are not favorable, it may remain apparently unchanged, but still alive and capable of germination, for some rears. When conditions are right, the embryo becomes larger, at first because its cells take in water; the endosperm also absorbs water; and the pressure caused by the swelling of the embryo and of the endosperm breaks the seed coats, which have been softened by the water that has soaked into and through them. The growing embryo digests and uses the food stored in the endosperm, which thus helps to start the embryo in its development. The radicle is the first part of the embryo to push out of the seed coats. It turns downward and develops into the primary root, except that, as in the squash, the upper end 
of the radicle, just below the point of attachment of the seed leaves, forms the base of the stem.

As the radicle and the seed leaves grow, the latter, which have already begun to form chlorophyl, are pushed above the surface of the soil. The upper end of the radicle becomes upright, the seed leaves spread out, and the plant, now provided with a root and leaves, is ready to make its own way in the world. The old seed coats, with what is left of the endosperm, are usually carried upward on the ends of the seed leaves, and as the leaves grow and spread out, the seed coats are thrown off. As the primary root grows into a long tap root, branch roots are formed. The plumule forms all of the stem excepting its very base. For a time, foliage leaves are borne directly upon the stem and its long branches; these early leaves are comparatively short and flatter than the later leaves. In the course of a few months, spur branches begin to appear, which bear foliage leaves of the ordinary kind; and from this time on, all the new foliage leaves are borne on spur branches.

156. Life Cycle of the Pine. - The course of events in the life of the pine can be understood only by comparing it with such plants as the moss and the fern. This comparison was first clearly made by Hofmeister ( $1824-1877$ ), who showed in this way the real nature of the different parts of the pine cones as well as that of the parts of an angiosperm flower. The central fact in the life of the moss, the fern, or the pine is the occurrence of two distinct generations - an asexual generation that reproduces by means of spores, and a sexual generation that reproduces by means of gametes. While the fern and the pine are alike in this central fact of having two generations, the pine is different from the fern in the following respects :

$a$. In the formation of two kinds of spores, of which one grows into a male plant and the other into a female plant. However, this is not peculiar to seed plants (of 
Which the pine is one), for, as we have seen, some of the relatives of the ferns have two kinds of spores.

b. In the keeping of the macrospore in the spore sac, which compels the female plant also to pass its whole life within the macrospore sac.

c. In the great reduction in size of the sexual generationa reduction which has gone further in the male plant than in the female plant. This reduction had begun in

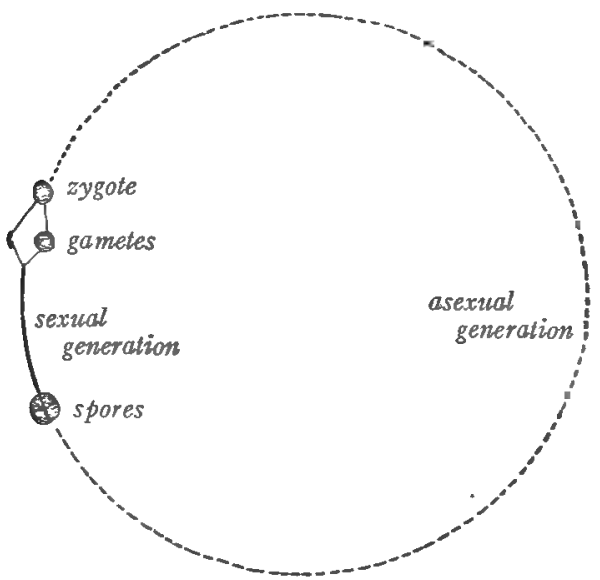

FIG. 77.- Diagram illustrating the life cycle of the pine.

the fern, whose sexual plant was much smaller than its asexual plant, but it has been carried much farther in the pine.

$d$. In the development of a pollen tube, which carries the male gamete to the egg. This has made it unnecessary for the male gamete to form special organs for moving itself about.

$e$. In the formation of a seed, containing an embryo which has stopped growing for a time. The distribution of mosses and ferns is brought about by the scattering of 
the spores; but in the pine the time at which the species is distributed has been shifted from the period of the spore to that of the seed. The seed is much better adapted to this purpose than the spore, because it can live for a long time without germinating, and because it contains much food for the new plant. Note that a seed is not a means of reproduction of the plant, as a spore is. It is itself a little plant, wrapped up in tissues belonging to the two previous generations.

The life cycle of the pine may be represented by a diagram (Fig. 77) not unlike those which have been used for the moss and the fern.

157. Seed Plants: Gymnosperms. - Each member of the most highly developed class of plants - the seed plants has a history much like that of the pine. The seed plants as a group have adapted themselves so well to present conditions upon the earth that they have spread over much the greater part of its land surface. It is because they are so well fitted to the conditions of existence that the largest and longest-lived plants are seed plants. Seed plants are divided into two distinct groups, named according to the ways in which they bear their seeds. In the smaller and more primitive group, to which the pine belongs, the seeds are produced on the surface of a leaf (although a leaf of very special form) or on a short branch. The members of this group are called gymnosperms or naked-seeded plants. A much larger group consists of those which, like the cucumber, form their seeds within a closed structure that becomes a fruit. Plants whose seeds are shut up in this way are called angiosperms or hiddenseeded plants.

158. Different Kinds of Pines. - The pines include about eighty species, which live almost entircly in the north temperate zone. Among them are some of the most valuable timber trees. Of the species native to North America, the best known is the white pine (Pinus strobus), forests of which 


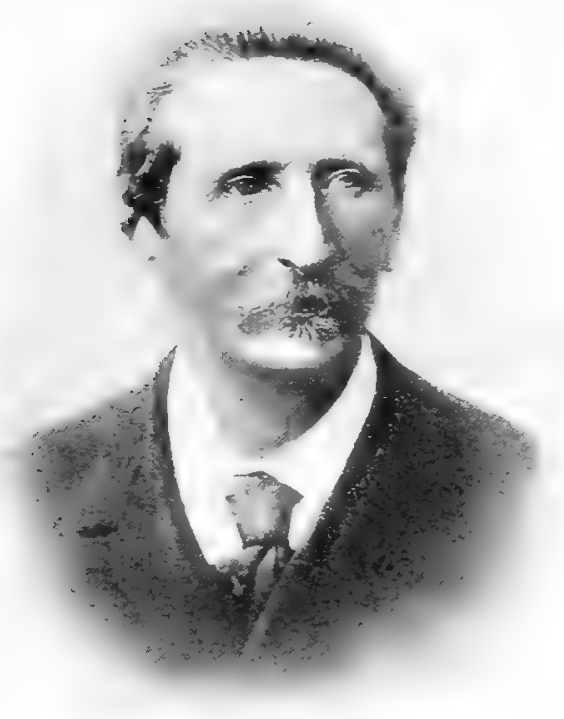

EDTARD STRASBI*RGER

Born at Warsaw. I8 4 ; died at Bonn, Ior 2. Contributed largely to our knowledge of the life histories of the seed plants and especially of their reproduction; founder of the study of the minute structure and the behavior of plant cells. 

formerly covered great areas in Canada and the northern United States. They have been largely destroyed because of the demand for white pine timber, and the tree is now being planted on a large scale by the national and state governments. About the beginning of the eighteenth century, the white pine was introduced into Europe, where it is called the " Wermouth pine." It is frequently seen in European parks, and is planted to some extent in forests.

Another common American species is the red pine, also called the "Norway pine" (Pinus resinosa). This is an important timber tree, though its wood is less valuable than that of the white pine. Pinus lambertiana, the "sugar pine" of the Pacific coast states, is the largest American tree next to the California redwoods. Its resin is sweettasting and edible. The Scotch pine, also called "Scotch fir," "Norray fir," and "Dantzic fir," is the commonest species in Europe, where it is a most important timber tree. It is a common ornamental tree in the United States, as is also the Austrian pine. Some pines have large, nut-like seeds whose inner parts (endosperm and embryo) are eaten. One of these nut-pines is found in northern California; the nuts of another, living in the Mediterranean countries, are largely used in Europe.

Aside from its wood, the most valuable product of the pine is its resin. By distillation, turpentine is obtained from the resin, and from the more solid substances that are left after distillation rosin is made. Tar is obtained by the dry distillation of the wood, and pitch by boiling down the tar. Most of the turpentine produced in the L'nited States comes from the long-leaved yellow pine and the Cuban (or slash) pine of the southern states.

159. Other Conifers. - The pine is a member of the largest order of gymnosperms, called conifers because the seeds of most of them are borne on cones. The seed-bearing structures of some members of the order, such as the red cedar 
and the ground hemlock, are not at all cone-like, but the other characteristics of these plants show that they are related to the cone-bearing forms. Most of the conifers are trees. A few are low shrubs, like the ground hemlock, or even creeping forms, like the creeping juniper. Other conifers are the

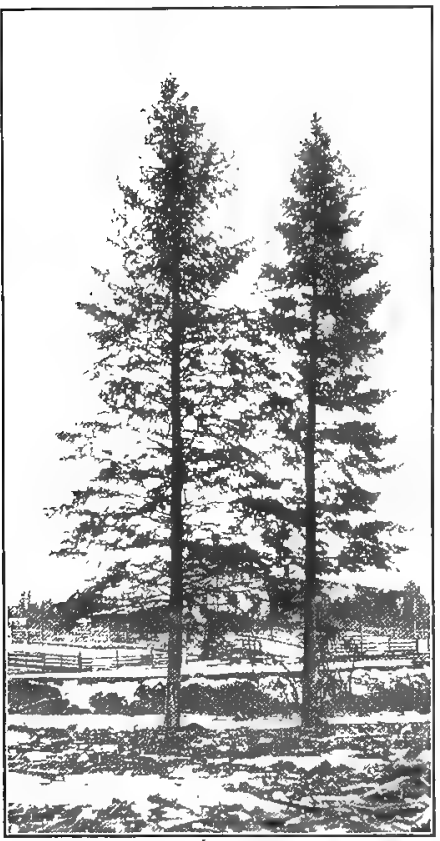

FIG. 78. - White spruce trees.

Photograph by L. S. Cheney. spruces; the firs; the larches (one of which is the American tamarack), whose foliage leaves, differently from those of most conifers, live for only one season and are shed in the fall; the arbor vitæ, or white cedar; the hemlocks; the giant redwood of California, which reaches a greater size than that of any other living plant excepting some Australian gumtrees; and the bald cypress of the southern United States, remarkable for its "knees," vertical outgrowths of the roots which rise several feet above the surface of the ground and which seem to be respiring organs. Many of these other conifers, like the pines, are valuable as timber trees and as sources of resin and of various special products such as Canada balsam and spruce gum. The spruce is the most important source of pulp for paper-making; but as it is becoming scarcer, the wood of some other trees, especially that of the balsam fir, is being used for this purpose. Attempts are being made also to find ways of using pulp obtained from 
the stems of various smaller plants. The "berries" of the juniper, which correspond to the ripe carpellate cones of the pine, are used in medicine.

160. Other Gymnosperms. - Aside from the conifers, there are comparatively few species of gymnosperms now living. The majority

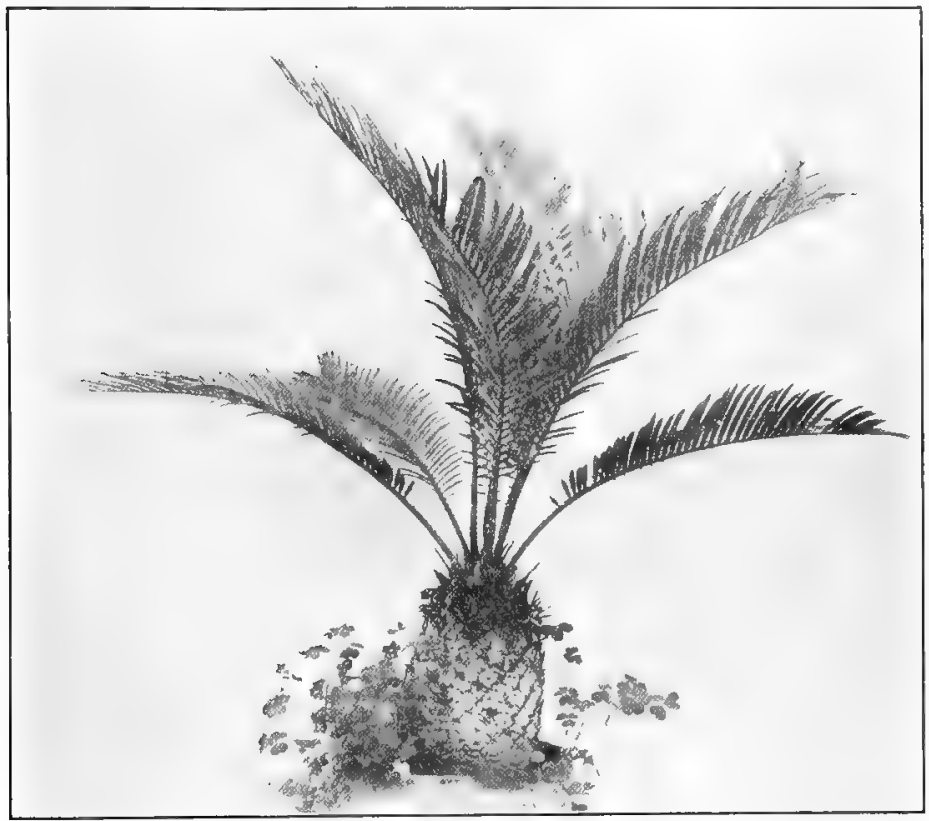

Fig. 79. - A cycad (Cycas revoluta).

of these belong to the tropical and subtropical order of cycads, represented in the United States by two species of Zamia which grow in Florida. The cycads have a thick stem, at the top of which is a crown of divided leaves very much like those of some ferns. In general appearance, the cycads are palm-like; some of them are called "sago palms " because a coarse sago is obtained from their pith. However, their similarity to the palms is misleading, for in many ways the cycads show themselves to be related to the ferns; and the fossil history of the order is sufficiently complete so that their descent can be traced 
back to very ancient ferns that were related to some tropical ferns of the present time. The modern cycads are the survivors of what was once a much larger group. While there can be little doubt that the conifers, including the pine, have also come from fern-like ancestors, their descent is not yet so well known as is that of the cycads. Another gymnosperm is Ginkgo, the "maidenhair tree" of China and Japan, many specimens of which are to be found in Europe and America. This also is a survivor of what was once a large group. The cycads and Ginkgo differ from all other seed plants (including the conifers) in the fact that their male gametes have vibrating hairs and so can swim about like those of the fern and the moss. However, the cycads and Ginkgo, like the pine, also have a pollen tube, which furnishes a path for the antherozoids to reach the eggs. 


\section{CHAPTER XII}

\section{THE BEAN}

161. Angiosperms: the Bean Plant. - The great majority of seed plants, unlike the pine, are angiosperms; they produce their ovules (macrospore sacs), and consequently their seeds, inside a closed vessel which is called an oidry. When the ovules develop into seeds, the ovary becomes a fruit. Almost all our cultirated plants are angiosperms; so also are most forest trees (apart from the cone-bearing ones) and most other conspicuous mild plants except the mosses and ferns. In studring the cucumber we have learned something of the structure and way of life of an angiosperm, and the bean is a convenient plant to use for a fuller study. Any of the numerous cultivated varieties of bean will answer for this purpose. Like the cucumber, the bean is an

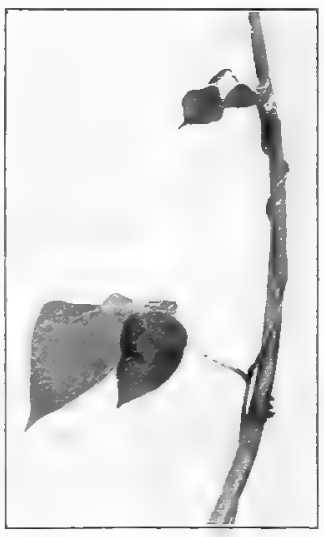

FIG. 80. - Portion of a bean stem twining about a support. annual; that is, none of its parts live through the winter and grow from year to year, as the trunk and roots of the pine do. Some varieties are low or "bush" beans; some are climbing or "pole" beans. The stem of a climbing bean coils about any slender object that it touches, such as a pole, or the stem or branch of another plant (Fig. 80). This coiling is due to an unequal growth of the stem on its different sides, which causes the upper 


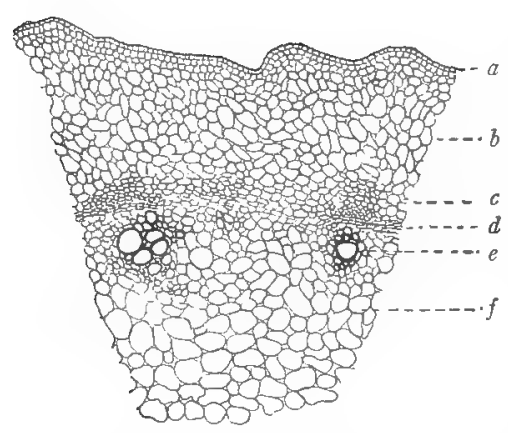

FIG. 8I. - A small part of a cross secof a bean; $a$, epidermis; $b$, cortex; $c$, bast; $d$, cambium; $e$, wood; $f$, pith. tion through a young portion of the stem

end to swing about in a way that will be explained more fully in Chapter XV. In all varieties the stem branches freely, each branch beginning as a bud in the axil of a leaf, and practically all that will be said about the stem applies also to the branches.

\section{Inner Structure of the} Stem. - For this study we may use a cross section through the younger part either of the main stem or of a good-sized branch (Fig. 8I); the section should be cut between the points of attachment of two leaves. In such a section we shall observe that the vascular bundles are arranged, like the bundles of the pine, in a hollow cylinder, which in the cross section looks like a ring. Between the wood and the bast of each bundle are one or two layers of cambium cells. In a section through an older part of the stem (Fig. 82), we find that the cambium makes a complete ring, and that its cells have begun to divide so as to form more wood on the inside and more bast on the outside of the ring. The bean stem therefore grows in thickness just as the pine stem does; but since the bean plant. lives only one season, its stem never grows to be very thick,

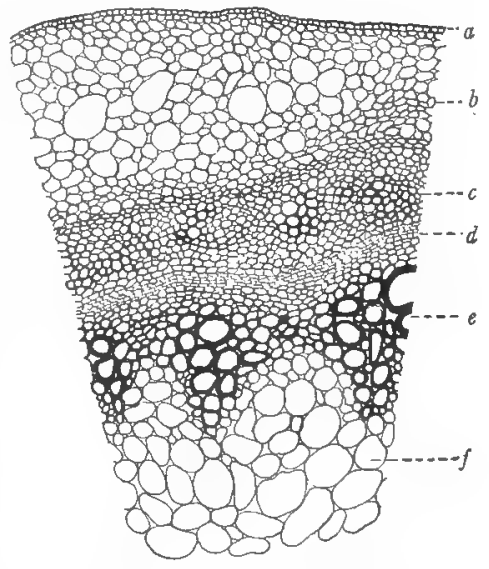

Fig. 82, - Part of a cross section through an older portion of the bean stem, in which the division of the cambium cells has begun and new bast and wood are being formed; $a$, epidermis; $b$, cortex; $c$, bast ; $d$, cambium; $e$, wood; $f$, pith. 
and since it never contains a large proportion of wood, it does not become hard like the stems of trees and shrubs. The vascular bundles in the stem branch from time to time, and the branch bundles run out from the stem into the branches and leaves.

163. Foliage Leaves. - The bean has nothing that corresponds to the scale leaves of the pine. All the leaves that are formed later than the two seed leaves are foliage leaves, except, of course, the special leaves (sepals, petals, stamens, and pistil) that constitute the flower, and except also some very small green leaves (bracts) borne in the flower clusters. The foliage leaves are alternately arranged upon the stem; that is, only one is borne at any particular level, and no two successive leaves arise from the same side of the stem. The blade of each leaf (Fig. 84) is divided into three leaf-

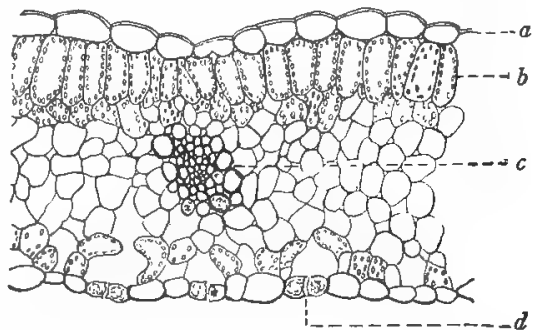

FIg. 83.- Part of a cross section of a leaf (of the lily); $a$, upper epidermis; $b$, layer of closely packed cells ("palisade layer"); $c$, a vascular bundle; $d$, an air-pore.

lets, each with a short stalk of its own. Two of the leaflets are attached to the sides of the leaf-stalk, opposite each other; the third is borne at the end of the leaf-stalk.

At the point where the leaf-stalk joins the stem or branch, there are two small structures that look like little leaves; they are called stipules and are really parts of the leaf to whose stalk they are attached. At the base of the stalk of each side leaflet, where it joins the leaf-stalk, there is also atr attachment like a stipule but smaller; and at the base of the stalk of the terminal leaflet are two similar attachments.

The blade of each leaflet has a midrib from either side of which pass off branch veins (vascular bundles), some large 
and some small. These branch veins in turn branch, their branches branch and so on, thus forming a network of veins like that in the cucumber leaf. The leaves as well as the stems and branches of many varieties of beans bear fine, short hairs. If we examine the leaves of a bean plant in the evening or at night, we shall see that their position is somewhat different from what it was during the day. Each leaflet has drooped so as to bring the three leaflets closer together, and the leaf as a whole stands more nearly

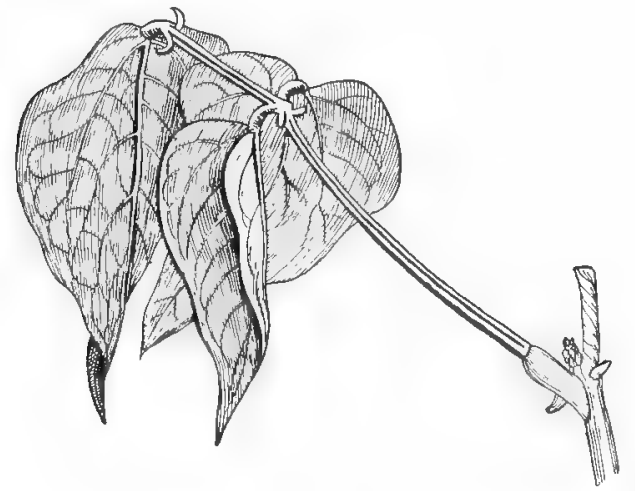

FIG. 84. - A bean leaf in its night position. After Sachs.

vertical and closer to the stem or branch. These changes in position are caused by a bending of the leaf-stalk and of the stalk of each separate leaflet. The bending of theleaf-stalk takes place in a short, thickened region near its base. The stalks of the leaflets are so short that practically the whole of each stalk takes part in the bending and so corresponds to the thicker part of the leaf-stalk. In the morning the leaves and leaflets move back to the position in which we are accustomed to see them during the day. The changes in the position of the leaves at night are often called sleep movemonts, although they really have nothing to do with anything like a sleep of the plant.

164. Roots. - The root system of the bean consists of a rather short primary root with many slender branches which themselves branch; some of the branch roots may 
become almost as thick as the primary root, and in many cases they are longer. Some short adventive roots also grow from the lower part of the stem. The root system of a bean bears many small swellings, in which are great numbers of bacteria. Something mas said in Chapter II about the bacteria that live in these swellings on the roots of the bean and of many of its relatives (see $\S+$ I and Fig. II). We have seen that these bacteria can use the nitrogen of the air, and that they are of great value to the host plant (in this case the bean) because they provide it with the nitrogen-containing substances that it needs for food.

165. Flowers. - These are borne in clusters. The stalk of the cluster (the peduncle) is in each case a branch or the end portion of a branch (or occasionally the end of the main stem). Each flower has a short stalk of its own (a pedicel) which grows from the axil of a very small leaf (a bract) that is borne on the peduncle. Each pedicel, therefore, is also a branch. The flower cluster of the bean is of the sort known as a raceme. Each flower is so attached to the peduncle that it stands out horizontally, or nearly so. For this reason we can speak of the upper and lower sides of a flower.

A bean flower (Fig. 85) seems at first sight entirely different from anything that we have seen in the pine or in any of the lower plants. Really, howerer, the flower of the bean corresponds rery closely to the cones of the pine. One difference lies in the fact that a single pine cone bears only one kind of spore leaves, whereas the same bean flower contains both microspore leares (stamens) and a macrospore leaf (which forms the pistil). Therefore, while the pine has tro kinds of cones, the bean has only one kind of flower. ${ }^{1}$ The flower has probably developed from a structure not

1 Many angiosperms, however, like the cucumber, bear stamens and pistils in separate flowers. In such cases the staminate and pistillate flowers correspond respectively to the staminate and carpellate cones of the pine. 
unlike a pine cone by a shortening and flattening of its central axis, so that the spore leaves are borne at nearly the same level, instead of at different levels upon a long axis. The number of spore leaves also is much reduced in the bean flower.

Another thing that distinguishes it from the pine cone is the presence, outside the spore leaves, of two sets of outer leaves (sepals and petals) which have nothing directly to do
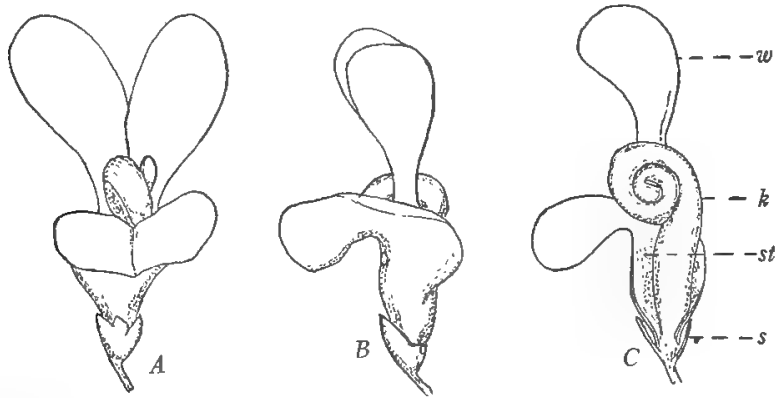

FIG. 85. - Three views of a bean flower: $A$, from the top; $B$, from the side; $C$, also from the side, after the removal of a wing and part of the standard; $s$, sepals; st, standard; $k$, keel; $u$, wing. The stamens and pistil are enclosed in the keel.

with spore production, but which are none the less important organs of the flower. Thus a flower, like a cone, is really the end of a stem or branch on which grow certain special leaves, some or all of which bear spores.

166. Sepals and Petals. - These parts develop before the stamens and pistil, so that the latter are covered and protected in the bud while they are growing. When the stamens and pistil are nearly or quite full grown, the bud opens - that is, the sepals and petals spread out. The five green sepals, which are the outermost parts of the flower, are united for the greater part of their length into a tube, their free ends projecting as short teeth from the edge of the tube. The petals of some varieties of the bean are 
white; those of other varieties are colored in various ways. The uppermost petal (the standard) is broad and erect, except that its lower part is bent so as to be horizontal and to cover the lower parts of the other petals. At its upper end the standard is two-lobed, so that it looks as though it might be composed of two petals; but this is not the case. On the sides of the flower and below the standard are two other petals, called wings; they are broad and rounded, but each is much narrowed at the base. Below the wings are the two remaining petals; they are narrow and are united, except at their ends, into a structure like a trough with its opening upward; this trough-shaped structure is the keel. Its outer end is spirally twisted.

167. Stamens. - Just within the petals are the stamens or microspore leaves, which here are not at all like foliage leaves. Of the ten stamens in the bean flower, nine are united by their filaments into a partial tube that is open on the upper side. This partial tube really forms a second
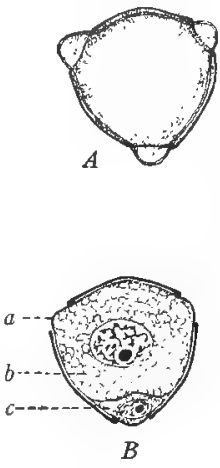

FIG. 86. $-A$, a pollen grain of the bean, as seen from the outside. $B$, a cross section of a pollen grain; $a$, one of the germ pores, where the outer layer of the wall is lacking, and where the pollen tube, surrounded by the inner layer of the wall, may push out when the pollen grain germinates; $b$, the vegetative cell; $c$, the generative cell. $C$, a pollen grain (of the lily) which has germinated; $d$, the two male gamete nuclei; $e$, the pollen tube; $f$, the nucleus of the vegetative cell, which has moved to the end of the tube. $B$ after a preparation by Miss Mabel Brown.

trough that lies inside the trough-shaped keel. When all the parts of the flower are in their usual positions, the one free stamen covers the open part of the trough made by the 
union of the other nine. This trough collects and holds the nectar, which is produced on the inner sides of the bases of the stamens. Each stamen is composed of a long, slender filament and a small anther. The anther contains two pollen sacs (microspore sacs) in which the pollen grains are borne.

The history of the pollen grains of the bean is much like that of the pollen grains of the pine. Each of the many microspores formed in the pollen sac is a young pollen grain; but the microspore germinates while still in the sac by dividing into two cells, so that when the pollen grain is shed it is no longer a microspore but a young male plant, which consists of a small generative cell and a large vegetative cell (Fig. 86, B). The wall of the pollen grain is comparatively thick; its shape and color and the nature of its outer surface differ in different species. When the grains are

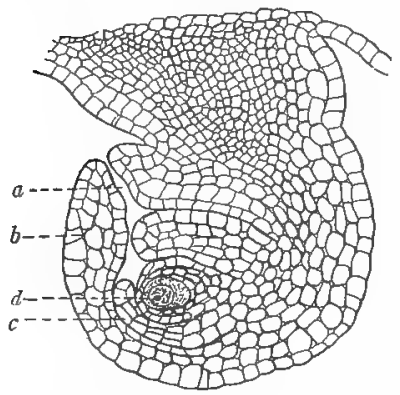

Fig. 87.-A bean ovule (macrospore sac); $a$, micropyle; $b$, outer integument; $c$, inner integument; $d$, macrospore mother cell. After a preparation by Miss Mabel Brown. ready to be shed, the sacs that contain them split open lengthwise.

168. The Pistil. - In the central part of the flower is a pistil, which may be thought of as a macrospore leaf that has been folded over along its midrib until its edges joined. As a result, the lower, enlarged part of the pistil (the ovary) contains a chamber within which the ovules (macrospore sacs) are borne. The ovary lies horizontally inside the trough formed by the nine united stamens; it is rather long and is the part which will develop later into a pod. The ovules, usually not less than four nor more than ten in number, are attached alternately to the two edges of the leaf. 
Since these edges touch each other, all the ovules lie nearly in a straight line; but if a pod is split open, we can see that in reality some of the ovules are attached to one edge and some to the other. Each ovule (Fig. $s_{i}$ ) has a thick stalk, which is bent in such a way that the body of the ovule is turned part way backward and its free end (with the micropyle) is near the wall to which the stalk of the ovule is attached. Two integuments are formed about the orule, instead of only one as in the pine; they leave a narrow opening (the micropyle) at the free end of the ovule.

The long, slender part of the pistil above the ovary is the style; the style, which contains a slender canal that is continuous with the carity of the orary, bends near the orary and turns upward; it lies inside the keel, and so its upper part is coiled in the same way that the end of the keel is. The upper end of the style is a little thickened, and on the inner side of this thicker part is the stigma. The surface of the stigma is rough, and when it is touched a stichy liquid oozes from it. The ovary and the lowver part of the style are covered with many short hairs, and there is another brush-like group of hairs on the inner side of the upper part of the strle, just below, and on the sides of, the stigma.

169. The Female Plant. - One cell within the ovule grows to be much larger than any of the others; this is the macrospore mother cell (d, Fig. $\left.s_{i}\right)$. It divides to form a row of three macrospores (instead of four, as in the pine) ; and one (the largest) of these macrospores, as in the pine, develops into a female plant (Figs. 88 and 89 ).

But the female plant of the bean is much smaller and simpler than the female plant of the pine. It consists of only seven cells. Each cell has one nucleus, except that the central cell, which is mucin the largest, contains two nuclei (Fig. 89, f). At the end of the female plant nearest the micropyle is a group of three cells; one of these three is the egg (Fig. 89, d). This little seven-celled plant remains throughout its life, like the female plant of the pine, shut up inside the ovule. 
170. Pollination. - The pollen of the bean is usually carried from the stamen to the pistil by insects. Insect-pollination is more economical and effective than the windpollination which is depended upon by the pine, because insects, flying directly from flower to flower, are likely to carry more of the pollen to the exact place where it is needed. The insects that pollinate the bean are, most commonly at least, large bumble-bees. The pollen drops out of the pollen sacs when it is ripe and is caught in the bottom of the keel. None of it falls upon the stigma, because the style projects beyond
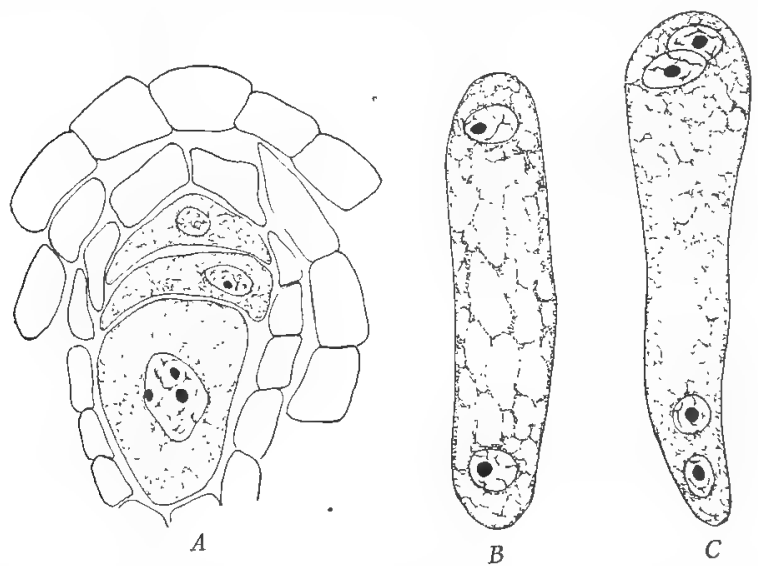

FIG. 88. $-A$, the three macrospores into which the macrospore mother cell of the bean ( $d$, Fig. 87 ) has divided. $B$ and $C$, stages in the development of the largest of the three macrospores into a female plant. After Miss Mabel Brown.

the stamens. In the keel, the pollen is covered by the wings and other parts of the flower. It cannot be blown or washed away, and it is protected from moisture, which is harmful to it as it is to the pollen of most plants.

When a bee alights upon one of the wings of the flower, both the wings and the keel are pressed downward. This allows the style to push out of the keel, and the hairs near 
its end brush out the pollen that has collected in the bottom of the keel. The nine united stamens are pressed downward with the keel, but the upper free one is not. A space is thus left between the free stamen and the group of nine. To reach the nectar, the bee must insert its proboscis to one side of the free stamen and into the trough formed by the united stamens. In doing this, the proboscis first touches the stigma; if there are pollen grains on the proboscis (which were collected on an earlier visit of the bee to another flower), they are brushed off on to the stigma and are held there by the sticky fluid that begins to flow when the stigma is touched. Next the bee's proboscis touches the brush of hairs on the style and some of the pollen grains that are held by the brush stick to the proboscis. When the bee leaves the flower, its proboscis is prevented from again touching the stigma by the hairs on the style, so that none of the pollen from this flower is left on its own stigma. The pollen that is carried away on the bee's proboscis may stick to the stigma of the next flower that it visits. Thus the structure of the flower favors cross-pollination - that is, the landing of pollen 
from the anthers of one flower upon the stigma of another flower.

When pollen is thus carried by insects from one flower to another, it does not necessarily follow that the second flower will be on another plant. But this will certainly be true in a large proportion of cases, especially since the different flowers of a plant open in general at different times; consequently the stigma of an older flower is likely to have been pollinated before a younger flower of the same plant opens. But it appears that if insects do not visit a bean flower, seeds are nevertheless sometimes formed. So it is evident that in such cases the pollen in some way reaches the stigma of the same flower - that is, self-pollination occurs. Just how this comes about is not yet known. The place in which the pollen grains of the bean finally land is very different from that which is reached by the pollen grains of the pine. This must be so, because the ovules of the bean are shut up inside the ovary, so that the pollen cannot, as in the pine, be carried to the ovules themselves.

Since a pollen grain of the bean must germinate upon the stigma far from any of the female plants (which are inside the ovules), the pollen tube has a much greater distance through which to grow than had that of the pine. The size and colors of the sepals and petals of many flowers seem to be of use in attracting the attention of insects to the places where nectar is to be found.

In general it is true that those angiosperms which, like the bean, have more or less showy flowers are insect-pollinated; and that others, such as the grasses and most of the forest trees, which have small, inconspicuous flowers, are wind-pollinated. There arc exceptions to the latter rule, because some insects seem to be attracted by the odors of the flowers as well as by their size and color, and so they may visit small flowers, such as the mignonette, that are fragrant. 
171. The Mature Male Plant; Fertilization. - The pollen tube, in the bean as in the pine, is an outgrowth of the vegetative cell of the pollen grain (Fig. 86, C). Soon after the tube begins to grow, the generative cell moves into the tube and there divides to form two male gametes. The mature male plant of the bean consists therefore of only three cells - the vegetative cell which includes the pollen tube, and the two male gametes. The pollen tube grows from the stigma down through the canal of the style, feeding as it grows on substances produced by the cells lining the canal; it pushes into the ovary, reaches an ovule, grows through the micropyle and into the tissues of the ovule, and finally its tip penetrates the female plant itself (Fig. 89). The end of the pollen tube now bursts, so that its contents are forced into the interior of the female plant. Of these contents, the vegetative nucleus and apparently the cytoplasm (includ. ing the cytoplasm of the male gametes) are of no further use, except perhaps as food. The nucleus of one male gamete unites with the egg nucleus, and the result of this union is the zygote which will develop into a new asexual plant. The other male gamete nucleus passes into the large central cell of the female plant and there unites with the two nuclei already present in this cell.

172. Formation of the Seed. - The central cell, containing the large nucleus that has been formed by the union of three, begins to develop into endosperm before the zygote begins to grow into an embryo; so that when the embryo is formed a supply of food is ready for it in the endosperm. The cells of the female plant, other than the egg and the large central cell, are crushed and disappear. The embryo feeds upon the endosperm; but the endosperm also continues to grow (Fig. 9o), using the surrounding tissue of the ovule for its food. However, the developing endo-

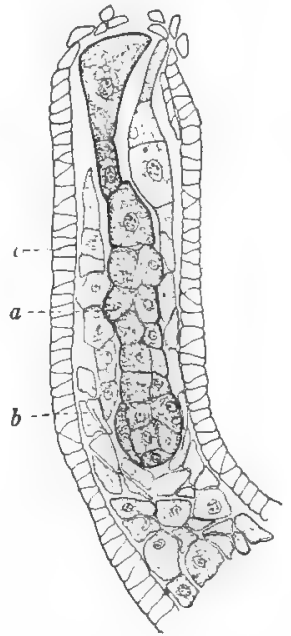

FIG. go. - A young bean embryo, almost surrounded by endosperm cells which will be used as food by the embryo; $a$, embryo; $b$, endosperm ; $c$, innermost layer of cells of the body of the ovule. After a preparation by Miss Mabel Brown. 
sperm is used as food for the embryo about as rapidly as the endosperm itself develops; and finally most of the food that had been stored in the ovule is transferred to the two seed leaves of the embryo. The ripe seed thus contains no endosperm, and the thick seed leaves fill much the greater part of the space inside the seed coats. In this respect the bean seed is like the seed of the squash.

The body of the embryo (consisting of radicle and plumule) is much smaller than the seed leaves. It lies between the
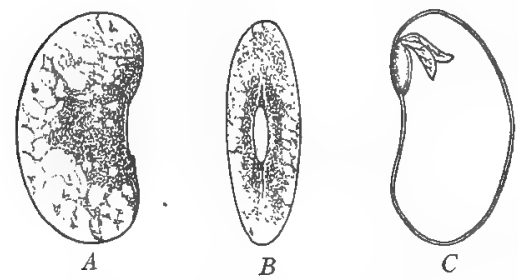

FIG. 9I. - $\mathrm{A}$ bean seed: $A$, as seen from the side; $B$, an edge view, showing the scar by which the seed was attached, and, just above, the micropyle; $C$, with one-half of the seed coat and one seed leaf removed, showing the plumule, radicle, and remaining seed leaf. seed leaves close to the edge by which the seed was attached to the pod. The end of the radicle projects from between the seed leaves and is turned toward the micropyle. The plumule is curved and bears two or three very small secondary lcaves. The food in the seed leaves is chiefly starch and proteins. The bean, like some other plants of the same family, such as the pea and the lentil, stores a comparatively large proportion of proteins in its seed leaves. This is one reason why the seeds of these plants are so valuable to us as food. Little or nothing of the body of the ovule is left in the ripe seed. The integuments develop into thin, hard seed coats.

The parts of the bean seed thus correspond closely to those of the pine seed, except that such cndosperm as was formed, although it resembled the endosperm of the pine seed, arose in a quite different way and disappeared before the seed was mature. In the ripe bean seed (Fig. 9I) the scar that marks the point at which the seed was attached to the pod 
is on one side - the side of the seed that is somewhat hollowed. Near one end of this scar is a small hole - the micropyle.

173. The Fruit (Fig. 92). - As the ovules grow into sceds, the ovary that contains them develops into a fruit (the pod). It grows rapidly. In the case of those varieties whose young pods are eaten in the form of "string beans," they are large enough for use ten or twelve days after pollination. The ovary is horizontal or nearly so, as we have seen, when the flower opens. But as it grows after fertilization, its weight bends the pedicel, and it hangs downward. The walls of the pod are green or greenish at first, but sooner or later they change, usually to yellowish or brownish, sometimes to other colors; and become thin, dry, and hard. The pods of some varieties are still green at the string bean stage; those of others are yellow at this time.

The base of the style remains as a pointed projection at the end of the pod; the rest of the style and the stigma wither after pollination. A small amount of tissue develops between the seeds, so that

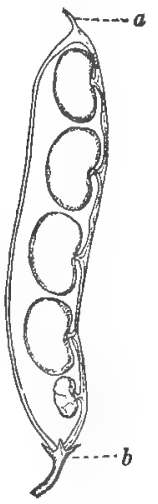

FIG. 92, - A bean fruit with half of the pod removed, showing the seeds and the way in which they are attached; $a$, the remains of the style; $b$, the sepals. each one lies in a separate cavity; but as the fruit ripens these partitions dry and shrivel away. A ripe pod shows a bulge corresponding to the position of each seed. In a cross section through the pod of many varieties of bean (Fig. 93), one sees a group of vascular bundles, containing many thick-walled cells, near one edge of the section, and two similar but smaller groups near the opposite edge. The inner layer of the pod also contains thick-walled cells. The groups of bundles near the edges of the pod 


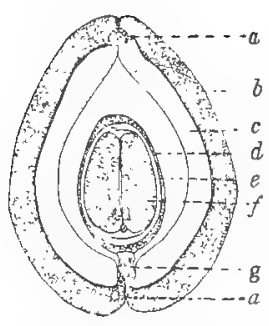

FIg. 93.- Cross section through a young bean fruit and a seed; $a$, groups of vascular bundles ("strings"); $b$, outer layer of the pod; $i$, inner layer; $d$, outer seed coat; $e$, inner seed coat; $f$, seed leaf; $g$, stalk by which the seed is attached to the pod.

are the "strings" that are familiar to every one who has shelled or cut up green beans. The strings and the inner tough layer of the pod were present in all the earlier varieties of beans; but in more recent years improved varieties have been produced in which the thickwalled cells are either lacking altogether from the vascular bundles and the inner layer of the pod, or else are late in developing.

174. Germination of the Seed (Fig. 94). - The conditions under which seeds will germinate have been carefully studied in connection with the bean and some of its relatives. One necessary condition is the presence of water, a good deal of which is absorbed by the seed coat and by the embryo. Bean seeds germinate more quickly if they are first placed in cold water and left there overnight. Another necessary condition is a suitable temperature. Bean seeds will not germinate, no matter how well they arc supplied with water, below $32^{\circ} \mathrm{F}$. nor above about $122^{\circ} \mathrm{F}$. Another condition is the presence of oxygen. Seeds will not germinate in an atmosphere from which the oxygen has been removed; nor will they germinate well in soil which is so thoroughly water-soaked that there is little or no air in its pores.

Germination begins by the

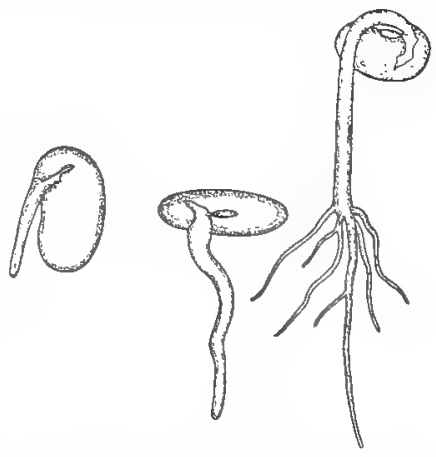

FrG. 94. - Stages in the germination of a bean seed and the devel. opment of the seedling. 
elongation of the radicle, which pushes out through the micropyle, cracking the seed coat as it does so. If the seed germinates below the surface of the ground, the process is very similar to the germination of the squash seed (see Chapter I, $\S_{2}$, and Fig. 2), except that there is nothing like the "peg" of the squash seed to holp in pushing off the seed coat. The radicle bends if necessary, so that its tip grows downward and forms the primary root. The upper part of the radicle now grows in such a way that the seed leaves and plumule are pushed upward. The seed leaves, and for a time the seed coat, protect the small secondary leaves and the tip of the plumule from injury by hard objects. After the plumule and seed leaves have reached the surface of the soil, the radicle, which has remained bent until now, straightens, the seed leaves separate, and the small secondary leaves grow and become green; they are the first foliage leaves of the plant. The large seed leaves become greenish but soon begin to shrivel and finally fall off. The food that they contain is used in the gromth of the radicle and plumule.

In some varieties of bean and in the pea the seed leaves remain within the seed coat below the surface of the soil, and merely separate so that the plumule may push out and up. In these cases, the plumule in its upward growth remains bent and so protects its delicate tip as well as the tender secondary leaves.

175. Life Cycle of the Bean. - Although their life histories are very much alike, the bean shows an advance over the pine in several respects. The chief points of difference between pine and bean, which are the same points that distinguish gymnosperms and angiosperms in general, are the following :

a. The spore leaves of the pine cone are borne at different levels upon a comparatively long axis; in the bean flower this axis is much shortened, so that all the 
spore leaves (stamens and pistil), as well as the sepals and petals, are borne at nearly the same level.

$b$. The seeds of the pine are borne on the exposed surfaces of the macrospore leaves; those of the bean are enclosed within the ovary, which has been formed by a folding of the macrospore leaf.

c. The sexual generation, already much reduced in the pine, is reduced still further in the bean. The female plant now consists of only seven cells, the male plant of only three.

d. The endosperm of the pine is formed before fertilization; it is the vegetative tissue of the female plant. That of the bean develops after fertilization from a cell whose nucleus has been formed by the union of two nuclei of the female plant with one nucleus of the male plant; it disappears before the seed is ripe; but in the seeds of the corn (see Chapter XIII) and in those of many other angiosperms, the endosperm is still present in the ripe seed, just as it is in the seed of the pine. The life cycle of the bean may be represented by a diagram substantially like that used for the pine (Fig. 77).

176. Species and Varieties. - The name "bean" is applied to many very different plants. But nearly all the plants that are cultivated for food in the United States and Canada under this name are varieties of two species of the genus Phaseolus. Most of the common field beans and garden beans belong to the species Phaseolus vulgaris; they are sometimes classed together as "kidney beans." A list of I 45 distinct varieties of kidney beans grown in the United States was prepared in 1907 , and it is estimated that in all, throughout the world, there are at least 500 varieties. Among the kidney beans are both low and climbing forms, and they differ greatly from one another in the color, shape, and size of their pods and seeds, as well as in various other ways. $P$. lunatus includes the Lima beans, of which there are perhaps fifty varieties, some low and some climbing. Lima beans are not so much grown in other parts of the world as they are in the United States. Several others of the 150 or more species of Phaseolus are cultivated in various parts of the world. $P$. multiflor 
the varietics known as "scarlet runner beans," that are raised both for food and for ornament. Certain varieties of $P$. acutifolius, a species native to the southwestern United States, have long been grown by the Indians for food and are now coming into general cultivation under the name of "tepary bean." P. radiatus, the "Adzuki bean," is much used in Japan and has been introduced into the United States.

177. Relatives of the Beans. - The beans belong to the pulse family, which includes more than 12,000 species. With one exception (the composite family) this is the largest family of living seed plants. Among the members of the family are hundreds of species that are useful to man. The seeds and fruits of many are used as food; the roots of some are eaten, and some supply substitutes for coffee and tea. Some are used as food for domestic animals. The wood of some trees belonging to this family is used in building, for cabinet work, or as a source of dyes. The fibers of some are used in making ropes, in weaving, and in paper-making. Others are sources of gums and balsams, starch, oils, and perfumes. A considerable number are drug-plants, and many are cultivated for ornament. Vicia faba, the "broad bean," is grown largely in Europe; the seeds are eaten, like those of the kidney beans, and the plant serves as food for horses and sheep. This is the plant to which the name bean was originally given. Other well-known members of the family are the pea, the lentil, lupines, vetches (which include Vicia faba), the asparagus bean, the cow-pea, the soy-bean, the hyacinth bean, the peanut (whose flower-stalks turn downward and grow after pollination, so that the fruits are pushed into the soil and ripen there) ; the clovers, alfalfa, the sensitive plant, the honey locust, the black locust, the sweet-peas, laburnum, wistaria, the tamarind, the acacias, the sunn hemp, and Indigofera (which supplies indigo). The drug known as "senna" consists of the dried leaves of Cassia; licorice is obtained from the roots of Glycyrrhiza.

178. Historical Note. - Phaseolus vulgaris, $P$. lunatus, and $P$. multiflorus (kidney beans, Lima beans, and scarlet runner beans) are natives of the American continent, but they are not now known in the wild condition. All three (including many varieties of kidney beans) were cultivated by the American Indians before the coming of Columbus. Seeds of Lima beans and kidney beans are reported to have been found in old Indian tombs in Peru. Kidney beans seem to have been introduced into Europe about the middle of the sixteenth century; Lima beans and scarlet runner beans were taken over later. Broad beans have been widely used in Europe for centuries; they were grown by the ancient Egyptians and by the lake-dwellers of Switzerland, and their origin is unknown. 


\section{CHAPTER XIII}

\section{THE INDIAN CORN}

179. The Stem. - The corn, like the bean, is an angiosperm; but it differs from the bean, as we shall see, in several

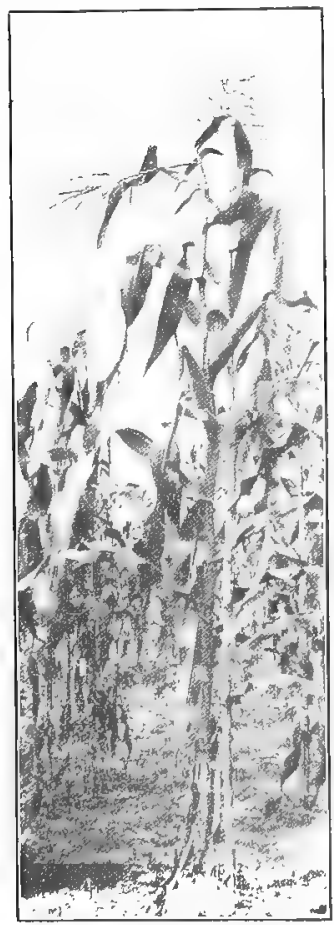

FIG. 95.- Indian corn plants. rather important respects. The upright stem is grooved on one side; at each joint of the stem the position of the groove changes from one side of the stem to the opposite side. The stem in most varietics of corn under ordinary conditions forms no branches except the special ones that bear flowers. Like the stems of the cucumber and the bean, it grows in length by means of a terminal bud. But its growth ceases when the "tassel" is formed at the top; so that the corn stem has a more definite limit of length than has the bean stem. The length of the stem is very different, however, in different varieties of corn, ranging, so it is said, from eighteen inches to thirty feet or more. The flowers and fruit are formed during the same year in which the seed germinates. The corn, therefore, like the bean, is an annual.

A cross section through the corn stem (Fig. 96) looks very different I56 
from one through the bean stem. The most striking difference is in the arrangement of the vascular bundles. Instead of being in a cylinder (a ring in cross section), the bundles are scattered through the stem. Another important point of difference is that there is no cambium: a vascular bundle of the corn consists only of wood and bast. There being no cambium, the

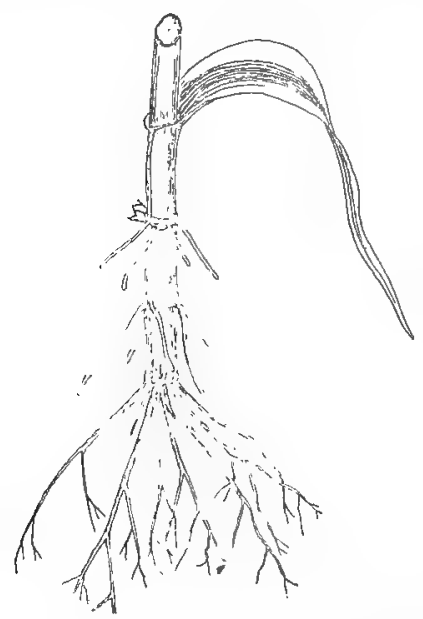

FIG. 97. - Lower portion of a corn stem, showing the cluster of roots growing from the base, the brace roots, and one (the third) secondary leaf. The very small blade of the first secondary leaf has withered, and only a portion remains of the blade of the second secondary leaf.

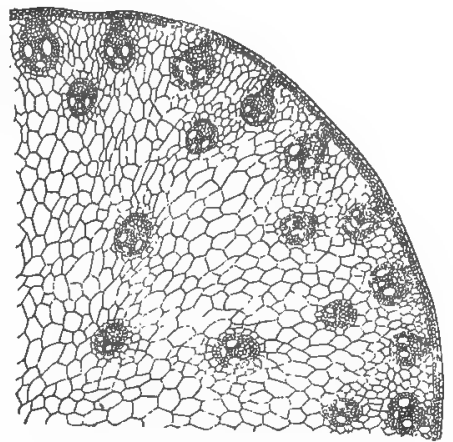

Fic. 96. - Part of a cross section through the stem of the Indian corn. After Stevens.

stem cannot grow in thickness after the cells of any particular part are fully grown. This is why the corn stem is of about the same diameter throughout its length, instead of being thicker toward the base as the bean stem is.

180. Foliage Leaves. - These are alternately arranged, like the leaves of the bean. A corn leaf (Fig. 95) has no leaf-stalk. The lower part of the leaf forms a sheath that surrounds the stem for some distance above the joint where the leaf is attached. The upper, outspread part of the leaf is the blade. On the inner side of the leaf, at the place where the blade joins 
the sheath, there is a short, thin outgrowth. The blade is long, drooping at the tip, narrow in proportion to its length, and has a long, slender point. Its edge bears many very fine teeth. On its upper surface a shallow groove runs lengthwise above the midrib. The arrangement of the veins looks quite unlike that in the bean leaf. Many veins start from the base and run nearly parallel with one another to the upper end of the leaf. The middle vein (midrib) is much the largest. The midrib and the veins that run parallel with it do not seem to be branched, as are the veins in the bean leaf. There really are many slender branch veins, which form a network; but these interlacing branches are so delicate that they are not easily seen, and therefore the leaf is said to be parallel-veined.

181. Roots. - The primary root does not become very 1ong. Early in the life of the young plant, other roots begin to grow from the lower part of the stem (Fig. I03, $C, D, E$ ); indeed, some of these roots were already present in the seed as very small swellings upon the sides of the plumule. Both the primary root and the roots that grow from the stem give rise to fine branch roots. The mature corn plant, therefore, has a cluster of slender branching roots (Figs. 97, 98)

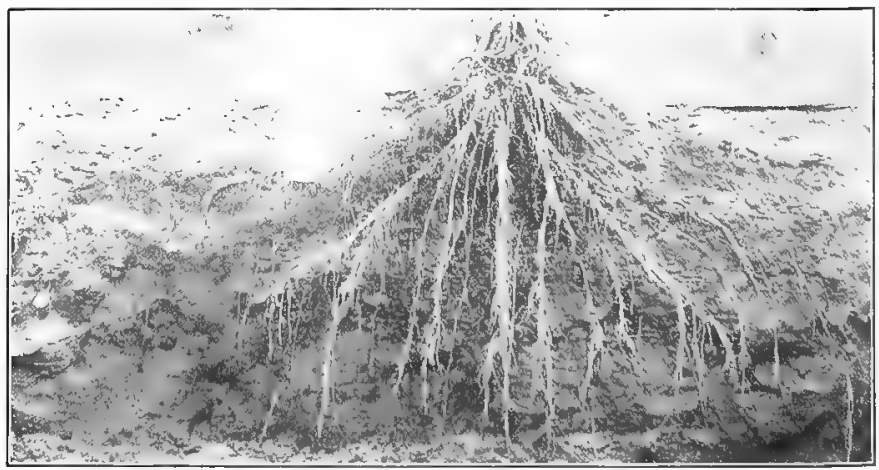

FIG. 98, - The root system of a corn plant at the time of flowering. 
all of much the same size, one of which is the primary root. As the plant grows, circles of new short roots (brace roots) grow from some of the lower joints of the stem above ground where the leaves are attached. The lower ones of these new roots reach down into the soil; later they shorten somewhat, so that the plant is firmly anchored to the soil.

\section{Flower Clusters; \\ Pistillate Flowers. -} The flowers of the corn, like those of the cucumber, are of two kinds, pistillate and staminate. Both kinds are borne in clusters. The cluster of staminate flowers is the "tassel." It is borne at the upper end of the stem, developing from the terminal bud. A cluster of pistillate flowers is an "ear." It develops from an axillary bud, and so each ear is found in the axil of a leaf. The ear or ears develop ordinarily in the axils of
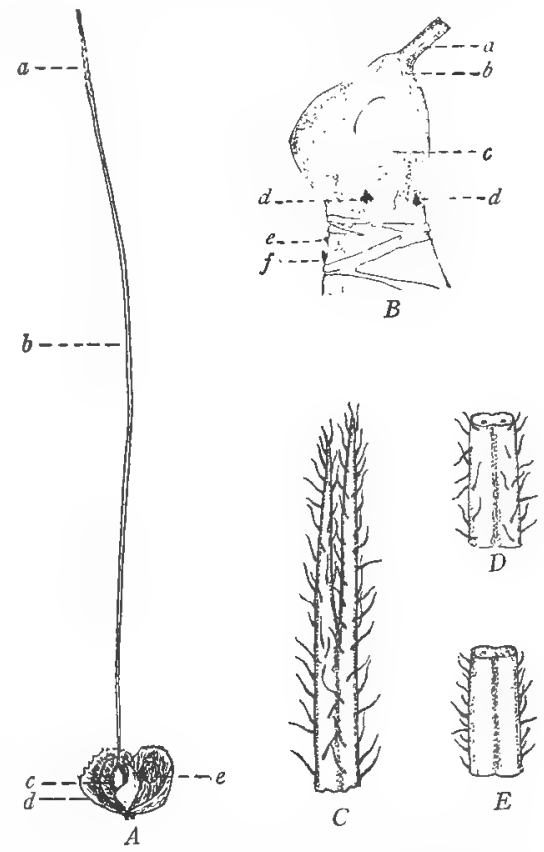

FIG. 99. $-A$, a spikelet from a young ear of Indian corn, bearing two pistillate flowers, one fully developed and one rudimentary; $a$, rough, hairy tip of stigma ("silk"); $b$, lower, less hairy part of stigma; $c$, ovary; $d$, scale-like leaves (bracts or "chaff"); $e$, the undeveloped flower. $B$, a spikelet on a larger scale, with the bracts and the greater part of the silk removed; $a$, base of the stigma; $b$, style; $c$, ovary; $d$, rudimentary stamens; $e$, pistil, and $f$, one of the stamens, of the undeveloped flower of the spikelet. $C$, tip of the stigma, which is forked and bears many hairs. $D$ and $E^{\prime}$, portions of the lower part of the stigma as seen from opposite sides. $A$ after Schmeil; $B, C, D, E$ after Weatherwax. 
some of the upper leaves. But if the ears that appear in the axils of these are removed while still very sma1l, new ones will be formed in the axils of some of the lower leaves.

The cob of an ear of corn is really a branch that bears many flowers, closely packed together. The husks that cover the ear are leaves of a special form, which protect the flowers
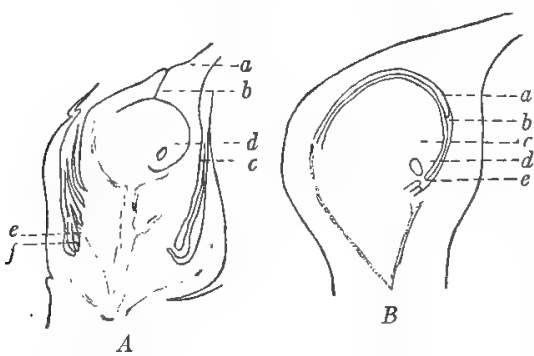

FIG. I00. $-A$, a lengthwise section through a pistillate spikelet of Indian corn; $a$, base of stigma; $b$, style, penetrated by a narrow canal; $c$, ovary; $d$, ovule; $e$, pistil, and $f$, stamen, of the undeveloped flower. $B$, a lengthwise section through an ovary; $u$, outer integument; $b$, inner integument; $r$, ovule; $d$, outline of the female plant, developed from the macrospore; $e$, micropyle. $A$ after Weatherwax; $B$ after True. and young fruits from injury. Each cob bears many spikelets (small branches), which are arranged in rows running lengthwise of the cob. Each spikelet (Fig. 99, A, B) bears two very small pistillate flowers. Of these two, the lower flower (that nearer the cob) in most varieties of corn never develops fully and never forms a kernel. The upper, fully developed flower of the spikelet has a single pistil formed, like that of the bean, by a single macrospore leaf; there are also three rudimentary stamens, which are hardly to be made out in a full-grown flower. Around and between the flowers there are scale-like leaves which are not parts of the flowers themselves but are probably to be thought of as bracts. These bracts make up the chaff that remains between the kernels after the ear is ripe.

The pistil consists of a rather large ovary containing a single ovule; a short projection, the style, at the outer end of the ovule and on its upper side (that is, the side turned toward the tip of the ear); and the " silk," which is 
attached at one side of the style and which seems to be an extremely long stigma. The silk projects beyond the husks; all along its surface are hairs, which are most numerous near the tip. The cluster of stigmas or silks hanging from the end of the ear thus furnishes an excellent means for catching and holding the pollen grains. The flowers at the base of the car are the oldest and first to mature, and therefore the kernels in this part of the ear develop first.

\section{Staminate Flow-} ers. - The tassel is a much-branched cluster of staminate flowers. The final branches of the cluster are spikelets, corresponding to the spikelets of the ear. Each spikelet of the tassel (Fig. IoI, $A$ ) also
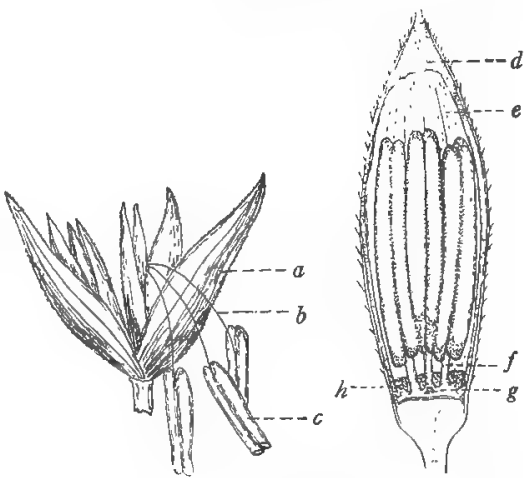

FIg. Ior. $-A$, a spikelet from the "tassel" of the Indian corn, bearing two staminate flowers; $a$, one of the bracts; $b$, filament; $c$, anther. $B$, a lengthwise section through an unopened staminate flower; $d$ and $e$, bracts; $f$, filament, now short, but which will become much longer when the flower opens; $g$, the rudimentary pistil; $h$, one of the two small sepal-like parts. $B$ after Weatherwax. bears two (or occasionally more) flowers, as well as several chaffy bracts or scales. A flower consists of three stamens, a rudimentary pistil, and two small, swollen, leaf-like structures that perhaps correspond to sepals. Each stamen is composed of a filament which in the mature flower is long and drooping, and a long anther which has four pollen sacs. Since there are many staminate flowers in a "tassel," the amount of pollen is very great; it has been estimated that as many as ,I $8,000,000$ pollen grains may be produced by a single corn plant. 
184. Pollination. - The history of the formation of the pollen grain within the pollen sacs, that of the macrospores within the ovule (macrospore sac), and that of the development of the female plant from one macrospore are so nearly the same in the corn and in the lily that it is not necessary to repeat what was said on these subjects in the previous chapter. Since pistils and stamens are borne (except in rare cases) in different flowers, pollination in the corn must be, strictly speaking, cross-pollination; but the pollen that falls upon a particular stigma may come from a staminate flower either on the same or on a different plant. Pollination may result from the mere falling of pollen from staminate flowers upon the silk of the pistillate flowers of the same plant; but more commonly pollination is brought about by the wind, just as it is in the pine, and this usually, though not always, means that the pollen from the staminate flowers of one plant is carried to the pistillate flowers of another.

185. Formation of Seed and Fruit. - The embryo and endosperm begin their development in the ovtle of the corn in much the same way that the corresponding processes begin in the bean ovule. But the embryo of the corn remains small; the endosperm continues to grow, using up most of the substance of the ovule as it does so, and finally the endosperm makes up the greater part of the bulk of the seed. As the seed grows, the embryo is pushed to one side; it lies at the base of the upper side of the ripe seed. The endosperm is full of food which will be used by the embryo when the seed germinates. Onc great difference between the bean and the corn seed is in the place in which the food is stored. Most of the food of the bean seed is in the seed leaves; most of that of the corn sced is in the cndosperm.

The greater part of the endosperm formed in the bean seed is used as food for the embryo before the seed ripens; but in the corn most of the endosperm is not used in this way until the seed germinates. The body of the embryo con- 
sists of a radicle, which is turned toward the base of the kernel, and a plumule, which is turned upward. The plumule bears several small secondary leaves. Wrapped about the radicle and plumule is a single broad, thick seed leaf (instead of the two seed leaves of the bean); this seed leaf separates the radicle and plumule on the inner side from the endosperm, and covers them on the outer side also, except for a very narrow strip. The wall of the ovary, which becomes the fruit coat (corresponding to the pod of the bean), remains thin and comes to be very closely united with the seed coat. Thus the corn kernel is a fruit containing a single seed; but, because the fruit coat and seed coat have grown so closely together, it is only by studying the way in which the kernel has developed from the ovary of the flower that we can make sure that the

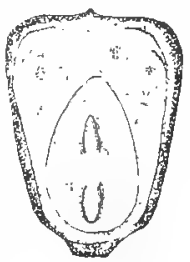

A

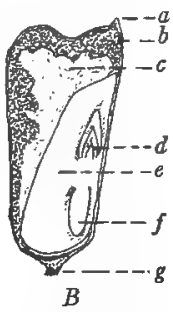

FIG. I02. $-A$, a side view of a kernel of Indian corn, with a portion of the fruit coat and seed coat removed so as to show the position of the embryo. $B$, a lengthwise section of a kernel, cut through the embryo; $u$, style; $b$, horny endosperm; $c$, starchy endosperm ; $d$, plumule, with secondary leaves; $e$, thick seed leaf, wrapped about the rest of the embryo; $f$, radicle; $g$, point at which the kernel was attached to the cob.

outer covering of the kernel is really something more than a seed coat.

At or near the free end of the kernel and on its upper side (that is, on the side turned toward the tip of the ear) is a small, sharp projection. This is the style; the stigma (silk) dried and withered after pollination but still remains attached to the style. The end of the kernel that is attached to the ear corresponds, of course, to the base of the ovary. Near this place are the micropyle and the point of attachment of the ovule within the ovary. But since these points are both covered by the fruit coat they cannot be seen from 
the outside; indeed, it is very difficult to make them out at all in the ripe kernel.

186. Kinds of Food in the Kernel. - Since the food stored within the kernel is the part of the corn plant that is valuable to us, it is worth while to learn something of its nature. The kernel contains four different kinds of substances that will be useful as food either to the young corn plant that may grow from the seed, or to the man or the animal that may eat it. These food substances are starch, which is present in the form of minute grains within the endosperm; sugars, also in the endosperm as well as to some extent in the embryo; fats, present in small amounts in the endosperm, but much more largely in the embryo; and proteins, present in the living matter of the embryo and in that of the endosperm as well, and especially in certain rounded bodies in the outermost layer of the endosperm next the seed coat. These four classes of food substances are exactly those of which our diet, as well as that of the lower animals, is chiefly made up, and it is the presence of these substances that makes the kernels of Indian corn and other grains so useful to us.

The food value of corn, as of wheat and rye, lies mainly in its starch. The other food substances (sugars, fats, and especially proteins) are present in too small amounts, and for these we must look mainly to other articles of food. Proteins are present in larger amounts in meats, eggs, cheese, and in some seeds such as beans and peas. The food substances mentioned are present in different proportions in different varieties of corn. In flint corns, the part of the endosperm next the embryo is closely packed with starch and is called the starchy endosperm; the part outside this, which contains somewhat less starch and somewhat more protein, looks clear and transparent, and is called the horny endosperm. The horny endosperm does not shrink when the kernel ripens, so that a kernel of flint corn remains plump. In dent corns, the starchy endosperm cxtends to the outer 
end of the kernel, the horny endosperm being present only on the sides. The starchy endosperm loses water and shrinks as the kernel ripens, so that the outer end of the kernel is indented. The endosperm of a pop corn is entirely or almost entirely horny. It is the expansion of water within the horny endosperm when the kernel is heated that causes an explosion or "popping" of the corn. The endosperm of sweet corns contains a large proportion of sugar and relatively little starch; the kernels lose much water as they ripen, and so become wrinkled.

187. Germination. - In most respects the germination of the corn kernel is much like that of the squash seed. The radicle breaks through the seed leaf, the seed coat, and the fruit coat, and then bends, if necessary, so as to grow downward into the soil (Fig. ro3, $A, B$ ). The plumule also breaks its way out and grows upward. At this time, the plumule and the smaller secondary leaves are surrounded by the first secondary leaf, which is so wrapped

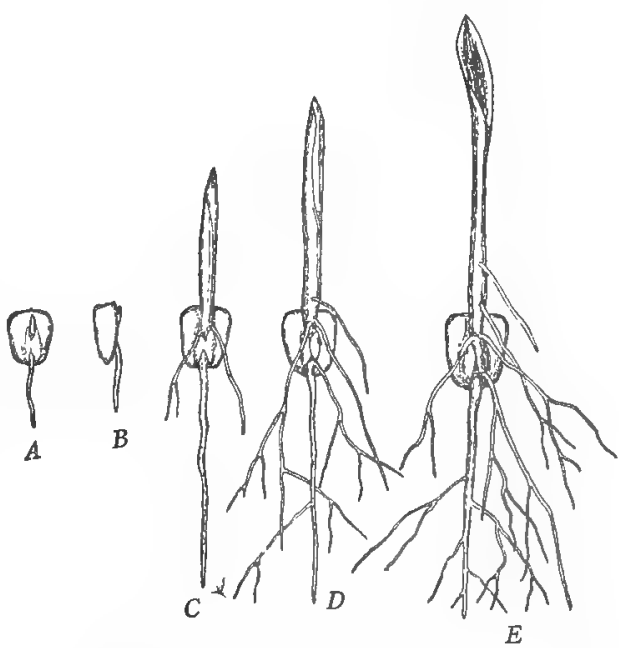

Frc. 103. $-A, B$, two views of a germinating kernel of Indian corn. $C, D, E$, stages in the development of a corn seedling; notice the points at which secondary roots arise.

about the plumule as to make a pointed structure with a hard, sharp point that pushes through the soil. In time the protecting secondary leaf unrolls slightly, so that the plumule with 
the later leaves can push on beyond it. This first secondary leaf remains small and forms almost no blade (Fig. I03, E). The next forms a small blade; and each later leaf, as it grows and opens, becomes larger than the preceding one, until finally the size of leaf is reached that is characteristic of the mature plant. Meanwhile the plumule has grown into an erect stem, on which the leaves are borne. The seed leaf remains within the kernel. It absorbs the food that is stored in the endosperm and passes this food on to the other parts of the seedling (radicle, plumule, and secondary leaves). After the food supply of the endosperm is used up, the seed leaf is no longer useful, and it soon dies. The seed leaf of the corn, therefore, never becomes a green foliage leaf.

188. Varieties of Corn. - Many varieties of Indian corn are in cultivation, but all of them seem to have been developed from a single species, Zea Mays. In I 899, a list was made of 507 varieties, divided among the following groups: pop corns, flint corns, dent corns, soft corns, and sweet corns. The flint corns, the dent corns, and the few varieties of soft corn that are cultivated are usually spoken of as "field corn." In addition to the five classes above named, two others are known. These are the pod corns, little grown except as curiosities, each of whose kernels is enclosed in a separate pod formed by a growth of some of the surrounding bracts; and the starchy-sweet corns, which are cultivated by certain Indian tribes.

189. Relatives of the Corn. - The Indian corn is a member of the grass family, whose 3500 species include all the wild and cultivated grasses, the bamboos, sugar cane, sorghum, broom corn, and the cereal grains (including, besides Indian corn, rice, wheat, barley, rye, oats, and millet). The closest known relative of Indian corn is teosinte. This is a native of Mexico, but it is raised as a fodder plant in many warm countries. It is much like Indian corn, excepting that its clusters of pistillate flowers are smaller and simpler than corn ears. It is thought by some that Indian corn may have originated long ago as a variety of teosinte; and that this new variety was found valuable by the Indians, who began to cultivate it.

190. Historical Note. - Indian corn is not now known to grow anywhere as a wild plant, excepting that now and then it escapes from cultivation and lives wild for a few generations. Its original home was on the American continent, probably in Mexico. It was widely 
cultivated by the natives of both North and South America when the continent was discovered by white men. The name "maize," commonly applied to Indian corn, is taken from a name that Columbus found in use among the natives of Haiti. In the United States the plant is usually known simply as " corn." In Great Britain, "corn " is a general term for the cereal grains, and Zea Mays is called either "Indian corn " or " maize." The cultivation of maize was introduced into Europe very early, and it is now found in all the temperate regions of the earth. In Italy, Austria-Hungary, Russia, and the Balkan States, and in Northern China, as well as in North and South America, it is an important agricultural crop. However, nearly 75 per cent of the world's production is supplied by the United States, where corn has for a long period stood first among field products. In I9I5, something over $3,000,000,000$ bushels of corn were produced in the United States. Most of the varieties known up to the middle of the last century were flint and dent corns, both of which were cultivated by Indians before the coming of white men. The first certain record of the cultivation of sweet corn is in $\mathbf{1 7 7 9}$, when it was obtained from the Indians of the Susquehanna Valley and introduced into the region about Plymouth, Mass. As late as I 854, only two varieties of sweet corn seem to have been known, so that its cultivation on a large scale is a very modern development.

191. Monocotyledons and Dicotyledons. - These are the two great groups into which angiosperms are divided. The monocotyledons are so named because their embryos have but one seed leaf (cotyledon); among them are the Indian corn and other grasses, the lilies and their relatives, the palms, and the orchids. The dicotyledons, whose embryos have two seed leaves, are much the larger group; they include most of our garden plants and common weeds and nearly all the common trees and shrubs excepting evergreens. The squash, pumpkin, and cucumber belong to one family of dicotyledons; the beans and their relatives belong to another family. Following are some of the differences between the two groups:

a. The vascular bundles in the stem of a dicotyledon are arranged in a cylinder; in this respect dicotyledons resemble the pine. The bast and wood of each bundle 
are separated by a cambium layer, the division of whose cells leads to the growth of the stem in thickness. The monocotyledons, as a rule, have the bundles in their stems scattered like those of the corn, and form no cambium layer. This is the reason why nearly all monocotyledons have slender stems and remain small plants. A few of them, however, including some of the palms, have a method of growth in thickness quite different from that of the dicotyledons, which enables them to become good-sized trees.

$b$. The leaves of monocotyledons are usually not lobed or divided into leaflets. They are nearly always parallelveined like corn or lily leaves. The leaves of dicotyledons are very various in form, but many of them are lobed like oak leaves, or divided like the leaves of peas and beans. They are netted-veined; that is, the veins are much branched, as in the cucumber and bean leaves, the branch veins interlacing so as to form a network.

c. The flowers of monocotyledons most commonly have their parts in threes or multiples of three; for instance, a lily flower has three sepals, three petals, six stamens, and but one pistil, which, however, is formed by the union of three macrospore leaves; a staminate corn flower has three stamens; a pistillate corn flower has only one pistil, consisting of a single macrospore leaf. Dicotyledons commonly have the parts of their flowers in fours or fues, or multiples of these numbers. Thus a cucumber flower has five sepals, five petals, and either three macrospore leaves or three stamens; but the three stamens seem really to represent five, four of which are united in pairs. The bean, another dicotyledon, has five sepals, five petals, ten stamens, and one macrospore leaf.

d. The embryo of a monocotyledon has one seed leaf; that of a dicotyledon has two seed leaves. 


\section{CHAPTER XIV}

\section{ROOTS AND THEIR USES}

192. Origin and Growth of Roots. - A root may originate in any one of three different ways: as a primary root, which develops from the radicle of the embryo and is continuous with the stem of the plant; as a branch root, growing out from the primary root or from an older branch root; or as an adventive root, starting from some part of the plant other than a root - usually from the stem or from a branch. A branch root or an adventive root nearly always begins its growth deep within the tissues of the organ (root, stem, or branch) from which it starts. This is one way in which a root usually differs from a branch, which begins as a swelling upon the surface of the organ that hears it. A root differs from a branch also, as a rule, in the arrangement of its tissues, in having

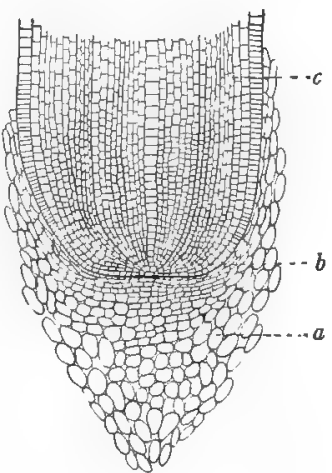

Frg. 104. - Lengthwise section through a root tip of the Indian corn; $a$, root cap; $b$, embryonic region; $c$, region of growth. its growing point protected by a root-cap, and in not bearing leaves: However, it is sometimes difficult to say whether a particular structure is a root or a branch, just as at other times we cannot be sure whether a certain organ is a branch or a leaf. So we must think of stems, branches, leaves, and roots as classes into which it is convenient to divide the organs of plants; but these classes 
are not always sharply separated, and sometimes we find an organ that will fit into one class about as well as into another.

There are three general forms that a root system may take: (I) The primary root may grow into a long tap root that

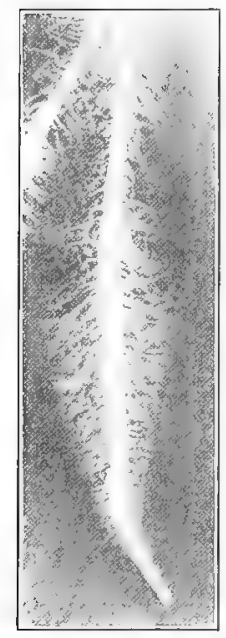

FIG. 105. - A barley root, showing the region just back of the tip in which root hairs are formed, and the region at little farther back in which they die and drop off. After Stevens. bears many branches; this form is rather common among gymnosperms and dicotyledons, particularly in those that become trees; (2) sometimes, as in the cucumber, the bean, and many other dicotyledons, the primary root remains short and gives rise to a cluster of long branches; (3) in many monocotyledons the root system consists largely or entirely of a cluster of adventive roots that grow from the lower part of the stem; the primary root may remain short (as in the corn) or it may die (as in the lily). But while most root systems fall into one or the other of these general classes, roots of very many different kinds and forms have been developed to meet different needs. The growth of a root in length goes on in a short zone just back of the root tip (c, Fig. I04). Back of the region of growth, and to some extent perhaps in this region itself, root hairs are borne. A little farther back still, the root hairs and the other cells of the epidermal layer have died and disappeared; these older parts of the root are commonly protected against the loss of water by the formation of cork in the outer walls of what are now the surface cells. Roots of gymnosperms and dicotyledons, especially of those which live for more than one ycar, grow in thickness and form 
bark; but the bark of roots does not grow so fast nor become so thick as that of stems often does.

193. Occurrence of Adventive Roots. - Not a few plants, like the Indian corn, produce adventive roots regularly and in considerable numbers. A potato shoot growing from an eye of a tuber sends out adventive roots from its lower part. Plants with long underground stems, like the may-apple, as well as many trailing plants, pro' duce adventive roots from time to time. As the older parts of such a plant, including its primary root, die, its root system comes to consist entirely of adventive roots. Some climbing plants form adventive roots in large numbers; but such plants usually remain connected with the soil by means of a primary root, and the adventive roots are useful chiefly to assist the plants in climbing. Many plants form adventive roots

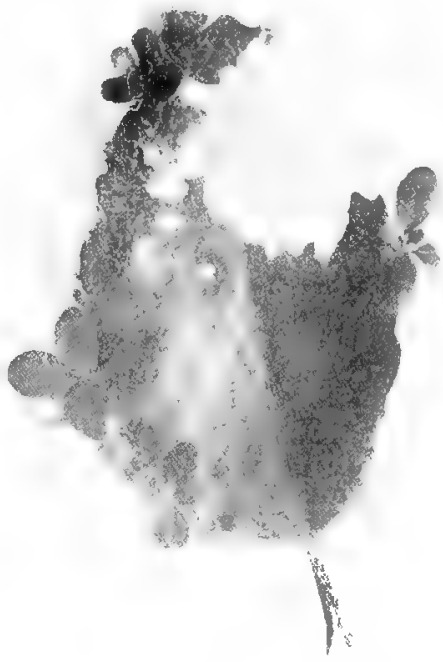

Fig. Io6. - A leaf of Bryophyllum which is producing new plants - a case of vegetative multiplication. This leaf was placed on moist sand, and in a few days adventive buds and adventive roots developed wherever the veins extended to the edges of the leaf.

in response to the stimulus of a wound. In some kinds of trecs, for example, girdling (see $\S 232$ ) is followed at first by the formation of adventive roots on the upper edge of the wound, and in other kinds it is followed by the formation of adventive buds (which may develop into branches) on the lower edge of the wound. If a leaf of a rex begonia is cut into several pieces and these are stuck 
into the soil, in a short time each piece may form adventive roots and an adventive bud, and so give rise to a complete new plant.

194. Vegetative Multiplication. - It is plain that the power which the begonia leaf has of forming adventive roots and buds is of great advantage to the plant because it can thus produce new plants under unfavorable conditions. Not many seed plants can develop new plants from a part of a leaf alone; but there are many cases in which a small part of a plant, by forming adventive roots or adventive roots and buds, can grow into a complete new plant. This fact is taken advantage of by gardeners and foresters, who grow new plants from cuttings more quickly and easily than they could from seeds. Thus a short piece of a young willow stem, stuck in the ground, forms adventive roots at its lower end and adventive buds at its upper end and so grows into a tree.

Many cultivated plants, such as grapes and currants, the flowering "geranium" (which is really a Pelargonium), coleus, and verbena, are propagated by means of cuttings. A cutting usually consists of a short branch bearing one or more leaves or buds. But a new plant of gloxinia, as of begonia, can be obtained from a single leaf or even from a piece of a leaf; and the bulb-scales of some lilies are used as cuttings. All these are cases of vegetative multiplication, because new plants are produced without waiting for pollination, fertilization, and the ripening of a seed. There are other kinds of vegetative multiplication that depend partly or entirely upon the development of adventive roots. One of these is the production of new strawberry plants by means of runners.

Layering, a method used by gardeners, is not unlike the one that the strawberry uses. In layering, a branch (of a blackberry or taspberry, for example) is bent over to the ground and part of it is covered with soil. Then, from the 
buried part, adventive roots grow into the ground (Fig. I07), and when the connection with the parent plant is broken, the new roots with the adjacent bud or buds form a new plant. The slender canes of the black raspberry, if allowed to grow long, bend over to the soil of their own weight and so perform the operation of layering for themselves.

\section{Work of Roots: Absorption.-} The different forms that roots take are closely connected with the kind of work that they have to do. The work of roots is of various kinds; it differs much with the location, size, and habit of the plant. Much has already been said of

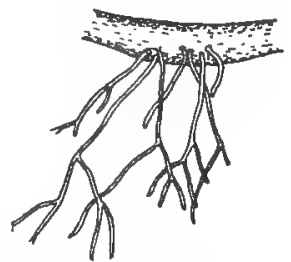

Fig. 107. - Vegetative multiplication by layering. A portion of a living stem was covered with soil and adventive roots have grown from the covered portion. the part that roots play in absorbing, usually from the soil, water and certain other substances that the plant needs. Since absorption goes on through the root hairs, and since these are short-lived and are borne only on the younger

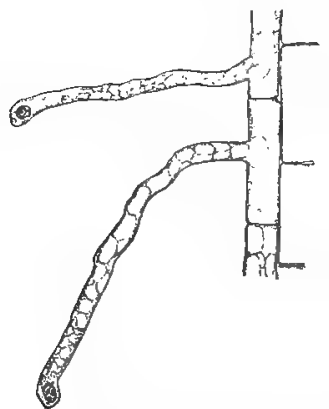

FIG. I08. - Root hairs of the barley. parts of each root, it is necessary that the root should continue to grow so that there shall always be a young region supplied with root hairs.

If the plant lives and grows for many years, the roots must continue to grow and branch, so that, as the parts of the plant above ground need more and more water, the root hairs may increase in number and may come into contact with a larger area of soil. The growth of the roots also brings them into deeper layers of the soil where there is likely to be a more steady supply of water. These are among the reasons why long-lived plants need much-branched root systems, composed of long but relatively 
slender roots that often reach to a great depth. Thus it is reported that old, well-grown trees may send their roots to a depth of sixty feet, provided the soil is deep enough and otherwise favorable for the growth of the roots. Annuals and small perennials have much shorter roots; still, the root systems of barley and mustard reach a depth of about three feet, those of clover and wheat a depth of six feet, and those of alfalfa, it is said, may extend nine feet below the surface of the ground. It is plain that, other things being equal, the plant whose roots grow to the greatest depth has the best chance of living through a dry season.

196. Conduction. - The water and other substances taken in by the root hairs must be carried from the extremities of the root system through the whole length of the branch roots and of the main root to the point where the latter joins the stem. All parts of the root system must also be supplied with food that has been manufactured in the parts of the plant above ground. The conduction of the sap and of manufactured foods goes on through the vascular bundles. Thus absorption and conduction in roots are closely related; the more extensive the root system becomes, the farther is the younger, absorbing portion of each root from the stem, and the farther therefore must sap and manufactured foods be carried.

197. Attachment and Support. - There are some plants, such as the duckweeds which float upon the surfaces of ponds and lakes, whose roots are merely absorbing and conducting organs. But as a rule plants depend upon their roots also to attach them to the soil or to the other substances on which they live. If the stem is above ground and erect, the roots are also a means of supporting the plant in its erect position. The larger the plant, naturally, the more important is the work of attachment and support. It is least important in plants whose stems, like that of the may-apple, are underground. The extensive, much-branched root system, which is 
best for the work of absorption, is also as a rule best for the support of an upright stem. So the need of support is an additional reason for pushing the roots of a tree deeply and widely into the soil. The roots of many plants, like the brace roots of the Indian corn, shorten after they have grown to some length - apparently through a change in shape of some of their cells - and pull the plant closer to, or more deeply into, the soil, thus attaching it more firmly.

Not a few trees support themselves by roots of special sorts. One form of supporting roots is seen in the "screw pines" (Fig. IOg), which are really not pines at all, but are monocotyledons. Some of them become good-sized trees. Their trunks send out adventive roots at various heights above the ground, which grow downward on all sides into the soil and become woody and firm. The base of the stem and the primary root often die, in which case the body of the tree is supported entirely on the stilt-like

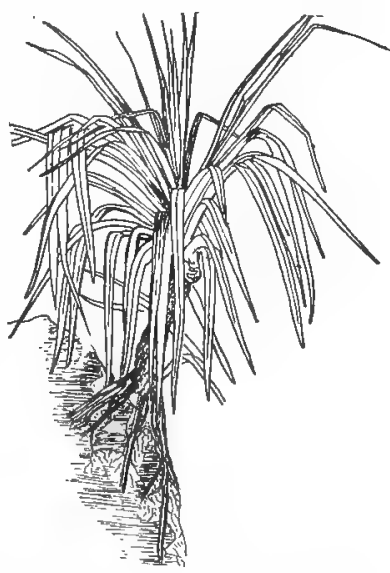

FIG. Iog. $-\mathrm{A}$ screw pine (Pandanus), showing the supporting roots. After Kerner. adventive roots. Mangroves (Fig. I Io) are trees that grow on low, swampy coasts, where the soil is moist and soft ; often they live within the strip that is covered during part of each day by the tide. They support themselves by roots that grow downward from all parts of the trunk and branches. The famous banyan trees of India support their lower horizontal branches by similar prop roots that push into the soil and grow to be thick and strong. These prop roots produce adventive branches and look like so many additional trunks. By means of these new branches and of the new prop roots 


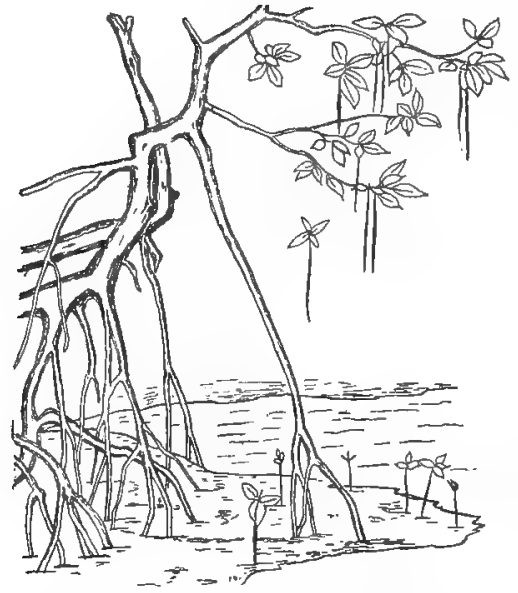

FIG. IIo. - A mangrove (Rhizophora conjugata), showing the numerous prop roots. After Kerner.

which they in turn produce, a single tree may extend over a great area. Stories are told of a banyan tree that sheltered Alexander's army of 7,000 men, and of another in whose shade was built a village of a hundred huts.

198. Storage.-Thickened roots that serve for the storage of food are likcly to be useful to man, and so it is that many plants with storage roots are cultivated. Such plants are often biennials, like the carrot, beet, turnip, and parsnip. The plant manufactures food during the first year of its life and stores it in the thick tap (primary) root. The work of absorption from the soil is done chiefly by short branch roots. It is not merely the root that lives over winter; there is a short, thick stem attached to the top of the root and not sharply marked off from it. During the plant's first year, this short stem bears a cluster of root leaves; the next year it grows into a tall flower-stalk, and much of the food stored in the root is used in forming flowers, seeds, and fruits.

But it is not only biennials that have thick storage roots. Radishes, for $\mathrm{ex}$ -

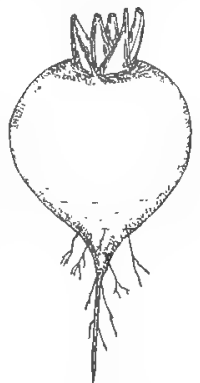

FIG. III, - Root of the radish, a typical storage root. The stem is the very short portion at the upper end of the large root, to which the leaves are attached. 
ample, are usually annuals. A radish may form a comparatively large root in a few weeks; if it is left in the ground, it goes on to produce flowers and seeds during the same season. The horseradish and the dandelion, on the other hand, are perennials, whose thick tap roots, containing storage food, live and grow for many years. The reserve food of the dahlia, another perennial, is stored, not in a tap root, but in a cluster of thick branch roots. The lower part of the stem with the roots attached is dug up and kept over the winter. In the spring it may be divided into as many parts as there are resting buds at the base of the stem, and each bud will grow into an upright, flower-bearing shoot. Roots like those of the dahlia are often called mberous roots; of course they must be distinguished from true tubers like those of the potato, which as we know are branches, not roots. The sweet potato, very differently from the ordinary potato, is a thickened branch root; it is, therefore, much like one of the tuberous roots of the dahlia. Tapioca is a starchy food obtained from the tuberous roots of cassava. Many orchids have rounded or branched tuberous roots, as well as other slender absorbing roots. The tuberous root, with a single bud attached, is the part of the orchid plant that lives over the winter and develops into a new plant the next spring. Some desert plants have thick roots which serve for the storage of water.

199. Respiration. - We must not overlook the fact that respiration goes on in roots as well as in all other parts of the plant where there are living cells. Roots are usually not in so good a position to obtain oxygen as are stems and leaves: Porous soils, if they are not water-soaked, contain a great deal of air in their crevices, and since oxygen makes up about one-fifth of the volume of ordinary air, roots living in such soils find enough oxygen. A hard, compact soil, or one that is water-soaked, may contain far too little air to meet the needs of roots. One important reason for the plowing and 
cultivation of soil is that it is thus made more porous and that a supply of air is carried down to a depth at which roots may use it. The draining of swamps and marshes removes the water which fills the crevices of the soil and at the same time draws a supply of air from above to replace the water. In this way, land that could not before be used for growing crops is reclaimed. One often sees dead trees about the edges of a lake which has been raised to an unusual height by a series of very wet seasons or by a dam in the stream below. In such a case, probably several reasons have contributed to the death of the trees; but one main reason is that their roots have been cut off from an oxygen supply because the soil in which they grow has been flooded with water. The roots died just as we should die if our supply of oxygen were cut off.

Many plants that live in or partly in water, like the waterlilies, provide for a supply of air to their stems and roots by large passages filled with air that run lengthwise through their stems or leaf-stalks. These air passages also help in making the stems and leaf-stalks lighter, and so in buoying them up in the water. The bald cypresses of the southern United States and Mexico, which live in swamps, have a striking means of obtaining air for their roots. The roots produce pointed, woody projections that grow directly up, sometimes to a height of two or three feet above the surface of the soil. These "cypress knces," which are conspicuous features of southern swamps, help to secure a supply of air for the roots. As a result of the respiration of roots, carbon dioxid is given off to the soil. When carbon dioxid is dissolved in water, it combines with some of the water to form carbonic acid. Thus the soil water about a respiring root contains a weak solution of carbonic acid, and this acid solution seems to help the plant by dissolving some of the soil substances which the plant needs and which would not dissolve in pure water. As we know, it is only dissolved substances that can be absorbed by root hairs. 


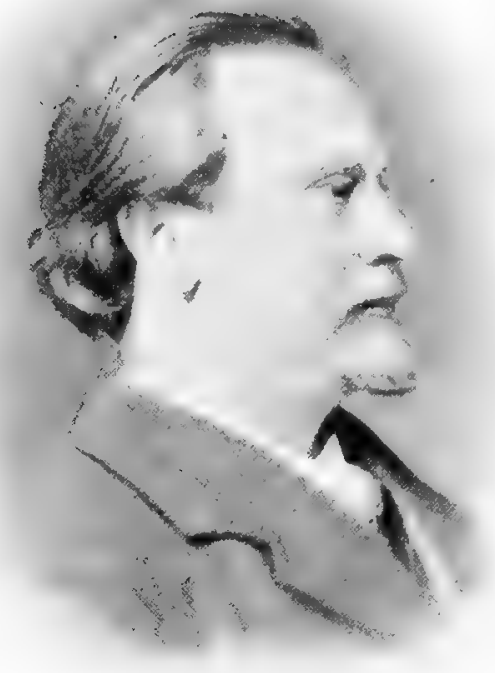

\section{JULIUS VON SACHS}

Born at Breslau, Germany, 1832 ; died at Würzburg, I897. A leader especially in the development of the study of plant physiology; although he made important contributions to knowledge in almost all branches of botany. Author of what was for many years the best textbook of botany, and of an important work on the history of botany. 

200. Roots of Climbing Plants. - Among the means used by climbing plants to attach themselves to the objects upon which they climb are various forms of adventive roots. Some tropical plants support themselves by wrapping their roots tightly about the trunks of trees. Some, like the vanilla, form slender root-tendrils, that are much like branch- and leaf-tendrils. The roots of a few climbing plants take the form of spines. The trumpet creeper has much-branched roots whose root hairs penetrate the fine crevices of the wall or other supporting object and so obtain a firm hold.

201. Roots of Parasitic Plants. - We have learned that many of the simpler plants that are without chlorophyl such as the rusts and some of the bacteria - obtain their food directly from living plants or animals, upon or in whose bodies they live. They are parasites. The great majority of the seed plants have chlorophyl and manufacture most or all of their own food. But even among the seed plants there are not a few which obtain at least part of their food ready made, and so are saved the trouble of making it for themselves. Some of these are saprophytes - that is, they feed upon dead organic substances, usually with the aid of fungi that live in or upon their roots or stems. Others are parasitic upon living plants. In plants whose habit of life is so unusual we may expect to find marked peculiarities of structure. These peculiarities appear largely in the roots, because it is by means of roots that such a parasite takes its food from the host.

The seedling of a dodder (Fig. II2) has a primary root which pushes into the soil, and a stem which grows in length rather rapidly and which may remain alive, if it does not become attached to a host plant, only so long as the supply of food in the seed holds out. If the stem comes in contact with a plant upon which it can live - which may, in the case of different species of dodder, be a plant of clover, hop, flax, or any one of a rather long list - it sends out small roots, or 
suckers, which push into the tissues of the host. The suckers grow until they reach the bast and wood of the host plant. Then they are in a position to rob the host of its manufactured food which is being transported in the bast, as
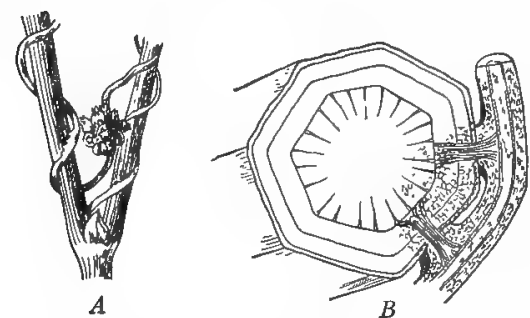

FIG. I I 2. $-A$, dodder growing upon a hop vine and bearing a cluster of flowers. $B$, a cross section of the hop vine, showing how the roots of the dodder grow into the host until they reach its bast and wood. After Kerner.

well as of the water and dissolved substances that have come up through the wood from the roots of the host. The primary root which attached the dodder to the soil now dies, as does also the lower part of the stem. The upper part of the stem grows rapidly, twining about the host plant, branching, and producing many suckers and great numbers of red flowers and fruits. But it forms no leaves, has no chlorophyl, and is entirely dependent upon the host for food. Some of the dodders are serious enemies of the gardener and of the farmer because of their attacks upon cultivated plants.

The mistletoes differ from the dodders in the fact that they have green leaves and so are only partly dependent upon the host plant. The European mistletoe is well known because its greenish branches, white berries, and evergreen leaves are much used for holiday decorations. It lives high up in the branches of trees, particularly of those trees which, like the poplars, firs, and apples, have a thin, soft bark. If a mistletoe seed germinates on a branch of such a tree, a slender sucking branch root pushes into the tissue of the host and grows until it reaches the wood. In the next year, new branch roots grow which run upward and downward within the bark of the host plant. From these branch roots 
new suckers are formed from time to time, which, like the sucker formed in the first season, grow inward through the tissues of the host until they reach the wood. Thus, while the suckers of the dodder take materials both from the bast and from the wood, the suckers of the mistletoe make connection only with the wood of the host, whence they absorb water and simple salts. Having green leaves, the mistletoe takes carbon dioxid from the air and manufactures for itself the more complex foods which the dodder takes from the host plant. The American mistletoes are similar to the European form in their manner of growth and of obtaining food, but are smaller plants. One of them is also used, though less extensively, for Christmas decorations.

Among the most remarkable parasitic plants are the Rafflesias and their relatives (Fig. $\mathrm{I}_{3}$ ). Their vegetative body consists only of a network of thread-like rows of cells, very much like the

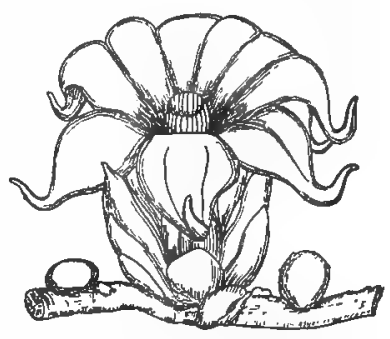

FIG. II3. - One of the RafHesia family (Brugmansia), growing as a parasite on the roots of Cissus. After Kerner. body of a fungus; this network lives and grows between the bark and the wood of prostrate stems and roots. The only part of the parasite that appears outside the tissues of the host is the large flower. That of one species of Rafflesia, found in Sumatra, is said to be the largest flower borne by any plant. When fully open, it has a diameter of three feet.

202. Mycorhizas. - A curious relation exists between many forest trees, including oaks, maples, poplars, and most of the conifers, and certain fungi whose branching threads are found living upon small branch roots of the trees. The fungous threads form a thick felt over the surface of a root; separate threads grow in between the cells of the cortex, and 
in some cases the fungous threads penetrate the root cells. It is thought by some who have studied these mycorhizas that the fungi are not, strictly speaking, parasitic upon the

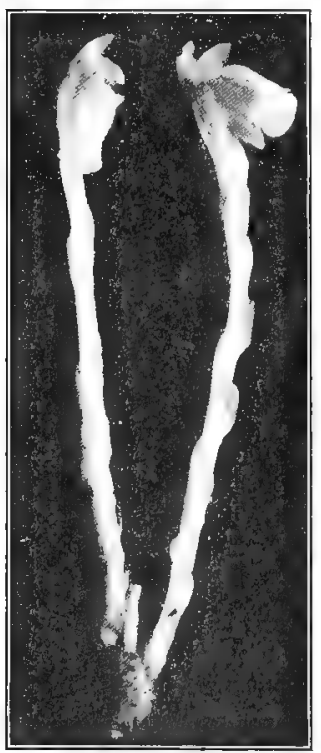

FIG. I I4. - The Indian pipe (Monotropa) ; a plant without chlorophyl, which lives upon organic substances in the soil with the aid of fungi which form a mycorhiza with its roots. trees; rather, there is a sort of partnership between a tree and the fungus living in its roots. The fungus finds a sheltered place in which to live, and probably also uses as food some of the substances in the root cells. On the other hand, it is thought that the fungous threads on the outside of the root assist the root by absorbing water and other substances, and so take the place of root hairs; it is not unlikely too that the fungus digests some of the organic substances, such as dead parts of plants, that are in the soil, and so changes them into a form which the tree can use as food. Thus, the tree seems to be indirectly saprophytic; with the aid of the fungus, it uses food materials which without such help would be quite useless to it. It is not only trees that enter into this kind of partnership with fungi; some herbaceous plants do the same thing. Among the latter are many members of the orchid family.

203. Roots of Epiphytes. - Epiphytes are plants that live above the ground on the surfaces of other plants, but are not parasitic upon them. Protococcus, when it lives on the trunks of trees, is an epiphytic alga. A good many mosses live on the trunks of trees. Epiphytic ferns and seed plants are found mostly on the trunks and branches 
of trces in tropical forests, where the air is always moist. Evidently there is not likely to be much soil nor a large supply of water in such places, although some water may accumulate in the crotches of the trees and in the hollows of the bark. Small amounts of dead material, such as leaves and parts of branches, may be cattght also among the branches and roots of the epiphyte, and by decaying there may supply on a small scale the substances that other plants obtain from the soil. Evidently the great problem for an epiphyte is to make the best possible use of such water and other food materials as may come to its roots. So we find that the roots of many epiphytes are especially well supplied with absorbing root hairs. The roots of some epiphytes, notably of tropical orchids, are surrounded by a special tissue composed of several layers of cells whose structure enables them

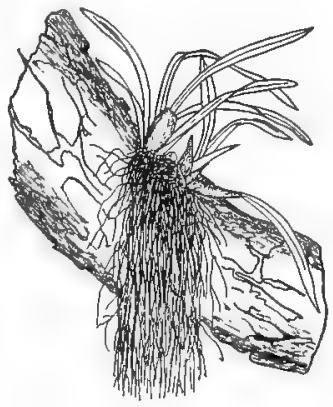

FIG. II5.-. In epiphytic orchid growing on the bark of a tropical tree; notice the abundant growth of roots. After Kerner. to absorb rain water and dew very rapidly and in large amounts and to pass the water on to the inner cells of the roots.

204. Direction of Growth of Roots ; Influence of Gravity. - If a young pea, bean, or corn seedling is removed from the soil in which it has started to grow and laid upon its side, the root soon begins to curve in such a way that finally its tip is turned directly downward. The curvature takes place a short distance back of the tip, in the region where the cells of the root are growing in length. Growth is faster on the side of the root turned upward than on the side turned downward, and it continues so until the tip is vertical. Plainly it is of advantage to a plant to have its root grow downward into the soil. But the fact that the plant is helped by this 
position of the roots does not explain how the roots come to grow in this particular way. A plant cannot choose to do a thing because that thing will help it. The direction in which a root or stem or other part grows is determined by the effect of outside influences upon the plant. An outside influence which can thus affect the growth or any other activity of a plant is called a stimulus.

The stimulus that has most effect in determining the direction of growth of roots is gravity. Most primary roots and adventive roots tend to respond to the stimulus of gravity by growing directly or almost directly downward. But branch roots coming from a vertical root do not as a rule grow straight downward; if they did, they would lie close beside the main root. As a matter of fact, branch roots grow downward but at an angle with the main root. Experiment shows that this difference in the direction of growth of branch roots is due to a different response on their part to the stimulus of gravity. The exact angle at which a branch root tends to grow varies with its position upon the plant and differs also in different species of plants. As a result of this tendency on the part of branch roots, they spread out from the main root and from one another, and the root system comes in contact with much more of the soil than it would if all the roots grew straight downward; the roots are thus in a position to absorb more water and other foods and the plant is more firmly anchored. However, if part of the main root is cut or broken away, one or more of the branch roots nearest the break will turn and grow straight downward. That is, the removal of part of the main root causes the branch roots to respond differently to the stimulus of gravity from the way in which they otherwise rould respond.

205. Responses to Other Stimuli. - While gravity is the stimulus chiefly concorned in most cases in determining the direction in which roots are to grow, it is by no means the 
only one. The actual position of a root is probably seldom exactly what it would be if gravity were the only stimulus at work. Most roots tend to grow away from the light. Most of them tend also to grow toward a supply of water, and some grow away from the air. Various substances in the soil may serve as chemical stimuli to roots; in some cases the roots grow toward.the substance in question; in other cases they grow away from it. The pressure caused by contact with a solid object, such as a stone, serves as a stimulus; the root bends, not necessarily at the point where it touches the hard body, but in the region in which its cells are growing; and the result of the bending often is that the root grows around an object that is in its way. The roots of parasitic plants like dodders and mistletoes, when they push into the tissues of a host plant, respond to a set of stimuli quite different from those which affect the growth of ordinary roots. Probably some of these are chemical stimuli and some are contact stimuli. 


\section{CHAPTER XV}

\section{STEMS AND BRANCHES AND THEIR USES}

206. Growth of the Stems of Seed Plants. - We have seen that, while new cells are being formed in the embryonic region at the tip of a stem, the older cells just back of the tip are growing longer. We have seen too that at the tip of the stem appear small swellings which are to grow into leaves and branches. The place on the stem at which a leaf (or a pair or circle of leaves) is attached is called a node; the part of the stem between two successive nodes is an internode. The swellings that will become leaves are at first very close together. The growth of the cells back of the tip pushes the young leaves somewhat farther apart and so lengthens the internodes. Some stems have little or no growth in length excepting this near the tip. Such a stem grows slowly and its internodes remain comparatively short. The stems of many palms grow in this way; but some of them live long enough and form enough short internodes so that they become tall trees. But in the stems of most seed plants growth continues for a time also in the older parts - that is, in the parts below the terminal bud. This growth is usually in the internodes, so that for some time the young leaves are pushed farther and farther apart. Growth of this kind is seen in the cucumber, the bean, the corn, and indeed in most of our common plants.

The length to which the internodes grow varies greatly in different plants; it is much affected, too, by the nature of the soil and by conditions of light, heat, and moisture. This is why, of two plants of the same variety grown under differ- 
ent conditions, one may be short and stocky, and the other tall and slender. The stems of some plants remain short for a time, because their internodes do not grow in length to any extent; then comes a period when the new internodes grow rapidly, forming a long, slender part of the stem. An example of this kind of growth is seen in the radish, whose foliage leaves are borne close together on the short lower part of the stem; the long upper part, that grows much later, bears the flowers. There are some plants whose nodes grow in length instead of the internodes; in the arbor vitæ (white cedar) the growth of the nodes stretches the bases of the leaves out along the stem; since the internodes remain short, the leaves are close to one another.

207. Nutation. - In a stem whose internodes continue to lengthen for some time, the rate of growth is not the same on all sides. At any particular time, growth is most rapid on one side of the stem and so the stem bends toward the opposite side. At a later time the region of most rapid growth is on a different side, and the stem is bent in another direction. The point of most rapid growth moves, as it were, more or less regularly about the stem. As a result, the direction in which the stem is bent is continually changing, and the tip of the stem swings around. Since the stem is steadily growing longer and pushing its tip forward as well as swinging it about, the movement of the tip is on the whole a spiral one. This movement of the stem tip is called nutation. Usually each internode, as it becomes older and ceases to grow, straightens so that the stem is not permanently twisted. Nutation is especially marked in climbing plants with twining stems, such as the bean and the morning glory. It is partly because of its nutation ${ }^{1}$ that a bean stem winds about any slender object with which it comes in contact. At first the coils of the stem are loose; but as each internode

1 The stimulus of gravity also plays a part in bringing about the winding of a bean or other twining stem. 
in time ceases to grow and straightens itself as much as possible, it is brought close against the supporting object. Therefore, the older parts of the stem are wound tightly about the support, but the younger part, including the internodes that are still growing, is loosely wound.

208. Stems of Different Forms. - There are many different kinds or species of seed plants which differ greatly in their ability to live and grow in different sorts of places. Some plants, such as the dandelion, have spread into many regions and many countries. But each kind of plant, nevertheless, can live only under a certain range of conditions, and as a rule this range is rather narrow. A plant that naturally grows on dry land will not usually live long if transplanted to a swamp; a tropical plant will not endure a cold climate. This means that each species is adapted to certain conditions of life; and different plants are adapted to different conditions by the different ways in which they are built up. Since various seed plants live under so many varying conditions in warm climates and in cold, in wet regions and in dry, on the soil, in the water, and perched high in the air upon other plants - it is not surprising to find great differences in the make-up of their stems as well as of their other parts. It is impossible here to speak of all the different forms of stems that seed plants possess; but some of the more common ones will be mentioned.

209. Herbaceous and Woody Stems. - Most of the smaller seed plants, especially those that live through but one growing season, have soft stems; this is because they contain comparatively little wood or other thick-walled tissues. Such plants are called herbs. Thè stems of other plants, particularly of those that live longer and grow to a large size, contain more wood and often a large proportion of other thickwalled tissues as well. Such stems are comparatively hard, and the plants to which they belong are called woody plants. A woody plant with an upright main stem that grows to a 
considerable height is a tree. One whose main stem remains short and gives rise near the ground to several branches is a shrub. The distinction between herbs, shrubs, and trees is an old and a convenient one, but it is purely artificial. One cannot distinguish sharply between herbs and woody plants, because practically all stems contain some wood and because there are all possible transitions between very soft and very

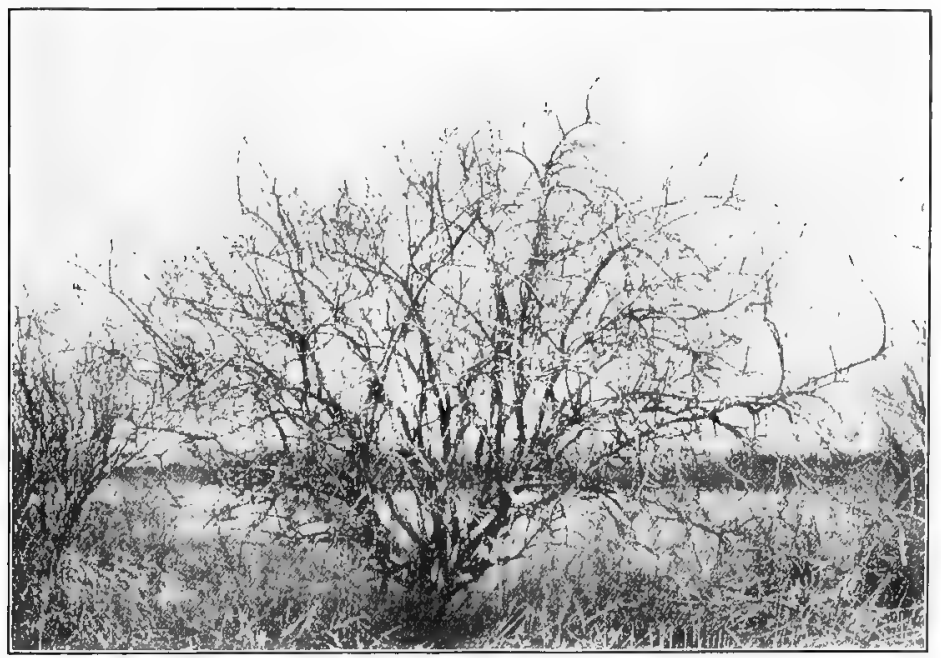

Frg. II6. - A shrub - the pussy willow (Salix discolor). Photograph by R. H. Denniston and G. Kemmerer.

hard stems. Likewise there is no hard and fast line between trees and shrubs. Some plants may grow either into trees or into shrubs, depending upon the conditions surrounding them.

210. Branched and Unbranched Stems. - Indian corn usually has no branches excepting the short ones that bear flowers - that is, the ears and tassels. Most other monocotyledons, like the corn, branch little or not at all above ground, except in their flower-bearing parts; although some, 
such as the lily, may form branches underground. The common greenhouse palms are familiar examples of plants whose stems ordinarily bear no vegetative branches. But their large flower clusters show that these stems, too, may branch. Indeed, it would be difficult to name a plant whose stem never branches under any circumstances; and it is only for the purpose of making a convenient distinction that the stems of most palms and of many other monocotyledons are said to be unbranched. On the other hand, the stems of most dicotyledons and gymnosperms branch abundantly. In its inner structure, and in the various forms that it may take, a branch of any plant is usually like the main stem, although there are certain special forms of branches that will be referred to later. It is often convenient to use the word shoot, meaning by it either a stem or a branch, together with the leaves and such other structures as it may bear.

211. Erect Stems. - The stems of a large proportion of seed plants grow upright and, whether herbaceous or woody, they form enough thick-walled tissue to support their own weight and that of their branches, leaves, and flowers. The great advantage to the plant of having an erect stem is that its leaves are carried upward and are separated so as to receive the greatest possible amount of light. We have already seen why light is necessary to green plants; and the effect of a partial lack of light is seen in the scarcity of small plants in a deeply shaded forest. An erect stem may be very much branched, like that of a pine; or, like that of a palm, it may be unbranched except in connection with a special purpose such as flower production. The shape of a plant with a branching stem depends in part upon the comparative rate of growth of the main stcm and of the branches. In some trees the main stem grows more rapidly, and consequently is always longer, than any of its branches. If all the branches of such a tree grow at about the same rate, the lowest, ones, being the oldest, are also the longest, and each branch is 
shorter than the one just below. Such regular growth is characteristic of most of the firs and spruces, and it gives to the crowns of these trees a symmetrical cone shape. The trunk of a pine likewise grows faster than its branches; but the branches do not grow at so even a rate, especially on an

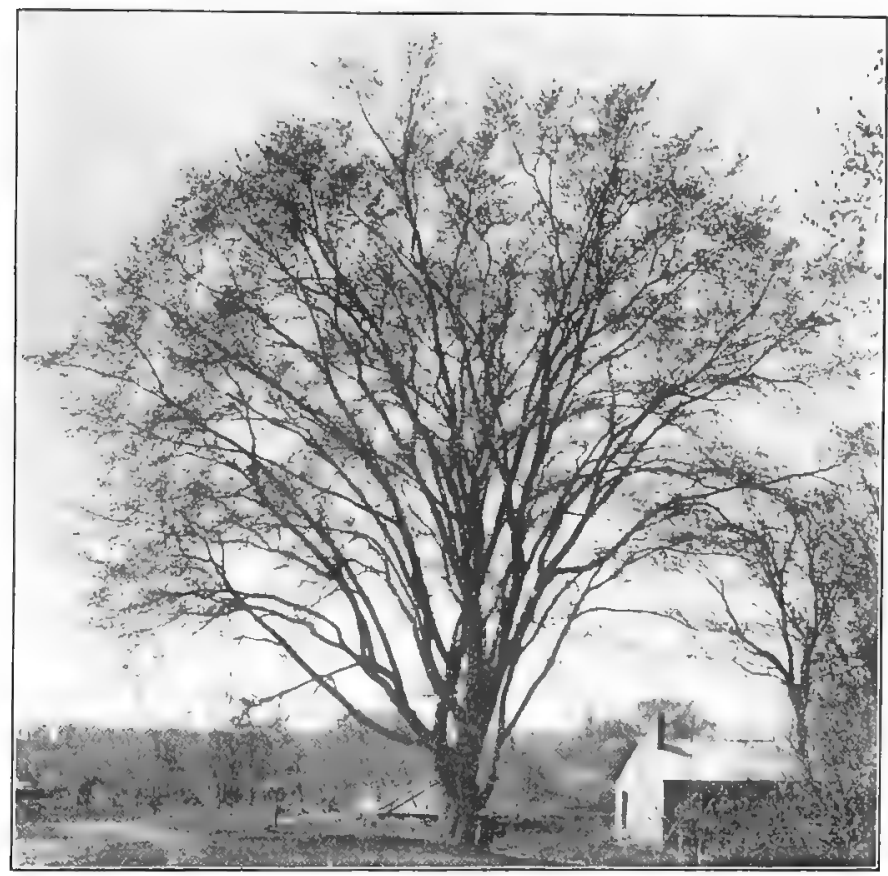

FIG. II7. - The white elm (Ulmus americana). Photograph by G. Kemmerer.

older tree, as do those of the firs and spruces. As a result, the crown of a pine tree, though conical in youth, is likely to become irregular in shape as it grows older. If the trunk does not continue to the top of the tree, but is replaced partway up by several large branches, the tree has a rounded crown such as is common in the oaks and maples. 
The form of a tree is also influenced by the angle at which the branches grow out from the trunk. If they are nearly horizontal like those of an oak, the tree has a broad crown; if they are nearly upright, as those of the Lombardy poplar

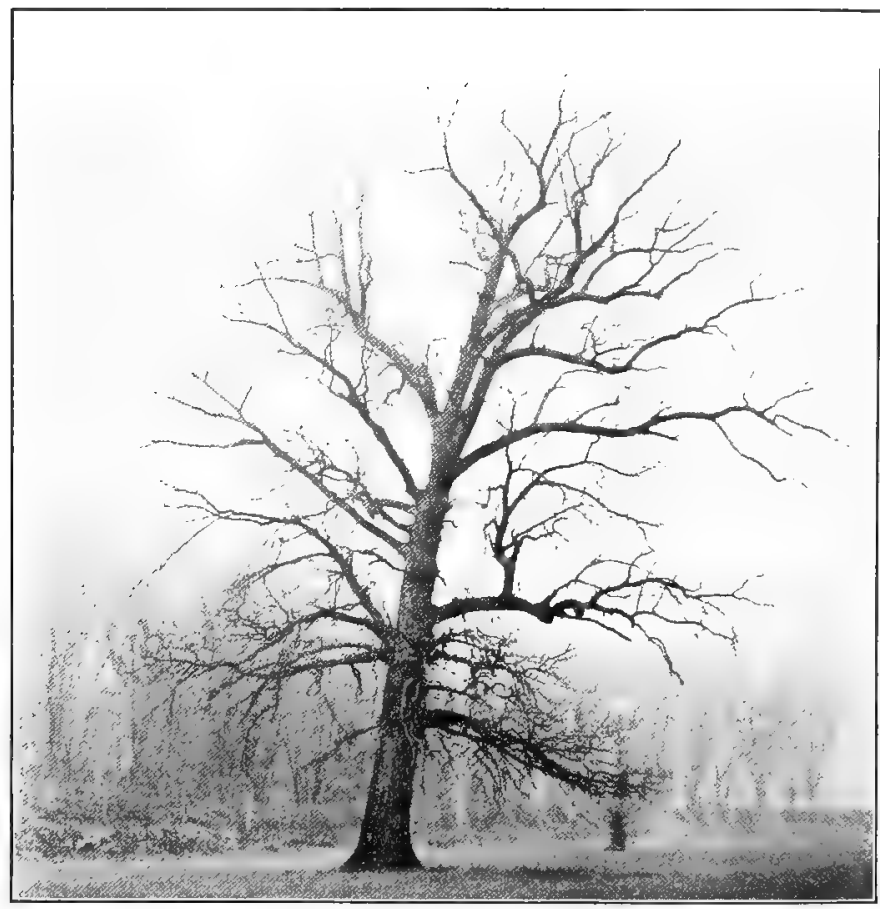

FIG. II8, - The swamp white oak (Qucrcus bicolor). Photograph by R. H. Denniston and G. Kemmerer.

are, the crown is narrow and cylindrical. Thus each species has a crown of characteristic form, which is determined by the factors that have been mentioned and by others, such as the number of the branches and their stiff or drooping habit. The same principles, of course, apply also to smaller plants with erect branching stems. 
212. Influence of Light. - One stimulus that affects the direction of growth of the parts of a plant is light. The stem of an erect plant responds to the stimulus of light by growing toward the point from which the light comes. If house plants stand near a window, their stems grow toward the window. Plants growing out of doors, unless they are close to a building or other large object, receive light from above and from all sides, but not from below; and as a result of the many-sided illumination they grow straight or nearly straight upward. But even an out-of-door plant does not at any particular moment receive the same amount of light from all sides. On a bright day, especially, the strongest light comes from the east in the forenoon, from near the zenith at noon, and from the west in the afternoon. If the growing parts of the stem react quickly to the stimulus of light, the position of the younger - that is, of the upper - parts of the plant will vary from hour to hour. The sunflower, whose head of flowers follows the sun in its daily course across the sky, shows plainly the tendency to grow in the direction of the brightest illumination. The older parts of the sunflower stem, which are no longer growing in length, are erect because in the long run they have received about as much light from the east as from the west, and about as much from the north as from the south.

The far-reaching effect of light conditions upon the growth of erect stems is seen in comparing the long, slender trunks of trees growing close together in a forest where they have been largely shaded by neighboring trees, with the shorter, thicker, much-branched trunk of a tree of the same species growing in an open field where it has been well lighted from all sides (see Figs. 64 and 65). The form of the forest tree has also been influenced by the early death of its lower branches whose leaves received too little light to enable them to make the food that the branches needed. 
213. Influence of Gravity and other Stimuli. - Stems that normally grow erect are affected also by the stimulus of gravity, but in a way opposite to that in which the same stimulus affects roots. This is shown by stems growing in darkness, like the shoots that grow from potato tubers which are stored in a damp, dark cellar. Such a shoot, even if in absolute darkness, still tends to grow upward, that is, in a direction opposite to that of the force of gravity. But its upward growth is often hindered by the fact that it is too slender and weak to hold itself erect, and so it may be only the growing end that turns upward. Ordinarily, the influence of light and that of gravity work in the same direction, and combine to induce stems to grow erect. But sometimes, as in the case of house plants standing near a window, these two influences work in different directions. In such a case the influence of light is usually stronger than that of gravity, and the plant becomes one-sided. The stimuli of light and gravity are not the only ones that affect the growth of erect stems and branches. It is probable that many other stimuli, such as moisture or dryness, air pressure, and changes of temperature, are of importance in connection with growth. Some of them certainly affect the rate of growth. But the effects of these and of other factors upon the direction of growth are not easy to study, because their influence is small in comparison with that of light and gravity.

214. Direction of Growth of Branches. - As a rule, the branches that come from an upright stem do not grow straight up; they grow either horizontally or more or less diagonally upward. The branches, like the main stem, are influenced in their growth by the stimuli of light and gravity. Probably most branches tend to grow toward the light. But since a branch is shaded more or less by the main stem and its leaves, as well as perhaps by other branches and their leaves, the stimulus of light alone would ordinarily cause it to grow, not directly upward, but in that direction from which it receives 
most light. The result of this tendency is that the branches are more or less spread out. If the upper part of the trunk of a tree is cut off, one (or more) of the uppermost branches turns and grows upward, because that is now the direction from which it receives most light.

The effect of the stimulus of gravity upon a branch is usually quite different from its effect on the main stem. Instead of tending to grow in a direction opposite to that of the force of gravity, as the stem does, the branch tends to grow at a right angle, or at some other definite angle, to the direction of the force. Thus the stimulus of gravity is an important factor in inducing branches to grow horizontally or diagonally. The final shape of a branch results from the combined effects of the stimuli of light and gravity (and in a measure doubtless of some other stimuli as well). The influences of light and gravity may have worked in the same direction, but oftener they have been more or less opposed, and the actual direction of growth of the branch is a compromise between the conflicting tendencies.

215. Hollow Upright Stems. - Many members of the grass family, such as wheat, have upright stems which are cylindrical and hollow except for a cross partition at each node. The outer solid part of the stem is thin, but it contains a large proportion of thick-walled cells. The stem is also supported in part by the bases of the leaves, each of which forms a sheath about the stem, extending for some distance upward from the node to which the leaf is attached. The stem is made still more stiff by silica, which is deposited in the walls of its epidermal cclls, and which makes the surface of the stem feel hard and harsh. Some grass stems contain so much silica that when one of them is burned a skeleton of silica remains that has the exact form of the stem. Grasses gain a great advantage from their hollow cylindrical stems, because this form gives the greatest resistance to sidewise strains with the use of the least material. The same mechanical principle 
is used in the building of bicycle frames, and in many kinds of machinery.

The largest grasses with hollow stems are the bamboos, which are inhabitants for the most part of tropical and sub. tropical countries, and some of which reach a height of 120 feet and a diameter of eight to twelve inches. Bamboo stems are best known to us by the fishpoles that are made from them. They also supply material for buildings, topes, mats, and kitchen utensils, and for a great variety of other uses. The grasses are by no means the only plants with hollow stems; very many annual plants have them. But as a family, the grasses have carried this principle of stem construction farther than any other group. Some plants, of which the sunflower is one, have the central part of their stems filled with a soft pith. This, so far as strength is concerned, amounts to much the same thing as having the stem hollow.

216. Trailing Stems. - As we have seen, a plant with an erect stem has the great advantage that its foliage leaves are carried up into the air, where they receive an abundance of light. There are localities, however, which are not suited to plants with erect stems. Such are the sides and tops of cliffs and of rocky hills, where the soil is too thin to allow of the growth of long roots, and where such plants as do grow are exposed to strong winds. Some plants with erect stems the red cedar, for example, and some shrubs and herbs do grow in such locations; but they are likely to be small and stunted and are usually few in number. In such situations we find other plants - such as the creeping juniper whose stems creep or trail along the surface of the ground. Trailing plants are not so much affected by winds as are upright plants; for this reason they do not need the support of long roots that penetrate deeply into the soil; and since, in locations like those described, they are not shaded by taller plants, their leaves receive the light that they need. In bogs, too, and in very sandy places, stuch as beaches, where 
the soil is too soft or too poor to support tall plants, we find many plants with trailing stems. The cranberry is a trailing bog plant. Some trailing plants also live in open woods; they are likely to form their flowers or their flowers and leaves very early in the spring, so that they ripen their fruits and even perhaps manufacture much of the year's supply of food before the leaves of the trees grow large enough to reduce their light. The trailing arbutus of the northern woods, whose flowers often open under the snow, is a trailing plant that has become adapted to life in forests.

Many trailing plants, as well as many erect plants, bear alternate leaves; but the stem of a trailing plant is likely to be twisted, so that, although the leaves borne at successive nodes really arise from different sides of the stem, the side from which any leaf arises is turned upward at that particular node. So, because of the twisting of the stem, all the leaves are in the most favorable position with reference to light. Usually the roots of a trailing plant grow in clusters at the nodes, and if by accident the stem is broken or killed between two nodes, the part on either side of the injured place becomes a separate plant. The power of multiplying in this way is important to a trailing plant, which because of its position is especially liable to injury. The branches of a trailing plant may also be separated and live as independent plants.

217. Climbing Stems. - Climbing plants, like trailing plants, can grow to a considerable length and can produce many leaves, flowers, and fruits without using a large amount of substance to build up a thick stem. The special advantage of climbing plants over trailing plants is that they can grow in the same localities that erect plants grow in, and so can compete with erect plants for access to sunlighta thing which trailing plants in general cannot do. Some climbing plants, such as beans and peas, are soft-stemmed annuals; others are woody-stemmed perennials, like the grape and the Virginia creeper. It is in tropical forests that woody 
climbing plants are found in largest numbers and grow to the greatest size. Running from tree to tree, they often form an inextricable tangle that reaches to the tops of the tallest trees. Many climbing plants, like the bean, have twining

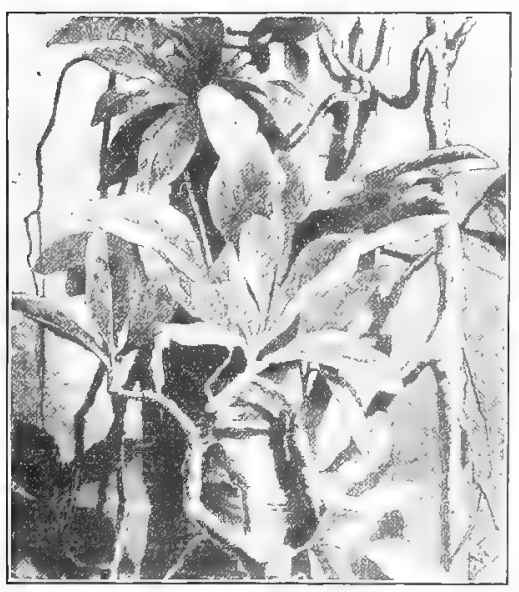

FIG. II9. - Climbing stem of a tropical plant. The branches grow into union where they touch one another, forming a lattice-work about the supporting stem. After Kerner.

are assisted in climbing by the possession of thorns or prickles.

218. Horizontal Underground Stems. - Many seed plants have underground woody stems. In some cases these stems are long and slender and grow horizontally from year to year like the stem of the bracken fern. The common may-apple (mandrake) has a stem of this sort. The parts of the plant that push above ground live for a single season, and the underground stem is the only part of the plant that lives from year to year. Adventive roots arise here and there upon the lower side of the stem. This stem, like an ercet stem, bears leaves; but they are small, dark-colored scales. In the axil 
of each leaf a bud is formed, which may grow either into an underground branch similar to the main stem, or into an erect branch that will push above the surface of the ground in the spring and bear leaves, flowers, and fruit. In the formation of such erect branches, the may-apple and many other seed plants with underground stems differ from the bracken fern, which sends only leaves above the surface of the ground. As in the case of the fern, the older part of the may-apple stem dies as the younger part grows.

In many plants, as for example in the Solomon's seal (Fig. I20), it is not an axillary branch but the end of the stem itself that turns upward and bcars leaves and flowers. The erect part of the stem dies in the fall, but the forward growth is continued underground by the last-formed axil-

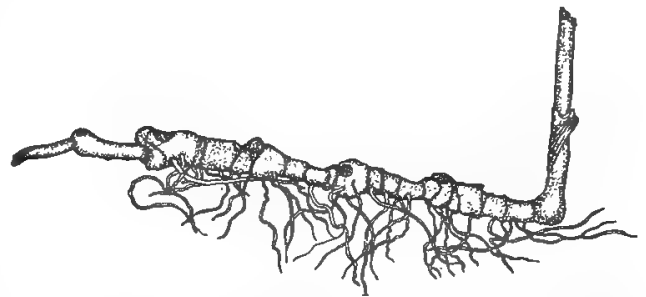

FIG. I20. - Underground stem of the Solomon's seal (Polygonatum), showing the joints that mark the growth from year to year, and the scars ("seals") left by the death of the upright shoots. lary bud. This

bud grows into a short branch that appears to be an extension of the main stem; the growing end of this branch in turn the next spring pushes up above the ground. The underground part of the plant, therefore, though it looks like a continuous stem, is really made up of a series of short branches. The large markings that give the name to the Solomon's seal are the scars left, one each year, by the death of the upright shoots. Many grasses and sedges are remarkable for their long, branching, underground stems. That of the quack-grass can be cut up into small pieces, each of which may become an independent plant. This is why quackgrass is so troublesome a weed. The formation of a sod by 
grasses is due to the interlacing of their underground stems and roots. Certain sedges and grasses have been largely planted on the dykes in Holland, and on sand dunes on the French coast which formerly drifted and were blown about, covering forests, houses, and even villages. The underground stems, branches, and roots form a tangle that binds the loose sand into a firm soil, in which trees may then be planted. The underground stems that we have been considering evidently do not respond to the stimulus of gravity in the same way that an erect stem does. On the contrary, they tend to grow at right angles to the direction of the force of gravity. But when an axillary branch or the end of the stem grows upward, it is because that part of the plant responds in the same way that the trunk of a tree does namely, by growing in a direction opposite to that of the force of gravity.

219. Other Forms of Stems and Branches. - The stems of most seed plants come within the classes that have been

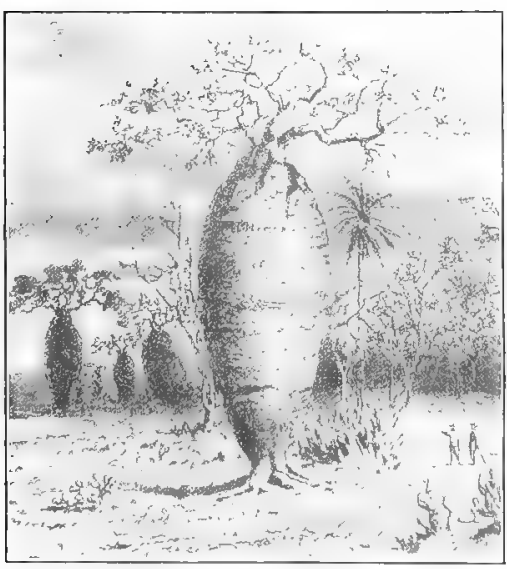

Fic. I2 I. - The "cotton tree," whose swollen stem serves for the storage of reserve food. After Kerner. described: erect stems, trailing stems, climbing stems, and horizontal underground stems. But now and then a stem or a branch takes on a form different from any of these. Some of the less common forms have already been mentioned. They are always of such nature as to meet a special need of the plant. Most stems contain tissues in which food is stored. This is especially true of thick, fleshy stems 
(Fig. I2I). But in some plants certain parts of the stem or of the branches are set apart as slorage organs, and several of the special stem structures that we have to consider are organs of this kind. Others are supporting organs, and still others serve as means of multiplication.

220. Bulbs and Corms. - A bulb consists of a short stem covered by fleshy leares; the leaves contain most of the plant's reserve food.
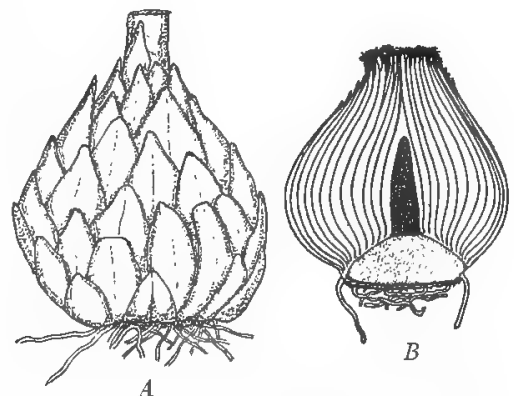

FIG. I22. - $A$, a lily bulb. $B$, the bulb of a hyacinth cut lengthwise through the middle. $A$ after Gray.

Some bulbs, like those of the onion, tulip, and hyacinth (Fig. I 22, B), have leaves so large that the outer ones completely cover the inner leaves. Others, including the bulbs of lilies (Fig. I22, $A$ ),

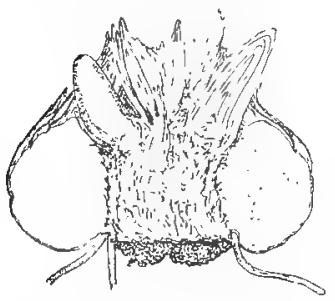

FIG. x23. - Gladiolus corms. Last year's corm, now dead and decaying, is in the center. On either side is a branch corm which is sending up a flowering shoot this year.

body like this is a corm. The jack-in-the-pulpit (Indian turnip) and the gladiolus (Fig. I23) also have corms. lap one another like the scales of a fish. "Multiplier" onions produce many branch bulbs in the axils of their bulb leaves. The crocus has a globular underground stem that sends up a flower-bearing shoot in the spring just as the onion bulb does. But this bulb-like body of the crocus is covered only by thin scales; nearly its whole thickness is made up of the stem, and most of the reserve food is stored in the stem instead of in the leaves. A

have smaller leaves that merely over- 
221. Tubers. - A potato tuber is the thickened end of an underground branch. Its "eyes" are buds, each of which is in the axil of a small scale leaf that may, however, be rubbed off uniess the tuber is very carefully removed from the soil. The "skin " of the tuber is a corky layer. Most of the cells within the tuber contain many grains of starch, which is the form in which the potato stores most of its reserve food. The "hilling " of a potato plant induces it to form more underground branches and so to increase the number of tubers. If, in hilling, a green branch that has been growing above ground is covered, this branch may form a tuber in the same way that a branch does which has been underground from the start. Sometimes, in an unusually cloudy, wet year, tubers are formed on the green branches that are entirely above ground. So it appears that the above-ground and underground branches are alike in being able to form tubers, and that the stimuli of darkness and moisture determine upon which branches tubers shall appear. When the other parts of the plant die, the tubers remain alive. They are therefore a means by which the plant lives over the winter and by which the number of plants is increased. As is well known, a whole tuber is not needed to produce a new potato plant; a tuber may be cut into several pieces, each of which, if it contains an eye, may give rise to a plant. Each bud grows out into a stem, which in turn produces leaves, adventive roots, and branches. Many other plants, less well known than the potato, bear tubers; among these are the Jerusalcm artichoke and the groundnut. The tuber of what is improperly called a "tuberous-rooted" begonia is really the base of the stem.

222. Permanently Green Stems. - The young parts of the stems of nearly all seed plants are green, and usually many of the outer cells retain some chlorophyl and manufacture some food for a long time - in the case of annual stems, often through practically the whole life of the plant. But 
as a rule, most of the chlorophyl is contained in the cclls of the leaves, which make much the greater part of the plant's carbohydrate food, the work of the stem being mainly other than that of food-making. There are plants, however, of which the asparagus (Fig. I24) is a familiar cxample, whose

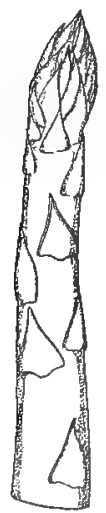

FIG. I24. - The tip of an asparagus shoot, showing the scale leaves in whose axils clusters of slender green branches will later appear.

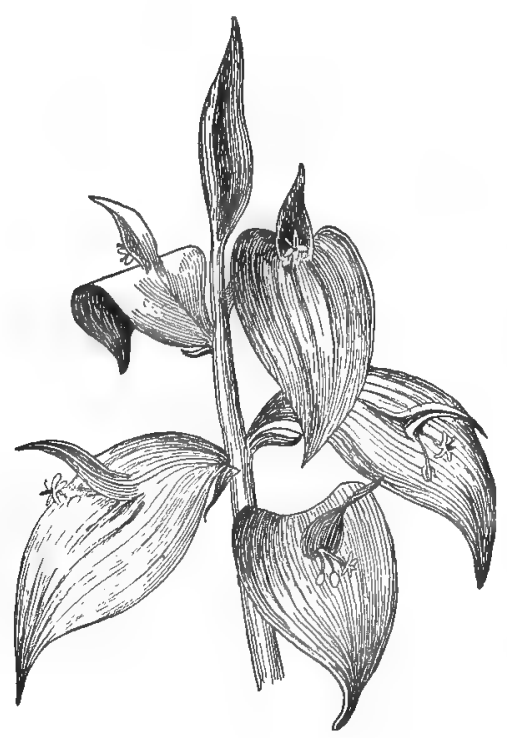

FIG. I25. - A shoot of Ruscus, with flat, green, leaf-like branches. Notice that these branches in turn may bear leaves and flowers. After Kerner.

leaves are reduced to scales or similar small structures, and whose stems and branches remain green and do most of the work of carbohydrate manufacture. When the young shoots of asparagus first push out of the ground, they bear only scale-like leaves; but if they are allowed to grow tall, from the axils of these leaves there grow clusters of fine, short, leafless green branches. Some plants, like the common greenhouse "smilax," have green branches that are broad 


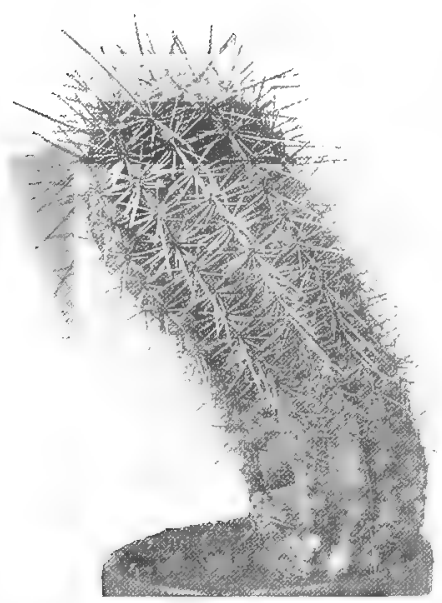

Fig. 126. - A cactus (Opuntia), whose stem is thick and green, and whose leaves are merely spines. and flat and look exactly like leaves; one can tell that they are branches only by noticing that each one grows from the axil of a scale-like leaf.

The thick green stems of the members of the cactus family and of some other plants living in very dry regions take on remarkable shapes. The leaves and most of the branches of nearly all cactuses are reduced to scales or spines. The advantage of such an arrangement will appear in connection with our study of leaves. The stems of cactuses not only manufacture and store food; they are organs for water storage as well, and are often an important source of water for travelers in the desert where these plants grow. The stem of the "nail-keg cactus" is said to yield sometimes as much as a pint of water.

\section{Runners. -} This name is given to certain branches (of the strawberry, for example) which sprawl on the surface of the ground, have long internodes, and

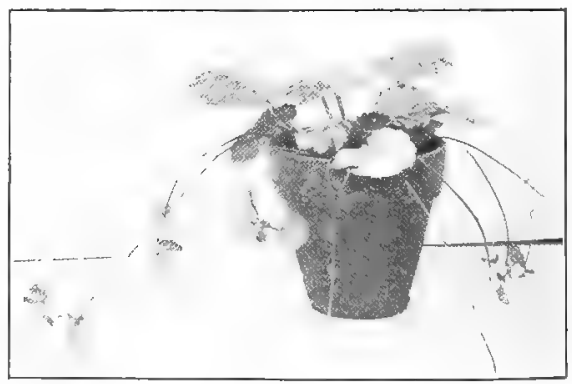

Fig. I 27. - The "strawberry geranium" (Saxifraga sarmentosit), which bears runners much like those of a strawberry. 
bear small lcaves. The large leaves that make most of the plant's carbohydrate food are borne on shorter, more erect branches. Each runner has a terminal bud which, under favorable conditions, can grow into a leafy shoot; and when the rest of the runner dies, the new shoot with the adventive roots that it bears is an independent plant. A new plant may be formed in a similar way from an axillary bud at any node of the runner. So the runner is a means of multiplication, because it gives rise to one or more new plants. A single strawberry plant may send out many runners, and thus in time come to be surrounded by a group of daughter plants. The white clover and some violets also multiply by means of runners.

224. Tendrils and Thorns. - Some plants have branch tendrils - that is, tendrils that are really branches; the greater number of tendrils, however, are leaf tendrils. Sometimes, in plants with branch tendrils, each tendril is a single long internode. This is true of the passion-flower. But in other plants, such as the Virginia creeper (Fig. I28, $A)$, a tendril consists of several nodes and internodes and may itself bear very small leaves from

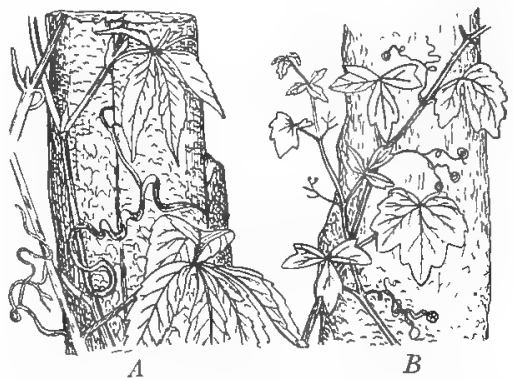

FIG. I28. - The Virginia creeper $(A)$, and the nearly related Japanese ivy $(B)$, showing how tendrils may assist in climbing. After Kierner.

whose axils grow branches that are also tendrils. It is not certain whether the tendrils of the cucumber and its relatives are branches or leaves. The growing point of a tendril, like that of a climbing stem, has a marked nutation. In addition, when any part of the tendril comes in contact with a solid object, the pressure acts as a stimulus that 
causes the tendril to grow more slowly at that point. Growth continues as before on the opposite side of the tendril, and as a result the tendril curves toward the object that it touches. As new points on the tendril come into contact with the object about which it is twining, growth is checked in the same way at those points, and so the curling continues until the tendril ceases to grow. Then the part of the tendril below the point at which it began to curl about the supporting object coils like a spring. This shortens the tendril and pulls the part of the plant from which it grows tightly against the support.

In the Virginia creeper and in some other plants (Fig. I28), when the end of a tendril touches a solid body it broadens

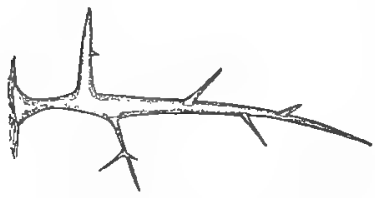

FIG. I 29. - $A$ branched thorn of the honey locust. out into a disk that fits closely into the cracks and uneven places in the support and so helps to hold the plant in place. These disks enable the plant to climb up the face of a wall or of a rock where there is no object slender enough for the tendrils to coil about. Thorns, like tendrils, are sometimes branches and sometimes leaves. They protect the plant from injury by making it unpleasant for animals to brush against or to eat it. Branch thorns are either simple like those of the hawthorn, the pear, and the blackthorn, or branched like those of the honey locust (Fig. I29). Many climbing plants, especially in the tropics, are assisted in climbing by thorns which are turned or curved backward and which catch in the trunks of trees.

225. The Strength of Stems. - Every erect stem that grows above ground is subject to strains that are severe in relation to the size of the plant. These strains result partly from the weight of the stem itself and of its branches, leaves, and flowers, which in the case of large trees amounts to 
thousands of pounds. There are strains due also to the pressure of the wind, to the occasional brushing of men and animals against the plant, to the fall of other plants against it, and the like. The strains brought to bear upon a stem are largely sidewise strains, and it must be able to give way more or less before a specially severe strain by bending without breaking, and must be able to straighten itself after the strain has passed.

Seed plants have met the need for this particular kind of strength in their stems by developing thick-walled cells that are longest in a vertical direction. The greater part of the trunk of a tree is composed of wood, and the wood, as we have seen in the pine, is made up largely of long, thick-walled cells, which help in strengthening the trunk as well as in conducting the sap. There are other long, thick-walled cells in the wood of the oak and of many other angiosperms (but not of gymnosperms), called wood fibers; as a rule these are narrower and shorter than the conducting cells. The fibers are strengthening cells but do not conduct sap. It is plain that if the various long cells in the wood ran crosswise instead of lengthwise of the trunk, the trunk would not be able to withstand the pressure of the wind but would be broken across by a relatively slight strain.

On the other hand, it is because these cells run lengthwise that the wood of a tree is easily split in that direction. We say that a split "follows the grain of the wood" - that is, it runs between the long wood cells, and if their course is for any reason twisted or wavy, the split surface is not smooth. A " knot" is a place in the stem from which a branch grew. At that point many of the wood cells of the stem ran diagonally or crosswise to connect with those of the branch; this crosswise course of many of the cells makes it difficult to split through a knot. Strengthening fibers similar to wood fibers occur also in the bast. In some plants these bast fibers are very long, and they are important elements in the strength 
of the stems of many herbaceous plants which, like hemp and flax, contain but little wood. The bark of the basswood (linden) likewise contains a large proportion of bast fibers. In addition to the strengthening cells in the wood and bast, many plants have thick-walled cells in their cortex. The runners of the strawberry, for example, have several layers of thick-walled cells just within the epidermis. Similar strengthening tissue is sometimes formed also in the pith.

226. Differences in Woods. - Everyone knows that the woods of different kinds of trees differ from one another in various ways. There are differences, for example, in hardness. Generally speaking, the wood of the pine and of other gymnosperms is comparatively soft; that of many common angiosperm trees, such as the oak, maple, walnut, and elm, is hard. But there are great differences in hardness between different angiosperm woods; and some, like the basswood, are as soft as the wood of most gymnosperms. Woods differ also in weight and durability. Differences in hardness, weight, and durability are to be found not only between woods of different species, but also between the woods of two trees of the same species that have grown under different conditions. By examining the structure of various woods, we can discover some of the causes of these differences in quality and can see why each kind of wood is useful for certain purposes and not for others.

227. Sapwood and Heartwood. - In most angiosperm trees, as in the pine, the older wood changes to heartwood. This is usually different from the sapwood in color, often harder and heavier because of changes that have occurred in its walls, and more durable because it is not so easily affected by decay-producing fungi. It is these qualities that make the heartwood valuable for building purposes. The time at which the change of saprood into heartwood begins to occur varies greatly. The oak begins to form heartwood early in life; the ash begins much later. When the change 
does begin, the sapwood is not turned into heartwood one ring each year as we might expect; but the thickness of the zone that is changed varies from year to year with the conditions of growth and with the age of the tree. The older the tree, the more rapidly the change takes place; for this reason, the zone of sapwood is narrower in old trees than in young

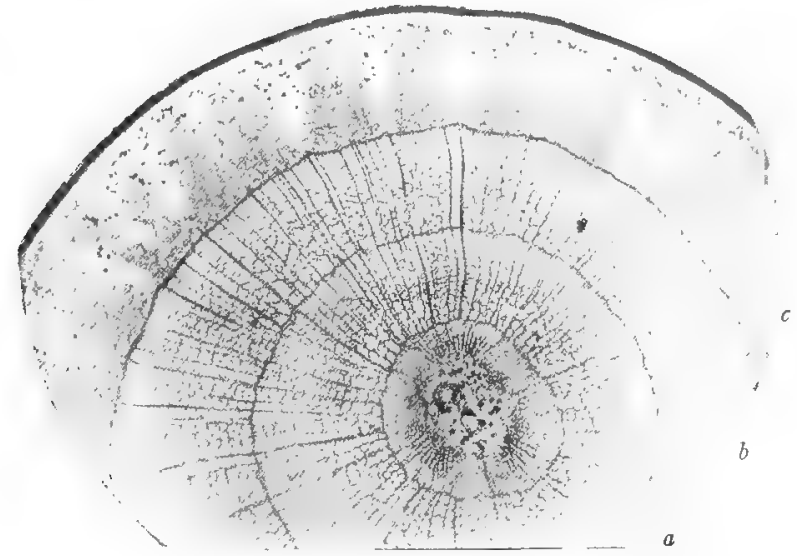

FIG. I30. - Part of a cross section of a three-year-old stem of basswood; $a$, spring wood formed during the past year; $b$, summer wood; $c$, bast. The large openings in the spring wood of each annual ring are sections of vessels.

ones. In some trees, as in the oak, the distinction between heartwood and sapwood is very sharp. This is especially true of the ebony, whose sapwood is white and its heartwood black. In some, including the ash, although the heartwood is harder and more solid than the sapwood, it remains of much the same color. In others, like the birch and the poplar, no material change of any kind takes place in the wood; it remains soft, light in weight, and unchanged in color.

228. Spring and Summer Wood. - Trees differ much in the thickness of their annual rings. Even in the wood of a single tree, some rings are much thicker than others. Differ- 
ences in the thickness of the rings might not affect the quality of the wood if the proportion of spring and summer wood in each remained the same. But if a thicker ring should mean a greater proportion of spring wood with its large, thin-walled cells, then of course the thicker the ring, the lighter and softer the wood as a whole will be. This is the case in the pine and in other gymnosperms. In good soil, well supplied with water, a pine tree grows rapidly; each annual ring is thicker than would otherwise be the case, and contains a greater proportion of large cells; consequently the wood is comparatively soft and light. But if the tree grows in poor or in dry soil, the annual rings are thinner, and since there are fewer large, thin-walled cells, the wood is harder and heavier. This rule, however, is modified by conditions of climate; thus pine trees grown in cold countries have thin rings, but their wood is comparatively soft. In angiosperm trees the effect of rapid growth is just the opposite of what it is in gymnosperms. The thicker the annual ring of an angiosperm, the greater is its proportion of summer wood. Therefore, an oak tree living under favorable conditions of soil, moisture, and temperature grows more rapidly and produces heavier, more solid wood than does a tree that grows under unfavorable conditions. The age of a tree also affects the thickness of its annual rings. The older the tree, the thinner are its rings. For this reason, a gymnosperm tree forms harder wood in its old age than in its youth; in an angiosperm tree, the laterformed wood is softer. In tropical countries, where the changes of season are less marked than with us, many trees (some Indian oaks, for example) continue to grow in thickness throughout the whole year. In such trees there is no distinction between spring and summer wood, and so of course there is nothing that corresponds to the rings that we find in the wood of trees of temperate countries.

229. Vessels. - We have seen that the sap passes upward in the pine trunk through certain long cells of the wood. 
The wood of angiosperms contains similar conducting cells, and with very few exceptions it contains vessels in addition. The wood of gymnosperms contains no vessels. A vessel is formed by a row of long cells whose walls are thickened and marked in the same ways as are those of the conducting cells already described. The cross walls between the cells disappear, and so the row of cells becomes a continuous tube. A

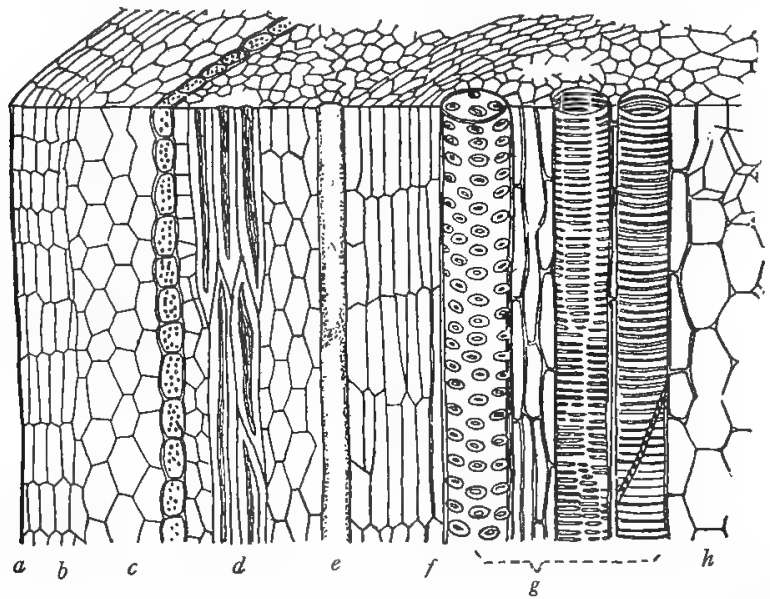

FIG. I3I. - A lengthwise section (diagrammatic) of a woody stem; $a$, epidermis; $b$, cork ; $c$, cortex; $d$, bast fibers; $e$, sieve tube; $f$, cambium; $g$, various types of wood cells; $h$, pith. After Kerner.

vessel is usually broader as well as much longer than a conducting cell. Both conducting cells and vessels die when they are fully formed, and so in any case it is through dead cells that sap passes from the roots to the leaves and flowers. The pores that are seen so plainly in cross sections of some woods are the vessels that have been cut across. Angiosperm woods differ much from one another in the number, size, and distribution of their vessels, and upon these points of difference the density and the strength of a wood very largely depend. For instance, while the vessels in a cross section of oak wood 
are visible to the naked eye, those in birch and willow are so narrow that they can be seen only with the aid of a microscope; but there are many more vessels in the wood of a willow than in the harder wood of an oak. The spring wood of the oak is made up almost entirely of vessels, the summer wood mostly of conducting cells and fibers. The vessels of the beech are scattered through both spring and summer wood. Those of the black walnut are in small groups; so are those of the ash, but here the groups are arranged in straight lines.

230. Medullary Rays. - These also differ much in different woods. Since they consist of thin-walled cells, the hardness and firmness of the wood are affected by the varying distances between successive rays, as well as by the thickness of each ray. Sometimes, as is often the case in the pine, a ray includes only one layer of cells. In other cases it is two, three, or several cells thick. Oak wood has two distinct kinds of rays, one very thin, the other thick. Rays also differ greatly in the distance to which they cxtend upward and downward in the trunk. In a board that is cut from a tree lengthwise, in such a way as not to pass through the center of the trunk, the medullary rays are cut more or less nearly straight across. If the board is so cut that it takes in the center of the trunk, the medullary rays are not cut crosswise but are parallel, or nearly so, to the surface of the board. A board cut in this latter way is quarter-sawed, and it is the markings due to the medullary rays that make quartersawed oak so beautiful a wood.

231. Milky Juices. - Some common plants, among them the milkweeds and the spurges, produce a white, sticky juice that runs out when a stcm or a leaf is broken. This juice is formed in certain long cells in the cortex of the stem and leaves. The liquid is a mixture of many substances. The milky juices of many plants, including the milkweeds, contain rubber. A good many tropical and subtropical trees and 
shrubs produce rubber in this way in large quantities. More than half the total supply of rubber comes from the Amazon Valley; the trees of that region whose juices yicld "Para rubber " belong to the spurge family. Gutta-percha, which is used for the insulation of electrical wires, especially in underground and submarine cables, as well as in the manufacture of hose, belting for machinery, golf balls, and in a variety of other ways, is obtained from the milky juices of some other tropical trees. The similar juice of a tree that grows in Mexico and Central America supplies chicle, the basis of most chewing gums.

232. Bark. - Each kind of tree has a bark of characteristic appearance. Think, in this connection, of the very different barks of the oaks, the poplars, the shagbark hickory, and the paper birch. The appearance of the bark of any trce depends in part upon the distance between the successive layers of cork cambium, and in part upon the planes in which these layers lie with reference to one another. If they are parallel or nearly so, broad bark layers are produced of even thickness, as in the case of the paper birch, whose successive layers of cork cambium are very near together. If the layers are not parallel but intersect one another, as they do in the oaks, the bark cracks into narrower pieces of various shapes. The thickness of bark depends largely upon the rate at which the cork cambium cells divide and upon the number of layers of cork cells that they form.

In the cork oak of southwestern Europe, which supplies the "cork" of commerce, a single layer of cork cambium remains active for several years. The first cork cells formed each year are flatter and darker than the later-formed ones, and so the whole thickness of cork tissue is marked off into layers, each representing a year's growth. This division into layers may be seen in large bottle corks.

Sometimes the true bark (that is, the layers of cork and other cells lying outside the cork cambium) is called "dry 
bark," and the layers of cortex and bast that lie between the cork cambium and the cambium proper are called "green bark." The dry bark protects the living tissues within from injuries by insects and larger animals; from infection by parasitic fungi; from the too rapid loss of water by evaporation, and to some extent from the effects of extreme cold. A wound that penetrates the bark and injures the tissues beneath is healed (provided it is not too extensive) by the growth and division of the living cells of the various tissues (cortex, bast, medullary rays, cambium, and wood) that are in contact with the wound. Ultimately bark is formed over the surface of the new wound tissue. "Girdling" consists in removing a strip of the bark and inner tissues down to the wood. If the girdling extends all the way around the trunk, the movement of food through the bast from the upper part of the tree to the roots is cut off ; in time the roots, being starved, will die, and the tree will be killed.

The bark of many trees contains large amounts of tannin, which is used in the curing or tanning of leather. The bark, first stripped from the tree, is so treated as to obtain from it a solution which contains the tannin as well as some other substances that affect the quality of the leather. Tanbark is obtained in largest quantities from the hemlock and the oaks; but the barks of the larch, willows, and other trees are also largely used, as well as various woods and other parts of plants, each producing a leather of a particular quality or color. Another important bark product is quinin, obtained from several species of trees belonging to the genus Cinchona. They are natives of South America, for which reason the bark is called "Peruvian bark" ; but there are Cinchona plantations in other warm countries as well. The drug cascara is obtained from the bark of a tree that grows near the Pacific coast from California to British Columbia.

233. Lenticels. - The surface of the trunks of many young trees, such as willows and poplars, is marked by small 
yellowish or brownish spots or ridges. If one of these spots is examined, it is found to have been caused by a break in the outer surface of the bark, through which a mass of the inner tissue has pushed out. Such a break in the bark is called a lenticel. It results from the formation by a cork cambium layer of a loose cushion of cells whose walls are not corky. The pressure of this cushion bursts the outer layers of bark. Through the opening so made, and through the spaces between the cells of the cushion, the air penetrates to the inner cclls of the cortex. If it were not for lenticels, the bark would cut off the living cells within, many of which still contain chlorophyl, from any supply of oxygen for respiration or of carbon dioxid for carbohydrate manufacture. As the bark grows thicker and its outer layers pecl off, new lenticels are not usually formed. But some trees with thin, smooth bark, like the paper birch (Fig. I32), continue to form lenticels even on the older parts of the trunk.

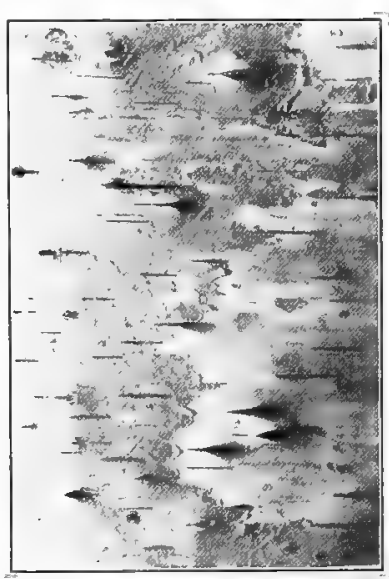

FIG, I32. - A piece of birch bark; the horizontal dark streaks are lenticels.

234. Buds. - We have already seen something of the structure of buds. A bud always contains the growing end of a stem or branch; if in addition it includes only young leaves and the small buds in their axils, it is a leaf bud; if it includes a flower or flowers, whether or not it contains leaves also, it is a flower bud. A flower bud, like a leaf bud, may be terminal or axillary. Often a flower bud can be recognized by its appearance; for example, the leaf buds of the apple tree are slender and pointed, the flower buds are thicker and rounded. When a bud is torn apart, one is often surprised to 
find how many different things have been wrapped up in so small a space. Thus the flower bud of the lilac contains the beginnings of many leaves and of a whole flower cluster, including perhaps a hundred or more flowers.

As a rule, a single bud is borne in the axil of each of the leaves on a stem or branch. There are exceptions to this rule, such as the asparagus, which has a cluster of short

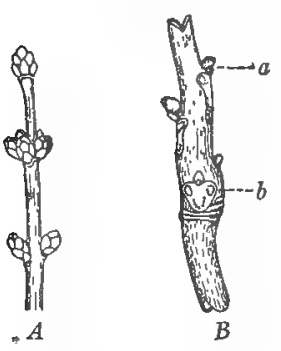

FIG. 133. $-A$, portion of a lilac stem, with a terminal bud and the four uppermost axillary buds. $B$, portion of an Ailanthus stem with accessory buds at $a$, only one of which will develop. Notice the conspicuous bundle traces in the leaf scar at $b$. branches (each developed from a bud) in the axil of each scale leaf. In general, the upper axillary buds, that is, those nearest the terminal bud of the stem or branch, are larger and more likely to develop than the lower ones. The difference in size between upper and lower buds is very marked in the lilac. The buds of an annual plant, like the cucumber, must develop very soon after they are formed, if they are to develop at all. Such buds have no covering for the young leaves, branches, and flowers that they contain. But perennial plants in temperate and cold countries form buds which must rest through the winter, and so require protection against the cold. Such buds are covered by scale-like leaves that never become foliage leaves but that usually fall off in the spring when the buds open. The grape and some other perennials form some naked axillary buds that develop at once, and other scaly axillary buds that rest throughout the remainder of the year in which they were formed and develop the next spring. But many perennials, including the lilac, the apple, and most trees, bear only scaly buds in their axils, which rest without further growth until the next spring.

As a rule, the terminal buds of a perennial plant grow con- 
tinuously during warm weather, and are then naked; but when they stop growing, upon the approach of cold weather, they form scales that cover and protect them until the next spring. This, as we have already seen, is the history of the terminal buds of the pine. By tearing apart a winter bud of the horse-chestnut, one gains a very good notion of the structure of buds in general and of scaly buds in particular. On the outside are thick scales that overlap and are held together by a sticky, varnish-like substance that covers their surfaces. The scales within the outer layer are thinner, and those farther in are more and more like ordinary leaves; in the center, finally, are the small, delicate leaves that will spread out and become green when the bud opens. In the spring the sticky substance that holds the outer scales together becomes soft, the scales separate and turn back, and the inner part of the bud grows out into a leaf-bearing branch. The scales and their varnish-like covering not only protect the young inner parts of the bud against the cold, but also prevent the evaporation of water from the bud. This is important at a time when, as in the winter months, the roots cannot obtain water from the soil.

235. Induced Growth of Buds. - In most plants only a very small proportion of the axillary buds actually develop into branches. If the terminal bud of a stem or branch dies or is destroyed, the axillary bud or buds just below the terminal one commonly grow out into a long branch or branches. This happens regularly in many shrubs. . For example, all the terminal buds of the lilac die each fall; in the spring the two uppermost axillary buds of each shoot - which are directly opposite each other-grow into upright branches. If the end of the shoot, including its upper axillary buds, is killed or cut off, some of the axillary buds below the killed region will grow into branches. As has been said, gardeners remove the tips of cucumber shoots to induce the plants to branch more freely than they otherwise would, and so to pro- 
duce more fruit. Apple and other fruit trees are pruned, both to obtain more compact, better-shaped trees, and also to cause the formation of less wood and more fruit.

In the cultivation of wheat it is especially important to encourage the development of axillary buds. In the axils of its lower leaves a wheat plant bears buds, each of which may develop into a stalk that ends in a head of grain. If the axillary buds do not develop, each plant has but one stalk and one head. Winter wheat, which begins its growth in the fall, develops slowly. Its axillary buds remain close to the damp soil, send out adventive roots, and so, being supplied with food, grow into fruitful stalks. But spring wheat, whose seed germinates in the spring, grows more rapidly. Its axillary buds are carried up quickly above the surface of the ground, and so are less likely to form roots and to grow into stalks. However, if the wheat ficld is rolled soon after the seeds have germinated, the young plants are buried more deeply; their axillary buds remain for a longer time in or close to the soil, form roots and stalks, and so the number of grain-bearing heads on each plant is increased.

Brussels sprouts are the axillary buds of a variety of cabbage in which these buds develop instead of the terminal bud that in other cabbage varicties grows into a single large head. The development of the axillary sprouts is encouraged, not in this case by destroying the terminal bud, but by removing the leaves in whose axils the buds are borne. The tiger lily bears bulb-like axillary buds, each of which may grow into a now plant. The bulblets of "top onions" belong in the same class.

236. Adventive Buds. - These may appear on practically any part of the plant - on the stem or branch, on a leaf, or on a root. Very often they develop in response to the stimulus of a wound. Plants differ greatly in their ability to producc adventive buds. It is plain that a plant which reacts to a wound stimulus by forming many adventive buds has 
an excellent means of replacing lost parts and sometimes of multiplying its numbers under unfavorable conditions. The branch that grows from an adventive bud is an adventive branch. New branches often appear upon the trunk of a tree about the place from which a branch has been removed. Often the new branches are adventive branches. But this is not always the case; for it has been found that the axillary buds of many forest trees can remain alive under the bark for a long time, in some cases even for years, without developing. Some of the new branches, therefore, that grow from the neighborhood of wounds, may come from resting buds that were originally formed in the axils of leaves.

When a branch is cut back, also, it often sends out several or many side branches, some of which may come from adventive buds and some from resting axillary buds. This tendency of trees when cut back to form new side branches is taken advantage of in the pruning of shade trees to secure a symmetrical top, in the production of dwarf trees and trees of various unusual forms, and in the trimming of ornamental shrubs and hedges. If the top of a willow is cut off, many new branches appear just below the cut surface and grow into a new compact head. What is called coppice growth results from the cutting off of the trunks of good-sized trees at the surface of the ground. The numerous adventive shoots that start are allowed to grow to the desired height and are then cut, to be used in basket-making, for small firewood, and for many other purposes, varying with the kind of tree from which they come. The removal of the first lot of shoots is followed by the growth of a new lot, and so the same root system serves for the rapid production of many crops. Various kinds of injuries - those caused, for example, by bruises, by biting and boring insects, and by the growth of the parasitic fungi that form "witches' brooms " - may furnish the stimulus for the development of adventive buds and branches. 
237. Hairs and Similar Structures. - Hairs, which appear upon many stems, are best studied in connection with leaves, upon whose surfaces they grow in great number and variety. Like root hairs, the hairs of stems and leaves, as well as those that are often borne on sepals, petals, and other flower parts, are outgrowths each of a single epidermal cell. A hair sometimes remains single-celled; sometimes it becomes a row of cells; sometimes it is branched. When present in large numbers, hairs form a felt over the surfaces of stems and leaves that helps to check the evaporation of water. Many plants which, like the mullein, grow in extremely dry soil, have very hairy stems and leaves. Winter buds are often protected by hairs as well as by scales. Sometimes the hairs form a woolly outer covering for the bud; sometimes they are inside the protecting scales. The prickles of roses, raspberries, blackberries, and gooseberries are like hairs in that they grow from the surface of the stem; but some of the cells below the epidermis, as well as the epidermal cells themselves, take part in their formation. These prickles protect the plant against injury by animals, and also, by penetrating objects with which they come in contact, help the stems of some plants, such as climbing roses and the hop, in climbing. Prickles look like thorns and serve much the same purpose; but that they are different in origin is shown by the fact that they come off with the bark when the latter is peeled off, while thorns (being either leaves or branches) do not.

238. Length of Life of Stems. - The stems of many plants live only through the growing season of a single year. Such short-lived plants are called ammuls. The cereal grains are all annuals. So are cucumbers, peas, beans, and many other garden plants. But some garden plants, like the cabbage, carrot, and beet, and many wild plants, have stems that live for two seasons. Such plants are bicnnials. A biennial bears no flowers during the first year of its life; 
it grows and stores away food (in the carrot and beet this is stored in large quantities in the root); in the second year it sends up a flower-bearing shoot, forms seeds, and then dies. There are some plants that live more than two years, but which, like biennials, flower oniy once in their life and then die. Bamboos belong to this class; so does the century plant, which is said to live from ten to fifty years before it bears flowers. The plants of another large class live for many years and bear many sets of flowers. These are perennials.

The long life of a perennial is due to the fact that it continues to grow and produce new tissues as its older parts die. It is not true that any one particular part of the plant lives for many years; the parts of an old plant that are now alive may be only a small fraction of the tissues that the plant has produced. In an old tree, for cxample, the heartwood, which makes up a large part of the bulk of trunk, branches, and roots, is dead. So are most of the full-grown cells of the sapwood, as well as all the cells in the outer part of the bark. In the case of a plant with a long underground stem, like the may-apple, the older parts of the stem and of the branches are steadily dying. Most annuals are herbaceous plants. Most perennials are woody, or at least the parts that live for more than a year are woody.

239. Limits of Life of Perennials. - A plant can live only so long as food substances can be carried between the absorbing root hairs (borne just back of the root tips) and the living tissues of its stem, branches, and leaves. The root tips of a tree or of a climbing plant are continually pushing farther into the soil, and the younger parts of the stem and branches which bear most of the growing buds and leaves are growing farther upward and outward. So, as the plant grows older, water must be carried farther, and it becomes more and more difficult to supply water to the growing parts. In time the supply of water will fall off, and as a 
result the growth of buds and the formation of new leaves will become slower; and the plant, poorly supplied with carbohydrate food because of its fewer leaves, will grow weaker and finally die. Thus an erect or climbing plant has a fairly definite limit of life, although the limit is very different in different species.

It is otherwise in plants with creeping or underground stems. The older parts of these stems with the roots at-

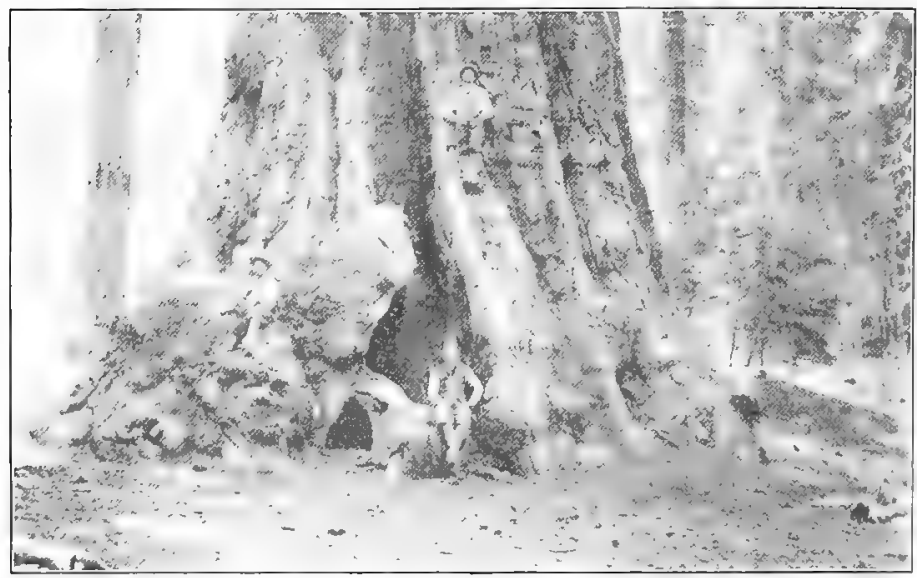

FIG. 134. - The base of one of the giant redwoods of California. Photograph by Squires.

tached to them are constantly dying; but the younger parts grow steadily forward, sending out new roots as they grow. So there seems to be no necessary limit to the life of plants such as these; so far as we know, a plant with a creeping or underground stem might live indefinitcly if the surrounding conditions remained favorable. Practically, the lives of most perennials are more or less shortened by injuries and by disease, and few if any reach the extreme age or the extreme size which would be possible if they remained perfectly healthy.

240. The Largest and Oldest Plants. - The tallest known trees are the gum trees of Australia; some of them reach a 
height of 500 feet. Next to these are the giant redwoods of California, the tallest of which are over 460 feet high. These figures, however, are excecded by those of the length of some of the woody climbing plants of tropical forests; thus rotang palms (from which rattan is obtained) are said sometimes to

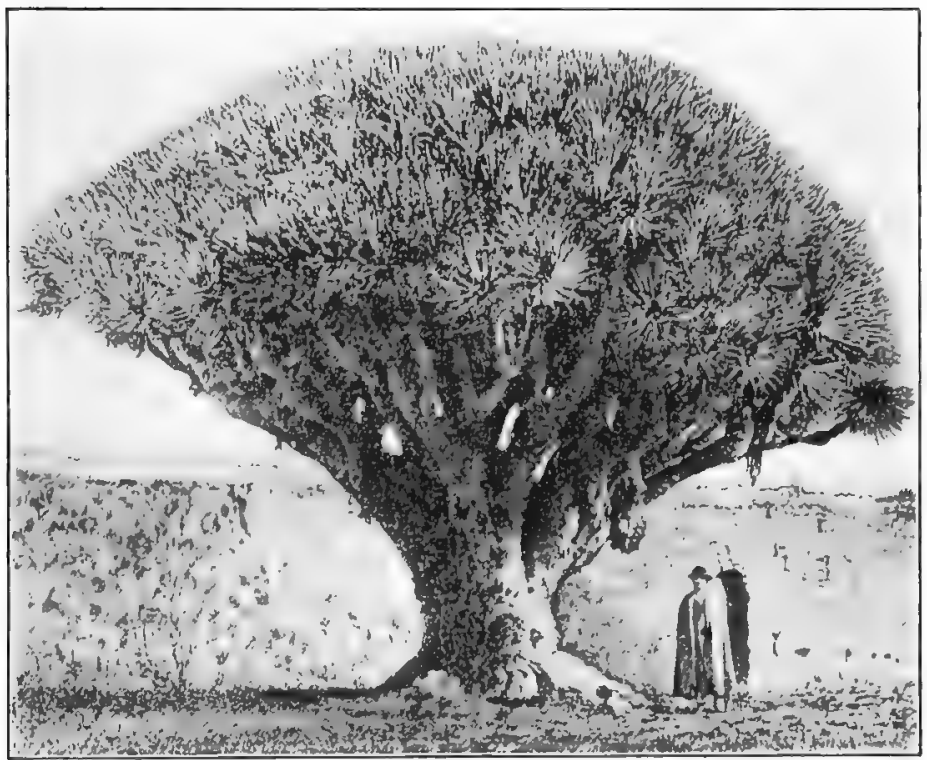

Fig. 135. - The "dragon tree" of Teneriffe. A member of the lily family. which, like a few other monocotyledons (including the palms), has a special method of growth in thickness and so is capable of developing into a tree. After Smalian.

grow to a length of nearly I 000 fect. The tallest trees are not the thickest ones. The diameter of the largest redwoods is not over thirty-five feet; that of the Australian gum trees does not exceed twenty-five feet. The European chestnut, however, though much shorter, may grow, it is said, to a diameter of over fifty feet. A famous bald cypress near Oaxaca, Mexico, has a diameter of a little more than fifty 
feet, six feet above the ground. Aside from conifers (including the redwoods), probably the largest tree in the United States is a sycamore at Worthington, Indiana, which is about I 50 feet high and 42 feet in circumference five feet above the ground. The ages of various large trees have been estimated at 4000 or 5000 years, and one famous tree, the "dragon tree" growing on the island of Teneriffe (Fig. I35), was said to be 6000 years old. Such estimates seem to be much exaggerated. There is evidence that the giant redwood, the true cypress, and the yew may live about 3000 years, and that the chestnut, one of the oaks, and the cedar of Lebanon may live 2000 years. Probably not much greater ages have been reached by any plants now living.

241. The Smallest Seed Plants. - These are members of the genus Wolffa. The common Wolffias of the United States and Canada consist each of a rounded green body which floats in ponds and lakes and is so small (at most not more than a sixteenth of an inch in diameter) that it may easily be taken for a minute seed. The rounded mass of cells is a stem, which branches by forming another small group of cells within a sort of pocket. The branch breaks away and becomes an independent plant. There are no leaves or roots, and each plant may bear two simple flowers, one consisting of a single stamen, the other of a single pistil.

242. Grafting. - It has been known since very ancient times that parts of two plants may be made to grow together into what is practically a single plant. In most cases the process of grafting consists in attaching a bud or small shoot (called the scion) from one plant to a plant or to the lower part of a plant of another sort, which is called the stock. The advantage of grafting varies in different cases. Sometimes a cultivated plant bears no seeds or its seeds do not germinate well, and it cannot easily be multiplied by other vegetative means, such as by layerings or cuttings. Scions of such a plant may be grafted upon stocks of less desirable 
varieties that are easily raised from seed. Sometimes a valuable plant produces seeds abundantly, but its seeds do not " come true." For instance, the sceds of our cultivated apples are likely to grow into trees whose fruit is very unlike, and usually poorer than, that of the parent tree. For this reason, apple seedlings can be used only as stocks, upon which may be grafted scions of the variety desired.

Sometimes grafting is used for a fruit that is not well adapted to the conditions of the region where it is to be raised. Thus, in the southern United States the plum is grafted upon the peach, whose roots grow better in sandy soil than do those of the plum; and in Russia, apple scions are grafted upon stocks of the Siberian crab-apple, which is better adapted to a severe climate. Sometimes the habit of growth of the scion is affected by the character of the stock. Thus dwarf pear trees are obtained by grafting the pear upon a quince stock. The quince has a small, slowly growing root system, which supplies soil materials slowly to the scion; as a result, the growth of the scion is slower than it would be if it were growing upon its own roots. It is only by some influence upon its food supply that the stock can affect the growth of the scion. Stories are told of changes of other sorts caused by the influence of the stock, for example in the color or flavor of the fruit or in the shape of the leaves of the scion; but such stories seem to be unfounded.

No one can tell, except by trying, whether a plant of a particular variety or species can be grafted upon one of another variety or species. As a.rule, a graft is more likely to be successful the more closely the stock and scion are related. In some cases, grafting is possible only between two closely related varicties; in others, it may be carried on between two species of the same genus; and some successful grafts have been made between members of different genera. Grafting is usually practiced with woody plants, especially with trees. Many herbaceous plants can be grafted, how- 
ever, and it is sometimes done, as for cxample with chrysanthemums, in order to have two or more kinds of flowers on the same plant. With a few exceptions, monocotyledons have not been grafted successfully.

243. Methods of Grafting (Figs. I36, I37). - The important fact in the actual work of grafting is that only like tissues will grow into union with one another; that is, bast will unite with bast, wood with wood, and cambium with
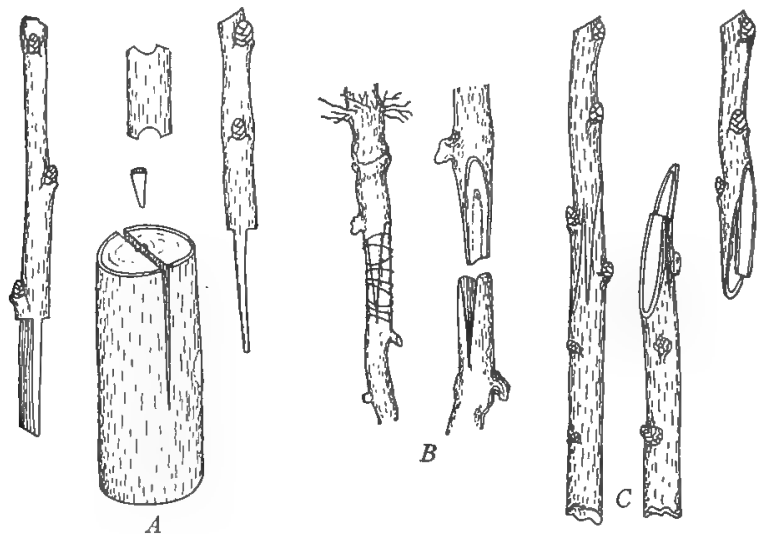

FIG. I36. - Various methods of grafting: $A$ and $B$, two forms of cleft grafts; $C$, a whip graft. After Gaucher.

cambitum. So, in making a graft, one must match the tissues of the scion with the corresponding tissues of the stock. Especially must cambium be matched with cambium. It is also important that a close joint be made and that the place of union of stock and scion be protected, ustually by graftingwax, until the wounded tissues have healed. Of the many methods of grafting that have been devised, only a few of the commoner ones will be mentioned. In a cleft graft the stock is split, and the scion, trimmed to a wedge shape, is inserted in the split. This method is largely used in the grafting of fruit trees, when the graft is made some distance 
above the surface of the soil. Bark grafting is similar, excepting that the split is made between the bark and the wood of the stock; it is used especially in grafting to rather large stems or branches. In a whip graft, used with small stocks in nurseries, both graft and scion are trimmed only from one side to a wedge shape (a split or tongue being left in the middle) and are fastened together with the cut surfaces in contact. This method is used also when the scion is attached directly to the root of the stock, as is often done with apples in the western United States. In a veneer graft,
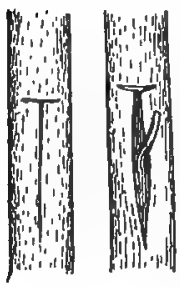

A

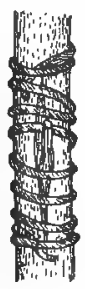

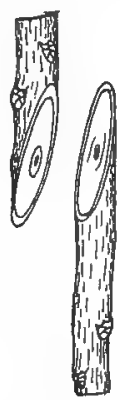
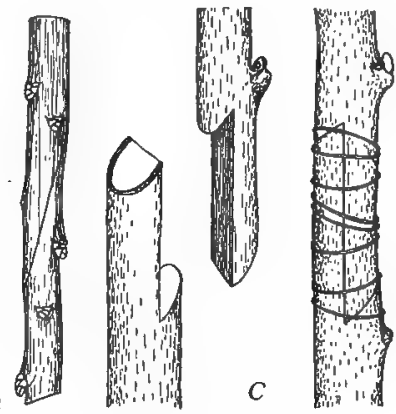

FIG. 137. - Various methods of grafting: $A$, budding; $B$, a contact graft; $C$, a form of saddle graft. After Gaucher.

the stock and scion are trimmed off slightly on one side, and the cut surfaces are placed together. This method is used largely. with ornamental greenhouse plants. Sometimes branches of two plants are attached, first being trimmed off slightly at the point of contact and allowed to unite while each is still growing upon its own roots. When the union is complete, the scion is separated from its root. This method is called inarching. Budding is practiced with small stocks, usually not more than a year old; the scion, a bud with a small strip of bark attached, is inserted into a slit in the bark of the stock. Apples, cherries, and other fruits are largely multiplied in nurseries by budding. 


\section{CHAPTER XVI}

\section{LEAVES AND THEIR USES}

244. Growth of Leaves. - As a general rule, a leaf differs from a branch in the fact that it can grow to about a certain size and no larger. While a leaf is enclosed in the bud, the cells divide but the leaf remains small, growing very slowly. Long before the leaf unfolds, its cells have ceased to divide; the leaf has all the cells that it ever will have. Thus the leaf remains with no further perceptible change until warm weather comes in the spring, when its cells begin to grow again, chiefly by the taking in of water; little new living matter is manufactured. The absorption of water can go on rapidly, and this is why leaves unfold and grow so quickly in the spring.

Each leaf is capable of growing to about a certain size. The exact size that a particular leaf will reach depends upon a good many factors, among them the amount of food and water that the plant can supply to it. So it happens that the different leaves on a single plant may be very different in size; the leaves of a plant growing in dry soil may be smaller than those of a plant of the same sort living in a moist place; and the leaves of a young tree are sometimes much larger than those of an old tree of the same kind. But in spite of all such differences, it is none the less true that the size to which a leaf may grow is limited by the number of cells that it formed while it was shut up in the bud; although conditions may prevent it from reaching the full size to which it might have grown, nothing can make it grow beyond the limit set by the number of its cells. 
245. Parts of a Leaf (Fig. I38). - Most foliage leaves, like those of the cucumber, are more or less clearly divided into a leaf-stalk and a blade. Sometimes, as in the case of the dandelion, the blade narrows gradually into the stalk, so that we cannot say just where one ends and the other begins. Some leaves, like those of most lilies, have no stalk at all; the blade is attached directly to the stem or branch of the plant. We have seen that the lower part of the leaf of the Indian corn forms a sheath that surrounds the stem for some distance. Such sheathing leaves are characteristic of the members of the grass family; but they are found in many plants of other families as well.

Many leaves have stipules. Some stipules, like those of the bean, are small; but some, as in the pansy and the pea, are so large that they may easily be taken for separate leaves. In any case, the stipules are really parts of the leaf to which they are attached. Compound leaves, like those of the bean, sometimes also have small stipulelike attachments at the base of the stalk of each leaflet in addition to the

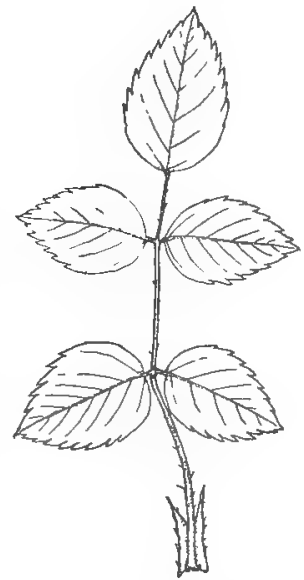

FIG. I38. - The leaf of a rose - a pinnately divided leaf with stipules. The leafets are toothed. stipules at the base of the leaf-stalk.

Usually both the leaf-stalk and the shoot (stem or branch) are thickened slightly at or near the point where the leafstalk is attached to the shoot. These two thickenings often run together so that we cannot distinguish just where the leaf-stalk ends and the tissues of the shoot begin. In many of the plants of the pulse family (including peas, beans, and clover) the thickening of the base of the leaf-stalk is especially marked. 
246. Hairs (Fig. I 39). - Hairs are usually most numerous on leaves, especially on their under surfaces; but they are borne also, and sometimes very abundantly, on stems and branches, on various parts of flowers, and on fruits. The downy appearance of the peach is due to a covering of soft, short hairs. Hairs are outgrowths each from a single surface cell, or in some cases from a small group of cells. Often a hair is a single long cell not unlike a root hair. One-celled hairs are sometimes bent so as to lie nearly parallel with the
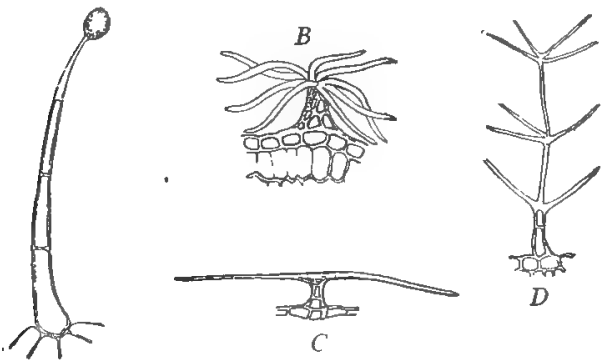

A

FIG. I39. - Hairs: $A$, of the common geranium (Pelargonium); $B$, of Correa speciose; $C$, of wormwood; $D$, of mullein. $B, C$, and $D$ after Kerner. surface of the leaf that bears them; in such a case, if they are numerous, they give a silky appearance to the leaf. In other cases the hair is composed of a row of cells, or even of several rows side by side. Sometimes it is branched, like the hairs of the mullein; sometimes instead of a hair a plate of cells is formed, like the chaffy scales of many ferns. In general, hairs are useful to plants because they prevent the too rapid evaporation of water.

Many plants living in very dry places, which can ill afford to give off much water to the air, have especially hairy leaves and stems. Thus the branched hairs of the mullein form a woolly coating which largely prevents currents of air from reaching the surface of the leaves and stem, and so prevents the rapid carrying away of moisture. The woolly coatings of some winter buds are useful in the same way, because during winter the roots cannot supply any considerable 
amount of water, and even a slight evaporation might cause the wilting and death of the buds. Some plants (such as many of the grasses and sedges) have stiff, sharp-pointed hairs which, like thorns and spines, protect the plant from destruction by hungry animals.

Some hairs are organs in which special substances are produced. Such hairs are glandular hairs; they are usually swollen at or near the end, and in this swollen part of the hair the substance it produces is stored. The glandular hairs of the nettle have made a forcible impression upon most of us; it is a slightly poisonous liquid formed in them that causes the unpleasant sting. The hairs of some tropical nettles produce still more poisonous substances whose effects are said to last for days. Nettles and plants with similar glandular hairs are carefully avoided by grazing animals. But the substances formed in the glandular hairs are by no means always poisonous. The varnish-like substance which covers the winter buds of the horse-chestnut is produced by glandular hairs borne on the bud scales. The bracts and ovaries of the pistillate flowers of the hop bear scale-like glandular structures that produce the bitter substance which makes hops valuable for medicinal purposes as well as in the manufacture of beer.

247. Shapes of Leaves. - One way in which species of seed plants differ greatly from one another is in the shape of their leaf-blades. These differences in shape are closely connected with differences in the course of the reins in the leaf. The leaves of most monocotyledons, like those of corn, are parallel-veined. In stuch a leaf, there is one vein running close to, and parallel with, each edge of the leaf. Parallel-veined leaves usually have entire margins - that is, margins that are not indented. Some monocotyledons and most dicotyledons have netted-veined leaves, many of whose veins run out toward the edge and there end abruptly. It is possible for the edge of the leaf to be indented or cut-in 
between the ends of two such veins, and this is why many dicotyledons (though by no means all) have leaves with more or less irregular outlines. If the indentations of the margin are shallow, the leaf is toothed. The cherry, apple, and elm have toothed leaves. If the indentations are deeper, as in the leaves of the common maples and the grape, the leaf is lobed. Sometimes the teeth, as in some grasses and sedges, or the lobes, as in holly and thistle leaves, are stiff and sharppointed; they serve the same protective purpose as do sharppointed hairs and spines. If the indentations cut down to the midrib, as in the pea, or to the base of the leaf, as in the horse-chestnut, the leaf is divided, and its parts are called leaflets.

Divided leaves are of two kinds with reference to the arrangement of the leaflets, and this arrangement is connected with the course of the veins. In many netted-veined leaves there is a single midrib, which gives off branch veins on both sides; these branch veins branch in turn, and so on. The cherry leaf has this arrangement. If a leaf with the veins so arranged is divided, the divisions cut down from either side to the midrib; the leaflets then are attached on both sides of the midrib as the divisions of a feather are attached to the quill. The leaf is pinnately divided. The bracken fern has pinnately divided leaves; so have roses (Fig. I38) and peas. Some netted-veined leaves, instead of a single midrib, have several large veins that start from a common point at the base of the blade and run out in different directions toward the edges of the leaf. This arrangement is seen in maple and grape leaves. If such a leaf is divided, the divisions cut down to the base of the leaf, and the leaflets are all attached to one another at their bases, somewhat like the fingers of a hand. Such a leaf, for cxample that of the horse-chestnut or of the clover, is palmately divided. The leaflets of a divided leaf, whether pinnately or palmately divided, may themselves be toothed, lobed, 
or divided. So leaves may be twice divided, like those of the bracken fern and the sensitive plant. Some ferns have leaves three times divided, and the common meadow-rue has a four-times-divided leaf.

There are many other points of difference in the shape of leaves; some are circular in outline, some are heart-shaped, some oval, some long and slender, and so on. These differences are important in the classification of seed plants, and for this reason each particular form of lcaf has been given a special name.

\section{Leaves of Different Shapes on the Same Plant. -} Not only are leaves of different shapes found on different plants; there are also differences in shape between leaves borne on the same plant. Strictly speaking, perhaps, no two leaves, even on the same plant, are ever of exactly the same shape. But the differences in most cases are comparatively small, and the foliage leaves of a particular plant usually follow the same general pattern. But there are exceptions to this rule. The leaves of the common mulberry vary in shape to an unusual extent, even on the same tree, some being deeply lobed, others heart-shaped and quite without lobing. There are not a few cases in which different parts of the same plant bear two very different kinds of foliage leaves. One class of such cases is seen in some plants the early internodes of whose stem remain very short. The result is the production of a cluster of leaves close together and close to the surface of the ground. These are commonly, but not properly, called "root leaves." Later the stem forms long internodes, so that a tall, upright shoot is produced bearing scattered leaves.

The root leaves and the upper leaves of the plant are often decidedly different in shape, although if a complete series of leaves is studied in the order of their age, a fairly gradual change will usually be found from the form of the lowest leaves to that of the uppermost ones. The common hare- 
bell, for example, has root leaves with rounded, almost circular blades, but its upper leaves are long and very narrow. There are some water plants that bear leaves of one sort under water and leaves of a very different form in the air; this is true, for example, of the yellow water crowfoot and of some of the pondweeds.

249. Special Kinds of Leaves: Seed Leaves. - Leaves, like stems and branches, adapt themselves to particular kinds of usefulness by taking on special forms, some of which are very different from the forms of ordinary foliage leaves. Most of the special kinds of leaves have already been mentioned in one connection or another. We know, for example, that the sepals, petals, and stamens of a flower are leaves adapted to special purposes, and that the pistil is either one leaf or else composed of two or more leaves united. But in this chapter we shall consider only those leaves that help in some of the vegetative work of the plant.

Seed leaves are usually different, sometimes very different, from the later-formed foliage leaves of the same plant. If the later leaves are divided, the seed leaves are likely to be simpler in outline; very frequently they are undivided, with entire margins, as is the case in the bean. Some seed leaves become green and for a time do the work of foliage leaves; this is true of the seed lcaves of the squash. On the other hand, the single seed lcaf of grasses, including the corn, is an absorbing organ which never gets outside the seed coat and never serves as a foliage leaf. In many seeds, such as those of the squash, the oak, and the bean, most of the reserve food is stored in the seed leaves, which therefore in such cases are very thick. Thus seed leaves serve a varicty of different purposes in different cases.

250. Scale Leaves and Bracts. - We have found that scale leaves are borne by many plants - covering winter buds, growing on underground stems, bulbs, and tubers, or on ordinary shoots, such as those of the pine and the 
asparagus. Most commonly they are protective structures. But bulb scales, like those of the lily and the onion, serve for the storage of food; and some scale leaves (for example, those of the asparagus) contain chlorophyl and manufacture a small amount of food. Scale leaves, except for their smaller size, are usually similar to the blades of foliage leaves; as a rule they have no stalks. Most flowers are borne at the ends of short branches, each of which grows from the axil of a leaf. This leaf may be an ordinary foliage leaf. But if a plant bears many flowers, and especially if the flowers are close together in a cluster, the leaves from whose axils the flower-bearing branches grow are likely to be smaller than the ordinary foliage leaves. Small leaves, so located, are called bracts. In some lilies that bear large numbers of flowers, the lower flowers grow from the axils of foliage leaves of about the ordinary size. The higher flowers are in the axils of smaller and smaller leaves, and the uppermost leaves are merely bracts. In such a case no sharp distinction can be made betwcen foliage leaves and bracts. When many flowers are borne very close together, as in the spike of the mullein or the head of the red clover, each individual flower grows from the axil of a very small, scale-like bract. The chaffy scales of the corn tassel and ear, and those of the heads of wheat, oats, and other grasses, are also bracts.

251. Thorns and Tendrils. - We have seen that some thorns are branches of a special form; others, though very similar in appearance, are really leaves or parts of leaves, or sometimes even roots. Many of the spines of cactuses seem to be leaves; others are probably reduced branches. The thorns of the barberry (Fig. I40) are leaves; some of them are simple, some
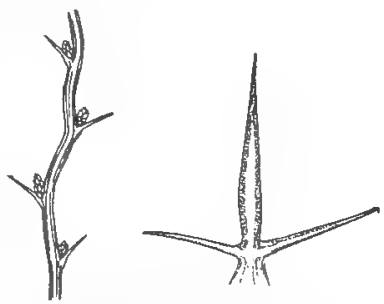

FIG. I40. - Simple and branched thorns of the common barberry. 
branched. The thorns of the black locust are merely stipules; and similar thorns are borne by various acacias and euphorbias (Fig. I4I), especially by species that live in warm, dry regions. A tendril, too, may be a branch, a root, a leaf, or part of a leaf. Sometimes, as in some relatives of the sweet pea, a whole leaf develops into a tendril. More commonly, as in the peas, sweet pea, and vetches,

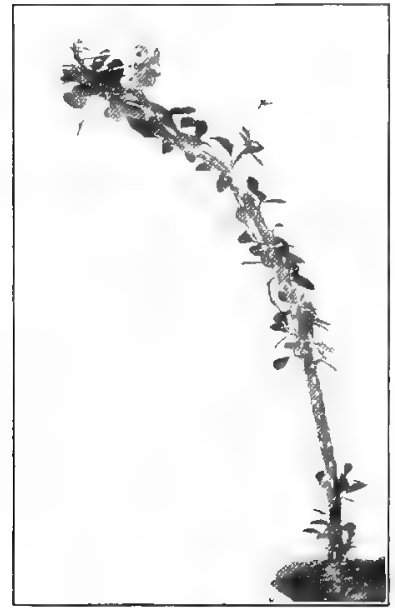

FIG. I4I. - Euphorbia splendens, a plant whose stipules take the form of thorns. the tendrils are merely some of the last leaflets, the lower parts of each leaf being of the ordinary form. In some Indian grasses, the midrib grows out beyond the blade in the form of a tendril. Sometimes stipules become tendrils, as in various species of Smilax. Sometimes, as in Clematis and in climbing varieties of Tropæolum (the common "nasturtium "), the leaf-stalk acts as a tendril, still bearing at its outer end a blade of the usual form.

\section{Insect-Catching Leaves.} - The leaves of a few plants have taken on very odd forms that make them traps for insects. These plants, although they have chlorophyl and can manufacture carbohydrates for themselves, use the softer parts of the insects' bodies for food. Such use of animal food is possible to but few green plants, most of which, as we have seen, can use the materials of animals' bodies only after they have been broken down, mainly by the action of bacteria, into much simpler substances.

Among the best known of the insect-catching plants is the " pitcher plant" of Canada and the eastern United States 
(Fig. I42). Each leaf-blade of this plant is curved into the shape of a pitcher which catches and holds rain water. Insects, attracted by nectar that is produced about the mouth of the pitcher, crawl into it. They are prevented from crawling back by strong, pointed hairs inside, which are turned downward. Finally the insects are drowned in the liquid in the pitcher. This liquid contains enzyms, produced by some of the cells that line the pitcher. The enzyms digest (that is, change to a soluble form) such parts of the dead insects' bodies as the plant can use for food, and the leaf cells absorb this dissolved food from the water. Pitcher plants of other species are found in the southern United States, on the Pacific coast, and in the tropical parts of the eastern hemisphere.

The

"sundews" catch insects in a very different way. The edges and the upper surface of each leaf bear thick glandular hairs (Fig. 143). On the swollen

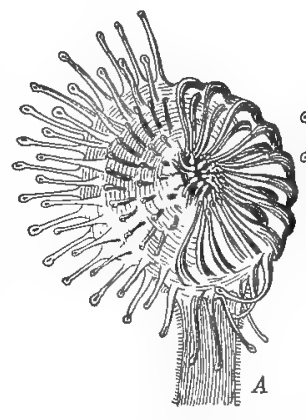

Frg. I43. - Leaves of a sundew (Drosera rotundifolia): $A$, after the leaf has been stimulated by the touch of an insect; $B$, a leaf in the unstimuend of each hair lated condition. After Kerner. 
is always a drop of thick liquid that glistens in the sun like dew. If an insect alights on the upper surface of the leaf, touching some of the hairs, it is caught in this sticky liquid. The touch of the insect serves as a stimulus to the leaf, which becomes curved, and the hairs bend over from all sides upon the insect. The soft parts of the insect's body are then digested by enzyms contained in the sticky secretion.

"Venus' fly-trap " (Fig. I44) has a leaf-blade of two parts, separated by the midrib; the two parts fold together upon
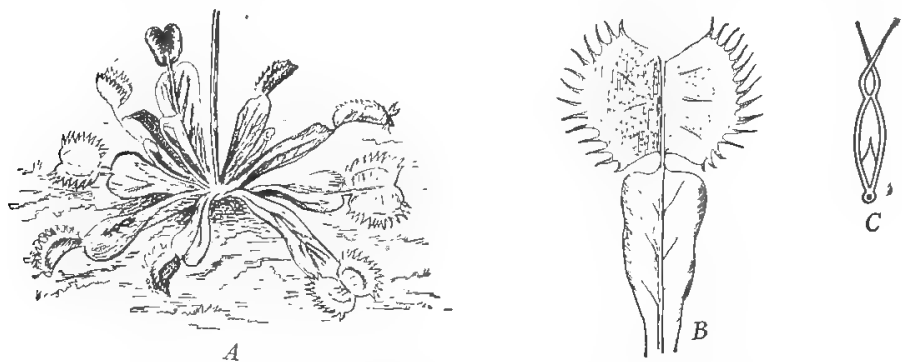

FIG. I44. - Venus' fly-trap (Dionca muscipula). A, a plant, some of whose leaves are open and some closed as the result of stimulation by an insect; $B$, a single leaf; $C$, a cross section of the upper part of a leaf, closed. After Kerner.

an insect that has touched any of the sensitive hairs on the upper surface of the leaf.

253. Arrangement of Leaves. - A plant like the lilac or the horsc-chestnut, whose leaves are borne in pairs at the nodes of the stem or branch, is said to have opposite leaves. In such plants, very commonly, though not always, the leaves of one pair grow in a direction at right angles to that of the next pair above or below; this is the case in the horse-chestnut. Some plants, for example some lilies (Fig. I +5), have their leaves in circles of three, four, or more at each node, instead of in pairs. I'ry many plants, however, like the bean and the cucumber, have only one leaf at each node; their leaves are alternate. In an alternate- 
leaved plant, if onc leaf is on the north side of the stem, the leaf next above may be on the south side, the next on the north, and so on. The leaves then are all in two vertical rows, and each leaf is directly above the second leaf below. Other alternateleaved plants have each leaf directly above the third leaf below; the leaves are then in three vertical rows. Still others have their leaves in five, eight, or more vertical rows.

Whether the leaves are

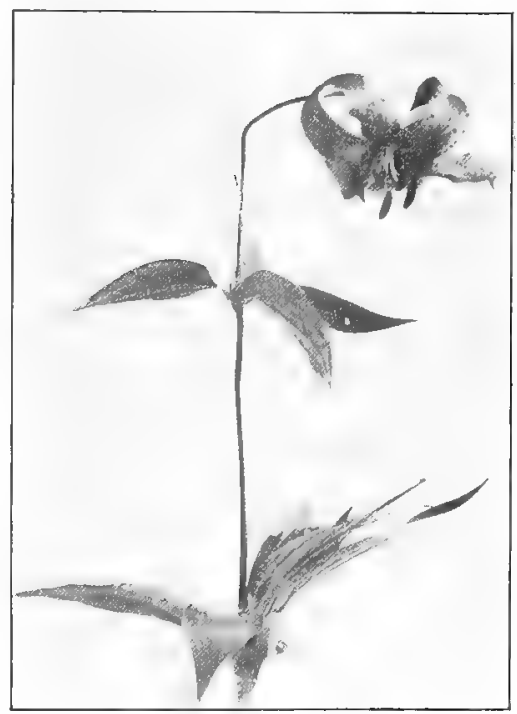

Fig. I45. - A plant of the wild yellow lily (Lilium canadense), whose leaves are borne in circles (whorls) of four or more. opposite, in circles, or alternate, we usually find that the result of their arrangement is that they overlap one another as little as possible. If we look down on a plant from above, we shall probably find that the leaves are so arranged that each fits in, as it were, to a space left between the leaves above (Fig. I46), so that each receives the greatest possible amount of light. The appearance is much like that of a mosaic FIG. I46. - The leaf mosaic of a primrose. floor, in which each angular 
piece of stone fits closely between the neighboring pieces. This is why such an arrangement of leaves is spoken of as a leaf mosaic. If the light comes chiefly from one side rather than from above, as in the case of a grape vine growing against a wall, the leaf mosaic is turned toward the side from which the light comes, and not upward.

254. Responses of Leaves to Light Stimuli. - The mosaic arrangement just described results partly from the fact that the leaves are attached to different sides of the stem. But no method of attachment of the leaves to the stem would of itself prevent overlapping; in particular, it could not provide for the fullest possible illumination of the leaves when the light comes from one side. The leaves of many plants, especially of plants growing in shady places, can adjust their own position so that the upper surface of their blades will receive the greatest amount of direct light. This adjustment is brought about partly by the greater or less growth in length of the leaf-stalk; sometimes the leaves on the same plant have stalks that differ greatly in length. The adjustment of the leaf to light is also helped by a tristing of the leafstalk, and sometimes too by a curving of the leaf-blade. Most of these changes are responses to the stimulus of light, although the stimulus of gravity plays a part also in determining the direction of growth and the position of the leaf. These responses are more complex and more difficult to study than the changes which occur in the direction of growth of stems and branches in response to stimuli.

There are some plants whose leaves do not so place themselves as to receive the greatest amount of light. These are especially plants that live in exposed places where the light is so intense, particularly in the middle of the day, that it might injure the leaves. The prickly lettuce is a fairly good illustration. Its leaves are nearly vertical instead of horizontal; some of them point toward the north, others toward the south. In this position the surfaces of the leaves receive 
the greatest possible amount of light in the early morning and late afternoon when the light is least bright, and the smallest possible amount at midday when it is most intense. This and other plants with similarly vertical leaves are sometimes called "compass plants."

255. Evaporation of Water. - Leaves are the parts of the plant from which water is chiefly lost by evaporation. When we consider the total area of the surfaces of the leaves of an ordinary plant and remember that water is continually evaporating from all these surfaces, we can see that a large amount of water must be lost. It has been calculated that a single oat plant in the course of its life gives off about I4 pounds of water; and that a birch tree with 200,000 leaves loses about two barrels of water per day. The water thus lost by the leaf cells that are in contact with the air is replaced by water that comes from the cells deeper within the leaf; these in turn draw upon the water in the wood cells of the veins and leaf-stalk; these take water from the wood cells (and vessels) of the branch or stem, these from the wood cells of the roots, these from the cells of the cortex, and these from the root hairs, which finally, as we know, absorb water from the soil. Thus there is what amounts to a steady stream of water passing from the soil through various tissues of the plant, but most of the way through the wood, to the outer cells of the leaves and thence into the air. The comparison of this current of water to a stream must not be pushed too far. The water really passes through a long series of cells and vessels, going from each cell or vessel to the next through the wall which separates them.

It is because of this continual passage of water upward and outward that the roots of a tree must penetrate to the deeper layers of the soil where a steady supply of water is to be had. It is because of the great need for water that the roots of a tree must branch abundantly, so that there shall be many growing root-tips, each with its zone of absorbing hairs. 
It is because of the steady evaporation of water from its leaves that a garden plant whose roots do not reach far into the soil wilts in dry weather; the cells of its stem and leaves lose so much water that they are no longer full and plump. This explains why, to keep the plant alive at such times, we must supply water to the soil; and it shows us one reason why the ground about the plant must be cultivated, so that the upper layers of the soil shall be broken up and loosened and thus prevented from giving off to the air the water which the plant so badly needs.

256. Necessity for the Water Current. - We know that in seed plants the leaves ordinarily contain most of the chlorophyl and manufacture most of the carbohydrates. The water which the leaves use in carbohydrate manufacture comes from the roots, and this is one reason why the plant must have a continuous series of conducting tissues leading from the younger parts of the roots (where water is taken in) to all parts of the leaves. The evaporation of water seems to be important on warm days also in helping to cool the leaves, which otherwise might be scorched by the sun's rays. In this respect, the evaporation of water from leaves is useful to the plant in the same way that the evaporation of perspiration from our own bodies is useful to us.

257. Dangers of too Rapid Evaporation. - The reasons just given explain why there must be a constant supply of water coming up from the roots; still, in most cases the amount of water that is necessary for these purposes is probably small in comparison with the amount that actually evaporates from the leaves. Not only is energy wasted in thus bringing up to the leaves more water than is needed for actual use; but also the evaporation is a source of real danger, because if the roots should not be able to supply enough water to make up for what is lost from the lcaves, the leaves and stem would wilt. Such a loss that cannot be made up is a serious matter; water constitutes a large 
part of the living matter itself as well as nearly all of the cell sap, and too great a loss of water stops the activities of living matter and finally kills it. This is what goes on in both wild and cultivated plants in a dry summer. Even large trees sometimes die after a series of dry seasons.

Much of the evaporation from leaves, although it is useless and even dangerous to the plant, is unavoidable, because leaves must expose a large surface to the air in order to absorb enough carbon dioxid, and also in order to receive sufficient light for carbohydrate manufacture. The exposure of a large leaf surface for these purposes means that much water will be lost by evaporation; and so the needs of the leaf for light and carbon dioxid scem to explain why the plant must do so much apparently unnecessary work in pumping up water from the soil.

258. How Evaporation is Checked. - So serious is the danger of too great a loss of water that many peculiarities in the structure of lcaves are to be explained by the need of keeping the rate of evaporation as low as possible. Chief among the devices for checking evaporation are the minute air-pores which are present in great numbers on the surfaces of leaves (see Fig. 52). The pores lead into intercellular spaces within the leaves. Experiment has shown that the gases of the air (including carbon dioxid) pass into and out of these pores and come into contact with the inner cells of the leaf about as readily as though these cells were not covered by the epidermis, while the evaporation of water from the inner cells is slower than it would be if the epidermis were not there. The practical effect, then, of the presence of air-pores and intercellular spaces is that the area of leafcells which can absorb carbon dioxid is greatly increased without a corresponding increase in the amount of water evaporated. This result is helped also by the fact that as a rule the air-pores are found (especially in plants living in dry places) on the lower surface of the leaf, which is shaded 
from the direct rays of the sun and which therefore, being cooler, loses water less rapidly by evaporation than would the upper surface if it were similarly provided with air-pores.

There are other ways, too, in which evaporation from leaves is checked. One of these, as we have seen, is by the produc-

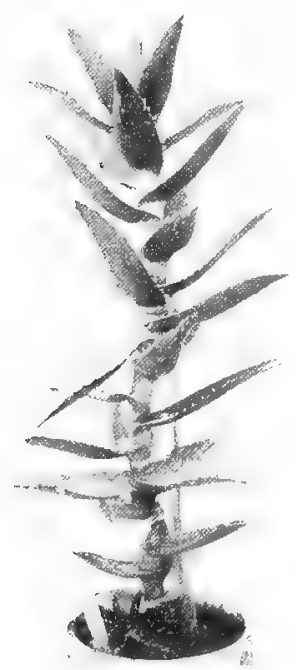

FIG. $147 .-$ An aloe, whose thick leaves serve for the storage of food as well as to check evaporation. tion of hairs. Another is by the formation of cutin, a substance somewhat like cork, with which the outer walls of the epidermal cells are permeated and which sometimes forms a thin layer on the outer surface of the epidermis that can be separated and peeled off. H'ax, which is sometimes formed on the outer surface of the epidermis, also helps to check evaporation. The wax may be in a uniform layer, causing the shiny appearance that is characteristic of the leaves of some willows and grasses, and of the surfaces of many fruits. Sometimes the wax takes the form of mealy particles; this is the "bloom" of plums and grapes, and of the leaves of the cabbage and the tulip. Cutin and wax are most abundant on the upper surfaces of leaves, hairs on the lower surfaces.

Another tendency often noticed in the plants of dry localities is to reduce in various ways the area of their leaf surfaces. Generally speaking, plants that live in moist, shady places where evaporation is slow, or in lands with mild, moist climates where the water supply is ample, have large, thin, and often divided leaves. The leaves of the plants of deserts and other very dry regions are seldom divided, for a divided leaf exposes more surface to the air than would an un- 
divided leaf of the same bulk. Plants living in dry localities also are likely to have especially thick leaves. The century plant, the bases of whose leaves are very thick, is an example. A thick leaf not only exposes less surface in proportion to its bulk and so reduces the danger of evaporation; its thick tissues also serve for the storage of water. The juices of the thick leaves of some relatives of the century plant are extracted by the Mexicans in great quantities and are used in preparing the drink called "pulque." An extreme reduction in size of leaves is seen in the various cactuses, in nearly all of which the leaves are merely small spines, and all the green, food-making tissue is contained in the stem and branches. The branches of the prickly-pear cactus not only do the work of leaves; they actually look like broad, thick leaves.

In the case of plants of temperate regions with evergreen leaves which remain alive for more than one year, the leaves have much the same characteristics as have those of the plants of dry regions. This is because much of the water in the soil is frozen during the cold months, and so the water supply of the roots is greatly reduced. Under such conditions, if evaporation were to go on freely from the leaves, they, and the plant as well, would die. This explains the advantage of the thick cutin layer and the waxy coating of such leaves as those of the evergreen hollies, the box, and the European mistletoe. It explains, too, the advantage of the small, needle-shaped leaves, well provided with cutin and in some cases with wax, of the pines and spruces. These latter are inhabitants for the most part of regions where the winters are long and cold, and where there is great need to guard against too rapid evaporation.

259. Manufacture of Food in Leaves. - Chlorophylcontaining cells differ from all the other cells of living plants and animals in their ability to manufacture carbohydrates out of water and carbon dioxid. In most seed plants the 
chlorophyl-containing cells are found chiefly in the leaves; the leaves are, therefore, among other things, the carbohydrate-making organs of the plant. They obtain carbon dioxid directly from the air, or from water if they live in water; the water that is needed is brought to them from the soil by means of the root hairs and the conducting tissues of the root and stem. The first form which the newly-made carbohydrates take is probably that of some of the simpler sugars such as glucose. It is in the making of sugars out of carbon dioxid and water that the work of the chlorophyl is done. Much of the sugar, as we shall see, is changed to starch, but with this change the chlorophyl has nothing to do.

The sugar, once formed, may be handled by the plant in any one of several ways. It may be used at once, in combination with some of the substances that the plant receives from the soil, in building up more complex materials, stuch as proteins and finally living matter. It may be broken down in the process of respiration, either in the cell in which it was formed or in another cell to which it has been passed on, so giving up its store of energy for use in doing some of the work of the plant. Or if, as is likely to be the case on a bright day, sugar is made more rapidly than it can be used, it may be stored away for later use. The carbohydrate food is usually not stored in the form of sugar, at least in the cell in which it was manufactured. Sugar, being soluble in the cell sap, would make the sap more and more dense and sirupy as its manufacture goes on. This would interfere with the movement of materials within the cell and possibly with other forms of activity of the living matter. For these and perhaps for other reasons, sugar is not usually a convenient form for the storage of large amounts of food.

As a rule, when the solution of sugar in the cell sap has reached a certain strength, some of it is changed into starch and stored in the form of small grains inside the chloroplasts. Starch is a compact form of food, and being insoluble it does 
not increase the density of the cell sap. So it is that during a bright day starch gradually accumulates in the green cells of a leaf. The change of sugar into starch is not brought about by the chlorophyl. Very likely this work is done by means of an enzym, but of this we are not certain. Toward night the manufacture of sugar and starch comes to a stop. During the night the starch that has been stored in the leafcells during the day is gradually changed back, by the action of a diastase, into a sugar, and this sugar, being soluble, passes slowly through the cell walls into neighboring cells, thence into the bast cells of the veins, and through them to the bast cells of the branch or stem, which in turn conduct it to all parts of the stem, branches, leaves, flowers, fruits, and roots. In each of these parts, some of the sugar is used in the building up of other substances and finally of living matter; some is destroyed in the process of respiration; and some may be stored for future use.

Stored food, in greater or less amounts, may be found in almost any part of the plant; but it occurs in largest quantity in organs that are specially adapted for permanent storage, such as thick stems and roots, bulbs, tubers, and seeds. The stored food may be in the form of glucose, as in the grape; it may be changed into a more complex sugar, as in the sugar beet and the sugar cane; more commonly it is changed into starch, as in the potato tuber and in the kernels of corn and of other grains; it may be changed into a fat, as in walnuts and hickory nuts; or it may be combined with other substances to form proteins, such as are found in considerable amounts in the seeds of peas and beans. Thus, during the night the cells of the leaf are relieved of most of the starch which they have accumulated during the day, though usually their supply is not quite exhausted by morning. The. next day, if conditions are favorable, the work of sugar- and starch-making is resumed, and in the following night most of the starch is again removed. Carbohydrate-making is 
thus the special work of the leaf-cells. They also take an important part in the building up of higher compounds, including proteins and living matter, out of the carbohydrates and the food substances derived from the soil. But this latter work is not peculiar to the cells of the leaf; it is probably going on more or less actively all the time in all the living cells of the plant.

260. Storage of Food in Leaves. - In general, the business of leaves is the manufacture of food; surplus food which is to be kept for a long time is usually stored in other organs of the plant. Nevertheless, there are not a few plants whose leaves are important storage organs. Leaves in which any considerable amount of food is stored are likely to be thicker than those which merely manufacture food and pass it on to other organs. The very thick leaves of the century plant, as we have seen, serve for the storage of water; they contain also other food substances, some of which are dissolved in the water. The bulb scales of lilies and onions are cxamples of underground leaves that are important storage organs; in the case of the onions, we profit by the provision which the plant has made for its own future needs.

261. Respiration. - This is another kind of work in which leaves play a large part, although it goes on in all parts of the plant where there are living cells. The importance of leaves in this process results from the fact that they expose a larger surface to the air and so can take in the oxygen that is needed for respiration more rapidly than can the other organs of the plant. The oxygen that is taken in by the living cells of a plant, whether it comes directly from the air as in the case of most sced plants, or from the water in case the plant is submerged, must pass through the cell walls in solution in water, just as do all other substances solid, liquid, or gaseous (excepting water itsclf), that enter or pass out of cells. Not all the oxygen is necessarily used in the cell that first takes it in; it may be passed on to cells 
farther within the tissues. In respiration, the substances already in the cells, including carbohydrates, fats, proteins, and possibly some of the living matter itself, are broken down into simpler substances, and the energy which was stored in them is set free. Part of the energy so set free shows itself in the form of heat; the temperature of an active part of the plant is therefore always a little above that of the surrounding air. Other portions of energy set free in respiration are used in building up complex food substances and living matter, in growth, in the movement of materials within the plant (such as sap that is pumped up from the roots to the leaves), and in the movements of leaves and other parts of the plant.

Of the simple substances formed in the breaking-down processes of respiration, the most abundant are water and carbon dioxid. The water remains within the cell where it is formed or passes to a neighboring cell. The carbon dioxid passes off through the cell wall into the air, unless it can be immediately used again in the building up of new carbohydrates. Therefore it is that the effect of respiration upon the atmosphere about the plant is just the opposite of that of carbohydrate manufacture. Respiration takes oxygen from the air and gives carbon dioxid to the air; carbohydrate manufacture takes carbon dioxid from the air and gives oxygen to the air. So long as a plant is growing and increasing in weight, it is making carbohydrates on the whole more rapidly than it is respiring; the net result of its activities upon the atmosphere is to decrease the amount of carbon dioxid and to increase the amount of oxygen.

The net result of the activities of colorless plants and of animals, which respire but do not make carbohydrates, is to decrease the amount of oxygen in the air and to increase the amount of carbon dioxid. Thus these two groups of living beings, green plants on the one hand and colorless plants, and animals on the other, neutralize each other's 
influence upon the air, and the members of each group supply the particular gas that the members of the other group need. During a bright day, green plants give off more oxygen to the air than they take in, because carbohydrate manufacture goes on then much more rapidly than respiration. During the night, green plants respire, but do not make carbohydrates; therefore, they take oxygen from the air and give off carbon dioxid.

\section{Movements of Leaves: The Sensitive Plant. - If} we turn a leaf until its lower surface is upward and its upper

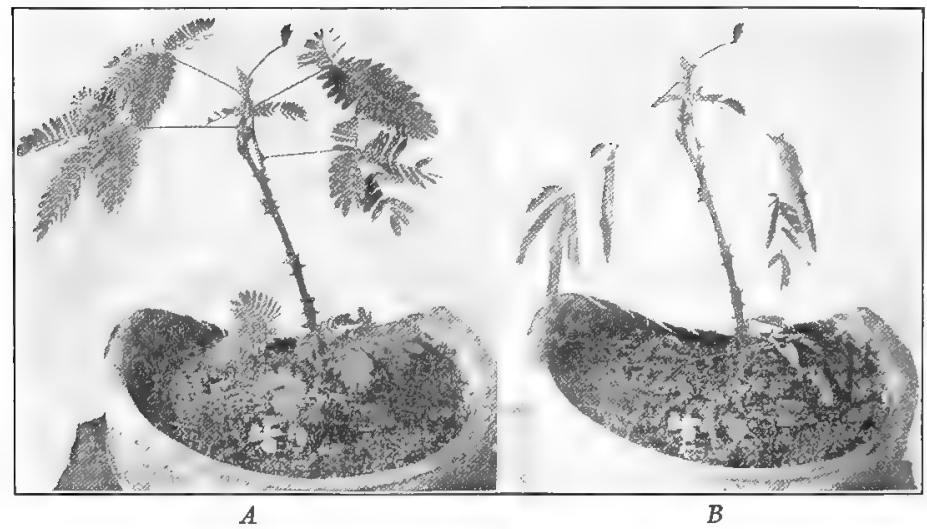

Fig. I48. - $A$, a sensitive plant whose leaves are in the ordinary expanded condition. $B$, the same plant, after its leaves and leaflets have responded to the stimulus of a blow.

surface downward, and fasten it in the new position, we shall find that in the course of some hours it has turned (usually by a twisting of the leaf-stalk) until the lcaf-blade faces in the same direction as before. This is one of the ways in which leaves can adjust their position in relation to light. A different and more rapid sort of leaf movement is seen in certain plants, one of which is the familiar " sensitive plant." This plant, like the bean, is a member of the pulse family; it is a 
native of South America. A leaf of the sensitive plant has four leaflets, each of which bears several pairs of secondary leaflets. If the tip of a secondary leaflet is very gently touched, that leaflet and the opposite one fold together; the bending takes place at the base of each leaflet. If instead of merely touching the leaflet we stroke it slightly, not only the one pair but all the pairs of secondary leaflets belonging to the same primary leaflet fold together. But they do not fold at the same time; first the leaflet touched and its mate fold, then the next pair, then the next, and"so on, and finally a bending occurs at the base of the primary leaflet so that it droops. That is, the stimulus is conducted through the central axis of the primary leaflet. This conduction through the cells of the leaf is similar to the conduction of a stimulus by means of nerves from one part of the human body to another part. But the conduction is much slower in the case of the plant. It seems to be through the cells of the vascular bundles that the stimulus is chiefly conducted, and these cells cannot be compared with nerves because their chief business is not, like that of nerves, the conduction of stimuli.

If the leaflet is struck more violently, not only the parts of one primary leaflet, but all the parts of the leaf, will be affected, and we can follow the conduction of the stimulus to the base of the first primary leaflet, and then from the bases to the tips of the other primary leaflets. In this case, each primary leaflet droops when the stimulus reaches its base, and finally the whole leaf droops because of a bending at the base of its stalk. The stimulus of a still more violent stroke may be carried still farther, so as to affect other leaves and even perhaps all the leaves of the plant. These movements of the leaflets and of the whole leaf take place, not only in response to the stimulus of a touch or a blow; they occur in the same way if a leaflet is stimulated by a weak electric current, by a slight cut or other wound, or by an irritating chemical substance such as hydrochloric acid. 
$\dot{A}$ change from light to darkness is also a stimulus. If the room or box in which a sensitive plant stands is darkened, the leaflets of the plant fold and its leaves droop, just as though some or all of the leaflets had been struck. If light is now admitted, the leaves gradually straighten up and the leaflets unfold; that is, the plant recovers from its stimulated condition. If a sensitive plant is placed for some minutes in an atmosphere saturated with chloroform, it loses the power to respond to stimuli of any sort, just as an animal does when it is chloroformed. Like the animal, the plant may return in time to its normal condition if the chloroform is removed; but if the plant is exposed to chloroform too long, it will die.

We have seen that a leaf-stalk is usually somewhat thickened at its base; the thickening or cushion is especially marked in the leaves of members of the pulse family, to which the sensitive plant belongs. The cushion is usually lighter green in color than the rest of the leaf-stalk. There is a similar, though smaller, cushion at the base of each primary leaflet, and a small one also at the base of each secondary leaflet. When wo touch a secondary leaflet, we may observe that the upward movement which brings this leaflet face to face with the one opposite is due to a bending in the cushion at its base; and the drooping of the whole leaf is brought about by a bending in the cushion at the base of the leaf-stalk. These cushions, then, act somewhat like hinges; and the movements of the different parts of the leaf result from changes that occur in the cushions when the leaf or one of its parts is stimulated. The change that takes place in one of these cushions at such a time results from a change in the amount of water present in some of its cells.

263. "Sleep Movements." - Although other plants of the pulse family have similar cushions at the bases of their leaflets and of their leaves, very few of them respond to stimuli by such rapid movements. However, many plants 
of this family, as well as some of other families, including various species of Oxalis, do respond to the stimulus of a change from light to darkness by changing the positions of their leaflets. The night positions of bean leaves have been referred to, and those of clover leaves are very similar. Upon the return of daylight the leaves and leaflets spread out again in the position with which we are more familiar.

264. Formation of Habits. - It has just been said that the night movements of leaflets and leaves are responses to the stimulus of a change from light to darkness. Another factor also may play a part in these movements. If a goodsized bean plant or sensitive plant is placed in a dark room, the leaves, as we should expect, take their night position. But if the plant is kept in the dark room, we find that after about twelve hours the leaves spread out into something like the position that they ordinarily occupy in the daytime, though they do not open so fully as they would if they were exposed to bright daylight. At the end of another twelve hours they fold; after twelve hours more they open; and so on for some days. If the plant is exposed to continuous light instcad of continuous darkness, the same thing happens. These results mean that, having been exposed alternately to light and darkness at intervals of about twelve hours during its life, the plant has formed the habit of changing the position of its leaves at those intervals, and that now, even if there is no change from light to darkness or vice versa, it goes on with its leaf movements in the way that it has formed the habit of doing.

A young plant which has been kept in continuous light all its life has not formed the habit of changing the position of its leaves each morning and evening. But as soon as it is placed under ordinary conditions of light and darkness, its leaflets begin to fold up each night and to spread out again each morning, and in time the habit becomes fixed upon the plant. The formation of a habit such as this by a plant is 
fundamentally the same thing as the formation of a habit by ourselves. It results from the fact that when living matter has done a certain thing once in response to a stimulus, some change takes place in it which makes it easier to do the same thing a second time; the third time it is easier than the

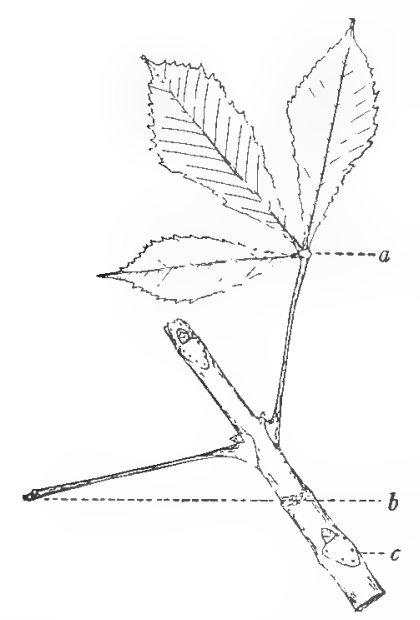

FIG. I49.-Portion of a branch of horse-chestnut, showing how the leaves and leaflets fall. At $a$, two leaffets have fallen; at $b$, all the leaflets have fallen, and only the petiole remains; at $c$, the petiole also has gone, and the leaf scar is shown with traces of the five vascular bundles that ran from the branch into the leaf.

just where it is attached to the stem or branch. These walls become softencd, so that a shaking by the wind, or sometimes a touch, is all that is necessary to break them and so to send the leaf to the ground. The walls of the layer of cells on either side of the softened region become permeated with cork. tions the act may become so easy that it is done without any external stimulus at all.

265. Fall of Leaves. - In the autumn the leaves of most of our trees and other common plants die and fall. If we examine a fallen leaf, we find that the surface where it has broken away from the stem or branch is as smooth as though it had been cut with a knife. The scar left on the stem or branch by the fall of the leaf is also smooth. This means that the leaf has not been torn roughly from its place of attachment, but that changes have taken place in the leafstalk which resulted in its separation from the shoot. As the end of the growing season approaches, a change takes place in the walls of a layer of cells extending across the leaf-stalk second; and after many repeti- 
Not only are whole leaves separated in this way from the plant that bears them; in the case of some divided leaves like those of the Virginia creeper or the horse-chestnut (Fig. I49), each individual leaflet is separated in the same way from the main stalk of the leaf. The fall of leaves may occur not only in the autumn, but at any time of the year when for some reason, such as lack of water, a part of the plant dies. So the dropping of leaves may be observed at almost any time on many common house and garden plants. The leaves of the pine, which live for several years, are cut off in the same way when they finally die. This method of bringing about leaf-fall is found, generally speaking, only in dicotyledons and gymnosperms. The leaves of most monocotyledons (such as the Indian corn and the lily), and of some dicotyledons like the oak, do not form a separation layer. As a result, although they may die and wither, they do not fall at once, but remain attached until they decay or are torn away.

266. How Do the Death and Fall of Leaves Help the Plant? - The answer to this question, as to so many others, lies in the plant's relation to water. We know that plants in those regions which have cold winters can obtain comparatively little water from the soil during the winter. Therefore, unless the area from which evaporation may take place is greatly reduced, the plant will be injured or killed by the too rapid loss of water which it cannot replace. Most of the plants of temperate regions that live over the winter (that is, biennials and perennials) avoid this danger by shedding their leaves, from which evaporation chiefly occurs, in the way we have just observed. The cork layer which covers the scar left on the stem or branch by the falling of the leaf serves to prevent evaporation at that point; it is also a protection against infection by the spores of parasitic fungi. Since most of the monocotyledons of temperate countries are either annuals, or perennials whose above-ground parts 
die each year, they have no need to go to the trouble of cutting off their leaves in order to prevent evaporation in the winter. There are plants, to be sure, even in cold regions, whose leaves do not drop in the fall. Conspicuous examples of this sort are the pines and other cone-bearing trees, which, however, are especially well protected against the rapid loss of water by the small area of their leaves, and by thick layers of cutin or wax. In warmer countries, on the other hand, where the ground is never frozen and there is always a supply of water for the roots, a much larger proportion of plants have leaves that remain alive and green throughout the year.

267. Autumn Colors. - The leaves of many common plants undergo changes of color in the autumn before they die. The autumn tints of leaves are chiefly yellows, reds, and browns, and combinations of these colors. These different colors arise in different ways. As the activities of the leaf lessen at the approach of autumn, its cells cease to make chlorophyl, and the chlorophyl that is present in the chloroplasts gradually disappears. The chloroplasts always contain more or less of a yellow coloring matter in addition to the chlorophyl. This yellow substance does not disappear as rapidly as the chlorophyl does, and so when the green color of the chlorophyl fades out, the rcllow color remains. The red colors of autumn leaves are due to substances which were not present earlicr, but which are formed in the cell sap (not in the chloroplasts) as the chlorophyl disappears. These substances are similar to those which give a reddish color to the young shoots of many plants in the spring; they are also like those found in the red leaves of the copper beech and other plants, in many red flowers and fruits, and in the root of the beet. The formation of red coloring matters is favorcd by cold weather and by the presence of sugars in the cells; indecd, it seems probable that sugars are used in their formation. 
When cork layers begin to be formed across the leaf-stalk in preparation for the fall of the leaf, the movement of sugar out of the leaf is checked; the leaf cells now contain more sugar than usual, and the conditions are favorable for the formation of red coloring matters. Bright sunlight also favors the formation of these red substances. The brown color of autumn leaves seems to be present, at least to a large extent, in the cell walls, which turn brown as they die.

268. Some Practical Uses of Leaves. - Although we use the leaves of many plants for food, their actual food value is in most cases rather small. Most of the more solid and really important articles of our diet, so far as they are supplied directly by plants, come from the stems, roots, seeds, and fruits in which plants store most of their reserve food. The value of the leaves that we eat lies rather in their stimulating and appetizing qualities. One may think in this connection of the leaves of onions, cabbage, lettuce, endive, spinach, celery, parsley, spearmint, sage, and of others that are used for salads, for flavoring, and in similar ways. Among the leaves that are important for their stimulating properties are those of tea and tobacco. The leaves of many plants, such as arnica, boneset, spearmint, digitalis, horehound, and witch hazel, contain substances that make them useful in medicine. Those of not a few tropical plants, among them some of the palms, supply fibers that are used in a variety of ways. Many leaves, especially those of the grasses, are also an important part of the food of many of the lower animals which we in turn use for food, as beasts of burden, and in other ways; and in this indirect way leaves are of very great value to man. 


\section{CHAPTER XVII}

\section{FLOWERS AND THEIR USES}

269. Flowers and the Relationships of Plants. - Every one knows that there are many kinds of flowers, differing from one another in size and color, in the shape and arrangement of their parts, and in the way in which they are borne upon the plant. One reason why much study has been devoted to flowers is that the structure of a flower tells us more about the relationships of the plant that bears it than does the structure of any of the vegetative parts - stem, leaves, or roots. This is because the vegetative parts change oftener and more rapidly in the course of the evolution of plants than flowers do.

The conditions under which plants live are continually though slowly changing, and they have been changing for ages. If a region that has been low and wet becomes high and dry, the species of seed plants that live in that region must either die out or undergo changes in their roots and leaves that will adapt them to the new conditions. The same is true if land that has been high and dry becomes low and swampy; or if the formation of a new mountain range affects the direction of the winds and the amount of rainfall in the country on either side. Changes such as these in the earth's surface have compelled the greatest variety of changes in the vegetative parts of plants, and so have resulted in the development of many new species. But a change in the conditions surrounding a plant is not so likely to make changes necessary in its flowers, which are not so 
directly concorned as are the stem, leaves, and roots in the plant's relations with the world outside.

Flowers, to be sure, have undergone changes during the millions of years that seed plants have existed; if this were not true, there would not be the great variety of flowers that we now find. But these changes have gone on much more slowly than have the changes in vegetative organs, and so all the members of a family may have kept very much the same flower structure, although in other ways they have come to be very different from one another. This is why the structure of flowers is so useful in fixing relationships. For example, the apple, the raspberry, the strawberry, and the rose are members of the same family. Their relationship is shown by the structure of their flowers; but one would hardly suspect it from an examination of their other parts.

270. Staminate, Pistillate, and Perfect Flowers. - In classifying angiosperms, we try to determine which of the many kinds of flowers are most primitive - that is, are most like the flowers of the original ancestor or ancestors of the angiosperms and which have departed farthest from the original condition. In a general way, it appears that the original angiosperm flowers were much like the cones of a pine, and that in the course of time advances have been made from this condition in several different directions.

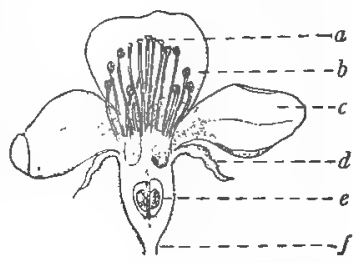

FIG. I50. - A lengthwise section through the flower of an apple (a perfect flower); $a$, stigmas; $b$, anthers; $c$, a petal; $d$, a sepal; $e$, ovary with ovules; $f$, flower-stalk. For example, angiosperm flowers seem to have been at first of two distinct sorts - staminate and pistillate. Many angiosperms of the present day, like the cucumber and the Indian corn, still have separate staminate and pistillate flowers. In this respect, the cucumber flower is more primitive than a flower which, like that of the 
Missing Page 
Missing Page 
arranged, not spirally, but in a definite number of circles. Thus the lily has one circle of sepals, one of petals, two circles of stamens, and one circle of macrospore leaves which have united to form a single pistil.

In the more advanced monocotyledons, the number of each sort of part has usually become three or six; in the more advanced dicotyledons, it is most commonly four or five or a multiple of four or five. In a particular flower, some of the parts may remain numerous although the other parts have become few and fixed in number; thus, the apple flower has five sepals, five petals, and usually five macrospore leaves, but many stamens. In other flowers, as in those of the bean and lily, all the parts are few and fixed in number.

273. Union of the Parts of a Flower. - In the more primitive flowers, all the parts are separate from one another; the sepals are attached to the flower-stalk below the other parts; the petals (if there are any) are next above the sepals, the stamens are next, and the attachment of the pistil or pistils is at the end or top of the stalk. This is the arrangement in a buttercup. But many flowers have departed from this condition, because some of their parts have grown together more or less. Often the petals are united into a tube for part of their length; as in the cucumber flower, or for their whole length, as in the morning-glory and the petunia. In flowers with united petals, the sepals are usually also united with one another in the same way; this is the case in the cucumber flower. Sometimes, as in the Roman hyacinth, both sepals and petals unite to form a single tube.

Often some or all of the stamens are connected writh one another. For instance, in the flower of the sweet pea, as in that of the bean, nine of the ten stamens are grown together by their filaments. All of the many stamens of the hollyhock or of the cotton are united by their filaments into 
a tube. In the flowers of the sunflower, the dandelion, and others of the composite family, the five stamens are united by their anthers, the filaments bcing separate. The stamens of some flowers are joined to the petals, or to the sepals, or to both. The Roman hyacinth has a stamen opposite, and partly united with, each sepal and each petal.

A pistil may be composed of a single macrospore leaf, as in the bean which has but one pistil, or in the strawberry which has many. But in many flowers the pistil is a compound structure formed by the union of two or more macrospore leaves. The pistil of the sunflower or of the dandelion is composed of two macrospore leaves; that of the lily or the hyacinth of three;

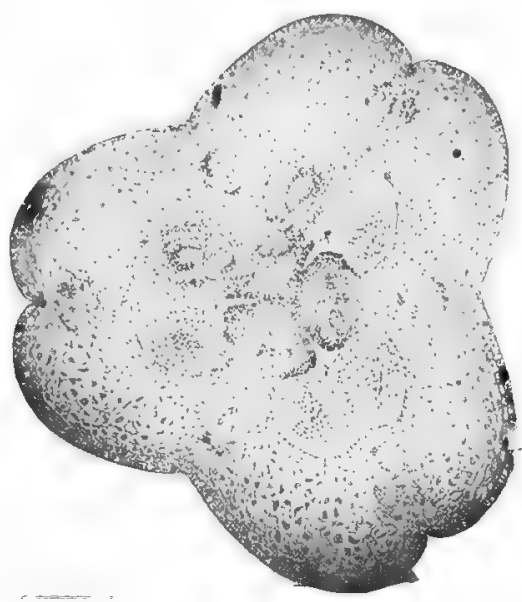

FIG. I54. - Cross section through the ovary of a lily, showing how it is formed by the union of three macrospore leaves. Six ovules appear in the section - two in each of the three cavities of the ovary. and that of the apple usually of five. These compound pistils are less primitive than the simple pistil of the bean or of the corn. Still another form of union of parts is seen in the pistillate flower of the cucumber. There the sepals and petals are grown together with the wall of the ovary. As a result, instead of being attached to the flower-bearing branch below the ovary, as in the lily flower for example, the sepals and petals seem to grow out of the top of the ovary. In the sunflower, sepals, petals, and stamens are united in the same way with the ovary wall. In this respect, 
the primitive condition is that found in the lily, whose sepals, petals, and stamens are all separate from the ovary wall.

274. Regular and Irregular Flowers. - The more primitive flowers are regular; that is, they can be cut in many ways into two like halves; a flower is irregular if there is only one direction in which it can be cut into two parts that are alike. An irregular flower can be said to have a right side and a left side; a regular flower is alike on all sides. Examples of regular flowers are those of the lily and the rose. The bean, pea, violet, and lady's slipper (Fig. I59) have irregular flowers. From what has now been said about the different forms of flowers, we see that the same flower may be primitive in some respects and advanced in others. For instance, the lily is primitive in having its parts all separate and in being regular in shape; it is advanced beyond the primitive condition in having both stamens and pistil in the same flower, in having sepals and petals, in having its parts few and arranged in circles, and in having a compound pistil. The bean flower is more primitive than that of the lily in having a simple pistil; it is more advanced in its irregular form, and in the union of its sepals, that of two of its petals, and that of all but one of its stamens.

275. Arrangement of Flowers. - A flower is always borne at the end of a stem or branch. If a plant bears more than one flower, then plainly all the flowers, or all but one, must be borne on branches. Sometimes the flower-bearing branches start here and there along the main stem in the axils of ordinary foliage leaves. But as a rule, if a plant has many flowers, its flower-bearing branches are short and are borne close together in the axils of small bracts. In this way a flower cluster is formed. The stalk of each individual flower in the cluster is called a pedicel; the stalk of the whole cluster, which may be the end of the main stem or may be itself a branch, is called a peduncle. Both peduncle and 
pedicels may vary much in length, and these variations result in flower clusters of different forms.

One of the simplest kinds of clusters is the raceme, in which both the peduncle and the pedicels are fairly long and all the pedicels are of about the same length. The lily-of-thevalley, the bean, and the currant have their flowers in racemes. In a spike, such as that of the plantain or of the mullein, the pedicels are so short that the flowers are very close to the peduncle, and the peduncle is shortened enough to bring the separate flowers close together. A catkin is much like a spike, excepting that it droops. The flower clusters of willows and of a good many other trees and shrubs are catkins. In a corymb, like that of a hawthorn, the peduncle is shortened; the pedicels are of unequal length, so that all the flowers are borne at about the same level and the cluster is more or less flat-topped. In a corymb the flowers that come from the lower part of the peduncle are the first to open. A cyme is like a corymb, excepting that the flower at the end of the peduncle (the central flower of the cluster) opens first, and those borne lower down on the peduncle open later. The flower clusters of pears and apples are small cymes. In an umbel, such as that of the cherry, the peduncle is so much shortened that all the pedicels arise at the same level. They are also of about the same length, so that an umbel, like a corymb, is flat-topped.

In a head, both peduncle and pedicels are much shortened, so that all the flowers are at about the same level and are very closcly packed together. The heads of the red clover are familiar. So are those of the members of the composite family, including the sunflower, the dandelion, and the thistle. The flowers of composites are so closely packed together that the head is thought of by most people as a single flower. This notion is helped by the fact that the outer flowers of the head are often (as in the sunflower and the daisy) different from the inner ones and look like 
petals; and by the further fact that just below the head are many bracts that look like sepals. Really, however, a single head of a sunflower, a daisy, or a dandelion contains many separate small flowers.

276. Compound Flower Clusters. - The kinds of clusters so far mentioned are simple; they have, in each case, a peduncle whose branches are the pedicels. But the branches of the peduncle may themselves branch, and so the pedicels may be branches of the third or fourth order. Such repeated branching gives rise to a compound flower cluster. A common form of compound cluster is the panicle, a compound racemc. The tassel of the Indian corn is a panicle. The flowers of the elder and of the mountain ash are borne in compound cymes. Compound umbels are common; they

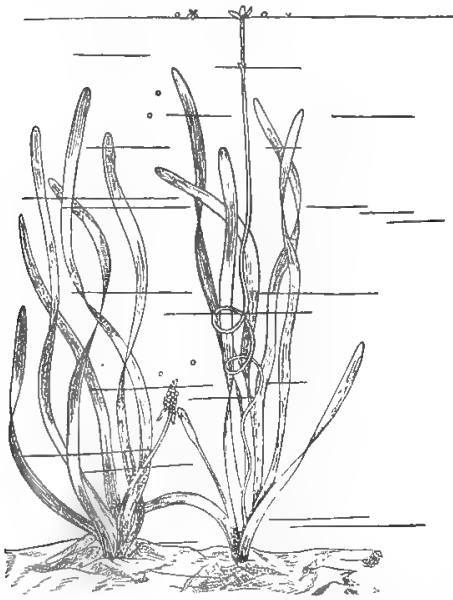

FIG. I55. - Tape-grass (Vallisncria spiralis). The plant on the left bears staminate flowers which, still unopened, are breaking away and rising to the surface of the water. The plant on the right bears a pistillate flower on a long stalk which reaches to the surface. After Kerner. are borne by many members of the parsley family, including the parsley, the carrot, and the parsnip.

277. Pollination: How It is Brought About. - By pollination is meant the carrying of the pollen grains from the anther that produced them to a stigma of the same or of another flower. The pollen of the great majority of angiosperms is carried to the stigmas either by the wind, as in the corn and other grasses; or by insects, as in the bean. Some agents other than the wind and insects bring about pollination in certain cases. Thus, 
there are some plants living in the water, such as the common tape-grass (also known as "eel-grass" and "wild celery," Figs. $5_{55}$ and I56), which depend upon currents of water to carry the pollen to.the stigma. It is not the pollen alone of the tapegrass that is carried, however, but the whole staminate flower. This floats about, as the illustration shows, until it comes in contact with a pistillate flower. There are some plants whose flowers are pollinated by humming birds and other birds, others are pollinated by snails and

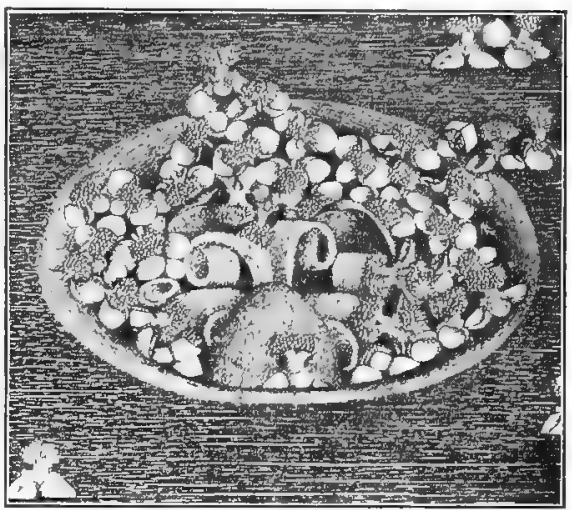

FIG. I56. - Staminate and pistillate flowers of the tape-grass. The staminate flowers are caught in a slight depression in the surface of the water about a pistillate flower, and the pollen of some of the stamens is thus brought into contact with the pistil. After Wylie. slugs, and a few in the tropics are pollinated by bats.

278. Pollination by the Wind. - It has already been pointed out that pollination by the wind is an extravagant method, because the pollen is scattered in a haphazard way and only an occasional grain can land upon a stigma. Nevertheless, many angiosperms, as well as all gymnosperms, depend upon the wind for pollination, and yet are very successful in forming seeds and in multiplying their numbers. Wind-pollinated angiosperms are chiefly plants that grow in locations where the wind may well serve their purpose. If they are small, like the grasses and sedges, great numbers of plants of the same species commonly grow close to one another in places like meadows and marshes where the wind 
has full sweep. Under such circumstances each stigma has a good chance of receiving pollen. Many shrubs and trees, such as the hazel, alder, elm, oak, and poplar, are windpollinated. Their flowers are high up above the ground, where they are reached by winds from all directions. Windpollinated plants necessarily produce much more pollen than is actually needed for pollination. Their pollen grains are usually small, smooth, and dry, so that they may be blown about easily and carried long distances. Their stigmas are often large, and branched or covered with projections in a
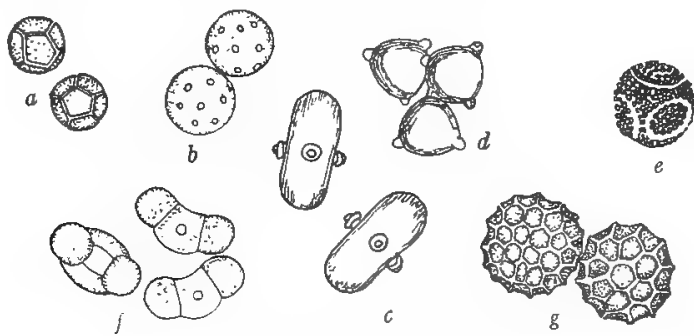

FIG. I57. - Types of pollen grains : $a$, pollen of one of the pinks (Dianthus); $b$, of the pumpkin; $c$, of Morina persica; $d$, of the enchanter's nightshade (Circca alpina); $\varepsilon$, of a passion-flower (Passiflora kermensina); $f$, of a pine (Pinus pumilio); $g$, of Cobøa scandens. After Kerner.

brush-like or feather-like fashion; this increases the chance that some of the pollen grains will be caught and held. As a rule, the flowers of wind-pollinated plants are small and have no bright-colored parts, no odor, and no nectar.

279. Pollination by Insects. - There are many more species of insect-pollinated than of wind-pollinated plants. As a rule, insect-pollinated plants produce less pollen than do wind-pollinated plants; on the other hand, their pollen grains are sometimes (though by no means always) comparatively large. Pollen grains which ate to be carried by insects are often covered with a sticky substance, and as a rule their outer surfaces are rough or provided with small 
spines or warts; thus they are likely to stick to insects' bodies and so to be carried about. The stigmas, too, are commonly rough and sticky. Insect-pollinated plants have various ways of advertising their presence to the insects whose assistance is needed. Many of them have large, brightly colored or white flowers. The plants that we raise for the beauty of their flowers are insect-pollinated; the size

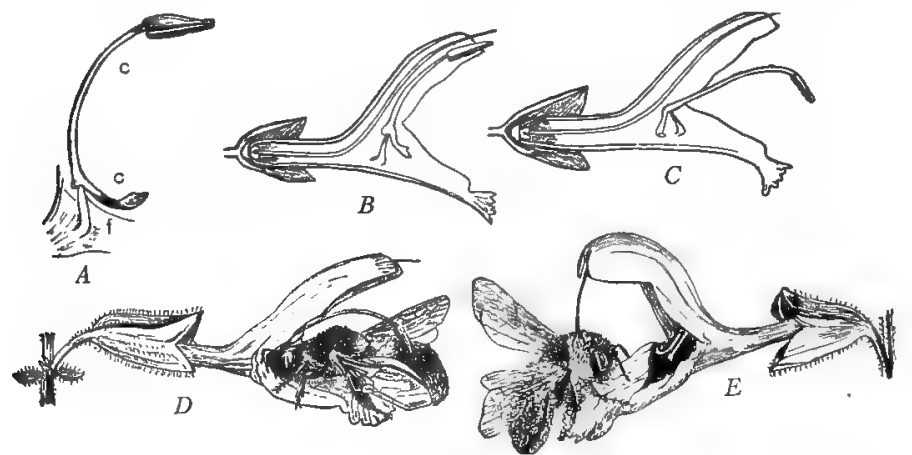

FIG. I58. - Salvia glutinosa, showing how cross-pollination is assured. $A$, a stamen; the short upright column $(f)$ is the filament; $c, c$, the long connective, bearing the anther at its upper end. $B$, a lengthwise section of a young flower, showing the anther in its natural position. $C$, the same, the anther having been pushed down by a bee pressing on the lower part of the connective. $D$, a bee visiting a young flower; the anthers have been pushed down and are touching the bee's back. $E$, a bee visiting an older flower whose pollen has been shed; the style has now grown long and hangs down so as to touch the bee's back at the same place at which it was touched by the anthers of the younger flower. After Kerner.

and color of the flowers have come about, not because they are beautiful, but because such flowers attract insects and in this way are useful to the plant. We have selected the plants for cultivation because the same things that make their flowers attractive to insects are also pleasing to us.

However, the flowers of many ctitivated plants have been made much larger and more showy by breeding than they originally were. Our large double roses and carnations, 
for instance, are very different from the single wild flowers from which they have been developed. The odors of flowers, too, are a means of letting insects know of their presence. Most of the odors that are attractive to insects are also, fortunately, pleasant to us. The odors of certain flowers are another reason why we have chosen for cultivation the plants that bear them. Some flowers, like carnations, are conspicuous to both sight and smell. Other plants, like mignonette, have small, inconspicuous flowers which attract insects chiefly by their odor. The pleasant-smelling substances contained in many flowers, such as roses, violets, jasmine, and lavender, are extracted and used in the manufacture of perfumes. Occasionally, however, odors that attract insects are very unpleasant to us; examples of this sort are the skunk cabbage and the carrion-flower.

280. Nectar. - Although it is true that flowers attract the attention of insects by their size, color, and odor, the insects do not visit flowers simply because they are beautiful or sweet-smelling. An insect flies or crawls to a particular flower because that flower may be useful to it in some way. Insects find different flowers useful in different ways. Most often the flowers supply them with a special sweet food called nectar. Nectar is produced in various parts of a flower, and in some cases even outside the flower; but usually it is found in such a place that when an insect visits a flower in search of nectar, some part of its body touches one or more anthers and so brushes off and carries away some of the pollen. The nectar of the horse-chestnut, for example, is formed at the bottom of the sepals; that of the cucumber and the pumpkin, in a cup formed by a union of the lower parts of the sepals and petals. The buttercups and lilies produce nectar on the lower part of each petal; that of the columbine is formed in the lower spur-like end of each petal; and that of the strawlycrry in the bottom of the flower, between the stamens and the pistils. Many of 
the features in which angiosperm flowers differ from one another - including the shape and color of sepals and petals, and the position of stamens, pistils, and nectaries - have developed with reference to insect-pollination.

The relation of their flowers to insects, therefore, has been a very important factor in the evolution of angiosperms; and one reason why the angiosperms as a group have been so successful in the struggle for existence is the fact that so many of them have secured the help of insects in pollination. The relations of insects to flowers have likewise been an important factor in the evolution of insects. Thus, butterflies and moths live entirely or chiefly upon nectar; they have a long, flexible, sucking proboscis, which can be pushed deep into the parts of flowers where nectar is to be found. The proboscis is of different length in different butterflies and moths, and each species seeks the flowers to which the length of its proboscis best adapts it. Bees not only feed upon nectar themselves, but they gather and store it up in the form of honey for the use of their young - a habit which makes the honey-bee and the nectar that it gathers of great practical interest to us. The mouth-parts of bees are especially adapted to the work of biting and sucking, which enables them to obtain nectar; and some of them, including the honey-bee, have a special apparatus on their hind legs, consisting of a mass of rough, stiff hairs to which pollen grains cling in great numbers.

281. Pollination of the Lady's-Slipper. - The lady'sslipper offers a very good illustration of the way in which a flower may be adapted to pollination by particular insects. The flower of the lady's-slipper has the form of a hollow sac with an opening at the top; this opening is partly closed by a flap. The edges of the opening in front of the flap are curved inward, so that insects of various sizes can get into the sac but cannot well get out at the same place. Inside, at the bottom of the sac, are juicy hairs that are 
eaten by insects; these hairs perhaps bear also small drops of nectar. If the insect is of the right size and strong enough, it can push its way out through the opening at either side of the flap; certain bees, for example, can do this; smaller insects, such as flies, cannot, but remain inside the sac and die there. On the under side of the flap (the side toward the inside of the sac) is the stigma; and on either side of

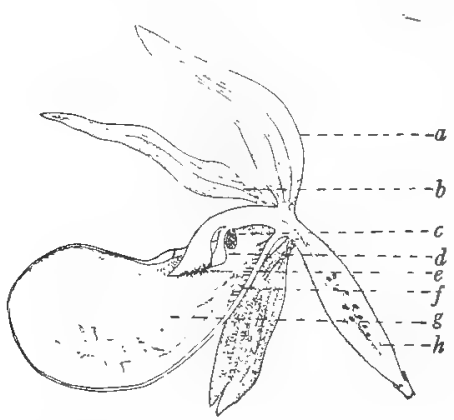

Fig. I59. - A lengthwise section through the flower of a wild lady'sslipper (Cypripedium acaule); a, one of the three sepals; $b$, a petal; $c$, the anther of a fertile stamen; $d$, a sterile stamen; $e$, the stigma; $f$, hairs at the bottom of the sac, $g$, which is composed of a single petal; $h$, the ovary.

it can be pollinated only by an insect of about a certain size; and often, as in the columbine and in flowers like the petunia, whose petals are united into a tube, the nectar can be reached only by an insect with a proboscis of at least a certain length. There are flowers that are adapted to pollination by only one particular kind of insect (see $\$ 2_{2} 83$ and 284 below).

282. Pollen as Food for Insects. - There are flowers including the common anemone, the roses, and the hepaticas - which depend upon insects for pollination, but which form 
no nectar, or practically nonc. The insects that visit such flowers eat the pollen instead of nectar; and the flowers produce so large an amount of pollen that, although a good deal is eaten by an insect visitor, enough clings to its body so that it is sure to carry some pollen to the next flower that it visits. This method of providing food for insects is by no means economical of pollen; but it is probably less extravagant, after all, than wind-pollination.

283. Insects that Lay their Eggs in Flowers: the Yucca Moth. - In some cases, an insect visits a flower, not to obtain food for itself, but to lay its eggs in a place where its young, when the

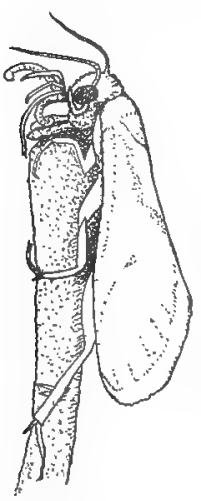

Fig. I6r. - The Yucca moth gathering pollen from an anther. After Riley. eggs hatch, may find food, or shelter, or both. The Yuccas, living in the southern United States and Mexico, are members of the lily family, with sword-like leaves and a tall stalk that bears many white flowers (Fig. I60). The flowers of various species of Yucca open at twilight and are visited by a certain night-flying moth. The female moth alights first on an anther. There she scrapes up a mass of the sticky pollen grains and rolls them into a ball. After the pollen is gathered, the ball is tightly held by a special long, flexible organ. Then the moth visits a pistil (usually of another flower), and by means of a sharppointed organ she pierces the ovary wall and deposits her eggs in the ovary among the ovules. Finally she visits the 
stigma of the same pistil and pushes the ball of pollen down into the hollow style - just as though she intended to make sure of the pollination of that particular flower. When the eggs hatch in the ovary of the flower, the young grubs eat some of the seeds into which the ovules have developed; after a time, the grubs escape through holes that they make in the ovary wall.

The ovules, of course, would not have grown into seeds if the flower had not been pollinated; therefore, the pol-

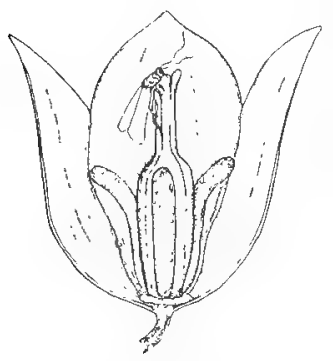

FIG. I62. - A Yucca flower; the moth is forcing a mass of pollen into the cavity of the style. After Kerner. lination by the mother moth insured a supply of food for her young. But the grubs eat only part of the many seeds that the ovary contains. So the plant secures a supply of seeds, and in this way it also is benefited by the visit of the moth. The pollen of Yucca is not carried by the wind; and if the moth for any reason does not visit the plant, no seeds are formed. The same thing is true if it is grown where the moth does not live, as for example in European gardens.

284. Pollination of the Fig. - The fig that we eat is not a fruit, but the hollow end of a peduncle inside which was borne a cluster of flowers. The arrangement of the flowers is shown in Figure 163 . It is the tissues of the hollow end of the peduncle that become soft and juicy. In eating a fig we bite many small, hard bodies; these are the real fruits. The flowers of the fig are of three kinds: staminate fiowers, pistillate flowers with long styles, and pistillate flowers with short styles. Certain trees bear figs which when young contain only long-styled pistillate flowers; the figs borne on other trees contain staminate flowers near the openings of their sac-like cavities and short-styled pistillate flowers in 
the lower part of each sac. Figs of both kinds are visited by the females of a certain kind of wasp.

Suppose that a wasp enters a fig which contains staminate flowers and short-styled pistillate flowers. She inserts her egg-depositing organ into a style and lays an egg in the ovary. After this egg hatches, the young insect grows rather rapidly and the tissues of the ovary wall surrounding it also grow, forming a gall. The young insect feeds on the cells of this gall. When it is fully grown, it breaks out of the gall. The female insects (but not the males) finally make their way out of the cavity of the fig. But in doing so an insect brushes against the anthers of the male flowers which are near the opening of the cavity and collects pollen on all parts of her body. The wasps which escape in this way visit other figs in order to find a place to lay their eggs. Some visit figs containing staminate and

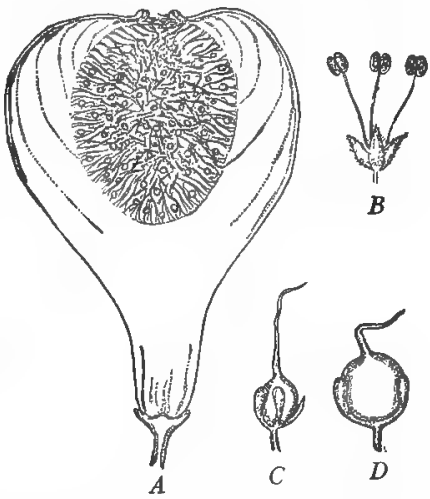

Frg. т63. $-A$, a fig, showing how the flowers are borne inside the hollow end of the peduncle. $B$, a staminate flower of the fig. $C$, a long-styled pistillate flower. $D$, a short-styled pistillate flower. After Kerner. short-styled pistillate flowers and repeat the history that we have just followed. Others visit figs of the other sort, which contain only long-styled pistillate flowers.

Coming in contact with these flowers, a wasp deposits on the stigmas some of the pollen with which her body is covered, and so pollination is brought about. But when she attempts to lay an egg in the ovary of one of these flowers, her egg-depositing organ is not long enough to reach to the base of the style. So the egg is laid, not in the ovary, but in 
the style. Here conditions are not favorable for its further development; the egg dies, and no gall is formed. Instead, in the ovary of this flower a seed is produced, and the ovary develops into a small, hard fruit. The short-styled flowers of the fig seem to be of no direct use to the plant. Indirectly they are useful, because they supply a place in which the eggs of the wasp can hatch, and so the species of insect which pollinates the plant is kept alive. The figs that contain only long-styled pistillate flowers, and in which thercfore fruits may be formed, are the ones that develop into edible figs. Most of the figs that contain staminate and short-styled pistillate flowers dry and fall early and so are useless. It is customary among fig-raisers to plant an occasional tree bearing figs of this latter sort, and branches of this tree on which figs are growing are hung on the branches of the trees that bear edible figs. This insures the pollination of the long-styled flowers in the edible figs and the development of seeds.

The figs of some varieties will ripen in a perfectly normal way even if none of their pistillate flowers are pollinated, although of course they contain no fruits or seeds. The figs of other varieties, however - including those which supply the dricd figs of commerce - will fall from the tree before they are fully grown, unless their flowers have been pollinated.

285. Cross-Pollination and Self-Pollination.-Crosspollination means the carrying of pollen from the anthers of one flower to the stigma of another flower which may be on the same or on a different plant. Self-pollination means the carrying or dropping of pollen from the anthers of one flower to the stigma of the same flower. There are pectliarities in the structure of many flowers, both those of wrind-pollinated and those of insect-pollinated plants, which make self-pollination either impossiblc or inuch more difficult than cross-pollination. The study of these peculiarities lias 


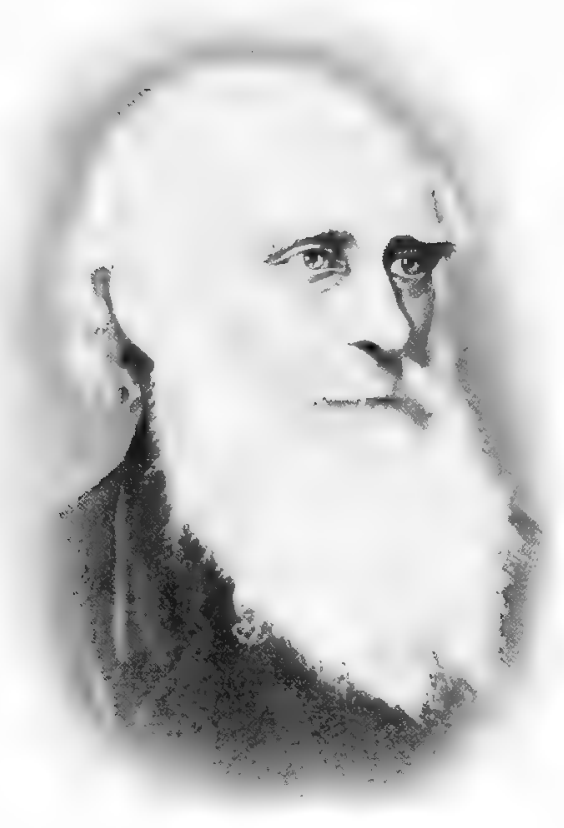

CHARLES DARWIN

Born at Shrewsbury, England, I809; died at Down, I882. First established on a basis of scientific observation and experiment the doctrine of the origin of new species of plants and animals through descent from older species - a doctrine first fully presented in 1859 in the Origin of Species. His work has been of revolutionary importance, not only in botany and zoölogy, but also in the other sciences as well as in history and philosophy. 

led many observers to conclude that cross-pollination is of greater benefit to plants than self-pollination. Darwin found that in many plants, though by no means in all that he studied, cross-pollination results in more vigorous and more productive offspring than self-pollination. Especially is this the case if the pollen and stigma are borne in flowers on different plants. The results of cross-pollination between flowers on the same plant are more like those of self-pollination, although even this kind of cross-pollination is sometimes more favorable than self-pollination.

The difference between the effects of cross-pollination between flowers on the same plant and those of cross-pollination between flowers on different plants is shown by some recent experiments. It is found that if the silk of Indian corn is dusted with pollen from the tassels of another plant and is kept free from the pollen of the same plant, the offspring is as a rule more vigorous, grows to a larger size, and bears more fruit, than that which results if the silk is dusted with pollen from the same plant. On the other hand, self-pollination often occurs in nature, and there are many kinds of plants in which it is the regular method and which do not seem to suffer from lack of self-pollination. However, in varieties of tobacco that are ordinarily self-pollinated, it is found that sometimes (though not always) plants of greater vigor result from cross-pollination.

286. Arrangements that Favor Cross-Pollination. - One of the simplest ways of securing cross-pollination between flowers on different plants is followed when the staminate and pistillate flowers are separate and borne on different plants. This is the case in the willows, the poplars, and the hop. The disadvantage of this arrangement is that both kinds of plant (that is, those with staminate and those with pistillate flowers) must grow near each other. If one sort of plant is missing in a certain locality, or if plants of the two kinds are too far apart, pollination does not occur and 
no seeds are formed. If, as in the cucumber and the Indian corn, staminate and pistillate flowers are separate but borne on the same plant, only cross-pollination can occur, but it may be between flowers on the same plant. However, under such conditions some pollen is quite certain to be carried from one plant to another.

Cross-pollination between flowers on different plants is sometimes made more likely by the fact that the flowers of the two sorts on a particular plant ripen at different times; either the staminate flowers ripen and shed their pollen before the pistillate flowers are ready for pollination; or else, as in the oaks and the walnuts, the pistillate flowers ripen and are pollinated before the staminate flowers are ripe. Among plants with perfect flowers (flowers containing both stamens and pistils) there are also many conditions that favor cross-pollination. One of the commonest, something like what we have just seen in plants with separate staminate and pistillate flowers, is the habit of ripening the stamens and the pistil of the same flower at different times. Sometimes, as in the onion, the gladiolus, and the members of the composite family, the stamens ripen first; in other cases, as in the horse-chestnut and in some varieties of tobacco, the pistil ripens before the stamens.

In those flowers whose stamens and pistil ripen at nearly the same time, the parts of the flower are often so arranged that pollen falling from the anthers is not likcly to land upon the stigma. An arrangement of this sort has been described in the bean, and the same result is brought about in different flowers in a great variety of ways.

A peculiar arrangement that favors cross-pollination between flowers on different plants is seen in many species of primroses (Fig. I64). These have perfect flowers, but they are of two different kinds, which are borne on different plants. The flowers of some plants have high stamens (that is, stamens set high up on the petals) and low (short) pistils: 
the flowers of other plants have low stamens (of about the height of the pistils of the first plant) and high pistils. An insect that visits a flower of the first kind receives pollen on the part of its body that touches an anther; when it visits a flower of the second kind, the part of its body that touched the anther of the first flower touches the stigma of the second and deposits pollen upon it. Another part of the insect's body touches the anther of the second flower, and when it visits a flower of the first kind it is that part of the body which touches the stigma.

Some plants even have stamens and pistils of three different lengths, and consequently three different kinds of flowers. There is still another way in which cross-pollination is sometimes favored. The pollen of some plants will not germinate on the stigma of the flower which produced it, nor even on the stigma of another flower of the same plant. In other

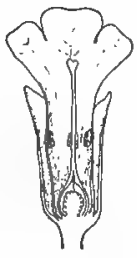

A

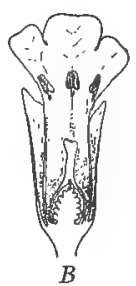

FIg. I64. - Primrose flowers: $A$, one with low stamens and high pistil; $B$, one with high stamens and low pistil. After Eichler and Prantl. cases, a pollen grain may germinate on the stigma of the same flower, but the pollen tube does not grow so rapidly nor become so long as it would if the pollen came from another flower, especially a flower borne on another plant. This is the condition in the rye, the pear, the carnation, and the American chestnut. In such cases, no seeds, or but few seeds, result from self-pollination, but many seeds are formed if cross-pollination occurs.

In other plants, however, pollen from the same flower is as effective, so far as seed production goes, as pollen from a different flower. This is true of oats, beans, peas, and many varieties of wheat. But although many seeds may result from self-pollination in these cases, it does not always follow that the plants that grow from these seeds will be as 
vigorous as though the seeds had been produced by crosspollination.

287. Self-Pollination. - This is by no means rare, in spite of the fact that so many features in the structure of flowers seem to favor cross-pollination. Even in species that are usually cross-pollinated, self-pollination is often provided for in case cross-pollination should fail. An instance of this kind is seen in the tiger lily, whose style, if pollen is not brought in from another flower, bends so as to bring its stigma into contact with an anther. There are also not a few plants in which self-pollination is the rule, and in which cross-pollination, if it happens at all, does so only rarely and accidentally. This is true, for example, of wheat, of most varieties of peas, and of some varieties of barley.

Some other plants produce small flowers that never open and in which therefore cross-pollination is quite impossible. Illustrations of this sort are the hog-peanut and some of our common violets. In the spring the violets bear the familiar flowers which open and which may be cross-pollinated. After these spring flowers disappear, and from time to time during the summer, small, green, bud-like structures appear at the ends of short stalks. These bud-like bodies are really flowers that never open. When the pollen-grains of these flowers are ripe, they germinate in the pollen sacs; the pollen tubes grow out through the walls of the sacs, find the stigma of the pistil, and grow through the style into the ovary. Thus, by means of these flowers the violet is independent of the visit of insects and is sure to produce seed; indeed, some of the violets form most of their seeds in the ovaries of these little closed flowers.

288. Hybrids. - Hybrids or crosses are plants produced by the union of gametes that belong to different species or varieties. In seed plants, such a union of different gametes of course results from the pollination of a flower by pollen 
from a flower of a different variety or species. It is plain that such a thing may happen in the case of wind-pollinated plants whose pollen is blown about in all directions; it happens also in insect-pollinated plants, because as a rule a particular insect visits several or many kinds of flowers. However, a hybrid does not always result when strange pollen lands upon the stigma of a flower; for often the pollen of one species will not germinate upon a stigma of another species; and even if the pollen grain does germinate, the pollen tube that grows from it may not reach the ovary, or if it does, the unlike gametes may not be able to unite. So hybrids are not so frequent as one might expect from the lavish way in which flowers produce and distribute their pollen.

Generally speaking, a hybrid is more likely to be formed the more nearly related the plants are to which the gametes belong. Thus there are many hybrids known between varieties of the same species. Many common garden varieties of roses, carnations, strawberries, peas, corn, and other cultivated plants are descended from hybrids of this sort. There are fewer, but still a good many, hybrids known between distinct species; and occasionally one is formed between plants of different genera. Hybrids may be produced by artificial pollination - that is, the pollen may be transferred by hand from a flower of one variety to the stigma of a flower of another variety. When this is done, care must be taken that the same stigma is not also dusted with pollen of a flower of its own kind. For this reason, the flower that is artificially pollinated is kept covered from a time when it is quite young until after it has set seed and its stigma and style have withered. If it is a perfect flower, its stamens must be removed before they are ripe, so that none of their pollen can possibly reach the stigma. A hybrid usually combines in a new way some of the qualities of one parent with some of the qualities of the other parent. 
Sometimes this new combination of qualities is a very valuable one. The production of hybrids is one of the means used to secure new varieties of plants, and some of the results that have been accomplished in this way will be discussed in Chapter XXIII.

289. Some Practical Uses of Flowers. - Apart from their value for ornamental purposes, the only practical uses to which flowers are put on a large scale are the manufacture of perfumes and drugs. They do not ordinarily contain food substances in large enough quantities to make them useful as articles of diet. The flowers of the cauliflower, however, are an exception to this rule. The head of the cauliflower is a thickened flower cluster which has been much changed during the centuries that it has been cultivated. We eat the flower buds, the flower-stalks, and the bracts. If the plant is kept alive through the winter and set out again the next spring, it sends up a tall flower-stalk that bears ordinary flowers, and that produces fruits and seeds.

The artichoke (or "French artichoke," so called to distinguish it from the "Jerusalem artichoke" whose tubers are eaten) is a member of the composite family. We eat the bracts which are attached just below the head of flowers, and the soft, thick end of the flower-bearing branch. The flowers themselves are not eaten. Cloves are the dried unopened flower buds of a tropical tree. The tree seems to be a native of the Molucca Islands, but it is now cultivated in various tropical countries. The dried buds contain about eighteen per cent of the oil known as oil of cloves. Among the flowers used for medicinal purposes are those of the arnica, calcndula, camomile, hemp, saffron, henbane, horehound, and peppermint. Pyrethrum or insect powder is made from the dried flowers of certain plants of the composite family. 


\section{CHAPTER XVIII}

\section{FRUITS AND SEEDS AND THEIR USES}

290. True Fruits and False Fruits. - We have seen that the fruit of an angiosperm consists of a fruit coat which encloses one or more seeds; often also there is more or less. tissue between the seeds. The fruits of many angiosperms, like those of the cucumber and the bean, contain more than one seed each; the fruits of many others are one-seeded. All the members of the grass family, for example, to which the corn belongs, have oneseeded fruits; so have the members of the composite family, which includes dandelions and thistles. In the composites and in most grasses, as in the corn, the fruit coat is thin and fits so closely about the seed that the whole fruit looks much like a seed. Our common

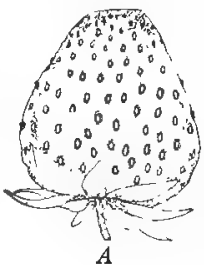

FIG. 165. $-A$, the false fruit of the strawberry. $B$, a lengthwise section of the same; $a$, swollen end of the pedicel; $b$, one of the small, hard, true fruits; $c$, the sepals. nuts, too, are one-seeded fruits. The shell of a hazel nut, a walnut, a hickory nut, a chestnut, or an acorn is the fruit coat; the part inside, which we eat, is the seed.

A fruit which, like all those mentioned so far, has been formed from the ovary alone (with its enclosed seed or seeds), is spoken of as a true fruit, because the word fruit is sometimes applied to a thing that is more than a true fruit. An example of the latter sort is the red "fruit" that we call a 
strawberry (Fig. 165). The soft, juicy part of a strawberry is really the thickened end of the pedicel to which sepals, petals, stamens, and pistils were attached; the little hard bodies that are borne in pits on the surface of the berry are one-seeded true fruits. Each true fruit has been formed from the ovary of one of the many pistils of the strawberry flower. A structure which, like a strawberry, is more than a true fruit (because it has been developed from something more than an ovary) is called a false fruit. This is not a

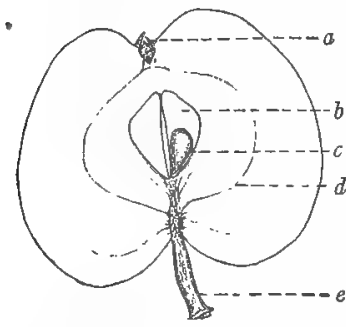

FIG. r66. - A lengthwise section through an apple; $u$, tips of the sepals; $b$, the part developed from the ovary (the "core"); $i$, a seed; $d$, line showing the course of a vascular bundle; $e$, the pedicel. very fortunate name, because there is nothing false about a strawberry; but it is a name that is rather widely used.

The fleshy part of an apple is formed by a thickening of the end of the pedicel and of the lower parts of the sepals, and only the core is developed from the ovary. The' apple, therefore, like the pear and the quince, which resemble it in this respect, is a false fruit. The fleshy part of the fig, another false fruit, is, as we have seen, the sac-shaped end of a peduncle; inside it are the small, seed-like true fruits. A pineapple is formed by the thickening of a whole flower cluster, including the separate flowers, the bracts, and the peduncle.

A raspberry or a mulberry might be called a compound fruit, because each little division of the berry is a separate fruit, containing a seed; as a matter of fact, each division of the mulberry is a false fruit because the juicy part is developed from the sepals. A blackberry is like a raspberry, excepting that the end of the pedicel also becomes soft and juicy and forms part of the berry that we eat. It is plain that fruits, whether true or false, can be borne only by angiosperms, 
because angiosperms are the only plants that produce seeds within an ovary. However, the word fruit is often also applied to things that are neither true nor false fruits; as, for example, to the pine cone. We must be cautious not to become confused by this and other careless uses of the word. In the present chapter, only the fruits and seeds of angiosperms will be considered.

291. How Fruits are Useful to Plants: Protection of Seeds. - No doubt the angiosperms have been greatly helped by the fact that their seeds are enclosed in fruits. But the advantages of this arrangement are by no means the same in all cases; various angiosperms produce very different kinds of fruits that are useful in different ways. In general, fruits are of use to the plants that bear them either because they protect the seeds, especially while the seeds are young and growing, or because they help in the scattering of the seeds. Some, like the fruits of the gooseberry and the orange, are useful in both these ways.

Many seeds have hard or tough seed coats which cover the softer parts inside; such seeds need little or no further protection, unless perhaps while they are quite young. But many seeds do need additional protection either from being eaten by animals, or from injury by extreme heat or cold or dryness. It is from dangers such as these that fruit coats protect the seeds of many plants. If a fruit coat is very hard, like that of a nut, the seed coat writhin is likely to be thin and tender. The fruits of most members of the gourd family, to which the cucumber and squash belong, have fruit coats that are firm but not so hard as those of nuts; the seeds of this family are also protected by tough seed coats.

The lemon, the orange, and their immediate relatives have leathery fruit coats; their seed coats, too, are hard and firm. In stone fruits, like the cherry, plum, and peach, the inner part of the ovary wall becomes the hard wall of the 
stone; the soft part inside the stone is the seed, and the seed coat is thin and soft. Some fruit coats, like those of the chestnut and the gooseberry, bear spines that protect them, especially while they are young and growing, from the attacks of animals.

\section{How Fruits Help in the Scattering of Seeds. - A} great many of the structures of both seeds and fruits are helpful to the plant because they bring about, in one way or another, a scattering of its seeds. Plainly it is a good thing for a species to have its seeds scattered so that it may spread over a wider area, provided enough seeds are formed. The more widely the seeds are scattered, the more there are that will fall in places where that particular kind of plant cannot grow; and unless a great many seeds are produced, so that a goodly number may still fall in favorable places, a wide distribution may be bad rather than good for the species. There are plants, such as the oak, the walnut, and the hickory, that have no particular means for distributing their seeds. The fruits or seeds of such plants simply fall to the ground under the plant that bore them; they are not scattered, except as they may be accidentally blown or rolled or knocked about for short distances. Of the plants whose seeds are more widely scattered, a good many depend upon the wind for this purpose. Sometimes the seeds alone are carried by the wind; but often the whole fruit is blown about. Fruits that are distributed in this way are nearly always small and light, and being small they are usually oneseeded fruits. Some, like the fruits of the maple and the elm, have wing-like attachments that increase their chances of being blown about. Many of the fruits of the composite family, such as those of the thistle and the dandelion, bear what looks like a tuft of hairs or bristles; these bristles are really the sepals of the flower, which have remained attached to the fruit.

Currents of water also play a large part in the scattering of 


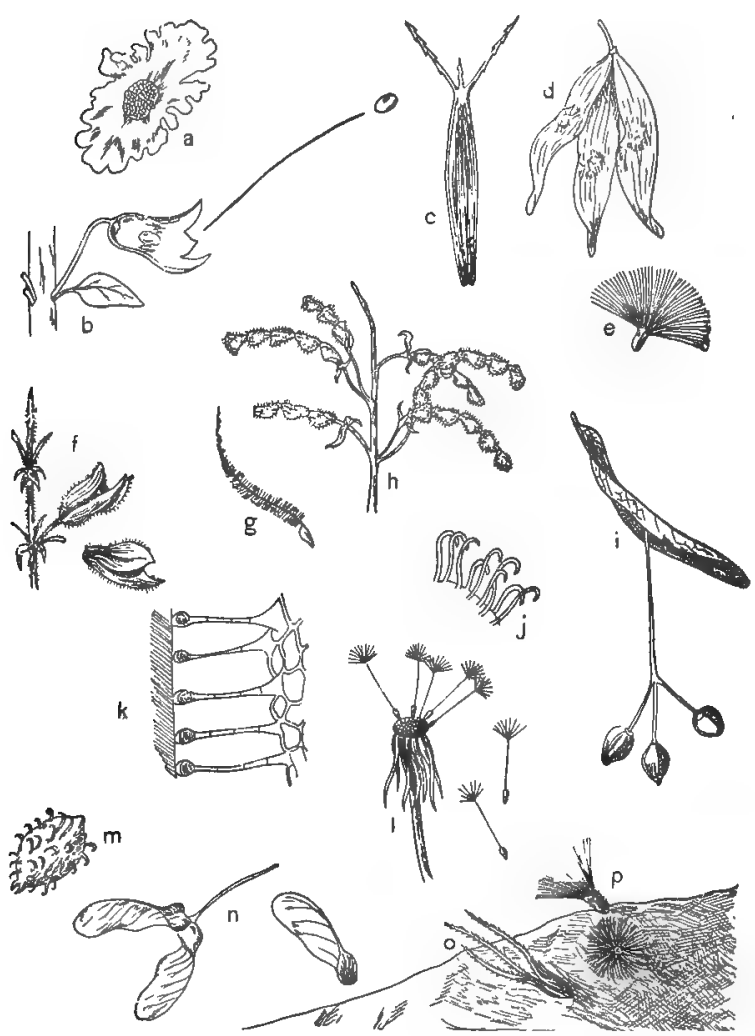

Frg. 167. - Various devices for the scattering of fruits and seeds. The following are carried by the wind: the seed of a Bignonia $(a)$; the fruit of Ailanthus $(d)$; the seed of a willow $(e)$; the fruit of the avens $(g)$; the fruits of the basswood (i), whose peduncle is united for a distance with a bract-like leaf; the fruits of the dandelion $(l)$; and maple fruits $(n)$. The fruits of the Spanish needles $(c)$, of Hedysarum $(h, j)$, and of the cocklebur $(m)$ attach themselves to passing animals. The sepals of Salvia gluinosa, surrounding the ripe fruits $(f)$, bear sticky glandular hairs which adhere to objects that they touch, as shown at $k$. When the germander plant $(b)$ is shaken, the fruits are discharged by a mechanism composed of the sepals and the elastic pedicel. The fruits of Egilops (o) and of Crupina ( $p$ ) creep by means of the hygroscopic movements of hairs and other parts. After Kerner. 
fruits and seeds. Their effect is seen in the distribution of species of plants, sometimes through long distances, along the shores of rivers and lakes, as well as along sea-coasts and from island to island in the seas and oceans. The coconut palm grows on tropical coasts, especially on coral islands, and its distribution depends very largely upon the carrying of its fruits from place to place by ocean currents.

Many different means are resorted to by plants to secure the scattering of their seeds by animals. The fruits of a good many common weeds have hook-like or barb-like attach-

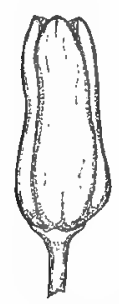
ments by means of which they cling to the coats of animals or to the clothing of human beings that brush against the plants on which they are borne. Some of these hook-like attachments, such as those of stick-tights and beggar-ticks, are outgrowths from the fruit coat; those of burdock burs and cockle-burs develop from

FIG. 168. - Ripe bracts just below the flower cluster. The fruit of a lily, be- wide distribution of the seeds of many
ginning to split at the top.

plants is due to the fact that their fruits or parts of their fruits are edible. An animal that cats such a fruit is of course likely to swallow the seeds also; but the latter are usually (though not always) protected by their seed coats from the digestive juices of the animal, and so pass uninjured through its alimentary tract and may be deposited a long way from the place where they were produced. While they are growing, and the seed coats are still soft and thin, the fruits that are later to be edible are usually hard and sour or bitter; it is only when they are ripe and the seed coats are fully formed that they are pleasant to eat. These edible fruits are of special interest to us. Among them are the stone fruits (cherries, plums, apricots, and peaches), gourd fruits (such as the pumpkin, squash, cucumber, and melons), citrus fruits 
(including the orange, lemon, and grapefruit), berries (currants, gooseberries, blueberries, cranberries, tomatoes, grapes, etc.), and the false fruits and compound fruits that have already been mentioned. Many of the edible fruits, as we have them now, have been greatly enlarged and improved by breeding.

The coats of a good many fruits (for example, those of the pea, the bean, and the morning glory) crack open when they are ripe, and so allow the seeds to fall or

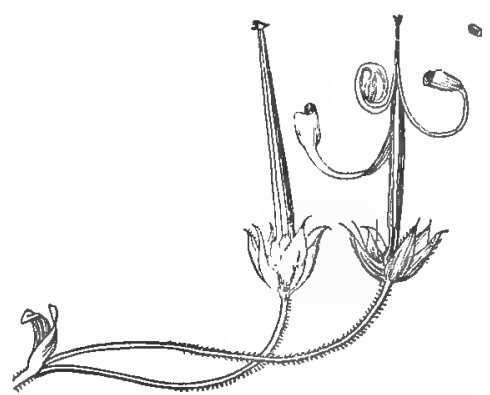

FIG. I69. - The discharge of the seeds of the cranesbill by the sudden opening of the fruit coat and the curling of the parts into which it splits. After Kerner. to be shaken out. Some fruit coats open in an explosive way so as to throw out the seeds, sometimes to a consider-

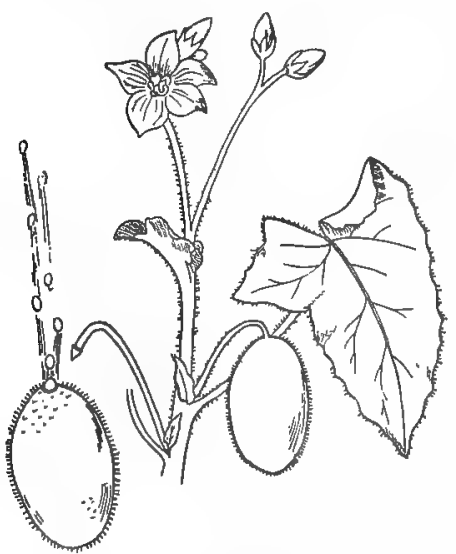

FIG. 170. - A branch of the squirting cucumber, showing a fruit falling from its stalk and discharging its seeds. After Kerner. able distance. The common touch-me-not of the gardens (known also as "balsam") is an instance of this kind; others are the cranesbills (Fig. I69), the violets, whose seeds are pinched or squeezed out by a contraction of the divisions into which the fruit coat splits, and the "squirting cucumber" (Fig. I70), whose seeds, with the juicy pulp surrounding them, are squeezed out through an opening in the end of the fruit. But the majority of fruits do not split when they 
are ripe. Their seeds become free only when the fruit is eaten or broken open, or when its coat decays; or, as is the case with the fruits of the corn, the thistle, and the oak, the seed germinates within the fruit coat, which, like the seed coat, is broken by the growth of the embryo.

293. Nature and Importance of Seeds. - We know that the seed contains a small plant (the embryo) whose growth has been stopped for a time. We know, too, that the embryo can begin to grow again when conditions become favorable; and that the seed also contains a good deal of food that the young plant may use in its growth. The habit of stopping the growth of the embryo at a certain point, and of shutting it up with a supply of food inside the seed coat, marks one great difference between the seed plants and all other plants. This habit is of great advantage, because the young plant so protected may be carried in one way or another to a long distance from the parent, may remain unchanged until conditions about it are favorable, and may then grow rapidly, using the food that was stored in the seed.

Just as different seed plants bear very different sorts of flowers and fruits, so they produce many different kinds of seeds. Every one knows that seeds vary greatly in size. In some plants (some orchids, for example) the embryo is still very small when the seed is ripe, sometimes consisting of only a few cells; in others (such as the bean and the Indian corn) it has a small root and stem (the radicle), a terminal bud (the plumule), and several leaves. Often, as in the corn, the food is nearly all stored in the endosperm; but some seeds, like those of the squash and the bean, contain little or no endosperm when they are ripe, and most of their food is stored in the seed leaves. Most seeds have a hard, tough seed coat; in the horse-chestnut and the Brazil nut the hard secd coat seems much like the fruit coat of a true nut, such as the walnut or acorn. Some seeds, on the other hand, like those of the true nuts and of stone fruits, have soft, thin seed coats; but 
in such cases the seed is usually protected by a specially hard layer that belongs to the fruit coat.

294. Kinds of Food Found in Seeds. - Many seeds are valuable to us because the food stored in them for the use of their embryos is in a form that we can easily use. The foods upon which the human race most largely depends are obtained from the seeds of three of the cereal grains - wheat, Indian corn, and rice. Many other seeds, too, such as those of other cereals, nuts, beans, peas, and lentils, though used to a less extent, are nevertheless very important sources of human food. Starch is by far the commonest form in which food is stored, both in seeds and in other parts of plants. It is starch that is present in largest amount in the seeds of the cereal grains, with the exception of the sweet corns. Starch is a convenient form of storage food because it is dry and compact, so that much can be stored in a comparatively small space, and because, although it will not itself dissolve in water, it may be casily and quickly changed to a substance (a sugar) which dissolves readily. Starch is a carbohydrate. Some other carbohydrate foods are found in seeds; especially some of the sugars (as in sweet corns) and cellulose, the substance of which cell walls are largely made. The cells of the endosperm of some seeds (for example, those of the date, the onion, and asparagus) have thick walls, and when the seeds germinate some of the cellulose of the endosperm cell walls is changed by means of an enzym to sugar, which is then used by the growing embryo.

Besides carbohydrates, the most important classes of food substances found in seeds are fats and proteins. Fats are present in small quantities in the seeds of corn and of many other plants. Some seeds contain large amounts of fats; examples are the walnut, the hickory nut, and the peanut, the seeds of the flax, from which linseed oil is made, those of the cotton, and those of the castor-oil bean. Proteins are present in small amounts in all seeds. Some seeds, especially 
those of the bean, the pea, and their relatives, contain large proportions of protein food. In the wheat kernel, as in that of the corn, proteins are stored chiefly in the form of little rounded bodies in the cells of the outer layer of the endosperm. This layer is mostly or entirely removed in making white flour, which thus contains much starch and only a very small proportion of proteins. The outer layer of the endosperm is kept, however, in the making of "whole wheat " flour, which therefore contains a larger proportion of proteins than white flour does.

295. Distribution of Seeds. - We have seen that the fruits of many plants are scattered in various ways. But in the case

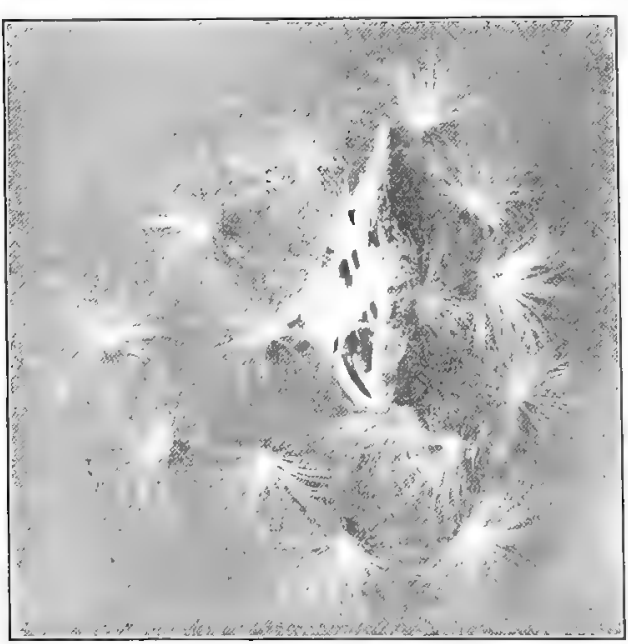

FIG. I7I. - A seed pod of the milkweed and escaping seeds. After Stevens. of other plants whose fruit coats split open, either while the fruits are still attached to the plant that bore them or soon after their separation from the plant, it is the seeds alone that must be scattered so far as they are to be scattered at all. Such seeds are distributed by means much like those that bring about the distribution of fruits. Many seeds are extremely small and light and may be carried by the wind to great distances. The blowing about of seeds is sometimes helped by the presence of wing-like outgrowths of the seed coat, such as those of the catalpa seed, or of tufts of hair like 
those on the seeds of milkweeds (Fig. I7I). The hairs attached to the seed coat of the cotton are used in making cotton thread and cotton cloth, and it is the presence of these hairs that makes the cotton plant so valuable. Some seeds, as well as fruits, are distributed by currents of water. Many others lodge in the fur or on the bodies of animals. By means of the mud that sticks to their feet, water birds are said to be important carriers of the seeds of water and marsh plants.

296. Germinating Power of Seeds. - The seeds of different plants differ greatly in the length of time that they remain able to germinate. As a rule, it is found that seeds germinate best the season after they were produced; that is, at this time the largest proportion of seeds begin to germinate, the growth of the embryos goes on most rapidly, and they are most likcly to grow into full-sized plants. After the first season the germinating power usually diminishes, but at very different rates in different cases. 'Some seeds will not germinate at all if they are more than a year old; some remain able to germinate for two or three years, and some for a much longer period. There is no doubt that some kinds of seeds can still germinate when thcy are sixty or seventy years old, and a few have been found to keep the power of germinating for as long as eighty-five years. There is probably no well-established case in which seeds have germinated at a much greater age than this; although stories, quite without foundation, are told of seeds that germinated after being buried in the ground for centuries, or after lying for thousands of years in Egyptian tombs.

The conditions under which seeds have been kept have much to do with their germinating power. For example, they must be kept dry; for if they become moist they are likely to begin to germinate, and then, conditions not being favorable for the completion of germination, the embryos die. The germinating power of most seeds is destroyed by exposure to extreme heat or cold. But to this rule there are 
exceptions; for certain seeds, if dry, may be exposed for some days to a temperature of about 480 degrees below zero Fahrenheit without destroying their power of germination.

"Seed-testing" consists in placing a considerable number of seeds, taken as a sample from a large lot, under conditions favorable for germination - for example, between sheets of blotting paper, in a germinating box, or in soil - and noting the percentage of the whole number that germinate successfully. It is important for the farmer or the gardener to be sure that the great majority of the seeds that he sows are likely to germinate, and for this reason various methods of practical seed-testing have been devised.

297. Development of Seeds or Fruits without Fertilization; Seedless Fruits. - In nearly all seed plants, no embryo, and therefore no seed or fruit, can be formed unless the egg is fertilized by a male nucleus. Some exceptions to this rule, however, are known to occur. The eggs of a few plants, among them the common dandelion, can develop into embryos without fertilization. Such plants, therefore, can form seeds and fruits without a previous fertilization and even without pollination. Certain other plants, including at least some varieties of cucumbers, produce fruits without pollination or fertilization; but a cucumber fruit so produced contains no developed seeds. A considerable number of plants, including apples, pears, and lemons, bear occasional seedless fruits; but in most such instances, differently from the case of the cucumber, it is probable that pollination and fertilization actually occur, but that the seeds for some reason fail to develop. By selection, species of seedless oranges and other fruits have been developed which are much better for eating than fruits with seeds. Seedless varieties, of course, can be propagated only by vegetative means, as by cuttings or grafts. The common banana has been seedless for centuries. 


\section{CHAPTER XIX}

\section{SOME IMPORTANT FAMILIES OF ANGIOSPERMS}

298. Classification of Plants. - So far as possible, plants are classified according to their relationships, so that a system of classification is much like a genealogical tree. Plants which are very like one another are said to be members of the same specics; for instance, our common apple trees bclong to the species known as Pyrus malus. Some species are composed of plants that are different enough from one another to be distinguished as varieties, but not different enough to constitute separate species. Thus there are many varieties of apples, some of which may have dereloped in the wild state, but most of which are the result of breeding. Species that are nearly related to one another are placed in the same genus. For example, the common apple (Pyrus malus), the Siberian crab-apple (Pyrus baccata), and the pear (Pyrus communis) belong to the genus Pyrus. Several or many genera make up a family, and several families, in turn, are grouped together to form an order. The genus Pyrus belongs to the rose family (or Rosacece); this family and some others make up the order Rosales. Since something new is constantly being learned about the relationships of plants, changes are made from time to time in their classification. New species are found, and the arrangement of species into genera, families, and orders must be changed to fit the newly discovered facts. However, the seed plants have been studied so long and so much is now known about them that the general outlines of their classification may be con- 
sidered fairly well settled; although it is true that many new species, even of seed plants, are described each year.

299. Families of Angiosperms. - Something was said in Chapter XVII about the reasons why flowers are helpful in determining the relationships of angiosperms. For the most part, it is the structure of their flowers and fruits that is used in arranging angiosperms in orders, families, and genera; species are distinguished from one another about as much by the peculiarities of their vegetative parts (stems, roots, and leaves) as by those of their flowers and fruits. As we already know, angiosperms are divided first of all into the two great groups of monocotyledons and dicntyledons. The monocotyledons include eleven orders, which are divided into forty-five families; these in turn include a total of about 24,000 species. In the group of dicotyledons there are forty orders, 240 families, and about ro9,000 species. In the present chapter only a ferv of the families of monocotyledons and dicotyledons will be mentioned. These families are selected either because of the large number of species that belong to them, or because they include some of the plants that are of greatest practical value to us.

\section{Monocotyledons}

300. The Grass Family. - This family contains about 4000 species, among which are the Indian corn and the other cereal grains. The grasses have small, simple flowers with chaffy bracts, all much like the flowers of the corn excepting that they are usually perfect. The fruits, with the exception of a few that are nut-like or berry-like, are kernels, similar to those of corn and wheat. Each kernel contains a single seed; the embryo lies at one side of the seed, surrounded by the seed leaf, and the endosperm makes up the greater part of the seed. The grasses have jointed, commonly hollow, stems, and alternate sheathing leaves arranged in two vertical rows. With the exception of the bamboos, they 
are all herbaceous plants. Besides the cereal grains and the sugar cane, sorghum, and broom corn, the grasses of most practical interest to us are the numerous species which, like timothy and blue grass, are used as forage plants, either for pasturage or for hay. The value of grasses for forage purposes depends largely upon the fact that the individual plants grow together in large numbers, so that a single species, or two or more species growing together, may cover large areas. Some, such as the common quack-grass, are annoying weeds. An oil obtained from the roots of vetiver (cuscus grass) is used in making perfumes. The tall, tree-like bamboos (see $\$ 2$ I5) have more or less woody stems.

301. The Sedge Family. - The sedges are much like grasses in general appearance and in most of their characteristics. Their fruits are nut-like, each containing a single seed; the embryo lies at the base of the seed, instead of at one side as in a grass seed, and is entirely surrounded by endosperm. The stems are usually three-sided and solid, and the leaves are arranged in three rows. Among the members of the family are some of the "rushes," the ornamental "umbrella plant," and the papyrus, whose pith was used in ancient times in the manufacture of paper.

302. The Palm Family. - The palms differ from the great majority of monocotyledons in the fact that the stems of most of them become woody. Most members of the family are trees, each bearing a crown of large leaves at its top. Some, like the rattan palms, are woody climbing plants. The fruits of palms are either stone fruits (like the coconut) or berries (like the date). The endosperm is often hard and horn-like; the endosperm of the coconut, however, consists of most of the edible " meat" and the milk. The hard part of the fruit of the date palm is endosperm, and "vegetable ivory" is made from the endosperm of another palm. Many of the palms are of great practical value to the inhabitants of the warm countries in which they live. The pith 
of some supplies sago. Palm oil comes from the fruits of certain palms that grow in western Africa and eastern South America. The betel nut is the fruit of another palm, and the fruits of various species, such as the date and the coconut, are edible. Copra, an important commercial product, is the dried meat of the coconut, which is used in the manufacture of coconut oil. Other products of various palms are wines, soap, wax (from the surface of the stem), fibers of various sorts (among them the coarse fibers from the leaf-stalks of the raffia palm), and building materials.

303. The Arum Family. - The members of this family have very simple flowers; usually many flowers are borne in a crowded spike which is partly surrounded and more or less covered by a large bract. Well-known examples of this floral arrangement are the Jack-in-the-pulpit (or "Indian turnip ") and the calla lily. Others of the family are the skunk cabbage and Acorus calamus, the "sweet flag," whose fleshy creeping or underground stems are usedin medicine under the name of calamus. Not a few arums are cultivated as house and grcenhouse plants because of the beauty or the oddity of their flower clusters and of the surrounding bracts. Some members of the family have corms, like that of the Indian turnip; the corms of a number of species are eaten after being cooked.

304. The Lily Family. - The flowers of this family are in general similar to those of the familiar cultivated lilies; the sepals are usually showy and similar to the petals; the flowers are nearly always perfect and regular, with six stamens and a single compound pistil; the fruit is either a pod or a berry. The family includes about 200 genera and about 2600 known species. The true lilies are members of the genus Lilium. Some of them, such as the tiger lily, the Easter lily, the goldbanded lily, and the Turk's cap lily, have been cultivated for centuries because of the bcauty of their flowers. Other members of the family cultivated for a similar reason are the 
tulips, the hyacinths, the lily-of-the-valley, and the yellow and orange day lilies. Aspidistra and Sansevieria are much raised in greenhouses because of their ornamental foliage. Among the food plants of the family are the onions, lceks, garlic, and chives, all members of the genus Allium, and the asparagus. Besides the species of asparagus that is cultivated for its edible shoots, several are grown for ornamental purposes. The "smilax" of florists (which is not a Smilax but a Myrsiphyilum) is a near relative of the asparagus. Some members of the family living in tropical countries are important fiber plants; one of them furnishes "bowstring hemp." Of several drug plants that belong to this family, the most important commercially are some of the Aloes. The juice of their leaves supplies the drug known as "bitter aloes," as well as certain valuable coloring materials. Some species of Aloe are much used in warmer cotuntries as ornamental plants, and in colder climates they are common in greenhouses. Among the familiar wild flowers of the United States and Canada are the bellwort, the dogtooth violets (which are not violets at all), Solomon's seal, false Solomon's seal, and the Trilliums. The Yuccas are conspicuous plants of the southern United States, Mexico, and Central America. The stems of one species of Yucca and of a few other members of the lily family have a method of growth in thickness which, though quite different from that which we have studied in the pine, results in some species in the development of trees. One of these is the "dragon tree," found in the Canary Islands, which grows to a height of fifty to sixty feet. A famous tree of this species on the island of Teneriffe was seventy feet high when it was destroyed by a storm in 1878 (see Fig. I35).

305. The Amaryllis Family. - This is very nearly related to the lily family; the members of the two differ in small details in the structure of the flowers and fruits. In the amaryllis family, the sepals, petals, and stamens are attached 
above the ovary, whereas in the lily family they are nearly always attached below. The present family also includes a good many plants that are cultivated for their flowers. Among the best-known are the amaryllis, narcissus, daffodil, jonquil, and tuberose. The agaves are plants of tropical America and the southwestern United States. The bases of their leaves are much thickened and serve for water storage. One of the agaves is that which we know as the "century plant"; the juice extracted from other agaves makes the Mexican drink pulqué; and certain agaves and other members of the amaryllis family supply a substitute for soap. Sisal hemp is made from the fibers of some of the agaves.

306. The Iris Family. -- This is closely related to the lily and amaryllis families. The members of the iris family have only three stamens instead of the six that are nearly. always present in the two preceding families. The stamens and perianth leaves are inserted above the ovary, as in the amaryllis family. To the iris family belong also a number of plants that are cultivated for their showy flowers; among them the crocus, several species of iris (fleur-de-lis), and the gladiolus. The drug and dyestuff known as safron is obtained from the dried stigmas of a species of crocus. The blue flag, whose underground stem and roots are used in medicine, is an American specics of iris. "Orris root" is the fragrant underground stem of a European iris.

307. The Banana Family. - This should be mentioned because of the importance of the fruit of the cultivated species of banana. Another species of the same genus is the tropical plant which bears the edible fruit known as the plantain; still another species growing in the Philippines supplies manila hemp.

308. The Orchid Family. - The members of this family are characterized by their irregular flowers, which are often of an extremely odd and striking appearance. The flower of the lady's-slipper (Fig. I 59) may be taken as an example, 
although the flowers of orchids take on a great variety of forms. The orchid family is the largest among the monocotyledons, having over 7000 species, but few of the species are plentiful and some are extremely rare. The oddity and rarity of many orchids have made them favorite objects of cultivation, and by long breeding some wonderfully bcautiful varieties have been developed. The lady's-slipper is among the best-known of the orchids that grow wild in temperate countries. The underground stems and roots of many (if not all) orchids are inhabited by fungi that are in partnership with the orchid plant and that assist it in securing food. In some cases it is found that a seed cannot develop into a plant unless it is infected by one of these fungi. Some orchids, like the coral-roots, have no chlorophyl and live a completely saprophytic life with the help of the fungi in their tissues. Many of the tropical orchids are epiphytes. The flavoring extract known as vanilla is obtained from the fruit of a tropical American orchid that is much cultivated in tropical countries; salep, used both as a food and as a drug, consists of the dried tubers of various European and East Indian orchids. Not many members of the family, however, have been found useful for other than ornamental purposes.

\section{Dicotyledons}

309. Forest Trees. - Certain small families, which are among the more primitive of the dicotyledons, include some of the common trees and shrubs. Thus the poplars and willows belong to the willow family; the walnuts, butternut, pecan, and hickory to the walnut family; the birches, ironwood, hop-hornbeam, hazels, and alders to the birch family; and the beeches, chestnuts, and oaks to the beech family.

310. The Nettle Family. - This large family also includes many trees, among them the elms and the hackberries. Its members have small flowers, simple in structure; the stamens 
and pistils are usually borne in separate flowers; in some species the two kinds of flowers grow on different plants, in others on the same plant. The fruits are one-seeded, and are often nuts or stone fruits. The nettles, which give the family its name, are unpleasantly familiar weeds. The white mulberry is important because its leaves are used as food for silkworms. Its berries, like those of other mulberries, are edible. It is a native of China and has been cultivated in Mediterranean countries since the twelfth century. The white, black, and red mulberries are used also as shade trees. The osage orange, much used for hedges, is a close relative of the mulberries. The six hundred species of the genus Ficus are mostly tropical; Ficus elastica is the india-rubber tree, the most important source of rubber in the castern hemisphere. "Rubber plants," common house plants in colder climates, are small specimens of this tree. The banyan tree belongs to the same genus, as does also the cultivated fig tree. The hop and the hemp are important members of the nettle family; the hemp is widely cultivated for its bast fibers which are used in making ropes and cloth. The hemp also supplies birdseed; the drug known as hashish is made from its flowers and leaves, and the drug cannabis from the dried flowering tops of the pistillate plants. The Asian plant that furnishes the fiber known as "ramie" or "China grass" is a member of the family. Another is the breadfruit tree, and another the upas tree of the East Indies, whose juice is used by the natives for the poisoning of arrows, and in regard to whose poisonous influence many cxtravagant tales used to be told. Several tropical members of the family besides Ficus elastica are sources of rubber.

311. The Goosefoot Family. - This is a small family whose members are mostly herbs living in prairies or waste places, many of them with fleshy leaves. The flowers are small and inconspicuous and are borne in large numbers in branched, spike-like clusters. The common edible beet, the 
sugar beet, and spinach are the important cultivated plants of the family. American wormseed is a drug plant of some importance. Several members of the family are well-known weeds; one of the commonest in the United States and Canada is the plant known as "lamb's quarters" or "pigweed " ; another pernicious weed is the Russian thistle.

312. The Pink Family. - The families of dicotyledons so far mentioned have, for the most part, small, inconspicuous flowers. Many of the pink family, however, have comparatively large and showy, and some of them very fragrant, flowers. The flowers are regular, usually with five (sometimes only four) sepals, the same number of petals if any (petals are sometimes lacking), and not more than twice as many stamens as sepals. The plants are mostly herbs with opposite, undivided leaves. Of the plants of this family that are grown for their flowers, the best known are the carnations, which are descended from a European species that has been in cultivation for many centuries. The common pinks and sweet williams are members of the same genus as the carnations. A good many common wild plants also belong to the pink family; among these are various chickweeds, the campions, the catch-flies, the corn cockle, and the bouncing bet.

313. The Crowfoot Family. - This is composed of herbs of temperate and cold countrics, whose regular flowers have either sepals and petals, or sepals alone that resemble petals, usually numerous stamens, and one or many simple pistils. The family includes many common wild plants; the buttercups, hepaticas, meadow-rues, anemones, marsh-marigolds, baneberries, clematis, and columbine are among them. The peony, some of the larkspurs, and species of columbine and clematis are cultivated for their flowers. The drugs known as black hellebore, golden seal, and aconite are supplied by members of this family; larkspur seed is also used medicinally. 
314. The Mustard Family. - The plants of this family are nearly all herbs, many of them with sharp-tasting substances in their stems, roots, or seeds. The flowers are regular, with four sepals, four petals, two short and four long stamens, and one two-parted pistil. The fruit is usually a pod-like structure whose wall when it is ripe splits into two parts that separate from a central partition to which the seeds are attached. Among the many cultivated or useful plants that belong to the mustard family are the radish, turnip, rutabaga, rape, cabbage, cauliflower, Brussels sprouts, kohl rabi, the mustard, horseradish, garden cress, and water cress. Swect alyssum, the candytufts, and the stocks or gilliflowers are raised for their flowers. Among the common weeds of the family are various mustards and the shepherd's purse.

315. The Saxifrage Family. - This family and the next are closely related. Most of the members of both have regular flowers, with five sepals and five petals. Most of the plants of the saxifrage family have not more than ten stamens and fewer macrospore leaves than sepals; often the macrospore leaves are united to form a compound pistil. The most important members in cultivation are the currants and gooseberries. Among those grown for ornamental purposes are the mock-orange (commonly called "syringa"), the hydrangeas and hortensia, and deutzia.

316. The Rose Family. - The members of this family differ from those of the preceding one as a rule in having more numerous - sometimes very numerous - stamens, and more than one pistil - usually at least as many pistils as sepals. The pistils are simple. The seeds are usually without endosperm, whereas the seeds of the saxifrage family contain endosperm. The rose family includes the great majority of plants that are cultivated for their fruits, at least in temperate countries, as well as many ornamental plants. One division of the family includes Spircea, some of whose species are ornamental shrubs. The members of another division 
have false fruits in whose formation the calyx takes part; to this division belong the quince, pear, apple, and crab-apple, the thorn-apple or hawthorn, the mountain ash, and the service berry. Another division includes the strawberry, the cinquefoil, and the avens; to another belong the brambles, the raspberry, blackberry, and some related plants with edible fruits; another includes the many species and varieties of roses; and to still another division, whose members have stone fruits, belong the cherry, plum, apricot, peach, and almond. The almond, as we buy it, corresponds to the stone of a plum or a peach; ; the outer layer of the fruit, corresponding to the fleshy part of a peach, has dried and split off.

317. The Pulse Family. - With one exception, this, with over I2,000 species, is the largest family of seed plants. The bean may be taken as a type. Most of the members have flowers and fruits constructed much like those of the bean, although not a few have regular or nearly regular flowers. Some of the more important plants of the pulse family were mentioned in Chapter XII.

318. The Flax Family. - This is very small, and is mentioned here only because of one important member, the flax plant. Flax has been cultivated for its strong bast fibers, which are used in making linen thread, in the countries about the eastern end of the Mediterranean for four or five thousand years. It is now raised chiefly in Europe, the United States, and India, both for the fibers and for linseed oil, which is made from its seeds.

319. The Rue Family. - This family is of practical interest because of one tropical and subtropical genus (Citrus), to which belong the orange, lemon, citron, and lime, all of which probably originated in southern Asia, and the grapefruit, a native of the Malayan and Polynesian islands.

320. The Spurge Family. - This is a large family, whose flowers, usually clustered, vary greatly in structure. Most 
of them have a three-parted pistil whose ovary splits into three parts in the ripe fruit. In the spurges themselves (belonging to the genus Euphorbia) each small cluster of flowers is surrounded by white or colored bracts that look like petals; the cluster thus is likely to be taken for a single flower, but it really contains a pistillate flower consisting only of a pistil, and a number of staminate flowers each with one stamen and no sepals or petals. The plant known as "Poinsettia" is a Euphorbia ; its showy, red, petal-like leaves are bracts. Some other Euphorbias are also grown for ornamental purposes. Mast of the plants of this family have a milky juice, from which, in the case of several species, rubber is obtained. Most important is the "Para rubber" furnished by two species of Hevea. The milky juice of a Moroccan Euphorbia is the source of a resinous gum; and the juices of certain members of the family are poisonous. Tapioca, obtained from the roots of the cassava, is an important food product of the tropics. Another member of the spurge family is the castor-oil plant.

321. The Vine Family. - Grapes are said to have been in cultivation longer than any other fruit. Those cultivated in Asia and Europe belong to the species Vitis vinifera. Varieties of this species are raised also in California; some are used in making wine, some for raisins, and some as table grapes. Most of the grapes cultivated in other parts of the United States belong to varieties that have been developed from several North American species; they are used mainly as table grapes. The small fruits of a variety of T'itis i'inifera are dried and sold as "Greek currants." It was to these fruits that the name currant was first given (from the name of the Greck city of Corinth), and later it was applied to the fruits that we now more commonly know as currants. The Virginia creeper (or woodbine), the Japanese ivy, and some other climbing plants also belong to this family. 
322. The Mallow Family. - This is characterized by flowers with five sepals, five petals, and usually many stamens of different lengths which are united by their filaments into a tube that surrounds several pistils whose ovaries are united into a ring or a compound pod. The genus of greatest practical interest is Gossypium, to which the cottons, the most important of fiber plants, belong. Somewhat more than half the world's supply of cotton is raised in the southern United States; outside the United States, the largest amounts are furnished by India, Egypt, and China. Okra (gumbo) is a close relative of the cotton. Another useful plant of this family is the marshmallow. Among the ornamental cultivated members are the abutilon, hibiscus, and hollyhock. The common mallow is a familiar weed.

323. The Violet Family. - Here only the violets will be mentioned. Among them are some of our best-known wild flowers. The violets raised by florists are descended from a wild European species, and the many varieties of pansies have been derived from crosses between two or more other European species.

324. The Cactus Family. - The characteristic feature of this family is the thick, fleshy stem, which takes on a variety of forms. In some species, such as the night-blooming cereus, the stem is tall and cylindrical; in some it is nearly or quite globular; in others, as in the prickly pears, it is jointed, each division being flat and more or less leaf-like. The leaves of most members of the family are represented only by small scales or spines, or both. Most of them are natives of the drier regions and deserts of the new world. Some of the prickly pears, of American origin, are cultivated for their fruit in Mediterranean countries, where they sometimes go by the name of "Indian fig."

325. The Parsley Family. - The botanical name of this family (Umbelliferce) refers to the arrangement of the flowers of nearly all its members in simple or compound umbels. 
An individual flower is small, with five sepals (which are sometimes very small), five petals, five stamens, and a pistil composed of two macrospore leaves with separate styles. The sepals, petals, and stamens are "inserted above the ovary " - that is, their lower parts are really grown together with the wall of the ovary so that they seem to grow from above it. The fruit is two-parted, each part containing a single seed. To the parsley family belong a number of plants, such as dill, coriander, parsley, fennel, caraway, angelica, anise, lovage, and celery, whose leaves, fruits, and other parts are eaten or used in the preparation of food because of their aromatic flavor. To it also belong the parsnip and the carrot, whose thickened roots are eaten. Several members - for example, asafetida, caraway, coriander, anise, and fennel - are sources of drugs; some, including the poison hemlock (also medicinal) and the water hemlock, are poisonous; and others, like the wild carrot, are familiar weeds.

326. The Heath Family. - The name comes from the heaths or heathers, which cover great areas in the Old World, living in waste places, on hillsides, and in sandy forests. Most of the members of this family are shrubs, with thick, shiny leaves, which are often densely covered with hairs on the lower surface. They are found for the most part either in comparatively dry locations or in swampy places. The flowers have four or five sepals, the same number of petals generally more or less united, as many or twice as many stamens, and a single compound pistil. Among the useful members of the family are the blueberries, cranberries, huckleberries, and wintergreen. The rhododendrons, azaleas, and kalmias are valued for their showy flowers. The "trailing arbutus "is one of the American representatives of the family. Another is the "Indian pipe," which has no chlorophyl but which lives as a saprophyte, being helped in securing its food from decaying matter in the soil by a fungus whose threads form a thick felt over the surfaces of its roots. 
327. The Convolvulus Family. - This, as well as all the other families to be mentioned later, is composed of plants whose petals, and generally the sepals as well, are united into tube- or bell-shaped structures. There are usually five sepals, the same number of petals and of stamens, and a single two-parted pistil. Many members of the family are climbing plants. The genus I pomeea includes the morning-glories, a number of which are in cultivation, and the sweet potato, whose thickened roots we eat. The bindweeds belong to the genus Convolvulus; some of them are troublesome weeds. The parasitic dodders were described in Chapter XIV.

328. The Mint Family. - The 3000 species of this family are chiefly herbs with four-sided stems and opposite leaves. Most of them have irregular, two-lipped flowers, with five sepals and five petals, four stamens, two of which are longer than the other two, and a two-parted pistil. The ripe fruit separates into four (occasionally fewer) parts, each containing a single seed. Many species contain aromatic substances that make them valuable for flavoring purposes, or as sources of perfumes and drugs. Well-known useful plants are the peppermint and spcarmint, pennyroyal, horehound, rosemary, lavender, sage, balm, savory, and thyme. Coleus is widely raised for ornamental purposes because of its variegated leaves, and some tropical species of Salvia (the sage) are cultivated for their showy flowers. The catnip, the horsemint, and some of the true mints (species of Mentha) are common weeds.

329. The Nightshade Family. - This includes chiefly round-stemmed herbs, whose flowers are usually regular, with five sepals, five petals, five stamens, and a two-parted pistil. The fruit is a many-seeded capsule or berry. The potato and the eggplant are members of the genus Solanum, to which the nightshades and the horse nettle, a troublesome weed, also belong. Tobacco, the tomato, the red peppers, 
the ground cherry (or "husk tomato"), and the petunia belong to the same family. Among the drugs obtained from members of this family are belladonna, hyoscyamus, and stramonium.

330. The Gourd Family. - The cucumber may be taken as a type of this family. The most important cultivated members were mentioned in Chapter I.

331. The Composite Family. - This is the most highly developed and the largest family of angiosperms. It includes about $r_{3}, 000$ species. Not only is the number of species large, but some of the species, such as the thistles and the dandelions, are represented by immense numbers of individual plants, and are so persistent and so successful in their methods of reproduction that they can be killed out only with the greatest difficulty. The members of the family are called composites because their separate flowers are so closely grouped together in a head that most persons think of the head as a single flower, especially since, just below it, there are green bracts that look like sepals. The flower of a composite has five sepals which take the form of a group of hairs, bristles, or scales ; five petals united into a tube that is often (as in the dandelion) prolonged on one side into a strap- or tongue-shaped structure; five stamens united by their anthers into a tube; and a pistil apparently composed of two macrospore leaves. Sepals, petals, and stamens are inserted above the ovary. The fruit is small, dry, and seedlike, containing a single seed; the calyx remains attached to the fruit, sometimes, as in the thistle, forming a means by which the fruit may be blown about. Considering the size of the family, not many of its members have been found useful for human food; among those that are so used are the chicory, endive, lettuce, dandelion, salsify (or vegetable oyster), the artichoke, and the Jerusalem artichoke. Many are grown as ornamental plants, among them the sunflower, daisy, dahlia, chrysanthemum, China aster, and ageratum. 


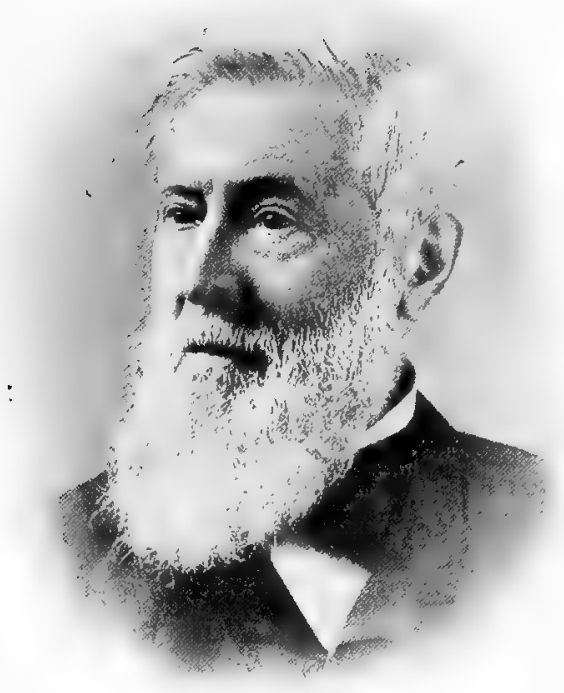

ASA GRAY

Born at Sauquoit, N.Y., I8ro; died at Cambridge, Mass., I888. The first great American botanist, and one of the greatest botanists of his time in any country. His Manual of Bolany (several times revised) has been for many years the leading authority in the identification of the seed plants and ferns of the northern and eastern United States and of Canada. 

Drugs are obtained from the boneset, burdock, camomile, dandelion, calendula, arnica, cchinacca, elecampane, tansy, and wormwood. Pyrethrum or insect powder is made from the dried flower heads of several composites. Wormwond is used in the preparation of the alcoholic drinks known as absinth and vermouth. The milky juice of a shrub known as guayule, which grows abundantly in certain parts of Mexico, is a source of rubber. Some of our commonest wild plants and weeds belonging to the composite family are the goldenrods, asters, wild sunflowers, coneflowers, ragweeds, and thistles, the hawkweeds, the beggar ticks, the dandelion, the yarrow, the may-weed, the cocklebur, the burdock, the wild lettuce, sagebrush, tansy, and chicory. 


\section{The Plant Kingdom}

The following is a brief outline of the classification of plants. In each group only those plants are mentioned that have been especially discussed in this book.

I. Thallophytes (comparatively simple plants).

I. Algæ (with chlorophyl).

a. Blue-green Algæ (very simple forms, much like bacteria except in color).

b. Green Algæ: Protococcus, Spirogyra.

$\left.\begin{array}{l}\text { c. Brown Algæ } \\ \text { d. Red Algæ }\end{array}\right\}$ Seaweeds.

2. Fungi (without chlorophyl).

a. Bacteria.

b. Slime Molds.

c. Alga-like Fungi: Bread Mold.

d. Sac Fungi: Yeasts.

e. Basidium Fungi: Wheat Rust, Mushrooms.

f. Imperfect Fungi:

3. Lichens (fungi which have formed a sort of partnership with simple algæ).

II. Bryophytes (moss-1ike plants).

I. Liverworts.

2. Mosses: Funaria.

III. Pteridophytes (fern-like plants).

I. True Ferns: Bracken Fern.

2. Water Ferns.

3. Horse-tails.

4. Club-mosses.

IV. Seed Plants (or Howering plants).

I. Gymnosperms: Pine.

2. Angiosperms.

a. Monocotyledons: Indian Corn.

b. Dicotyledons: Squash, Pumpkin, Cucumber, Bean. 


\section{CHAPTER XX}

\section{SOME USEFUL PLANTS AND PLANT PRODUCTS}

332. Cereal Grains. - Much has been said in previous pages (see especially Chapter XIII) of the cereal grains wheat, Indian corn, rye, oats, barley, rice, and millet. All the cereals supply food to a greater or less extent both for man and for domestic animals. Food for man is obtained from the fruit of the plant (the kernel or grain), in the form of flour or meal, the extracted starch, and a grcat variety of "cereal foods " or " breakfast foods"; domestic animals eat the kernels (especially of oats and corn), and also the leaves and stalks - the latter in the form of straw or "fodder." As a group the cereal grains are by far the most important source of food, and the progress of civilization has been in large measure dependent upon the increase of the areas within which they are cultivated. Of this group of plants, wheat is most valuable because it contains the best proportions of different food substances - especially starch and proteins. In most parts of the world that are occupied by the white race, wheat is the chief vegetable food. Rice, however, which contains a larger proportion of starch than any of the other cereals, is actually depended upon by a larger number of people than is wheat. Rice is said to be the principal food of from one-third to one-half the population of the earth. Rye largely takes the place of wheat in the colder or less fertile regions of Europe. Oats are used most widely as food for horses, and barley is most important as a source of ma1t for the brewing of beer. Millet is used chiefly as food for animals, although it is used as food for man also in some parts 
of the world. The straw of wheat, rye, and rice is used in hat-making, for mats and ropes, for thatching, and in a variety of other ways. With the cereals should be mentioned the sorghums, numerous varieties of which have been under cultivation for many centuries. The kernels of sorghum are used as food for man and for animals; the stalks are used as fodder; and the sweet juice of some varieties is

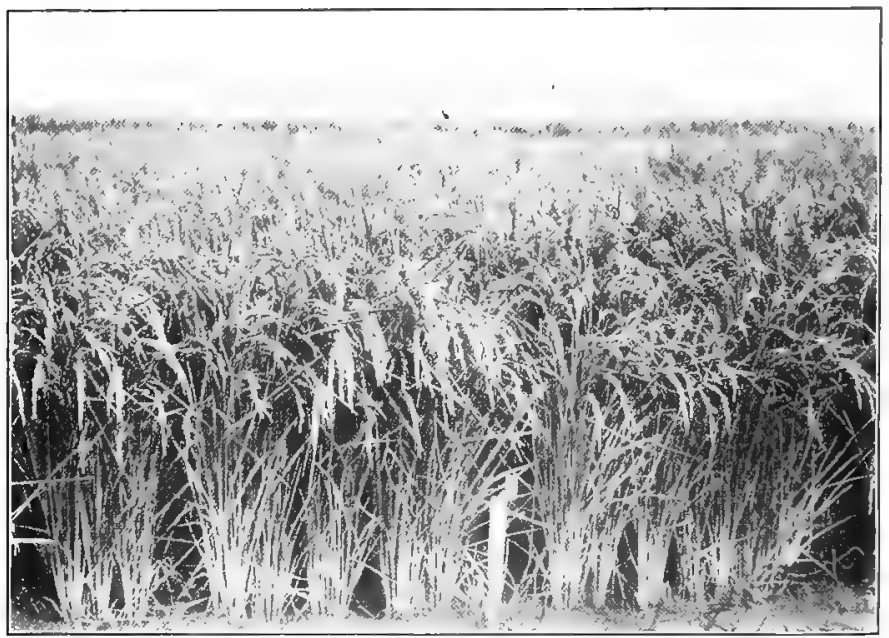

FIG. I72. - A field of rice.

a source of sirup and sugar. Broom corn, whose stem-ends and branched flower-stalks are used in the United States for brushes and brooms, is a variety of sorghum.

333. Other Starch-producing Plants. - Aside from the cereal grains, the most important starchy food is the tuber of the potato. The potato plant is a native of America, probably of South America, but is now cultivated throughout a large part of the civilized world. Starch is cxtracted on a large scale from many plants by grinding the part of the plant which contains it and then washing with water. The 
greater part of the starch thus prepared is from potatoes and corn; but it is also obtained from other cereals (especially rice), from beans, and from the arrowroot plant. Tapioca is the starch extracted from the roots of the cassava, and sago is the starch obtained from the pith of certain palms. Dextrin, a gum-like substance, is made by treating starch with hot dilute acids. It is used for giving a smooth finish to paper, for stiffening cotton cloth, in making mucilage, and for other purposes.

334. Sugar-producing Plants. - By far the greater part of the sugar in the market is obtained from the stalk of the

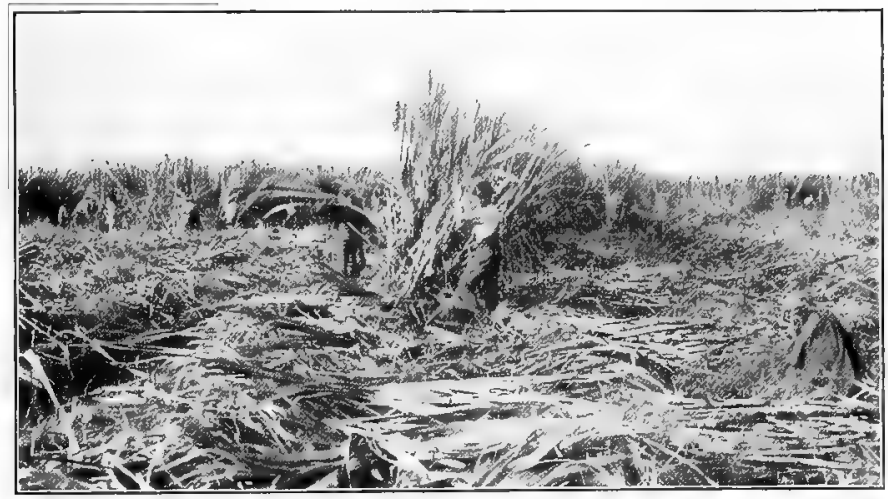

FIG. I73. - Harvesting sugar cane in Louisiana.

sugar cane and from the root of the beet. The sugar from both sources is alike, and in either case it is called cane sugar. The juice of the beet or sugar cane is pressed out and evaporated; the sugar which then appears in the form of crystals is separated from the remaining liquid (the molasses), and after being refined and recrystallized is sold in the form of granulated sugar, pulverized sugar, or loaf sugar. Sugar is also made on a comparatively small scale from the juice of some palm trees, from that of the sorghum (although this is 
more largely used in making sirup), and from the sap of the hard maple. Dextrose, otherwise known as glucose or grape sugar, occurs in grapes and many other fruits, and in honey. In nature it is usually associated with levulose (a sugar very similar to dextrose) and sometimes also with cane sugar. Dextrose is made commercially on a large scale by treating starch with sulphuric acid. It is only about three-fifths as sweet as cane sugar, and is correspondingly less valuable. It is largely used in brewing and in the making of sirups and candies.

335. Foods for Animals. - Besides the cereal grains, which are relatively as important for domestic animals as they are

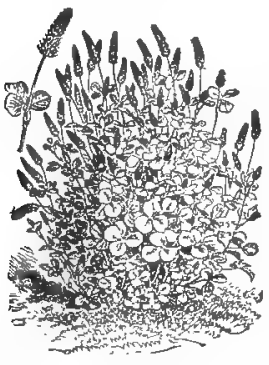

FIG. I74. - The crimson clover. for man, there are many forage plants that is, those which animals eat, either fresh as they are growing, or dried in the form of hay. The most extensively used forage plants are various grasses, some of them wild and some cultivated. Some of the sedge family are also useful in the same way, being commonly known also as "grasses." In addition, certain members of the pulse family are very important forage plants; their value for this purpose is due in large part to their ability to use the free nitrogen of the air with the help of the bacteria that live in their roots. It is for this reason that the clovers, alfalfa, the cow pea, and the soy bean can be raised successfully on nitrogen-poor soils and are valuable, especially if the crop is plowed under, in increasing the proportion of nitrogen-containing substances in the soil. Of several clovers used as forage plants, the most widely cultivated, especially in the northern United States, is the red clover. Crimson clover, a species of European origin, is raised to a considerable extent in the southeastern United States. Alfalfa has long been grown in Europe, and more 
recently has been extensively cultivated in the western United States; its cultivation is being extended eastward. The cow pea, which is closely related to the common bean, is grown most extensively in the southern United States. The soy bean, a native of China and Japan, is also being increasingly grown in the United States as a forage plant. The hyacinth bean, a native of India, is recommended as a forage plant and has beẹn cultivated for this purpose to

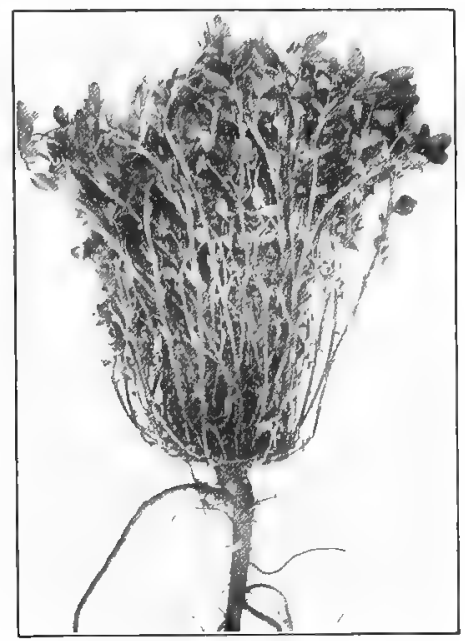

FIG. I 75. - An alfalfa plant. some extent; but its chief use thus far, especially in tropical and subtropical countries, has been as food for man. The

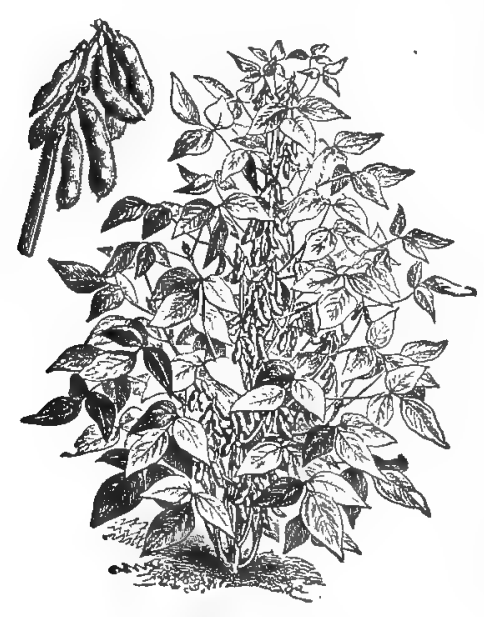

FIG. I76. - The soy bean. common pea is also largely grown in some parts of the United States as a forage crop.

Various seeds, especially those rich in oil, supply valuable foods for animals. Thus, cotton seeds are used as food for cattle, and cottonseed meal is made from what remains of the kernels after the oil has been pressed out. Oil cake is similarly made from the embryos of corn grains from which the oil has been extracted; lin- 
seed oil cake is produced in the same way from flax seeds, and coconut oil cake from the inner part of the coconut.

336. Beverages. - Aside from water (which is the basis of all liquids suitable for drinking) and milk, practically all of the great variety of beverages used in different parts of the world are derived from plants, either directly by extracting the juices, or by fermenting or fermenting and distilling. Comparatively few of the beverages so obtained are entirely lacking in stimulating qualities; among the non-stimulating ones are coconut milk, fresh grape juice, and fresh cider. Trees of two Brazilian species (as well as other sorts in other regions) are known as "cow trees" because of their milk-like juice, which is used for food. With the non-stimulating beverages must be included various coffee substitutes made by roasting or otherwise treating some of the cereal grains; and chicory, whose roasted and ground roots are largely employed as a substitute and adulterant for coffee.

Much more extensively used than any thus far mentioned are those mildly stimulating beverages whose effect is due to a substance produced by the plant from which they are made. Of this class, tea and coffee are best known. Tea is made from the young leaves of a plant that is grown in Japan, China, India, Ceylon, and Java, and to a small extent in South Carolina and some other localities. Coffee is made from the bean-like seeds of a shrub or small tree. More than threefourths of the world's supply of coffee comes from Brazil; smaller amounts are produced in Mexico, Central America, the West Indies, Venezuela, and Java. The stimulating substance (caffein or thein) is the same in both tea and coffee. Chocolate and cocoa come from the seeds of the cacao tree. Chocolate is made by roasting, crushing, and grinding the seeds into a fine paste; it contains about fifty per cent of oil. If part of the oil is removed, the substance remaining is cocoa. The cxtracted oil is cocoa butter. Chocolate and cocoa contain a small proportion of a stimu- 
lating substance, similar to caffein, called theobromin. Brazil or Paraguay tea, prepared from the dricd leaves of a member of the holly family, is used in some of the countries of South America. It also contains caffein.

Alcoholic beverages of one sort or another are used in all parts of the world. Most important of the fermented beverages, produced by the action of yeasts, are wines (made mostly from grapes) and beers (made from barley malt to which hops have been added). There are many other fermented drinks used in particular countries or localities; for example, pulqué, made in Mexico from the juice of some of the agaves; saké, a Japanese drink made from rice; and toddy, made in various tropical countries from the sap of the coconut palm and from other materials. By distilling fermented beverages, liquors containing a larger proportion of alcohol are obtained. Whisky is made in this way from the fermented juices of rye, corn, or sometimes of other grains. Gin is distilled from rye or other grain and flavored with juniper berries; vodka is distilled from rye or potatoes; and rum from the juice of the sugar cane. Brandy is distilled from wine, mescal from pulqué, and arrack from toddy. Absinth is made by stecping wormwood in alcohol or in a strong liquor.

337. Other Stimulants and Narcotics. - Aside from the stimulating beverages already mentioned, plants supply a number of substances that are used for their stimulating or narcotic effects in other than liquid form. Of these the best known is tobacco. The tobacco plant was originally a native of America, but its cultivation and use now extend to almost all parts of the world. Many other substances, most of them more powerful than tobacco, are used both for their narcotic effect and in medicine. Opium is made by drying the juice which exudes from cuts in the unripe fruits of the white poppy. It is extensively used, especially in Asiatic countries. Morphin and laudanum are prepared 
from opium. Cocain is obtained from the leaves of the coca tree. The leaves themselves are chewed by the people of Bolivia and other South American countries. Cola nuts are chewed by the natives of Africa. The tree that bears them grows in western Africa, the West Indies, and Brazil.

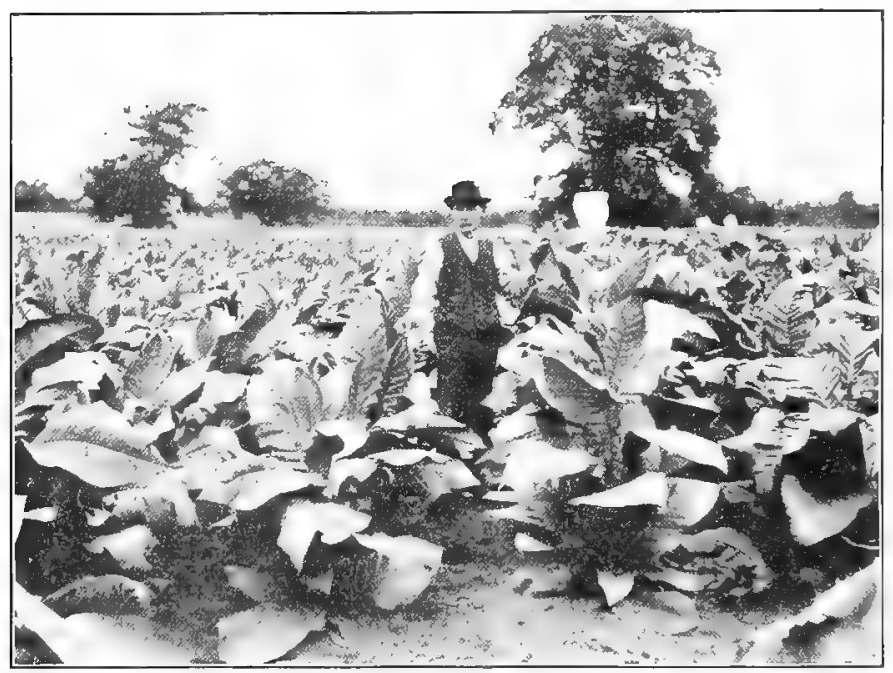

FIG. I77. - A field of tobacco.

The nuts contain a large proportion of caffein and some theobromin. Areca nuts (or betel nuts), the seeds of a palm, are chewed in India and other Asiatic countries. Hashish, prepared from the dried leaves of the hemp, is used for smoking and also in the preparation of a beverage.

338. Oils. - The oils which are stored in fruits, seeds, and other parts of plants belong to the class lnnown as fatty oils. A fatty oil is characterized by the fact that on treatment with a dilute alkali, such as caustic soda or potash, it forms a soap and glycerin. The fats of animal bodies belong to this same class of fatty oils. Various vegetable oils are used in 
making soaps as well as in numerous other ways. Olive oil, obtained by pressing the ripe fruit of the olive tree, is the most valuable for food purposes. It is largely adulterated with other oils of vegetable origin, such as cottonsced oil, obtained by grinding and pressing the kernels of cotton seeds, and peanut oil, pressed from peanuts. Peanut butter is made by grinding but not pressing the peanuts. The plant from whose seeds castor oil is made belongs to the spurge family. The oil is used in making soaps and lubricants, in medicine, and in the manufacture of oilcloth, artificial leather, and celluloid. Treated with sulphuric acid, castor oil, as well as olive oil or cottonseed oil, forms what is known as "turkey red oil," which is largely used in treating cotton fabrics so that they can be colored with certain coal tar dyes. Linseed oil, made from flax seed, has the prop-

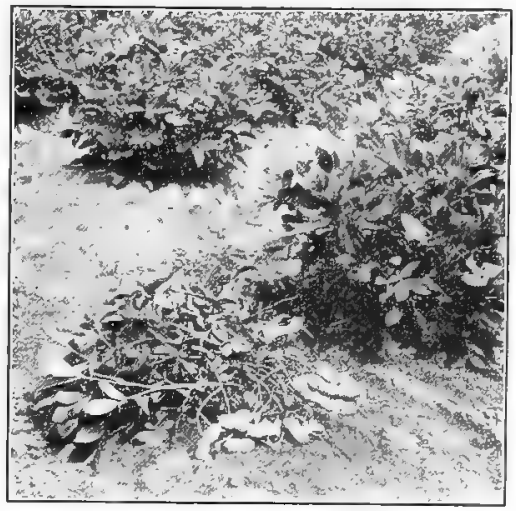

Fig. I78. - Peanut plants. erty of drying quickly if exposed to the air, leaving a varnish-like residue; this property makes it valuable in paints and varnishes. Linseed oil enters into the manufacture of linoleum, and, when thickened by long boiling, it forms the basis of printer's ink. Corn oil, made from the embryos of corn kernels, is used as a substitute for linseed oil in paints; it is also used in making soaps and lubricants. Corn oil, as well as linseed oil, can be vulcanized by heating with sulphur, so forming a substitute for rubber. An oil pressed from hemp seeds is also used, like linseed oil, in paints and in soap-making. The kernel of the 
ripe coconut, broken up and dried in the sun, is called copra, and is one of the most important commercial products of the islands of the south Pacific. It is from copra that coconut oil is pressed. This oil is used in southern Asia and the East Indies as a cooking and illuminating oil, and in other parts of the world for cooking and in making candles and soap. Among the numerous other vegetable oils that are put to practical uses are those obtained from the sunflower, soy bean, walnut, poppy seed, and almond.

339. Waxes. - The waxy coating on the surfaces of leaves and fruits is in some cases removed and used in various ways. Thus the wax from the fruit of myrtle bushes, known as myrtleberry or bayberry wax, is mixed with beeswax for use in candle-making. Japan wax, from the fruit of some Japanese sumachs, is used in a similar way, as well as in making furniture polish, wax matches, and waxed paper. The wax from the leaves of some palms is also of commercial importance.

340. Gums and Resins. - These are obtained by drying or otherwise treating the juices of plants. Gum arabic comes from trees of acacia species growing in Egypt, Arabia, and neighboring countries; gum senegal from an acacia that grows in northwestern Africa; and other gums from acacia trees in different parts of the world. Gum tragacanth is from the stems of species of Astragalus. By boiling certain seaweeds (marine algæ) gelatine is obtained. Agar-agar is a seaweed gelatine, much used in bacteriological cultures and for similar purposes, as well as medicinally; it comes from eastern and southeastern Asia and the neighboring islands. "Irish moss" is a gelatinous seaweed.

Certain hard resins, used in making varnishes, are called copals. There are many copals, usually named for the locality from which they come. One of the best is Zanzibar copal. It is obtained in part from liring trees, but the best is found in fossil form in the ground. The name gum dammar 
is given to several resins obtained from southeastern Asia, which are also used in making varnishes. Other much-used or well-known resins are myrrh, frankincense, asafetida, benzoin, mastic, Japanese lacquer (from the sap of one of the sumachs that supply Japan wax), balsam of Peru, and gamboge.

341. Spices. - The substances that are used as spices come from different parts of plants, most often from the fruits and seeds. Mustard consists of the ground seeds of several species of Brassica. Pepper is the fruit of a vine, a species of Piper. White pepper and black pepper are the same in origin; the difference between them results from the way in which the fruit is treated. Red pepper or Cayenne pepper is the ground pods of species of Capsicum, belonging to the same family as the potato. The red pepper of our gardens is also a Capsicum. Allspice is the dried unripe fruit of the pimento tree, a native of the West Indies but cultivated chiefly in Jamaica. Nutmegs are the kernels of the fruit of a tree (Myristica) that is grown in various warm countries; the dried seed coats, removed from the kernels, are mace. Caraway seeds are used to some extent in both the Old World and the New. Cloves are the dried flower buds of a tropical tree. Ginger is the dried underground stem of a plant that is raised in various tropical countries. Turmeric comes from the underground stems of another member of the ginger family. Its most familiar use is in curry powder, in which it is combined with other spices; it is also used as a yellow dye and in other ways. Cinnamon is the dried bark of a tree that grows in Ceylon, and cassia bark and cassia buds come from a similar tree of China and northern India.

342. Flavors and Perfumes. - These are usually in the form of extracts from flowers, fruits, leaves, or other parts of plants. Very commonly the extract is obtained by distilling the plant parts with water. Some, such as orange and lemon oils, are simply pressed - in these cases from the rind of the fruit. Some flower extracts are obtained by a process of 
absorption in lard or other fat. Since spices are used for flavoring, and since many flavoring extracts are made from spices, the line between spices and flavors is not a sharp one. Most of the substances which largely or entirely make up flavoring extracts and perfumes and give them their characteristic properties, belong to the class known as volatile oils or essential oils - a distinct class from the fatty oils already spoken of. Mustard oil and clove oil are well-known examples of this class. Vanilla extract is obtained from the unripe fruit of a Mexican orchid. Other essential oils much used in flavors, perfumes, or both, are those from roses (" attar of roses "), lavender, bergamot, violet, wintergreen, peppermint, rosemary, coriander, bay, and cinnamon. Many of the essential oils are now made in the laboratory more cheaply than they can be obtained from plants. It is for this reason that some of the perfumes and flavors now largely used are not actually derived from the plants whose names they bear.

343. Medicines. - The number of plants whose parts, bark, seeds, dried leaves, flowers, etc., - or extracts from whose parts, are or have been used in medicine, is very large. Some of these plants have been referred to in previous chapters. In many cases the medicinal properties reside in the essential oils, and the cxtracted oils themselves are much used in medicine. Some of the plant products that have been spoken of on a previous page as used for their stimulating or narcotic properties are also useful medicinally. This is especially true of opium, from which morphin and laudanum are obtained, and of coca leaves, which are the sotrce of cocain. A number of drug plants are being increasingly grown on a commercial scale in the United States.

344. Fiber Plants. - With the exception of silk, wool, and asbestos, all the important fibrous materials used in the weaving of fabrics and in the making of twine, rope, and the like, are derived from plants. Of fiber plants, the most important is cotton, which has been cultivated from very 
ancient times. At present, more than half of the world's supply is raised in the southern United States. The cotton

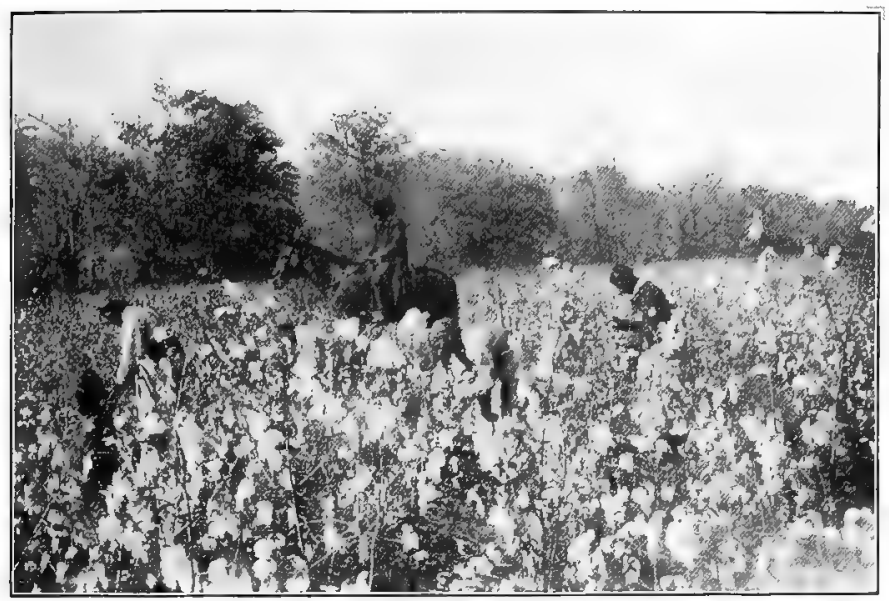

FIG. I79. - A field of cotton.

fiber is a long, single-celled hair borne on the seed. The fibers are separated from the seeds by the machine known as a cotton gin. Cotton yarns are used in the weaving of cambric, muslin, cheesecloth, duck, and other fabrics. Cotton threads are largely used with silk or wool in the weaving of mixed goods. Cotton treated with a solution of caustic soda is "mercerized"; the fibers are much changed and take on a silky appearance.

Linen is made from the bast fibers of the stem of the flax plant. The varieties of flax that are raised primarily for seed (from

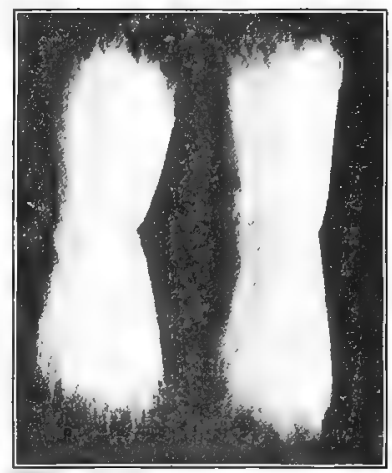

FIG. I 80. - Cotton seeds with fibers attached. 
which linseed oil is obtained) are different from those that supply a high-grade fiber. On the other hand, "fiber flax" yields a considerable quantity of seed, though less than can be obtained from the varieties of "seed flax." About four-fifths of the world's supply of fiber flax is raised in Russia, though the best fiber comes from Belgium. About one-third of the total manufacture of linen is carried on in Ireland. Very little fiber flax is raised in the United States (less than 2000 acres), but about 3,000,000 acres are devoted to the growth of seed flax. The plants that are to furnish the fibers are pulled from the ground before most of the seeds are fully ripe.

Hemp is made from the bast fibers of the hemp plant, of which also Russia is the largest producer. The fibers are longer and coarser than those of flax, but not so strong; they cannot be bleached white. They are used for twine, rope, and coarse fabrics. Jute, used also for twine and rope, as well as in carpets', burlap, and gunny cloth, is made from the bast fibers of plants that grow in India. Sisal hemp, used especially in making binding twine, is obtained from the fibers of the leaves of an agave, which is raised chiefly in Yucatan. Manila hemp comes from the leaf-stalks of a tree related to the banana which grows in the Philippines. While those just mentioned are the most important commercially, the fibers or fibrous stems of many other plants are used in similar ways in different countries. Among them may be mentioned New Zealand flax, Tampico hemp, sunn hemp, bowstring hemp, ramic, coconut fiber (from the outer husk of the nut), raffia, rattan, and bamboo.

345. Dyestuffs. - Most of the coloring substances used for dyeing fabrics, in giving color to paints and stains and the like, were formerly derived from plants. But in the last fifty or sixty years the manufacture of aniline dyes out of substances derived from coal tar has become a very important industry. The coal tar dyes can be made so cheaply, and in such a vast variety of shades suitable for different purposes, that they 
have very largely displaced vegetable dyes. However, some dyestuffs obtained from plants are still important commercially.

Indigo is one of the vegetable dyes that has been largely replaced, though it is still used to some extent - as for example in "bluing." It is obtained from the juices of several tropical plants, mostly species of Indigofera. Logwood extract is a red substance derived from the wood of a tree growing in Central America and the West Indies. It can be used only in connection with a mordant, which causes the fabric or other substance that is to be dyed to take and hold the color. The color obtained is usually black, but it may be violet, blue, or gray, depending upon the mordant used. Madder is a red dye produced by powdering the dried roots of a plant grown in central Europe and southern Asia. Arnotto, a yellow dye used in coloring butter and cheese, is made from the pulp of the fruit of a shrub of Central and South America and the West Indies. Safflower, a red coloring matter used as a flavoring, in face rouge, and in making a dye for silk, is the dricd flowers of a plant of the composite family. Other vegetable dyes are fustic, quercitron, saffron, henna, litmus, and turmeric. 


\section{CHAPTER XXI \\ WEEDS AND POISONOUS PLANTS}

346. Weeds. - A weed has been defined as a "wild plant that has the habit of intruding where not wanted." It does not follow that weeds are necessarily useless or harmful; indeed, many of them may at times be useful; and some annoying weeds belong to species which are or have been cultivated but which make a nuisance of themselves then they grow in the wrong place. Some plants that are not particularly troublesome in their original home grow so rankly as to be very annoying weeds when introduced into a new country. Practically all our weeds are herbaceous; they may therefore be cither annuals, growing rapidly from seed and dying at the end of the season, or biennials or perennials whose above-ground parts die each fall. To be successful as a weed, a plant must have some very efficient method of increasing its numbers; and for this purpose it depends usually either upon the production of a great number of seeds, which are often specially well provided with devices for distribution, or upon multiplication by means of long, branching underground stems.

347. Injury Caused by Weeds. - As a general thing, the greatest objection to weeds is that they reduce the crop of the cultivated plants among which they grow. They do this by crowding the useful plants and so reducing their supply of light, moisture, and the food substances that the plants must take from the soil. It has been suggested, too, that weeds give off to the soil substances that may be poisonous to other plants. The presence of such a weed as the Canada 
thistle interferes with the harvesting and handling of a crop, and may greatly reduce its value. Thus a forage crop, such as hay, is much less valuable if it contains a large proportion of wceds that domestic animals will not eat or that, if eaten, may injure them. The presence of weed seeds in a crop of wheat or oats may greatly reduce the market value of the grain. Sometimes parasitic fungi or insects live on weeds and pass from the weeds to related useful plants. Some weeds are poisonous to man or to domestic animals; these will be discussed on a later page.

\section{Some Ways in which Weeds} May be Useful. - When land is allowed to lie fallow - that is, when it is not cultivated for one or more years - it becomes covered by a growth of grasses and weeds. When these die, their substance helps to enrich the soil by adding to its supply of organic materials. In this way a soil that has become poor may be considerably improved by the growth of weeds. However, as a general thing the same or greater good can be accomplished

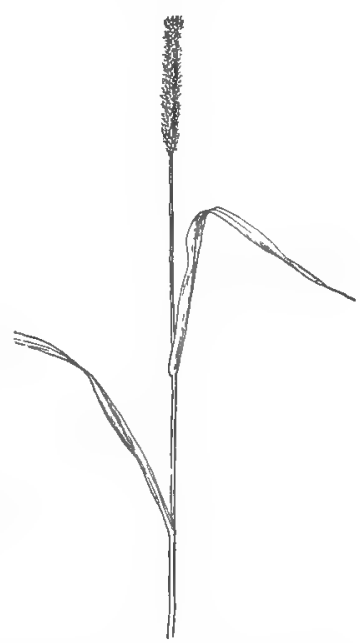

FIG. I8I. - Pigeon grass. After lleed. more quickly by a proper rotation which includes at reasonable intervals a crop of alfalfa or some other member of the pulse family. Weeds also help, during the time of the year when crop plants are not being grown, in holding the soil together by means of their root systems, thus checking erosion, and also preventing the washing away of the nitrogen-containing substances that are so important to soil fertility.

349. Annual Weeds. - A large proportion of common weeds are annuals. Being annuals, they must depend upon 
an abundant production of seeds to insure their perpetuation and spread; and some of our annual weeds are remarkable for the vast numbers of flowers, fruits, and

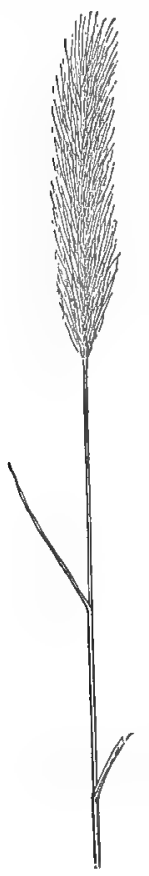

FIG. $182 .-$ Squirrel-tail grass. After Weed. seeds that they bear. A striking example of this sort is the common ragweed, abundant along roadsides and in neglected fields. The ragweed is a composite. Other weeds of the same family which likewise bear seeds in great abundance are the maywced, cocklebur, horseweed, and prickly lettuce. The grass family, too, contributes a number of troublesome annual weeds, among them chess, wild oats, squirrel-tail grass, pigeon grass, crab grass, and bur grass. The dodders and the wild morningglory are representatives of the convolvulus family; the buffalo bur and the jimson weed of the nightshade family; the lamb's quarters and the Russian thistle of the goosefoot family; and the wild mustard and French-weed (penny cress) of the cress family: The pigweed, purslane, smartweed, and chickweed are also common and widespread.

\section{Biennial Weeds.}

This group is a comparatively small one. It is plain that, like annuals, biennials must depend chicfly upon seeds for their perpetuation and increase. The composite family, whose members have such effective means of producins and scattering their seeds, contributes a few important weeds to the biennial group.

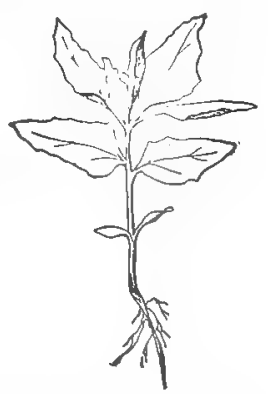

FIG, I83. - Lamb's quarters. Ifter Wreed. Among them are the common thistle (bull thistle) and some of its immediate relatives; the burdock, skeleton weed, and 
black-eyed Susan. The wild carrot and the wild parsnip, both members of the parsley family, arc biennials; and so are the mulleins, the bluewced, the hound's tongue, and the wild teasel.

351. Perennial Weeds. - The weeds of this group multiply by means of seeds, but the fact that parts of them live from year to year makes it possible for them to increase their numbers in other ways as well. Many of them, such as the Canada thistle and the horse-radish, spread very readily by means of the growth and branching of

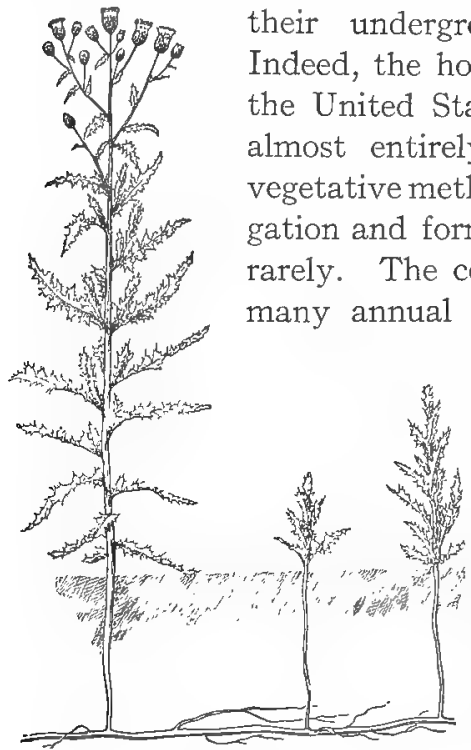

FIG. I85. - The Canada thistle. After Weed.

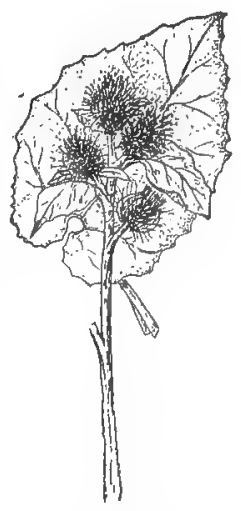

FIG. I84. - The burdock. After Weed. rarely. The composite family, to which so many annual and biennial weeds belong, contributes also a goodly number of perennial weeds; the list includes the Canada thistle, the field sow thistle, the ironweed, the dandelion, and the marguerite or oxcye daisy. Among the grasses that cause trouble as weeds are the wellknown quack grass, the Johnson grass, and Bermuda grass. Other perennial weeds are the bindweeds, horse nettle, milkweeds, plantains, field garlic, Indian hemp, field sorrel, and yellow dock. The brake is one of 
the few ferns that make themselves troublesome in this way.

352. How Weeds are Introduced and Spread. - As we have seen, most of our weeds, whether annual, biennial, or

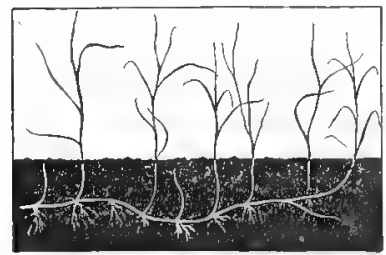

FIG. 186, - The quack grass. perennial, produce great numbers of seeds, and depend largely or entirely upon seeds for their distribution. The most successful weed, therefore, is the one that has the most effective means of scattering its seeds or fruits. An excellent example of a very successful weed is the dandelion, whose plumed fruits are so casily carried to great distances by the wind. Something was said in Chapter XVIII about the various ways in which seeds and fruits are scattered, and most of the means of distribution mentioned in that chapter are employed by some of the common weeds. That so many of the composite family are weeds is due to the excellent means of fruit distribution - especially distribution by the wind - that the members of that family have developed. Besides composite weeds - including the dandelion, thistles, and wild lettuce - a good many members of othor families depend likewise upon the wind; examples are the milkweeds,

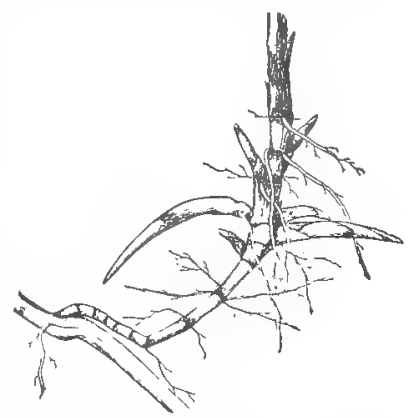

Fig. 187. - The Johnson grass. with tufts of hairs attached to their seeds, and many of the grasses and sedges, whose fruits are very small and light. Among the weeds whose fruits attach themselves to the bodies of animals, some composites, too, - such as the cocklebur and the burdock, - are conspicuous. 
But besides these methods of secd and fruit distribution which are common to many plants, there are a number of others that are peculiar to weeds and must be specially guarded against. For instance, weed fruits and seeds are often carried into new regions by railway trains; and one often finds newly introduced weeds and other plants growing

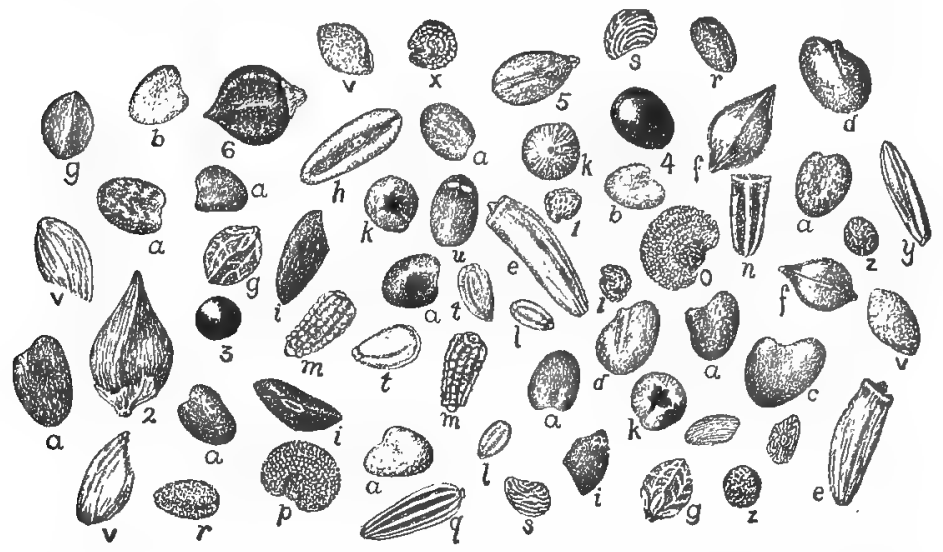

FIG. I88. - A mixture of seeds commonly found in low-grade alsike clover seed: $a$, alsike clover; $b$, white clover; $c$, red clover; $d$, yellow trefoil; $e$, Canada thistle; $f$, dock ; $g$, sorrel; $h$, buckthorn ; $i$, rat-tail plantain; $k$, lamb's quarters; $l$, shepherd's purse; $m$, mayweed; $n$, scentless camomile; $o$, white campion; $p$, night-flowering catch-fly; $q$, ox-eye daisy ; $r$, small-fruited false flax; $s$, cinquefoil; $t$, two kinds of peppergrass; $u$, catnip; $u$, timothy; $x$, chickweed; $y$, Canada bluegrass; $z$, clover dodder; $I$, mouse-ear chickweed; 2 , knot-grass; 3 , tumbling amaranth; 4, rough amaranth; 5, heal-all; 6, lady's thumb. After Hillman.

beside railway tracks, and perhaps spreading gradually from there into neighboring fields. When weeds grow undisturbed among cultivated plants, their seeds are likely to be harvested with the crop; as a result, the weed seeds are distributed with those of the harvested crop, as chess seed with wheat, wild oats with cultivated oats, and dodder with clover or alfalfa seed; or the seeds, like those of many 
undesirable grasses, are distributed with hay or straw. Weed seeds are carried too by harrows and other implements used in tillage; by threshing machines; in many stock feeds; and very extensively in fresh manures. Some plants, spoken of as "tumble weeds," which have short roots, are easily torn from the soil when they are dead, and are blown or rolled by the wind from place to place, scattering seeds as they go. This class of plants includes the buffalo bur, the horse nettle, the pigweed, the ragweed, and the Russian thistle.

It has already been said that perennial weeds, while they may depend largely upon seeds for their distribution (consider the dandelion, for example) also have the possibility of multiplying their numbers by vegetative means. The commonest of these means is that used by the Canada thistle, namely, the branching of an underground stem, the branches becoming separate plants by the death of the older parts of the stem. Some of the grasses, notably quack grass, spread in the same way; and many other weeds spread by means of a rapid growth of underground stems and roots. Runners, like those of the strawberry, are produced by some of the hawkweeds. Tubers are formed by a few weeds; nut grass (a member of the sedge family) is a tuber-bearing weed, and the Jerusalem artichoke, though not usually growing so abundantly as to be troublesome, may be placed in the same class. The field garlic is an illustration of a weed whose perennial underground part is a bulb instead of an elongated stem.

353. The Control and Destruction of Weeds. - That has just been said regarding the ways in which weeds spread may suggest methods by which they are to be controlled. So far as concerns annual and bicnnial weeds, and indeed many perennial weeds also, it is plain that they will be eliminated if they can be prevented from forming seeds. This can be done by cultivation, which kills the weeds before they have "gone to seed," or even by cutting off their tops early and frequently enough. This is why many of the wecds that appear in 
lawns disappear in a comparatively short time if the lawns are regularly mowed; and it is a reason for the mowing of fence rows and for the cutting of weeds that appear in pastures. Sometimes it is helpful to burn weeds, especially if they have begun to form their seeds when they are cut. When such precautions as these are taken, and the original weed plants die or are destroyed, there is no chance for the species to appear in the following year. But unfortunately these simple methods are not finally effective against weeds whose seeds are carried long distances by the wind. No matter how carefully thistles may be eliminated from a field, or dandelions from a lawn, the owner is at the mercy of his neighbor; and if the neighbor persists in raising a good crop of thistles or dandelions each year, only a continuous warfare will keep them from making serious trouble on another's premises. This is the rcason that lies back of the enforcement of laws against noxious weeds; one person cannot make much headway in the fight without help from the community.

Each of the different ways in which weed seeds may be introduced requires to be guarded against by special precautions. It is important to use in every case only the cleanest seed that can be obtained - seed, that is, which is free from weed seeds. It is commonly advised that a hay crop be cut early; one advantage of this practice is that weeds growing among the crop are prevented from going to seed and thus having their seeds distributed with the hay. Most of the weed seeds in a manure pile rot rather quickly; the danger from manure can, therefore, be largely met by allowing it to rot thoroughly. Of the tumbleweeds, probably the worst is the Russian thistle, which is one of the most dangerous weeds in the prairie region of the western United States. Its migration is stopped whenever it meets a good fence; fences, therefore, offer a means of combating the spread of this and similar weeds. Tumbleweeds are of comparatively little 
importance in a country where trees are plentiful, because there are many obstacles to their travels about the country. Those perennial weeds which spread by means of underground stems and roots offer a set of special problems. Usually such weeds must be dealt with by thorough cultivation; the exact methods to be adopted will depend upon the nature of the weeds that are making the trouble and upon the character of the crop that is being raised on the same land. Even though cultivation does not directly reach all the underground parts of the weeds, it may nevertheless be successful in killing them by keeping down their top growth, because the roots and underground stems are dependent upon the food that is manufactured by the leaves, and will die in time if this source of food is shut off.

A proper rotation of crops, in addition to its other advantages, offers means of dealing with weeds; forinstance, weeds that become established in a field of wheat can be destroyed the following year if cultivated crops be raised in the same field; or they may be largely overcome by a forage crop, such as grass or alfalfa, which interferes with the growth of weeds by shading them, and is cut for hay before most of the weeds have ripened their seeds. It is found that some weeds, especially those with rather broad leaves, such as the wild mustard, horse nettle; dandelion, and Canada thistle, growing in pastures or grain fields, can be killed by the use of poisonous sprays. The grasses and grains have narrow leaves which do not catch and hold much of the poisonous solution, whercas the larger leaves of the weeds hold enough of the poison to injure or kill them. The substances most used in these sprays are iron sulphate, copper sulphate, and common salt. Directions for weed spraying are given in the bulletins of various state experiment stations. Sometimes it is found advisable to smother weeds that occupy as yet but a small patch by covering them with building paper, or with straw or manure; and many other special methods have been 
devised for dealing with the problems raised by the growth of particular weeds.

\section{Plants Poisonous When}

Eaten. - A rather large number of plants contain substances that render them poisonous in greater or less degree when eaten by human beings. Fortunately, the

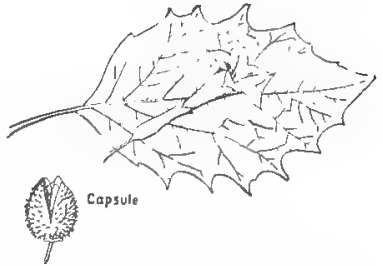

FIG. I89. - The jimson weed. After Weed. number of poisonous plants to be found in any one locality is ordinarily comparatively small, and it is easy to become acquainted with all the dangerous ones that are likely to be met. The poisonous plants most commoniy confused with harmless ones are perhaps some of the mushrooms (see Chapter VIII, § I09). Another poisonous fungus of considerable importance is the ergot, which is parasitic upon rye and other grains and upon some wild grasses. Of the

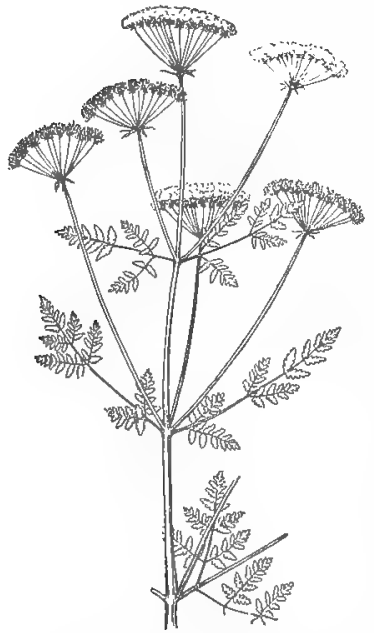

FIG, Igo. - The poison hemlock (conium). After Weed. much more numerous poisonous sced plants, it is true in many cases that the same substance which gives the plant its harmful character also makes it valuable, when properly used, as a medicine. To the class of poisonous medicinal plants belong aconite, belladonna, conium (poison hemlock), hellebore, American false hellebore, henbane, lobelia, pokeweed, and stramonium ("jimson weed").

Conium seems to have been the source of the extract which, under the name of "hemlock," was used by the Greeks and Romans for the punishment of criminals. The water hemlocks, belonging to the 
genus Cicuta, are closely related to conium and are likewise extremely poisonous. Several human deaths are caused each year by the eating of the parts, especially the roots, of the water hemlock and poison hemlock. The similarity of these plants to the clitivated parsnip seems to have been the foundation of the widespread though incorrect notion that the parsnip becomes poisonous if allowed to grow wild. Sometimes the seeds of conium have been mistaken for those of anise, and the leaves for those of parsley, with fatal results.

Corn cockle, a rather common weed in grain fields, is poisonous. The chief danger from it seems to arise from the mixing of the seeds with wheat or other grains. Fiour made from wheat containing cockle seeds has been known to produce serious, sometimes fatal, effects.

The juices of various spurges are poisonous. Two cultivated species which sometimes cause trouble are caper spurge and "snow-on-thc-mountain." The seeds of the former, if eaten in too large numbers, cause illness and even death; and the poison of snow-on-the-mountain is carried by honey made from the nectar of the flowers. Honey obtained from the broad-leaf laurel also is said sometimes to be poisonous; and children are reported to have been poisoned by eating the young shoots of this plant which they mistook for wintergreen. The narrow-leaf laurel and the great laurel are likewise poisonous.

There has been much discussion as to the poisonous nature of the black nightshade. The ripe fruits are said to have been eaten in considerable quantities without bad effects; on the other hand, cases have been reported of the poisoning of domestic animals by the eating of the leaves, and experiments seem to show that the berries are sometimes poisonous. The berries and leaves of the bitterswect, which, like the nightshade, belongs to the same genus as the potato, have been found to be somewhat poisonous.

There are some plants which are regularly, used for food in 
spite of the fact that they are poisonous in the condition in which they are gathered. Thus, the fresh shoots of the pokeweed are used like asparagus; but the water in which the shoots are first boiled must be discarded because of the poisonous substance dissolved in it; and it is important that no part of the root be eaten. The fruits of the horse-chestnut and its relatives, the buckeyes, are poisonous; but those of the California buckeye are said to be used by Indians after the poisonous substance is removed by proper treatment. The fruits of the horse-chestnut are fed to cattle in England, the poison keing first removed. The root of cassava, from which tapioca is obtained, is another illustration. The tapioca is the starch of the root; to obtain it the root is ground up and thoroughly washed to remove the poisonous substance that it contains. Other plants that have been found to be more or less poisonous are the lily-of-the-valley, staggerbush, branch ivy, and false jessamine.

355. Plants Especially Dangerous to Animals. - Important members of this class are numerous species of larkspur. Some European larkspurs have long been considered poisonous to stock; and serious losses of cattle and horses occur in the mountainous grazing regions of the western United States, caused by the eating of the native larkspurs. Curiously enough, experiments seem to show that sheep are not poisoned by these plants, although there are differences of opinion upon this point. Serious damage is caused to horses, cattle, and sheep in the western United States by certain plants, poisoning by which at first causes a sort of hallucination or insanity, for which reason the plants causing the trouble are called "loco weeds." The disease ends after some months in the death of the poisoned animal. The woolly loco weed, found from South Dakota and Wyoming to Texas and New Mexico, is an Astragalus; the stemless loco weed, which ranges from British America to Mexico, is an Oxytropis; both are members of the pulse family. Some species of lupine, belonging 
to the same family, have also been found to be poisonous to livestock if eaten in sufficient quantities. Another poisonous member of the pulse family is the rattlebox. Still another western poisonous plant that causes important losses, especially of sheep, is the death camas (Zygadenus).

The leaves of the black cherry are poisonous when partially wilted, and cattle are sometimes killed by eating the leaves from cut branches. Some deaths have been reported, too, of children who ate the kernels of black cherry sceds, or who swallowed the fruits whole. The partially wilted leaves of some other cherries and the kernels of many, perhaps of all, cherries and plums, are poisonous. The sneezeweed, a composite, which when powdered is used medicinally to produce sneezing, has been known to kill sheep, cattle, and horses which, unfamiliar with the plant, have eaten it. As a rule, however, animals avoid the plant. Corn cockle, American false hellebore, the buckeyes and the horse-chestnut, water

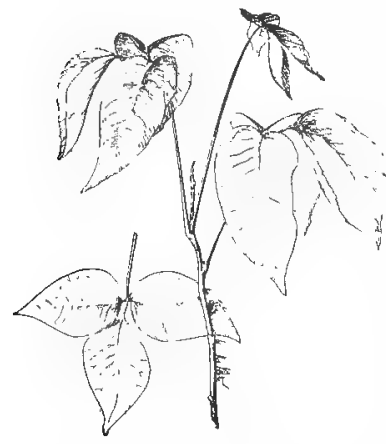

Fig. I9I. - The poison ivy. After Weed. hemlock, poison hemlock, and the broad-leaf laurel, already referred to as poisonous to human beings, are also dangerous to animals.

356. Plants Poisonous to the Touch. - Well-known representatives of this class are poison ivy, poison oak, and the poison sumach (poison elder). All these belong to the same genus (Rhus) as the common sumachs. Their irritating effects upon the skin are due to an oil which is found in all parts of the plant; it is soluble in alcohol and is destroyed by an alcoholic solution of sugar of lead. Some of the primroses produce a somewhat similar irritation of the skin in many persons. The milky juices of the caper spurge, snow-on-the-mountain, and other spurges 
cause a serious irritation of the skin; and some species of lady's-slipper are reported to have an effect upon some persons very like that of poison ivy.

357. Hay Fever. - Just as some substances produced by plants cause irritation of the skin, others give rise to serious difficulties because they are poisonous to the mucous membranes of the nasal passages, eyes, and throat. The irritated condition that gives rise to "hay fever" and "rose fever" is due to the poisonous action of the pollen of certain plants. The plant that seems to cause most trouble in this way is the common ragweed which grows abundantly along roadsides and on waste

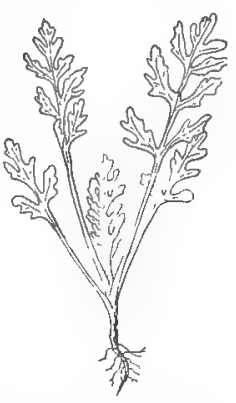

Fig. I92. - The ragweed. After Weed.

land. Some cases of hay fever are apparently caused by the pollen of certain grasses. 


\section{CHAPTER XXII}

\section{FORESTRY AND FOREST MANAGEMENT}

358. Meaning of Forestry. - A generation ago "forestry" would have been considered, by people of the Western Hemisphere at least, as synonymous with lumbering, which concerns itself with the problem of how best to get the products of the forest into the market in the form of lumber. During recent years, however, forestry has come to be thought of as primarily concerned with the ways and means of raising repeated crops of forest trees on land that may not be suitable for the growing of ordinary farm crops; and, as we shall learn, there are many problems other than that of the mere growing of timber which must be considered in connection with forestry.

359. History of Forestry. - Sritzerland and Germany were the first countries that seriously undertook to control the cutting and replanting of forest areas. The city of Zürich, as early as the year 853 , took orer the supervision of a forest area, and since the middle of the fourteenth century this area has been cut and the products have been handled by a city commission. Large tracts in Germany have been well cared for by cities and provinces since the thirteenth century, and in that country schools of forestry were early established. During the French Revolution there was a ruthless destruction of forests covering the more elevated regions throughout France; as a result, not only was there soon a lack of timber, but the floods carried sand and gravel from the exposed slopes on to the farm lands below. The replanting of mountain slopes was undertaken by local com. 
munities and cities and by national commissions, which have done such excellent work that many of the forest areas compare favorably with those of Germany. Not only were the old areas replanted, but extensive tracts of land along the sea coast, where the sands shifted and at times covered entire farms, were taken over and planted with forest trees. Other European and Asiatic countries have definite forest

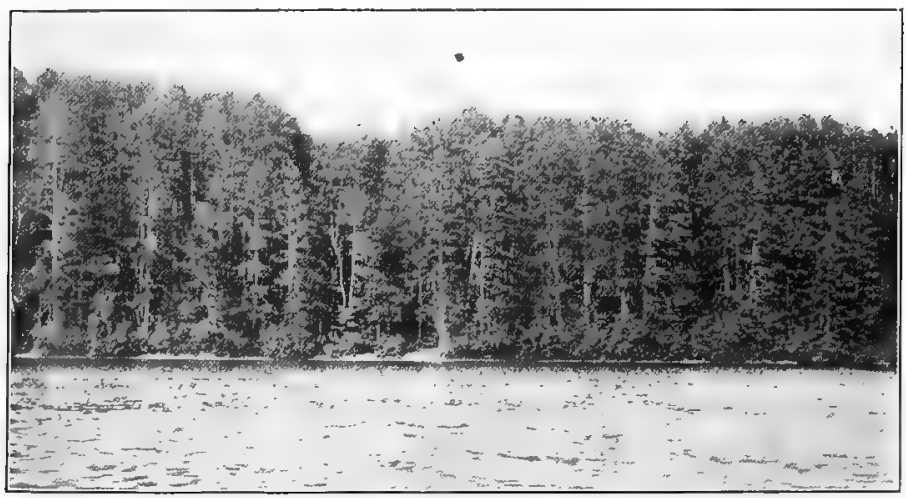

FIG. I93. - A natural coniferous forest. Photograph from the Wisconsin State Conservation Commission.

policies, and Japan ranks with Germany and France in the results obtained from her forests.

It was not until about I875 that a serious interest in forestry began to develop in the United States and Canada. $U_{p}$ to this time it had seemed as though the forests were inexhaustible. Sporadic efforts had been made in earlier years by cities and by a few states to control in part the cutting of timber. Some of the early settlements in New England made laws regulating the cutting and sale of timber products. William Penn in 1682 declared that one acre must be kept in forest for each five acres cleared. It is unfortunate that with this precedent the state of Pennsylvania should at present be in worse condition than any other eastern state 
because of the reckless use of her forests. Timber was in great demand as the Pennsylvania coal mines were developed, and the forests were cut but no effort was made to reforest the cutover areas.

A forest agent was appointed in the United States Department of Agriculture in 1876 ; this agency became a division in 1886 , and in 1897 the work had grown to such an extent that a separate Bureau of Forestry was established. In I89I laws were passed making it possible for the President to set aside, from the national domain, forest lands as public reservations.

360. National Forests in the United States. - President Harrison set aside the first forest areas, and before the end of his administration more than $\mathrm{I} 3,000,000$ acres were established as forest reserves. President Cleveland added $22,000,000$ acres of valuable forests. Some land was added during President McKinley's term, but it remained for President Roosevelt to establish a definite forest policy. The western part of the United States was carefully studied, and wherever possible forest lands were set aside. These withdrawals were so extensive that at the end of the Roosevelt administration the national forests included almost I 95,000,$\infty 00$ acres under the control of a body of men trained in most part for forest service. Since rgog this area has been somewhat diminished because of the opening for settlement of the better agricultural lands within the reserves, and at present the national forest areas in the United States, Alaska, and Porto Rico comprise about i $85,000,000$ acres, including about one-fifth of the national timber supply, and divided into more than 160 national forests. These forests are now open for the widest possible use. The old timber is sold, trees are continually being planted, roads are being built, grass lands within their boundaries are leased and furnish food for about one-sixth of the meat-supplying animals of the country; homesteads are found wherever the land is best suited for 


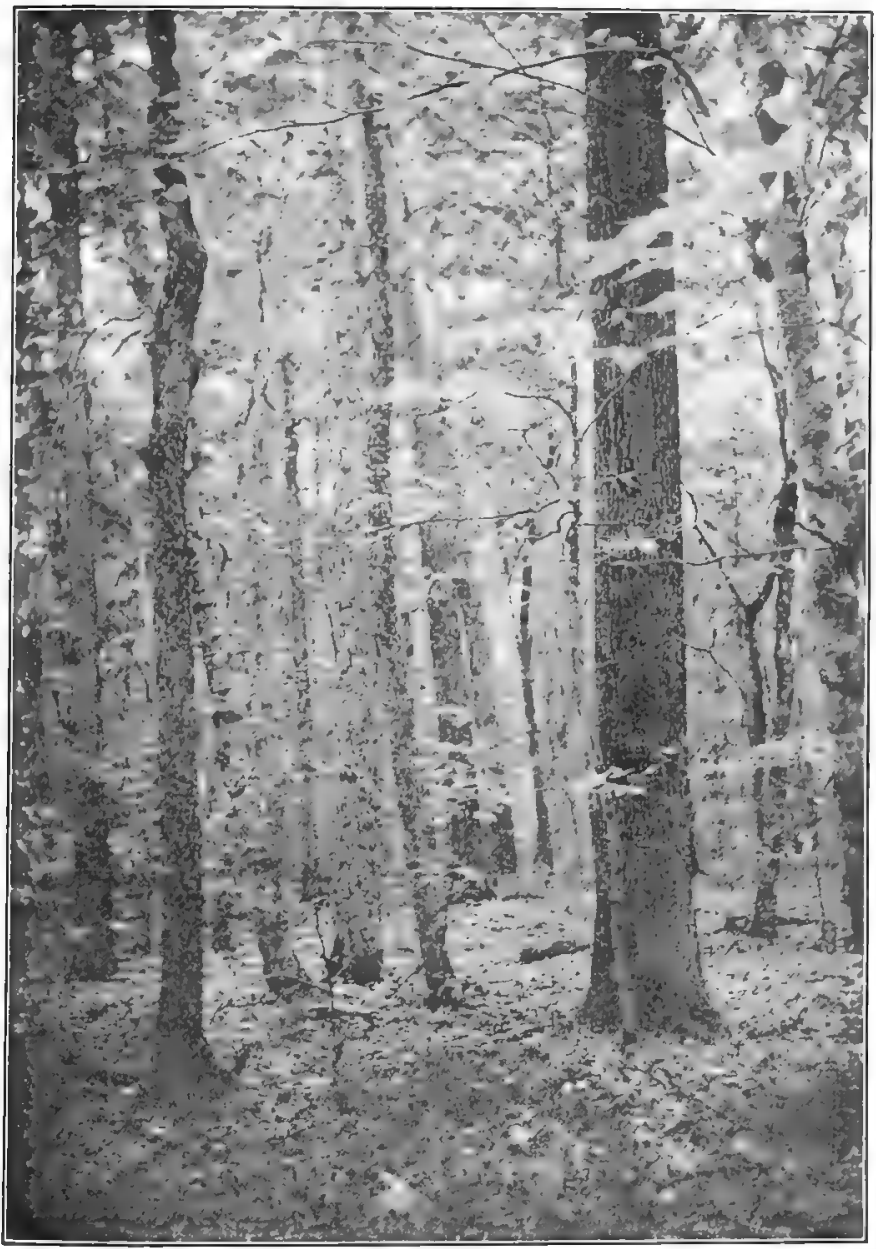

FIG, I94. - A virgin forest of mixed hardwoods. Photograph from the Wisconsin State Conservation Commission. 
farming; many mines are located within the forests, and the immense water power available in them is being gradually developed.

361. State and Private Forests. - Fourteen states have established forest areas for timber supply and for the purpose of protection against floods. These areas comprise at pres-

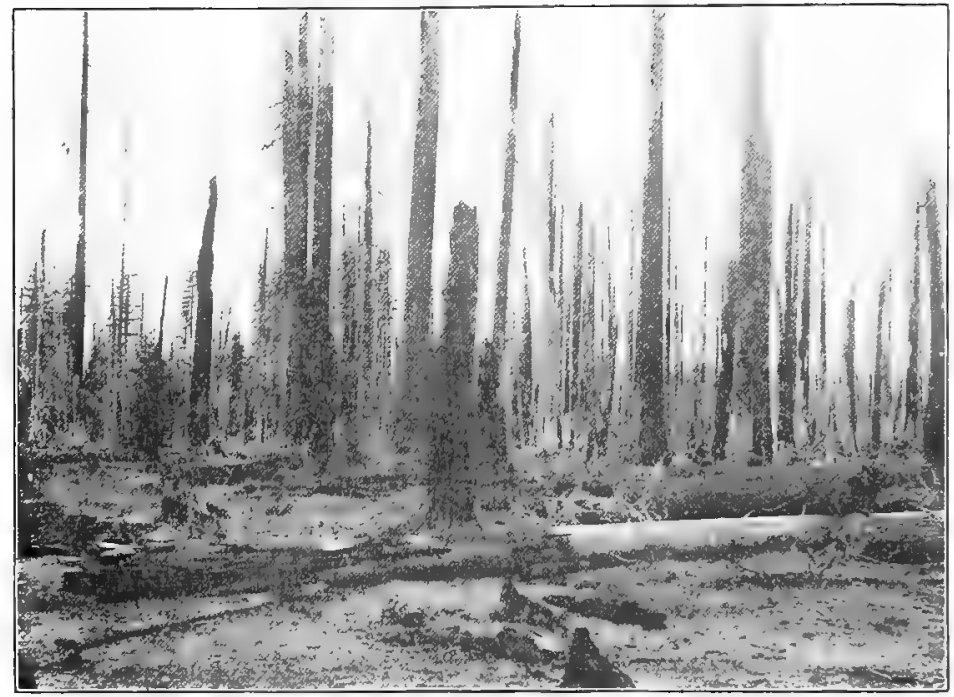

FIG. 195. - The results of a fire due to improper lumbering methods.

ent almost 4,000,000 acres. Railway companies are planting large tracts which will in time supply ties and poles. Within the past ten years more than a million acres of forests have been planted by private individuals, and many states are encouraging the planting of woodlots on the poorer farm lands, which will not only furnish a steady supply of fucl but will also yield good returns as an investment. Many states have established nurseries which supply young plants for the reforestration of cutover areas as well as trees for private forests and woodlots. 
362. Canadian Forests. - Canada is more fortunate than the United States in the fact that many of her largest forests are still intact and under the supervision of the national and provincial governments. The fact that the poptlation of the Dominion of Canada is much smaller than that of the United States had resulted in the Canadian forests being almost untouched at the time when a demand arose for a definite forest policy. Very stringent national laws were passed

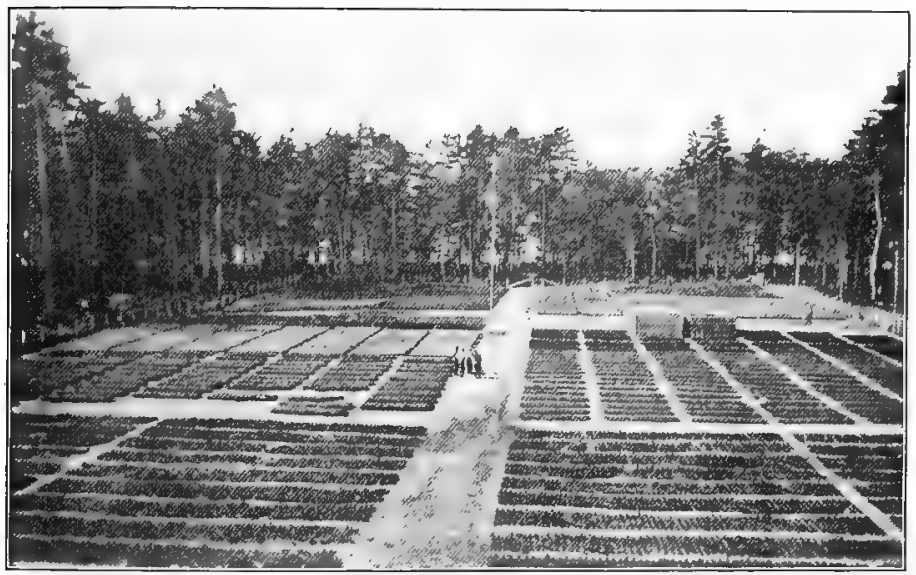

Fig. $196,-$ A portion of the state forest nursery at Trout Lake, Wisconsin. Photograph from the Wisconsin State Conservation Commission.

determining the policy of the various provinces, as well as regulating in a general way the forests which had passed into the possession of some of the larger railways and the immense tracts owned by the Hudson Bay Company. So, although her forests have been at times carelessly handled, and although, as a result, disastrous fires have destroyed large quantities of timber, Canada has at present the richest forests in the world; they are rivaled only by some of the tropical forests and by the extensive forested areas in Russia and Siberia. 
363. Need for Government Management. - The early settlers in most regions of the United States and Canada found the timber so abundant that no effort was made to conserve it. Indeed, all the trees over large areas were girdled and allowed to die and fall in order that fire might then aid in clearing the land. This method was not only wasteful of timber because the fires destroyed the dead trees, but the heat

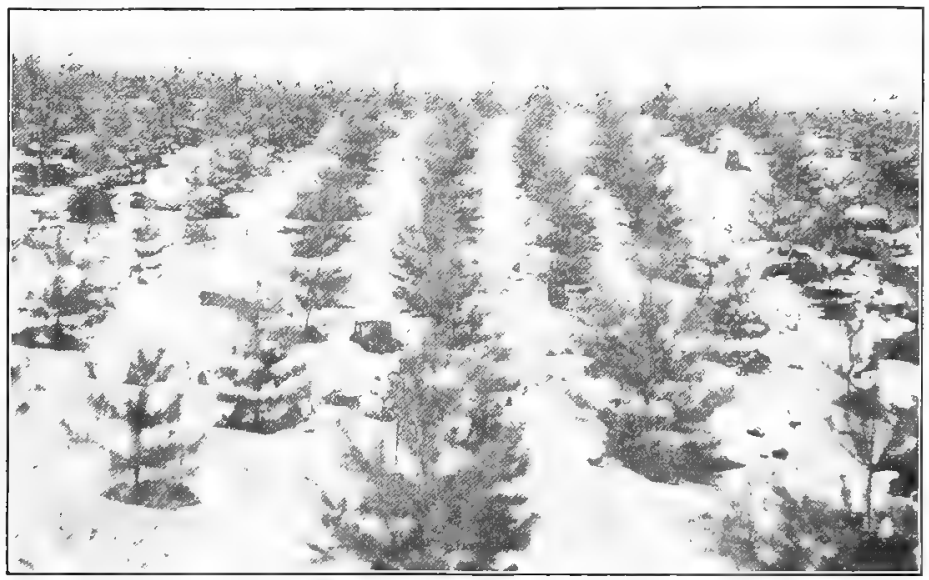

FIG. I97. - Seven-year-old white pines in the state forest nursery at Trout Lake. Photograph from the Wisconsin State Conservation Commission.

was often so intense that all the decaying plant material in the upper layers of the soil was also destroyed.

Lumbermen did not believe there would ever be a shortage in the timber supply; consequently they took only the best trees and left the smaller ones and much waste material which later furnished fuel for violent fires that icrastated vast tracts and destroyed the living as well as the dcad timber, in many cases with loss of life as wcll. Under the care of the national and state forest services, and in many cases with the help of private concerns, the fire losses are gradually decreas- 
ing, although even within recent years the losses from fire in some states have exceeded the entire season's cutting. During I 916 very considerable damage was caused by fires in the national forests of the United States, and a total of almost 300,000 acres were burned over. The actual loss per acre is now comparatively small because steps are at oncc taken to dispose of the remaining timber before it has begun to decay. During the same year two very serious forest fires occurred in Canada: one, on the castern slope of the Rocky

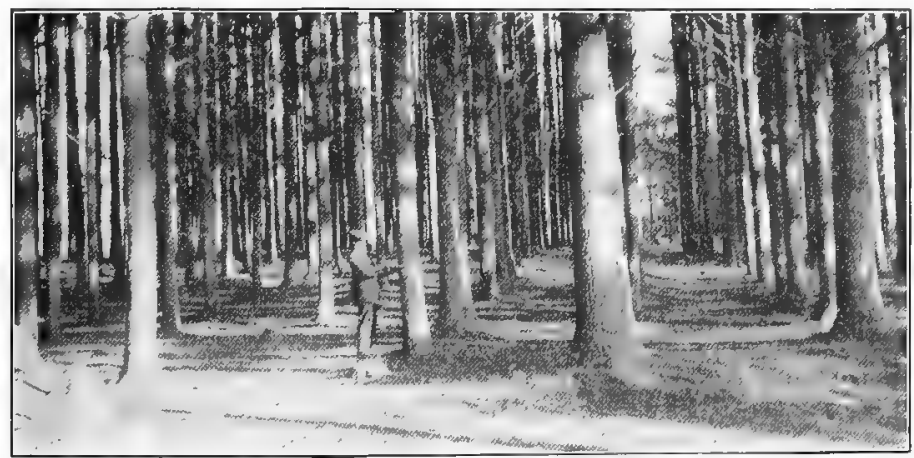

FIG. I98. - A 56-year-old plantation of white pine at Sharon, Massachusetts. Photograph from the Wisconsin State Conservation Commission.

Mountains, did damage to the extent of several million dollars; the other, more serious in that it resulted in the loss of many lives, burned over large areas in the province of Ontario.

The forests of the United States have been so decreased by this prodigal use of lumber that at present it is being. cut more than three times as fast as it is renewed by growth. It has been estimated that at the present rate of cutting all the virgin forests outside the national reserves will have disappeared by 1950. There has likewise been reckless cutting of the timber for which the demand was greatest, so that certain kinds are almost gone. This condition of affairs is 
coupled with the fact that the disappearance of the forests has been followed in many localities by serious floods which have caused great damage to property, at the same time carrying sand and gravel from the head waters of streams and depositing it upon the good farms of the lowlands. The damage caused in this latter way is estimated at more than $\$ 2,000,000$ a year in the state of Wisconsin alone.

364. Improvement of Methods. - The use of lumber per capita is much greater in the United States than in any other country of the world, being more than twenty times that reported for England and more than six times that in Germany. The methods of lumbering used in the New World, although much improved in recent years, are still much less economical than European methods. The proportion of waste in these operations in France and Grermany is about four or five per cent, but throughout the United States and Canada over sixty per cent of the timber is wasted.

Although the better mills are making use of a large part of the materials obtained from trees, many are still as wasteful as ever. Each year, however, means of handling the refuse are being introduced, and although the European record may never be equaled under American conditions, millions of dollars worth of timber products that are now wasted annually will be saved. Closer cutting in the forest, saving the branches and tops of trees for pulp wood or for distillation, greater care in handling the logs as they pass through the mill, and a variety of other means are being used to reduce the waste. State, national, and provincial foresters are teaching the protection of the standing timber against the ravages of insects and disease; laws are being passed to protect the forests from destructive fires, as well as to encourage the replanting of cutover areas. These are some of the methods by which it is hoped that our timber supply may be conserved.

Many lumber companies have lately taken another impor- 
tant step in this direction. Tree cutting is being so planned that the more mature timber may be cut each year and renewed by the growth of the uncut trees. When this is properly done, the same amount of timber may be cut each year and thus a definite supply can be permanently relied upon. Some states have endeavored to encourage this sort of con-

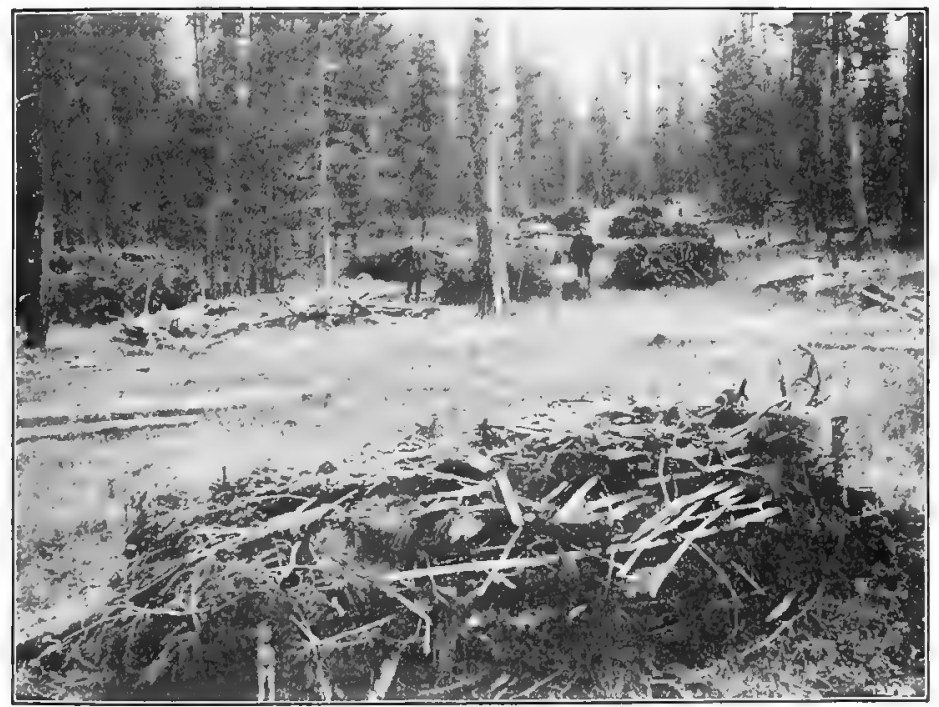

Fig. I99. - A well-managed forest; brush piled to prevent fire.

servative lumbering by regulating the taxes on timber lands according to the proportion of trees cut.

365. Forest Regions of the United States. - The northern forests include those of the New England states, New York, the portions of other states covered by the Allegheny Mountains, and the states of Michigan, Wisconsin, and Minnesota. This region has been until recently the home of the pine industry. The forests of northern New York and Maine are still an important source of spruce for paper pulp, although large amounts of pulp wood are now imported into the 
United States from Canada. The white and Norway pines were at their best in the three lake states, and some valuable tracts of these trees still remain; but nowhere else in the world, perhaps, has lumbering been carried on in so wasteful a fashion.

There is a mixture of hardwoods throughout this region, hard maple, birch, and beech being abundant in the northern part; covering some of the mountain slopes of the southern part are forests of chestnut, basswood, chestnut oak, and yellow poplar; and white, black, and red oak are abundant in places. The forests of Michigan, Wisconsin, and Minnesota, becatse of the soil and water conditions, were made up mainly of coniferous woods, including white and Norway pines, hemlock, white and black spruce, balsam and cedar; abundant stretches of larch covered the more swampy areas. Hardwoods, such as elm, maple, basswood, and birch, are found in considerable quantity. The jack pine is found on sandy areas at the edges of the heavier growths of timber.

The South Atlantic and Gulf states are covered in part by immense forests of the long-leaved yellow pine (Pinus palustris), which furnishes at present about one-third of the annual lumber cut of the country. The forests, except in the lowlands, are composed almost entirely of pine, and conditions are such that it is easily handled. The longleaved and Cuban pines of these forests are the chief sources of turpentine, and the turpentining methods used have as a rule made the trces almost worthless for timber. Cypress, the most enduring of woods, cottonwood, ash, sycamore, red gum, elm, hickory, and many species of oals are found in the lowlands and along streams; the cypress is at its best in the more swampy regions.

A region comprising a considerable portion of the eastern and southern slopes of the Alleghenies and cxtending north and west into the central states cast of the $\mathrm{M}$ [ississippi is known as the hardwood belt. Here are found beech, hickory, 
white ash, maples, cottonwood, walnut, and white, black, and red oaks. The forests, however, are not continuous, and all are mixed. As most of these forests were on land that is valuable for farming, large parts of them have already disappeared, and in many localities they are now represented only by woodlots in the pasture lands.

The forests of the Rocky Mountains arc characterized by the presence of the western yellow pine with the Douglas fir and some spruce, and, in the southern half, the piñon pine. The most heavily wooded region of the United States is found in the Pacific Coast forests, where are found also the largest trees in the world. The principal timbers are Douglas fir, western yellow pine, redwood, red cedar, hemlock, and Sitka spruce.

366. The Forests of Alaska, Porto Rico, and Hawaii. The Alaskan forests are quite extensive and are made up mostly of fir, spruce, and hemlock. Those of Porto Rico contain many valuable cabinet woods, as do also the more extensive forests of the Philippines where some of the most valuable woods are found. Little attention has yet been paid to these forests because of the many difficulties connected with lumbering operations. The importation of live stock into Hawaii completely destroyed the tropical forests because grazing exposed the roots and the trees soon died. As a result, the heavy floods soon carried lava, ashes, and débris into the sugar plantations of the lowlands, and the problem became so serious that a careful study was made of the situation. Cattle were restricted to definite areas, and trees which would grow very rapidly were planted on all slopes to protect the lands from further floods. Gradually these trees have been replaced by commercial timber, and the forests will soon be yielding an income.

367. Forest Regions of Canada. - Extending from the Atlantic Coast to the slopes of the Rocky Mountains are vast forests similar to those of the northern United States. They 
are most extensive in the provinces of New Brunswick, Quebec, and Ontario, but extend into Labrador and around the southern shores of Hudson Bay to the Alaskan boundary.

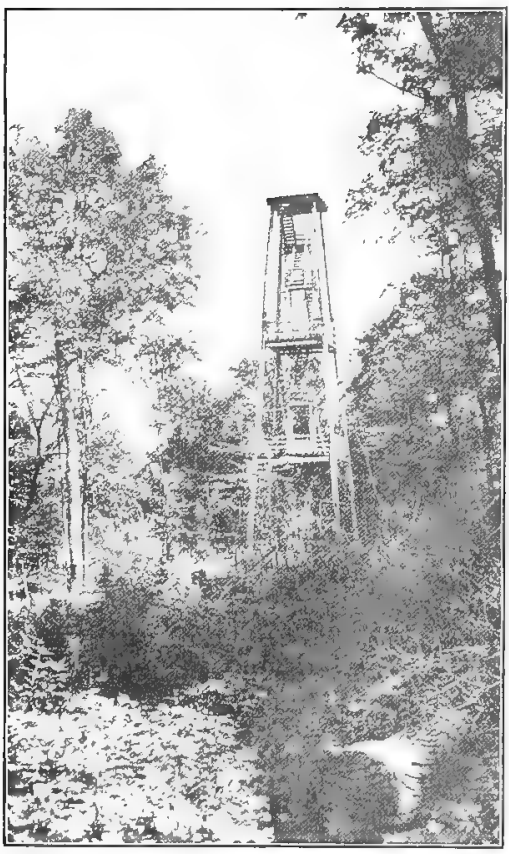

FIG. 200. - A lookout tower, 75 feet high, on an elevation in a forest. By means of such towers watch is kept over large tracts of forest, and if a fire breaks out it may quickly be located. Photograph from the Wisconsin State Conservation Commission.
The greatest spruce forests in the world are found here, as well as rich areas of white pine and hemlock. The forests of Alberta and British Columbia are very much like those already described for the northern Rocky Mountains and the Pacific Coast. The giant redwood is not found here, nor are the other trees as large as some of those found in the western United States, but the forests cover so great an area as to compare farorably in productive power with the richest forests of the world.

368. Lumbering.-Under this term are included all the operations through which a $\log$ goes from the time that a tree is felled in the forest until it is in

final shape for one of the many wood-using industries. A tree is felled, usually by means of a crosscut saw, cut into suitable lengths (generally sixteen feet, although in the West and South they are often sixuy or more feet long); then 
hauled or skidded to the place from which it may be transported to the saw mill. Formerly, logs were floated down streams to saw mills, but this has been found so wasteful that now they are nearly all hauled by rail; this is especially true of the hardwoods, which soon become water-logged and sink. In many of the Eastern and Northern forests the methods are not greatly improved over those of fifty years ago; but in the Western forests, where logs of great size must be handled, machinery is largely used in all lumbering operations.

The first saw mill in the New World was erected at Berwick, Maine, in $163 \mathrm{r}$. It was a very simple affair, comparable as to size with the small portable mills now in use that are capable of cutting from 2000 to 4000 board feet a day. Many of the larger modern saw mills can cut more than a half million board feet in the same time, all the operations being performed by intricate machinery. The log is carried into one of these mills by an endless chain and is then placed on a "carriage" which carries it past the saw so that pieces of varying thickness may be cut off. The sawyer controls these operations by means of levers and determines in a general way what type of lumber shall be cut from each individual log. All the earlier saw mills used heavy circular saws, many of which wasted almost a half inch each time a piece was cut off; these are now almost entirely replaced by the "band saw " in the shape of a continuous sted band which is more economical with material and which will cut through much larger logs. From this saw the main part of the log and the pieces that have been cut from it go to other saws which cut them into their final forms, such as heavy timbers, planks, or boards; the smaller pieces are cut into laths or shingles, or are used in making matches and excelsior, or are distilled in order to obtain various by-products. The lumber taken from the mill is piled in open piles to allow it to dry ; after drying it is taken to the planing mill where it is finished for market. 
369. Various Uses of Wood. - The chief wood products are lumber, firewood, railway ties, posts and poles, mine timber, pulp wood, and tanbark. Lumber makes up about half of the total amount of these products, and firewood

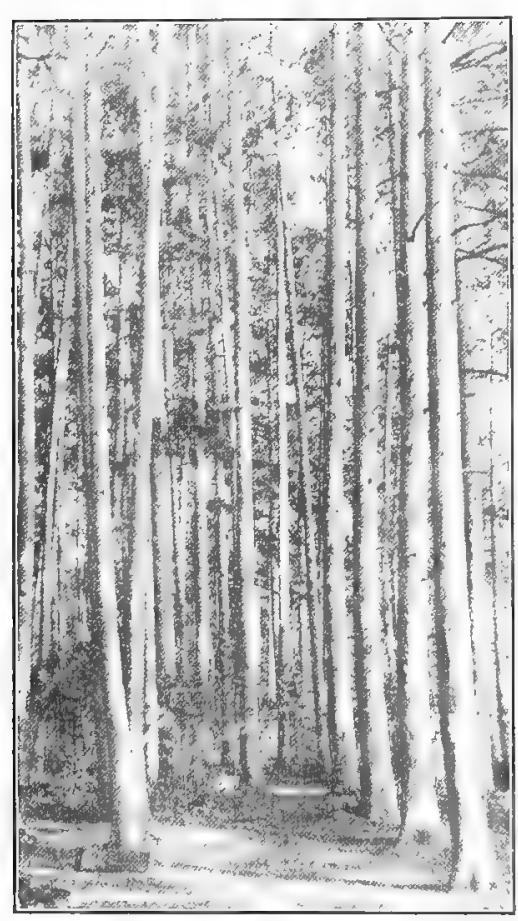

Fig. 20I. - A grove of miture red pines ("Norway" pines) at Trout Lake, Wisconsin. Photograph from the Wisconsin State Conservation Commission. about one third of the total. About zo per cent of the lumber is made into finished building material such as flooring, sash, doors, and siding; about 25 per cent is used as rough lumber; io per cent is used in the making of boxes and crates; 5 per cent in the mantfacture of cars; 3 per cent for furniture; about 7 per cent is exported; and the remainder is used in various other ways. Spruce, poplar, and larch have been most used for wood pulp, but now many other of the softer woods are being used. Oak and hemlock bark and chestnut wood are used in tanning leather; over a million cords of bark and two hundred thousand tons of wood are used in this way each ycar.

370. Wood Distillation. - The production of turpentine and rosin has been for many years an important industry in the southern states. Almost 30,000,000 gallons of turpentine and more than $3,000,000$ barrcls of rosin are produced 
annually. The waste material from many saw mills is now distilled by various processes, producing great quantities of wood alcohol, turpentine, formaldehyde, tar, creosote, and a variety of other products. The gases given off in some of these processes are used as fuel, and the charcoal which remains is valuable. A cord of long-leaved pine will produce in this way twenty-four gallons of turpentine, thirty-three gallons of pyroligneous acid, used in making vinegar, explosives, and, when united with other substances, many pigmènts; one hundred and twenty gallons of tarry and oil products, which may again be distilled; and there remain fifty-six bushels of very good charcoal.

371. Other Wood Products. - The making of veneers (thin slices or sheets of wood) has become an important industry in late years. Formerly only the expensive woods were used in this way, and the veneers of these woods were put over cheaper woods in the manufacture of furniture; but now many of the cheaper woods are cut into veneers, from which boards can be built up that are lighter and stronger than if they were made of a single piece, and are less likely to warp. Excelsior, made by shredding the wood with sharp spurs or knives, is used in great quantities in making mattresses, in upholstering, and in packing glassware, furniture, and metals, as well as in a number of other ways. The making of maple sugar and sirup is an important industry in Vermont, New Hampshire, and New York; and maple sugar is made to some extent in all the north central states. Most of this work is done between the middle of March and the middle of April. A single tree may produce in a season about two pounds of sugar or a quart of sirup. 


\section{CHAPTER XXIII}

\section{PLANT BREEDING}

372. What Plant Breeding Is. - As we have seen, the varieties of Indian corn are numbered by hundreds; and there are many varieties of potatoes, apples, roses, and indeed of most of our cultivated plants. Most of these varieties have arisen since the plants in question have been in cultivation. All the varieties of Indian corn, for example, are probably descended from a single wild species, and the great majority of them have appeared since corn began to be cultivated by white men. All the varieties of potatoes probably came from a single species, and all the apples (including the crabs) from three species. Some varieties of cultivated plants originated without anyone's knowing exactly when they appeared or where they came from; but most of them have developed because some of the men who were growing plants tried to obtain varieties that would better serve their needs. The improvement of old sorts of plants or the development of new sorts is plant breeding. The few varieties of corn that were cultivated by the American Indians when white men first came to the continent had probably developed and been preserved quite accidentally; but most of the varieties that have appeared since have been the result of more or less systematic breeding.

The development of varieties of cultivated plants is similar in many respects to the development of varieties and species among plants that are growing wild. Just as the many cultivatcd varieties of potatocs are descended from a single wild species of Solamm, so that and all the other species of the 
same genus (including the eggplant and the nightshades) came in turn from a single still older species. But one difference is worth noting between the varieties that have developed among wild plants and those that have been produced by breeding. No variety can exist for any length of time in the wild state unless it is particularly well fitted to the conditions about it, and especially unless it has very effective means of reproduction. But there are many varieties of cultivated plants which would be quite unable to live, or to reproduce, or both, if they were not carefully cultivated and propagated by artificial means. We do not know, for example, what the original ancestor of the Indian corn may have been; but none of its presentday varieties thrives except in cultivation. If some corn plants do spring up in a wild state, their descendants die out in the course of two or three generations at most, largely because they have no way of distributing their heavy fruits.

The wild ancestors of our cultivated plants were in almost all cases much less useful or attractive to man than their cultivated descendants

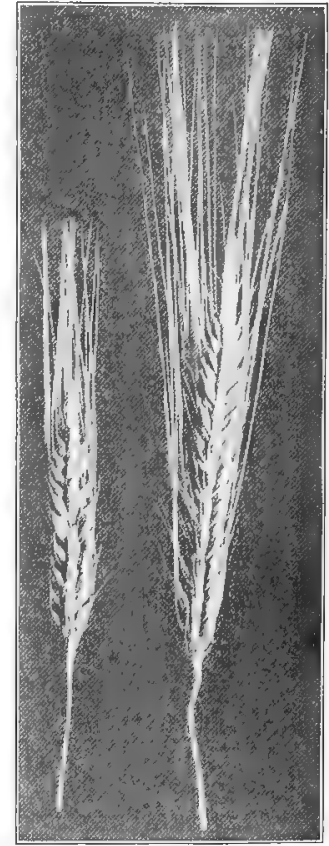

FIG. 202. - The result of seven years of breeding. The head of barley on the right is one of a variety developed from one represented by the head at the left.

are. The original plants must, how-

ever, have had some valuable qualities, or men would not have begun to cultivate them. After the cultivation of a particular species began, it was noticed that some individual plants of the species were better adapted than others to the purpose 
for which they were grown. Long ago - no one can say just when - men learned that the seeds of large plants are more likely to produce large plants than the seeds of small ones are, and that the seeds of a plant with large fruits are, on the whole, most likely to produce plants with large fruits. So, here and there, growers began to pick out and to sow the seeds of those particular plants which seemed to them most valuable. This kind of selection was the beginning of plant breeding, which therefore goes back a long way. But it is only in rather recent times that breeding has been carried on according to definite plans and on a large scale.

373. What Plant Breeders Try to Do. - One of the most important things to be considered in the breeding of a variety of plants is its yield of fruits, seeds, flowers, or other useful parts. Sometimes breeders aim at a high yield for each individual plant - each apple tree, or rose bush, for example. But often it is more important to consider the yield of all the plants that can be raised in an acre or in some other limited area; for a greater yield may often be obtained from a large number of small plants, each one yielding comparatively little, than from the smaller number of large plants that might be raised on the same piece of land.

Closely related to the question of yield is that of the length of the season during which the plant produces flowers or fruits. As a rule, a particular sort of plant has a short bearing season, ranging from a few days to a few weeks. Sometimes this period may be lengthened by breeding; thus, rose varieties have been developed that bloom at intervals throughout the whole summer. But more commonly the same end is reached by breeding different varieties which bear at different times; and so we have early and late cherries, early and late apples, and early and late potatoes. Early varieties are likely to be especially valuable; the highest prices are paid for the first strawberries or the first peaches that appear in the market; and so it is well worth 
while to produce a new form that will be a little earlier than any existing variety.

Another quality of great importance is the plant's ability to resist diseases. Much attention is being paid by plant breeders to the development of disease-resistant varieties -

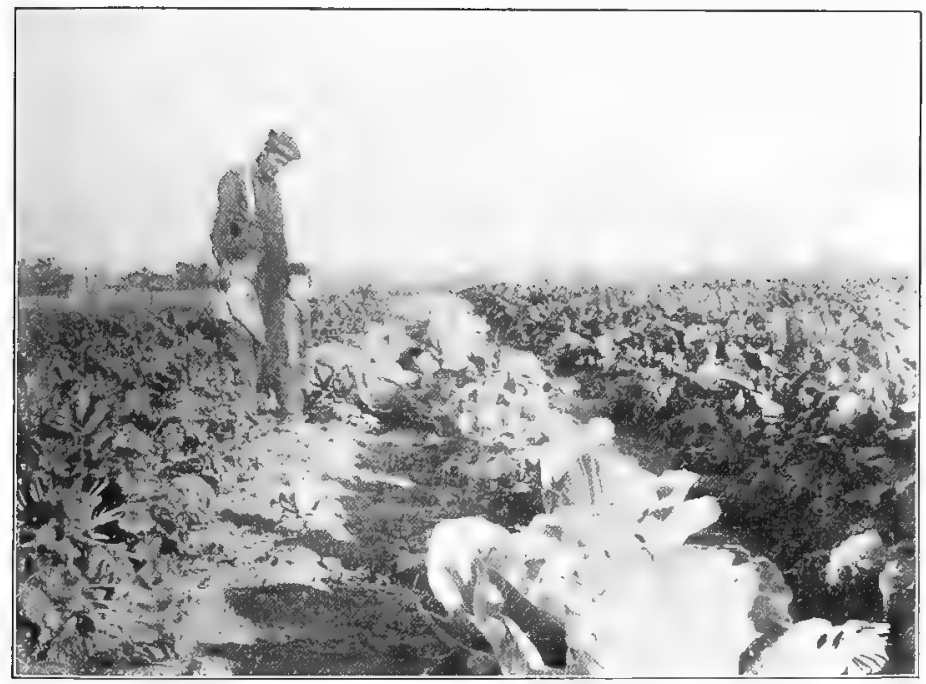

FIG. 203. - Breeding for disease resistance. Seeds were obtained from a single plant which remained healthy in a field of cabbages otherwise badly affected by a disease known as "yellows." The seeds were planted with those of other varieties in a diseased field, and the result is here shown. Only the plants in the row grown from the selected seed were normal. After Jones and Gilman.

varieties, that is, that are not attacked or are attacked only to a small extent by a particular disease. For some time it has been known that certain apple varieties are little affected by rust; durum wheat also resists rust; and varieties of cotton, watermelon, and flax have been obtained that are resistant to a class of very destructive diseases known as wilts. Other characteristics of plants that may be influenced 
by breeding are the size, shape, color, taste, and keeping quality of fruits and other edible parts, and the size, color, and odor of flowers.

All these qualities and many others that might be named are of a more or less general nature; a single variety of apple or of potato or of rose might conceivably be bred which would combine in itself all the desirable general qualities, excepting perhaps that of a long bearing season. In addition, however, there are local and special conditions to be met, which

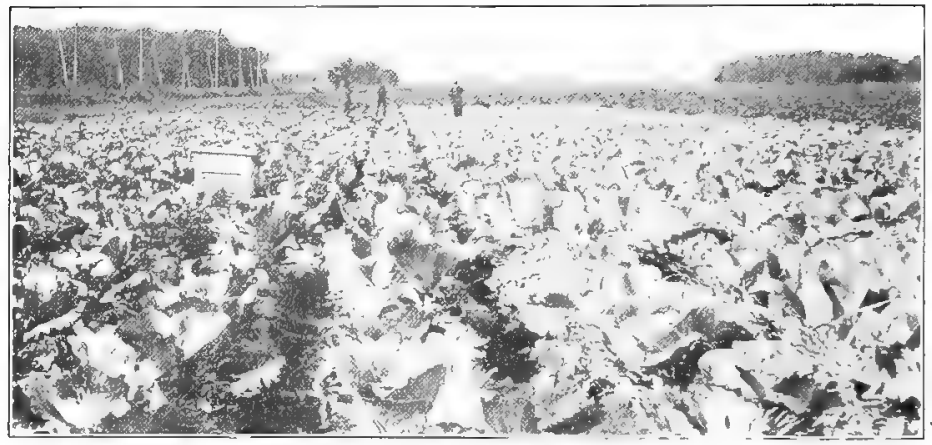

FTG. 204. - Breeding for disease-resistance. A crop of healthy plants grown from the seed of those shown in Figure 203. This seed was sown in a field in which other varieties had been a complete failure because of yellows. The selected variety gave 95 per cent of a normal yield. After Jones and Gilman.

make it necessary to develop many different varieties of the same species. Most important, perhaps, of the local conditions are those of climate. Varieties that are adapted to a locality where the growing season is long and where rain is abundant are not likely to thrive where the summers are short and there is little rain. In the great grain-raising countries much work has becn and is being done to produce different varieties of wheat, oats, barlcy, and ryc that will grow well and yield good crops under different conditions of climate. The whole world is benefited whenever a variety is obtained 
that may profitably be raised in a region where the cultivation of that kind of crop has hitherto been impossible. This is especially true if the new variety is suited to dry regions, such as the arid and semi-arid parts of the western United States. Soil conditions, too, differ greatly; some varieties of plants grow best in sandy soil, others in clay; some in soils that are rich in organic matter, and others in soils that are comparatively poor.

Sometimes varieties must be bred to meet local tastes and fashions. In some localities there is almost no market for apples unless they are large and highly colored, while in other places at the same time dull-colored apples of ordinary size but of good flavor sell readily. It is often true, too, that different varieties of the same or of related species must be bred for different purposes. Thus there are table grapes, raisin grapes, and wine grapes; apples that must be used soon after they are picked, and apples that can be kept in good condition for winter use.

374. Selection. - No two plants of the same variety are exactly alike. In an ordinary field of wheat, some plants have larger heads than others. The grains from the plants with larger heads are likely on the average to produce largerheaded plants than will the grains from plants with smaller heads. Therefore, if we wish to obtain a race of wheat with large heads, we may select our seed grain from those plants which come nearest to being what we desire, and on the whole we shall improve the variety of wheat in this particular respect. In the same way we may select seed grain with reference to the number of heads per plant, the size of individual grains, the strength of stem, the ability of the plant to endure drought, its resistance to rust, or with reference to a combination of any two or more of these qualities. Such a selection of the seeds of the most desirable plants has played a very large part in the breeding of cultivated varieties.

Until quite recent years seed selection has usually consisted 
simply in choosing the seeds of a good many plants in a patch or in a field that were above the average with respect to the desired qualities, and in repeating the same process year after year. But the results of this method of selection have not always been satisfactory. Although the average of the variety can usually be raised in the direction wished, the

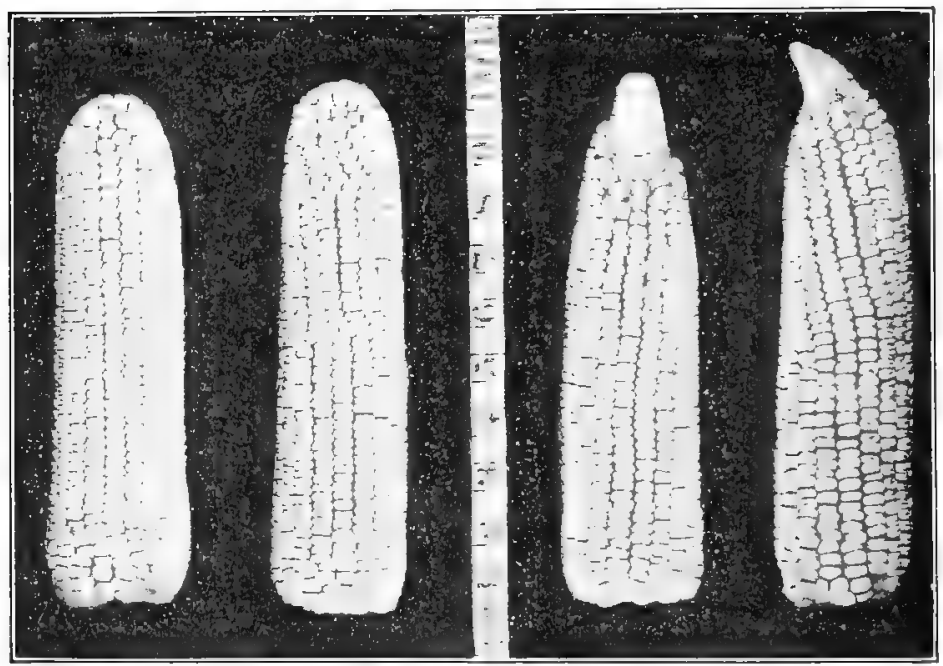

FIG. 205. - The improvement of corn by selection. The well-formed, well-filled ears at the left belong to a variety that was developed from one represented by the ears on the right.

improvement is sometimes small; moreover, many plants in each generation are below the average, and if the practical growers do not continue to select their seed carefully each year, the seed of the inferior plants will be mixed with that of the better ones and the variety will deteriorate rapidly. To a certain extent these disadvantages are avoided by another method of selection which is now largely used.

The newer method is based on the fact that the inherited qualities of a plant cannot always be judged from its appearance. 
This is true because the size of the plant, the number and size of its flowers and fruits, and many of its other characteristics depend both upon the qualities that it inherits from its parents and upon the conditions under which it grows. Thus a wheat plant that under favorable conditions would bear large heads may bear small ones in a bad season, or if it grows in poor soil or in a dry place; and a plant whose heads would ordinarily be small may under unusually favorable

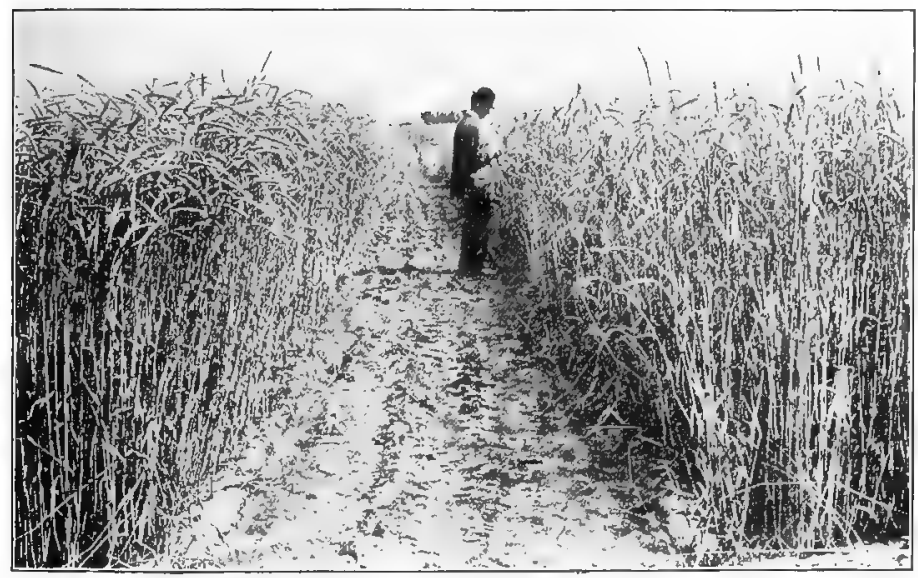

FIG. 206. - Breeding plots at the Wisconsin Experiment Station. These plots are so small that it is possible to give attention to individual plants.

conditions bear fairly large ones. Now, an ordinary variety of wheat is a mixture of many races, some of which inherit a tendency to produce large, some a tendency to produce medium, and some a tendency to produce small, heads. So, when we select a number of plants with large heads, it is quite likely that some or even most of them belong to really largeheaded ràces; but some may belong to small- or mediumheaded races and only happen, because of specially favorable circumstances, to bear large heads. The grains from the plants of the large-headed races will produce plants whose 
heads on the average are large, though there will be differences in size due to external conditions; but the grains from the plants of other races will not, on the average, produce large-headed plants. So, although the average size of head may have been increased by selection, the variety is still mixed becatse it contains both large-headed and smallheaded races. If a new selection of the same sort is made each year, the average of the variety may slowly be raised for a number of seasons, and afterward kept up by continued selection; but we are not likely to produce in this way a pure large-headed variety.

A pure variety may be obtained, however, by using the more modern method of selection. This consists in selecting, as before, the grains of several or many large-headed plants, but in sowing those from each plant in a separate plot. The offspring of each original plant are kept separate, and by studying the offspring for one, two, or more generations it is possible to determine which of the plants that were first selected really belonged to large-headed races and which did not. Then, by breeding from the descendants of that original plant which passed on in the highest degree the tendency to bear large heads, a variety is established which consists of a single race; it is a thoroughbred variety and has the same advantages that a thoroughbred variety of horses or cattle has. When such a variety is obtained, it is less likely to deteriorate than a variety obtained by the older method, which is almost certain to be mixed. However, as we shall see, selection cannot be entirely neglected even after a pure variety has been established. ${ }^{1}$

1 Strictly speaking, a "pure varicty," in the sense in which the expression is used here, is possible only in the case of a plant which, like many of the wheats, is regularly self-pollinated. In species or varieties that are ordinarily cross-pollinated, any plant is sure to combine within itself qualities derived from various races, and with each generation new qualities are likely to be introduced. However, even in cross-pollinated species, it is possible to obtain by close inbreeding between nearly related or carefully selected plants races that are approximately pure, at least with 
375. Mutations. - If a variety selected as just described would never change - that is, if its seeds grew year after year into plants which, on the average, when raised under similar conditions, were like the plants that bore the seeds then the work of selection for any particular quality might be done once for all. But as a matter of fact, varieties, no matter how pure they may be at the start, do not remain unchanged. In each generation, the individual plants of a variety differ from one another in many ways. Most of the differences result from differences in the conditions under which the plants grow; such differences are not passed on through the seeds to the offspring, and so do not affect the purity of the variety. But now and then a plant differs from its parents or from any of its immediate ancestors in a way that is not caused, at least directly, by external conditions. Such a mutation, as a difference of this kind is called, is due to causes that we do not understand; unlike the differences that result from external conditions, it is likely to be passed on to the offspring. A mutation may therefore be the starting point of a new race. By the

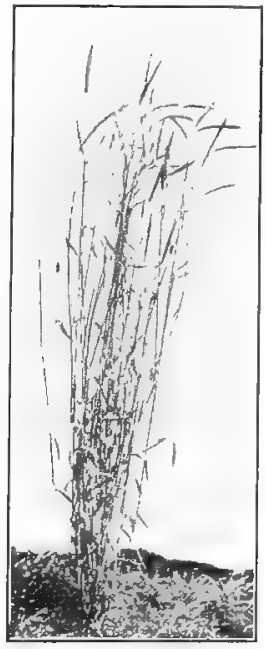

Fig. 207. - A stool of rye grown at the Wisconsin Experiment Station from a single seed of an improved variety. appearance of new races in this way, a pure variety in the course of time becomes a mixed variety. Some of the races resulting from mutations are sure to be undesirable. There may occur, for instance, in a large-headed variety of wheat a plant that not only itself bears small heads, but which, if

reference to certain important qualities. Such a race, while not strictly speáking pure, is thoroughbred in the same sense that a closely inbred race of cattle or horses is thoroughbred. 
its grains are planted, will give rise to a small-headed race. To prevent a lowcring of the average of the variety, the new small-headed race must be weeded out by selection. This explains why selection must be continued, even after a valuable pure variety has been established.

On the other hand, mutations sometimes give rise to races that are improvements on the variety from which they come. Among the members of a large-headed variety a plant with heads larger than the average may appear, which will pass on to its offspring a tendency to bear especially large heads. By selecting the grains of such a plant and of its offspring, we may obtain from the large-headed race that was first selected a new race with still larger heads. Thus, by taking advantage of mutations that lead in the right direction, a variety may be improved step by step. However, the amount of improvement that can be made in any particular direction is limited. We could hardly hope by selection, no matter how long continued, to produce wheat twenty feet high, or with heads a foot long. When an attempt is made to breed for a particular quality, by either the older or the newer method of selection, improvement may be rapid for a few generations; but then it becomes slower and slower, and finally a point is reached beyond which no perceptible advance can be made. After this time, about all that selection can do is to remove undesirable mutations when they appear in order to keep the variety at the level it has reached.

As a rule, a mutation results in only a small difference between parent and offspring; but now and then the difference is great enough to be conspicuous, as when a double flower appears on a plant belonging to a race with single flowers. A plant that shows such a striking mutation is often called a sport. Sometimes a sport gires rise to a valuable new variety. The double-flowered varieties of roses, carnations, violets, and many other cultivated plants, and the seedless varieties of oranges and other fruits have been 
developed from sports. Very likely the same thing is true of the cabbage. At any rate, the plant which is thought to have been the original of the cultivated cabbage, and which still grows wild on the seaside cliffs of western and southern Europe, has no head, but instead a cluster of root leaves.

376. Hybridization.- - Something was said in Chapter XVII (\$ 288) about the production of crosses or hybrids when the stigma of a flower is dusted with pollen from a flower of another variety or of another species. A hybrid usually possesses some of the qualities of one parent com-

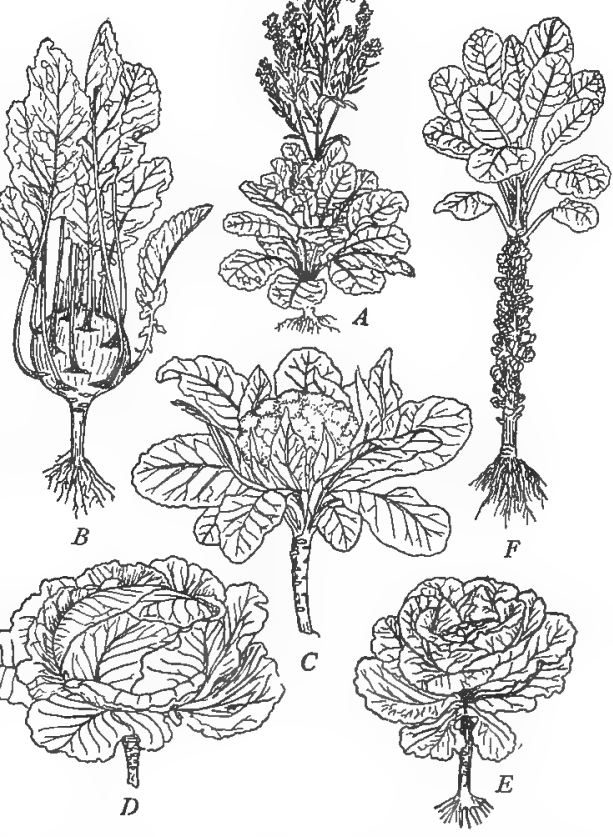

Frg. 208. - The wild Brassica oleracea (A), from which the cultivated plants shown are believed to have been derived; $B$, kohlrabi; $C$, cauliflower; $D$, cabbage; $E$, Welsh or Savoy cabbage; $F$, Brussels sprouts. After Smalian.

bined with some of the qualities of the other parent. Hybrids frequently result from the carrying of pollen from flower to flower by the wind or by insects. Such accidental hybrids are sometimes troublesome in plant breeding, because they introduce impurities into varieties that it is desired to keep 
pure. Accidental hybridization may be prevented by planting each variety at a distance from any other that might be crossed with it; or by covering the flowers with sacs of gauze or of oiled paper during the time that their stigmas are able to receive pollen. But occasionally the new combination of qualities that appears in a hybrid makes it a more useful plant than either of its parents. Plant breeders produce hybrids, when they wish them, by artificial cross-pollination - that is, they deposit the pollen from a flower of one variety by means of suitable instruments upon the stigma of a flower of another variety. In such a case, the stigma must be protected from pollen of its own kind. This is done by bagging the flower, and, if it contains both stamens and pistil, by removing the anthers before their pollen is ripe.

The exact combination of qualities that appears in a hybrid is not as a rule permanent, because the seeds of a hybrid commonly grow into plants that differ from one another. It is sometimes said that the offspring of a hybrid "split up " into different sorts of plants. These offspring combine in themselves in various ways different qualities of the original parents of the hybrid, including qualities that did not appear in the hybrid as well as qualities that did. Suppose now that a hybrid combines the qualities of its parents in such a way as to make it a useful new sort of plant. We cannot as a rule hope to obtain a crop of plants like the hybrid by planting its sceds, because it is likely that many of the plants that grow from these seeds will be different from the hybrid. But we can make the hybrid the starting-point of a new variety of plants like itself if it can be multiplied in vegetative ways - for example, by buds, cuttings, or grafts - because a plant produced by vegetative multiplication is, with very rare exceptions, like its parent. Since apple trees are multiplied by grafts and cuttings, a new apple variety may be propagated from a hybrid. Many of our most valuable varieties of apples have in fact been 
propagated from accidental hybrids, and a seed of such an apple is for this reason likely to grow into a tree very different from the parent. Many varieties of potatoes, which are multiplied by cuttings from the tubers, are also hybrids.

When a hybrid forms seeds as a result of self-pollination or of pollination between flowers of the same plant, its offspring commonly "splits up" in accordance with certain fairly definite rules. ${ }^{1}$ Some (but by no means all) of these offspring, differently from the original hybrid, breed true - that is, their seeds grow into plants like themselves, the seeds of this next generation into similar plants, and so on. It is possible, then, to obtain from some of the offspring of a hybrid new races that can be propagated by means of seeds. Plant breeders may therefore combine hybridization with a selection among the descendants of the hybrid. It is only in quite recent years that the possibility of producing new races in this way has been at all well understood, and even yet we have much to learn about the laws that govern the splitting up of the offspring of hybrids. Still, many valuable varieties have been produced in the past by breeders who selected in a more or less haphazard way the most promising among the descendants of a hybrid that they had obtained either accidentally or intentionally. Now breeders know much better than they did even ten or fifteen years ago what to expect when they produce a hybrid. They may hope to secure from among its offspring a new race that will combine in itself the desirable qualities of both parents of the hybrid. But to secure just the combination of qualities that is wished, it is often necessary to raise the hybrid plants and their offspring in great numbers; sometimes tens of thousands or even hundreds of thousands of plants must be grown before the exact combination appears.

${ }^{1}$ Discussions of these rules (the "Mendelian laws"), with their modifications and their applications to the production of new varieties, will be found in any modern book on plant or animal breeding. 
377. The Breeders of Plants. - Until about the middle of the last century, plant breeding was done almost entirely by private persons and firms - especially by seed raisers, nurserymen, and florists. Here and there an individual farmer, gardener, or amateur flower grower interested himself in the production of new varieties. It was men of these types who developed most of our present varieties, and they are still doing extremely valuable work. Perhaps the best known of the private breeders of the present time is Luther Burbank, among whose productions are varieties of potatoes, raspberries, and walnuts, the stoneless plums, and the Shasta daisy. But much of the most thorough and important breeding work is done nowadays under the direction of national, state, and provincial governments. Most of the European countries have departments that devote much attention to the improvement of cultivated plants. In North America, the United States and Canadian Departments of Agriculture have many plant breeders at work on experimental farms which are so located as to test varieties of plants under all possible conditions. In addition, each state of the United States and each province of Canada has an experiment station, and in nearly every one of these stations the same sort of work is being carried on. The departments of agriculture and the experiment stations are also doing much, through their bulletins and by other means, to spread a knowledge of the methods of plant breeding, and especially of seed selection, among the men who actually raise plants on farms, in orchards, greenhouses, and market gardens. New varieties are developed and tested at experimental farms; but they may be kept up to a high standard and even improved by careful selection of seed each year, and this work of seed selection can in many cases be done as well by practical growers as by professional breeders. 


\section{CHAPTER XXIV}

\section{PLANT DISEASES}

378. Disease-producing Fungi. - From previous chapters a knowledge has been gained of the importance of bacteria, rusts, and mushrooms, and of the damage that some of the members of these groups of fungi do by producing diseased conditions in other plants. There are, however, many fungi beside those that we have specially studied which are responsible for diseases that, in the case of cultivated plants, result in losses amounting to many millions of dollars each year. Every plant of economic importance is attacked by one or more parasitic fungi, and a simple enumeration of the diseases that they cause would occupy more space than can be given to this chapter. So only a comparatively few diseases, which are well known and are of great practical importance, will be briefly described. The fungi that produce plant diseases belong to the following groups :

a. Bacteria. These were discussed in Chapter II. Some of the diseases that they cause are described in $\$ \S 379$ and 380 below.

b. Slime Molds. Each of these very simple plants consists of a single cell which is sometimes quite large, containing many nuclei but possessing no cell wall. When it is mature, the whole cell divides into many small spores. Each spore may become a free-swimming cell which later develops into a mature plant. (See $\$ 38 \mathrm{I}$.) 
c. Alga-like Fungi. These possess many characteristics in growth and reproduction which indicate that they may have arisen from the algæ. The bread mold and its relatives are among the members of this group. Some of the parasitic forms are discussed in $\$ \$ 382-384$.

d. Sac Fungi. These produce usually at least two types of spores; those of one type are produced on threadlike projections from the plant body; spores of a second sort are borne in small sac-like structures which most commonly contain eight spores, but in some species contain more or fewer than eight. The sacs are in most cases partly or entirely surrounded by interlacing branches of the fungus, which form a fruiting body of characteristic form. (See $\$ \S 385-389$.)

e. Basidium Fungi. The mushroom and its relatives belong to this group, in which the rusts and the smuts (\$390) are usually included.

f. Imperfect Fungi. To this group belong a large number of disease-producing fungi. They are called " imperfect" because it is believed by most students of fungi that we do not know their entire life history. Many formerly listed in this group have been found, when their whole history ras worked out, to be sac fungi; others have been referred to the basidium fungi. (See $\$ 39$ I-393.)

379. Pear Blight. - This disease, known also as "fire blight " and "twig blight," is probably the most important bacterial disease affecting cultivated plants. It attacks the apple, crab-apple, pear, quince, and some related plants. The ravages of the disease are so serious that the growing of pears and apples has been almost entirely given up in some regions of the United States. The bacteria that cause it live in the inner tissues of the twigs and branches. The first symptom that is likely to be noted is a withering of the leaves, flowers, and younger branches in from two to four 
weeks after flowering. The branches are at first slightly swollen, then they turn dark brown, and soon the tissues shrink and wilt conspicuously (Fig. 209). If it is not checked at this time, the disease will extend into adjacent tissues, and may readily be carried by insects to other branches and to neighboring trees. It is especially likely to be spread by insects just after a rain, because at such times a gummy substance is excreted on the surfaces of diseased branches, in which substance are countless living bacteria. The bacteria live through the winter in the diseased tissues, and in the following spring when the tree resumes its growth they may infect the living tissues of the tree or may be carried by insects to still other plants. The bacteria also live in cankers on various parts of apple trces, and these cankers are prolific sources of new infections.

The only means known for controlling the disease is the cutting out and burning of diseased branches as soon as they

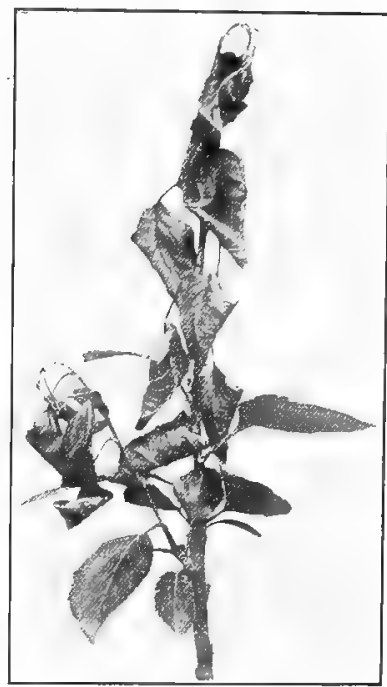

FIG. 209. - A branch of an apple tree attacked by the fire blight. Notice the characteristic appearance of the younger portions, which look as though they had been scorched. are discovered. An infected branch must be cut at some distance below the place where the disease is evident, because some of the bacteria are usually present below the darkened portions. Great care must also be taken to see that the pruning knife or saw does not come into contact with the diseased tissues, for in that case the cutting tool itself will carry the disease from tree to tree. 
Some varieties of apples and pears are apparently more resistant to the disease than others, but their resistance seems to be dependent at least in part upon climatic conditions. A variety which is fairly resistant in one locality sometimes proves to be very susceptible in another region.

380. Other Bacterial Diseases. - Crown gall, which causes peculiar enlargements of stems and roots at the surface of

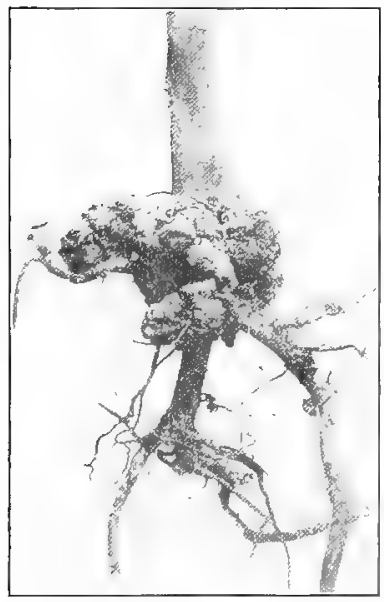

Fig. 210. - The crown gall of the apple. Soft, spongy swellings are formed at or just below the surface of the soil. This disease is likely to be found on grafted nursery stock. the soil, is becoming a serious menace in regions where apples are grown. It also attacks various other plants, such as raspberries, grapes, walnuts, and willows. It can be eliminated only by planting such nursary stock as is absolutely free from the disease and by destroying any plant found affected. The black rot of cabbage has entirely ruined the cabbage industry in many localities. The bacteria enter through the air-pores and water-pores of the leaves. The leaves turn to a yellowish color, the veins become black, and as the disease spreads to other parts of the plant the leaves fall off and soon the plant withers and dies. A rotation of crops and clean seed beds have so far been the only means of control, although it seems possible that in the near future resistant varicties may be developed. The bacteria that cause the wilts of the cucumbers and melons live in the wood cells and vessels, which thus become clogged up. The parts of the plant above ground therefore do not 
receive their necessary supply of water, and so wilt and die. The bean blight is another important bacterial disease.

381. Club Root of Cabbage. - This disease, also known as " club foot," has long been a serious menace to the cabbage industry in Europe. The estimated damage in Russia alone for a year is over $\$ 5,000,000$. The disease is likewise found in almost all regions in the United States where cabbages are grown extensively. Young plants are stunted and many die at this stage; others continue to live but never form a head that is marketable. The roots are stimulated to excessive growth, and swellings (Fig. 2II) are caused; these swellings are often only slight enlargements on the sides of the roots, but in other cases they reach a considerable size. The parasite, which is usually considered to be one of the slime molds, is known to attack the cabbage, turnip, cauliflower, radish, rutabaga, and Brussels sprouts, and has been found on the mustards

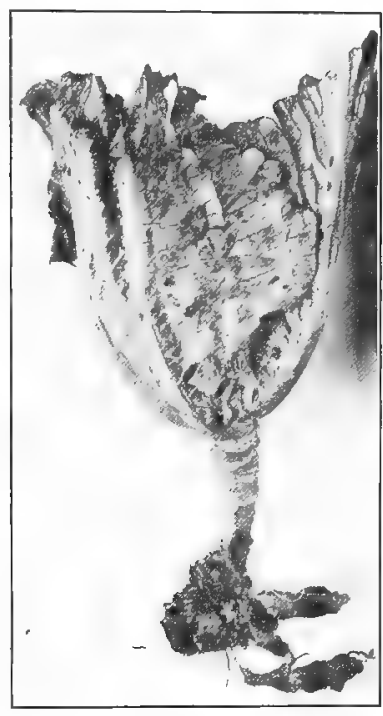

FIG. 2II. - The club root of cabbage. The younger roots and the lower portions of the stem become greatly swollen; the plants are weakened and often killed. and other weeds. The thick-walled spores of the fungus live through the winter in the soil and in diseased tissues. In the spring the spores germinate and infection takes place in the roots of young plants. No means has yet been discovered for the control of this disease, but rotation of crops and care in planting only healthy individuals may considerably check the loss. 
382. Damping off. - Much loss is occasioned in greenhouses, seed beds, and often in fields by fungi which attack young plants at the surface of the soil. An infected plant at first appears slightly water-soaked; soon it wilts, and then, as the shoot falls to the soil, the fungus spreads to all its parts and in a short time kills the plant. The fungus

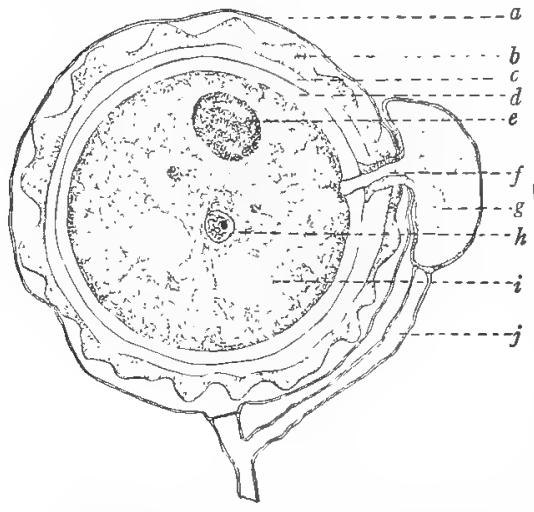

FIG. 212. - The zygote of one of the "damping off" fungi; $a$, wall of the oögone, an organ in which the egg was formed; $b$, outer wall, , , middle, and $d$, inner walls of the zygote; $e$, fat body; $f$, a tube through which the antherozoid passed to unite with the egg; $g$, antherid; $h$, zygote nucleus; $i$, a vacuole in the cytoplasm of the zygote; $j$, the branch of the fungus on which the antherid was borne. which most commonly causes this trouble lives as a saprophyte in the upper layers of rich, moist soils. The plant body of the fungus is made up of delicate threads much like those of the bread mold; it reproduces by means of spores, each of which, when it becomes free, divides into several small cells that can swim about in water by means of delicate vibrating threads. Gametes are also produced which unite to form thickwalled zygotes (Fig. 2 I) ; it is probably by means of these zygotes that the fungus lives through the winter. Similar troubles are also caused by several quite different fungi, among them some of the black molds and some of the imperfect forms. Damping off can be partially prevented by sterilizing the soil either by heating it or by the use of formaldehyde; it can be checked, too, by carcful cultivation so that the fungi are not allowed to grow on the refuse that may be present. 
No plants should be used which come from seed beds or greenhouses in which damping off is known to have occurred.

383. Downy Mildew of the Grape. - This disease appears on young branches and leaves of both wild and cultivated grapes and is not uncommon wherever grapes are grown. It may at times cause considerable damage, especially to slow-growing varieties. The disease was introduced into Europe from the United States, and in a short time it almost ruined the grape-growing industry over extensive arcas. An affected leaf shows irregular yellowish areas on the upper surface, and at the same time spore-bearing branches appear on the lower surface of the leaf immediately below the discolored spots. Irregular dark areas appear also on the stem, and at times the fungtus is so abundant on the young fruit as to give it a downy appearance, whence the name "downy mildew." It is only when the fruit is diseased that any considerable loss is caused in the United States. The fungus lives between the cells of the host, sending short, rounded branches into the living host cells and

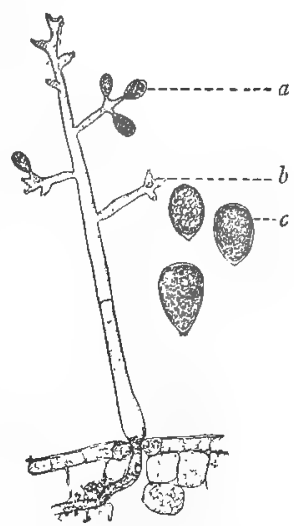

FIG. 213. - A sporebearing branch of the downy mildew of the grape, making its appearance through an air pore on the under side of the leaf; $a$, a portion of the branch with spores attached ; $b_{;} ;$former place of attachment of a spore; $c$, a spore, much enlarged. thus robbing them of their food. The spores are borne on peculiarly branched structures that project beyond the surface of the host (Fig. 2I3) and produce free-swimming cells like those of the damping-off fungus, which in turn germinate and produce the new growth upon the grape. The large thick-walled zygotes are not very commonly found, although they do occur. 


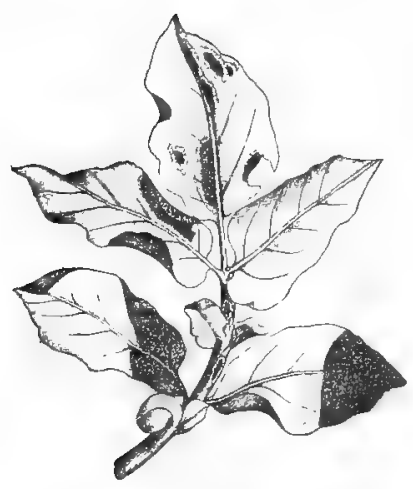

FIG. 2I4. - A potato leaf attacked by the late blight.

This fungus can be fairly well controlled by spraying the grape plants with the well-known Bordeaux mixture. ${ }^{1}$

\section{Late Blight and Rot of} Potato. - This, commonly called the "potato disease," is at times very destructive and has been responsible for the "potato famines" of history. Because of its destructiveness it has been extensively studied and was one of the first plant diseases against which governments waged a real warfare. The fungus that causes the disease is very common in some of the northern United States, and its spread may at any time when conditions are favorable become a serious problem. It seems to prefer the colder climates and wet, heavy soil. The fungus first attacks the potato leaves, causing spots which are purplish in color when wet, but brown when dry. The discase may be confined to the leaf; but it may spread to the stem and finally to the tubers, causing a dry rot of the latter if they are growing in dry soil or a wet rot if the soil is heavy and wet. The discased tubers are very likely to decay in storage bccause many of their

1 Bordeaux mixture. This is probably the most important and most commonly used of fungicides. The formula usually regarded as standard is the following, known as the " $5-5-50$ " formula:
Copper sulphate, 5 pounds.
Stone lime, 5 pounds.
Water, $\quad 50$ gallons.

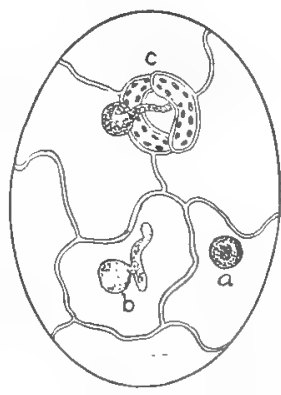

Fig. 2I5. -1 few cells of a potato leaf on which spores of the late blight fungus have landed; $a$, a spore; $b, a$ germinating spore; $c$, a germinated spore, the germ tube from which is entering an air-pore of the leaf. After Weed. 
outer cells have been killed by the fungus so that it is easy for decay-producing fungi to enter. The fungous body is very much like that of the downy mildew fungus, excepting that the short branches that enter the host cells are also thread-like and much more delicate than the main branches. The spores also are very much like those of the downy mildew fungus, and the large, thick-walled zygotes are very rarely found. The disease may be kept under control by the use of the Bordeaux mixture, making from three to five applications at intervals of about two weeks. Some varieties of potato seem to be more resistant than others, but their resistance appears to depend partly upon conditions in the locality in which they are grown, because potatoes described as resistant in one region may prove very susceptible in another.

385. Brown Rot. This disease attacks the peach, plum, cherry, apricot, and related plants. The damage done by the brown rot fungus (one of the sac fungi) is enormous, a conservative estimate placing the annual loss in past

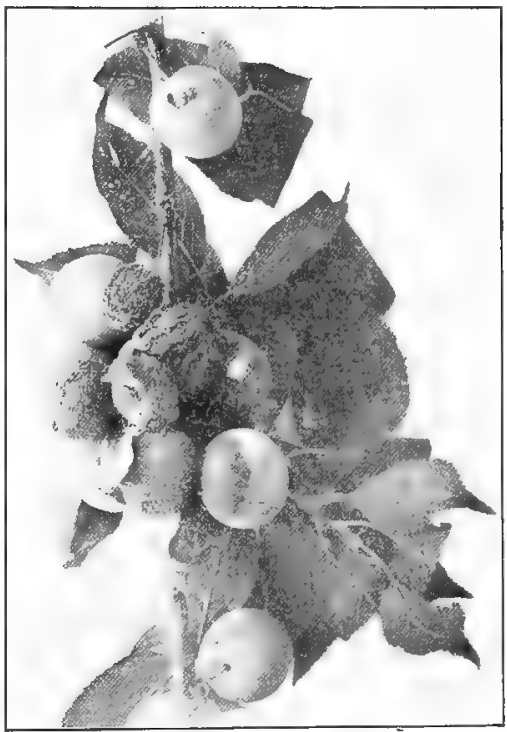

FIG. 216. - A branch bearing peaches affected by the brown rot. years at over $\$ 5,000,000$. It usually attacks the fruit, but may cause damage to flowers, leaves, and small branches. On the fruit, the disease first appears as a small, dark, decayed spot which gradually enlarges until it covers perhaps the 
entire fruit. The fruit now decays, and in the meantime the fungus produces an abundance of spores, which may be scattered by the wind or may remain on the stems and leaves to spread the disease the following year. The fruit finally becomes hard, shriveled, and wrinkled (Fig. 2I6); in this condition it either remains on the stem or falls to

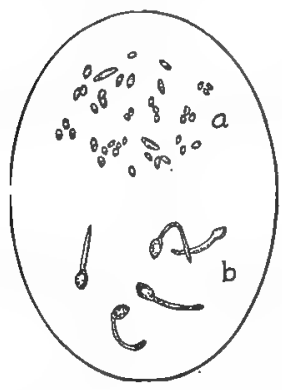

Fra. 217. - Spores of the brown rot fungus at $a ; b$, germinating spores. After Weed. the ground. The next spring the plant body of the fungus, which has remained dormant in the decayed fruit, develops a saucer-shaped fruiting body on a short stalk. Within this saucer are borne an immense number of small sacs in each of which eight spores are produced. In order to check the ravages of this fungus it is necessary to remove the diseased portions of the plant as soon as they are discovered. These, with the decayed fruits from the tree and ground, should at once be burned, because the spores may be carried to a considerable distance by the wind. Spraying also helps to check the growth of the fungus. For this purpose, modifications of the ordinary Bordeaux mixture and a lime-sulphur wash are probably the best. ${ }^{1}$

386. Powdery Mildews. - More than sixteen hundred species of seed plants are known to be attacked by one or another of these parasitic fungi. Although strict parasites,

1 Lime-sulphur wash. This can be obtained in prepared form, or it may be made according to the following formula:

$\begin{array}{ll}\text { Flowers of sulphur, } & \text { ro pounds. } \\ \text { Stone lime, } & \text { Io pounds. } \\ \text { II ater, } & 50 \text { gallons. }\end{array}$

The lime is poured into a barrel, three to five gallons of water are added, then the sulphur is sifted in and the whole mixture is stirred while the lime is being slaked. More water is added as the mixture becomes healed. When the lime is entircly slaked the rest of the water may be added. 
they do very little harm to many of the plants upon which they live; on the other hand, if conditions are favorable for their growth they may cause much damage. Powdery mildews are found from the tropics to Greenland. The leaves of the host plant are usually the parts affected, but the mildew may appear on the young branches and on the fruit as well. The plant body of the fungus, composed of a tangled mass of delicate light-colored threads, is found on the surface of the host; projecting from these threads into the host cells are variously shaped short branches which absorb food. On upright branches spores are borne, which spread the fungus during the growing season. Later there usually appear little dark spherical fruiting bodies with peculiar projections from their lower portions. Within the fruiting bodies one or more sacs are formed, which contain usually eight spores each. One of these mildews sometimes causes considerable damage to young peach trees; another attacks the gooseberry. The apple and strawberry are also affected, and the powdery mildew that attacks grapes has at times caused immense losses both in the United States and in Europe.

387. Black Knot. - This disease affects plums and cherries and is so vigorous in its attacks that it has entirely ruined the plum and cherry orchards in various parts of New York and of some of the other Atlantic states. In the eastern portions of the United States the fungus thrives well both on wild and cultivated forms; but in some regions farther west it is found only on wild varieties, and cultivated plums and cherries are often not affected, even though growing near diseased trees of related wild species. The knot appears in early spring as a conspicuous swelling, usually on one of the smaller branches of the tree (Fig. 2I8). The bark cracks and breaks off and the exposed tissues turn to a deep olivegreen color. At this time abundant spores are formed from short threads arising from the surface of the knot. These 
spores continue to be produced for three or four months. In the meantime the knot has been growing in size and has turned almost black, and small rounded swellings have appeared on the surface; these swellings contain a second

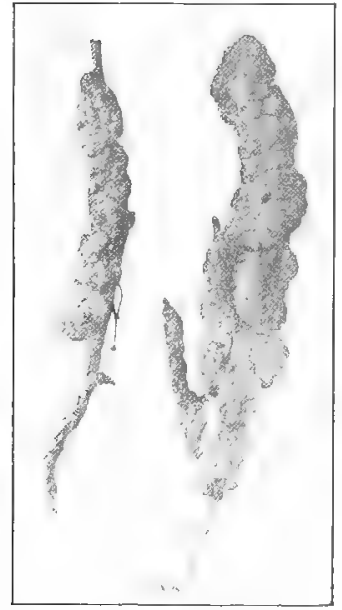

FIG. 2I8. - Portions of two branches of the chokecherry attacked by the black knot. The fungus grows in the tissues of the host, producing large, irregular swellings which will eventually encircle the stem and kill all beyond the diseased portion. type of spore. During the late summer another set of rounded bodies appear on the knot; these remain over the winter, and in the spring they are found to contain many small sacs, in each of which are eight spores. The only known means of controlling this discase is to cut out and destroy the knots. This means is successful only if there is coopperation on the part of growers, not only in cleaning out their orchards but also in carefully watching the wild varieties for the appearance of knots.

388. Black Rot of Grapes.-This disease causes great damage to the grape crop if weather conditions are favorable. It is most serious if the days are warm and moist, and its ravages are greatly checked by a short spell of cool, clear days. Although the greater harm comes from the injury to the fruit, the disease is found on the leaves, and from these, under favorable conditions, it may soon spread to the fruit. On the leaves small brown spots appear, which rapidly grow in size and number, giving the leaf a wrinkled appearance. UTpon the fruit a small spot, purplish in color, is first noticed. This grows, and finally the whole fruit decays and shrivels. Spores are produced in abundance upon the affected parts, 
and by their means the disease spreads rapidly. The shriveled fruits lie on the ground, and the next spring portions of the fungous body which have remained within them begin to grow again and produce the spore sacs. Until a few ycars ago this fungus was known only in North America, but now it is reported as doing considerable damage to grapes in southern Europe. Cleanliness in the orchard, the removal of all diseased portions of the plants, and spraying with the Bordeattx mixture, will almost climinate the discase.

389. Chestnut Blight, or Bark Disease of the Chestnut. This disease has been known for only a few years, but it threatens to destroy every chestnut tree in the United States. The damage already done is estimated at from $\$ 60,000,000$ to $\$ 75,000,000$, and no remedy so far tried has been of any avail. The government authorities, with aid from various states, are making efforts to eradicate the disease, but it has obtained such a start in some regions that all hope of saving the forests has been given up. The fungus grows in the outer layers of twigs, stems, and trunks, and gradually kills the tissues around the part affected; this dauses the death of all the parts of the tree above the diseased region. The diseased parts show a characteristic light brown color, but before long all the affected tissues shrivel. Through the cracks thus produced, as well as through the natural openings in the bark, short branches of the fungus grow outward and produce spores which spread the disease. Spores produced in sacs appear during the autumn; but the spore sacś may continue to be formed for a long time, some having been obtained from tissues eighteen months after the diseased condition was first noticed. A Japanese chestnut seems to be immune to the disease, and efforts are being made to secure hybrid forms which may also be immune.

390. Smuts. - These very common diseases produce black, powdery masses upon the Indian corn and upon various other grains and grasses. The swellings caused by 


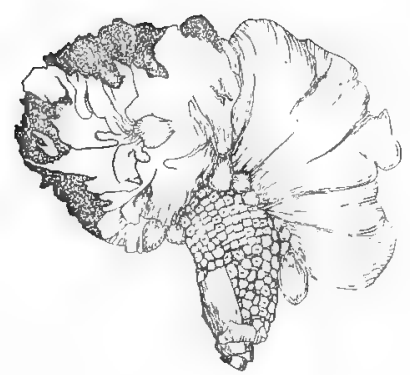

FIG. 2 I9. - A smutted ear of corn. Notice the immense size of the diseased kernels. The dark portion of the figure represents masses of escaping spores.

the corn smut are sometimes as large as a man's fist; they occur on the stem, leaves, or roots, in the ears or in the tassels. A large part of an ear, or even a whole ear, may be replaced by the black masses. The fungus that causes the disease is made up of branching threads which grow between the cells of the host plant and send branches into the cells to obtain food. The fungus does not kill the host cells at once; on the contrary, it stimulates many of them to rapid growth and division, thus causing the appearance of a swelling. The host cells are finally killed, and then the fungous threads divide into very short cells which bccome dark, thick-ivalled winter spores. These spores may germinate in any moist place, producing a short, threadlike plant of four or five cells, each of which in turn may give rise to small thin-walled spores (sporidia), which when they are carried to a corn plant cause a new infection. The corn smut affects only the tissues in the neighborhood of its place of entrance. The only method known for controlling this disease is to remove and destroy all the swellings before the winter spores are formed.

The common loose smut of oats can infect the oat plant only when it is a ium.

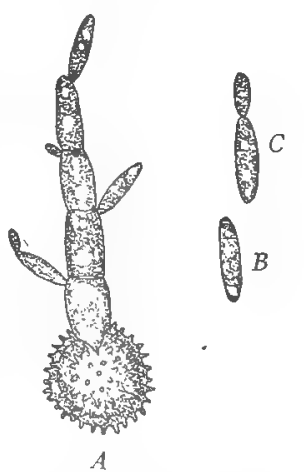

FIG, 2 20. - $A$, a germinated winter spore of the corn smut, the short plant which grows from the spore, and the small spores (sporidia) which this plant bears. $B$, a single sporidium. $C$, a sporidium which is budding to form a new sporid- 
very young seedling. The fungus grows with the growth of the host, forming its spores in the young oat kernels; finally the kerncls and the chaffy scales enclosing them are largely replaced by masses of the winter spores. The oat smut can be controlled by treating the seed grain in such a way (for example, with formaldehyde or hot water) as to kill the spores that adhere to the grain, without killing the grain itself. The stinking smut of wheat, so called because of its disagreeable odor, like the oat smut forms its spores in the kernel, but it does not entirely destroy the kernel or the surrounding chaff.

The damage done by the corn smut in the United States has been estimated at $\$ 50,000,000$ per year. The oat smut causes an estimated yearly loss in the United States of about $\$ 3,000,000$. The stinking smut formerly destroyed from one-half to three-fourths of the wheat crop. The loss
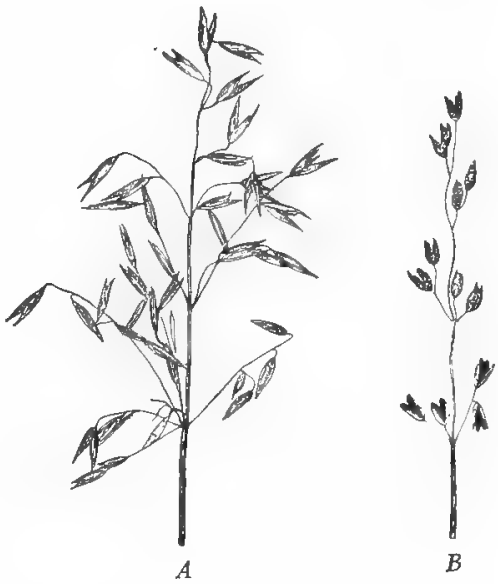

Fic, 22I. $-A$, the head of a healthy oat plant. $B$, the head of an oat plant attacked by the loose smut. has been greatly decreased by treating the seed grain, but is still considerable in parts of the United States and Canada.

391. Common Scab of Potato. - This disease is found wherever the potato is grown. It produces rough, scabby spots on the surface of the potato, which are often deepened by larvæ and insects. The fungus may live in the soil for years, and the tubers may become diseased at any time during the growing season. For these reasons it is necessary to practice long rotations and to plow under green 
crops in order to eliminate the disease. It has been found that lime, ashes, and horse manure tend to increase the growth of the fungus. Care must be taken to use only disinfected potatoes for planting.

392. Peach Scab. - This is a common and well-known disease, found on almost all second-and third-grade peaches

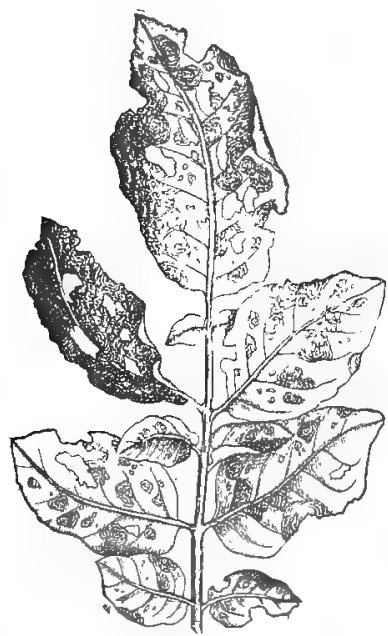

Fig. 222. - A potato leaf attacked by the early blight.

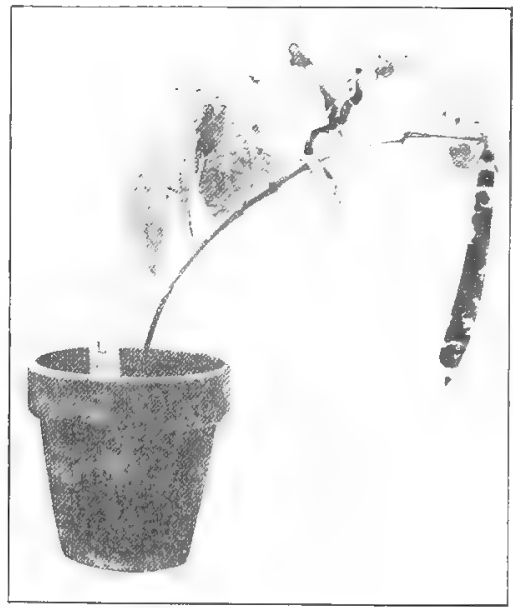

FIG. 223. - A bean plant inoculated with the imperfect fungus which causes anthracnose - a disease which is at times very serious, attacking the younger parts of the stem, the leaves, and the pods.

and apricots. It causes small, circular, dirty spots over the greater portion of the fruit. If the spots are very numerous, the skin of the fruit is likely to crack, making possible the entrance of decay-producing fungi. This disease is often associated with the brown rot of the peach and sometimes causes equal loss to the grower. Leaves and twigs may also become infected; the fungus may continue to live in the twigs for several years and so be a continual source of spread of the disease. The means of control suggested for 
the brown rot are also successful with the scab, and the immense losses of past years are not apt to occur in the future.

393. Early Blight of the Potato. - This disease may at times cause almost as much damage as the more dreaded late blight already described. It causes brownish spots on the leaves, around which appear concentric lighter rings. When the spots become enlarged the leaf dies, and thus, since the food supply is reduced, the tubers produced are usually small. The same fungus also attacks the tomato, causing a smaller crop of this fruit. Spraying will check the disease except under very unfavorable conditions. The peach leaf curl, stem rot of the clover, root rot of tobacco, canker of currant and gooseberry, ergot of rye and timothy, leaf spot of the strawberry, apple scab, bitter rot of the apple, blight of ginseng, dry rot of the potato, flax wilt, and the anthracnose of the bean are other plant diseases of considerable economic importance. 



\section{APPENDIX I}

\section{DIRECTIONS FOR LABORATORY AND FIELD WORK}

Many plants will grow readily in the classroom, adding to its attractiveness, and at the same time furnishing material for study and experiment. They may be grown either in pots or in window boxes; the latter can be bought or easily made. Good loamy soil with plenty of humus should be used. The following plants are quite hardy and should be tried before an attempt is made to grow others which may prove much more difficult: Geranium, Pelargonium, Begonia, umbrella plant, ferns, Vinca, wandering Jew (Tradescantia), rubber plant (Ficus), century plant, and various cacti.

Methods of making simple aquaria for the cultivation of algæ and other water plants are described in Hodge's Nature Study and Life.

\section{Chapter I}

See the footnote on page I. Should the flowers of squash, pumpkin, or cucumber not be available at the time this chapter is taken up, some other reasonably simple flower may be used - such, for example, as the buttercup, anemone, crocus, hyacinth, lily, strawberry, morningglory, petunia, or tomato. In case such a substitution is made, it will be necessary for the teacher to modify the directions here given so far as they apply to the flowers.

1. Put some squash or pumpkin seeds into lukewarm water and leave them in the water over night. Examine these soaked seeds and compare them with unsoaked ones.

2. Notice the scar at the pointed end of a seed. What caused it? In one end of the scar and a little to one side of the point of the seed, find a deep hole or depression, the micropyle. If there is more than one depression, the micropyle is the deepest. How far into the seed does the opening of the micropyle go? 
3. Remove the seed coat. Can you see that it is composed of more than one layer? Just within is the thin, green, papery endosperm. Remove this. All that now remains belongs to the embryo.

4. Carefully cut away one of the thick seed leaves of the embryo. There remains the second sced leaf, and attached to it are the radicle and plumule. Which of these two is larger? Which is turned toward the micropyle?

5. Examine the plumule with a hand lens. It can be studied better in seeds that have been soaked for two or three days. How many small leaves does it bear?

6. Cut another seed lengthwise in such a way that each seed leaf will be cut through the middle. Draw one of the cut surfaces, showing the seed coat, endosperm, seed leaves, plumule, and radicle.

7. Plant some seeds, which have been soaked over night in cold water, an inch below the surface of moist sand or sawdust. After the first two or three days pull up a seed or two each day and study the way in which they germinate.

8. Where does the seed coat crack when the seed germinates? Which part of the embryo pushes out first? Which way does it turn? Study the growth of the embryo into a seedling; what changes take place in each part of the embryo? Study the way in which the seed coat is finally pushed off.

9. Draw in outline three young seedlings at different stages in their development.

10. Sow some cucumber seeds in moist sand. After a seedling has developed one or two secondary leaves, wash off the sand or sawdust very carefully from the root system. To what parts of the roots does the sand or sawdust stick most closely? Why? Can you tell by examination where the stem ends and the root begins?

11. Can you distinguish the primary root from the branch roots? Do the latter also branch? Lay the plant down, spread out the roots as flat as possible, and sketch the root system.

12. Study the root hairs of a very young seedling from a seed germinated between pieces of moist filter paper or blotting paper. Can you see the hairs with the naked eye? Examine them with a hand lens. On what part of the root do they grow? 
13. Examine a full-grown leaf from an older plant. What is its shape? What are the parts of the leaf? What differences do you find between the upper and lower surfaces? Study the veins and the way in which they branch. Notice that they form a fine network. Study the hairs with a hand lens. On what parts of the leaf do you find them? On what parts are they most numerous? Where are the largest hairs borne?

14. What is the shape of the stem? Is it solid or hollow? How are the leaves arranged on it? Can you find a bud in the axil of each leaf? Where are the branches attached to the stem? Where are the tendrils attached?

15. Draw a portion of the stem and two successive leaves attached to it, with the axillary buds. Show the veins in one leaf.

16. Examine the bud at the end of the main stem or of a branch. Tear it apart carefully. Of what parts do you find it composed? How many young leaves do you find in it?

17. Remove the parts, one by one, from a pistillate flower; from a staminate flower. Draw the circle of sepals so removed, cut in one place and spread out flat; draw the circle of petals in the same way; a pistil, naming the parts; a stamen, naming the parts.

18. Follow from day to day the development of the ovary. into a fruit. Cut a ripe or nearly ripe fruit crosswise and draw one of the cut surfaces, naming the parts.

19. Make a list of the different varieties of cucumber and of squash grown in your locality. What are the important points of difference between them? What particular advantage has each variety, and for what special uses is it best suited?

\section{Chapter II}

1. Place some hay in a dish of lukewarm water, cover it, and put it in a warm place. After two or three days examine a very small drop of the water under the high power of the microscope. It will be found to contain a great many organisms of different sorts, among them some having the shape of short rods with rounded ends. Most of these are probably cells of Bacillus subtilis. Are they colored? Some are swimming actively, others are quiet. Describe their movement. 
2. Examine a rod that is not moving. Little can be seen of its structure because of its small size. You will observe that it does not change its shape, being kept rigid by the cell wall. Does the protoplasm appear granular? Draw a cell.

3. Study the rows or chains of cells. How are the chains formed? Are the ends of individual cells rounded or flattened? Draw a chain in outline, showing the cell boundaries.

4. Examine a bit of the scum that forms on the surface of the infusion after a few days. In it will be found many bacteria held together by a sticky substance. Are the cells moving or quiet? Are they single or in colonies?

5. Look for bacteria of other forms in the infusion. They are more likely to appear after some days. Draw in outline such forms as you find, on the same scale as your previous drawings.

6. In the scum from an old infusion, look for chains of cells in which spores are being formed. Draw such a colony if you find one.

7. What causes the unpleasant odor that the infusion gives off ?

8. Boil a good-sized potato with its skin on for fifteen or twenty minutes. Then, with a clean, sharp knife that has been sterilized in a flame, cut the potato into thin slices, being careful not to touch the cut surface with the fingers. Seven petri dishes and covers must be prepared in advance. Each should be carefully washed and then boiled in clean water while the potato is boiling. When the potato is ready to slice, remove the petri dishes from the water one at a time, pour out the water and place in the bottom a piece of perfectly clean filter paper which, if possible, has been sterilized by heat in a dry oven for a half-hour. Dip the paper into the water in which the petri dishes are boiled. Handle dishes and paper with stout forceps which have also been sterilized in a flame. Place a slice of potato in each petri dish on the filter paper and cover at once. All this work must be done as quickly as possible.

9. Leave one dish covered. Uncover a second one and leave it exposed to the air of the room for a half hour, then cover it again. Uncover a third one long enough to make a scratch on the surface of the potato with a needle that was first sterilized, then dipped into a hay infusion. The fourth potato slice should be inoculated in the same way with material from the floor of the room. 
10. The four dishes now accounted for should be numbered and kept on a shelf or other convenient place in the room, not in the direct sunlight, where they may be examined from day to day.

11. Inoculate the three remaining slices from some fresh milk. Place one of these in a window where it will receive as much direct sunlight as possible, one in a dark closet or other dark room, and the third in an icebox.

12. Examine all the cultures carefully, without removing the covers, once a day for a week; make a full record of all that you observe in each culture with respect to the following points:

a. The appearance of spots (bacterial colonies) on the surface of the potato. Compare with Figure Io, page 24 .

b. The color of the spots.

c. Their shape, and growth from day to day. Some of the spots may develop a fuzzy appearance. Examine these with a hand lens. If a spot contains fine threads, it is not composed of bacteria, but of a mold, belonging to a higher order of plants.

$d$. Changes in the appearance of the potato due to the action of the bacteria.

13. What do you conclude from these experiments as to:

a. The presence of bacteria in the air? In the dust on the floor? In milk?

b. The rate of multiplication of bacteria?

c. The effect of sunlight on the development of bacteria? Of darkness? Of heat? Of cold?

14. Examine under the microscope bacteria from your different cultures. Note the different shapes and sizes that you find.

15. Why are the care and inspection of city water supplies extremely important?

16. What serious disease is especially likely to be carried by impure drinking water?

17. How may impure water be treated to make it safe for drinking?

18. Why should living and sleeping rooms have abundant sunlight and fresh air?

19. Why are tuberculous patients kept in the open air as much as possible? 
20. What kinds of floor coverings (carpets, rugs, linoleum, cork, or simply hardwood flooring) are best for rooms used by large numbers of people? Why?

21. Why do many cities and some states require the testing of cattle for tuberculosis?

22. Why should the surface of a wound be kept open for a time instead of being allowed to heal over as soon as possible?

23. Why do teeth that are not kept clean decay?

24. What stbstances are used as "antiseptics"? How are they used?

25. Why are milk, meat, and other foods kept in refrigerators in warm weather?

26. Why are fruits and vegetables heated or boiled before being canned?

27. Why must the cans in which they are placed be tightly sealed?

28. Why do preserves containing a large proportion of sugar keep well without being tightly sealed?

\section{Chapter III}

1. Observe the greenish patches on the bark of trees or on the shaded parts of a stone wall. How is the green substance distributed? Is it a thin or a thick layer? Is it more abundant on one side of a tree than on another? Why? Can you scrape it off in sheets? Remove some of the material, bring it into the laboratory and place it in a damp place or sprinkle it with water. What changes take place in its appearance?

2. Mount a small portion of the green material in water, tear it apart carefully and examine it under the microscope. Look for small green cells which are alone or in twos or fours. These are cells of Protococcus. Do you ever find more than four cells in a colony? If so, are they all in one layer?

3. Can you see that each cell is surrounded by a transparent wall? This appears most clearly on the sides where two cells are attached to each other.

4. Is the green color scattered all through the cell? If not, can you see that it is contained in a body (the chloroplast) with a definite outline? 
5. Draw a single cell, showing all the parts that you can see.

6. Draw in outline colonies of two and of four or more cells.

\section{ChAPTER IV}

Baker's yeast or any of the various yeast cakes or fresh compressed yeast may be used for this study. Brewer's yeast, if it is to be had, is preferable, and especially "top" yeast, which has rather large cells. In many places, however, top ycast is not readily obtainable.

1. Into a battery jar or other convenient glass jar containing molasses solution (one part of molasses to ten parts of water), drop a cake of compressed yeast or a similar amount of whatever yeast is used. Cover the jar, set it in a warm place, and observe it as often as possible for two or three days.

2. Soon, probably within a few hours, bubbles of gas will be seen rising to the surface of the liquid. What changes take place in the appearance of the liquid? Does it remain clear? Does a scum form on the surface?

3. Notice the odor of the liquid after a day or two. To what is it due?

4. When the bubbles are rising freely, mount a drop of the liquid and examine it under the microscope. It will be found to contain yeast cells, some single, some in chains.

5. Study a single cell. What is its shape? Compare it as to size with the bacillus and Protococcus already studied. Is it colored? Has it a wall? What is the appearance of the protoplasm? Are any bodies visible in the protoplasm? Have any of them a noticeable color? There may be one large, clear space (a vacuole), or perhaps two or three small vacuoles.

6. Draw a cell on a large scale, showing all the parts that you can see.

7. Find a cell that has a small projection ( $a$ bud) at one end. Find others, showing buds of different ages. What does a bud finally become? How, if at all, is it separated from the larger cell with which it was at first connected?

8. Draw in outline three stages in the development of buds.

9. Do you ever find more than two cells connected? Draw in outline the largest colony you find. 
10. Immerse a funnel in a battery jar containing an active yeast culture, the upper (small) end of the funnel being just below the surface of the liquid. Insert a test tube filled with the same solution over the open end of the funnel, so that the open end of the tube is below the surface of the liquid in the jar. If this is carefully done, the tube remains flled with the liquid. Fasten it in this position. Bubbles of gas will rise in the tube and displace the liquid. When most of the liquid is displaced, turn the tube containing the gas right side up. Light a splinter and insert it into the tube. What happens to the light? Why? What is the gas in the tube?

11. Place another active yeast culture in a wide-mouthed bottle. Cork the bottle. Through the cork pass a bent tube, one end of which is above the surface of the yeast culture, and the other end of which dips into some lime-water in a tumbler. The gas formed by the yeast will pass into the lime-water. What changes take place in the appearance of the lime-water? Why?

12. Prepare three jars with molasses solution and yeast. Cover one with dark paper so as to shut out all the light and keep it beside your first culture (described in $\S I$ ).

13. Place a second in a cool place - in an ice box if one is available.

14. The third jar should be washed thoroughly in boiling water, and the solution for this jar should be boiled for five minutes after the yeast is added but before placing it in the jar. After the solution is placed in the jar, cover it tightly and place it beside the first culture.

15. Watch the different cultures and make careful notes of the results, comparing them with the first culture. What do you conclude as to the following points:

w. Does darkness or light affect the activity of the yeast?

$b$. Does cold affect it ?

c. What happens to the yeast when it is heated to the boiling point? Compare with bacteria in this respect.

16. Place some yeast in molasses to which no water has been added. Keep it in a warm place. Does fermentation take place? Why? 


\section{CHAPTER V}

1. Examine a mass of Spirogyra growing on the surface of a jar of water in bright sunlight. How do the plants feel to the touch? What is their color? Notice the bubbles of gas tangled among the plants.

2. Compare a similar culture which has been kept in the dark for at least twelve hours. Are the plants on the surface of the water, or at the bottom? Why? Do the plants differ in appearance in any way from those that have stood in the light?

3. Disentangle from the mass a single thread-like plant or as large a part of one as possible. How long is the thread? Is it branched?

4. Examine a plant under the microscope. Notice that it is made up of cells joined end to end. Are the cells alike in length? In thickness? What is the shape of a cell?

5. Study a single cell, noting the parts mentioned below. Some of these parts can be seen more clearly if the plant is placed for a short time in a weak solution of iodine in potassium iodid. This kills the living materials of the cell and stains them yellowishbrown. However, the cell should first be studied while alive, and everything possible observed in the living condition.

a. The outer wall.

b. The cross wall between two adjoining cells; compare this with the outer wall.

c. The layer of slimy cytoplasm, containing granules. Is it in motion?

d. The green chloroplast or chloroplasts. What is the shape of one? Can you trace it from one end of the cell to the other? Where does it lie with reference to the wall? Where does it lie with reference to the slimy cytoplasm?

$e$. Colorless bodies (pyrenoids) imbedded in the chloroplast. In the iodine solution a blue or blue-black color will appear just outside each pyrenoid; if the iodine acts long enough, the color may become so dense that the pyrenoid itself appears to be stained. What is the meaning of this blue color?

$f$. The nucleus, a rather dense spherical or ellipsoidal body at or - near the center of the cell; it contains a globular, somewhat brighter body, the nucleole. 
g. A thin film of slimy cytoplasm just outside the nucleus.

$h$. Strands of slimy cytoplasm running in all directions from the layer about the nucleus to the layer just within the wall.

$i$. The central vacuole. What is its shape? What does it contain?

$j$. Draw very carefully a single cell, naming all the parts.

6. Place a number of plants in alcohol in a test tube. Close the end of the tube with a cork and set it away. Examine it the next day. Is the alcohol colored? Lift the plants out of the alcohol. Are they still green?

7. Examine one of these plants under the microscope. Are the chloroplasts still present in the cells? What is the relation of the chloroplasts to the green coloring matter (chlorophyl)? What has happened to the chlorophyl?

8. In a large glass jar that stands in a sunny place and contains a vigorous culture of Spirogyra in water, completely immerse an inverted funnel, so that all the plants are held within or below the larger end of the funnel. Invert a test tube full of water so that its open end fits over the neck of the funnel, and fasten the tube in this position. The bubbles of gas formed by the plant will rise and replace the water in the test tube. When the tube is filled with gas, remove it and insert into it a glowing match or splinter. If the experiment is successful, the glowing end of the match or splinter will burst into flame. What does this show as to the nature of the gas in the test tube? How was this gas produced by the plant?

9. Determine by a similar experiment whether or not the same gas is produced by plants kept in darkness.

10. If living plants in process of conjugation are available, they should be used for the following study. Otherwise, material preserved in alcohol or formalin may be used. Notice that two plants place themselves parallel for part or all of their length. Study the following steps in the process of conjugation:

$a$. The appearance of a swelling on the side of each cell which is turned toward the other plant.

b. The growth of these swellings from two cells, one in each plant, until they touch each other.

c. The disappearance of the walls of the swellings at the point where they meet; the two swellings now form a continuous conjugation tube. 
d. The gradual contraction and rounding up of the respective cells

(gametes). What parts of the cells take part in this rounding up? Do the two gametes begin to contract at the same time?

$e$. The passage of one (the male) gamete through the tube into the cavity occupied by the other (the female).

$f$. The union of the two gametes into a single rounded cell (the zygote).

g. The formation of a thick wall about the zygote. Notice that the zygote occupies less space than was filled originally by either of the two gametes that have united to form it.

11. Should the material at hand show the lateral method of conjugation - which is less common than the method above described - the conjugation tube will be seen to be formed between two adjacent cells of the same plant instead of between cells of two different plants.

\section{Chapter VI}

1. Place a slice of moist bread (not wet enough to be soggy) in an evaporating dish; leave the dish uncovered for a half-hour; then cover it and let it stand in a moderately warm place. If the surface of the bread seems to be drying out at any time, add a little water. In the course of one or two days fluffy spots will appear on the surface of the bread; in a day or two more, the molds which cause these spots begin to form spores, and the spots take on a more powdery appearance. Among these molds Rhizopus is almost sure to be one; it can be recognized by the presence of stout upright branches at the top of each of which is a globular spore sac.

2. If Rhizopus is overgrown by other molds, as sometimes happens, it will be best to prepare a practically pure culture. This can be done by transferring from the first culture, by means of sterile forceps, a small amount of the mold bearing spore sacs to a slice of bread that has been freshly cut with a sterile knife, moistened with boiled water, and placed in a sterilized evaporating dish which is kept covered.

3. Study the young spots on the bread with a hand lens. Notice that each spot consists of a tangle of branched threads, white or grayish while young. There are two kinds of branches-some that grow horizontally along the surface, and some that grow downward into the bread. 
4. Describe the arrangement of the branches and the relation of the two kinds to each other. Do the branches differ in size? Is a single branch of the same diameter throughout its length? Which kind digests and absorbs food from the bread? By means of which kind of branches does the plant spread over the bread?

5. Somewhat later, upright branches appear. Where do they grow from? What do they bear at the upper end? Of what use are they to the plant? What is the advantage of their upright growth?

6. As the mold grows older, what changes take place in its appearance? What changes occur in the bread? What has happened to the starch and other solid substances in the bread?

7. Mount in water a small part of a young mold plant. Examine a branch under the compound microscope. Is it made up of small cells like a thread of Spirogyra? Find the following parts, comparing each with the corresponding part of a Spirogyra cell:

a. The cell wall.

b. The granular protoplasm. What is its color?

ı. Vacuoles. Are they of the same or of different sizes?

d. Oil drops, similar to the smaller vacuoles, but yellowish in color.

8. Compare, with reference to all the parts named above, a branch from an older mold plant.

9. Draw on a large scale a small portion of a branch of a young plant, naming all the parts.

10. Sketch different stages in the growth of an upright branch and in the formation of the spore sac at its upper end.

11. Crush under the cover glass a mature spore sac. Note:

a. The outer wall, which breaks under a very slight pressure.

$b$. The numerous spores which have been enclosed within the wall of the sac. Are they all of the same shape? Of the same size?

c. The dome-shaped central portion of the spore sac, surrounded by a wall that is attached to the remaining basal part of the wall of the sac.

12. Study a single spore under the high power. What can you see as to the structure of its wall? Of its protoplasm? Draw a spore.

13. Spores may be germinated in the course of a day or two in a good-sized drop of water on a slide. The slide should be kept on 
moist filter or blotting paper under a battery jar or in a covered evaporating dish, so that the water on the slide will not evaporate. In such a culture find spores and young plants showing different stages in germination and growth.

14. Notice that germination begins by a swelling of the spore; next there appears a projection (or sometimes two or three projections) on the surface of the spore. Follow the growth of a projection. Into what does it develop? How long is it before the first branch appears?

15. Make outline drawings of three stages in the germination of the spore.

16. If spores from plus and minus strains of Rhizopus ${ }^{1}$ are mixed and sown upon bread, gametes and zygotes will be formed at the places where branches from plants of the two strains come in contact. Or if a culture of Sporodinia (the mushroom mold) can be,obtained, it will be found to produce gametes and zygotes, because in this mold conjugation occurs between gametes formed on different branches of a single plant.

17. Notice the outgrowth of swellings from two neighboring branches. The swellings grow into short branches whose ends are in contact. Look for the following stages :

a. Cell division, resulting in the formation of a gamete at the end of each short branch.

b. The disappearance of the walls of the gametes where they touch each other.

c. The union of the gametes into a single cell - the zygote.

d. The growth and rounding up of the zygote.

$e$. The formation of a thick wall about the zygote. Is this wall smooth? What is its color?

18. Are the short branches which bear the gametes alike? Are the gametes themselves alike?

19. Compare conjugation in the bread mold and in Spirogyra.

20. Draw a ripe zygote with the short branches which hold it, showing the attachment of the latter to the longer branches of the parent plant or jlants.

1 Cultures of the separate strains may be obtained from some of the companies that supply plant materials for class use. 


\section{Chapter VII}

Barberry leaves should be collected when the cluster cups are at their best - in ordinary seasons in April or May. The leaves may be pressed and dried for class use. Collect rusted wheat and other grains during the summer and fall. Cedar apples may be gathered during the fall and winter; the infected leaves of apple, crab, and hawthorn in the early summer months.

1. Study infected barberry leaves and note the position and size of the diseased areas. What is their color? Are the leaves swollen? With a hand lens study carefully the diseased spots. What differences do you find between the spots on the upper and those on the lower surface of a leaf? Draw a portion of the upper and a portion of the lower surface, showing the spots.

2. Under the microscope study a cross section of a barberry leaf. On the lower surface find a cluster cup. What is its boundary? How are the spores (spring spores) borne in the cup? What is the shape of a spore? Draw a spore.

3. In the upper surface of the leaf do you find cavities in which small spore-like cells (spermatia) are produced? (The spermatia themselves, being very small, will probably not be seen.)

4. Study rusted wheat stems and leaves. What is the shape and size of the patches (sori) in which the rust spores are borne? Compare a sorus with a cluster cup. Do the sori differ in color? If so, how? Draw a sorus.

5. Extract a portion of a light-colored sorus and examine it in a drop of water under the microscope. Study the summer spores; if possible, find one still attached to its stalk. Draw a spore on the same scale as your drawing of the spring spore.

6. Examine in the same way some winter spores obtained from a dark-colored sorus. Compare a winter spore with a spring spore and a summer spore as to size, shape, color, and thickness of wall. Draw a winter spore on the same scale as your drawings of the other spores.

7. Compare the rust of some other grain with the wheat rust. Are the sori similar in all respects? Do you find summer spores and winter spores? Are they different in any way from the corresponding spores of the wheat rust? 
8. Soak a cedar apple in water for a few minutes, then place it on moist filter paper or blotting paper and cover it with a tumbler. Examine it after a few hours; note the finger-like projections that it has pushed out. Mount a small bit of one of these projections in water and study it under a microscope. It will be found to contain spores. Which kind of spores of the wheat rust do those in the cedar apple resemble?

9. Compare the cluster cups of the rust on the apple (or of the very similar rusts on the crab-apple or hawthorn) with those of the rust on the barberry. What differences do you find?

\section{Chapter VIII}

It is not necessary, though preferable, to study in the laboratory the same species of mushroom that is described in the text. Mushrooms of various kinds may be gathered at any time during the summer or fall, and are readily preserved in 70 per cent alcohol. Be certain to obtain portions of the vegetative threads. Fresh horse- or cowdung, placed in a battery jar and covered, will produce a good crop of mushrooms for class study in from ten to fourteen days. Mushroom spawn, readily obtained from dealers, may be planted and will give abundant material for study, if the necessary conditions for its cultivation are at hand. Directions for planting and for the care of a mushroom bed are given with the spawn purchased. Atkinson's Mushrooms, Edible, Poisonous, etc. has an interesting chapter on the cultivation of mushrooms.

1. Examine material that shows various stages in the development of fruiting bodies. Notice the thread-like underground vegetative portions of the plant. Find also swellings ("buttons") of different sizes.

2. Cut one of the larger buttons in half from top to bottom; what structures do you find inside?

3. Study the way in which the buttons develop into fruiting bodies. By means of sections made as above described, follow the development of stalk, cap, and gills. Sketch sections showing two stages in development.

4. Study a full-grown fruiting body. Notice:

a. The shape, size, and color of the cap. Does it bear scales? What is the color of the flesh when it is freshly broken? Does the color change after it is broken? 
b. The shape and arrangement of the gills; their color. Does the color change as the fruiting body grows older? If so, can you find what causes the change?

c. The shape, size, and color of the stalk. Is it smooth or scaly? Is it solid or hollow? How is the cap attached to the stalk? Is the stalk always perfectly vertical? If not, is the cap horizontal or tilted? Of what advantage is it to have the cap carried up above the ground?

d. Is there a ring? A cup?

6. Sketch a fruiting body.

6. Place a small portion of a gill in water, crush it slightly, and examine it under the microscope. Notice that it is made up of delicate branching threads. Look for swellings (basidia) at the outer ends of some of the threads. Do you find spores? What can you make out as to their formation? Draw a portion of a branching thread; a basidium (if seen); a spore.

7. Cut off the stalk of a full-grown living mushroom; place the cap gill-side downward on a shect of smooth paper and cover it with a tumbler or battery jar. After a few hours examine the spore print. What is the color of the spores? How are they arranged on the paper? What is the cause of this arrangement? (It will be well to use both light-colored and dark paper unless one is sure in advance of the color of the spores.)

8. Observe mushrooms growing in a dung culture. Compare them in all respects with the mushroom already studied. Can you determine what special means any of them have to secure the distribution of their spores?

9. Compare any other mushrooms that you can obtain with those already studied. If possible, examine one of the poisonous Amanitas; notice the ring near the top and the cup-like swelling at the base of the stalk.

10. Study the manner of growth of the fruiting body of a bracket fungus. Notice especially the structure of the lower surface. How and where are the spores borne?

11. Make a list of the mushrooms and other basidium fungi that you find growing.

\section{Chapter IX}

Any common species of moss will do almost equally well for this study; different species may be used, if it is found more convenient, 
for the study of different organs and different portions of the life history. It should be noted, however, that any other moss will differ in details from the one described in the text. Moss spores can be germinated without much trouble on moist bricks or tiles. Germination is slow and may require several weeks.

1. Examine a "moss plant." Of what parts is it composed? In what position does it grow? Does the stem branch?

2. How are the leaves arranged? What is the form of a leaf, as seen under a hand lens? Can you see veins? Are there differences between the leaves borne on different parts of the plant? Draw a leaf in outline.

3. What differences do you find between male and female heads - that is, the ends of stems or branches on which antherids and archegones are borne? Tear apart a head of each sort. How are the sex organs arranged? What other structures do you find in the heads? Sketch an antherid and an archegone. How many gametes are borne in each?

4. Examine different stages in the development of the asexual plant. How does it secure its food? How is it attached to the sexual plant? What is the origin of the cap that is carried for a time on the top of the asexual plant? How do the spores escape when they are ripe? Draw a sexual plant to which an asexual plant is attached, naming all the parts of each.

5. Press out the spores from a ripe spore sac and examine them under a microscope. What is their shape? Their color?

6. If material is available, study and draw a portion of the protonema, which has grown from a germinated spore. This is the first stage in the history of the sexual plant. Can you discover how the leafy branches (commonly known as "moss plants") arise from the protonema?

7. Find as many different kinds of mosses growing out of doors as possible. In what sort of places does each kind grow?

\section{Chapter $\mathrm{X}$}

For this, as for some of the preceding studies, it is not necessary to use the species described in the text, though this is preferable. The bracken fern is to be found growing almost everywhere. The leaves and stems may be dried; it will be well also to preserve parts of spore- 
bearing leaves in 70 per cent alcohol or in 4 per cent formalin for the study of the spore sacs and spores. The sexual plants may be obtained by sowing spores in late summer or fall upon damp soil, sand, peat, or sphagnum, which should first be sterilized by heating in an oven, if possible, and after the sowing kept moist (but not wet). It is best to sow the spores of several species, since there are great differences in germinating power. Germination may require several weeks, or in the case of some species several months. Sexual plants can also be obtained from dealers in botanical supplies.

1. What are the parts of a fern plant? What is their relation to one another? Which are the longer-lived parts? How does the stem branch? Are all parts of the stem alive?

2. Can you find the growing end of the stem or of a branch? What parts do you find at or near the growing end?

3. Cut across a stem between the points where two leaves are given off. Study the cut surface of the stem with a hand lens and sketch it. What different tissues can you make out? How many vascular bundles are present? Are they of the same size?

4. Where are the roots borne? Where are the youngest roots? What is the shape of a root? Its length? Does it branch?

6. Where are the younger leaves to be found? What is the appearance of the youngest leaf you can find? How do the leaves change as they grow older? Are there portions of dead leaves still attached to the stem?

6. What are the parts of a full-grown leaf? Does it bear hairs or scales? If so, where? Describe the structure of the leaf-blade. Draw one of the smallest divisions of a leaf, showing the arrangement of the veins.

7. Peel off a portion of the epidermis (outer layer of cells) from the lower surface of the leaf and examine it under the microscope. Do you find air-pores? Are they few or many? Do the guard cells differ from the other cells of the epidermis in shape, size, or color? Draw an air-pore with a few of the neighboring cells.

8. Where are the spore sacs borne? Are they single or in groups? How are they protected? Examine and draw a spore sac. What are its parts? By alternately moistening and drying a ripe spore sac, try to induce it to open under a microscope and to 
observe how the spores are thrown out. Examine some of the spores. How do they compare with the spores of a moss?

9. Study the sexual plant of a fern. What is its shape? How large is it? Which is its oldest part? Its youngest part? Where are the rhizoids? What is their work?

10. Where are the antherids? The archegones? Are there few or many of each? Draw a sexual plant as seen from the under side, showing the positions of the rhizoids, antherids, and archegones. Look for moving antherozoids; they will break out of the ripe antherids if the sexual plant is placed in water.

11. If material is to he had, study a young asexual plant still attached to the sexual plant. Can you find the primary leaf, primary root, young stem, and foot? How does the primary leaf compare with the leaves that are formed later?

12. Collect and make a list of the different kinds of ferns that you find growing. In what kinds of places do the different species live?

13. Make another list of such relatives of the ferns as you find water ferns, horse-tails, and club-mosses.

\section{Chapter XI}

1. Examine branches of a pine tree. Can you distinguish between long branches and spur branches? Do both kinds grow longer from year to year? Do both grow thicker from year to year?

2. Find scale leaves and foliage leaves. Where is each borne? How do they differ in size, shape, and color? Draw a twig, showing both kinds of branches and both kinds of leaves.

3. Can you determine by examining a long branch how much of it has grown during the present year, and how much during each previous year? What marks the end of each year's growth? Where do new long branches start? New spur branches?

4. Study a cross section cut through a long branch not far back of the terminal bud. Can you distinguish epidermis, cortex, vascular bundles, and pith? How are the vascular bundles arranged? What are the parts of a vascular bundle? In which part of a bundle do you find the largest cells? Draw a large enough portion of the section to show the different tissues. 
5. Study a cross section through a part of a branch that is three or more years old. Compare it with the section previously studied. What changes have taken place in the wood? In the bast? Where are the new cells being formed which add to the thickness of the branch? What kinds of cells do you find in the medullary rays? Can you distinguish between spring and summer wood? Why can we tell the approximate age of a tree or of a branch by counting the annual rings? Is bark being formed? If so, can you make out in the section how its formation goes on? In what parts of the stem do you find resin passages? Draw a portion of this section.

6. Where and how are the small staminate cones of the pine borne? What are the parts of a cone?

7. Examine a single microspore leaf torn from a staminate cone. Do you find pollen sacs? How many? Where are they borne? Draw a microspore leaf showing the pollen sacs.

8. Break open a pollen sac and examine with a compound microscope the pollen grains that escape. Draw a single pollen grain.

9. Compare a young carpellate cone with a staminate cone. Is it made up of similar parts? How are the carpellate cones borne? On what part of a branch do you find the youngest cones? The year-old cones? The ripe cones?

10. On what part of a macrospore leaf are the macrospore sacs (ovules) borne? How many macrospore sacs on a leaf? What parts can you make out in a sac? Draw a macrospore leaf, showing the sacs.

11. Compare a year-old cone with the young cone just studied. What changes have taken place in the macrospore leaves? In the macrospore sacs?

12. Study a still older cone, bearing mature seeds. From what has each seed developed? What is the wing-like structure attached to a seed? How do the seeds escape from the cone?

13. "Nut pine" seeds are best for the study of the structure of the seed. On the outside is a hard coat ; from what did it develop? Crack open this coat; is there an inner seed coat? Inside find the endosperm and the embryo. Of what parts is the embryo composed? 
14. Make a list of the kinds of pines and other gymnosperms that you find growing in your locality. Which of them are native plants? Which have been introduced from other parts of the world?

\section{Chapter XII}

1. Watch the growth of the stem of a climbing bean from day to day and observe how it climbs. Compare this with the way in which tall peas and sweet peas support themselves in an upright position.

2. Where are branches borne? Do they twine like the main stem? Do the branches themselves branch?

3. How does the blade of a bean leaf compare with that of a leaf of a cucumber or squash? What is the arrangement of the veins in a leaflet? Draw a leaf and a portion of the stem or branch to which it is attached, naming the parts of the leaf. Is there a bud in the axil of the leaf?

4. Observe the position of the leaves and leaflets after dark. Compare it with their position during the day. Can you find other plants growing either in- or out-of-doors that show such differences in the positions of their leaves by day and by night?

5. What is the form of the root system of the bean? Can you recognize the primary root? Do the roots branch? Notice especially the small swellings that are likely to occur at various places on the roots. What organisms live in the swellings? How are these organisms important to the bean plant? Draw a small portion of the root system, showing some of the swellings.

6. In a cross section of the stem can you make out epidermis, cortex, vascular bundles, and pith? Compare the arrangement of the vascular bundles with their arrangement in the pine stem. In what part of each bundle is the wood? The bast? Draw a portion of the section.

7. Study a cross section of a leaf. Notice the upper and the lower epidermis. Are the cells of the layer just below the upper epidermis different in any way from the other cells of the leaf? What kind of cells make up most of the thickness of the leaf? Are there spaces between the cells? In what cells do you find the 
greater number of chloroplasts? Where are the vascular bundles? How do they compare with the bundles in the stem?

8. Where are flowers borne? How many flowers does one plant produce? Do all the flowers of a plant open at the same time?

9. Remove, one by one, the parts of a flower. How many sepals are there? How many petals? How many stamens? What striking peculiarities do you note in the sepals? In the petals? In the arrangement of the stamens? Cut away the sepals and petals from the right or left half of another flower; draw the remainder of the flower as seen from the cut surface. What are the parts of the pistil? Can you find the ovules (macrospore sacs)? If so, how many are there? How are they borne? Dissect and draw the pistil.

10. What changes take place in the ovary as it develops into a fruit? What changes take place in other parts of the flower? What is the form of the fruit? How are the seeds borne inside the fruit? How are they set free? From what did each seed develop? Draw a fruit from which one-half the fruit coat has been removed, allowing the seeds to be seen.

11. Put some bean seeds into lukewarm water and leave them over night. Examine them the next morning and compare them with unsoaked seeds. On what part of a seed is the scar by which it was attached? Where is the micropyle?

12. Remove the seed coat. Is it composed of more than one layer? All within the seed coat is the embryo. Why is there no endosperm? What is the largest part of the embryo? Why?

13. Remove one of the seed leaves and find the plumule and the radicle. In what direction is each of these parts turned? How many secondary leaves are borne on the plumule? Draw an embryo from which a seed leaf has been removed.

14. Study the germination of the seed and the development of the seedling, following $\$ \$ 7-9$ of the laboratory directions for Chapter I.

15. Make a list of the varieties of beans that you find in cultivation. Which are pole beans and which bush beans? In what other respects do the varieties differ?

16. List the other cultivated and wild plants that you find belonging to the pulse family. 


\section{Chapter XIII}

1. Examine a leaf of the Indian corn. How is it attached to the stem? What are the parts of a leaf? "Compare in this respect with a bean leaf. How are the leaves arranged on the stem? How do the upper and lower surfaces of a leaf-blade differ from each other? What is the arrangement of the veins in a leaf? Can you find teeth on the edges of the blades? Draw a leaf showing its attachment to the stem, and the veins.

2. What is the shape of the stem after all parts of the leaves have been removed? Is the stem thicker below than above? Compare in this respect with the bean stem. Is it swollen at any point? Is it solid or hollow? Does it branch?

3. Study the bud at the end of the stem. Tear it apart. How many and what parts do you find in it?

4. In a cross section of the stem, see if you can make out the parts mentioned in $\S 6$ of the directions for the study of the bean. What differences do you find between the corn and bean stems? Draw a portion of the section.

5. Compare the root system of the corn with that of the bean. Do the roots branch? Are any roots produced above the surface of the ground? If so, from what points on the stem do they grow? How do they help the plant?

6. The pistillate flowers are borne on the ear. Just where is the ear produced? How many ears on each plant? What is the cob? What are the husks? How are the flowers arranged on the cob? How many pistils in a flower? What are the parts of a pistil? What is the silk? Can you find any parts in the flower other than the pistil? Notice the scales or "chaff" surrounding and between the flowers. Draw a complete pistil.

7. Examine a tassel, which bears the staminate flowers. Can you see how the flowers are arranged? How many stamens in each flower? What are the parts of a stamen? Where is pollen formed? Can you find other parts of the flower than the stamens? Notice the scales that surround the flower. Draw a stamen.

8. Compare the ovary of a young flower with one that has begun to develop into a fruit (or kernel), and also with a full-grown kernel. 
How does the ovary change as it grows into a fruit? What changes take place in the cob? In the husks?

9. What is the shape of a ripe corn kernel? What differences do you notice between its two broad sides? Can you find where the silk was attached?

10. Place kernels in lukewarm water and leave them over night. How have they been changed by the soaking? Peel off the seed coat and the fruit coat, which have grown together. Inside find the endosperm and the embryo. Which makes up the larger part of the kernel? On which side of the kernel is the embryo located? Separate the embryo from the endosperm. Notice that the embryo is surrounded by the thick seed leaf.

11. With a sharp knife split another soaked kernel lengthwise so as to cut through the middle of the embryo. With the aid of a hand lens, find the following parts of the embryo: seed leaf, radicle, plumule, secondary leaves. Draw the cut surface so as to show these parts as well as the endosperm and the outer coat of the kernel.

12. Study the germination of the corn seed as directed in $\$ \S 7$ and 8 of the directions for the study of the squash or pumpkin seed. Notice especially what happens to the seed leaf, the first secondary leaf, and the later leaves; also how, after the primary root has begun to grow, other roots start. Where do they grow from? Draw in outline three seedlings of different ages.

13. After a seedling has developed one or two ordinary leaves, pull it up and wash its roots very carefully. To what parts of the root system does the sand or sawdust stick most closely? IThy? Is the kernel still attached to the young plant? If so, what holds it in place?

14. Compare ears of flint, dent, sweet, and pop corn. How do they differ? How do their kernels differ?

15. Make a list of the varieties of corn that are grown in your neighborhood. How do they differ? To what class (flint, dent, sweet, or pop) does each variety belong? IThat advantages does each variety have?

16. Compare varieties of corn whose kernels are of different colors (yellow, red, black, etc.). In what part of the kernel is the color located? 
17. Make a list of the uses to which the different parts of the corn plant are put - kernels, cobs, husks, stems, and leaves.

18. Why is so large a part of the world's corn crop produced in the United States? Which states in the United States produce the most corn? Why are these states best suited to corn growing?

19. Further suggestions for practical study may be found in Farmers' Bulletins 409 and 6I7, published by the United States Department of Agriculture.

\section{Chapter XIV}

1. Study the root systems of as many as possible of the following: dandelion, clover, sweet potato, radish, beet, dahlia, some of the grasses or grains, and some small trees and shrubs. Which of those studied have large primary roots? Which have branching primary roots? Which have clustered roots? Which have fibrous roots?

2. With a hand lens examine cross sections of roots of corn, of pea, and of some woody plant. Find the epidermis, cortex, vascular bundles, and pith. How does the arrangement of these tissues compare with their arrangement in the stems that you have studied? Sketch a section. Look for the beginnings of secondary roots. Where do they start?

3. Study the roots of an onion or other plant growing in water. Notice the cap-like mass of cells (root cap) covering the tip of the root. What is the function of the root cap?

4. Study a prepared longitudinal section of a root tip under the compound microscope. Can you recognize the root cap? The region of embryonic cells? How do the cells in the older parts of the section differ from the embryonic cells?

5. Mark with India ink an actively growing bean root, preferably one not more than two inches long, at intervals of one-fourth inch. Place the plant in a moist chamber and examine it from day to day. In what part does most of the growth in length take place?

6. By means of pins, fasten bean seedlings with roots about an inch in length to a block of wood so that the roots point in various directions. Place the block in a moist chamber and observe the seedlings after twenty-four hours. In which direction do the roots 
now point? If they have bent, in what part of each root did the bending take place?

7. Sprout seeds of radish, barley, and corn in sand or sawdust, and when the roots are an inch or more long pull up some of the plants. Note how the sand or sawdust sticks to the roots. What holds it in place? What does this suggest as to the proper care to be taken of the roots in transplanting young cabbage or tomato plants?

8. Test such roots as those of beets, carrots, and sweet potatoes for (a) starch, (b) sugar, and (c) proteins. $^{1}$

9. Fasten a root of sweet potato or carrot in a bottle or tumbler which contains water enough to cover the lower part of the root. Observe the vigorous growth of the leaves which soon appear. What is the source of food supply for the growth of the leaves?

\section{CHAPTER $\mathrm{XT}^{\top}$}

1. Study with a hand lens a cross section of a basswood stem several years old. Can you tell the age of the stem? What differences do you find between spring and summer wood?

2. Study an underground stem of quack grass, iris, or Solomon's seal. How old is it? How can you tell? What is the extent of each year's growth?

3. Examine a potato tuber. What structures indicate that it is really a stem? Put a potato into a tumbler partly filled with water and examine after a few days. What changes have taken place?

4. Cut a thin section across a potato tuber and hold it toward the light. Can you find regions that correspond to those found in stems that you have previously studied?

5. Cut off the lower end of a potato tuber and place the cut end in a dish containing red ink. After some time cut across the tuber

I (a) Treatment with iodine, which turns starch blue, is the ordinary test for starch. (b) Boil small portions of the root to be tested, and while the liquid is still warm add sluwly a few drops of Fehling's solution. If sugar is present, the liquid will take on a yellowish color, and soon a yellowish or reddish precipitate will appear at the bottom of the test tube. (c) Gently heat in water portions of the roots to be tested, then add a few drops of nitric acis. If proteins are present, a ycllow color will appear, which turns to a deep orange if some drops of ammonia are added and the whole is again gently heated. 
and note the path through which the liquid has been conducted. Can you detect vessels with the hand lens? Perform the same experiment with stems of other plants and compare the results.

6. Place a young potted bean plant, preferably one five or six inches high, upright in a dark box which has a small opening in one end. Examine it after twenty-four hours, and again after forty-eight hours. What changes do you observe?

7. Place a similar plant on its side in a perfectly dark box. Examine it after two days. What changes have taken place? What do you conclude from this and the preceding experiment, as to the responses of a stem to the stimuli of light and gravity?

8. Mark a young bean stem at intervals of one-fourth inch with India ink; after twenty-four hours note where growth has taken place. Compare this result with that of your similar study of the bean root.

9. Secure portions of stems of alder, cherry, willow, maple, lilac, and other plants. Note the positions of buds. What is their relation to leaves or leaf scars? Note especially the buds of the lilac. Do you observe anything characteristic of them which explains the shape of a lilac bush?

10. Place portions of various woody stems in a dish containing water, and if possible cover the whole with a larger jar. Examine the stems from day to day for a week or more. Do you find that growth has taken place at regions where no buds were present? What happens when a willow tree has the greater number of its branches removed?

11. Tear apart a fairly large bud, such as the winter bud of a lilac or of a horse-chestnut. What covers the bud on the outside? What structures do you find inside? How many leaves does it contain? What is at the center of the bud?

12. Study thorns of various types. Which of them seem to be branches?

13. If an orchard containing young trees is available, it may be possible to make a study of various types of grafting, budding, and layering. Compare the methods used with those described in the text. If possible, some work in actual budding or grafting 
should also be done, using the figures and descriptions in the text as guides. ${ }^{1}$

14. Name the principal timber trees found in your neighborhood.

15. Is there any difference in texture between the wood of rapidly growing and that of slowly growing trees? Which makes the better timber?

16. Which is better for timber, a tree grown in the open or one grown in a forest? Why?

17. What are the objects to be gained in pruning timber trees? Orchard trees? Ornamental trees and shrubs?

18. Where are the principal timber areas of your state?

19. What is meant by quarter-sawed lumber? What timbers are cut in this way? Consult a carpenter as to methods.

20. What are the relations of the sugar, rubber, and turpentine industries to your stem studies?

\section{Chapter XVI}

1. Bring in leaf-bearing portions of several common plants for instance, the clover, strawberry, apple, and cherry - and compare the leaves with those that you have already studied in the following respects:

u. Their arrangement on the stem.

b. Their division into stalk and blade.

c. The presence of stipules, and their comparative size. Do you find leaves without stipules?

2. What leaves do you find with parallel veins? With pinnate veins? With palmate veins?

3. What leaves do you find that are simple? What that are pinnately divided? What that are palmately divided?

4. Compare the leaves of a young oak, basswood, or grape with those of an older plant of the same kind. That differences have appeared in the leaves as the plant grew older?

${ }^{1}$ Grafting wax may be made by first heating and then thoroughly mixing equal parts of beeswax, tallow, and linsect oil. Soft cutton twine or strips of cheesecloth saturated with this mixture should be used in binding the parts. The wax should cover all cuts and cracks in order to prevent evaporation and to keep out fungi and insects. It may readily be kneaded into shape if slightly warmed in the hand, or it may be softened by the addition of more oil. 
5. Find as many as possible of the following special leaf structures and determine the special use of each to the plant:

a. Hairs or scales.

b. Layers of cutin or wax.

c. Disagreeably smelling, or poisonous, substances.

d. Sharp teeth, or cutting edges.

e. Small, thick leaves.

6. Find as many leaves as possible that have taken on some of the following special forms: thorns or spines; tendrils; bracts; scales; forms adapted to catch insects.

7. Study and draw a cross section of a leaf of English ivy, nasturtium, or sunflower, noticing the following tissues:

a. Upper epidermis; how many layers of cells? Are air-pores present?

$b$. One or more layers of closely packed cells just below the upper epidermis. What is their shape?

c. The spongy part of the leaf, containing air spaces. What are the shapes of the cells?

d. Veins. To what structures in the stem do they correspond?

$\boldsymbol{e}$. The lower epidermis. Compare with the upper epidermis.

8. Boil some freshly picked nasturtium leaves for a few minutes, then soak them in hot alcohol for half an hour. What happens to the chlorophyl? Now place them for a few minutes in a solution of iodine. What color do the leaves take on? What does this color change teach you?

9. Pin two small pill boxes or circular disks of cork on opposite sides of a leaf so as to exclude the light from part of the leaf (the leaf being still attached to the plant); leave the plant in bright light for a day or two. Then cut off the leaf and treat it as you did the leaves in the previous experiment. Compare the results of the two experiments. How do you explain the difference?

10. Obtain a begonia or some other plant whose leaves have airpores only on their under surfaces. Coat the under surfaces of some of the leaves with vaseline and leave the plant in bright light for a day or two. Then remove the vaseline with benzine and treat the leaves as in the two preceding experiments. Explain your results. 
11. Place a young, vigorously growing plant in a battery jar containing a little water. Tie a piece of cloth over the top of the jar and around the plant, so that only the leaves are exposed. Coat the cloth well with paraffin or vaseline so that no water can evaporate from the battery jar or from the stem of the plant. Weigh the whole carefully, then place it in the light. After twentyfour hours, weigh it again. Explain your results.

12. Arrange cut leaves of various plants with the lower ends of their stalks in red ink. After a short time remove them and examine for the paths taken by the ink through the leaves.

\section{Chapter XVII}

1. Study several common flowers; compare them with the flowers you have already studied as to:

u. Numbers of sepals, petals, stamens, and pistils.

$b$. Whether or not any of the parts are grown together.

c. Whether the ovary is inferior or superior.

d. Whether the pistils are simple or compound (that is, composed of one or more than one macrospore leaf).

e. Whether the flower is regular or irregular.

$f$. Shape, size, and structure of the ovary.

g. Length and shape of the style.

$h$. Adaptation of the stigma for catching and holding pollen.

2. What common plants have their flowers in racemes? In umbels? In spikes? In heads? In panicles?

3. Study with a hand lens the anthers of several common flowers. Notice the number and shapes of the anther sacs; the way in which they open to let the pollen escape; whether the pollen is sticky or dry and powdery. Examine pollen grains of tro or three different flowers under the compound microscope; draw the grains.

4. Shake the pollen of various plants into dishes containing respectively five per cent, ten per cent, and fifteen per cent cane sugar solutions. Cover the dishes. After twenty-four hours examine to see which grains have germinated and how germination came about. Draw a germinated pollen grain.

5. Find as many as possible of the following adaptations : flowers that bloom at night only; flowers that bloom by day and close in the evening; nectar-producing structures; "guides" which seem 
to point the way to the places where nectar is produced; peculiar shapes of flowers which adapt them to pollination by particular insects; structures which keep out some insects. Of what advantage is each of these adaptations to the plant?

6. If possible, study some of the common wild violets in bloom. INotice the showy flowers, and then look for other much less conspicuous flowers that never open. (Not all species of violets have these inconspicuous flowers.) What parts do the flowers of the latter sort have? In what way do they differ from the showy flowers? Of what use to the plant are the inconspicuous flowers?

\section{Chapter XVIII}

1. Obtain such common fruits as are available. Determine from what structure present in the flower each part of the fruit has been developed. What changes has each structure undergone?

2. Note the number of seeds present in each fruit. How are the seeds protected?

3. Collect the fruits of several of our common weeds. Do you find any special means in each case for the scattering of the fruits or seeds?

4. Make a list of common seeds with, and of those without, endosperm.

5. Soak the seeds of several common plants in cold water for twenty-four hours; place some of each sort under different conditions of temperature, keeping them between pieces of moist filter paper or blotting paper. Note the percentage of germination in each case. What differences do you find between different kinds of seeds in their power of germination? What influence does temperature have upon germitiation?

6. Germinate soaked seeds in darkness and in light. Which is the more favorable for germination? Are all seeds alike in this respect?

7. Place some soaked seeds in a bottle filled with water which has been boiled to drive out the air. Seal the bottle or cover the water with a layer of oil and observe from day to day. Do the seeds germinate? Explain.

8. Sprout seeds of corn, peas, and beans. When the stems are a half-inch long, remove one or both cotyledons of the beans and 
peas and cut away the endosperm of the corn. Compare the further growth with that of normal seedlings.

9. Take seeds of several plants, such as beans, peas, radish, and corn; divide those of each sort into three groups: large, medium, and small. Plant each lot under as nearly as possible the same conditions and observe the germinating seeds and seedlings from time to time. Do you find that there is any relation between the size of a seed and the size and vigor of the plant that grows from it? If so, which size of seed gives the best results?

10. If possible, secure some seeds that were gathered before they were ripe, some of the same sort gathered when they were just ripe, and others that remained on the plant for some time after ripening. Plant them and observe to determine the length of time needed for germination and the rate of growth of the plants that grow from each lot.

\section{Chapter XIX}

In connection with the study of this chapter, if time allows, the class may well be given practice in identifying some of the common wild plants. In this work, the pupil learns not only the names of particular plants and their reference to the appropriate families, orders, and classes; he also learns - what is perhaps more important - how to identify unknown plants by means of a manual. A list of some of the leading manuals available for the identification of the seed plants and ferns in various parts of the United States and Canada will be found in Appendix II.

\section{Chapter XX}

1. Make a list of twenty of the more important plants raised in your neighborhood which supply food for man. That part of the plant is used in each case? Irhat changes does the plant undergo to make it suitable for use?

2. Name ten foods derived from plants which are imported from other parts of the world.

3. What cultivated plants growing in your neighborhood are used as food for animals? That wild plants?

4. What plants have you seen growing that supply fibers? For what purposes are their fibers used? What other sorts of plant 
fibers are used in making the different kinds of cord, binding twine, rope, sacking, etc. that you may find in various shops and stores?

b. What plants growing in your locality are used in any of the following ways: as medicines, for stimulants, for beverages, as sources of oils, waxes, resins, perfumes, or dyestuffs?

6. If possible, a visit should be made to a museum in which economic plants and their products are exhibited. Notes may be taken of the different plants observed, of the regions in which they grow, and of the ways in which they are treated to make them of use.

7. A visit may also be paid to a convenient flour mill, beet sugar factory, or other factory in which plant products are manufactured. Each of the processes concerned in the transformation of the raw material into its final form should be carefully observed.

8. Materials for study may often be obtained from large concerns manufacturing starch, sugar, cocoa, and other food products, cotton seed products, or cotton cloth and other fabrics, showing the stages that the plant materials have passed through in the process of manufacture.

\section{Chapter XXI}

Students should bring in some of the common weeds of the locality and become familiar with their general appearance. Especial attention should be paid in this study to the poisonous weeds. If a small plot of weedy ground is available for the purpose, the experiment may be tried of spraying it two or three times at intervals of a week with a twenty per cent solution of iron sulphate. Compare the effects of this treatment on the grasses and on the broad-leaved weeds.

\section{Chapter XXII}

1. The class should visit a neighboring forest or wood lot to observe the different species of trees and their arrangement. Are the various kinds of trees irregularly scattered or are those of each sort in a group by themselves? How do the trees growing in a forest differ from those of the same kind grown in the open? What is meant by "self-pruning"? How does it come about? 
2. If timber is being cut, make a study of the various processes concerned: Is there much waste? What might be done with the parts of the trees that are not used? How are the logs handled after the trees are cut down?

3. A study may also be made of shade and ornamental trees, special attention being paid to those which are of economic importance.

4. A saw mill should be visited if possible. Even a portable mill is well worth visiting. Follow the $\log$ from the time it enters until it leaves the mill. What is meant by straight cut lumber? Quartersawed lumber?

5. A visit to a lumber yard should be made. Note what kinds of wood are found. What names are given to the various kinds of lumber? For what are the different kinds used? A furniture store or a cabinet maker's shop will show some of the more valuable woods. Where are they obtained? For what are they used?

6. Visit if possible some wood-using industry such as a chair or furniture factory, box factory, wagon works, or pulp mill; observe the woods used and the processes employed in the making of the finished product.

\section{Chapter XXIII}

If there is opportunity to do so, the class should visit a greenhouse or other place where plant-breeding is being done. Notice whether or not all new plants are grown from seeds. If not, what methods of multiplication are used? Do all the seeds of any plant grow into plants exactly like the parent? What methods are used in crossing plants? What is the object of crossing? What methods of selection are in use? If new races produced by selection are available, compare them with the parent races. What improvement has been brought about by selection? Lists may be made by pupils of such varieties as they find in cultivation of the wheat, pea, tomato, potato, or other common plant. What are the advantages of each variety? Why is it worth while to have more than one variety of a particular species? What can you find out about the history of common cultivated varieties? Have full records generally been kept in the past of plant-breeding work? 


\section{Chapter XXIV}

It will not be feasible in most schools to do any formal work in connection with the subject of this chapter. Students should be on the lookout for plants attacked by parasitic fungi, and, with the aid of the teacher, should learn to place in their appropriate groups the more important disease-producing fungi such as smuts, rusts, powdery mildews, downy mildews, damping-off fungi, and those which cause leaf- and fruit-spots. Lists may also be made of the plant diseases that are most troublesome in the immediate locality, and the students should become familiar with the means by which these particular diseases may best be checked. Help may always be had from the nearest agricultural experiment station in the identification of parasitic fungi. 


\section{APPENDIX II}

\section{REFERENCE BOOKS}

The following is a list of books which may be used to supplement the text. An attempt has been made to select a comparatively small number of works which will prove most helpful, copies of some or many of which are likely to be in the school library. With a few exceptions, references to secondary school textbooks have not been included. Copies of various textbooks are sure to be accessible and should be freely used by the teacher; but their inclusion in any considerable number would have made the present list too long. The same may be said of the bulletins of the United States Department of Agriculture and of the various state experiment stations; a list of the latter is given in Appendix.III. Lists of bulletins and circulars may be had from the Superintendent of Documents at Washington and from the directors of the experiment stations. The interest of pupils in the study of particular plants, and in such general topics as lumbering, forestry, grafting, plant breeding, and plant diseases, may be greatly stimulated by giving them access to these official publications. Some bulletins which are likely to prove especially helpful have been listed, but they are an inconsiderable fraction of the number that may be used to advantage.

\section{Chapter I}

Bailey: The Standard Cyclopedia of Horticulture, 2 d edition, vol. ii, pp. 905-910. The Macmillan Company.

Bergen: Essentials of Botany, pp. 4, 5, 23, 24. Ginn and Company. Corbett: Cucumbers. Farmers' Bulletin 254, U. S. Department of Agriculture.

\section{Chapter II}

Abel: Care of Food in the Home. Farmers' Bulletin 375, U. S. Department of Agriculture.

Bennett and Murray: A Handbook of Cryptogamic Botany, pp. 449-456. Longmans, Green and Company. 
Conn: Bacteria, Yeasts, and Molds in the Home. Ginn and Company.

Duggar: Fungous Diseases of Plants, chap. ix. Ginn and Company.

Jordan: A Textbook of General Bacleriology. W. B. Saunders and Company.

Lipman: Bacteria in Relation to Country Life. The Macmillan Company.

Rogers: Bacteria in Milk. Farmers' Bulletin 490, U. S. Department of Agriculture.

Rogers: Home Pasteurization of Milk. Circular 152, Bureau of Animal Industry, U. S. Department of Agriculture.

Sedgwick and Wilson: An Introduction to General Biology, chaps. xvi, xvii. Henry Holt and Company.

Stevens: Introduction to Botany, pp. 254-26I. D. C. Heath and Company.

\section{Chapter III}

Coulter: A Textbook of Botany, pp. I02-104. D. Appleton and Company.

Curtis: Nature and Development of Plants, $3 \mathrm{~d}$ edition, pp. 182-183. Henry Holt and Company.

Gager: Fundamentals of Botany, pp. 252-255. P. Blakiston's Son and Company.

Sedgwick and Wilson: An Introduction to General Biology, chap. xiv. Henry Holt and Company.

\section{Chapter IV}

Atwater: Bread and Breadmaking. Farmers' Bulletin 389, U. S. Department of Agriculture.

Conn: Bacteria, Yeasts, and Molds in the Home. Ginn and Company.

Coulter, Barnes, and Cowles: A Textbook of Botany, vol. I, pp. 70-7I, 409-410. American Book Company.

Curtis: Nature and Development of Plants, 3 d edition, pp. 248-250. Henry Holt and Company.

Sedgwick and Wilson: An Introduction to General Biology, chap. xv. Henry Holt and Company.

Stevens: Introduction to Botany, pp. 256, 26I-263. D. C. Heath and Company. 


\section{Chapter V}

Bennett and Murray: A Handbook of Cryptogamic Botany, pp. 264-267. Longmans, Green and Company.

Coulter, Barnes, and Cowles: A Textbook of Botany, vol. I, Pp. 38-4I. American Book Company.

Strasburger, Jost, Schenck, and Karsten: A Textbook of Botany, 4th English edition, pp. 348-349. The Macmillan Company.

Vines: Elementary Textbook of Botany, p. 256. The Macmillan Company.

\section{Chapter VI}

Bennett and Murray: A Handbook of Cryptogamic Botany, pp. 335-34I. Longmans, Green, and Company.

Bergen and Davis: Principles of Botany, pp. 239-242, Ginn and Company.

Conn: Bacteria, Yeasts, and Molds in the Home. Ginn and Company. Curtis: Nature and Development of Plants, 3d edition, pp. 224-227. Henry Holt and Company.

Gager: Fundamentals of Botany, pp. 256-267. P. Blakiston's Son and Company.

\section{Chapter VII}

Bennett and Murray: A Handbook of Cryptogamic Botany, pp. 383-387. Longmans, Green, and Company.

Bergen and Davis: Principles of Botany, pp. 260-264. Ginn and Company.

Carleton: Cereal Rusts of the United States. Bulletin I6, Division of Vegetable Pathology, U. S. Department of Agriculture.

Curtis: Nature and Development of Plants, 3d edition, pp. 25 I-257. Henry Holt and Company.

Duggar: Fungous Diseases of Plants, chap. xiv. Ginn and Company. Freeman: Minnesota Plant Diseases, pp. 159-164, 282-293. University of Minnesota.

Gager: Fundamentals of Botany, pp. 272-276. P. Blakiston's Son and Company.

Jones and Bartholomew: Apple Rust and its Control in Wisconsin. Bulletin 257, Wisconsin Agricultural Experiment Station.

Milburn and Bessey: Fungoid Diseases of Farm and Garden Crops, pp. 48-55. Longmans, Green and Company.

Olive: Rusts of Cereals and other Plants. Bulletin I09, South Dakota Agricultural Experiment Station. 
Strasburger, Jost, Schenck, and Karsten: A Textbook of Botany, 4th English edition, pp. 405-409. The Macmillan Company.

\section{Chapter VIII}

Atkinson: Mushrooms, Edible, Poisonous, etc. Henry Holt and Company.

Atkinson and Shore: Mushroom Growing for Amateurs. Bulletin 227, Cornell University Agricultural Experiment Station.

Clements: Minnesota Mushrooms. University of Minnesota.

Duggar: The Cultivation of Mushrooms. Farmers' Bulletin 204, U. S. Department of Agriculture.

Gager: Fundamentals of Botany, pp. 276-284. P. Blakiston's Son and Company.

Long: The Death of Chestnuts and Oaks Due to Armillaria mellea. Bulletin 89, U. S. Department of Agriculture.

Patterson: Mushrooms and Other Common Fungi. Bulletin I75, Bureau of Plant Industry, U. S. Department of Agriculture.

\section{Chapter IX}

Barnes and Heald: Analytic Keys to the Genera and Species of North American Mosses. University of Wisconsin.

Bennett and Murray: A Handbook of Cryptogamic Botany, pp. I36-I49. Longmans, Green and Company.

Bergen and Davis: Principles of Botany, chap. xxiv. Ginn and Company.

Campbell: The Structure and Development of Mosses and Ferns. The Macmillan Company.

Coulter, Barnes, and Cowles: A Textbook of Botany, vol. I, pp. II5-I2 I. American Book Company.

Curtis : Nature and Development of Plants, 3 d edition, chap. vii. Henry Holt and Company.

Grout: Mosses with a Hand-Lens. A. J. Grout, 360 Lenox Road, Brooklyn, New York.

Grout: Mosses with Hand Lens and Microscope. A. J. Grout. Strasburger, Jost, Schenck, and Karsten: A Textbook of Botany, 4th English edition, pp. 436-442. The Macmillan Company.

\section{Chapter $\mathrm{X}$}

Bennett and Murray: A Handbook of Cryptogamic Botany, pp. 64-82. Longmans, Green and Company. 
Campbell: The Structure and Development of Mosses and Ferns. The Macmillan Company.

Clute: Our Ferns in Their Haunts. Frederick A. Stokes Company. Coulter, Barnes, and Cowles: A Textbook of Botany, vol. I, pp. 155-I7o. American Book Company.

Cox: Eradication of Ferns from Pasture Lands in the Eastern United States. Farmers' Bulletin 687, U. S. Department of Agriculture.

Curtis: Nature and Development of Plants, 3 d edition, chap. viii. Henry Holt and Company.

Gager : Fundamentals of Botany, chaps. xii-xiii. P. Blakiston's Son and Company.

Sedgwick and Wilson: An Introduction to General Biology, chaps. viii-x. Henry Holt and Company.

Strasburger, Jost, Schenck, and Karsten: A Textbook of Botany, 4th

English edition, pp. 442 446, 449-454. The Macmillan Company. Underwood: Our Native Ferns and their Allies. Henry Holt and Company.

Wright: Flowers and Ferns in their Haunts. The Macmillan Company.

\section{Chapter XI}

Coulter and Chamberlain: Morphology of Gymnosperms. D. Appleton and Company.

Gager: Fundamentals of Botany, chap. xxvi. P. Blakiston's Son and Company.

Gray: Nere Manual of Botany, $7^{\text {th }}$ edition. American Book Company. (Contains a list and descriptions of the gymnosperms growing wild in the central and northeastern United States and the adjacent parts of Canada.)

Hall and Maxwell: Uses of Commercial Woods: Pines. Bulletin 99, Forest Service, U. S. Department of Agriculture.

Mohr: Timber Pines of the United States. Bulletin I3, Forest Service, U. S. Department of Agriculture.

Penhallow: A Manual of the North American Gymnosperms. Ginn and Company.

Schorger and Betts: The Naval Stores Industry. Bulletin 229, U. S. Department of Agriculture.

\section{Chapter XII}

Bailey: The Standard Cyclopedia of Horticulture, 2d edition, vol. I, pp. 458-463. The Macmillan Company. 
Corbett: The School Garden. Farmers' Bulletin 218, U. S. Department of Agriculture.

Corbett: Beans. Farmers' Bulletin 289, U. S. Department of Agriculture.

Fltharty: Bean Growing. Farmers' Bulletin 56r, U. S. Department of Agriculture.

Tracy: American Varieties of Garden Beans. Bulletin I09, Bureau of Plant Industry, U. S. Department of Agriculture.

\section{Chapter XIII}

Bowman and Crossley: Corn. Bowman and Crossley, Ames, Iowa.

Halligan: Fundamentals of Agriculture, pp. 83-104. D. C. Heath and Company.

Hartley: The Production of Good Seed Corn. Farmers' Bulletin 229, U. S. Department of Agriculture.

Hopkins: The Structure of the Corn Kernel and the Composition of its Different Parts. Bulletin 87, Illinois Agricultural Experiment Station.

Hunt: Cereals in America, chaps. ix-xviii. Orange Judd Company. Myrick: The Book of Corn, chaps. ii-iv. Orange Judd Company.

Sargent: Corn Plants, chaps. i-iv, xi-xviii. Houghton, Mifflin and Company.

Shamel: Manual of Corn Judging. Orange Judd Company.

Shoesmith: The Study of Corn, chap. i. Orange Judd Company.

Sturtevant: Varieiies of Corn. Bulletin 57, Office of Experiment Stations, U. S. Department of Agriculture.

\section{Chapter XIV}

Curtis: Nature and Development of Plants, $3 \mathrm{~d}$ edition, chap. ii. Henry Holt and Company.

Duggar : Plant Physiology. The Macmillan Company.

Ganong: A Textbook of Botany for Colleges, chap. v. The Macmillan Company.

Kerner and Oliver: The Natural History of Plants. Henry Holt and Company.

King: Physics of Agriculture, chaps. i, iv. Mrs. F. H. King, Madison, Wisconsin.

Osterhout: Experiments with Plants, chap. iii. The Macmillan Company.

Stevens: Plant Anatomy, 3 d edition, chap. vi. P. Blakiston's Son and Company. 


\section{Chapter XV}

Coulter, Barnes, and Cowles: A Textbook of Botany, vol. I, pp. 239247. American Book Company.

Ganong: A Textbook of Botany for Colleges, chap. iv. The Macmillan Company.

Jones: How the Maple Lives and Works. Bulletin 103, Vermont Agricultural Experiment Station.

Osterhout: Experiments with Plants, chap. v. The Macmillan Company.

Peirce: A Textbook of Plant Physiology, chaps. iii-v. Henry Holt and Company.

Stevens: Plant Anatomy, 3d edition, chaps. ii, iii, vii, x. P. Blakiston's Son and Company.

Ward: The Oak. D. Appleton and Company.

\section{Chapter XVI}

Bergen and Davis: Principles of Botany, chaps. $x-x i i$. Ginn and Company.

Coulter, Barnes, and Cowles: A Textbook of Botany, vol. 1, pp. 31833I; vol. 2, pp. 52 I-644. American Book Company.

Curtis: Nature and Development of Plants, 3d edition, chap. i. Henry Holt and Company.

Duggar: Plant Physiology. The Macmillan Company.

Ganong: A Textbook of Botany for Colleges, chap. iii. The Macmillan Company.

Kerner and Oliver: The Natural History of Plants. Henry Holt and Company.

MacDougal: Practical Textbook of Plant Physiology. Longmans, Green, and Company.

Stevens: Introduction to Botany, chap. v. D. C. Heath and Company.

\section{Chapter XVII}

Bergen and Davis: Principles of Botany, chaps. xiii-xv, xxxii. Ginn and Company.

Coulter: Plant Structures, chap. xiii. D. Appleton and Company.

Coulter, Barnes, and Cowles: A Textbook of Botany, vol. 2, chap. v. American Book Company.

Darwin: The Effects of Cross- and Self-Fertilisation in the Animal Kingdom. D. Appleton and Company.

Gray: Lessons in Botany, pp. 72-II7. American Book Company. 
Kerner and Oliver: The Natural IIistory of Plants, vol. 2. Henry Holt and Company.

Knuth: Pollination of Flowers. 3 volumes. Henry Frowde, Amen Corner, E. C., London, England.

Stevens: Introduction to Botany, chap. viii. D. C. Heath and Company.

\section{Chapter XVIII}

Beal: Seeds of Michigan Weeds. Bulletin 260, Michigan Agricultural Experiment Station.

Bergen and Davis: Principles of Botany, chaps. i, ii, xvi, xxxiii. Ginn and Company.

Coulter, Barnes, and Cowles: A Textbook of Botany, vol. 2, chap. v. American Book Company.

Curtis: Nature and Development of Plants, 3d edition, pp. 127-I36. Henry Holt and Company.

Kerner and Oliver: The Natural History of Plants, vol. 4. Henry Holt and Company.

Peirce: A Textbook of Plant Physiology, chap. vii. Henry Holt and Company.

Stevens: Introduction to Botany, chap. ix. D. C. Heath and Company.

\section{Chapter XIX}

To the following may be added an indefinite number of state and local lists and manuals, each of which will be useful to schools within the area that it covers.

Apgar: Ornamental Shrubs of the United States. American Book Company.

Apgar: Trees of the Northern United States. American Book Company. Armstrong and Thornber: Field Book of Western Wild Flowers. G. P. Putnam's Sons.

Blakeslee and Jarvis: Trees in Winter. The Macmillan Company.

Britton: Manual of the Flora of the Northern States and Canada. Henry Holt and Company.

Britton: North American Trees. Henry Holt and Company.

Britton and Brown: An Illustrated Flora of the Northern United States, Canada, and the British Possessions. 3 volumes. Charles Scribner's Sons.

Chapman: Flora of the Southern United States. American Book Company.

Coulter and Nelson: New Manual of the Botany of the Central Rocky Mountains. American Book Company. 
Cowles and Coulter: A Spring Flora for High Schools. American Book Company. (For the north central and eastern United States.)

Dame and Brooks: Handbook of the Trees of New England. Ginn and Company.

Frye and Rigg: Elementary Flora of the Northwest. American Book Company.

Gray: New Manual of Botany, 7th edition. American Book Company. (For the central and northeastern United States and the adjacent parts of Canada.)

Gray and Bailey: Field, Forest, and Garden Botany. American Book Company.

Hough: Handbook of the Trees of the Northern States and Canada, East of the Rocky Mountains. R. B. Hough, Lowville, New York.

Howell: Flora of the Northrwest. J. K. Gill and Company, Portland, Oregon.

Keeler: Our Native Trees. Charles Scribner's Sons.

Keeler: Our Northern Shrubs and How to Identify Them. Charles Scribner's Sons.

Lounsberry: A Guide to the Trees. Frederick A. Stokes Company.

Mathews: Field Book of American Wild Flowers. G. P. Putnam's Sons. Nelson: An Analytical Key to some of the Common Flowering Plants of the Rocky Mountain Region. D. Appleton and Company.

Nelson: Spring Flora of the Intermountain States. Ginn and Company. Piper and Beattie: Flora of Northwest Coast. New Era Printing Company.

Sargent: Manual of the Trees of North America (exclusive of Mexico). Houghton, Mifflin and Company.

Schaffner: Field Manual of Trees. Adams Company, Columbus, Ohio. Small: Flora of the Southeastern United States. John K. Small, Perry Ave. and 207th St., Bedford Park, New York City.

Tracy: Flora of the Southeastern States. Ginn and Company.

Wright: Flowers and Ferns in their Haunts. The Macmillan Company.

\section{Chapter XX}

Bailey: Cyclopedia of American .Igriculture. \& volumes. The Macmillan Company.

Bailey: The Standard Cyclopedia of Horticulture. 6 volumes. The Macmillan Company.

Burkett and Poe: Cotton. Doubleday, Page and Company.

Fraser: The Potato. Orange Judd Company. 
Halligan: Fundamentals of Agriculture, chap. iv. D. C. Heath and Company.

Hunt: Cereals in America. Orange Judd Company.

Hunt: Forage and Fiber Crops in America. Orange Judd Company.

Sargent: Plants and their Uses. Henry Holt and Company.

Spillman: Farm Grasses in the United States. Orange Judd Company.

Stockberger: Drug Plants under Cultivation. Farmers' Bulletin 663, U. S. Department of Agriculture.

Stubbs and Purse: Sugar Cane. D. G. Purse, Savannah, Georgia.

Toothaker: Commercial Raw Materials. Ginn and Company.

\section{Chapter XXI}

Beal: Michigan Weeds. Bulletin 267, Michigan Agricultural Experiment Station.

Blatchley: The Indiana Weed Book. The Nature Publishing Company, Indianapolis, Indiana.

Chesnut: Principal Poisonous Plants of the United States. U. S. Department of Agriculture, Division of Botany, Bulletin 20.

Chesnut: Thirty Poisonous Plants of the United States. Farmers' Bulletin 86, U. S. Department of Agriculture.

Clark and Fletcher: Farm Weeds of Canada. Government Printing Bureau, Ottawa, Ontario.

Cox: Weeds: How to Control Them. Farmers' Bulletin 660, U. S. Department of Agriculture.

Georgia: A Manual of Weeds. The Macmillan Company.

Henkel: Weeds Used in Medicine. Farmers' Bulletin I88, U. S. Department of Agriculture.

Pammel: Manual of Poisonous Plants. L. H. Pammel, Ames, Iowa.

Pammel: Weeds of Farm and Garden. Orange Judd Company.

Shaw: Weeds and How to Eradicate Them. Webb Publishing Company. Weed: Farm Friends and Farm Foes. D. C. Heath and Company.

\section{Chapter XXII}

Bryant: Logging. John Wiley and Sons.

Collins: Practical Tree Surgery. Year Book, U. S. Department of Agriculture, 19I3.

Defebaugh: History of the Lumber Industry in America. The American Thresherman, Chicago. 
Fernow: Care of Trees in Street, Lawn, and Park. Henry Holt and Company.

Graves: Principles of Handling Wood Lots. Bulletin 42, Forest Service, U. S. Department of Agriculture.

Kellogg: The Timber Supply of the United States. Circular 166, Forest Service, U. S. Department of Agriculture.

Kellogg and Hale: Forest Products of the United States. Bulletin 74, Forest Service, U. S. Department of Agriculture.

Moon and Brown: Elements of Forestry. John Wiley and Sons.

Peck: Opportunity in Forest Planting for Farmers. Year Book, U. S.

Department of Agriculture, 1909.

Pinchot: Forestry and Lumber Supply. Circular 25, Forest Service,

U. S. Department of Agriculture.

Pinchot: Primer of Forestry. Farmers' Bulletins 173 and $35^{8}$, U. S. Department of Agriculture.

Price, Kellogg, and Cox: Forests of the United States. Bulletin I7r, Forest Service, U. S. Department of Agriculture.

Roth: A First Book of Forestry. Ginn and Company.

Stone: Shade Trees, Characteristics, Adaptation, Diseases, and Care.

Bulletin I 7o, Massachusetts Agricultural Experiment Station.

Weiss: The Preservative Treatment of Fence Posts. Circular II7,

Forest Service, U. S. Department of Agriculture.

Winkenwerder: Forestry in the Public Schools. Circular 130, Forest Service, U. S. Department of Agriculture.

\section{Chapter XXIII}

Bailey and Gilbert: Plant Breeding. The Macmillan Company.

Cook: Wild Wheat in Palestine. Bulletin 274, Bureau of Plant Industry, U. S. Department of Agriculture.

Fraser: The Potato. Orange Judd Company.

Harwood: New Creations in Plant Life. The Macmillan Company.

Hunt: The Cereals in America. Orange Judd Company.

Hunt: The Forage and Fiber Crops in A merica. Orange Judd Company. Montgomery: Experiments in Wheat Breeding. Bulletin 269, Bureau of Plant Industry, U. S. Department of Agriculture.

Sargent: Corn Planis. Houghton, Mifflin and Company.

Stuart: Group Classifications and Varietal Descriptions of Some A merican Potatoes. Firmers' Bulletin 176, U. S. Department of Agriculture.

Wight: The Varieties of Plums Derived from Native American Species. Farmers' Bulletin 172, U. S. Department of Agriculture. 


\section{Chapter XXIV}

Arthur and Stuart: Corn Smut. 12th Annual Report, Indiana Agricultural Experiment Station, pp. 84-135.

Duggar: Fungous Diseases of Plants. Ginn and Company.

Freeman: Minnesota Plant Diseases. University of Minnesota.

Halligan: Fundamentals of Agriculture, chap. vi. D. C. Heath and Company.

Jones and Gilman: Control of Cabbage Yellows. Research Bulletin 38, Wisconsin Agricultural Experiment Station.

Massee: A Textbook of Fungi. The Macmillan Company.

Milburn and Bessey: Fungoid Diseases of Farm and Garden Crops. Longmans, Green and Company.

Moore: Oat Smut and its Prevention. Bulletin II I, Wisconsin Agricultural Experiment Station.

Swingle: The Prevention of Stinking Smut of Wheat and the Loose Smut of Oats. Farmers' Bulletin 250, U. S. Department of Agriculture.

Weed: Farm Friends and Farm Foes. D. C. Heath and Company. 


\section{APPENDIX III \\ THE STATE AND TERRITORIAL AGRICULTURAL EXPERIMENT STATIONS}

\author{
Alabama - \\ College Station: Auburn \\ Canebrake Station: Uniontown \\ Tuskegee Station: Tuskegee In- \\ stitute \\ Alaska - Sitka \\ Arizona - Tucson \\ Arkansas - Fayetteville \\ California - Berkeley \\ Colorado - Fort Collins \\ Connecticut - \\ State Station: New Haven \\ Storrs Station: Storrs
}

Delaware - Newark

Florida - Gainesville

Georgia - Experiment

Guam -- Island of Guam

Hawaii - Honolulu

Idaho - Moscow

Illinois - Urbana

Indiana - Lafayette

Iowa - Ames

Kansas - Manhattan

Kentucky - Lexington
Louisiana -

State Station: Baton Rouge

Sugar Station: Audubon Park, Nere Orleans

North Louisiana Station: Calhoun

Maine - Orono

Maryland - College Park

Massachusetts - Amherst

Michigan - East Lansing

Minnesota - University Farm, Si. Paul

Mississippi-Agricultural College Missouri-

College Station: Columbia

Fruit Station: Mountain Grove

Montana - Bozentan

Nebraska - Lincoln

Nevada - Reno

New Hampshire - Durham

New Jersey - New Brunswick

New Mexico - State College

New York -

State Station: Generva

Cornell Station: Ithaca

North Carolina -

College Station: West Raleigh

State Station : Raleigh

North Dakota - Agricultural College 


\section{AGRICULTURAL EXPERIMENT STATIONS}

Ohio - Wooster

Oklahoma-- Stillwater

Oregon - Corvallis

Pennsylvania - State College

Porto Rico -

Federal Station: Mayaguez

Insular Station: Rio Piedras

Rhode Island - Kingston

South Carolina - Clemson College

South Dakota - Brookings
Tennessee $-K$ noxville

Texas - College Station

Utah - Logan

Vermont - Burlington

Virginia - Blacksburg

Washington - Pullman

West Virginia - Morgantown

Wisconsin - Madison

Wyoming - Laramie 


\section{APPENDIX IV}

\section{BOTANICAL SUPPLIES}

Following is a brief list of the addresses of persons and firms who supply materials of various sorts that may be needed for laboratory work in botany. This list makes no pretension of being complete.

Seeds, Plants, and Bulbs

-W. Atlee Burpee and Company, Burpec Buildings, Philadelphia. Currie Brothers Company, 384 East Water St., Milwaukee.

Henry A. Dreer, 7 I + Chestnut St., Philadelphia.

Peter Henderson and Company, 35-37 Cortlandt St., New York.

J. M. Thorburn and Company, 53 Barclay St., New York.

Utah Rare Plant Company, Salt Lake City, Utah.

Vaughan's Seed Store, 43 Barclay St., New York; 84-86 Randolph St., Chicago.

Plants and Plant Parts, Living, Dried, and Preserved in Alcohol or Formalin; Herbarium Supplies, Microscopic Preparations

Biological Supply Company, io6 Edgerton St, Rochester, New York. Cambridge Botanical Supply Company, Waverley, Massachusetts.

Marine Biological Laboratory, Supply Department, Woods Hole, Massachusetts.

- Professor M. S. Markle, Earlham College, Earlham, Indiana. The Plant Study Company, P. O. Box I5, Cambridge, Massachusetts. -St. Louis Biological Laboratory, University Heights, St. Louis, M Lissouri. Dr. W. N. Steil, Biology Building, Madison, Wisconsin.

Microscopes, Projection Lanterns, Glassware, and other Laboratory Equipment

Bausch \& Lomb Optical Company, Rochester, Ner York.

Cambridge Botanical Supply Company, Waverley, Massachusetts.

Central Scientific Company, 41 2-420 Orleans St., Chicago.

Chicago Apparatus Company, 557-559 West Quincy St., Chicago. 
The Chicago Laboratory Supply and Scale Company, 39 West Randolph St., Chicago.

Columbia School Supply Company, Indianapolis.

Conrad Slide and Projection Company, 4028 Jackson Blvd., Chicago.

Goder-Heimann Company, 87 East Lake St., Chicago.

E. Leitz, 30 East I8th St., New York.

E. H. Sargent and Company, 125-127 West Lake St., Chicago. Spencer Lens Company, Buffalo, New York. 



\section{GLOSSARY}

Adventive. A term applied to roots, buds, or branches borne in any other than the usual place.

Alga. A comparatively simple plant (simpler than a moss or liverwort) which contains chlorophyl.

Alternate leaves. Those of which only one is borne at a particular node on a stem or branch; the leaves at two successive nodes are on different sides.

Annual. A plant which completes its entire life cycle in a single season.

Anther. The head, or upper part, of a stamen, in which the pollen grains are borne.

Antherid. The organ of a moss, liverwort, or higher plant in which male gametes are produced.

Antherozoid. A motile male gamete.

Archegone. The egg-producing organ of a moss, liverwort, or higher plant.

Axil. The upper angle between a leaf and the stem or branch on which it is borne.

Axillary. Borne in, or growing from, an axil; as axillary buds, or axillary flowers.

Bark. The dry portion of a stem or root lying outside the cork cambium. The tissues between the cork cambium and the cambium proper are sometimes called green bark, to distinguish them from the true or dry bark.

Basal. Referring to that part of a structure or organ nearest its base or point of attachment.

Basidium. A large cell borne on the surface of one of the gills of a mushroom, or on the corresponding surface of any of the related fungi, at whose end the spores are produced.

Bast. The part of a vascular bundle through which manufactured food is conducted; also called the phloem.

Biennial. A plant which requires two years in which to complete its life cycle, usually storing food the first year and bearing flowers and fruit the second.

Bract. A small leaf from whose axil a flower grows.

Bulb. A short shoot covered with thick, fleshy leaves, as in the onion or lily. 
Cambium. A layer between bast and wood by the division of whose cells the stem or root grows in thickness.

Carbohydrate. A substance composed of carbon, hydrogen, and oxygen, and belonging to the class which includes starch and the sugars.

Carpel. One of the parts of a compound pistil; a macrospore leaf.

Carpellate. Referring to a cone which bears carpels (macrospore leaves). Also used in the same sense as pistillate.

Catkin. A more or less dense, scaly flower cluster like that of the poplar, alder, or willow.

Cell. A unit of living matter. A plant or an animal may be a single cell, or may be composed of several or many cells.

Chlorophyl. The green coloring matter found in the cells of many plants.

Chloroplast. A small chlorophyl-containing body found in the cells of green plants.

Conjugation. The union of like gametes, such as those of Spirogyra or of the bread mold.

Cork. A substance (also called suberin) which permeates the walls of certain cells, especially of those formed from the cork cambium; the term cork is also applied to the cells themselves whose walls contain suberin.

Corm. A solid bulb-like structure not covered by thick leaves.

Cortex. The part of the stem lying between the epidermis and the region in which the vascular bundles are contained.

Corymb. A flat-topped or convex flower cluster whose outermost flowers are the oldest.

Cotyledon. A seed leaf.

Cross-pollination. The falling or depositing of pollen from the anther of one flower upon the stigma of another flower.

Cutin. A secreted waxy layer on the outer surface of the epidermis, especially of leaves or fruits.

Cutting. A severed portion of a plant from which a whole new plant may be developed.

Cyme. A flat-topped or convex flower cluster in which the central flower is the first to open.

Cytoplasm. All the substance of a cell contained within the cell wall, except the nucleus.

Digest. To change an insoluble substance into a form in which it may be dissolved.

Egg. A female gamete.

Embryo. The young resting plant contained in a seed. 
Endosperm. The food-containing tissue lying outside the embryo and within the seed coat.

Enzym. A substance produced in a living cell which causes or hastens particular chemical changes in other substances.

Epidermis. The outer layer of cells of leaves, stems, roots, or fruits. Epiphyte. A plant which grows, usually at some distance above the ground, upon another plant but not parasitic upon it.

Family. A group of related genera.

Fermentation. Any one of many chemical changes produced by simple organisms such as yeasts or bacteria ; especially, but not exclusively, those in which bubbles of gas are given off.

Fertilization. The union of unlike male and female gametes.

Fiber. An elongated, usually slender cell with firm walls; as bast fibers or wood fibers.

Filament. The stalk-like part of a stamen below the anther.

Fruit. A ripened ovary with the seed or seeds inclosed within it.

Fungus. A comparatively simple organism which contains no chlorophyl.

Gamete. A cell which may unite with another cell, thus forming a zygote.

Genus. A group of related species.

Germinate. To begin to grow, ustually after being for some time in a resting or dormant condition; applied to spores, zygotes, and seeds.

Gill. One of the vertical flaps on the under side of the cap of a mushroom, on whose surface spores are borne.

Glandular. Applied to a structure whose function is the secretion of some special substance.

Grafting. The attachment of the parts of two plants in such a way that they will grow together.

Head. A dense cluster of flowers on a very short axis.

Heartwood. The hard inner layers of the wood of the trunk and larger branches of a tree or shrub. Distinguished from saprood.

Host. An organism (plant or animal) on or in whose tissues a parasitic organism lives.

Hybrid. A plant produced by the crossing of two species or varieties.

Imperfect. Applied to a flower having either stamens and no pistil, or a pistil (or pistils) and no stamens.

Infection. The establishment of a parasite in or upon the tissues of a host, 
Integument. The layer, or one of the layers, of tissue surrounding the ovule, which develops into the seed coat or coats.

Internode. The parts of a stem or branch between two successive joints or nodes.

Keel. The two lower (usually united) petals of the flowers of most of the members of the pulse family.

Lenticel. An opening in the bark of a woody plant, through which the gases of the air may reach the inner tissues.

Macrospore. The larger kind of spore of a plant which produces spores of two kinds.

Macrospore sac. A structure in which macrospores are produced; in seed plants, the same as the ovule.

Medullary rays. Radial rows or layers of thin-walled cells, cutting through the wood or bast of a gymnosperm or dicotyledon.

Micropyle. An opening through the integument or seed coat.

Microspore. The smaller kind of spore of a plant which produces two kinds; in seed plants, the young pollen grain.

Microspore sac. A cavity in which microspores are produced. In seed plants, the same as a pollen sac.

Nectar. A fluid, commonly sweet, secreted usually in some part of the flower for the attraction of insects.

Node. One of the joints of a stem or branch, at which a leaf or leaves arise.

Nucleole. A small, usually rounded body lying within a nucleus.

Nucleus. A definite portion or organ of a living cell bounded by a membrane; distinguished from the cytoplasm.

Nutation. The movement in a more or less nearly spiral direction of the end of a stem or branch, due to unequal rates of growth on different sides.

Opposite leaves. Those of which two are borne, opposite each other, at the same node of a stem or branch.

Order. A group of related families.

Organic. Belonging to, or produced by, an organism.

Organism. A living being - plant or animal.

Ovary. The lower part of a pistil, containing one or more cavities in which an ovule (macrospore sac) or ovules are borne.

Ovule. The macrospore sac of a seed plant; a small body which may develop into a seed. 
Palmate. Arranged like the fingers of a hand; contrasted with pinnate.

Panicle. An open or loose flower cluster; a compound raceme.

Parasite. An organism which lives in or upon another organism (the host), and obtains some or all of its food from the host.

Pedicel. The stalk of each individual flower in a cluster.

Peduncle. A flower stalk; used to designate either the stalk of a solitary flower or the common stalk of a cluster.

Perennial. A plant which remains alive for more than two years.

Perfect. Applied to a flower having both stamens and pistil or pistils.

Petal. One of the leaf-like parts of a flower next within the sepals. Some flowers have no petals; if present, they are usually the most conspicuous parts of the flower.

Pinnate. Arranged like the parts of a feather; applied to the veins or divisions of a leaf.

Pistil. A structure borne in the central part of a flower, consisting of one or more carpels.

Pistillate. Applied to a flower having a pistil or pistils but no stamens.

Plumule. The part of an embryo which is above the cotyledons.

Pollen. The small bodies (pollen grains) produced in an anther.

Pollen sac. A chamber in which pollen grains are formed; the same as a microspore sac; also called an anther sac.

Pollen tube. An outgrowth from the germinating pollen grain, by means of which the male gametes of a seed plant are carried to the neighborhood of the egg.

Pollination. The falling or depositing of pollen from the anther upon the stigma.

Primary leaf. The first leaf, or one of the first leaves, formed by an embryo; in seed plants, the same as a seed leaf.

Primary root. The first root; in a seed plant, the primary root develops from the lower end of the radicle.

Protein. One of a class of very complex substances produced in living cells. Proteins are important constituents of all living matter.

Protonema. The thread-like vegetative growth produced by the germinating spore of a moss.

Protoplasm. The total liquid and semi-liquid constituents of a cell; everything inside the cell wall.

Ptomain. One of a class of substances produced by the action of bacteria in the decomposition of organic substances. Some of the ptomains are extremely poisonous.

Putrefaction. The decay of organic substances by the action of bacteria and other minute organisms. The term is especially applied to those forms of decay in which offensive odors are given off. 
Pyrenoid. A small body found in the cells of green algæ, whose function is the manufacture of starch. It is very commonly imbedded in a chloroplast.

Race. A group of plants or animals, very similar and closely related. Raceme. An elongated flower cluster, with many short pedicels borne at different levels upon the peduncle.

Radicle. That part of an embryo below the seed leaf or leaves.

Respiration. The breaking down of living substance and food in a living organism, as a result of which energy is set free for the use of the organism. Commonly respiration involves the taking in of oxygen and the giving off of carbon dioxid.

Response. The change produced in a cell or organism as the result of a stimulus; also called a reaction.

Rhizoid. An elongated cell or row of cells by means of which a plant absorbs food materials from the soil or water.

Root cap. The protective cap-like mass of cells covering a root tip.

Rudimentary. Not fully developed.

Sap. The liquids of a plant, especially those found in the vascular bundles. The water and dissolved substances transported through the wood constitute the crude sap; the manufactured foods transported in the bast are the elaborated sap.

Saprophyte. A plant which obtains its food from dead or decaying organic materials.

Sapwood. The moist, usually comparatively soft, outer layers of the wood of the trunk and larger branches of a tree or shrub.

Scion. The shoot or bud which is grafted upon a stock.

Secondary leaf. Any leaf formed later than the primary leaf or leaves. Secondary root. Any root formed later than the primary root.

Seed. A structure developed from an ovule; it consists of a small plant (the embryo), surrounded by nutritive and protective layers.

Seed leaf. The first-formed leaf, or one of the first-formed leaves, of an embryo.

Seedling. A young plant just beginning to grow from a germinated seed.

Selection. The choice of plants (or animals) having certain desirable qualities, to be used as the parents for the next generation; a method used in the production of improved strains and breeds.

Self-pollination. The falling or depositing of the pollen from an anther upon a stigma of the same flower. 
Sepal. One of the outer circle of leaf-like parts of a flower. Most commonly the sepals are comparatively small and green; but in some flowers they are large and white or brightly colored.

Sheath. The basal portion of a leaf which more or less surrounds the stem, as in the members of the grass family.

Sorus. A spot or region in which spores are formed.

Species. A name applied to a group of plants so nearly alike that they may be referred to by the same name.

Spermatium. A small spore-like cell produced in great numbers by the wheat rust and many other rusts. The spermatia seem to be entirely functionless.

Spike. A dense, elongated flower cluster in which the individual pedicels are very short.

Spikelet. A small or secondary spike; used in connection with the flower clusters of members of the grass family.

Spore. A reproductive cell that can develop into a new plant. In some of the bacteria, the name is applied to a specially resistant condition into which an ordinary cell may pass.

Spore sac. A structure in which spores are borne.

Sporidium. One of the kinds of spores produced by rusts. It is borne on a very small plant which grows from the germinating winter spore.

Spring spore. One of the spores of the wheat rust produced on the barberry, or the corresponding spore of any other rust; also called an aciospore or acidiospore.

Stamen. One of the parts of a flower which bears pollen; a microspore leaf.

Staminate. Applied to a flower having stamens but no pistil.

Standard. The large upper petal of the flowers of many of the pulse , family.

Stigma. The upper part of a pistil, on which the pollen grains land.

Stimulus. A change outside a cell or organism which causes a change in the processes going on within the cell or organism.

Stipule. A leaf-like appendage at the base of a leaf-stalk.

Stock. The basal part of a plant (root, or stem and root) upon which a graft is made.

Strain. A race or breed of plants or animals. Especially applied to two sorts (plus and minus strains) to which the plants of the bread mold and some of its relatives belong. The difference between plus and minus strains is probably a sexual difference.

Style. The slender, often hollow, portion of a pistil between the stigma and the ovary. 
Summer spore. A spore produced by the rust on the wheat during the summer, or the corresponding spore of other rusts; also called a urediniospore or uredospore.

Tap root. A primary root which persists as the plant grows and which pushes directly downward.

Tendril. A slender outgrowth, especially of climbing plants, by means of which the plant may attach itself to neighboring objects.

Terminal. Referring to that part of a structure or organ farthest from its place of attachment.

Toxin. One of a class of poisonous substances produced by parasitic bacteria.

Tuber. A thickened portion of an underground stem or branch.

Umbel. A flower cluster in which all the pedicels arise from the peduncle at about the same level.

Vacuole. A portion of the protoplasm of a cell, surrounded by a membrane, and containing a watery solution of various foods and other substances.

Variety. A group of plants that are very similar; a sub-division of a species.

Vascular bundle. A group of conducting cells, consisting either of wood, bast, or both wood and bast.

Veil. A membrane which for a time attaches the cap of a mushroom to its stalk, and so covers the gills.

Vein. One of the vascular bundles of a lcaf, usually appearing as a light green line.

Vessel. A long tube produced by the breaking down of the cross walls in a row of cells.

Whorl. A circle of three or more leaves borne at the same node.

Wing. One of the lateral petals of the flowers of many of the pulse family.

Winter spore. A two-celled spore produced by the rust on the wheat, or the corresponding spore (not in all cases two-celled) of other rusts; also called teliospore or teleutospore.

Wood. The part of a vascular bundle through which water and dissolved substances (usually obtained from the soil) are transported; also called $x y$ lem.

Zggote. A cell produced by the union of two gametes. 


\section{INDEX}

Absorption by roots, 173

Agar-agar, 322

Agaricus campestris, 78

Ailanthus, buds, 216

Air, influence on growth, I 85

Air-pores, IOI, I20, I39, 243

Alcoholic fermentation, 35-37, 3I9

Alfalfa, 27, 3I 7

Algæ, 32, 39, 3I 2 ; brown, 49, 50, $5 \mathrm{I}$; green, 48,49 ; of water supplies, 49 ; red, $49,50,52$

Aloes, 244, 299

Amanita muscaria, 8I

Amanila pantherina, 80

Amanita phalloides, 8I

A manita verna, 80

Amaryllis family, 299

Angiosperms, I32, I37, I53, 312; families of, 295-3II

Annual plants, Io, I $37, \mathrm{I} 56,220,329$

Annual ripgs, II 7, 209, 2 IO

Antherids, of fern, I03, IO4; of moss, $86,88,89$

Antherozoids, of fern, I04, I05; of moss, 89,90

Anthracnose of bean, 388

Anthrax, 26, 29

Anthurium andreanum, flower, 26I

Antitoxin, diphtheria, 24

Apple, crown gall, 376 ; fire blight, 374,375 ; flower, 259 ; fruit, 284 ; rust, $70-72$

Arbor vitæ, 187

Archegones, of fern, I03, I04, I05; of moss, 88, 89; of pine, I 24 , I 26,127

Armillaria mellea, 79

Arum family, 298
Asexual generation, of fern, I05-I08; of moss, 86, 90, 9I, 93, I07; of pine, II 3, I 27, I 28, I 30, I 3 I

Asexual reproduction, 57

Asparagus, 203

Asparagus rust, 72

Attachment of plants by roots, I74

Autumn colors of leaves, 256

Bacillus, of anthrax, 26; of Asiatic cholera, I6, I7; of chicken cholera, I6; of lockjaw, I8, 2I, 26; of splenic fever, I6; of typhoid fever, 2 I, 25

Bacillus subtilis, $\mathbf{I} \mathrm{I}-\mathrm{I} 5$

Bacteria, II $-29,34,38,53,373-377$

Bacterium, of diphtheria, 2I, 24; of tuberculosis, 21, 22-24, 29

Bamboos, I96

Banana family, 300

Banyan trees, I 75

Barberry, rust, $60-63$

Bark, II 8, I7I, 213

Barley, root, I70; root hairs, I7o, 173; rusts, 69

Basswood, stem, 209

Bast, II5, II6, II7, I38, 209

Bast fibers, 207, 2II

Bean, anthracnose, 388; blight,

377 ; stem, 187

Beans, I37-I 55

Beech family, zor

Begonia, vegetative multiplication, I I I

Beverages, 318

Biennial plants, $I 76,220,330$

Birch bark, 215 
Birch family, 30 I

Bittersweet, 338

Blackberry, rust, 72

Black knot, 383,384

Black molds, 59

Black rot, of cabbage, 376 ; of grapes, 384

Blight of bean, 377

Bordeaux mixture, 72, 380, 381, 382, 385

Brace roots, I $57, I 59, I 75$

Bracken fern, 97-108

Bracts, I4I, I59, I60, I6I, 235

Branches, I86-227; comparison with roots, $\mathrm{I} 69$; of bean, $\mathrm{I} 38$; of $\mathrm{cu}-$ cumber, 4,7 ; of fern, 97 ; of moss, 87,94 ; of moss protonema, 92, 93; of pine, II4, II 5 , II9

Brassica oleracea, 369

Bread mold, 53-59, 94

Breeding of plants, $358-372$

Broom corn, 314

Brown rot, 38I, 382

Brugmansia, I8I

Brussels sprouts, 218,369

Bryophyllum, vegetative multiplication, I7 I

Bryophytes, 3 2 2

Buckthorn, rust, 70

Bud scales, Ir4, II 5, II9, 2 6

Buds, 2I5-219; adventive, Ixg, I7I, I 72, 2I8; axillary, 7, 2I6-2I8; flower, 7,215 ; leaf, 7,215 ; of fern stem, 97 ; of moss protonema, 93; terminal, $6, \mathrm{II} 3, \mathrm{I} 44, \mathrm{Ix}_{5}$, I56, 2 I 6

Bulbs, 20r

Burdock, 33i

Cabbage, 361, 362, 369; black rot, 376 ; club root, 377

Cactus family, 307

Cactuses, 204, 245

Cambium, II6, II 7, I38, 2II ; cork, II 8,2 I3
Canada thistle, 328, 33I, 334

Cankers, 375

Carbohydrate manufacture, 4I, 43, $45,87,245^{-248}$

Carbohydrates, 42, 43, 55, 291

Catkin, 265

Cauliflower, 282, 369

Cedar, red, rust, 69, 70, 7I, 73

Cell, division, I4, 3O, 3I, 33, 36, 45, 55 ; sap, $4 \mathrm{I}$; walls, I2, 30,40

Cereal grains, 3 I 3 ; rusts, 69

Cherry, black knot, 383

Chestnut blight, 385

Chlorophyl, 30, 40, 42, 256

Chloroplasts, 3I, 40, 47

Chocolate, 3 I 8

Cinchona, $2 \mathrm{I}_{4}$

Cilrullus antgaris, ro

Cladophora, 48, 49

Classification of plants, 295, 3 I 2

Climbing plants, 179, I97, I98

Clover, 27 ; crimson, $3 \mathrm{I} 6$

Cloves, 282

Club-mosses, i Io

Club root, 377

Cob of Indian corn, 160

Cocoa, 3 I 8

Coffee, 318

Compass plants, $24 \mathrm{I}$

Composite family, I 55, 3 ro

Conduction, of foods, 99,174 ; of stimuli, 25 I

Cones of pine, I 22, I 26, I 29, I4I

Conifers, I $33-\mathrm{I} 35$

Conium, 337

Conjugation, in Spirogyra, $46-48$; in wheat rust, 62

Convolvulus family, 309

Coppice growth, 2.19

Copra, 322

Cork, II 2, I 7O, 2II, 2 I 3

Cork cambium, II8, 213

Corms, 20r

Corn, I56-I68; pollination of, 277 ; root tip, I69; rust, 70 ; smut, $385-$ 387 
Cortex, II 5, II 8, I3 $8,208,2$ II

Corymb, 265

Cotton, 307, 324

Cotton tree, 200

Cranesbill, seed discharge, 289

Cress family, $33^{\circ}$

Crocus, corm, 20I

Cross-fertilization, 105

Cross-pollination, $x 47,276-280,370$

Crowfoot family, 303

Crown gall, 376

Cucumber, 4-10, 294; squirting, 289

Curumis melo, to

Cucumis sativus, to

Cucurbita maxima, to

Cucurbita moschata, ,

Cucurbita pepo, ro

Currant rust, 72

Cutin, 244

Cuttings, 172,370

Cycads, 135

Cycas revoluta, I35

Cyme, 265

Cypress knees, I34, I78

Cytoplasm, 40

Damping off fungi, 378

Dasya elegans, 52

Decay, I 7

Dicotyledons, I67, 312; comparison with monocotyledons, I68; families, $30 \mathrm{I}-3 \mathrm{II}$

Digestion, I3, 55

Dionca muscipula, 238

Diphtheria, 24

Diseases of plants, $373-389$

Disease-resistant varieties, 36 I, 362

Distillation of wood, $35^{6}$

Division of cells, I4, 30, 3r, 33, 36, 45,55

Dodders, ז79, 180

Downy mildew, 379

Dragon tree, 223, 224, 299

Drosera rotundifolia, 237

Dyestuffs, 326
Egg, of bean, I45; of lily, 147; of fern, 104, 105; of moss, 88, 89; of pine, I 24,126

Elm, white, I9I

Embryo, of bean, I49, I5O, I52; of fern, I05, I06; of Indian corn, 162, I63; of moss, 90; of pine, I27, I2. ; of squash, I, 2

Endosperm, I, 2, I27, I 28, I49, 162, I6 3, I6 4

Enzyms, 13, 35, 43

Epidermis, 99, II 5, I 20, I38, I39. 2 II

Epiphytes, I82, I83

Euphorbia splendens, 236

Fairy rings, 82

Fall of leaves, $254^{-2} 56$

Families of angiosperms, 295-3 II

Fats, 55, 164, 320

Female plant, of bean, $145, \mathrm{I}_{4} 6$; of lily, I47; of pine, I24, I26, I28

Fermentation, I7, I9, 35, 3I9

Fern, comparison with pine, I3O-I 32

Ferns, 97-I I 2

Fertilization, in bean, $\mathrm{r}_{49}$; in fern, Io5; in moss, 9०; in pine, 126 , I 29

Fiber plants, $324-326$

Fig, pollination of, $274-276$

Fire blight, 374, 375

Flavors, 323

Flax, 305,325

Flax family, 305

Floral parts, arrangement, $26 \mathrm{I}$; number, 261 ; union, 262

Flower clusters, 14I, 264-266

Flowers, $258-282$; of bean, I4I-I45; of cucumber, 7-9; of Indian corn, I $59-162$

Fomes applanatus, 83,84

Food, in Indian corn kernel, I64; in seeds, 29I; manufacture by plants, $3 \mathrm{x}, 4 \mathrm{I}-43,245-248$; of bacteria, I2; of bread mold, 55 ; of yeasts, 34 ; storage of, 248 
Forage plants, 316

Forestry, 342-357

Forests, Alaskan, 353; Canadian, 347,353 ; Hawailan, 353 ; national, 344 ; of the United States, 344346, 35I-353; Porto Rican, 353; private, 346 ; state, 346

Fruit coat, Io, I6 63

Fruit, of bean, I5r, I52; of cucumber, 9; of Indian corn, $163-165$; of lily, 288

Fruits, 132, 137, 283-290

Fucus, 50

Funaria hygrometrica, 86, 87

Fungi, 37, 312, 373; alga-like, 374; basidium, $83-85,374$; bracket, 83,84 ; disease-producing, 373 ; imperfect, 374 ; sac, 374

Gametes, male, of bean, 149 ; of pine, I 26

Gametes, of bread mold, 57; of fern, IO4, IO5; of moss, 88, 89; of rust, 62,63 ; of Spirogyra, 46,47

Germ tube, 64,67

Ginkgo, I36

Girdling, 2 I4

Gladiolus, corm, 20I

Glandular hairs, 23I

Gooseberry, rust, 72

Goosefoot family, 302

Gossypium, 307

Gourd family, Io, 3 ro

Gourds, Io

Grafting, 224-227

Grape, black rot, 384 ; downy mildew, 379

Grapes, 306

Grass family, I66, I95, 296

Gravity, influence on growth, I83, 194, I95, 200

Ground hemlock, I34

Growth, of leaves, 228; of roots, I83-185; of stems in length, I86; of stems in thickness, II5-II8, I 38,299
Gums, 322

Gutta-percha, 2 I 3

Gymnosperms, I32, I53, 3I 2

Habits, formation of, 253

Hairs, 5, 220, 230, 244; glandular, $23 \mathrm{I}$

Hay fever, 34I

Head, 265

Heartwood, I I8, 208

Heath family, 308

Hemp, 326

Herbs, 188

Hollyhocks, rust, 72

Honey locust, thorn, 206

Horse-chestnut, fall of leaves, 254 ; winter buds, 2 I 7

Horse-tails, Io9

Husks of Indian corn, I6o

Hyacinth, bulb, 20 r

Hybrids, $280-284,369-371$

Hygrophorus virgineus, 82

Immunity, 25, 26

Indian corn, I56-I68; pollination of, 277 ; root tip, I69; rust, 70 ; smut, $385-387$

Indian pipe, I82

Insect pollination, I46-I48, 268-270

Integuments, I23, I 24, I 26, I 28 , $\mathrm{I} 44, \mathrm{I} 45, \mathrm{I} 60$

Internodes, I86

Iris family, 300

Jack-in-the-pulpit, flower, 260

Japanese ivy, 205

Jimson weed, 337

Johnson grass, 332

Junipers, rust, 69, 70-72

Kelps, 50, 5I

Kernel of Indian corn, I63-165; germination of, $x 65$

Kohl rabi, 369 
Lady's-slipper, pollination of, 27I, Mallows, rust, 72 272

Lagenaria vulgaris, ,

Lamb's quarters, 330

Larkspur, 339

Late blight of potato, 380

Layering, I72, I 73

Leaf mosaic, 239

Leaf, of lily, I39; primary, of fern, Iо6

Leaves, 5, 228-257; night position of, I40, 252; of bean, I39, 140, I53; of cucumber, 5; of fern, 97,98, IOO, ІоІ, І02, 107; of Indian corn, I56, I57; of moss, 86, 87; of pine, II4, II9, I20, I23, I3O; secondary, I, 4, 5, I5O, I 53; seed, I-3, I27, I30, I5O, I52, I63, 234

Lenticels, 2 I4, 2I 5

Lettuce, prickly, 240

Light, influence of, on growth, I85, I93, I95, 240

Lilac, buds, 2I6, 217

Lilium canadense, 239

Lily, bulb, 20I ; family, 298; flower, 26 I fruit, 288 ; leaf, 139 ; ovary, 263 ; wild yellow, 239

Lime-sulphur wash, 38 .

Liverworts, 95

Living matter, 44

Lockjaw, 26

Loco weeds, 339

Lumber, $35^{6}$

Lumbering, 354

Lycopodium, I Iо

Macrospore leaves, I23, I24, I28, I44

Macrospore sacs, I24, I26, I44

Macrospores, I23, I24, I45, I46; germination of, I 24

Maidenhair tree, $\mathrm{r} 36$

Male plant, of bean, I44, I49; of pine, I25-127

Mallow family, 307

Mandrake, 198

Mangroves, I75, I76

Marchantia, 95

Marsilea, Io9

May-apple, I98

Medicines, 324

Medullary rays, II 7, 2 I2

Melons, Io

Mendelian laws, 37 I

Micropyle, 1, I23, I 26, I27, I44, I50, I 60

Microspore leaves, I22, I23, I43

Microspore sacs, I22, I23, I44

Microspores, I23, I25, I44; germination of, I25, I44

Mildew, downy, 379; powdery, 382

Milkweed, 292

Milky juices, 212

Millet, $3^{\text {I } 3}$

Mint family, 309

Mistletoe, I 80

Mold, bread, 53-59, 94

Molds, 53 ; black, 59

Monocotyledons, I67, 3I2; comparison with dicotyledons, I68; families of, 296-30I

Monotropa, I 82

Mosaic, leaf, 239

Moss, comparison with pine, I30-I 32

Mosses, 86-96

Movements of leaves, $250-252$

Mucor, 59

Multiplication, vegetative, I7I, I 72, I97, 370

Mushrooms, 74-85

Mustard family, 304

Mutations, 367-369

Mycorhizas, $x 8 x$

Narcotics, 319

Nectar, I44, I47, 270

Nereocystis, 5 I

Nettle family, zor

Nightshade, black, 338; family, 309 
Nodes, 186

Nuclei, 3I, 33, 34, 40, 55, 62, 66

Nutation, I87

Oak, swamp white, I92

Oat, rusts, 69 ; smut, 386,387

Odors of flowers, $36 \mathrm{I}$

Oils, essential, 324 ; fatty, 320-322; volatile, 324

Opuntia, 204

Orange, 285

Orchid family, 300

Orchids, epiphytic, 183

Ovary, 8, 9, I37, I44, I59, I60

Ovules, 8 , I23, I $24, \mathrm{I} 26$, I 28 , I44, 145,160

Palisade layer, 139

Palm family, 297

Pandanus, 175

Panicle, 266

Parasitic bacteria, I 2

Parasitic fungi, $60,80,85$

Parasitic seed plants, I79-I8I

Parsley family, 307

Pasteurization of milk, 20

Peach scab, 388

Pear blight, 374

Pear rust, 73

Peas, 27 , I53

Peat mosses, 94

Pedicels, I4I, 264

Peduncles, I4I, 264

Pepper, 323

Perennial plants, I77, 221, 33I

Perfumes, 323

Petals, 8, 9, I42, I48, 260

Phaseolus aculifolius, I55

Phaseolus lunatus, I54, I55

Phaseolus multiflortis, I54, I55

Phascolus radialus, 155

Phaseolus vulgaris, 154,155

Phycomyecs, 59

Pigeon grass, 329

Pilobolus, 59
Pine, blister rust, 72; comparison with bean, I53; long-leaved yellow, 352; red (Norway), 352, 356 ; white, $348,349,352$

Pineapple, 284

Pines, II3-I36

Pink family, 303

Pinus Lambertiana, $₫ 33$

Pinus palustris, 352

Pinus resinosa, I33

Pinus sirobus, 132

Pistils, 8, I4I, I44, I59, I60, 263; rudimentary, 9, I60, I6I

Pitcher plants, 236, 237

Pith, II5, II6, I38, I96, 2 I I

Plankton, 5I

Plant breeding, 358-372

Plant diseases, $373-389$

Plant products, 3 I $3-327$

Plum black knot, 383

Pod of bean, $\mathrm{I}_{44}, \mathrm{I}_{5} \mathrm{I}, \mathrm{I}_{52} 2$

Poison hemlock, 337

Poison ivy, 340

Poison oak, 340

Poisonous plants, 80, 8I, 337-34I

Pollen, 9, 268; as food for insects, 272 ; of bean, I43, I44, I48; of cucumber, 9; of Indian corn, I6r ; of lily, germination, I43; of pine, I22, I23; of pine, germination, I25; sacs, I22, I23, I6I; tube, 9, I 26, I $29,143,147$, I 48, I 49

Pollination, $266-280$; of bean, $146-$ I48; of Indian corn, I62; of pine, I25, I 26 , I 29

Polygonalum, I99

Pond scums, 39

Potato, 3I4, 358; early blight, 388 , 389 ; late blight, 380 ; rot, 380 ; scab, 387 ; tubers, 202

Powdery mildews, 382

Pressure, influence on growth, 185

Prickles, 220

Prickly lettuce, 240

Primrose, flowers, 278, 279; leaf mosaic, 239 
Prop roots, $175.1,6$

Protection of seeds, 285

Proteins, 4I, 43, I5O, I64, 29 I

Protococcus, 30-32, 182

Protonema, 92

Protoplasm, I 2, I 5, 34, 40, 55

Psalliola arvensis, 76

Psalliota campestris, is

Pteridophytes, 3I 2

Pleris aquilina, 97

Ptomains, 2I

Puccinial, 73

Puccinia graminis, 69

Puffballs, 85

Pulse family, I $55,229,305$

Pumpkin, to

Pure varieties, 366

Putrefaction, I

Pyrenoids, 40. 42

Quack grass, 332

Quercus bicolor, 192

Quinin, 214

Raceme, I4I, 265

Races, specialized, 69

Radish, $1 ; 6,187$

Rafferias, I8I

Ragweed, 34I

Raspberry, 284; rust, i2

Redwoods, I34, 222, 223

Reproduction, asexual, 57 ; of bacteria, I4; of bread mold, 5;-59; of Prolococcus, 3I; of Spirogyya, $45-48$; of yeasts. 33,36 ; sexual, ' 48,$5 ; .63,66$

Resin of pine, II 4, II 5. I33

Resin passages, $\mathrm{II}_{5}, \mathrm{II}_{\overline{6}}^{-}, \mathrm{I}_{2} \mathrm{O}$

Resins, 322

Respiration, I3, I . 34, 44, I7, 248 250

Rhizoids, of fern, IO2, IO3, IO4; of moss, 8,, 85.93

Rhizophora conjugata, $1 ; 6$

Rhizopus nigricans, 53-59
Rice, 313, 3rt

Rockweed, 50

Root hairs, 3, +. Ioo, I 2 I, I $; 0$, I73

Roots, 4, I69-I85; of bean, I4O; of climbing plants, I79, I98; of cucumber, 4 ; of epiphytes, I83; of fern, 98, I00, I06, I07, Io8; of Indian corn, I57, I58, I75; of parasitic plants, I79, I85; of pine, I2I, I3O; of squash, 2,3

Rose family, 304

Rose, leaf, 229; rusts, i2

Rothtion of crops, $336,376,387$

Rubber, 2 I 2

Rue family, 305

Runners, 204, 334

Ruscus, 203

Rusts, $60-73,83$

Rye, 3I3; rusts, 69

Saccharomyces, 37

Salix discolor, 189

Salita glulinosa, pollination of, 269

Saprophytic bacteria, I2, I6

Saprophytic fungi, 55, 59, 80, 85

I Saprophytic seed plants, I 79, I 82, 30I

Saprood, Ir8, 208

Sargassum, 50

Saxifrage family, 304

Scale leaves. II4, II 5 , II9, 2I6, 234

Scales of ferns, 97,98

Scleroderma vnulgare, 85

Screrr pines, $1-5$

Seaweeds, 49

Sedge family, 297

Seed coats, 1, 2, I 27, I 28, I 52, I63

Seed leaves. $1-3,127,150,152,163$, $23+$

Seed, of bean, $149-15^{2}$; of bean, germination, $152 ;$ of cucumber, IO; of Indian corn, I62-164; of Indian corn, germination, 165 ; of pine, 12;-I29; of pine, germination, 129; of squash, 1, 2; of squash, germination, 2, 3 
Seed plants, I32, 137, 312

Seed testing, 294

Seedless fruits, 9, 294

Seedling, of bean, I52; of Indian corn, I65; of squash, 3

Seeds, 28I-294, 333

Selaginella, г то

Selection, 360, 363-366, 37 I

Self-fertilization, I05

Self-pollination, I48, 276, 280

Sensitive plant, $250-252$

Sepals, 7-9, I42, I48, I 51,260

Sex organs, of fern, IO3, I04; of moss, 86,88

Sexual generation, of fern, 102,103 , ro7; of moss, $85-89,93$; of pine, I 24, I 25, I 28

Sexual reproduction, $48,57,63,66$

Shaggy mane (mushroom), $8 \mathrm{I}$

Shrubs, I89

Silk of Indian corn, I59, I6r, I63

Sleep movements, I 10, 252

Slime molds, 373, 377

"Smilax," 203

Smuts, 83, 385-387

Solomon's seal, I99

Soy bean, 3 I 7

Spawn, mushroom, 78

Specialized races, 69

Spermatia, 60, 62, 63, 73

Spices, 323

Spike, 265

Spikelets of Indian corn, I59-I6I

Spirillum, I7

Spirillum of recurrent fever, I6, I7

Spirogyra, 39-49, 57, 59

Spore formation, advantages, 58

Spore leaves, I 22, I4 2

Spore sacs, of bread mold, 54, 56, 58 ; of fern, IOI, IO2; of moss, $87,90-92$

Spores, of bacteria, II, I5, 20, 2I, 36 ; of bread mold, $55-58$; of bread mold, germination, 56 ; of fern, xот, то2; of fern, germination, IO2; of moss, 92 ; of moss, germination, 92; of mushrooms, $77,79,8 \mathrm{I}-83$; of mushrooms, distribution, 77 ; of mushrooms, germination, 78 ; of rusts, $60-68$, $70-72,83$; of rusts, germination, $64-66,71$; of yeasts, 36

Sporodinia, 59

Sports, 368

Spring wood, II 7, 209

Spruce, white, I 34

Spurge family, 305

Spurges, 338

Squashes, I-4, Io

Squirrel-tail grass, 330

Stamens, 8, 9, I4I, I43, I6I; rudimentary, 9, I59, I60

Starch, 42, I64, 246, 247

Stem, of bean, I37, I38, I87; of cucumber, 4 ; of fern, $97,98,99$, Io6; of Indian corn, I56, I57; of moss, 87 ; (trunk) of pine, II3I I 9

Stems, I86-227

Sterilization of milk, 20

Stimulants, 3 I9

Stimuli, I83-I85, 2I8, 240

Stipules, I39, 229

Storage in roots, 176

Strains, plus and minus, 57

Strawberry, 283

Streplococcus pyogenes, 16

Sugar beet, 3I5

Sugar cane, 3 55

Sugar-producing plants, 3 I 5

Sugars, $36,42,164,246,247,3$ I 5

Summer wood, II 7,209

Sundews, 237

Sunflower, 193

Support of plants by roots, $174^{-1} 7^{6}$

Tap roots, I I I, I30

Tape-grass, 266, 267

Tassel of Indian corn, I59, I6r

Tea, 3 I 8

Tendrils, 5, 6, 205, 236 
Teosinte, 166

Tetanus, 26

Thallophytes, 3 I 2

Thistle, Canada, 328, 33I, 334

Thorns, 206, 235, 236

Tissue, false, 77

Tissues, of bean leaf, I39; of bean stem, I38; of fern stem, 98,99 ; of Indian corn stem, 157 ; of pine leaf, 120 ; of pine stem, II4-II 8

Tobacco, 3I9, 320

Toxins, bacterial, 22, 24-27

Trailing stems, Ig6

Trees, 189; ages of, 224; forest, 30I; forms of, I90-I92; size of, 222-224

Trunk of pine, II 3 -II9

Tuberculosis, 22-24

Tuberous roots, I77

Tubers, 202, 334

Tumble weeds, 334

Turpentine, $\mathrm{x} 33,352,356$

Twig blight, 374

Typhoid fever, 25

Ulmus americana, IgI

Umbel, 265

Vacuoles, 33, 34, 4I, 55

Vallisneria spiralis, 266,267

Vascular bundles, of bean, $\mathrm{I}_{3} 8, \mathrm{I}_{39}$, I5I, I52; of fern, 99-IOI; of Indian corn, 157 ; of pine, II5, II6, I20, I2I

Vaucheria, 48, 49

Vegetative multiplication, I7I, I72, I97, 370

Veins, 5, IOI, I39, I 58

Veneers, 357

Venus' fly-trap, 238

Vessels, 210-2 I 2

Vicia faba, I 55
Vine family, 306

Violet family, 307

Virginia creeper, 205, 206

Walnut family, $30 \mathrm{r}$

Water current, 24I, 242

Water, evaporation from leaves, $24 \mathrm{I}-245$; influence on growth, I85

Water ferns, Io9

Water hemlock, 337

Wax, 244, 245

Waxes, 322

Weeds, 328-34I

Wheat, axillary buds, 2r 8 ; durum, 68, 36I ; macaroni, 68; rusts, $60-68,73$; smut, 387

Willow family, $30 \mathrm{I}$

Willow, pussy, I89; vegetative multiplication of, I72

Wilts, 376

Wind pollination, I25, I48, I62, 267

Witches' brooms, 72, 2 r9

Wolffia, 224

Wood, II5-II7, I2I, I38, 207, $2 \mathrm{Ir}$; distillation, 356 ; durability, 208; fibers, 207; hardness, 208; products, 356,357 ; uses, 356 ; weight, 208

Yeasts, $33-38$

Yucca gloriosa, 273

Irucca, pollination of, 273,274

Zamia, I35

Zea Mays, т66, I67

Zygote, of bean, I49; of bread mold, 57, 58; of damping off fungus, 378 ; of fern, I05; of moss, 90; of pine, I 27 ; of rust, 62,63 ; of Spirogyra, 46,47 







DES 11949 
(1)

(1)

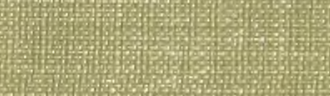

(1)

$\log ^{2}$

4.

(3)

(3)

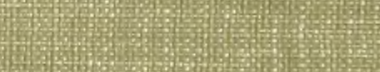

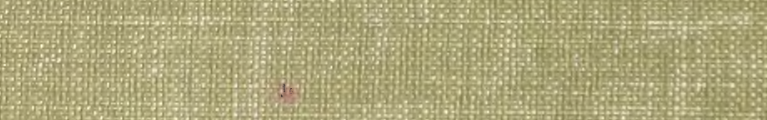

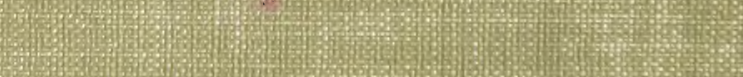
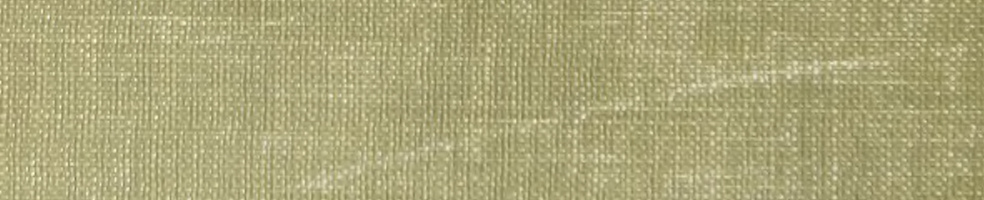

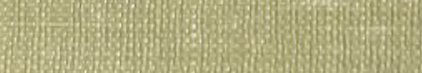

S.

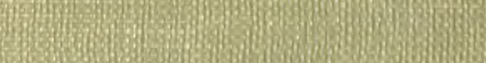

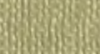

2 